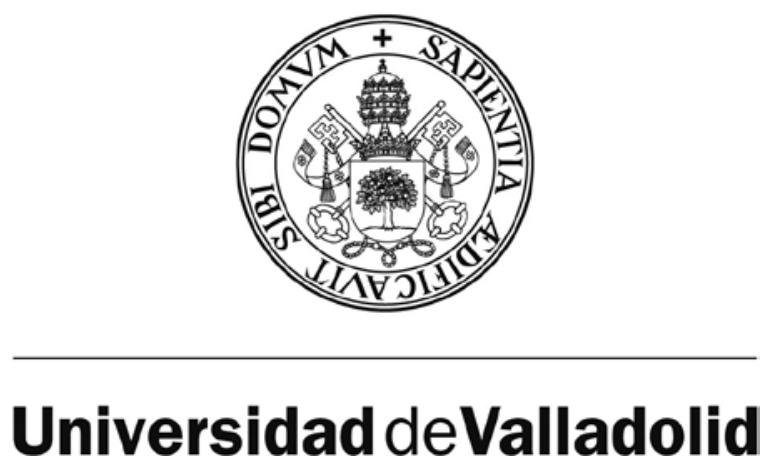

FACULTAD DE CIENCIAS ECONÓMICAS Y EMPRESARIALES DEPARTAMENTO DE ECONOMÍA APLICADA

TESIS DOCTORAL:

\title{
EL ABANDONO ESCOLAR TEMPRANO: UN ESTUDIO DE LOS FACTORES EXPLICATIVOS EN LAS COMUNIDADES AUTÓNOMAS ESPAÑOLAS
}

Presentada por D. Siro Bayón Calvo para optar al grado de doctor por la Universidad de Valladolid

Dirigida por:

Dra. Olga Ogando Canabal 

"El hombre puede pasar por sabio cuando busca la sabiduría; pero si cree haberla encontrado es un necio."

Proverbio persa 

Índice general 



\section{Capítulo 1 : La importancia de la educación y el capital humano en el} crecimiento y bienestar económico y social ............................................................29

1.1. Introducción....................................................................................................31

1.2. La economía de la educación, la teoría del capital humano y sus

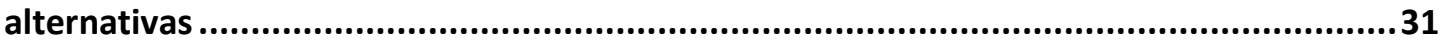

1.2.1. El origen de la economía de la educación ................................................... 31

1.2.2. La teoría del capital humano ………………............................................. 33

1.2.3. Alternativas a la teoría del capital humano............................................... 37

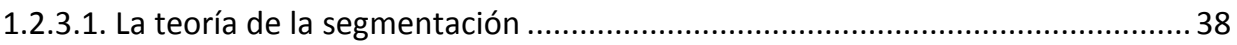

1.2.3.2. Las teoría del filtro y la señalización ............................................................ 39

1.2.3.3. La teoría de la competencia por los puestos de trabajo ................................ 42

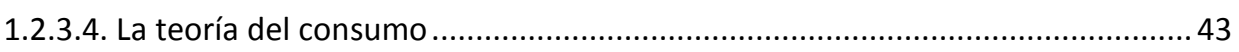

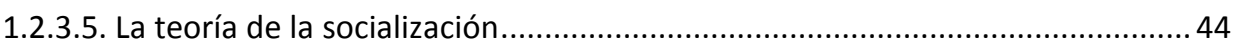

1.3. El papel de la educación y el capital humano en el crecimiento económico 45

1.3.1. Los modelos de crecimiento exógeno: El modelo de crecimiento de Solow 46

1.3.1.1. Primera versión

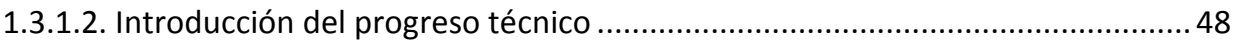

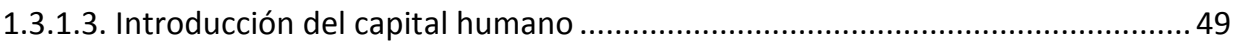

1.3.2. Los modelos de crecimiento endógeno........................................... 51

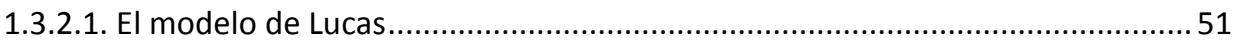

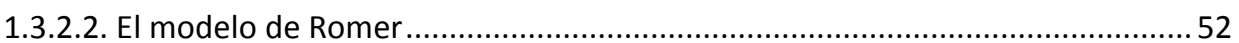

1.3.3. El debate sobre el efecto del capital humano en el crecimiento económico

1.4. Externalidades de la educación y la escolarización en la economía y el bienestar social

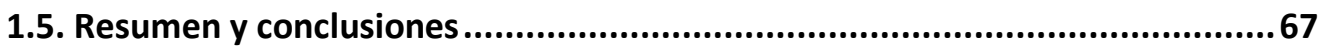

\section{Capítulo 2 : El abandono escolar temprano como objetivo de los}

programas de reformas estructurales de la Unión Europea.............................69

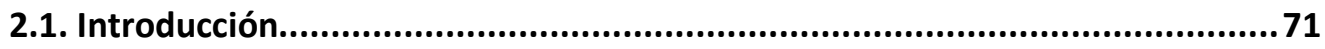

2.2. Los programas de reformas estructurales y el contexto de la Unión 
2.2.1. La Estrategia de Lisboa.

2.2.1.1. Los objetivos del ámbito educativo y el marco estratégico ET 2010

2.2.1.2. El Informe Kok y el Informe del Grupo de Alto Nivel .......................................79

2.2.1.3. La nueva Estrategia de Crecimiento y Empleo .................................................. 81

2.2.1.4. Los resultados de la Estrategia de Lisboa ........................................................ 84

2.2.2. La Estrategia Europa 2020 .................................................................... 86

2.2.2.1. Europa ante el cambio de contexto macroeconómico ……...............................86

2.2.2.2. La renovación de los objetivos de las reformas estructurales en la

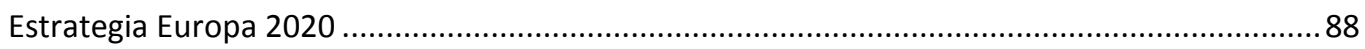

2.2.2.3. Los objetivos del ámbito educativo y el marco estratégico ET 2020 ................89

2.3. El contexto de España y la adaptación de los objetivos de las estrategias

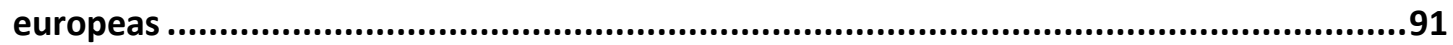

2.3.1. El contexto económico y el desarrollo de los Programas Nacionales de Reformas durante la aplicación de la Estrategia de Lisboa.....

2.3.2. El contexto económico y el desarrollo de los Programas Nacionales de Reformas durante la aplicación de la Estrategia Europa 2020. 100

2.4. Resumen y conclusiones 108

\section{Capítulo 3 : El concepto y los factores explicativos del abandono escolar}

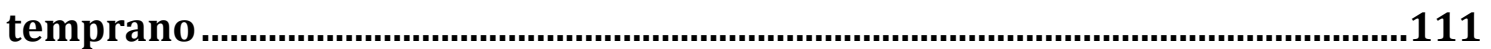

3.1. Introducción.

3.2. Definiciones, acepciones y metodología de cálculo del abandono escolar temprano ............................................................................................................113

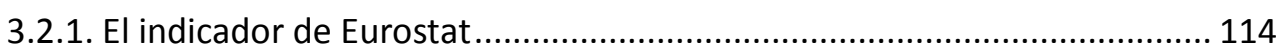

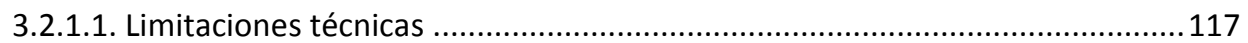

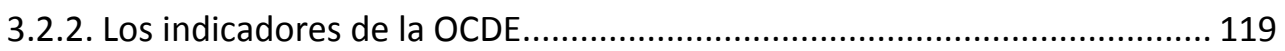

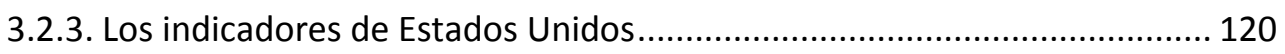

3.2.4. Otras definiciones e indicadores de abandono escolar temprano............. 121

3.2.5. La relación conceptual del abandono escolar temprano con otros indicadores educativos

3.3. Los factores explicativos del abandono escolar temprano. Una revisión de la literatura 126

3.3.1. Factores del contexto educativo 127

3.3.1.1. Gasto público en educación .................................................................... 128

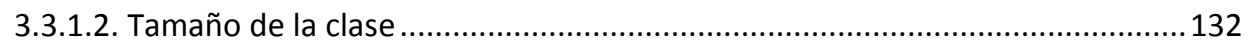




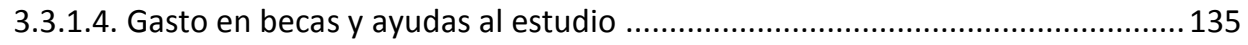

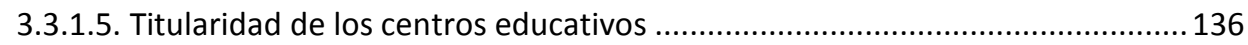

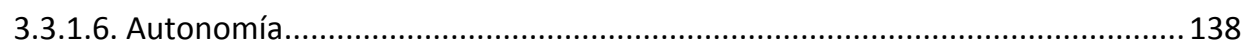

3.3.1.7. Comprensividad del sistema educativo .......................................................... 139

3.3.1.8. Evaluación y rendición de cuentas ................................................................ 140

3.3.2. Factores del contexto económico ..................................................... 141

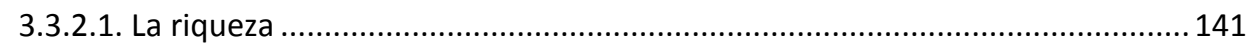

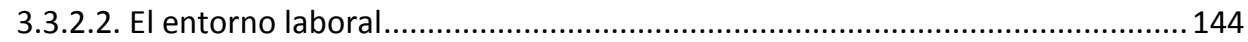

3.3.3. Factores del contexto socio-cultural .................................................. 149

3.3.3.1. Nivel instructivo del entorno familiar y social............................................. 149

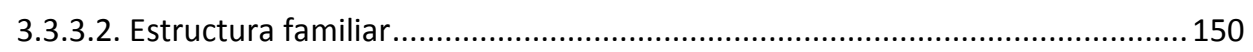

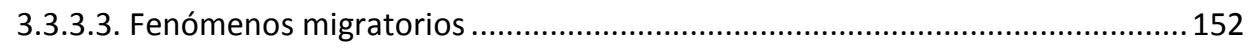

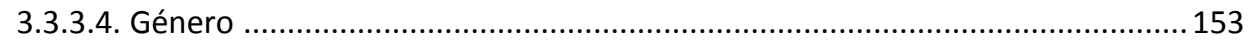

3.4. Resumen y conclusiones ...................................................... 155

\section{Capítulo 4 : Análisis de evolución y caracterización del abandono} escolar temprano en las comunidades autónomas españolas ...........................157

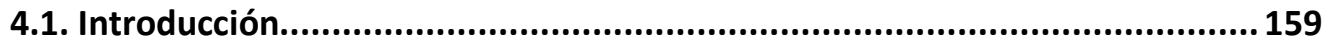

4.2. Evolución de las tasas de abandono escolar temprano .............................. 163

4.3. Caracterización de la tasa de abandono escolar temprano......................... 172

4.4. La relación del abandono escolar temprano con otros fenómenos educativos 181

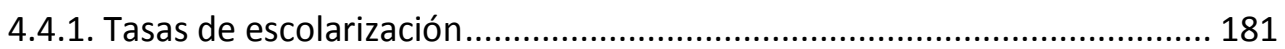

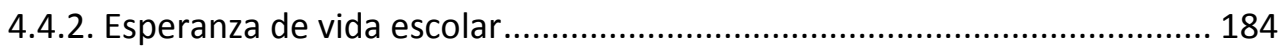

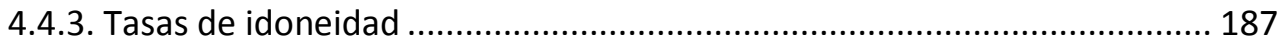

4.4.4. Tasas de graduación ................................................................... 190

4.4.5. Resultados de los test de competencias.......................................... 192

4.5. Resumen y conclusiones ....................................................... 197

\section{Capítulo 5 : Análisis de los factores explicativos del abandono escolar} temprano en las comunidades autónomas españolas ......................................199

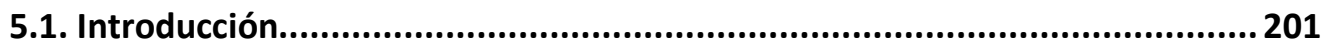

5.2. Análisis de los factores del contexto educativo ................................... 202

5.2.1. Factores de gasto en educación ....................................................... 202

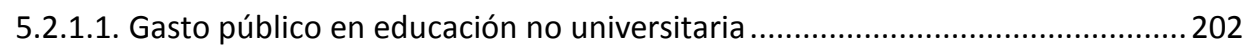




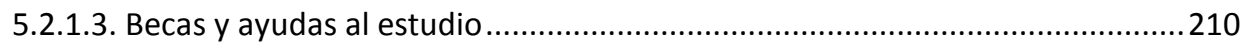

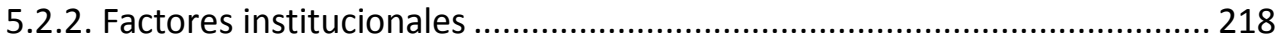

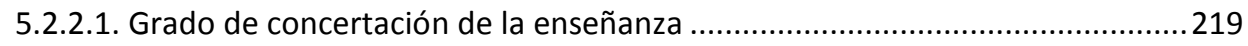

5.3. Análisis de los factores del contexto económico ................................224

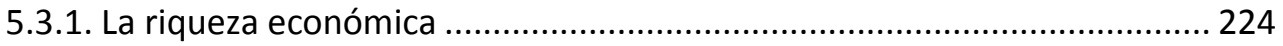

5.3.2. El mercado laboral ..................................................................... 231

5.4. Análisis de los factores del contexto socio-cultural ...............................243

5.4.1. Nivel educativo de la población adulta............................................ 243

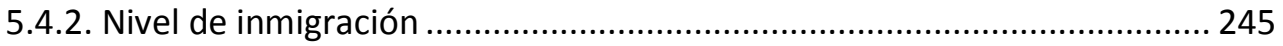

5.5. Resumen y conclusiones ...........................................................249

Capítulo 6 : Un análisis de panel de datos de los factores explicativos del

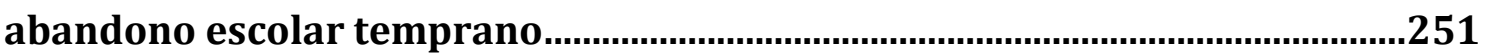

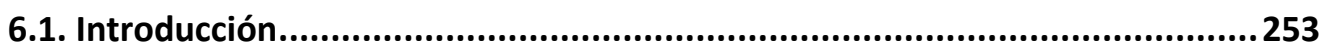

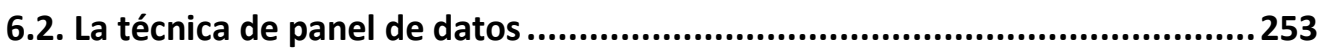

6.3. Especificación del modelo........................................................................254

6.4. Estimación del modelo .............................................................................258

6.5. Discusión de resultados ............................................................................269

6.6. Resumen y conclusiones. .........................................................................277

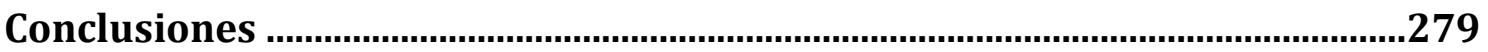

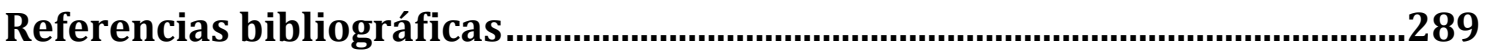

ANEXO I: Tablas y gráficos adicionales del Capítulo 2 .........................................313

ANEXO II: Estructura del sistema educativo español..........................................319

ANEXO III: Estadísticas adicionales del Capítulo 4 ...........................................323

ANEXO IV: Estadísticas adicionales del Capítulo 5 ............................................331

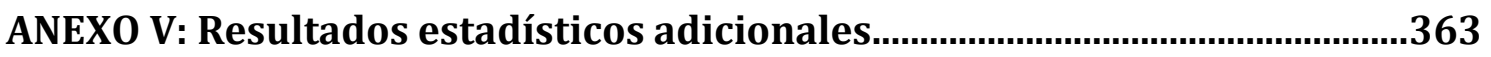

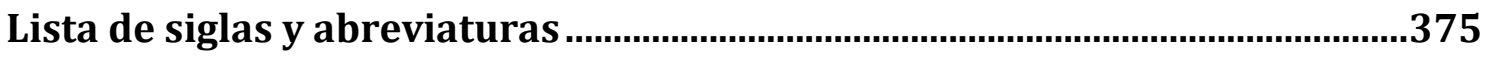


Índices de Tablas, Gráficos y Cuadros 



\section{ÍNDICE DE TABLAS}

Tabla 2.1. Objetivos estratégicos generales y específicos ..........................................76

Tabla 2.2. Objetivos generales del marco estratégico ET 2010 .....................................76

Tabla 2.3. Indicadores de seguimiento del marco estratégico ET 2010.........................78

Tabla 2.4. Progreso de los objetivos generales de la Estrategia de Lisboa ......................84

Tabla 2.5. Progreso de los indicadores de seguimiento del marco estratégico ET

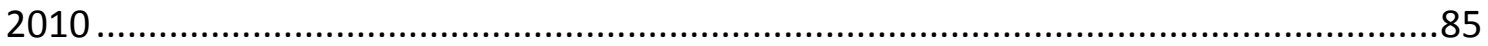

Tabla 2.6. Principales indicadores macroeconómicos en la Unión Europea-27 .............87

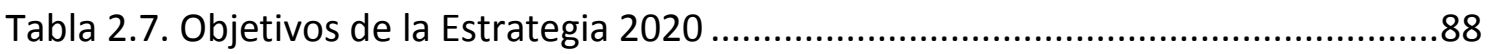

Tabla 2.8. Objetivos generales del marco estratégico ET 2020 ..................................89

Tabla 2.9. Indicadores de seguimiento del marco estratégico ET 2020 y evolución ......90

Tabla 2.10. Relación de objetivos específicos del Programa Nacional de Reformas

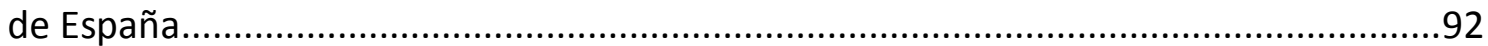

Tabla 2.11. Relación de los ejes de acción del Programa Nacional de Reformas de España.

Tabla 2.12. Indicadores y objetivos del PNR de España 2005 sobre el eje de aumento y mejora del capital humano

Tabla 2.13. Principales indicadores macroeconómicos en España

Tabla 2.14. Progreso de los indicadores de seguimiento del marco estratégico ET 2010 en España.

Tabla 2.15. Indicadores de seguimiento del marco estratégico ET 2020 para España

Tabla 2.16. Líneas de actuación y medidas financiables del PCT-RATE 104

Tabla 2.17. Progreso de los indicadores de seguimiento del marco estratégico ET 2020 en España. .108

Tabla 6.1 Relación de variables explicativas. 255

Tabla Al.1. Clasificación simplificada de los niveles CINE (Clasificación Internacional Normalizada de la Educación)

Tabla Al.2. Directrices integradas para el crecimiento y el empleo (2005-2008) ..........315

Tabla Al.3. Directrices integradas de la Estrategia Europa 2020 316 


\section{ÍNDICE DE GRÁFICOS}

Gráfico 4.1. Escolarización en educación primaria (por cada 10.000 habitantes) .........160

Gráfico 4.2. Distribución de la población activa por nivel de estudios finalizados (1964-2013, \%)

Gráfico 4.3. Evolución de las tasas de escolarización en los años 90 en España (\%)....162

Gráfico 4.4. Evolución de la tasa de abandono escolar temprano (varios países, 2000*-2013, \%)

Gráfico 4.5. Diferencias regionales en las tasas de abandono escolar temprano en

la Unión Europea (promedio de años 2010-2013, \%)

Gráfico 4.6. Tasa de abandono escolar temprano en las CCAA españolas (año

$2013, \%)$

Gráfico 4.7. Evolución de las diferencias regionales en las tasas de abandono escolar temprano en las CCAA españolas (años 2000-2013, \%)

Gráfico 4.8. Abandono escolar temprano en las CCAA españolas (año 2000 versus $2013, \%)$

Gráfico 4.9. Evolución de las tasas de abandono escolar temprano según género (años 2002-2013, \%)

Gráfico 4.10. Evolución de las tasas de abandono escolar temprano según edad (años 2002-2013, \%)

Gráfico 4.11. Evolución de las tasas de abandono escolar temprano según

titulación alcanzada (años 2002-2013, \%)

Gráfico 4.12. Evolución de las tasas de abandono escolar temprano de los individuos no titulados en ESO, según edad (años 2002-2013, \%)

Gráfico 4.13. Evolución de las tasas de abandono escolar temprano de los individuos titulados en ESO, según edad (años 2002-2013, \%)

Gráfico 4.14. Evolución de las tasas de abandono escolar temprano según su ocupación (años 2002-2013, \%)

Gráfico 4.15. Evolución de las tasas de abandono escolar temprano según su nacionalidad (años 2002-2013, \%)

Gráfico 4.16. Evolución de las tasas de abandono escolar temprano según nivel

de estudios máximos alcanzados por la madre (años 2002-2013, \%) ....

Gráfico 4.17. Tasa de abandono escolar temprano versus tasa de escolarización a los 17 años en las CCAA españolas (año 2013 - curso 2011/12; \%)

Gráfico 4.18. Tasa de abandono escolar temprano versus esperanza de vida escolar a los seis años en las CCAA españolas (año 2013 - curso 2000/01; \%).

Gráfico 4.19. Tasa de abandono escolar temprano versus tasa de idoneidad a los quince años en las CCAA españolas (año 2013 - curso 2009/10; \%). 
Gráfico 4.20. Tasa de abandono escolar temprano versus tasa bruta de graduación en ESO en las CCAA españolas (año 2013 - curso 2009/10; \%) ....

Gráfico 4.21. Tasa de abandono escolar temprano versus puntuación media en la Evaluación General de Diagnóstico 2010 en las CCAA españolas (año 2013 2010; \%, puntuación media).

Gráfico 4.22. Tasa de abandono escolar temprano versus puntuación media en el estudio PISA 2012 en las CCAA españolas (año 2013 - 2010; \%, puntuación media)

Gráfico 5.1. Tasa de abandono escolar temprano versus gasto público en educación no universitaria por alumno en las CCAA españolas (año 2013 - curso 2010/11; \%, €/alumno)

Gráfico 5.2. Tasa de abandono escolar temprano versus número medio de alumnos por grupo en ESO en las CCAA españolas (año 2013 - curso 2010/11; \%, alumnos/grupo)

Gráfico 5.3. Tasa de abandono escolar temprano versus gasto público en becas y ayudas al estudio por etapas educativas en las CCAA españolas (año 2013 cursos 2006/07, 2010/11 y 2011/12; \%, €/alumno)

Gráfico 5.4. Tasa de abandono escolar temprano versus distribución porcentual de alumnado de ESO en la enseñanza privada concertada en las CCAA españolas (año 2013 - curso 2010/11, \%)

Gráfico 5.5. Tasa de abandono escolar temprano versus distribución porcentual del gasto de educación no universitaria en conciertos y subvenciones a la enseñanza privada en las CCAA españolas (año 2013 - 2011, \%)

Gráfico 5.6. Tasa de abandono escolar temprano versus PIB per cápita en las CCAA españolas (año 2011; \%, €).

Gráfico 5.7. Tasa de abandono escolar temprano versus tasa de riesgo de pobreza en las CCAA españolas (año 2013, \%).

Gráfico 5.8. Tasa de abandono escolar temprano versus tasa de paro en las CCAA españolas (años 2013 y 2011, \%)

Gráfico 5.9. Tasa de abandono escolar temprano versus porcentaje de ocupados en el sector construcción en las CCAA españolas (año 2008, \%) .

Gráfico 5.10. Tasa de abandono escolar temprano versus salario medio anual por trabajador menor de 25 años en las CCAA españolas (año 2008; \%, €)

Gráfico 5.11. Tasa de abandono escolar temprano versus índice de descualificación de la población ocupada en las CCAA españolas (años 2006 y 2013, \%)

Gráfico 5.12. Tasa de abandono escolar temprano versus índice de descualificación de la población adulta en las CCAA españolas (año 2012, \%)

Gráfico 5.13. Tasa de abandono escolar temprano versus proporción de la población inmigrante joven en las CCAA españolas (año 2011, \%) .... 


\section{ÍNDICE DE CUADROS}

Cuadro 4.1. Tasas de abandono escolar temprano en la Unión Europea-28 (Años 2000, 2010, 2013 y objetivo (\%)

Cuadro 4.2. Tasas de abandono escolar temprano por CCAA (\%) 170

Cuadro 4.3. Tasas de escolarización a los 17 años por CCAA (\%). 182

Cuadro 4.4. Esperanza de vida escolar a los seis años por CCAA ( $n$ ㅇ de años) 185

Cuadro 4.5. Tasas de idoneidad a los quince años por CCAA (\%) 188

Cuadro 4.6. Tasas brutas de graduación en ESO por CCAA (\%) 191

Cuadro 4.7. Resultados de la Evaluación General de Diagnóstico 2010 por CCAA (puntuaciones medias)

Cuadro 4.8. Resultados del Estudio PISA 2012 por CCAA (puntaciones medias) 195

Cuadro 5.1. Gasto público por alumno en educación no universitaria por CCAA (€/alumno).....

Cuadro 5.2. Número medio de alumnos por grupo en ESO por CCAA (alumnos/grupo)

Cuadro 5.3. Gasto público en becas y ayudas al estudio en Educación Primaria por CCAA (€/alumno).

Cuadro 5.4. Gasto público en becas y ayudas al estudio en ESO por CCAA (€/alumno)

Cuadro 5.5. Gasto público en becas y ayudas al estudio en la segunda etapa de la educación secundaria por CCAA ( $€$ /alumno)

Cuadro 5.6. Distribución porcentual del alumnado de ESO en enseñanza privada concertada por CCAA (\%)

Cuadro 5.7. Distribución porcentual del gasto público de educación no universitaria en conciertos y subvenciones a la enseñanza privada por CCAA (\%) ......222

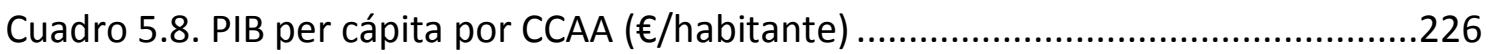

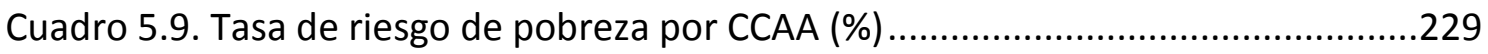

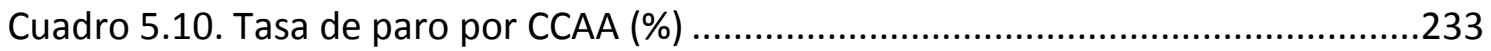

Cuadro 5.11. Tasa de paro de la población menor de 25 años por CCAA (\%) ..............235

Cuadro 5.12. Porcentaje de ocupados en el sector construcción por CCAA (\%) ..........237

Cuadro 5.13. Salario medio por trabajador menor de 25 años por CCAA (\%) ..............239

Cuadro 5.14. Índice de descualificación de la población ocupada por CCAA (\%) ..........242

Cuadro 5.15. Índice de descualificación de la población adulta por CCAA (\%).............244

Cuadro 5.16. . Proporción de la población inmigrante joven por CCAA (\%) .................247 
Cuadro 6.1. Estadísticas descriptivas de las variables del modelo

Cuadro 6.2. Resultados de la estimación agrupada por MCO......................................259

Cuadro 6.3. Resultados de la estimación del modelo de efectos fijos..........................260

Cuadro 6.4. Resultados de la estimación del modelo de efectos aleatorios .................261

Cuadro 6.5. Resultados de la prueba de Breusch y Pagan para efectos aleatorios ......261

Cuadro 6.6. Resultados del test de Hausman

Cuadro 6.7. Resultados de la estimación del modelo de efectos fijos con efectos temporales.

Cuadro 6.8. Resultados de la prueba F de efectos temporales.....................................264

Cuadro 6.9. Resultados del test de Wooldridge para paneles de datos .......................265

Cuadro 6.10. Resultados de la estimación del modelo de efectos fijos con efectos

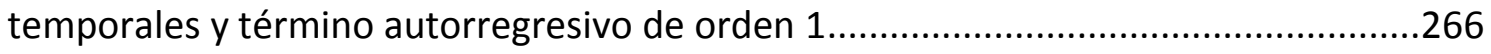

Cuadro 6.11. Resultados del test modificado de Wald para paneles de datos ............267

Cuadro 6.12. Resultados del Test $Q$ de Frees.

Cuadro 6.13. Resultados de la estimación de mínimos cuadrados generalizados

factibles para panel del modelo de efectos fijos con efectos temporales.

Cuadro 6.14. Resultados de la estimación de errores estándar corregidos para

panel del modelo de efectos fijos con efectos temporales

Cuadro 6.15. Estimaciones paramétricas de panel de datos de los factores explicativos de las de la tasa de abandono escolar temprano en las CCAA españolas.

Cuadro Al.1. Tasa de empleo en la Unión Europea. Años 2000 - 2013 (\%) ..................316

Cuadro AI.2. Inversión en I+D en la Unión Europea. Años 2000 - 2013 (\% del PIB)......316

Cuadro Al.3. Fondos aportados por el Ministerio de Educación, Cultura y Deporte al programa de reducción del abandono escolar temprano, por comunidad autónoma. Años 2007 - 2012 (euros)

Cuadro All.1. Esquema de la estructura del sistema educativo español

Cuadro Alll.1. Abandono escolar temprano en la Unión Europea-28, años 2000 $2013(\%)$

Cuadro Alll.2. Abandono escolar temprano en las CCAA españolas, años 2000 $2013(\%)$

Cuadro Allı.3. Tasas de escolarización a los 17 años, cursos 2000/01 - 2012/13 (\%)

Cuadro Alll.4. Esperanza de vida escolar a los seis años, cursos 2000/01 2012/13 (\%)

Cuadro Alll.5. Tasas de idoneidad a los quince años, cursos 2000/01 - 2012/13 (\%). 
Cuadro AllI.6. Tasas brutas de graduación en ESO, cursos 2000/01 - 2011/12 (\%) .....330

Cuadro AIV.1. Gasto público por alumno en educación no universitaria en las

CCAA españolas, cursos 2000/01 - 2011/12 (€/alumno)

Cuadro AIV.2. Gasto público en educación no universitaria por CCAA españolas,

cursos 2000/01 - 2011/12 (miles de €)

Cuadro AIV.3. Número de alumnos de educación no universitaria en las CCAA españolas, cursos 2000/01 - 2011/12 (no de alumnos)

Cuadro AIV.4. Número medio de alumnos por grupo en ESO en las CCAA

españolas, cursos 2000/01 - 2011/12 (alumnos/grupo).

Cuadro AIV.5. Gasto público en becas y ayudas al estudio por alumno en

Educación Primaria en las CCAA españolas, cursos 2000/01 - 2011/12 (€/alumno)....337

Cuadro AIV.6. Gasto público en becas y ayudas al estudio en Educación Primaria en las CCAA españolas, cursos 2000/01 - 2011/12 (miles de $€$ )

Cuadro AIV.7. Número de alumnos en Educación Primaria en las CCAA españolas, cursos 2000/01 - 2011/12 (miles de alumnos).

Cuadro AIV.8. Gasto público en becas y ayudas al estudio por alumno en ESO en las CCAA españolas, cursos 2000/01 - 2011/12 (€/alumno)

Cuadro AIV.9. Gasto público en becas y ayudas al estudio en ESO en las CCAA españolas, cursos 2000/01 - 2011/12 (miles de $€$ )

Cuadro AIV.10. Número de alumnos en ESO en las CCAA españolas, cursos 2000/01 - 2011/12 (miles de alumnos).

Cuadro AIV.11. Gasto público por alumno en becas y ayudas al estudio en educación secundaria segunda etapa (bachillerato y ciclos formativos de grado medio) en las CCAA españolas, cursos 2002/03 - 2011/12 (€/alumno).

Cuadro AIV.12. Gasto público en becas y ayudas al estudio en educación secundaria segunda etapa (bachillerato y ciclos formativos de grado medio) en las CCAA españolas, cursos 2002/03 - 2011/12 (miles de $€$ ).

Cuadro AIV.13. Número de alumnos en educación secundaria segunda etapa (bachillerato y ciclos formativos de grado medio) en las CCAA españolas, cursos 2002/03 - 2011/12.

Cuadro AIV.14. Distribución porcentual del alumnado de ESO en la enseñanza privada concertada en las CCAA españolas, cursos 2001/02 - 2011/12 (\%)

Cuadro AIV.15. Distribución porcentual del alumnado de ESO en la enseñanza privada no concertada en las CCAA españolas, cursos 2001/02 - 2011/12 (\%)..

Cuadro AIV.16. Distribución porcentual del gasto de educación no universitaria en conciertos y subvenciones a la enseñanza privada en las CCAA españolas, años $2000-2011$ (\%)

Cuadro AIV.17. PIB per cápita a precios constantes en las CCAA españolas, años 2000 - 2013 (€/habitante) 
Cuadro AIV.18. PIB a precios constantes en las CCAA españolas, años 2000 - 2013 (millones de $€$ )

Cuadro AIV.19. Número de habitantes en las CCAA españolas, años 2000 - 2013

(miles de habitantes)

Cuadro AIV.20. Tasas de crecimiento medio anual acumulativo del PIB per cápita, PIB total y número de habitantes.

Cuadro AIV.21. Tasa de riesgo de pobreza en las CCAA españolas, años 2004 $2013(\%)$

Cuadro AIV.22. Tasa de paro en las CCAA españolas, años 2002 - 2013 (\%)

Cuadro AIV.23. Tasa de paro de la población menor de 25 años en las CCAA españolas, años 2002 - 2013 (\%)

Cuadro AIV.24. Porcentaje de ocupados en el sector construcción en las CCAA españolas, años 2008 - 2013 (\%)

Cuadro AIV.25. Salario medio por trabajador menor de 25 años en las CCAA españolas, años 2004 - 2012 (€).

Cuadro AIV.26. Índice de descualificación de la población ocupada en las CCAA españolas, años 2002 - 2013 (\%) .

Cuadro AIV.27. Índice de descualificación de la población adulta en las CCAA españolas, años 2000 - 2012 (\%) .

Cuadro AIV.28. Proporción de la población inmigrante joven (15-24 años) en las CCAA españolas, años 2000 - 2011 (\%)

Cuadro AIV.29. Cálculo del índice de masculinidad de la población joven en las CCAA españolas, año 2013 y diferencias ( $n$ o de personas, \%)

Cuadro AIV.30. Cálculo de la proporción de hogares con tres o más hijos y hogares monoparentales en las CCAA españolas. Año 2013 y diferencias (miles de hogares, \%)

Cuadro AV.1. Resultados de parámetros de variables explicativas en regresión simple con tasa de abandono escolar temprano realizadas en el Capítulo 5 .

Cuadro AV.1. (continuación) Resultados de parámetros de variables explicativas en regresión simple con tasa de abandono escolar temprano realizadas en el Capítulo 5.

Cuadro AV.2. Resultados de la estimación de panel de datos agrupadas por MCO.....367

Cuadro AV.3. Resultados de la estimación de panel de datos con efectos fijos .368

Cuadro AV.4. Resultados de la estimación de panel de datos con efectos aleatorios

Cuadro AV.5. Resultados de la estimación de panel de datos de efectos fijos con efectos temporales 
Cuadro AV.6. Resultados de la estimación de panel de datos de efectos fijos con término autorregresivo de grado 1 y efectos temporales

Cuadro AV.7. Resultados de la estimación de panel de datos de efectos fijos incorporando efectos temporales por mínimos cuadrados generalizados factibles....372

Cuadro AV.8. Resultados de la estimación de panel de datos de efectos fijos incorporando efectos temporales por el método de estimadores con errores estándar corregidos para panel...... 
Introducción 

La frecuencia y notoriedad con la que problemas educativos como el abandono escolar temprano, el fracaso escolar o los resultados de los informes PISA (Programme for International Student Assessment) aparecen en los medios de comunicación no es baladí, sino reflejo de la importancia que la sociedad en su conjunto otorga al campo de la educación. Esta importancia tiene su raíz en la creencia, casi generalizada, de que la educación es un sector fundamental para el crecimiento económico y la mejora de la calidad de vida de los ciudadanos.

Esta preocupación, compartida por la práctica totalidad de países occidentales, tiene su reflejo en las cuantiosas partidas presupuestarias que se destinan al sistema educativo por parte del sector público. La proliferación de estudios e investigaciones por un lado, y de test de evaluación por otro, ponen también de manifiesto la importancia que se otorga a la educación.

Dentro del ámbito de la educación, el abandono escolar temprano es una de las principales preocupaciones. Tanto es así que la Comisión Europea ha incluido el indicador de abandono escolar temprano en sus programas de reformas estructurales, con el objetivo de que éste se vea reducido por debajo del $10 \%$ en el año 2020 . Esto se debe a la concepción compartida de que el abandono escolar temprano supone un problema que condiciona la formación de capital humano y su repercusión en la economía y que, por tanto, tiene unos costes en términos de competitividad, al considerar que la posición estratégica de la economía de la Unión Europea debe basarse en priorizar el conocimiento como fuente principal de crecimiento económico. Además, se confiere especial importancia a la reducción del abandono escolar temprano a la hora de fomentar la cohesión social.

El abandono escolar temprano es definido por Eurostat como la proporción de jóvenes de entre 18 y 24 años que tienen como estudios máximos superados la primera etapa de la educación secundaria (que en el sistema educativo español se corresponde con la Educación Secundaria Obligatoria) y que no están escolarizados ni recibiendo formación en la actualidad. Se trata, por lo tanto, de un indicador de resultados proyectado en una franja de edad en la que la escolarización no es obligatoria. Esto supone que en la generación del abandono escolar intervengan un 
amplio abanico de factores, no sólo educativos, sino también económicos, como los costes de oportunidad asociados a la escolarización postobligatoria en términos de empleo, que pueden suponer un factor de expulsión del sistema educativo.

Desde hace años, España presenta unos datos alarmantes, con unas tasas de abandono escolar temprano que doblan la media europea de forma persistente. El caso español es de especial singularidad, puesto que presenta unas amplias diferencias regionales. En este sentido, cuenta con comunidades autónomas como País Vasco y Navarra, con niveles en torno a la media europea; mientras que varias comunidades de la mitad sur han presentado históricamente niveles superiores al 30\% - 35\%.

El comportamiento dispar de las regiones españolas en cuanto al nivel de abandono escolar temprano es la fuente de la que surgen las principales preguntas de investigación de la presente tesis doctoral. ¿A qué se deben las marcadas diferencias entre comunidades autónomas en el nivel de abandono escolar temprano?. ¿Pueden tener éstas su origen en factores asociados al contexto educativo, económico o sociocultural a nivel regional? Estas preguntas dan origen al objetivo principal de esta investigación, que es realizar un estudio sobre la incidencia de los factores explicativos del abandono escolar temprano en las comunidades autónomas españolas. Junto a este objetivo principal, surgen otros objetivos complementarios, como investigar la relación que presenta el abandono escolar temprano con otros indicadores educativos, o la aproximación al perfil sociodemográfico de alumnado en riesgo de abandonar el sistema educativo de forma prematura.

Para llevar a término los objetivos anteriormente apuntados, se han empleado distintas metodologías. En primer lugar, es necesario señalar que para la recopilación de datos se han utilizado fundamentalmente las siguientes fuentes: la base de datos de Eurostat, elaborada por la Comisión Europea; las estadísticas de "Las Cifras de la Educación en España" y los mapas de indicadores del "Sistema Estatal de Indicadores de la Educación (SEIE)", elaborados por el Ministerio de Educación, Cultura y Deporte (MECD) y difundidos por el Instituto Nacional de Evaluación Educativa (INEE); y la Encuesta de Población Activa (EPA), realizada por el Instituto Nacional de Estadística (INE). No obstante, conviene tener en cuenta las limitaciones que presentan las 
fuentes de datos utilizadas, ya que, en la mayoría de las ocasiones, contienen información de muestras poblacionales, por lo que hay que tomar con cierta cautela los resultados obtenidos.

El periodo de estudio es, en términos generales, el comprendido entre el año 2000 y 2013. La elección de este periodo de referencia se justifica por coincidir con el desarrollo de las Estrategias de Lisboa y Estrategia Europa 2020. No obstante, dependiendo del tipo de variable utilizada, en ocasiones se ha considerado un periodo de estudio más acotado.

Para la búsqueda de las referencias bibliográficas, se han utilizado con asiduidad las bases de datos de Scopus, la Web of Science (WOS) y Dialnet, así como las distintas revistas electrónicas suscritas por la Biblioteca de la Universidad de Valladolid, entre otras. En cuanto al formato de las referencias bibliográficas, se corresponde con las normas de la APA (American Psychological Association) en su sexta edición, y para su recopilación y edición se ha utilizado la plataforma bibliográfica Refworks.

Las técnicas de análisis aplicadas han consistido en la utilización, en primer lugar, de análisis de regresión simple, que permite visualizar y explicar la relación de las distintas variables empleadas con el abandono escolar temprano de manera sencilla y directa. En segundo lugar, se han utilizado técnicas de panel de datos, con el objeto de dar respuesta a la necesidad de plantear un modelo multivariante. Para la representación gráfica de los análisis de regresión simples se ha utilizado el programa estadístico SPSS (Statistical Package for Social Sciences), y para el panel de datos STATA, mientras que el resto de tablas, cuadros y gráficos han sido editados con el tradicional paquete ofimático Microsoft Office.

Por otro lado, conviene señalar que parte del trabajo aquí desarrollado ha sido presentado como trabajo en curso en los siguientes congresos científicos:

- XXXVIII Reunión de Estudios Regionales, organizada por la Asociación Española de Ciencia Regional en Bilbao (noviembre de 2012).

- XI Jornadas Internacionales de Política Económica, organizadas por la Universidad de País Vasco en Bilbao (mayo de 2013). 
- XII Jornadas de la Asociación de la Economía de la Educación, organizadas por la Universidad de A Coruña en A Coruña (julio de 2013).

- XII Jornadas Internacionales de Política Económica, organizadas por la Universidad de Castilla-La Mancha en Toledo (mayo de 2015).

En relación a la estructura, la presente tesis doctoral se divide en seis capítulos, cuyo contenido se resume sucintamente a continuación. El primer capítulo, titulado "La importancia de la educación y el capital humano en el crecimiento y bienestar económico y social" resume las aportaciones de las principales teorías como la teoría del capital humano y sus alternativas. Se estudia el debate acerca de la influencia de la educación y el capital humano en el crecimiento económico. Por último, se presta atención a las externalidades positivas que presenta la educación en la economía y en el bienestar social. Por tanto, este primer capítulo sirve de introducción y justificación del tema que ocupa la tesis doctoral.

El segundo capítulo, denominado "El abandono escolar temprano como objetivo de los programas de reformas estructurales de la Unión Europea", estudia el papel que ha ocupado el abandono escolar temprano como objetivo en las políticas de reformas estructurales de la Unión Europea. En este contexto, se realiza una descripción de los objetivos principales de las estrategias de Lisboa, la Estrategia de Crecimiento y Empleo y la Estrategia Europa 2020. Este capítulo permite evidenciar la importancia que para la política al más alto nivel tiene el problema objeto de estudio en esta tesis.

En el tercer capítulo, denominado "El concepto y los factores explicativos del abandono escolar temprano", se definen los indicadores y definiciones utilizadas por los distintos organismos internacionales que tratan el problema del abandono escolar temprano, centrándose en la definición propuesta por Eurostat, que es la utilizada oficialmente en la Unión Europea, describiendo sus características, metodología de cálculo y limitaciones. En segundo lugar, se realiza una extensa revisión de la literatura acerca de los factores que se han identificado para explicar el fenómeno aquí estudiado, y que se estructuran en tres bloques: educativo, económico y socio-cultural. 
En el capítulo cuatro, titulado "Análisis de evolución y caracterización del abandono escolar temprano en las comunidades autónomas españolas", se estudia el problema concreto del abandono escolar temprano y sus características. Se investiga la evolución del indicador, estableciendo un análisis comparativo con el resto de países de la Unión Europea, se realiza un perfil del alumnado que abandona prematuramente los estudios, y, por último, se estudia la evolución, situación y relación de distintos indicadores educativos tales como el fracaso escolar, tasas de idoneidad, o resultados de los principales test de adquisición de competencias del alumnado, entre otros, con el abandono escolar temprano, con el objeto de comprobar la relación endógena de éste con otros indicadores.

El capítulo cinco, que lleva por título "Análisis de los factores explicativos del abandono escolar temprano en las comunidades autónomas españolas", analiza individualmente la evolución y la situación regional de las distintas variables extraídas de la literatura, susceptibles de influir en la tasa de abandono escolar temprano. El análisis se realiza desde una perspectiva regional, estudiando la posible relación de cada variable utilizada con el abandono escolar temprano.

El capítulo seis, denominado "Un análisis de panel de datos de los factores explicativos del abandono escolar temprano" recoge el modelo multivariante empleado, que consiste en la realización de estimaciones de panel de datos con una selección de variables extraídas de la literatura y del análisis individual de variables realizado en el capítulo cinco. En este capítulo además, se lleva a cabo una discusión de los resultados teniendo en cuenta tanto el panel de datos como las regresiones realizadas anteriormente, estableciendo comparaciones con los resultados obtenidos por otros trabajos e investigaciones.

Finalmente, se exponen las principales conclusiones que se extraen de esta tesis doctoral y se recogen las referencias bibliográficas utilizadas, así como los distintos anexos que completan la información y los análisis descritos a lo largo de la tesis doctoral.

En definitiva, la presente investigación trata de arrojar luz sobre un problema que constituye una máxima prioridad para las políticas públicas, adoptando un 
enfoque regional, que permite observar el grado en el que factores asociados al contexto de cada región han influido en el nivel de su tasa de abandono escolar temprano. 
Capítulo 1: La importancia de la educación y el capital humano en el crecimiento y bienestar económico y social 



\subsection{Introducción}

Comprender las motivaciones que fundamentan el objeto de estudio en cualquier investigación es un factor clave para entender la conexión que ésta tiene entre la teoría existente y la evidencia empírica. En este sentido, el primer capítulo de esta tesis doctoral tiene por objetivo sintetizar las principales teorías y estudios empíricos que se han ocupado de mostrar la relevancia que la educación tiene para el crecimiento y bienestar económico y social de los distintos países.

Para ello, en primer lugar se describe sucintamente el origen de la economía de la educación, haciendo referencia a los economistas pioneros que sentaron precedente en esta disciplina. La descripción de la teoría del capital humano, así como sus principales características y alternativas planteadas constituyen el núcleo de este primer epígrafe.

Un segundo punto desarrolla los principales modelos de crecimiento económico que han incluido formalmente el capital humano en sus especificaciones, para, en un tercer epígrafe, analizar el estado de la cuestión sobre la discusión, todavía hoy activa, que la literatura ha desarrollado durante los últimos treinta años sobre el impacto del capital humano en el crecimiento económico.

En el cuarto epígrafe se resumen los impactos indirectos y externalidades que la educación y la formación produce sobre la economía y el bienestar social en general. Por último, se realiza un breve epígrafe que resume las principales conclusiones del presente capítulo.

\subsection{La economía de la educación, la teoría del capital humano y sus alternativas}

\subsubsection{El origen de la economía de la educación}

Como apuntan Carnoy, Miller y Luschei (2005), la economía de la educación es una disciplina relativamente nueva, cuyo desarrollo y expansión se concreta en los últimos cincuenta años, como consecuencia de la importancia de la educación en un 
contexto de economía globalizada, a causa del incremento de la producción de bienes y servicios basados en conocimiento.

En este sentido, según Carnoy et al. (2005), existen tres razones fundamentales por las cuales los estudiosos de la economía están interesados en investigar en la educación:

- En casi la totalidad de países del mundo el gasto en educación constituye una proporción muy importante de los presupuestos públicos y privados.

- El sistema educativo es uno de los empleadores más importantes de mano de obra cualificada.

- La mayoría de los gobiernos sostiene la premisa de que, en un contexto de economía globalizada basada en el conocimiento como la actual, la existencia de un stock de capital humano cualificado está relacionada con un incremento del crecimiento económico.

El propio Adam Smith ya sostuvo que el nivel de conocimientos de la población constituía un motor para garantizar el progreso económico, por lo que lo incluyó dentro de la definición clásica de capital. Sin embargo, Smith consideraba el trabajo como un factor homogéneo, ya que la mayoría de la mano de obra existente era de carácter agrícola.

La concepción del trabajo como un factor homogéneo fue también considerada por economistas clásicos como John Stuart Mill, David Ricardo y Karl Marx. Más adelante, Irving Fisher transformó las concepciones sobre el trabajo, ya que su definición de capital incluía las habilidades propias del individuo.

En la teoría keynesiana, la educación es considerada como un bien de consumo desde una óptica destinada a contabilizar la renta nacional. Por el contrario, la formación en el trabajo constituía una inversión que realiza el empresario con el objetivo de obtener una rentabilidad futura de la misma. En este sentido, esta concepción de la educación como bien de consumo impedía imputarla como factor de crecimiento económico. 
Así pues, no fue hasta después de la segunda guerra mundial cuando empezó a conformarse la teoría del capital humano, a raíz del interés por explicar el crecimiento económico registrado por las economías de varios países; y la desigualdad salarial, cuya base se fundamentaba en las rentas percibidas por el trabajo.

Con el objetivo de establecer un punto de partida, son varios los autores que identifican el discurso del economista norteamericano Theodore Schultz en la reunión anual de la AEA (American Economic Association) en 1960 como nacimiento de la disciplina de la economía de la educación. En este discurso, Schultz (1961) ${ }^{1}$ habla por primera vez de capital humano como un concepto al que se puede atribuir y asimilar conocimientos como consecuencia de una decisión de inversión premeditada, y por la que se explica una parte del crecimiento económico agregado.

Por otro lado, Blaug (1982) es también considerado uno de los padres de la economía de la educación, que la define como una rama específica de la economía que estudia el papel que juega la educación como factor del desarrollo económico².

\subsubsection{La teoría del capital humano}

La teoría económica tradicionalmente ha modelizado la educación como si de otro bien se tratara y ha planteado la demanda educativa como una elección de los individuos y de la sociedad entre los costes y los beneficios que están asociados a la decisión de inversión en la misma.

Los pioneros de la teoría del capital humano fueron Schultz, (1960 y 1961), Becker $(1962,1964)$ y Mincer (1974); todos ellos provenientes de la Universidad de Chicago, consideraban la inversión educativa susceptible de ser planteada como un cálculo económico, por lo que establecieron la hipótesis de que la productividad de un individuo depende de su dotación de capital humano. Desde este punto de vista, individuos y sociedades han invertido sucesivamente en formación de capital humano

\footnotetext{
${ }^{1}$ El discurso pronunciado en diciembre de 1960 fue publicado al año siguiente en el trabajo titulado "Investment in Human Capital" por la American Economic Review, no 51 (1961).

2 Esta definición aparece en el prólogo del libro "Introducción a la economía de la educación", de Blaug (1982).
} 
hasta llegar al punto donde el rendimiento marginal de su inversión es igual al rendimiento en otras inversiones alternativas.

Así pues, los individuos han invertido en educación en previsión de una obtención futura de renta mayor, y los estados han acompañado este esfuerzo como medio de inversión en la capacidad productiva futura del país. De este planteamiento se deduce que las capacidades de los individuos se pueden adquirir, y por tanto, no son innatas; es decir, se desarrollan a través de la familia, el sistema educativo y el aprendizaje adquirido en el puesto de trabajo.

Como señalan Lassibille y Navarro Gómez (2004), a pesar de las similitudes con el capital físico, el capital humano plantea una serie de peculiaridades que conviene discernir. En primer lugar, el capital humano es inherente a las personas, y por tanto, no se puede disociar, por lo que éste influye en todas las actividades que realiza el individuo, ya que constituye un activo del que los individuos no se pueden deshacer.

Por su parte, la ONU (Organización de Naciones Unidas) describe el capital humano como aquel bien productivo que integra trabajo, habilidades y conocimientos (United Nations, 1997), mientras que la OCDE (Organización para la Cooperación y el Desarrollo Económico) lo define como "el conocimiento, habilidades, competencias y atributos integrados en los individuos que facilitan la creación de bienestar económico, social y personal" (OECD, 2001a).

En concreto, la aportación de las ideas de la teoría del capital humano se sintetiza en las tasas de rendimiento interno privadas y públicas de la educación, que se determinan en función de la comparación del conjunto de costes que se derivan de la inversión en capital humano, con los beneficios que ésta reporta, tanto a nivel privado como a nivel social.

Por el lado de los beneficios, éstos se pueden clasificar según su naturaleza, en monetarios o no monetarios, y dentro de estos, en privados o sociales. El beneficio monetario es el mayor nivel de remuneración que percibe un individuo debido a su mayor productividad, que a su vez es consecuencia de su mayor cualificación, y que se ha corroborado a lo largo de la historia en numerosos estudios de perfiles de renta, según los cuales, existe una correlación positiva entre las rentas del mercado de 
trabajo y la cualificación obtenida por los individuos en el sistema educativo. Además de la mayor remuneración, según esta teoría, la educación confiere a los individuos dotes organizativas y financieras que se traducen en una mayor eficiencia en la producción de bienes económicos.

Los beneficios no monetarios, por otro lado, contribuyen a una mayor cultura, acceso a la información, mayor estatus social, mejores hábitos sanitarios y comportamiento cívico de los individuos, lo que redunda en unos beneficios sociales que están asociados a una menor tasa de criminalidad, mayor tendencia a la democratización de la sociedad, libertad de expresión y mejora de las actitudes y valores sociales. En definitiva, según la teoría del capital humano, la educación contribuye directa e indirectamente al aumento del bienestar del individuo y de la sociedad.

En el otro lado de la balanza se sitúan los costes que supone la demanda de educación, que también pueden ser privados o públicos. Dentro de los costes privados, es decir, aquellos que son soportados por los individuos, podemos distinguir entre los siguientes:

- Costes directos de escolaridad: Aquellos que están directamente relacionados con el desarrollo de la actividad educativa, como pueden ser los gastos de matrícula, libros de texto y material escolar, entre otros.

- Costes complementarios, que están asociados con la escolaridad, como son los gastos de transporte, comedor escolar, residencia, entre otros.

- Costes de oportunidad, que se corresponden con las rentas a las que los individuos renuncian al permanecer formándose.

Desde una perspectiva pública, los costes en educación se corresponderían con los que se detallan a continuación:

- Costes públicos: Engloban todos los gastos destinados a garantizar el correcto funcionamiento del entramado del sistema educativo de un estado. Entre otros, destacan los gastos en infraestructuras, los salarios del personal docente y de servicios, gastos en material escolar, equipamiento y gastos corrientes, como puede ser la electricidad o la calefacción. 
- Costes de transferencias: Se trata de las becas y ayudas al estudio que ponen a disposición las administraciones públicas para subvencionar la actividad educativa de aquellas personas que cumplen unos requisitos previamente determinados.

- Costes de oportunidad, que de forma similar al caso de los individuos se derivan de la renuncia a destinar recursos a otras partidas presupuestarias.

Recogiendo lo anterior, la teoría del capital humano sintetiza la disyuntiva de inversión educativa mediante el cálculo de la tasa de rendimiento interno de la educación, que se realiza aplicando de forma análoga una tasa de rendimiento interno:

$$
V_{t}=\frac{E_{t}}{(1+r)^{t}}
$$

donde " $V_{t}$ " es el valor actual de una cantidad futura esperada " $E_{t}$ " percibida dentro de años " $t$ " a una tasa de descuento " $r$ ".

De la misma manera, se puede calcular el valor actual tanto de los beneficios como de los costes de la educación, en cuyo caso la tasa de rendimiento interno de la educación " $i$ " sería el tipo de interés que hace que el valor actual de beneficios de la inversión en el futuro sea igual al coste actual, es decir:

$$
\sum_{t=N+1}^{T} \frac{E_{t}}{(1+i)^{t}}=\sum_{t=1}^{N} \frac{C_{t}}{(1+i)^{t}}
$$

, donde " $N$ " representa la duración del tiempo de formación y " $T$ " es la duración de la vida laboral del capital humano.

Esta tasa de rendimiento de la educación mide la rentabilidad marginal de alcanzar un determinado nivel educativo, de forma que cuanto más alta sea la tasa de rendimiento de un nivel educativo, más atractivo representa para el individuo desde el punto de vista financiero, y por tanto, tendrá un mayor nivel de demanda de educación. 
Otra de las formulaciones más utilizadas son las ecuaciones desarrolladas por Mincer (1974), que desarrolló las denominadas funciones de ganancias a partir de la siguiente expresión logarítmica:

$$
\operatorname{Ln} Y_{i t}=\beta_{0}+\beta_{1} E+\beta_{2} T-\beta_{3} T^{2}+\varepsilon_{i t}
$$

, donde " $\mathrm{Y}$ " representa las ganancias del individuo " $\mathrm{i}$ " en el periodo temporal " $t$ ", que depende del nivel educativo obtenido " $E$ " $y$ el tiempo " $T$ " invertido en educación postobligatoria ${ }^{3}$, constituyendo la base del estudio microeconómico de los retornos de la educación. Cabe mencionar además que esta especificación se desarrolla bajo la aceptación de los siguientes supuestos:

- La educación es un bien de inversión.

- Existe información perfecta.

- No hay restricciones en el mercado de capitales.

- La inversión en educación post-obligatoria supone reducir el tiempo de trabajo.

De esta forma, las formulaciones de la teoría del capital humano proporcionan una información sintética que puede orientar las decisiones de la política económica y educativa teniendo en cuenta un criterio de rentabilidad económica y social, y verifica la premisa por la cual la educación y la formación son una forma de inversión privada y pública en individuos con vistas a obtener unos ingresos de rentas mayores en el futuro, que se fundamenta en la relación de causalidad entre la productividad del trabajador y el nivel formativo alcanzado por este.

\subsubsection{Alternativas a la teoría del capital humano}

Desde los años setenta, la teoría del capital humano ha sido objeto de críticas que ponían en tela de juicio sus postulados fundamentándose, principalmente, en que la relación entre la productividad de los individuos y su nivel formativo o educación adquirida se basaba en una mera observación intuitiva, pero no en una demostración

\footnotetext{
${ }^{3}$ Mincer (1974) considera la especificación cuadrática de este término en la función de ganancias con el objetivo de recoger la concavidad observada en el perfil de edad - ganancias.
} 
empírica. Entre estas teorías alternativas destacan la teoría de la segmentación, la teoría del filtro, la teoría institucionalista, la teoría de la socialización y la teoría del consumo.

No obstante, pese a presentar enfoques alternativos interesantes, y a que han renovado el estudio de las externalidades de la educación, algunos autores como Lassibille y Navarro Gómez (2012) consideran que no existe, por el momento, una contrastación empírica alternativa que sea robusta y coherente.

\subsubsection{La teoría de la segmentación}

Desarrollada por Doeringer y Piore (1971), la teoría de la segmentación o teoría de los mercados de trabajo segmentados concreta su crítica a los fundamentos de la teoría del capital humano a través de la explicación de la estructura del mercado de trabajo. En este sentido, esta teoría propone una estructura de mercado de trabajo dual, formada por un sector primario, con salarios elevados y contratos de carácter indefinido; y por un sector secundario, caracterizado por suministrar salarios bajos y contratos de carácter temporal. Ambos sectores del mercado de trabajo se caracterizarían por tener unos requisitos de acceso predeterminados y un sistema de funcionamiento distinto.

De esta forma, el sector primario estaría formado por mercados de trabajo internos, regidos por un conjunto de reglas y procedimientos administrativos independientes de las fuerzas económicas, cuyo acceso estaría justificado por la caracterización de puestos de trabajo con mayor responsabilidad y con unos requisitos de formación más altos (Doeringer y Piore, 1971); mientras que el sector secundario lo formarían los mercados de trabajo externos, cuyo funcionamiento es similar al de un mercado de subastas, basado en una mayor competitividad y flexibilidad laboral. Además, esta teoría apunta a que una vez dentro del mercado de trabajo secundario, la movilidad hacia el primario plantea muchas dificultades.

Ante la estructura segmentada del trabajo, esta teoría argumenta que la renta del trabajo que perciben los individuos está asociada al segmento de trabajo en que éste se encuentra, relegando el papel de la educación y la formación como posible 
requisito de acceso a ciertos segmentos de empleo. En esta dinámica, las rentas percibidas por el trabajo dependen de los atributos y elecciones que el individuo ha realizado y de las elecciones del empresario y las características del mercado de trabajo en el que se encuentra.

En un trabajo aplicado al mercado de trabajo británico, Leontaridi (2002) corrobora la existencia de diferencias en los retornos de la educación entre los dos segmentos del mercado de trabajo apuntados por Doeringer y Piore (1971), que se ponen de manifiesto especialmente a través de la existencia de mecanismos de promoción y movilidad en la carrera laboral. No obstante, en un trabajo previo, el mismo autor (Leontaridi, 1998) realiza una revisión de las principales aportaciones teóricas que han estudiado la evidencia de esta estructura de segmentación de mercados, concluyendo que queda patente la falta de consenso producida por la ausencia de un modelo formal y consistente que pruebe los postulados de esta teoría.

\subsubsection{Las teoría del filtro y la señalización}

La teoría del filtro es, probablemente, la teoría alternativa al capital humano que más desarrollos y debate ha suscitado. Formulada por Arrow (1973), desarrollada por Spence (1973) y Stigliz (1975), y caracterizada por disponer de una multiplicidad de denominaciones como teoría credencialista, de la certificación, señalización o identificación, posiciona a la educación y la formación recibida por el individuo como un revelador de sus aptitudes y capacidades innatas, de forma que ésta no aumenta per se su productividad en el trabajo. Por consiguiente, en este modelo la educación es utilizada por las empresas como indicador de productividad probable, en base al cual éstas toman las decisiones de contratación.

Bajo estos modelos subyace la idea de que los conocimientos adquiridos en la enseñanza son en ocasiones generalistas y que su eficacia en el mundo profesional no está contrastada (Wiles, 1974). De esta forma, los niveles o certificaciones educativas o formativas alcanzados tiene una función informativa e identificativa, cuya inversión se justifica en el ahorro para los empresarios a la hora de establecer un sistema de elección de su fuerza laboral, y que se justificaría en el supuesto de que no existe información perfecta, sino que ésta es imperfecta y asimétrica. 
Por consiguiente, y en contraposición a la teoría del capital humano, la relación de causalidad entre el nivel educativo alcanzado y el nivel de rentas percibido se debe a que el primer término es un revelador de las capacidades y aptitudes del individuo, y por tanto, de su productividad.

Dentro de la teoría del filtro se pueden establecer, a su vez, dos modelos:

- El modelo de señalización (Spence, 1973), en el que la educación supone un incremento de los ingresos por el mero hecho de poseerla, siendo identificada por el empresario como un indicador de la productividad esperada del trabajador.

- El modelo de filtro (Arrow, 1973; Rotchschild y Stigliz, 1976), en el que la educación alcanzada por el trabajador es utilizada como criterio de selección y clasificación para diferentes puestos de trabajo; es decir, según este modelo, el nivel educativo sería un instrumento que permite asignar los puestos de trabajo a los individuos según su nivel de eficiencia relativa. Según este modelo, que distingue a los individuos en dos grupos en base a su habilidad o capacidad; los individuos más capaces se verían obligados a adquirir un nivel de educación más alto del que estrictamente necesitan para ocupar los puestos asociados al salario que desean, con el objetivo de diferenciarse de los trabajadores menos capaces. Este fenómeno supondría, de hecho, una ineficiencia en el sentido de Pareto (De la Rica e Iza, 1999).

Por su parte, Layard y Psacharopoulos (1974) evalúan la veracidad de la teoría del filtro mediante la aplicación de contrastes. Por un lado, encuentran que los trabajadores que habían comenzado pero no completado una formación de tipo universitaria habían obtenido unos salarios comparativamente mayores que sus trabajadores análogos que no habían iniciado este tipo de formación, de lo que concluyen que más que el título, la formación recibida era la explicación a este diferencial.

Un segundo contraste plantea la incoherencia de la hipótesis de identificación, a través de la observación de trabajadores con alto nivel formativo que aumentan sus salarios a lo largo del tiempo a un nivel más rápido comparativamente con los 
trabajadores de niveles educativos inferiores. Otros estudios, como el de Horowitz y Sherman (1980) evidencian también los postulados de la teoría del filtro, demostrando que sí existe una relación entre educación y productividad.

Sin embargo, diversos estudios han obtenido resultados contradictorios. En este sentido, estudios pioneros como el de Willis y Rosen (1979) demostraron que la decisión de matricularse en enseñanzas universitarias dependía positivamente de la renta futura esperada. De forma similar, Hungerford y Solon (1987) testan el concepto de sheepskin effect, referido al efecto relativo de la adquisición de títulos educativos sobre el resto de individuos que no los poseen, demostrando su veracidad a través de la encuesta de población activa de Estados Unidos (CPS, Current Population Survey). De la misma manera, Heywood (1994) obtiene resultados similares, aunque su significatividad se reduce al caso de algún determinado sector de la economía. Esta distinción entre sectores también fue apuntada por Riley (1979), que esgrime que la señalización es significativa en aquellos sectores en donde la productividad del trabajo es difícil de medir.

No obstante, estos trabajos son cuestionados por otros estudios como el de Groot y Oosterbeek (1994), que arguyen que la teoría de la señalización es incapaz de observar efectos como los que generan la repetición de curso o el abandono temprano de los estudios; o como el trabajo posterior de Riley (2001), que recoge el devenir de estas teorías en los últimos 25 años y denota la falta de capacidad explicativa de estos modelos a la hora de argumentar el comportamiento racional de abandonar los estudios de forma temprana por parte de los individuos.

Para el caso español, destaca el trabajo de Valiente García (2003), en el que realiza una estimación del rendimiento de la decisión de inversión educativa, obteniendo que el nivel máximo de estudios alcanzado tiene una mayor capacidad explicativa que el número medio de años de escolarización, lo que supone un posible argumento de la veracidad de la teoría del filtro. Por su parte, Landeras y Pérez de Villarreal (2003) apuntan a la existencia de ruidos que distorsionan la capacidad reveladora de las titulaciones, poniendo en tela de juicio el supuesto de las certificaciones como filtro perfecto. También son destacables los trabajos 
desarrollados por Corugedo, García Pérez y Martínez Pagés (1990 y 1992) y Corugedo de las Cuevas, García y Martínez (1991), en los que se demuestran las diferencias de obtener un título para el caso de las enseñanzas medias, lo que pone de manifiesto la validez de las teorías de la señalización.

En cualquier caso, la desconfianza mostrada por buena parte de los teóricos de la economía de la educación se ha basado en la consideración de las hipótesis de la señalización y el filtro como fundamentos axiomáticos demasiado cerrados (Brown y Sessions, 2004). Sin embargo, algunos trabajos destacados ponen en tela de juicio estos supuestos y ubican el rol de estas teorías como un complemento, más que una alternativa, a los fundamentos de la teoría del capital humano (Spence, 2002; San Segundo, 2001), sugiriendo un rol dual - de señalización y de contribución a la productividad - de la educación. El espíritu de este postulado ya lo recogía Wolpin (1977), que en su trabajo concluía que "el hecho de que la educación desempeñe una función de señalización de las capacidades innatas es tan difícil de negar como la afirmación de que la educación aumenta esas capacidades innatas".

\subsubsection{La teoría de la competencia por los puestos de trabajo}

La teoría de la competencia por los puestos de trabajo, también denominada teoría institucionalista o teoría de la cola, y desarrollada en los trabajos de Thurow (1975) y Thurow y Lucas (1972), establece que la productividad de los trabajadores es una función del trabajo y no un rasgo identificativo de los trabajadores. Es decir, la productividad y por tanto, los salarios, están ligados a los puestos de trabajo más que a las personas.

Para esta teoría, la cualificación obtenida en el sistema educativo no es más que una señal visible mediante la cual el empresario evalúa la capacidad de adquirir formación del individuo, es decir, su entrenabilidad. Por ello, es considerada una derivación de la teoría del filtro. Esta teoría establece que el orden de preferencia a la hora de acceder a un puesto de trabajo está determinado en base a las cualidades inherentes (innatas y no modificables) y adquiridas de los trabajadores; y el salario de estos estaría determinado por la posición relativa que ocupa en la cola de trabajo. 
Por otro lado, Thurow (1975) diferencia entre formación general y formación específica, siendo la segunda la adquirida en el puesto de trabajo, que constituye un instrumento de adaptación al mundo profesional. Así pues, los trabajadores ya dentro del mercado de trabajo tendrían una ventaja comparativa respecto a los trabajadores que aún no están dentro.

Empíricamente, también destaca la ausencia de un modelo robusto. A modo de ejemplo, el trabajo de Van Ours y Ridder (1995) para el caso holandés sostiene que esta caracterización del mercado de trabajo, por la que los individuos compiten entre sí por los puestos de trabajo es sólo factible para el caso de individuos con un alto nivel educativo, mientras que para aquellos con estudios medios o básicos este supuesto no es verificable. Khalifa (2010) por su parte realiza un trabajo empírico para el caso de los Estados Unidos en el que corrobora las hipótesis de esta teoría.

Cabe mencionar, por otro lado, que los desarrollos de este modelo teórico han propiciado el estudio de fenómenos como la sobre-educación (over-schooling) y el crowding-out, proceso por el que los trabajadores con más cualificaciones desplazan en la cola de trabajo al resto, al ocupar los primeros puestos de trabajo de baja cualificación. Entre los numerosos trabajos en este campo merece la pena señalar aportaciones como las de Duncan y Hoffman (1981), Dolado, Felgueroso y Jimeno (2000), Gautier, Van der Berg, Van Ours y Ridder (2002), y Leuven y Oosterbeek, (2011), entre otras.

\subsubsection{La teoría del consumo}

Los economistas Kodde y Ritzen (1984), principales referencias de esta teoría, plantean que los individuos derivan utilidad del tiempo que invierten en el aprendizaje, y que por tanto, éste tiene la misma dinámica que un bien normal, es decir, depende positivamente de la renta disponible y negativamente de los costes que el aprendizaje supone.

Leuven y Oosterbeek (2011) apuntan que el hecho de que los individuos deriven utilidad y satisfacción del consumo de educación lleva a explicar por qué algunos individuos invierten en educación más de lo que su trabajo o expectativa de 
trabajo requiere (over-schooling) o menos de lo requerido para desempeñar el puesto que ocupan (under-schooling). De la misma manera, el estudio aplicado al caso de los Estados Unidos realizado por Gottschalk y Hansen (2003) también introduce la importancia de la heterogeneidad de las preferencias como explicación del incremento de trabajadores sobre-cualificados en puestos de trabajo que no requieren un alto nivel formativo. Ello induciría que los trabajadores han optado por adquirir un nivel determinado de educación y formación no sólo por la expectativa de salario, sino también por la utilidad derivada de la educación recibida.

No obstante, las investigaciones empíricas para contrastar esta teoría han llevado a la confluencia con otros modelos que sostiene una concepción de la educación como inversión, desarrollando un modelo mixto en el que los individuos demandan educación en función de la utilidad derivada del aprendizaje y de la esperanza de una retribución salarial futura mayor. En definitiva, los planteamientos de este modelo teórico suponen que los individuos invertirían una cantidad mayor que la óptima en el modelo de capital humano, ya que se considera la función de la educación como bien de consumo y como bien de inversión de manera simultánea.

\subsubsection{La teoría de la socialización}

Formulada por los economistas Bowles y Gintis (1975 y 1976), representantes de la escuela radical norteamericana, desarrollaron una teoría fundamentada en un enfoque marxista según la cual el papel de la educación consistía en socializar a los individuos, asociando por tanto al sistema educativo el papel de integrador en el sistema de producción capitalista y de reproductor de sus valores sociales.

En este sentido, la educación sería un mecanismo transmisor de la clase y el estatus social de forma intergeneracional. Esta teoría, también sustentada por las aportaciones de sociólogos como Bernstein (1977), establece que la pertenencia a una determinada clase social induce unos códigos y hábitos culturales que determinan el éxito futuro de los individuos y que por tanto, no existiría una relación de causalidad probada entre la cantidad de educación recibida y las rentas obtenidas que explicara las diferencias en cuanto a riqueza. Así pues, y a diferencia de la teoría del capital humano, la teoría de la socialización introduce la influencia del origen socioeconómico 
como el determinante clave del nivel de rentas alcanzado y de la cantidad de educación y formación recibida.

Más recientemente se han realizado estudios como el de Bowles y Gintis (2002), que demuestran el papel que juega la transmisión intergeneracional de la desigualdad de las rentas recibidas por las generaciones futuras. Por otro lado, Rumberger (2010) encuentra, para el caso norteamericano, una relación fuerte entre origen socioeconómico y desempeño académico, pero una relación modesta con los salarios, lo que atenúa la importancia del concepto de transmisión intergeneracional en la determinación de los salarios.

Como conclusión a este epígrafe, queda patente la divergencia de argumentos entre la teoría del capital humano y sus críticas, entre las que han destacado las teorías credencialistas. Asimismo, es necesario tomar con precaución cada uno de los postulados de estas teorías, teniendo en cuenta cada punto de vista para completar una visión más amplia del funcionamiento de la demanda de educación, habida cuenta de los ambiguos resultados obtenidos en los numerosos contrastes empíricos que se han realizado.

\subsection{El papel de la educación y el capital humano en el crecimiento económico}

Una vez realizada una revisión a la teoría del capital humano y las diferentes teorías críticas que la complementan, es preciso analizar el papel que juega la educación en el crecimiento económico de forma agregada, desde su inclusión formal en los primeros modelos de crecimiento hasta la discusión sobre el alcance de esta relación que la literatura ha producido en las últimas décadas, como consecuencia del aumento del interés por parte de numerosos economistas a partir de la segunda mitad del siglo XX.

Tal y como se ha especificado en el epígrafe 1.2.2. , la teoría del capital humano relaciona positivamente la educación recibida por el individuo con su productividad en el trabajo, y por lo tanto, la renta que éste percibe se ve incrementada. Esta relación establecida a nivel individual posee influencia en el ámbito 
macroeconómico, ya que si la mejora del capital humano permite el aumento de la productividad de los individuos, ello tiene también una influencia positiva sobre el nivel de desarrollo económico de los países. En este sentido, autores como Heckman y Klenow (1997) y Krueger y Lindahl (2001) han desarrollado comparaciones que relacionan los estudios empíricos microeconómicos que utilizan las denominadas ecuaciones mincerianas, con los trabajos que analizan la importancia de la educación en el ámbito macroeconómico, obteniendo resultados similares.

Merece la pena señalar trabajos pioneros como el de Nelson y Phelps (1966), Jorgenson y Griliches (1967) o el de Denison (1962), que realizó una medición de la contribución de la educación al crecimiento económico de los Estados Unidos entre 1930 y 1960, utilizando para ello una función de producción de Cobb - Douglas. En este estudio, Denison (1962) llegó a la conclusión de que el 23\% del crecimiento económico registrado por la economía norteamericana en el periodo señalado venía efectivamente explicado por el stock de capital humano.

\subsubsection{Los modelos de crecimiento exógeno: El modelo de crecimiento de}

\section{Solow}

Los modelos de crecimiento económico exógeno son aquellos que se caracterizan por la inclusión de variables que inciden en el crecimiento de manera exógena. El modelo de Harrod-Dommar puede ser considerado el punto de partida de los posteriores modelos de crecimiento. Desarrollado por los economistas keynesianos Harrod (1939) y Domar (1946), son modelos formulados de manera independiente pero que en la literatura aparecen de forma conjunta, dado que llegaron a conclusiones similares. El modelo de Harrod-Domar, en definitiva, se fundamentaba en la búsqueda de condiciones necesarias (y exógenas) para conseguir una situación de crecimiento limitado por la demanda y la inversión. No obstante, el presente epígrafe incluye el desarrollo del modelo de Solow, dado que sirve de referencia para la explicación posterior de la inclusión del capital humano. 


\subsubsection{Primera versión}

El modelo de crecimiento de Solow (1956), basado en las premisas de la teoría neoclásica, es en primera instancia un modelo que no considera el progreso técnico ni el capital humano como fuente de crecimiento económico. De esta forma, el modelo de crecimiento de Solow, en su primera versión, establece que en la economía de un país se produce y consume un único bien " $Y$ ", utilizando para ello dos factores productivos: el capital físico " $K$ " y el trabajo " $L$ ", simplificados en una función de tipo Cobb - Douglas con rendimientos de escala constantes, por lo que:

$$
Y=F(K, L)=K^{\propto} L^{1-\propto}
$$

, donde " $\propto$ " es la elasticidad que representa la participación relativa de los factores y toma valores comprendidos entre 0 y 1 . A partir de esta función, podemos calcular el producto per cápita " $y$ " a través de la siguiente ecuación:

$$
y=\frac{Y}{L}=f(k)=\frac{K^{\propto} L^{1-\propto}}{L}=\left(\frac{K}{L}\right)^{\propto}=k^{\propto}
$$

Esta expresión del producto per cápita constituye la primera ecuación fundamental del modelo de Solow. Por lo tanto, el primer modelo de crecimiento de Solow establece que el producto per cápita es una función de la cantidad empleada de capital por trabajador " $k$ ".

La segunda ecuación fundamental del modelo de crecimiento de Solow es la que determina el aumento del stock de capital por trabajador, representado por el término " $k$ ". Para ello, suponiendo que la economía es cerrada y que por tanto la inversión en capital es igual al ahorro, el aumento del stock de capital humano vendría dado por:

$$
\dot{k}=s f(k)-(\delta+n) k
$$

, donde " $s$ " representa la proporción de la renta destinada al ahorro, " $\delta$ " refleja la tasa de depreciación del capital y " $n$ " la tasa de crecimiento de la población. En esta expresión, tanto la tasa de depreciación del capital como la tasa de crecimiento de la 
población son valores constantes y mayores que cero. Como se puede observar, la acumulación de stock de capital por trabajador en una economía depende positivamente de la tasa de ahorro del mismo y negativamente tanto de la tasa de depreciación del capital como de la tasa de crecimiento demográfico.

La especificación de las dos ecuaciones fundamentales del modelo de crecimiento de Solow marcan el funcionamiento de la economía de un país. La primera determina, dada una situación inicial concreta, el nivel de producción por trabajador de una economía, mientras que la segunda ecuación refleja la variación del stock de capital per cápita en el siguiente periodo.

De esta forma, la economía se desarrollaría hasta llegar a un llamado "estado estacionario", en el que la tasa de crecimiento del capital y de la producción - ambas en términos per cápita - serían iguales a cero, y por consiguiente, la producción y el capital por trabajador no variarían, es decir, la economía se encontraría en una situación de equilibrio.

\subsubsection{Introducción del progreso técnico}

El postulado del primer modelo de crecimiento de Solow establece que en el largo plazo, las economías no pueden crecer sine die, una afirmación que en la observación no encontraba su contrastación empírica, debido al prolongado crecimiento de algunos países, que no estaba explicado por el incremento de la tasa de crecimiento experimentada por el capital físico. Es por ello por lo que en 1957, Solow de nuevo, plantea la inclusión en el modelo del denominado progreso técnico (Solow, 1957).

Este progreso técnico, de carácter exógeno, tiene la capacidad de influir sobre la eficiencia del trabajo, por lo que en la especificación de la función de producción de una economía, se ajustaría de la siguiente forma:

$$
Y=F(K, E L)=K^{\propto}(E L)^{1-\propto}
$$

, donde la variable " $E$ " es la eficiencia del trabajo, que representa los conocimientos y aptitudes que poseen los individuos de una sociedad concreta sobre 
los métodos de producción. Cuanto mejor es la tecnología existente, la eficiencia del trabajo aumenta, influyendo positivamente en la productividad del factor trabajo.

El progreso técnico según el modelo de crecimiento de Solow crece a una tasa constante, por lo que, de manera análoga al epígrafe anterior, la ecuación mediante la cual se llega al estado estacionario o de equilibrio de la economía viene denotada por la siguiente ecuación.

$$
\dot{k}=s f(k)-(\delta+n+g) k
$$

, donde " $g$ " representa la tasa de crecimiento del progreso tecnológico, que está relacionada de forma negativa con la acumulación de capital.

En el estado estacionario, la producción por trabajador en una economía es constante, mientras que la eficiencia del trabajo está creciendo a una tasa "g" y la población a una tasa " $n$ ", por lo que la producción total crecería a una tasa "n + g".

En definitiva, el progreso técnico o productividad, también conocido por el término de "residuo de Solow", expresaría el comportamiento del crecimiento económico que no vendría explicado por los factores de producción clásicos, y que ayudaría a fundamentar teóricamente los continuados crecimientos registrados por las economías de varios países. No obstante, la nueva formulación del modelo presentaba la limitación de no explicar la procedencia del progreso tecnológico, ya que constituía una variable exógena del mismo. Como bien señaló Abramovitz (1956), el residuo constituiría una medida de ignorancia a la hora de explicar el crecimiento económico; es decir, nos permitiría saber que existen factores ocultos que explican el fenómeno, pero que son desconocidos.

\subsubsection{Introducción del capital humano}

Pese a que la introducción del capital humano no fue formulada por Solow, es pertinente la inclusión de este apartado en el presente epígrafe, debido a que esta mejora fue realizada sobre su propio modelo. La introducción del capital humano en el modelo de crecimiento de Solow fue especificada por los economistas Mankiw, Romer 
y Weil (1992) en la publicación de su célebre trabajo "A contribution to the Empirics of Economic Growth".

La nueva especificación, que aparece recogida en la Ecuación 1.9, se formuló bajo la premisa de que el capital humano engloba los conocimientos y las cualificaciones que adquieren los individuos por medio de la educación, por lo que incrementa la capacidad de producir bienes y servicios.

$$
Y=F(K, E L, H)=K^{\propto}(E L)^{1-\alpha-\beta} H^{\beta}
$$

, donde " $H$ " representa al capital humano y " $\beta$ " la elasticidad parcial respecto al capital humano. Esta nueva especificación supone la inclusión del capital humano como un tercer factor, por lo que el término " $E$ " no incluiría el capital humano, sino la tecnología. Debido a la dificultad de elaborar los datos para cuantificar el capital humano, Mankiw et al. (1992) utilizan como variable proxy la proporción de trabajadores en edad de trabajar que se están formando.

De forma análoga a la segunda ecuación fundamental del modelo de crecimiento de Solow con progreso técnico incorporado, se puede definir la tasa de acumulación del stock de capital humano " $\dot{h}$ ", especificado a través de la siguiente ecuación.

$$
\dot{h}=s f(h)-(\delta+n+g) h
$$

Al igual que ocurre con el capital físico, el capital humano se deprecia con el tiempo, ya que los conocimientos y habilidades de los individuos necesitan de un reciclaje para evitar su obsolescencia; y está afectado por la tasa de crecimiento de la población y la tasa de crecimiento del progreso técnico.

Los resultados obtenidos por Mankiw et al. (1992) demuestran el impacto positivo y significativo del stock de capital humano en el crecimiento económico. Por consiguiente, la reformulación del modelo de crecimiento de Solow, denominado a partir de esta contribución modelo MRW (Mankiw - Romer - Weil), establece que el nivel de producción de una economía depende de sus tasas de acumulación de capital 
físico y capital humano. No obstante, como se expone a continuación, este modelo presenta ciertas limitaciones, puesto que no explicita el origen del progreso técnico.

\subsubsection{Los modelos de crecimiento endógeno}

Los modelos de crecimiento endógeno suponen la contraposición al principio de exogeneidad del progreso técnico, entendiendo que el crecimiento a largo plazo experimentado por diversas economías se debe, precisamente, a la acumulación de capital humano, siendo éste endógeno, ya que responde a incentivos económicos, sujetos al esfuerzo de inversión de las economías en formar a su capital humano. Los principales modelos de crecimiento endógeno con capital humano fueron los formulados por los economistas norteamericanos Lucas (1988) y Romer (1990).

\subsubsection{El modelo de Lucas}

Merece la pena señalar el trabajo de Uzawa (1965) como precursor de la inclusión del papel de la educación como factor del crecimiento, trabajo en el que se fundamentó la aportación posterior de Lucas (1988). Según el modelo de Lucas (1988), el capital humano se puede dividir en información y en saber, y posee como características la de ser acumulable y apropiable por los individuos, por lo que tiene un valor productivo. De esta forma, la variación del stock de capital humano vendría representada por la siguiente ecuación:

$$
\dot{h}=h \varphi(1-u)
$$

, donde " $u$ " representa el tiempo de trabajo dedicado a la actividad productiva, de lo que se deduce que el término " $(1-u)$ " refleja el tiempo de trabajo que se dedica a formación. El término " $\varphi$ " representa el nivel de rendimiento máximo de la formación, que según esta ecuación, depende inversamente del tiempo de trabajo dedicado a la producción.

El modelo planteado por Lucas especifica la función de producción de una economía basándose en la premisa de que la cantidad de trabajo efectivo empleada en la producción depende del número total de trabajadores " $N$ ", su nivel de cualificación 
" $h$ " y el tiempo que éstos dedican al trabajo efectivo " $u$ ", teniendo la función de producción la siguiente especificación:

$$
Y=F(K, L)=A K^{\propto}(u h L)^{1-\propto} h_{a}^{\partial}
$$

, donde " $h a$ " refleja el efecto externo del capital humano sobre la producción, y cuya amplitud depende a su vez del término "७". Esta última variable representa el impacto externo que el capital humano puede ejercer sobre la producción, ya que el stock de capital humano individual se ve influido por el resto de individuos que le rodean, y supone una externalidad que puede acelerar el crecimiento.

En consecuencia, la educación y la formación tienen un efecto externo que no se tiene en cuenta en las decisiones de inversión en educación, que hace que el nivel de inversión agregado sea inferior al óptimo, y que los gobiernos deban hacerse cargo de los costes que esta inversión conlleva en aras del crecimiento económico futuro. En definitiva, según este modelo, un crecimiento económico sostenido en el largo plazo es sólo factible si el stock de capital humano crece sin límites.

Posteriormente, Lucas (1993) señaló que la principal fuerza motora del crecimiento económico es el capital humano, y que son las diferencias en la dotación de capital humano las que evidencian las diferencias entre países en cuanto a su desarrollo económico y bienestar. Lucas (1993) señala varios modos de acumulación de capital humano (escuelas, centros de investigación y universidades, entre otros), aunque reconoce que el conocimiento sobre la importancia de cada uno de estos tipos de acumulación de capital humano es limitado. Según Lucas (1993), para comprender los periodos de rápido crecimiento de una economía, el aprendizaje a través del puesto de trabajo, constituye el factor más importante; por ello, es imprescindible que el progreso técnico y el conocimiento se incorporen al capital humano para que éste tenga poder de influencia sobre el crecimiento económico.

\subsubsection{El modelo de Romer}

Para Romer (1986, 1990), la generación de ideas en el ámbito empresarial constituye una externalidad sobre la función de producción, ya que los nuevos 
conocimientos permiten desarrollar e innovar en nuevos bienes y además, aumentar la productividad de los trabajadores. Además, el impacto de este progreso tecnológico no se limita únicamente a las empresas que invierten en investigación, sino que influye en las empresas que le rodean.

De este modo, Romer especifica la siguiente función de producción:

$$
Y=F(K, L)=A K^{\propto} L^{1-\propto} k^{\omega}
$$

, donde " $k$ " representa la externalidad que produce la generación de ideas, cuya amplitud es reflejada por el término " $\omega$ ".

En su modelo, Romer utilizó la tasa de alfabetización como variable para medir la educación, y los años de escolarización posteriores a la enseñanza secundaria para representar la capacidad científica, capacidad de generación de ideas o capacidad de innovación que influye directamente sobre el término que engloba el progreso tecnológico. Consecuentemente, la cantidad de capital humano acumulado a través del progreso tecnológico viene, en este modelo, determinada por la capacidad científica, que depende, a su vez, del esfuerzo inversor tanto público como privado.

\subsubsection{El debate sobre el efecto del capital humano en el crecimiento económico}

Tras la aparición de los principales modelos de crecimiento económico, la proliferación de literatura sobre la relación entre capital humano y crecimiento ha sido exponencial, aunque los resultados obtenidos son ambiguos. Pese a que el capital humano es un concepto amplio que incluye diversos aspectos como la salud de los individuos, en la gran mayoría de los estudios que aquí se analizan el capital humano está asociado a los conocimientos adquiridos a través del sistema educativo. En este sentido, la literatura ha estudiado esta relación desde dos enfoques distintos (FreireSerén, 2001).

Por un lado, a través del denominado efecto nivel, que posiciona el capital humano como un input más de la función de producción estándar, constituyéndose éste como un argumento adicional al capital físico y la fuerza de trabajo. Esta 
expresión puede sintetizarse de forma general en la siguiente ecuación expresada en logaritmos, donde el término " $a_{i t}$ " representa la productividad total de los factores de una economía "i" en el periodo de tiempo " $\mathrm{t}$ ":

$$
y_{i t}=\propto_{k} k_{i t}+\propto_{l} l_{i t}+\propto_{h} h_{i t}+a_{i t}+\varepsilon_{i t}
$$

Por otro lado, el llamado efecto tasa, asociado a las teorías de crecimiento endógeno, relaciona el progreso técnico como una función del nivel de stock capital humano, es decir, el capital humano afectaría al crecimiento a través de su incidencia sobre la productividad total de los factores, cuya función vendría representada mediante la siguiente expresión:

$$
a_{i t}=\propto_{h} h_{i t}+\propto_{b h} h_{i t} b_{i t}+\propto_{b} b_{i t}+\propto_{g} g_{i t}+\varepsilon
$$

, donde " $b_{i t}$ " expresa la brecha tecnológica entre la economía "i" y la frontera tecnológica mundial; $y$ " $g_{i t}$ " es un indicador del esfuerzo inversor en I+D+i.

Aunque existe consenso en la literatura sobre la relación positiva entre capital humano y crecimiento económico a través del efecto tasa, los resultados de varios estudios sobre el efecto nivel son, en numerosas ocasiones, contradictorios (FreireSerén, 2001). En esta breve revisión de la literatura se va a incidir en aquellos trabajos de relevancia que ayudan a entender, en términos generales, la evolución y el estado actual de la cuestión, dado el amplio volumen de trabajos que versan sobre este campo.

Uno de los primeros estudios que pusieron en entredicho la relación que en este epígrafe se analiza es el de Kyriacou (1991), que estima una ecuación para 87 países en la que estudiaba la incidencia del capital humano, a través de los años de estudio de la fuerza laboral, en el crecimiento económico, utilizando una función de producción Cobb-Douglas expresada en diferencias. El coeficiente del capital humano de esta estimación resultó ser no significativo y de signo negativo, por lo que Kyriacou (1991) realizó una segunda estimación en la que sólo selecciona aquellos países de la muestra más ricos, obteniendo un cambio de signo en el coeficiente de capital humano, aunque éste carecía de significatividad. Según el autor, este cambio de signo 
indicaba la posible existencia de una barrera de capital humano inicial a partir de la cual éste tiene una relación positiva con el crecimiento.

En la misma línea, Benhabib y Spiegel (1994) realizan otra estimación con una muestra de 78 países mediante una función de producción similar a la explicada en la Ecuación 1.14, obteniendo también un coeficiente negativo y no significativo, por lo que realizan otra estimación a través de una función de producción en la que el capital humano se presenta como factor endógeno del progreso técnico. En esta segunda estimación, que mediría el efecto tasa, sí que obtienen resultados significativos y positivos. Tanto los estudios de Kyriacou (1991) y Benhabib y Spiegel (1994) ponen en duda la consistencia del efecto nivel derivado del modelo MRW (Mankiw et al., 1992), demostrando que la contribución del capital humano al crecimiento económico se explica más adecuadamente a través del efecto tasa.

Además, estos primeros trabajos sirvieron para buscar explicaciones a la falta de significatividad arrojada en las estimaciones realizadas; explicaciones que desarrollaron autores como Temple (1999), que arguye que en los trabajos anteriormente citados existe una notable heterogeneidad en la muestra de países escogida, que reduce su significatividad debido a la existencia de algunos países en vías de desarrollo que representan casos muy atípicos, por su reducido tamaño y su extrema pobreza. Así pues, Temple (1999) reestima la función de producción de diferencias utilizada por Kyriacou (1991) y Benhabib y Spiegel (1994), pero eliminando de ella los casos que considera que alteran artificialmente la estimación, llegando a unos resultados más robustos y demostrando, para una muestra de 64 países, que existe una relación positiva y significatividad entre el output de producción y el stock de capital humano como variable independiente en la función de producción estándar propuesta en el modelo MRW.

En este sentido, son de gran relevancia las conclusiones aportadas por Azariadis y Drazen (1990), ya que determinan que existe un umbral de stock de capital humano a partir del cual los países experimentan crecimiento económico y mejoras en las externalidades que ello provoca; y por debajo del cual el nivel de capital humano carece de significatividad. El concepto de umbral también sirve de explicación 
complementaria a los resultados obtenidos por Kyriacou (1991) y Benhabib y Spiegel (1994), y ha sido utilizado con frecuencia para explicar la no significatividad de la mejora de resultados educativos tras el aumento del gasto en educación por parte de determinados países. De la misma forma, Lau, Jamison, Liu y Rivlin (1996) muestran también este umbral para el caso de Brasil, estableciendo que una economía debe de contar con una mínima masa crítica de escolarización básica antes de que los retornos de la educación se puedan manifestar y trasladar al crecimiento económico.

Por otra parte, Nonneman y Vandhout (1996) realizan una ampliación del modelo MRW en el que introducen la inversión en I+D+i de forma endógena como medida de la contribución del know-how tecnológico al crecimiento económico en los países de la OCDE. El nuevo modelo que proponen explica, en mayor medida $(80 \%$ frente al $65 \%$ del modelo MRW), las fuentes de crecimiento de las economías, pero sin embargo, encuentra que el coeficiente del capital humano pierde significatividad frente al modelo MRW.

No obstante, algunos autores han hecho énfasis en la importancia de la variable utilizada para reflejar la medida del capital humano. En este sentido, Murthy y Chien (1997) critican que en las estimaciones anteriores del modelo MRW realizadas por Nonneman y Vandhout (1996) se obvia la enseñanza primaria, secundaria y superior, lo que evidencia una carencia del estimador del capital humano. Así pues, construyen una medida que integra los porcentajes de años de escolaridad en las tres etapas educativas mencionadas a través de unas medias ponderadas, obteniendo que el impacto del capital humano en el crecimiento económico de los países de la OCDE es positivo e incluso mayor que en el modelo MRW.

Otro estudio desarrollado por Barro (1996) muestra que el capital humano, medido a través de la variable de años de escolarización en educación secundaria y posterior para los hombres de más de 24 años tiene un efecto positivo y significativo en el crecimiento económico. Sin embargo, Barro (1996) utiliza otras variables como los años de escolarización en educación primaria (para el mismo grupo objetivo y también para el caso de las mujeres), que se muestra no significativo. A su vez, encuentra que pese a que la escolarización de mujeres no tiene un efecto directo a 
través del capital humano en el crecimiento económico, sí puede existir un efecto inverso a través del impacto que la escolarización de las mismas presenta sobre la tasa de fertilidad (relación negativa), que a su vez influye en el crecimiento económico.

Además del indicador utilizado para representar el capital humano, hay que tener en cuenta las metodologías empleadas, ya que, en los estudios empíricos anteriormente citados, se utilizan, en la mayoría de ocasiones, regresiones simples en las que se cuenta normalmente con una sola observación por país. En esta línea, Islam (1995) propone un análisis utilizando un panel de datos con efectos fijos por países y los años de escolarización como medida del capital humano de la serie elaborada por Barro y Lee (1993). Los resultados muestran que las diferencias en el nivel tecnológico entre países son un factor altamente explicativo de las diferencias de crecimiento económico que éstos han experimentado, mientras que otorga una menor significatividad e impacto al capital humano, poniendo por tanto en duda, una vez más, los resultados obtenidos por el modelo MRW.

Esta divergencia de resultados empíricos también tiene su reflejo en estudios de carácter regional en el contexto español. Así pues, Serrano (1996) realiza un estudio en el que utiliza dos indicadores de capital humano para el caso de las comunidades autónomas españolas: años medios de escolarización y proporción de trabajadores con un determinado nivel educativo. En el trabajo se critica cierta arbitrariedad de los trabajos que versan sobre esta materia a la hora de hacer suposiciones sobre la relación directa y proporcional entre el capital humano y la formación recibida (Serrano, 1996). Los resultados obtenidos muestran que la variable que representa los años de escolarización no contribuye de forma significativa a la productividad, mientras que la variable alternativa utilizada - el porcentaje de ocupados con al menos estudios medios - sí resulta significativa. Serrano (1996) descubre que la contribución del capital humano a la productividad no sólo es positiva, sino mayor que la apuntada por los estudios anteriormente mencionados, llegando a la conclusión de que la elección de la variable proxy de la dotación de capital humano es primordial para realizar un análisis preciso. 
En la misma línea, Gorostiaga (1999) realiza otro análisis utilizando la función de convergencia derivada del modelo MRW, utilizando datos de las regiones españolas e incluyendo efectos fijos para reflejar la existencia de estados estacionarios heterogéneos, siguiendo las recomendaciones metodológicas propuestas en el trabajo de Islam (1995). Los resultados obtenidos por Gorostiaga (1999) identifican una relación negativa y significativa del capital humano con el crecimiento económico. De esta forma, se sugiere una vez más la problemática inducida por el hecho de incluir una variable temporal de escolaridad como medida proxy del capital humano, y también se esgrime la posibilidad de que el capital humano afecte a la función de producción de una economía influyendo sobre la tasa de crecimiento del progreso técnico. En base a esta consideración, desarrolla un modelo alternativo en el que la tecnología crece a una tasa de crecimiento que depende del nivel de stock de capital humano, obteniendo unos resultados que aún siendo poco robustos, eliminan el signo negativo del capital humano, ofreciendo una estimación más realista.

La contradicción patente entre el argumento intuitivo de que los mayores resultados de escolarización y educativos deberían impulsar por sí mismos un crecimiento económico, y los resultados obtenidos, que denotaban la debilidad de esta relación, siendo en el mejor de los casos positiva pero débil, llevaron también a Pritchett (2000) a analizar este fenómeno. Según su investigación, existen tres factores que pueden explicar estos resultados. Por un lado, cabe mencionar el marco institucional, que no habría sabido desarrollar un servicio educativo que traduzca los esfuerzos de inversión en know-how productivo. En segundo lugar, la tasa de crecimiento de la demanda de fuerza de trabajo con un determinado nivel de conocimientos habría variado considerablemente entre países, y el rendimiento marginal de la tasa de retorno sería por tanto, muy heterogéneo; y por último, hay que hacer mención a la distinta cultura educativa y su capacidad de transmisión del conocimiento, que no se vería traducida siempre en un aumento de la productividad.

Por otra parte, De la Fuente y Doménech (2002), en la misma línea iniciada por Steedman (1996), señalan que la principal causa de que un amplio número de trabajos asigne un efecto negativo a la contribución del capital humano al crecimiento es la 
mala calidad de los datos empleados, unido a las singularidades de la metodología empleada en las estimaciones. En este sentido, la mayoría de bases de datos utilizadas en la literatura tendrían ruido, además de que las técnicas de estimación empleadas presentan el inconveniente de poseer una mayor sensibilidad a los errores de medición de las propias variables ${ }^{4}$. Como es lógico, la construcción de bases de datos con información sobre escolarización está sujeta a la disponibilidad de datos primarios fiables y sometida, en ocasiones, a la aplicación de criterios subjetivos. Además, conviene mencionar la escasa información disponible acerca del nivel educativo de la población en algunos de los países en vías de desarrollo.

Una de las respuestas a estos problemas es la planteada por Krueger y Lindahl (2001) y De la Fuente y Doménech (2002), que proponen un ratio de fiabilidad construido sobre la base que relaciona el ruido con el contenido de las distintas series de datos utilizadas, corrigiendo de esta forma el denominado "sesgo de atenuación" que infravalora el impacto del capital humano sobre la productividad. Así pues, el análisis de las bases de datos sobre escolarización tradicionalmente utilizadas en este campo, tales como las de Kyriacou (1991) y Barro y Lee (1993, 1996 y 2000) presentan unas ratios de fiabilidad respetables aunque continúan poseyendo un sesgo de atenuación potencialmente alto (De la Fuente y Doménech, 2002). Las bases de datos, calculadas en base a la información suministrada por organismos internacionales como la UNESCO (United Nations Educational, Scientific and Cultural Organization), presentan también problemas de comparabilidad, al existir diferencias entre países en la definición de la educación secundaria y educación terciaria. Por su parte, Krueger y Lindhal (2001) obtienen unos resultados positivos y significativos de la relación entre el número de años medio de escolarización en el sistema educativo y el crecimiento económico, tras corregir los errores de medición diagnosticados en las bases de datos mencionadas.

Otra de las críticas formuladas a los trabajos realizados es que no tienen en cuenta el posible efecto opuesto que puede tener el crecimiento en la acumulación de

\footnotetext{
${ }^{4}$ Generalmente, este tipo de errores tienen que ver con el hecho de que al utilizarse paneles con datos mayores en el corte temporal que transversal, los errores tienden a cancelarse cuando se promedia sobre periodos de tiempo largos (de la Fuente, 2002).
} 
capital humano. De esta forma, Freire-Serén (2002) asume un nuevo enfoque de la acumulación del capital humano, en la que el nivel de renta alcanzado por una economía determinada influye en la acumulación de stock de capital humano a través del aumento del deseo de los individuos de incrementar su nivel educativo. Para demostrarlo, realiza un análisis empírico aplicado a las regiones españolas, utilizando un modelo en el que el proceso de acumulación del capital humano es representado mediante la siguiente función:

$$
\dot{H}_{t}=\gamma \widetilde{Y_{t}}-(\eta+n) \widetilde{H_{t}}
$$

, donde " $\gamma$ " introduce información sobre como la economía traduce el nivel de rentas alcanzado a aumentos de la adquisición de educación formal por parte de la población; mientras que " $\eta$ " representa la tasa de depreciación del capital humano. Usando un sistema no lineal, estima estos dos parámetros, llegando a la conclusión de que el término " $\gamma$ " tiene un impacto positivo y significativo sobre la acumulación de capital humano, en contraposición a los resultados obtenidos por Gorostiaga (1999), lo que pone de relieve la necesidad de utilizar un sistema que simultáneamente considere la endogeneidad del proceso de acumulación de capital humano.

Por otro lado, la utilización de indicadores alternativos de capital humano comienza a dar sus frutos con trabajos como el de Hanushek y Kimko (2000), que se basa en los resultados de los test de competencia científico-matemática realizados por la International Association for the Evaluation of Educational Achievement (IEA) y la International Assessment of Educational Progress (IAEP). Este trabajo obtiene resultados significativos sobre la productividad y el crecimiento, y evidencia la hasta entonces falta de utilización de indicadores que reflejaran la calidad - y no tanto la cantidad - del stock de capital humano de las economías. Ello respondía a la necesidad de ponderar los años de escolarización en países con sistemas educativos de calidad dispar, ofreciendo una solución en la que se tenía en cuenta la adquisición cognitiva por parte del alumnado, utilizando para ello los test de competencias. Además, Hanushek y Kimko (2000) realizan estimaciones adicionales que tienen en cuenta nuevas variables, como el número medio de años de la formación de la población 
adulta, la tasa de crecimiento de la población o la proporción del gasto en educación en relación al producto interior bruto.

De la Fuente y Doménech (2006), en un trabajo posterior que explora de nuevo la calidad de las bases de datos internacionales sobre escolarización, comprueban que las series de datos contienen una notable cantidad de ruido, y que la mayor parte de las mismas son implausibles debido a los cambios en los criterios de clasificación y a las diversas inconsistencias de los datos. Además de las bases de datos anteriormente señaladas (Kyriacou, 1991; Barro y Lee, 1993, 1996 y 2000), los autores revisan la fiabilidad de las bases de datos construidas por Lau, Jamison y Louat (1991), Lau, Bahlla y Louat (1991), y Nehru, Swanson y Dubey (1995). Estos trabajos alternativos suponen una mejora debido a que tienen en cuenta importantes aspectos como las tasas de supervivencia y los flujos de repetidores y abandonos de la educación.

Por su parte, el trabajo de Cohen y Soto (2007) trata de subsanar también los problemas derivados de la mala calidad de los datos, construyendo una base de datos basada en clasificaciones homogéneas de escolarización a través de datos de la OCDE y la UNESCO. Realizando dos estimaciones (por medio de regresiones y mediante panel de datos), obtienen resultados positivos y significativos de la contribución del capital humano al crecimiento económico mediante el denominado efecto nivel. De estos resultados, extraen la conclusión de que la reducción de errores de medición en las series como consecuencia de la mayor calidad de la base de datos utilizada es el factor explicativo de los resultados obtenidos, y de los resultados ambivalentes y poco significativos obtenidos en estudios anteriores.

Más tarde, Prados de la Escosura y Rosés (2010) realizan estimaciones para el caso español utilizando la base de datos de Nuñez (2005) para el periodo 1850-2000, utilizando cohortes de edad cada cinco años en las que los años de escolarización de cada cohorte están ponderados por su representatividad en la población de entre 15 y 64 años, teniendo en cuenta para ello datos tanto de mortalidad como de inmigración, y obteniendo la conclusión de que el efecto de la contribución del capital humano al crecimiento económico en España es limitado, y se da únicamente a través del efecto tasa. 
Uno de los últimos trabajos en este prolífico campo es el de Barro (2013), que sintetiza el marco empírico derivado del modelo neoclásico de crecimiento en la siguiente ecuación:

$$
\dot{y}=F\left(y, y^{*}\right)
$$

, donde " $\dot{y}$ " es la tasa de crecimiento per cápita de una economía, que es una función del output de producción actual (y) y el output de producción objetivo $\left(y^{*}\right)$. Según esta especificación, para un valor de output dado, la tasa de crecimiento de una economía se relaciona positivamente con el objetivo de producción de esta. El objetivo depende, a su vez, del funcionamiento del gobierno, la gestión de la propiedad privada, la capacidad de ahorro, la apertura del comercio exterior y la tasa de inflación. En la demostración empírica, Barro plantea al igual que en trabajos anteriores los problemas de comparabilidad entre bases de datos ${ }^{5}$.

Paradójicamente, el trabajo de Barro (2013) apunta que el incremento del nivel de PIB per cápita en los países ricos tiene un efecto negativo sobre las tasas de crecimiento, pese a que estaría relacionado positivamente con otras variables como años de escolarización, menor tasa de fertilidad o una mejor legislación. Además, el gasto público en educación tendría un efecto positivo pero no significativo estadísticamente.

En lo que a capital humano se refiere, Barro (2013) señala que éste actúa a través de dos canales en el crecimiento económico: facilitando la asimilación tecnológica y acelerando la convergencia de países con déficit de capital físico. Al igual que en la mayoría de trabajos, Barro (2013) utiliza el promedio de años de escolarización para la población masculina de 25 años o más con educación secundaria o superior como medida del stock de capital humano. En el trabajo empírico, demuestra que esta variable tiene un efecto positivo y significativo sobre el crecimiento económico, de forma que la escolarización de un año más en el sistema

\footnotetext{
${ }^{5}$ Barro (2013) compara las bases de datos de desempeño educativo de la OCDE (OECD, 1998a) con la elaborada por él mismo (Barro y Lee, 2000), presentando problemas de comparabilidad entre niveles educativos, bien sea por diferencia de criterio en cuanto a la división entre niveles educativos, bien sea por la utilización de rangos de edad heterogéneos.
} 
educativo produce un incremento en la tasa de crecimiento del $0,44 \%$. No obstante, el trabajo también identifica que este efecto es finito debido al resultado de la convergencia, ya que la escolarización afectará al crecimiento económico y este a su vez lo hará en el nivel de PIB per cápita, lo que autolimitará la capacidad de crecimiento en el largo plazo.

Barro (2013) utiliza también otras variables para analizar el efecto sobre las tasas de crecimiento y observa que algunas tienen un efecto negativo $y / o$ no significativo, como la escolarización de mujeres en educación secundaria (probablemente debido a la discriminación de género del mercado laboral de diversos países, que evidencia una infrautilización de capital humano), o la escolarización de hombres en educación primaria, aunque ésta supone un prerrequisito indispensable para el acceso a la educación secundaria. Además, el análisis constata que pese a la insignificancia de las variables que tienen que ver con la escolarización femenina, ésta sí que tiene un efecto positivo y significativo si tenemos en cuenta el impacto indirecto que ésta realiza sobre la tasa de fertilidad.

Al igual que Hanushek y Kimko (2000), Barro (2013) también encuentra relación positiva, significativa y más fuerte ${ }^{6}$ entre los indicadores de calidad educativa (competencia lectora, científica y matemática) y crecimiento económico, especialmente en el caso de los resultados de competencia en ciencias, obtenidos a partir de la base de datos de Summers y Heston (1991) ${ }^{7}$.

Al margen de la bibliografía aquí mencionada, merece la pena reseñar otros enfoques alternativos de la contribución del capital humano al crecimiento. En este sentido, se pueden citar trabajos como los de Keesing $(1965,1966)$, que explica esta relación a través de la aportación que la mejora del capital humano implica en el aumento de la internacionalización y el comercio exterior a través de la mejora de la

\footnotetext{
${ }^{6}$ El coeficiente del resultado de competencia matemática implica que un crecimiento en un punto en los resultados implica un $1 \%$ de crecimiento anual frente al $0,2 \%$ que implica el incremento de un punto en la escolarización.

${ }^{7}$ No obstante, la muestra de países para las variables que tienen que ver con resultados de competencias es más reducida (43 países), estando los países en vías de desarrollo subrepresentados (sólo 14 países con un PIB per cápita inferior a los 5.000 dólares) debido a las limitaciones para obtener los datos.
} 
competitividad, lo que supone una fuente de crecimiento económico. Otro mecanismo indirecto es el apuntado por Martín y Velázquez (2002), que sostienen que la dotación de capital humano es un factor de atracción determinante en las decisiones de inversión extranjeras. Por último, cabría destacar el efecto migratorio de la demanda de mano de obra altamente cualificada, que contribuye efectivamente al crecimiento económico del país de destino (Martín, Velázquez, Sanz, Crespo, Perales y Turrión, 2000).

\subsection{Externalidades de la educación y la escolarización en la economía y el bienestar social}

Aunque la mayoría de estudios se han centrado en evidenciar la relación entre capital humano y productividad y rentas, el nivel de educación y de formación de los individuos tiene otras externalidades positivas sobre la sociedad, pese a que éstas son difíciles de medir, ya que en la mayoría de ocasiones, representan impactos indirectos y retardados (Psacharopoulos y Patrinos, 2004; McMahon, 2004). En este sentido, es importante tener en cuenta que el capital humano no sólo es un concepto restringido a la educación y la formación, sino que integra otras dimensiones de inversión en los individuos, como es la salud, factor que puede marcar diferencias en los países en vías de desarrollo (De la Fuente, 2004), ya que las diversas formas de inversión en capital humano tienen el denominador común de aumentar la calidad de trabajo y la productividad (Caneda González y Fernández-Jardón Fernández, 2000).

La educación y la formación continua desarrollan la competencia total de las personas, las prepara para vivir en sociedad y fomenta, por tanto, unos mejores valores sociales, lo que también redunda en una mayor integración social y un menor gasto asistencial. En este sentido, Levin (2009) estima que por cada graduado en educación post-obligatoria, el ahorro total para el sector público asciende a 209.100 dólares, repartidos entre el aumento de ingresos fiscales y el ahorro en partidas de gasto asistencial. Dickson y Harmon (2011) señalan que en el prolífico campo de estudio de los retornos de la educación, los economistas quizás han subestimado el efecto de la educación sobre aspectos clave como la satisfacción con el trabajo 
desempeñado, la mejora de las relaciones sociales, el aumento de la confianza en uno mismo y la seguridad, entre otros; efectos que en términos agregados suponen una contribución a la hora de cimentar los valores de la confianza y el compromiso cívico necesario en la sociedad.

Por otro lado, Rumberger y Lim (2008), en un estudio que recopila los resultados de una multitud de trabajos empíricos sobre abandono escolar, compara los estudiantes graduados con los que abandonaron sus estudios antes de graduarse, descubriendo que los segundos, además de presentar unos salarios más bajos, eran más propensos a sufrir mayores tasas de desempleo, menores estándares de salud, tasas de mortalidad más altas, y mayor tendencia a desarrollar comportamientos criminales, aumentando todo ello por tanto su dependencia respecto al gasto asistencial.

En cuanto a el comportamiento criminal, Lochner y Moretti (2004) establecen dos mecanismos por los que la educación reduce o previene estos fenómenos. Por un lado, el aumento teórico esperado de los salarios como consecuencia de la mayor escolarización hace que el coste de oportunidad de cometer crímenes y el coste del tiempo en prisión sea elevado. Por otro lado, la educación lleva implícitos unos valores tendentes a aumentar la aversión al riesgo, fomentar la tolerancia hacia los demás y mejorar la respuesta a impulsos violentos. De esta forma, demuestran empíricamente, en un estudio aplicado a los Estados Unidos, la consistencia de la relación inversa entre escolarización y actividad criminal. Ello implica también la existencia de beneficios que no son contabilizados en las tasas de retorno interno de la educación, y que hacen que las tasas de retorno social de la educación sean más amplias.

Belfield y Levin (2007) por ejemplo, demuestran que cada graduado en educación secundaria ahorra más de 200.000 dólares al gobierno, y que reducir la tasa de abandono escolar podría generar más de 45 billones de dólares en beneficios para la sociedad a largo plazo. En cuanto a los salarios, el informe llevado a cabo por el Departamento de Educación de los Estados Unidos (Chapman, Laird, Ifill y KewalRamani, 2011) pone de manifiesto que los ingresos medios de los individuos son de 25.000 dólares anuales para aquellos que no completaron el certificado de 
educación general, y de 43.000 dólares para aquellos que así lo hicieron. Por su parte, Rouse (2005) estima en 550.000 dólares la pérdida total de ingresos de aquellos que abandonaron el sistema educativo antes de obtener una titulación de educación secundaria frente a los que sí lo hicieron.

En patrones de salud, existen numerosos estudios que avalan la relación entre escolaridad y estándares de salud. El informe sobre estadísticas de salud elaborado por el Departamento de Salud y Servicios Humanos de los Estados Unidos (Pleis, Ward y Lucas, 2010) suministra una extensa relación de datos que subrayan que a menor nivel de educación, existe un mayor riesgo a padecer diversas enfermedades.

Según uno de los informes del estudio PISA (OECD, 2007), el aumento de la escolarización de los individuos aumenta las posibilidades de estos de acceder a unos mejores estándares de salud. Lleras-Muney (2005), por su parte, señala que un año adicional de escolarización supone un decremento de entre un 1,3\% y un 3,6\% en las probabilidades de fallecer durante los siguientes diez años.

Otro impacto indirecto ya mencionado en el epígrafe anterior es el efecto que tiene la educación sobre la reducción de la fertilidad, a través del aumento del coste de oportunidad que para las mujeres supone tener hijos (Rosenzweig y Schultz, 1989; Barro, 1991) Cabe recordar además que conceptualmente, la salubridad de la población es un elemento más del capital humano, por lo que influye por sí mismo sobre el crecimiento económico (Barro, 2013).

En definitiva, los trabajos de investigación realizados posicionan la educación no sólo como un factor primordial a la hora de explicar el aumento de la productividad, las rentas y el crecimiento económico, sino que muchas veces la inversión educativa incide de forma complementaria sobre otros factores que actúan indirectamente sobre estas variables (López-Bazo y Moreno, 2012), como es el caso del uso óptimo de la tecnología (Stevens y Weale, 2004). De esta forma, la acumulación de capital humano es un factor que se ha utilizado de forma recurrente para explicar las diferencias en el desarrollo económico entre distintos países (Acemoglu, 2008). 
Mazzonna (2014) analiza la influencia del estatus socioeconómico de partida sobre el nivel de rentas y de bienestar futuro, concluyendo que la educación supone un papel intermedio determinante en la moderación del proceso entre desigualdades en el origen y desigualdades en las condiciones socioeconómicas futuras.

Además, con el desarrollo de la globalización y la sociedad de la información, la inversión en educación ha cobrado un papel trascendental en la formulación de las políticas de reformas estructurales en todo el mundo, que resaltan la idea de que cada vez existe una mayor interdependencia entre la cualificación de la mano de obra y el desarrollo económico (Carnoy et al., 2005).

En este sentido, según Bridgeland, Dilulio y Morrison (2006) el abandono de la educación tiene unas consecuencias especialmente dañinas en una era post-industrial y tecnológica en la que los individuos necesitan un grado mínimo de educación cada vez mayor para competir con garantías en un mercado laboral cada vez más globalizado. Por su parte, la Comisión Europea estima que reduciendo en un punto la tasa de abandono escolar temprano, la economía europea podría crear cerca de medio millón de puestos de trabajo cualificados entre la población joven cada año (Comisión Europea, 2011a).

En definitiva, la falta de un nivel de educación y formación cada vez más alto, supone la puesta en riesgo de exclusión de los individuos que no alcancen unos determinados estándares, necesarios para desenvolverse, integrarse y desarrollarse en la actual sociedad del conocimiento.

\subsection{Resumen y conclusiones}

Como bien apuntan Caneda González y Fernández-Jardón Fernández (2000), desde el surgimiento de la economía como disciplina, el estudio de las causas del crecimiento de la economía ha sido continuo. En este sentido, este primer capítulo se ha centrado en analizar el estudio del factor que engloba todo lo relacionado con el capital humano, teniendo como referencia tanto los modelos microeconómicos como los modelos de crecimiento macroeconómico. 
Así pues, se han puesto de relieve las diferentes teorías que ayudan a entender el papel de la educación y su impacto sobre el crecimiento económico y la rentabilidad individual, destacando la teoría del capital humano, base del estudio de la economía de la educación, y sus alternativas; y por otro lado los modelos de crecimiento exógeno (modelo de Solow y ampliaciones del modelo MRW) y endógenos (modelos de Lucas y Romer), estudiando la discusión empírica que ha suscitado la proliferación de numerosos trabajos durante los últimos treinta años. Asimismo, se han recogido las externalidades positivas que la educación tiene sobre la sociedad, y que pueden redundar también en el crecimiento económico.

En definitiva, la educación y su valor dentro del concepto de capital humano como generador de riqueza individual y colectiva constituye una pieza fundamental en la rentabilidad individual de las personas y el desarrollo económico y social de los países, lo que ha explicado el crecimiento económico continuado de numerosas economías occidentales y las diferencias en el nivel de riqueza económica de distintos países. No obstante, son numerosos los problemas econométricos y de fiabilidad de datos que se han detectado en un gran número de estudios y que en el presente capítulo son objeto de análisis.

Por consiguiente, la política económica debe de tener en cuenta y posicionar la inversión en educación como un objetivo estratégico, no sólo por el impacto en el crecimiento económico, sino por su contribución al bienestar social y personal. 
Capítulo 2: El abandono escolar temprano como objetivo de los programas de reformas estructurales de la Unión Europea 



\subsection{Introducción}

Según Tinbergen, las reformas estructurales tienen por finalidad cambiar o modificar, totalmente o en parte, los fundamentos o bases esenciales del sistema económico. En este sentido, estas reformas poseen un carácter amplio, ya que suponen una triple implicación económica, social e institucional (Cuadrado Roura et al., 2010). Dentro de las reformas estructurales, las políticas educativas conforman un pilar básico, ya que tienen un impacto directo en el desarrollo socioeconómico de los países y en la integración social de sus ciudadanos.

El abandono escolar temprano ${ }^{8}$ es, en este sentido, una de las principales preocupaciones sociales, cuyo objetivo de reducción no es exclusivo de las políticas educativas de España, sino que tiene su origen en las más importantes e influyentes organizaciones institucionales a nivel internacional, como la UNESCO, la OCDE y la Unión Europea, que han situado la reducción de este problema como una estrategia clave para frenar la exclusión social y evitar, así, la lógica pérdida de eficiencia de la inversión educativa. La relevancia de este objetivo se manifiesta, por ejemplo, en la inclusión del mismo como uno de los cinco objetivos clave para la consecución de la Estrategia Europa 2020, además de estar incluido como indicador en la Estrategia Española de Desarrollo Sostenible, así como en los sucesivos Programas Nacionales de Reformas (PNR) de España.

De esta forma, tras analizar las principales teorías que explican el interés de los individuos y las sociedades en invertir en educación y capital humano, en este capítulo se presenta una visión global de la formulación de los distintos programas de reformas estructurales de la Unión Europea desde la óptica de las políticas económicas y educativas; estudiando, en particular, la importancia que se ha conferido al objetivo de reducción del abandono escolar temprano en todas ellas. Por otro lado, un segundo epígrafe recoge la aplicación a nivel nacional de los programas de reformas, y las

\footnotetext{
${ }^{8}$ El abandono escolar temprano se concreta en un indicador elaborado por Eurostat, que se define como el porcentaje de individuos de entre 18 y 24 años que ha finalizado como nivel educativo máximo la primera etapa de la educación secundaria y que no sigue recibiendo ningún tipo de formación.
} 
principales medidas que se han implementado para reducir el problema del abandono escolar temprano.

\subsection{Los programas de reformas estructurales y el contexto de la Unión Europea}

\subsubsection{La Estrategia de Lisboa}

La Estrategia de Lisboa, también conocida como Agenda de Lisboa o Proceso de Lisboa, surgió como respuesta a la necesidad de plantear un nuevo modelo de desarrollo que tenía sus precedentes en el "Informe Delors" (European Commission, 1993), que es considerado el documento de referencia pionero en el diseño de una política coherente y global sobre la sociedad de la información. El Informe Delors realizaba un diagnóstico que señalaba la infrautilización de la mano de obra y la sobreutilización de recursos naturales, lo que debía llevar a una reflexión sobre cómo superar el modelo de desarrollo económico invirtiendo esta relación. Para ello, el informe planteaba la necesidad de diseñar unas políticas macroeconómicas y sectoriales concretas, para conseguir tal finalidad.

Además del Informe Delors, cabe destacar, en el ámbito de la educación y la formación, precedentes como el libro blanco sobre la sociedad del conocimiento (European Commission, 1995), presentado en 1996, año europeo del aprendizaje permanente; y el Tratado de Ámsterdam, firmado en 1997, que sirvió para subrayar la necesidad de una acción comunitaria conjunta para promover el acceso a la educación y la formación.

La Estrategia de Lisboa es, en síntesis, un programa de desarrollo aprobado durante la celebración del Consejo Europeo en la capital lusa en marzo del año 2000. Esta estrategia (Consejo Europeo, 2000) tenía como propósito coordinar las políticas nacionales y comunitarias para incrementar, así, el crecimiento de la economía europea en el medio y largo plazo. De esta forma, la Estrategia de Lisboa se centró en desarrollar un programa de reformas de carácter estructural que aglutinaba una serie de medidas interdependientes, agrupadas en tres ejes de actuación: económico, 
social, y medioambiental, con el fin último para la siguiente década de convertir a la economía europea "en la economía, basada en el conocimiento, más competitiva y dinámica del mundo, capaz de crecer económicamente de manera sostenible con más y mejores empleos y con mayor cohesión social" (Consejo Europeo, 2000). Para alcanzar este objetivo, la Comisión diseñó una estrategia global cuyos objetivos globales eran los siguientes:

- Mejorar las políticas relativas a la sociedad de la información y de I+D, además de acelerar un proceso de reformas estructurales que impulse la competitividad, la innovación y la culminación del mercado interior.

- Incrementar la inversión en capital humano, con el objetivo de paliar la exclusión social, modernizando el modelo social europeo.

- Aplicar una política macroeconómica que proyecte un mantenimiento de las sólidas perspectivas económicas y de crecimiento.

También hay que hacer mención al carácter homogeneizador del planteamiento de la Estrategia, ya que se hizo bajo el espíritu de actuar conjuntamente, creando sinergias y bajo la premisa de que las acciones puestas en marcha por un Estado serían mucho más eficaces si el resto actuaba concertadamente.

Así pues, la Unión Europea se encontraba ante el más amplio y coherente conjunto de reformas estructurales adoptado desde la creación de las propias Comunidades Europeas y el lanzamiento de la Unión Monetaria (Matías Clavero, 2005). Cabe señalar, en este punto, que el contexto en el que se plantearon y diseñaron estas reformas era de crecimiento y estabilidad económica, cuyas previsiones para los años venideros eran también de prosperidad económica. Sin embargo, el año 2001 trajo consigo un periodo de fuerte incertidumbre a raíz del estallido de la denominada "burbuja tecnológica", que ponía en tela de juicio el potencial de la economía del conocimiento, y que se vio alimentada de forma paulatina en los años venideros por la recesión del comercio internacional, los escándalos contables y la nueva situación geopolítica derivada de los ataques terroristas del 11-S y las guerras de Afganistán e Irak. 


\subsubsection{Los objetivos del ámbito educativo y el marco estratégico ET}

2010

En la Estrategia de Lisboa se prestó especial atención a la educación, a la formación, y al modo en que ésta se podía posicionar como una forma de alentar el crecimiento, por lo que se fijaron unos objetivos que debían dar respuesta a los retos que el nuevo entorno planteaba, y que se concretaban en cuatro desafíos.

En primer lugar, hay que mencionar el reto que planteaba el mercado de trabajo, marcado por el intenso cambio tecnológico, lo que hacía imprescindible el fomento del aprendizaje permanente. En segundo lugar, la estructura demográfica presentaba una dinámica de envejecimiento exponencial que comprometía el modelo social europeo y el desarrollo sostenible. En tercer lugar, era necesario enfrentarse a la exclusión social y garantizar la igualdad de oportunidades, para lo que la educación y la formación suponían unos instrumentos vehiculares. Por último, el Consejo de Educación remarcaba el carácter amplificador de la Unión Europea, e instaba a los países candidatos a formar parte de la misma, a integrar los objetivos de la Estrategia y a trabajar, de forma conjunta, en aras de alcanzar puntos de encuentro previos, necesarios para futuras anexiones.

En este marco conceptual subyacía la idea de que una sociedad caracterizada por el crecimiento de la globalización y el cambio tecnológico, tenía que basar su modelo de crecimiento en el conocimiento, dada la posición de relativa desventaja respecto a los Estados Unidos, y la creciente "amenaza" de los nuevos países emergentes.

Señaladas las prioridades de la Estrategia de Lisboa, el Consejo Europeo de Lisboa y el Consejo Europeo de Feira, de junio de 2000, instaron al Consejo de Educación y a la Comisión a que iniciaran un proceso de reflexión y un periodo de consultas a los Estados miembro para plantear un marco estratégico que integrase los futuros objetivos de los sistemas de educación y que propusiera una serie de indicadores que la Comisión presentó en septiembre de ese mismo año (Comisión Europea, 2000). En esa comunicación, la Comisión propuso un total de 32 indicadores estructurales de seguimiento de la estrategia, quedando pendientes otros 14 por 
desarrollar. Entre ellos, el abandono escolar temprano ${ }^{9}$ se fijó como uno de los seis indicadores relativos a la cohesión social, con el objetivo de reducir su nivel hasta la mitad para el año 2010.

En enero de 2001, la Comisión emitió el informe en el que se incluían las respuestas de los Estados miembro (Comisión Europea, 2001), que manifestaban las necesidades o preocupaciones comunes para el futuro de sus sistemas educativos y de formación, y que el Consejo de Educación, en un informe al Consejo Europeo, también recogió y ratificó en febrero de 2001 (European Council, 2001).

El Consejo de Educación remarcaba además la necesidad de contar con una planificación educativa que sirviese como marco de adaptación a una sociedad en la que la información y la comunicación ejercían un carácter estructurador y transformador en la economía y las relaciones sociales. Así pues, el Consejo de Educación estableció los tres objetivos estratégicos generales y los objetivos específicos en el ámbito educativo, que se relacionan en la Tabla 2.1, para los diez años de aplicación de la Estrategia de Lisboa.

\footnotetext{
${ }^{9}$ En ese informe el indicador fue denominado como "proporción de abandono temprano de la escuela sin continuar la educación o la formación".
} 
Tabla 2.1. Objetivos estratégicos generales y específicos

\begin{tabular}{|c|}
\hline OBJETIVO 1: Mejorar la calidad y eficacia de los sistemas de educación y formación \\
\hline $\begin{array}{l}\text { - Mejorar la educación y formación de los profesores y formadores. } \\
\text { - Desarrollar las competencias necesarias para la sociedad del conocimiento. Asegurar la } \\
\text { alfabetización completa y la mejora de habilidades numéricas y lingüísticas de la población. } \\
\text { - Asegurar el acceso a las TICs para toda la sociedad. } \\
\text { - Promover la mayor escolarización en estudios técnicos y científicos, especialmente entre } \\
\text { las mujeres. } \\
\text { · Hacer un mejor uso de los recursos humanos y financieros, implementando sistemas de } \\
\text { calidad y evaluación de la eficiencia. }\end{array}$ \\
\hline OBJETIVO 2: Facilitar el acceso a toda la ciudadanía a la educación y la formación \\
\hline $\begin{array}{l}\text { - Crear un ambiente abierto y adaptado de aprendizaje, flexibilizando los mecanismos de } \\
\text { acceso y mejorando la información y orientación. } \\
\text { - Incrementar el atractivo del aprendizaje. } \\
\text {. Fomentar la participación ciudadana, la igualdad de oportunidades y la cohesión social. }\end{array}$ \\
\hline $\begin{array}{l}\text { OBJETIVO 3: Abrir la educación a la sociedad y fomentar la implicación de los agentes } \\
\text { sociales en la educación }\end{array}$ \\
\hline $\begin{array}{l}\text { - Fortalecer los lazos de la educación con el mercado laboral, la investigación y la sociedad en } \\
\text { general. } \\
\text { - Desarrollar el espíritu emprendedor. } \\
\text { - Fomentar el aprendizaje de idiomas extranjeros. } \\
\text { - Incrementar la movilidad y los programas de intercambio educativo y de formación. }\end{array}$ \\
\hline
\end{tabular}

Fuente: European Council (2001)

Teniendo en cuenta lo anterior, el Consejo de Educación, coordinadamente con

la Comisión, presentó en la reunión del Consejo Europeo en Barcelona en marzo de 2002 un programa de trabajo detallado, denominado posteriormente Educación y Formación 2010 "ET 2010"10", para el seguimiento de los objetivos concretos de los sistemas de educación y formación en Europa (European Council, 2002). En este programa o marco estratégico se resumieron y redefinieron en cinco los objetivos generales en el terreno educativo que se reflejan en la Tabla 2.2.

Tabla 2.2. Objetivos generales del marco estratégico ET 2010

- La educación y la formación europeas deben ser reconocidas mundialmente por su máxima calidad y relevancia.

- Los sistemas de educación y formación deben contar con mecanismos de compatibilidad para garantizar la movilidad.

- Las cualificaciones de los ciudadanos deben ser homologables y válidas en toda la Unión Europea.

- Todos los ciudadanos, con independencia de su edad, deben tener acceso al aprendizaje continuo.

- Europea debe promover la cooperación y la movilidad con otras regiones del mundo

Fuente: European Council (2002)

${ }^{10}$ Education and Training 2010. 
En este informe además, se remarcaba la necesidad de aplicar el nuevo Método Abierto de Coordinación, consistente en el intercambio de buenas prácticas, en la consecución de una convergencia de resultados y en el enfoque descentralizado en la ejecución de las medidas, con diversas fórmulas de cooperación entre los diferentes agentes. Por otro lado, se detallaba la organización y planificación de la aplicación de cada uno de los trece objetivos específicos que daban respuesta a los objetivos estratégicos planteados, y que se articulaban en un total de 42 cuestiones clave. Además, se recalcaba que estos objetivos no estaban planteados únicamente en base a una finalidad económica, sino que también hacían referencia a la meta de mejorar la participación ciudadana activa, cuestión también apuntada por el Parlamento Europeo (European Parliament, 2002).

De forma paralela, los ministros de educación de los distintos países de la Unión Europea firmaron, en noviembre de 2002, la denominada "Declaración de Copenhague", que supuso un acuerdo clave en materia de cooperación en el ámbito de las políticas educativas relativas a la formación profesional y a la formación continua, cuyos postulados de mejorar el reconocimiento de cualificaciones y competencias, transparencia y la calidad de los programas también fueron señalados como necesarios por el Consejo Europeo (European Council, 2003a) ${ }^{11}$, constituyendo el punto de inicio del conocido como "Proceso de Copenhague".

En mayo de 2003, las conclusiones del Consejo Europeo recogían las consideraciones apuntadas en los informes anteriores y subrayaban la necesidad de establecer un conjunto de indicadores de seguimiento, denominados puntos de referencia de rendimiento medio europeo en educación y formación (European Council, 2003b), que se enumeran en la Tabla 2.3.

\footnotetext{
${ }^{11}$ Aunque la cita hace referencia a 2003, el contenido de la resolución fue adoptado el 19 de diciembre de 2002, y es fruto de las conclusiones del Consejo de Educación que se reunió el 11 y 12 de noviembre de 2002.
} 
Tabla 2.3. Indicadores de seguimiento del marco estratégico ET 2010

- Abandono escolar prematuro: El porcentaje de jóvenes de entre 18 y 24 años que tienen como máximo la primera etapa de educación secundaria y no prosiguen con sus estudios debía ser, como máximo, del $10 \%$.

- Matemáticas, ciencias y tecnología: La proporción de graduados en estos campos debía aumentar en un 15\%, además de reducir el desequilibrio detectado entre sexos.

- Conclusión de la enseñanza secundaria superior: El 85\% de los ciudadanos de la Unión Europea con una edad de 22 años debería haber completado con éxito la educación secundaria segunda etapa ${ }^{12}$.

- Capacidades básicas: El porcentaje de ciudadanos de 15 años con rendimientos no satisfactorios en aptitud lectora debería disminuir en un $20 \%$ como mínimo ${ }^{13}$.

- Formación permanente: El porcentaje de población entre 25 y 64 años que participa en algún tipo de formación deberá ser al menos del 12,5\%.

Fuente: European Council (2003b)

Es, por tanto en el año 2003, en el que se concreta por primera vez el indicador de abandono escolar temprano como objetivo específico. En noviembre del mismo año, una nueva comunicación de la Comisión Europea (European Commission, 2003) denotaba que las reformas emprendidas por los Estados miembro no estaban a la altura de los retos señalados, y que el ritmo de las mismas no permitiría alcanzar los objetivos planteados. Por ello, la Comisión propuso los siguientes cuatro ejes sobre los que pivotar para relanzar el marco estratégico ET 2010:

- Concentrar las reformas en los puntos determinantes de cada Estado, actuando con eficacia y cooperación.

- Definir estrategias coherentes y globales, incluyendo las reformas nacionales en el contexto europeo.

- Adoptar un marco de referencia para las cualificaciones de la educación superior.

- Crear un mecanismo de seguimiento de los progresos realizados, en base a informes anuales remitidos por los Estados miembro a la Comisión.

En definitiva, y tal y como apunta Pépin (2006), el papel que ocupó la educación y la formación en la Estrategia de Lisboa reflejó hasta la fecha, el mayor grado de

${ }^{12}$ Nivel CINE 3. Los niveles CINE se refieren a la Clasificación Internacional Normalizada de la Educación, formulada por la UNESCO. La estructura de esta clasificación se sintetiza en la Tabla Al.1 del Anexo I.

${ }^{13}$ Se consideraba como insatisfactorio el conjunto del nivel 1 e inferior en la prueba de lectura del Informe PISA. 
reconocimiento de la importancia de este sector para el desarrollo económico y social de la Unión Europea.

\subsubsection{El Informe Kok y el Informe del Grupo de Alto Nivel}

En marzo del año 2003 se publica - a instancias de la Comisión Europea - el Informe Kok ${ }^{14}$ (Kok, 2003), en el que se realiza un análisis transversal de contexto en el marco de la incorporación de diez nuevos países a la Unión ${ }^{15}$, que suponían el incremento de la población de la Unión en unos 75 millones de habitantes. El informe plantea un estudio de los beneficios y costes de estas adhesiones, teniendo como perspectiva los objetivos de reformas estructurales planteados en la Estrategia de Lisboa.

En cuanto a los efectos de la adhesión, el informe apunta a los beneficios de añadir 75 millones de potenciales consumidores al mercado europeo, produciendo una intensificación del comercio, mayores economías de escala, aumento de la competitividad, resultando todo ello en un mayor crecimiento económico global. No obstante, el informe hace también referencia a posibles desafíos que se podían presentar, como la moderación salarial en el empleo de baja cualificación como consecuencia de la afluencia migratoria, o un desequilibrio entre los estándares de vida entre los antiguos y nuevos países; pero estos posibles desajustes serían compensados mediante el aumento de la productividad.

Sobre la Estrategia de Lisboa, el informe calificaba de pobre la actuación de los Estados y la consecución de los objetivos programados, y de autocomplaciente la actitud de varios países respecto al desempeño y esfuerzo realizado. No obstante, se remarcaba el carácter adaptativo de las nuevas incorporaciones a la Unión, muchas de las cuales estaban caracterizadas por realizar una transición exitosa desde modelos

\footnotetext{
${ }^{14} \mathrm{El}$ Informe Kok fue denominado de esta forma en referencia a Wim Kok, antiguo primer ministro de Países Bajos (1994 - 2002) y cabeza visible del informe en cuestión.

${ }^{15}$ La nuevos Estados miembro fueron República Checa, Chipre, Eslovaquia, Eslovenia, Estonia, Hungría, Letonia, Lituania, Malta y Polonia; haciéndose efectiva la incorporación el 1 de mayo de 2004.
} 
intervencionistas provenientes de la antigua Unión Soviética a modernas economías de mercado.

El Informe Kok concluye que los beneficios potenciales compensaban sobradamente las posibles desventajas que se pudieran plantear, haciendo hincapié en la aplicación compartida de políticas que la Unión había de tomar en consideración.

Un año después de la publicación del Informe Kok, el Consejo Europeo invitaba a la Comisión a crear un grupo de expertos denominado "Grupo de Alto Nivel", encabezado de nuevo por Wim Kok, para que realizase una evaluación independiente, en el marco de una revisión intermedia de la Estrategia de Lisboa, con el objetivo de conocer el alcance de los logros planteados y la propuesta de nuevas medidas y estrategias a llevar a cabo con el fin de alcanzar los objetivos propuestos en la Estrategia de Lisboa.

Ocho meses después, el Grupo de Alto Nivel presentó el informe encomendado bajo el título "Hacer frente al desafío. La Estrategia de Lisboa para el crecimiento y el empleo" (Kok et al., 2004). En este informe, se apuntaba que, en términos generales, se habían cosechado unos resultados decepcionantes, y que ello era debido a la conjunción de una mala evolución de los factores externos, por un lado, y una mala planificación de las actuaciones de los Estados, por otro. Ante ello, el Informe reclamaba una actuación más decidida y uniforme de los Estados, que hiciese frente a unos retos cada vez más acuciantes, en términos demográficos (envejecimiento) y económicos (aumento del diferencial de crecimiento respecto a las economías norteamericana y asiáticas).

En el ámbito de la sociedad del conocimiento, el informe señalaba la importancia de la inversión en investigación y desarrollo plasmada en la Estrategia de Lisboa, que no tuvo la aplicación requerida ni por parte de los Estados miembro ni por parte del sector privado. Además, se recalcaba la posición relativa desfavorable frente a Estados Unidos en cuestiones como el volumen de inscripción de patentes, el número de científicos, y el número de universidades de prestigio y de publicaciones científicas, entre otros indicadores. 
Entre otras recomendaciones ${ }^{16}$, el Informe confería una especial importancia al capital humano y a la necesidad de mejorar los sistemas de educación y formación bajo el pretexto de contar, en el futuro próximo, con un stock de personas altamente cualificadas capaces de ocupar puestos de responsabilidad en sectores dinámicos que creasen un alto valor añadido. A su vez, se sugirió que el número de jóvenes que abandonaban sus estudios de forma prematura debía reducirse a la mitad, dado que la falta de instrucción de la población supondría unas consecuencias nefastas en términos de desempleo y exclusión social. Así pues, el informa aconseja a los Estados miembro a cooperar con los interlocutores sociales y que, coordinadamente, adopten estrategias nacionales de aprendizaje permanente que afronten el cambio tecnológico, el desempleo, y el reto de la prolongación de la vida activa.

En cuanto al aspecto normativo y metodológico de la Estrategia, el informe hacía referencia a ámbitos de actuación para los que la Comisión Europea carecía de competencias, por lo que propuso una nueva forma de actuación que complementara el tradicional método comunitario de legislación con el método de coordinación abierto que involucrase a todos los actores necesarios.

En definitiva, la aportación de este informe, además de recalcar la necesidad de mantener unos objetivos ambiciosos y un mayor compromiso por todas las partes implicadas, sugería un modus operandi más eficaz que asegurase el éxito - hasta el momento no conseguido - de los objetivos planteados por la Estrategia de Lisboa, con un nuevo enfoque centrado en el crecimiento y el empleo, bajo la premisa de conseguir, conjuntamente, una economía más productiva, con un alto valor añadido y un alto índice de empleo.

\subsubsection{La nueva Estrategia de Crecimiento y Empleo}

Los objetivos comentados previamente - junto con otros referidos a empleo, investigación, desarrollo e innovación - se definieron para el periodo temporal de diez

16 El informe aconsejó la necesidad de tomar medidas para reducir los trámites administrativos, implementar incentivos fiscales y subvenciones para fomentar el gasto en I+D, y mejorar y simplificar la legislación europea relativa a propiedad intelectual para favorecer la innovación. 
años que constituía la estrategia de Lisboa. En consecuencia con lo anterior, los primeros cinco años, hasta 2005, los Estados miembro desarrollaron una serie de políticas de ámbito nacional y comunitario. No obstante, en la revisión intermedia, el Consejo Europeo afirmó que los avances que se habían alcanzado hasta la fecha eran muy escasos, por lo que se hacía necesario un replanteamiento de la estrategia inicial.

El Consejo Europeo, sin embargo, reafirmó el papel indispensable del conocimiento y la innovación como los motores del crecimiento sostenible, apoyándose - como hemos visto con anterioridad - en trabajos como el Informe Kok (Kok, 2003) o el Informe elaborado por el Grupo de Alto Nivel (Kok et al., 2004). En este contexto, se identifica a la productividad del trabajo como variable clave para conseguir un aumento en la oferta agregada y así lograr de forma permanente una convergencia real, reconociendo la importancia del papel que juega la educación en ese aspecto.

Al contexto desfavorable, se unía además la falta de determinación con la que algunos gobiernos aplicaron las medidas acordadas en la Estrategia de Lisboa, debido a sus debilidades estructurales y circunstancias coyunturales. Ante este panorama, en la revisión intermedia de la Estrategia de Lisboa se encontraron diversos aspectos que permitían concluir que la situación de la economía europea se encontraba en unos niveles más bajos que en marzo del año 2000, y que por tanto, el objetivo de convertir a la economía europea en la más competitiva y dinámica del mundo, basada en el conocimiento, se diluía.

Un indicador que evidenciaba esta realidad era que el diferencial de crecimiento de Europa respecto a sus competidores, afectados también en mayor o menor grado por el entorno descrito anteriormente, no se había reducido de forma significativa, lo que se traducía en el pensamiento de que esa economía basada en el conocimiento que se pretendía alcanzar todavía no se había puesto en marcha. Esta realidad, además, situaba a la economía de la Unión Europea en una posición peligrosa respecto a sus competidores emergentes - China e India principalmente - cuyas economías estaban cada vez más especializadas en productos de alto valor añadido. Por consiguiente, era necesario una reinterpretación de la estrategia de Lisboa que 
llevase a la economía europea a realizar una transición capaz de crear unas estructuras económicas que la convirtiesen en la economía líder a nivel mundial, a la vez que se protegiese y garantizase el modelo social europeo.

Este casi nulo comportamiento del diferencial de crecimiento respecto a otras zonas se explicaba por dos factores principalmente. El primero de ellos era el bajo nivel de insumo de mano de obra presente en la Unión Europea, que tenía su razón de ser en la existencia de una tasa de empleo baja y un reducido número de horas de trabajo. El segundo factor determinante era el nivel limitado de crecimiento de la productividad, como consecuencia de la escasa inversión empresarial y la poca especialización en nuevas tecnologías de la información y de la comunicación.

Es en este punto, cuando se decide concentrar las medidas en el eje económico, y en el que, además, se modifica el nombre de la Estrategia de Lisboa por el de Estrategia de Crecimiento y Empleo, según la cual, cada uno de los Estados miembro debía presentar un documento en el que recogiese sus planes y objetivos específicos, iniciándose así la presentación de los sucesivos Programas Nacionales de Reformas (PNR) de los distintos países.

En consecuencia, el Consejo Europeo desarrolló un total de 23 directrices integradas ${ }^{17}$ con el fin de relanzar la Estrategia de Lisboa, focalizándola en el problema de reanimar el crecimiento y el empleo en Europa para, de esta forma, servir de guía en el diseño de los PNR que los Estados miembro debían presentar. Aunque las 23 directrices integradas se concentraban en el objetivo del crecimiento y el empleo, la educación seguía estando en un primer plano, dado que se instó a los Estados a acometer acciones que ampliasen y mejorasen la inversión en capital humano y a adaptar los sistemas de educación y de formación a las nuevas exigencias del mercado. En este sentido, el diagnóstico al que hacen frente estas acciones es el de un sistema en el que demasiados individuos no acceden al mercado laboral debido a su insuficiente cualificación, lo que supone un factor que aminora las posibilidades de alcanzar la economía basada en el conocimiento a la que se pretendía llegar.

\footnotetext{
${ }^{17}$ Para consultar las directrices integradas, ir a Tabla Al.2 del Anexo I
} 


\subsubsection{Los resultados de la Estrategia de Lisboa}

Como ya anticipó el informe elaborado por el Grupo de Alto Nivel (Kok et al., 2004), la Estrategia de Lisboa es frecuentemente criticada por representar el espíritu del optimismo irracional de finales de los años noventa en torno al por entonces moderno concepto de "economía del conocimiento".

A la hora de realizar una valoración del grado de éxito de la Estrategia de Lisboa, hay que tener en cuenta la dificultad que ello conlleva debido a diversos factores. Al cambio de contexto que ha registrado la economía no sólo de la Unión Europea, sino a escala mundial, hay que añadir las ampliaciones en el número de miembros de la Unión, que casi se había doblado, pasando de 15 a 27 miembros $^{18}$.

En términos generales, el resultado general de la Estrategia de Lisboa no fue satisfactorio. La Tabla 2.4 refleja la evolución de los dos grandes objetivos planteados. Por un lado, la tasa de empleo, cuya situación de partida era el $63,4 \%$, ha registrado un leve aumento de 0,8 puntos en todo el periodo, alcanzando en 2010 un 64,2\%, por lo que distaba notablemente del objetivo del $70 \%$ planteado inicialmente. Por otro lado, la inversión en I+D como porcentaje del PIB apenas mejoró, pasando de un 1,85\% en el año 2000 a un 1,93\% en 2010, quedando lejos el objetivo inicialmente planteado, de alcanzar el $3 \%$ del PIB ${ }^{19}$.

Tabla 2.4. Progreso de los objetivos generales de la Estrategia de Lisboa

\begin{tabular}{|l|c|c|c|c|}
\hline & Situación & Objetivo & Situación & \\
& $\mathbf{2 0 0 0}$ & $\mathbf{2 0 1 0}$ & $\mathbf{2 0 1 0}$ & Progreso \\
\hline Tasa de empleo & $63,4 \%$ & $70 \%$ & $64,2 \%$ & $+0,8 \%$ \\
Inversión en I+D (\% del PIB) & $1,85 \%$ & $3 \%$ & $1,93 \%$ & $+0,08 \%$ \\
\hline
\end{tabular}

Fuente: Eurostat

A pesar de lo señalado anteriormente, según la propia Comisión Europea (European Commission, 2010a), sí se produjeron avances positivos, como la creación

\footnotetext{
${ }^{18}$ Además de la ampliación anteriormente comentada de la UE-25, en el año 2007 se materializó la incorporación de Rumanía y Bulgaria en la Unión, pasando ésta a estar conformada por un total de 27 Estados miembro.

${ }^{19}$ No obstante, hay que tener en cuenta que los datos del año 2000 se corresponden al conjunto de la Unión Europea de los 15, mientras que los datos del año 2010 reflejan el conjunto de la Unión Europea de los 27. En el Cuadro Al.1 y Cuadro Al.2 se puede consultar la evolución de los dos indicadores para el periodo 2000 - 2013.
} 
de 18 millones de puestos de trabajo nuevos antes del impacto de la crisis, la reducción de la burocracia administrativa, la mejora de la sostenibilidad, y, especialmente, la generación de un entorno de consenso, propicio al debate, que ha puesto de manifiesto la necesidad de programar reformas estructurales de forma coordinada.

En el campo específico de la educación y la formación, la Tabla 2.5 resume los progresos alcanzados sobre los indicadores de seguimiento planteados en el marco estratégico ET 2010 (European Council, 2003b).

Tabla 2.5. Progreso de los indicadores de seguimiento del marco estratégico ET 2010

\begin{tabular}{|l|c|c|c|c|}
\hline \multicolumn{1}{|c|}{ Indicador de seguimiento } & $\begin{array}{c}\text { Situación } \\
\mathbf{2 0 0 0}\end{array}$ & $\begin{array}{c}\text { Objetivo } \\
\mathbf{2 0 1 0}\end{array}$ & $\begin{array}{c}\text { Situación } \\
\mathbf{2 0 1 0}\end{array}$ & Progreso \\
\hline Abandono escolar temprano. & $17,6 \%$ & $10 \%$ & $14 \%$ & $-3,6 \%$ \\
$\begin{array}{l}\text { \% graduados superiores en Matemáticas, } \\
\text { Ciencias y Tecnología. }\end{array}$ & $10,7 \%^{(2)}$ & $\Delta 15 \%$ & $15,2 \%$ & $\Delta 42,05 \%$ \\
$\begin{array}{l}\text { \% población con al menos estudios de } \\
\text { enseñanza secundaria superior. }{ }^{\left({ }^{(1)}\right.}\end{array}$ & $76,7 \%^{(4)}$ & $85 \%$ & $79 \%$ & $+2,3 \%$ \\
$\begin{array}{l}\text { Capacidades básicas: \% de ciudadanos de } 15 \\
\text { años con rendimientos insatisfactorios en } \\
\text { aptitud lectora. }\end{array}$ & $19,8 \%$ & $\nabla 20 \%$ & $19,6 \%{ }^{(5)}$ & $\nabla 0,2 \%$ \\
$\begin{array}{l}\text { \% de población que participa en la formación } \\
\text { permanente. }\end{array}$ & $7,1 \%$ & $12,5 \%$ & $9,1 \%$ & $+2 \%$ \\
\hline
\end{tabular}

Fuente: Eurostat

(1) Proporción de ciudadanos de entre 20 y 29 años graduados (niveles ISCED 5 y 6) en ciencia y tecnología por cada 1.000 habitantes de ese grupo de edad.

(2) Dato de 2001.

(3) Proporción de ciudadanos de entre 20 y 24 años que ha completado, al menos, la segunda etapa de la educación secundaria (niveles ISCED 3a, 3b o 3c).

(4) Dato de 2002.

(5) Dato de 2009.

(6) Proporción de población de entre 25 y 64 años que ha recibido educación y/o formación en las cuatro semanas precedentes a la realización de la encuesta.

De esta forma, podemos observar que de los cinco indicadores de seguimiento, únicamente en uno se había alcanzado el objetivo propuesto. Es el caso de la proporción de graduados en ciencias, matemáticas y tecnología, cuyo objetivo de aumento en un $15 \%$ se vio claramente alcanzado (se registra un incremento de más de un $42 \%)$. 
El abandono escolar temprano se redujo 3,6 puntos, progreso insuficiente para alcanzar la tasa objetivo del $10 \%$, para la que aún quedaba otra reducción de cuatro puntos. En cuanto a la proporción de población con estudios completados de enseñanza secundaria superior, se produjo un aumento de 2,3 puntos, situándose esta tasa en un $79 \%$, seis puntos por debajo del objetivo planteado (85\%). La proporción de alumnos de 15 años con rendimientos insatisfactorios en aptitud lectora, evaluada a través del informe PISA ${ }^{20}$, tuvo una reducción ínfima, de tan sólo el $0,2 \%$, frente al $20 \%$ marcado, mientras que la participación de la población en la formación permanente experimentó un aumento de dos puntos, restando aún 3,4 puntos para alcanzar el objetivo del $12,5 \%$. Así pues, se puede observar que, a pesar de que en todos los indicadores de seguimiento se registró una evolución positiva, quedaba aún un largo recorrido pendiente para alcanzar los objetivos planteados.

\subsubsection{La Estrategia Europa 2020}

Tras el impacto de la crisis económica, y al llegar a término el periodo temporal de la Estrategia de Lisboa, cuyos objetivos en buena medida no se habían cumplido, la Comisión Europea empezó a trabajar en el diseño de una nueva estrategia para los siguientes diez años, teniendo en cuenta el profundo cambio de contexto que había experimentado la economía mundial y europea.

\subsubsection{Europa ante el cambio de contexto macroeconómico}

La crisis económica iniciada en 2008, cuyas consecuencias se vienen sufriendo hasta la actualidad ha sido objeto de un número ingente de análisis y estudios. En lo que al ámbito europeo se refiere, el impacto de la crisis ha supuesto la volatilización de los progresos alcanzados durante buena parte de la década precedente a la recesión. En este sentido, la Tabla 2.6 muestra tres de los indicadores macroeconómicos de referencia en los años 2008 y 2010, evidenciando un deterioro sustancial en términos de PIB, tasa de desempleo e índice de producción industrial.

\footnotetext{
${ }^{20} \mathrm{El}$ informe PISA (Programme for International Student Assessment) es un estudio realizado por la OCDE que evalúa las competencias en lectura, ciencias y matemáticas del alumnado de 15 años a escala internacional, junto con otras variables socioeconómicas y educativas.
} 
Tabla 2.6. Principales indicadores macroeconómicos en la Unión Europea-27

\begin{tabular}{|l|c|c|c|}
\hline \multicolumn{1}{|c|}{ Indicador } & Situación & Situación & Evolución \\
& $\mathbf{2 0 0 8}$ & $\mathbf{2 0 1 0}$ & \\
\hline PIB per cápita $^{(1)}$ & $25.100 €$ & $24.600 €$ & $\nabla 2 \%$ \\
Tasa de paro $_{\text {Índice de producción industrial (Año 2010=100) }}$ & $7 \%$ & $9,6 \%$ & $+2,6 \%$ \\
\hline
\end{tabular}

Fuente: Eurostat

(1) Datos a precios corrientes

A pesar de la crisis que la economía europea atravesaba desde el año 2008, ésta adolecía de una serie de carencias estructurales que convenía afrontar con celeridad para no sólo superar la recesión, sino evitar volver al estado inmediatamente anterior a ella. Estas debilidades fueron resumidas por la Comisión (Comisión Europea, 2010b) en las tres siguientes:

- El diferencial de crecimiento económico era significativamente inferior en relación a los competidores, hecho que venía explicado por la menor productividad, junto a otros factores como la menor inversión en I+D+i, unas estructuras empresariales menos dinámicas, un marco regulatorio más burocratizado y un uso poco intensivo de las TICs.

- Europa presentaba unas tasas de empleo más bajas, especialmente en el caso de las personas de entre 55 y 64 años y en las mujeres.

- La estructura demográfica se caracterizaba por una población cada vez más envejecida, proceso que venía acelerándose desde el año 2007, y que ponía a prueba el modelo social europeo.

Este panorama descrito planteaba nuevos desafíos en el marco de elaboración de la nueva Estrategia Europa 2020. En este sentido, la Comisión Europea (European Commission, 2010b) estableció un triple reto. En primera instancia, Europa debía hacer frente a la cada vez mayor presencia de competidores emergentes que suponía la globalización, y que constituía una amenaza en términos de competitividad. Por otro lado, la volatilidad del sistema financiero, que había dejado en evidencia las consecuencias de un sistema que carecía de una regulación eficaz, y que se traducía en la generación de desequilibrios. En último lugar, se planteaba el reto de superar la dependencia energética de combustibles fósiles como el petróleo, cuyo uso amenazaba tanto la seguridad económica como climática. 
Los anteriores desafíos presentaban, además, un importante carácter regional en cuanto a la dispar vulnerabilidad de cada una de las regiones y la necesidad de plantear tipologías de actuaciones e intensidades distintas para hacer frente a las mismas, como ya apuntaban informes previos (European Commission, 2008).

\subsubsection{La renovación de los objetivos de las reformas estructurales en}

\section{la Estrategia Europa 2020}

La Estrategia Europa 2020 fue concebida, en junio de 2010, bajo la premisa de que la salida de la crisis debía ser el punto de entrada en una nueva economía social de mercado sostenible, más inteligente y más respetuosa con el medio ambiente, en la que la prosperidad se basara en la innovación, en la cohesión social y en una mejor utilización de los recursos, y cuyo principal motor debía ser el conocimiento (European Commission, 2010b). En esencia, no se había modificado el espíritu de la anterior Estrategia de Lisboa, sino que la nueva Estrategia Europa 2020 suponía una continuidad en la consecución de los objetivos que se plantearon en el año 2000.

No obstante, conviene apuntar que sí se apreciaba una modificación en el tono en el que se marcaban las aspiraciones, de forma que se hacía referencia a unos objetivos y finalidades más creíbles y realistas, olvidando la proclamación de la ambiciosa y quizás poco realista meta de alcanzar la economía basada en el conocimiento "más competitiva y dinámica del mundo" (Pépin, 2011). De esta forma, la nueva estrategia se vertebra en torno los cinco objetivos principales que se recogen en la Tabla 2.7.

Tabla 2.7. Objetivos de la Estrategia 2020

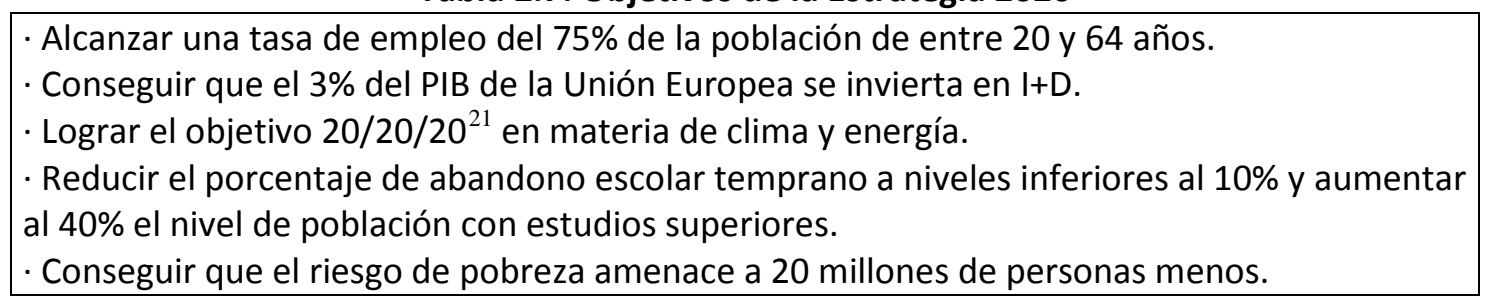
Fuente: European Commission (2010b)

${ }^{21}$ El objetivo 20/20/20 se subdivide en los siguientes tres objetivos específicos: Reducir un $20 \%$ el consumo de energía primaria, reducir el $20 \%$ de las emisiones de gases de efecto invernadero, y conseguir la presencia de un $20 \%$ de las energías renovables. 
Por otro lado, la Comisión renovó las directrices integradas de la anterior Estrategia de Lisboa con el objetivo de servir de guía en el diseño de los PNR ${ }^{22}$.

\subsubsection{Los objetivos del ámbito educativo y el marco estratégico ET}

2020

A la hora de formular las bases de la nueva estrategia, se hizo especial referencia en la identificación de nuevas fuentes de crecimiento y puestos de trabajo que permitiesen establecer una "economía social de mercado sostenible", para lo que se consideraba fundamental seguir aplicando medidas en el marco estratégico de la educación y la formación. De este modo, el Consejo Europeo, recogiendo el testigo de la antigua Estrategia Educación y Formación 2010 “ET 2010” estableció, en el año 2009 los objetivos estratégicos de la renovación del marco estratégico Educación y Formación 2020 “ET 2020”23, que se muestran en la Tabla 2.8.

Tabla 2.8. Objetivos generales del marco estratégico ET 2020

- Hacer realidad el aprendizaje permanente y la movilidad, desarrollando los marcos de cualificaciones nacionales vinculados al Marco Europeo de Cualificaciones, flexibilizando las vías de aprendizaje, extendiendo y aplicando la Carta Europea de Calidad para la Movilidad. - Mejorar la calidad y la eficacia de la educación y la formación, incrementando el atractivo de los programas educativos y fomentando la adquisición de las competencias clave por parte de los ciudadanos.

- Promover la equidad, la cohesión social y la ciudadanía activa, ofreciendo una educación preescolar de alta calidad e incluyente.

- Incrementar la creatividad y la innovación, incluido el espíritu empresarial, en todos los niveles de la educación y la formación, garantizando el funcionamiento del triángulo del conocimiento y promoviendo las asociaciones entre el mundo académico y el empresarial.

Fuente: Consejo Europeo (2009)

Como se puede observar, los objetivos generales planteados son similares a los formulados en el marco estratégico ET 2010 (ver Tabla 2.2), pero en el nuevo marco estratégico ET 2020 se explicita la necesidad crear asociaciones entre el mundo académico y empresarial, poniendo un mayor acento en la necesidad de fomentar la creatividad, la innovación y el espíritu empresarial.

Especificadas las directrices principales de actuación, la Comisión Europea instó a las naciones a abordar el problema del abandono escolar temprano - entre muchos

\footnotetext{
${ }^{22}$ Para consultar las directrices integradas, ir a Tabla Al.3 del Anexo I.

23 "Education and Training 2020".
} 
otros - en el marco de sus PNR, diseñando estrategias y acciones para conseguir el objetivo marcado, que en este caso era, y es, el de conseguir una tasa de abandono escolar temprano en la Unión Europea inferior al 10\%. Para dar cuenta de los logros alcanzados, se instó también a las naciones a informar sobre los objetivos nacionales de la Estrategia Europa 2020, a través de las Encuestas Anuales sobre el Crecimiento (Comisión Europea, 2011a, 2011b, European Council, 2011).

Para monitorizar el progreso de los objetivos descritos, se formularon los valores de referencia de los indicadores de seguimiento del marco estratégico ET 2020, expuestos en la Tabla 2.9, que se desarrollaron en consonancia con los que sirvieron de guía para el anterior marco estratégico ET 2010.

Tabla 2.9. Indicadores de seguimiento del marco estratégico ET 2020 y evolución

\begin{tabular}{|c|c|c|c|c|}
\hline Indicador & $\begin{array}{c}\text { Situación } \\
2010\end{array}$ & $\begin{array}{c}\text { Objetivo } \\
2020\end{array}$ & $\begin{array}{l}\text { Último } \\
\text { dato }\end{array}$ & Progreso \\
\hline $\begin{array}{l}\text { Aprendizaje permanente: \% de población de } \\
\text { entre } 25 \text { y } 64 \text { años que participa en } \\
\text { actividades de educación y formación. }\end{array}$ & $9,1 \%$ & $>15 \%$ & $10,7 \%^{4}$ & $+1,6 \%$ \\
\hline $\begin{array}{l}\text { Competencias básicas: \% de jóvenes de } 15 \\
\text { años con bajo rendimiento en: }\end{array}$ & & & & \\
\hline - Matemáticas. & $22,90 \%^{2}$ & & $23,65 \%^{5}$ & $+0,75 \%$ \\
\hline · Comprensión lectora. & $20,62 \%^{2}$ & $<15 \%$ & $19,71 \%^{5}$ & $-0,91 \%$ \\
\hline - Ciencias. & $18,45 \%^{2}$ & & $18,77 \%^{5}$ & $+0,32 \%$ \\
\hline $\begin{array}{l}\text { Enseñanza superior: } \% \text { de población de entre } \\
30 \text { y } 34 \text { años con un nivel educativo } \\
\text { completado de educación superior }{ }^{1} \text {. }\end{array}$ & $33,4 \%$ & $>40 \%$ & $36,6 \%^{4}$ & $+3,2 \%$ \\
\hline Abandono escolar temprano. & $13,9 \%$ & $<10 \%$ & $12 \%^{4}$ & $-1,9 \%$ \\
\hline $\begin{array}{l}\text { Escolarización infantil: \% de niños de entre } \\
\text { cuatro años y la edad de escolarización } \\
\text { obligatoria en la educación infantil. }\end{array}$ & $92,6 \%^{3}$ & $>95 \%$ & $93,2 \%^{6}$ & $+0,6 \%$ \\
\hline
\end{tabular}

Fuente: Eurostat, Consejo Europeo (2009), Ministerio de Educación (2011) y OECD (2010a)

(1) Niveles CINE 5 y 6.

(2) Promedio de la UE-27 excluyendo Malta y Chipre por no disponibilidad de datos. Datos correspondientes al año 2009 (OECD, 2010a).

(3) Promedio de la UE-27 para el año 2010.

(4) Dato provisional. Año 2013.

(5) Promedio de la UE-27 excluyendo Malta por no disponibilidad de datos. Datos correspondientes al año 2012 (OECD, 2014a).

(6) Promedio de la UE-27 para el año 2011.

Como se puede observar, el abandono escolar temprano continúa siendo uno de los cinco principales indicadores de seguimiento, cuyo nivel en 2010 asciende al 
$13,9 \%$, teniendo por objetivo su reducción a valores inferiores al $10 \%$ de promedio en la Unión Europea y habiendo registrado un descenso hasta el $12 \%$ en el año $2013^{24}$.

El resto de indicadores presenta, en términos generales, una evolución favorable respecto a la situación de partida, salvo los indicadores de competencias básicas referidos a los resultados del estudio PISA, que muestran una evolución desfavorable en el caso de competencia en matemáticas y en ciencias, y en cualquier caso distante del objetivo de reducir la proporción de alumnado en niveles inferiores por debajo del $15 \%$. Por su parte, el aprendizaje permanente se ha incrementado en 1,6 puntos, mientras que el objetivo de enseñanza superior es el que mejor comportamiento ha obtenido, registrando un aumento de 3,2 puntos en la proporción de población de entre 30 y 34 años que ha completado un nivel educativo superior. En cuanto a escolarización infantil, la escasa mejora del indicador se puede explicar principalmente por la correspondencia de los datos a un intervalo de tiempo limitado a un año.

\subsection{El contexto de España y la adaptación de los objetivos de las estrategias europeas}

\subsubsection{El contexto económico y el desarrollo de los Programas Nacionales de Reformas durante la aplicación de la Estrategia de Lisboa}

España, al igual que el resto de miembros de la unión, presentó su Programa Nacional de Reformas (PNR) en octubre de 2005 (Ministerio de la Presidencia, 2005), centrado en dos objetivos principales: alcanzar la plena convergencia en renta per cápita con la Unión Europea en el año 2010, y alcanzar una tasa de empleo de al menos el $66 \%$. Al margen de estos dos objetivos prioritarios, se definieron una serie de objetivos específicos, que se enumeran en la Tabla $2.10^{25}$.

\footnotetext{
${ }^{24}$ Para el año 2014, el dato provisional de abandono escolar temprano para la UE-28 es del $11,1 \%$.

${ }^{25}$ Además de los siete objetivos específicos mencionados, el PNR establecía un objetivo adicional de carácter transversal consistente en el incremento de la eficiencia energética y la reducción de las emisiones de $\mathrm{CO}_{2}$, con el objetivo de cumplir los compromisos de España con
} 
Tabla 2.10. Relación de objetivos específicos del Programa Nacional de Reformas de España

- Reducir la ratio de deuda pública en relación al PIB, hasta el 34\%, reorientando, al mismo tiempo, el gasto público hacia las actividades que fomenten el incremento de la productividad.

- Aumentar la red ferroviaria hasta los $35 \mathrm{Km} / 1.000 \mathrm{Km}^{2}$, además de reducir la tasa de accidentalidad en carretera en un $40 \%$.

- Reducir hasta la mitad (15\%) la tasa de abandono escolar temprano en 2010, con el objetivo de alcanzar la media europea, planteando un objetivo intermedio de reducir el indicador hasta el $20,1 \%$ en el año 2008.

- Duplicar la inversión en I+D hasta el $2 \%$ del PIB en 2010, con el objetivo intermedio de alcanzar el $1,6 \%$ en el 2008, y aumentar hasta el 7\% del PIB los recursos que la economía española dedica a las TIC (con el objetivo intermedio de llegar hasta el 6,3\% en el año 2008).

- Mejorar la posición española en relación con los indicadores de competencia, convergiendo, en el año 2010, en aquellos casos en los que se encontraran por debajo de la misma.

- Incrementar la tasa de empleo femenino desde el $48 \%$ hasta el $57 \%$; reducir la tasa de desempleo juvenil desde el $22,1 \%$ hasta el promedio de la UE-25 (18,6\%); y disminuir la siniestralidad laboral.

- Aumentar en un $25 \%$ la creación de nuevas empresas, especialmente en el caso de los jóvenes y las mujeres.

Fuente: Ministerio de la Presidencia (2005)

Respecto a las políticas de educación y formación, se señaló la necesidad de articular una política económica que dotara a la economía española de un capital humano mejor formado, una inversión en $1+D+i$ suficiente y unas infraestructuras adecuadas. Prueba de ello es la inclusión de la reducción del abandono escolar temprano como uno de los siete objetivos específicos que España se planteó como medio para alcanzar los dos objetivos de convergencia en términos de renta per cápita y empleo, si bien hay que señalar que este objetivo distaba del objetivo de la Unión de reducir hasta el $10 \%$, como mínimo, este indicador. No obstante, y como la nueva estrategia señalaba, la fijación de los objetivos y medidas adoptadas debía de tener en cuenta la situación inicial de cada país y sus limitaciones, por lo que el objetivo de reducción del abandono escolar temprano debía de ser ambicioso pero alcanzable.

El PNR de España vertebró en siete ejes fundamentales (ver Tabla 2.11) las acciones de política económica necesarias para dar respuesta a las 23 directrices integradas, planteadas por el Consejo Europeo, y a los objetivos específicos del propio PNR (Ministerio de la Presidencia, 2005).

el Protocolo de Kioto, y en coherencia con el modelo de desarrollo sostenible propuesto en la Estrategia de Lisboa. 
Tabla 2.11. Relación de los ejes de acción del Programa Nacional de Reformas de España

- Eje 1: Refuerzo de la estabilidad macroeconómica y presupuestaria.

- Eje 2: El Plan Estratégico de Infraestructuras y Transporte (PEIT) y el Programa de

Actuaciones para la Gestión y Utilización del Agua (AGUA).

- Eje 3: Aumento y mejora del capital humano.

- Eje 4: La estrategia de I+D+i (INGENIO 2010).

- Eje 5: Más competencia, mejor regulación, eficiencia de las AAPP y competitividad.

- Eje 6: Mercado de trabajo y diálogo social.

- Eje 7: El Plan de Fomento Empresarial.

Fuente: Ministerio de la Presidencia (2005)

El Eje 3, de aumento y mejora del capital humano, otorgaba prioridad a la necesidad de reducir los niveles de abandono escolar temprano, que constituía una piedra angular para contribuir al crecimiento económico y conseguir la igualdad de oportunidades. No obstante, el tercer eje integraba otros objetivos relativos a la educación y formación, como es el aumento del nivel de escolarización de niños de entre 0 y 3 años, la reducción del fracaso escolar, la mejora de los resultados del informe PISA, el incremento en el número de titulados superiores en ciencias, y el aumento de la formación permanente.

La Tabla 2.12 muestra la relación de indicadores de seguimiento que se establecieron sobre el tercer eje, de aumento y mejora del capital humano, así como la cuantificación de la situación de partida en la que se plantearon (año 2004), y los objetivos intermedios (año 2008) y finales (año 2010). 
Tabla 2.12. Indicadores y objetivos del PNR de España 2005 sobre el eje de aumento y mejora del capital humano

\begin{tabular}{|c|c|c|c|}
\hline Indicador & \begin{tabular}{|c|} 
Situación \\
2004
\end{tabular} & $\begin{array}{l}\text { Objetivo } \\
2008\end{array}$ & $\begin{array}{c}\text { Objetivo } \\
2010\end{array}$ \\
\hline \multicolumn{4}{|l|}{ Educación infantil } \\
\hline Escolarización a los 2 años & $21,7 \%$ & $27 \%$ & $>30 \%$ \\
\hline \multicolumn{4}{|l|}{ Educación Obligatoria } \\
\hline Porcentaje de titulados en ESO & $70,2 \%^{(2)}$ & $76 \%$ & $>80 \%$ \\
\hline Resultados Informe PISA ${ }^{(1)}$ - Comprensión lectora & $21,1 \%^{(3)}$ & $18 \%$ & $16 \%^{(3)}$ \\
\hline \multirow[t]{2}{*}{ Resultados Informe PISA ${ }^{(1)}$ - Matemáticas } & $\begin{array}{c}23,2 \%^{(4)} \\
23 \%^{(3)}\end{array}$ & $\begin{array}{l}27 \% \\
19 \%\end{array}$ & $\begin{array}{l}29 \%^{(4)} \\
17 \%^{(3)}\end{array}$ \\
\hline & $25,6 \%^{(4)}$ & $30 \%$ & $32 \%^{(4)}$ \\
\hline Resultados Informe PISA ${ }^{(1)}-$ Ciencias & $487^{(5)}$ & 500 & $>500$ \\
\hline \multirow[t]{2}{*}{ Aprendizaje de lenguas extranjeras } & $15 \%{ }^{(6)}$ & $13 \%$ & $11 \%$ \\
\hline & $17 \%^{(7)}$ & $19 \%$ & $21 \%$ \\
\hline \multicolumn{4}{|l|}{ Educación Secundaria Superior } \\
\hline Abandono escolar prematuro & $30,4 \%$ & $20 \%$ & $15 \%$ \\
\hline Graduados en educación secundaria superior (20-24 años) & $62,5 \%$ & $74 \%$ & $80 \%$ \\
\hline \multicolumn{4}{|l|}{ Educación Superior } \\
\hline $\begin{array}{l}\text { Ingreso en la educación terciaria (universitaria y formación } \\
\text { profesional de grado superior) }\end{array}$ & $46 \%$ & $51 \%$ & $>53 \%$ \\
\hline $\begin{array}{l}\text { \% de titulados superiores en ciencias, matemáticas y } \\
\text { tecnología }\end{array}$ & $12 \%$ & $13 \%$ & $13,5 \%$ \\
\hline \multicolumn{4}{|l|}{ Formación continua } \\
\hline Porcentaje de población que recibe formación permanente & $5,2 \%$ & $10 \%$ & $12,5 \%$ \\
\hline
\end{tabular}

Fuente: Ministerio de la Presidencia (2005)

(1) Informe PISA 2003 (OCDE, 2004).

(2) Dato del curso $2002-2003$.

(3) Porcentaje de alumnos situados en los niveles 0 y 1 de rendimiento en PISA. El objetivo era reducir en un $25 \%$ el porcentaje de alumnos en los niveles más bajos de competencia. Hay 6 niveles, siendo el 0 el nivel más bajo y el 6 el nivel más alto.

(4) Porcentaje de alumnos situados en los niveles 4,5 y 6 de rendimiento en el Informe PISA. El objetivo era aumentar en un $25 \%$ el porcentaje de alumnos en los niveles más altos de competencia.

(5) Puntuación de España en el Informe PISA. El objetivo era superar la puntuación media de la OCDE, situada en 500 puntos.

(6) Porcentaje de alumnos situados en los niveles 1 y 2 (los más bajos) de competencia en las evaluaciones nacionales. El objetivo consistía en reducir ese porcentaje en un $25 \%$.

(7) Porcentaje de alumnos situados en los niveles 5 y 66 de competencia en las evaluaciones nacionales. El objetivo suponía incrementar ese porcentaje en un $25 \%$.

A efectos de la necesidad planteada por la Comisión, de establecer un mecanismo de evaluación, el PNR estableció, a través de la Comisión Delegada del Gobierno para Asuntos Económicos, la elaboración de un Informe Anual de Seguimiento del PNR, que incluiría la revisión de las medidas implantadas y el grado de consecución de los objetivos propuestos. 
Como se refleja en la Tabla 2.12, España se fijó como objetivo reducir la tasa de abandono escolar temprano hasta el $20 \%$ para el año 2008 y hasta el $15 \%$ para el año 2010, y disminuir de esta forma la amplia brecha existente respecto al resto de países europeos. Para alcanzar este y el resto de objetivos planteados en el terreno de la educación, se diseñaron una serie de medidas que, sin embargo, no hacían alusión explícita al problema del abandono escolar temprano. Únicamente la política de becas y ayudas al estudio, cuyo aumento previsto para el año 2006, de 40.000 nuevos becarios, con un incremento total del gasto de 85 millones de euros, era el único factor directo que se esperaba que tuviera un efecto significativo en la tasa de abandono escolar temprano.

Una vez presentados los programas nacionales de reformas para cada uno de los 25 Estados miembro, la Comisión Europea redactó, en el año 2006, un informe en el que se evaluaba cada uno de ellos, calificando el programa español como "ambicioso, coherente y comprensivo" (European Commission, 2006), pese a que se formuló una crítica en cuanto a la no priorización de los objetivos específicos y a la inexistencia de una planificación precisa en las acciones a desarrollar para lograr la consecución de los mismos.

Cabe destacar también que en ese mismo año, 2006, se puso en marcha la Ley Orgánica de Educación (LOE), que tal y como recoge el primer informe anual de progreso del PNR de España (Ministerio de la Presidencia, 2006), venía a implementar una serie de recursos económicos que, en el terreno de la lucha contra el abandono escolar temprano, se traducían en programas de apoyo y refuerzo que conferían a los alumnos una enseñanza más personalizada, atendiendo así las necesidades específicas de cada uno de ellos, favoreciendo la permanencia del alumnado en el sistema educativo más allá de la educación no obligatoria.

En el informe anual de progreso del PNR de 2007 (Ministerio de la Presidencia, 2007) se hablaba ya de un cambio de tendencia, ya que, a tenor de los resultados observados (descenso de la tasa de abandono escolar temprano del 31,7\% en 2004 al 29,9\% en 2006), se tenía la certeza de que se había producido un punto de inflexión y que, pese a que las mejoras conseguidas distaban aún demasiado del objetivo 
propuesto, ello se debía a que las modificaciones que se habían introducido en el sistema educativo no se podían ver trasladadas a los resultados hasta transcurridos varios años.

También en el año 2007, la LOE incluyó dentro del plan para el apoyo a su implantación, el Programa de Cooperación Territorial para la Reducción del Abandono Temprano de la Educación (PCT-RATE), plan que fue publicado en noviembre de 2008 por la Conferencia Sectorial de Educación (CSE), tras su diseño junto a las comunidades autónomas (Ministerio de Educación, Política Social y Deporte, 2008). Este plan contaba con la financiación del Ministerio de Educación, Política Social y Deporte (MEPSYD), que aportó, entre los años 2007 y 2010, el 40\% de los fondos, siendo el resto complementado por las comunidades autónomas ${ }^{26}$.

En cuanto a las medidas introducidas en el sistema educativo, se incrementó el número de plazas de los Programas de Cualificación Profesional Inicial (PCPI), que ofrecían una alternativa de formación a los alumnos mayores de 16 años que no disponían del título de graduado en ESO; se ofertó al alumnado que abandonaba la posibilidad de obtener un certificado de acreditación de competencias básicas que facilitase posteriormente su reinserción; se flexibilizaron las vías para continuar los estudios en las etapas postobligatorias; y se desarrollaron programas preventivos para determinados colectivos en riesgo de abandono.

En cuanto a los centros educativos y el profesorado, se impulsaron los programas de orientación del alumnado y los programas de atención y refuerzo para la educación personalizada; se mejoraron los programas de coordinación entre el profesorado; y se fomentó la formación al profesorado que trabajaba con alumnado de riesgo.

En el ámbito de las familias y los jóvenes que han abandonado el sistema educativo, se impulsaron medidas como el reconocimiento del aprendizaje no

\footnotetext{
${ }^{26}$ Para consultar las cantidades transferidas a las distintas comunidades autónomas, ver Cuadro Al.3 del Anexo I.
} 
formal ${ }^{27}$; los servicios de orientación y seguimiento de estos jóvenes; y la promoción de ofertas de nuevas oportunidades y de la educación a distancia y semi-presencial. En este sentido, se señaló la necesidad de establecer itinerarios flexibles ${ }^{28}$.

Por otro lado, en el plan se hacía referencia a la posibilidad de introducir medidas en el ámbito laboral, dirigidas a promover la compatibilización entre formación y empleo, y el establecimiento de programas de orientación profesional junto con las corporaciones locales.

En el informe anual de progreso del PNR de 2008 (Ministerio de la Presidencia, 2008), se observaba un nuevo repunte de la tasa de abandono escolar temprano, que alcanzaba el 31\% de promedio en España, haciéndose una especial referencia a la gran divergencia hallada entre las diferentes comunidades autónomas españolas. Además, en este informe se especifican acciones concretas para reducir las tasas de abandono escolar temprano, consistentes en actuaciones orientadas a la retención de los estudiantes en el sistema educativo, así como estrategias de reinserción educativa, como los programas de segunda oportunidad.

En el informe anual de progreso de 2009 del PNR (Ministerio de la Presidencia, 2009), se urgía de manera especial la necesidad de seguir afrontando el problema del abandono escolar temprano, cuya tasa prácticamente doblaba la media europea, pese a que en el mismo informe no se presentaba el dato concreto, argumentando el cambio registrado en la metodología de cálculo de la tasa de abandono escolar temprano por parte de Eurostat ${ }^{29}$.

\footnotetext{
${ }^{27}$ Para ello, se aprobó el Real Decreto 1224/2009, de 17 de julio, de reconocimiento de las competencias profesionales adquiridas por experiencia laboral.

${ }^{28}$ La Ley $2 / 2011$, de 4 de marzo, de Economía Sostenible, en su vigésima cuarta disposición final, modificaba la Ley Orgánica 2/2006, de 3 de mayo, de Educación, estableciendo la posibilidad de acceder a los CFGM (Ciclos Formativos de Grado Medio) a aquellos alumnos que hayan superado los módulos obligatorios de un PCPI (Programa de Cualificación Profesional Inicial) o un curso de formación específica de acceso. Esta Ley además, permite la convalidación de módulos profesionales con materias de Bachillerato, y flexibiliza el acceso a los CFGS (Ciclos Formativos de Grado Superior).

${ }^{29}$ Este cambio en la metodología proporcionaba al indicador mayor precisión, ya que se tomaba en consideración la evolución del indicador a lo largo del año, dado que se realizaba un promedio de los cuatro trimestres del año, en vez de un dato fijo (el del $2 \circ$ trimestre).
} 
Es preciso señalar en este punto que desde la segunda mitad de 2008, España venía sufriendo una situación de recesión económica provocada por la crisis financiera internacional y acelerada por el sobredimensionamiento del sector de la construcción en nuestro país, con unas pésimas consecuencias en cuanto a desempleo y endeudamiento del sector público y privado, que se verían profundamente acentuadas durante los años venideros. Prueba de ello son las caídas del PIB y el índice de producción industrial, que se vieron acompañadas de una notable subida de la tasa de desempleo, como muestran los datos de la Tabla 2.13. Consecuentemente, este cambio de contexto tuvo sus efectos sobre los principales objetivos fijados en los programas nacionales de reformas.

Tabla 2.13. Principales indicadores macroeconómicos en España

\begin{tabular}{|l|c|c|c|}
\hline \multicolumn{1}{|c|}{ Indicador } & Situación & Situación & Evolución \\
& $\mathbf{2 0 0 8}$ & $\mathbf{2 0 1 0}$ & \\
\hline PIB per cápita ${ }^{(1)}$ & $23.819 €$ & $21.587 €^{(2)}$ & $\nabla 9,3 \%$ \\
Tasa de paro & $11,2 \%$ & $19,9 \%$ & $+8,7 \%$ \\
Índice de producción industrial (año 2010=100) & $118,3 \%$ & $100 \%$ & $-18,3 \%$ \\
\hline
\end{tabular}

Fuente: Instituto Nacional de Estadística (INE)

(1) Dato en términos constantes, tomando como referencia los índices de volumen encadenados con base 2008 de la estadística de la Contabilidad Regional de España del INE. (2) Estimación provisional.

En el terreno de la política educativa, la nueva realidad económica no hacía sino más acuciante la necesidad de mejorar la adaptabilidad del capital humano a las necesidades del mercado de trabajo, por lo que la reducción del abandono escolar temprano seguía posicionándose como un objetivo prioritario. En este sentido, cabe señalar la evolución del mercado de trabajo español, ya que desde el año 2000 se había producido un amplio retroceso de la tasa de paro, que estaba especialmente ligado al auge de sectores de exponencial crecimiento durante esa etapa como la construcción y el turismo.

Poniendo el foco en los objetivos específicos marcados dentro del tercer eje, de aumento y mejora del capital humano, en el PNR español, la siguiente Tabla 2.14 muestra el progreso logrado respecto a la situación de partida (año 2004) y los objetivos inicialmente planteados. 
Tabla 2.14. Progreso de los indicadores de seguimiento del marco estratégico ET 2010 en España ${ }^{30}$

\begin{tabular}{|c|c|c|c|c|}
\hline Indicador & \begin{tabular}{|c|} 
Situación \\
2004
\end{tabular} & $\begin{array}{l}\text { Objetivo } \\
2010\end{array}$ & $\begin{array}{l}\text { Situación } \\
2010\end{array}$ & Progreso \\
\hline \multicolumn{5}{|l|}{ Educación infantil } \\
\hline Escolarización a los 2 años & $21,7 \%$ & $30 \%$ & $44,4 \%$ & $+22,7 \%$ \\
\hline \multicolumn{5}{|l|}{ Educación Obligatoria } \\
\hline Porcentaje de titulados en ESO & $70,2 \%^{(2)}$ & $80 \%$ & $80,5 \%$ & $+10,3 \%$ \\
\hline $\begin{array}{l}\text { Resultados Informe PISA }{ }^{(1)} \text { - Comprensión } \\
\text { lectora (\% alumnos en niveles inferiores y } \\
\text { superiores) }\end{array}$ & $\begin{array}{l}21,1 \%^{(3)} \\
23,2 \%^{(5)}\end{array}$ & $\begin{array}{l}16 \%^{(3)} \\
29 \%^{(5)}\end{array}$ & $\begin{array}{l}19,5 \%^{(4)} \\
21,1 \%^{(4)}\end{array}$ & $\begin{array}{l}-1,6 \% \\
-2,1 \%\end{array}$ \\
\hline $\begin{array}{l}\text { Resultados Informe PISA }{ }^{(1)} \text { - Matemáticas (\% } \\
\text { alumnos en niveles inferiores y superiores) }\end{array}$ & $\begin{array}{c}23 \%^{(3)} \\
25,6 \%^{(5)}\end{array}$ & $\begin{array}{l}17 \%^{(3)} \\
32 \%^{(5)}\end{array}$ & $\begin{array}{l}23,7 \%{ }^{(4)} \\
25,7 \%^{(4)}\end{array}$ & $\begin{array}{l}+0,7 \% \\
+0,1 \%\end{array}$ \\
\hline $\begin{array}{l}\text { Resultados Informe PISA }{ }^{(1)}-\text { Ciencias } \\
\text { (puntuación total) }\end{array}$ & $487^{(6)}$ & 500 & 488 & +1 \\
\hline \multicolumn{5}{|l|}{ Educación Secundaria Superior } \\
\hline $\begin{array}{l}\text { Abandono escolar prematuro } \\
\text { Graduados en educación secundaria superior } \\
\text { (20-24 años) }\end{array}$ & $61,2 \%$ & $80 \%$ & $\begin{array}{l}28,4 \% \\
61,2 \%\end{array}$ & $\begin{array}{c}-3,6 \% \\
=\end{array}$ \\
\hline \multicolumn{5}{|l|}{ Educación Superior } \\
\hline $\begin{array}{l}\text { Población que ha completado al menos la etapa } \\
\text { de educación secundaria segunda etapa }{ }^{(7)}\end{array}$ & $46 \%$ & $53 \%$ & $52,6 \%$ & $+6,6 \%$ \\
\hline $\begin{array}{l}\text { Proporción de titulados superiores en ciencias, } \\
\text { matemáticas y tecnología }\end{array}$ & $12,5 \%$ & $13,5 \%$ & $13,9 \%$ & $+1,4 \%$ \\
\hline \multicolumn{5}{|l|}{ Formación continua } \\
\hline $\begin{array}{l}\text { Porcentaje de población que recibe formación } \\
\text { permanente }\end{array}$ & $4,7 \%$ & $12,5 \%$ & $10,8 \%$ & $+6,1 \%$ \\
\hline
\end{tabular}

Fuentes: Eurostat, Ministerio de la Presidencia (2005) y MECD (2013)

(1) Los datos de situación 2004 provienen del Informe PISA 2003 (OCDE, 2004).

(2) Dato del curso $2002-2003$.

(3) Porcentaje de alumnos situados en los niveles 0 y 1 de rendimiento en PISA. El objetivo era reducir en un $25 \%$ el porcentaje de alumnos en los niveles más bajos de competencia. Hay 6 niveles, siendo el 0 el nivel más bajo y el 6 el nivel más alto.

(4) Dato Informe PISA 2009 (OCDE, 2010).

(5) Porcentaje de alumnos situados en los niveles 4,5 y 6 de rendimiento en el Informe PISA. El objetivo era aumentar en un $25 \%$ el porcentaje de alumnos en los niveles más altos de competencia.

(6) Puntuación de España en el Informe PISA. El objetivo era superar la puntuación media de la OCDE, situada en 500 puntos.

(7) Porcentaje de población de entre 25 y 64 años que ha completado al menos la etapa de educación secundaria segunda etapa (niveles ISCED 3a, 3b o 3c). Este indicador es sustituido por el inicial de "ingreso en la educación terciaria".

Como se puede comprobar, existe disparidad en la consecución de los objetivos planteados en el año 2005. Por un lado, indicadores de capital humano como la

${ }^{30} \mathrm{El}$ indicador de aprendizaje de lenguas extranjeras no se muestra debido a la no disponibilidad de datos para el año 2010. 
escolarización a los 2 años, el porcentaje de titulados en ESO, o la proporción de graduados en carreras científico - técnicas, han alcanzado los niveles propuestos para el año 2010. Por otro lado, son varios los indicadores que, a pesar de presentar una evolución positiva, su progresión no ha permitido alcanzar los objetivos iniciales; es el caso de la proporción de población con estudios secundarios superiores, o del indicador de formación continua.

Sin embargo, en la mayoría de casos, la evolución registrada en los indicadores es negativa o ha tenido una progresión manifiestamente insuficiente, como es el caso del indicador de abandono escolar temprano, la tasa de graduación en estudios de educación secundaria segunda etapa, o los resultados del Informe PISA en general. Por consiguiente, y a pesar de los progresos y mejoras apuntadas, se puede considerar, en términos generales, como mediocre la evolución de los indicadores en el ámbito de la educación y formación.

\subsubsection{El contexto económico y el desarrollo de los Programas Nacionales}

\section{de Reformas durante la aplicación de la Estrategia Europa 2020}

Como se ha comentado anteriormente, el periodo de aplicación de la Estrategia Europa 2020 comienza en un contexto de crisis económica generalizada. A la crisis financiera internacional se le suman una serie de desequilibrios y características específicas que sirvieron de acelerador de los problemas estructurales y coyunturales de la economía española, como fueron el sobredimensionamiento del sector inmobiliario, la evolución del crédito, la falta de competitividad, y la dualidad y alta temporalidad del mercado de trabajo.

Como consecuencia, España sufrió un severo ajuste que se materializó en unas caídas del PIB del 3,7\% en 2009 y del 0,1\% en 2010, y en el aumento de la tasa de paro hasta el 19,9\% y más de 4,5 millones de parados para el año 2010 (ver anterior Tabla 2.13). Además, las finanzas públicas se situaron en un nivel de déficit elevado, que ascendía en el año 2009 al 11,1\% del PIB ${ }^{31}$.

\footnotetext{
${ }^{31}$ Dato del Banco de España (2011)
} 
En cuanto a los desafíos que planteaba el nuevo escenario, el Banco de España (2009) instaba a dar solidez al sistema financiero, proveyendo a éste de un marco regulatorio eficaz que evitase los comportamientos excesivamente especulativos en las fases expansivas y la escasez de crédito en las fases recesivas. Por otro lado, el parón productivo generado por la crisis forzaba a plantear la aplicación de políticas expansivas de demanda y la conveniencia de una política monetaria que mantuviese los tipos de interés bajos. En cuanto a la baja competitividad de la economía, cada vez era más acuciante la necesidad de llevar a cabo reformas que mejorasen el sistema educativo y las políticas de inversión en I+D+i. Por último, y con una tasa de empleo que superaba el $20 \%$ en España, la necesidad de reformar el mercado de trabajo era inexorable.

En relación a los objetivos de educación y formación, la Tabla 2.15 reproduce los indicadores de seguimiento del marco estratégico ET 2020 para España, mostrando la situación de partida en el año 2010 y los objetivos previstos para los años 2015 y 2020. 
Tabla 2.15. Indicadores de seguimiento del marco estratégico ET 2020 para España ${ }^{32}$

\begin{tabular}{|c|c|c|c|}
\hline Indicador & $\begin{array}{l}\text { Situación } \\
2010\end{array}$ & $\begin{array}{l}\text { Objetivo } \\
2015\end{array}$ & $\begin{array}{c}\text { Objetivo } \\
2020\end{array}$ \\
\hline $\begin{array}{l}\text { Aprendizaje permanente: \% de población de entre } 25 \text { y } \\
64 \text { años que participa en actividades de educación y } \\
\text { formación. }\end{array}$ & $10,8 \%$ & - & - \\
\hline $\begin{array}{l}\text { Competencias básicas: \% de jóvenes de } 15 \text { años con bajo } \\
\text { rendimiento en: }\end{array}$ & & & \\
\hline - Matemáticas. & $23,7 \%^{2}$ & - & $15 \%$ \\
\hline - Comprensión lectora. & $19,6 \%^{2}$ & - & $15 \%$ \\
\hline - Ciencias. & $18,2 \%^{2}$ & - & $15 \%$ \\
\hline $\begin{array}{l}\text { Enseñanza superior: \% de población de entre } 30 \text { y } 34 \\
\text { años con un nivel educativo completado de educación } \\
\text { superior }{ }^{1} \text {. }\end{array}$ & $40,6 \%$ & - & $44 \%$ \\
\hline Abandono escolar temprano. & $28,4 \%$ & $23 \%$ & $15 \%$ \\
\hline $\begin{array}{l}\text { Escolarización infantil: \% de niños de entre } 4 \text { años y la } \\
\text { edad de escolarización obligatoria que participan en } \\
\text { educación infantil. }\end{array}$ & $99,4 \%^{3}$ & $100 \%$ & $100 \%$ \\
\hline
\end{tabular}

Fuente: Eurostat, Consejo Europeo (2009), Ministerio de Educación (2011) y OECD (2010a)

(1) Niveles CINE 5 y 6.

(2) Dato correspondiente al año 2009.

En cuanto al objetivo de reducción del abandono escolar temprano, como se puede observar, España se planteaba un objetivo intermedio para el año 2015 de reducir el indicador hasta el $23 \%$, objetivo que, aún siendo ambicioso, resultaba más realista, siendo el objetivo para el año 2020 el 15\%. Este objetivo también era señalado en el PNR presentado en el año 2011 por España, que continuaba otorgando una especial importancia a este problema, reconociendo la pobre evolución del indicador, que seguía situándose, una década después, en prácticamente el doble que el promedio de la Unión Europea. Esta situación era en parte atribuida a una serie de obstáculos, que el PNR identifica en los siguientes:

- Existencia de un alto porcentaje de alumnos que no consiguen la titulación de ESO.

- La escasa valoración social de la educación en determinados ambientes.

${ }^{32}$ Además de los indicadores de seguimiento expuestos, se instaba a la Comisión a definir nuevos indicadores que sirvieran de punto de referencia para el aprendizaje de lenguas extranjeras, la empleabilidad y la movilidad. 
- Dificultades específicas de transición entre la ESO y etapas postobligatorias.

- Insuficiente oferta de plazas de Formación Profesional y de Programas de Cualificación Profesional Inicial (PCPI).

Para hacer frente a los obstáculos citados previamente, el PNR apuntaba las siguientes medidas en la línea de reducir la tasa de abandono escolar temprano:

- Seguir con la política expansiva de dotación de plazas PCPI, estableciendo el objetivo de alcanzar la cifra de 80.000 para el año 2012 .

- Continuación de la política de becas, introduciendo la beca salario destinada a estudiantes de FP superior.

- Aumento del presupuesto destinado al programa PROA ${ }^{33}$ (Programa de Refuerzo, Orientación y Apoyo).

- Continuar con el Programa de Cooperación Territorial para la Reducción del Abandono temprano de la educación y la formación.

Tal y como apunta el PNR de 2011 (Ministerio de la Presidencia, 2011), el impacto de estas medidas, cuya aplicación se inició en el año 2007, se vería a partir del año 2010, ya que hasta la fecha, las cohortes de edad que marcaba el abandono escolar temprano se correspondían con aquellas cuya etapa de escolarización y/o abandono no había coincidido en el periodo de aplicación de las medidas puestas en marcha.

En cuanto al Programa de Cooperación Territorial para la Reducción del Abandono Temprano de la Educación (PCT-RATE), a partir del año 2010 el Ministerio de Educación pasó a financiar el 100\% de los fondos, habiéndose invertido un total de 202 millones de euros en el periodo $2007-2012^{34}$. El programa planteaba una serie de medidas agrupadas en cuatro líneas de actuación que eran objeto de financiación por

\footnotetext{
${ }^{33}$ El Plan PROA es un programa de cooperación territorial del Ministerio de Educación y las comunidades autónomas que tiene por objetivo hacer frente a las necesidades derivadas del entorno socioeconómico del alumnado mediante un conjunto de medidas de apoyo a los centros educativos.

${ }^{34}$ Para consultar las cantidades transferidas a las distintas CCAA, ver Cuadro Al.3 del Anexo I.
} 
parte del Ministerio de Educación, que se resumen en la Tabla 2.16, y que estaban alineadas con las recomendaciones emitidas por la Comisión Europea ${ }^{35}$.

Tabla 2.16. Líneas de actuación y medidas financiables del PCT-RATE

\begin{tabular}{|c|}
\hline \\
\hline $\begin{array}{l}\text { - Elaboración de estudios para identificar zonas en las que se dan tasas elevadas de } \\
\text { abandono, conocer y analizar sus causas y los perfiles de los alumnos que abandonan, con el } \\
\text { fin de valorar y diseñar vías específicas de intervención. } \\
\text { - Campañas de sensibilización, generales y específicas, según colectivos, para dar valor a la } \\
\text { formación, dirigidas tanto al alumnado como a sus familias. }\end{array}$ \\
\hline \\
\hline $\begin{array}{l}\text { - Establecimiento de estrategias concretas en los centros educativos para la identificación del } \\
\text { alumnado en riesgo de abandono escolar y aplicación de medidas orientadas expresamente } \\
\text { a lograr el éxito escolar de dichos alumnos, reforzando las actuaciones de los Departamentos } \\
\text { de Orientación y los programas de apoyo y seguimiento académico. } \\
\text { - Programas específicos en aquellas zonas y colectivos en los que se dan las mayores bolsas } \\
\text { de abandono escolar (inmigrantes, minorías étnicas, zonas especialmente deprimidas) } \\
\text { favoreciendo la cooperación y coordinación con diferentes entidades y administraciones } \\
\text { locales y regionales. }\end{array}$ \\
\hline C) Medidas de orientación y seguimiento \\
\hline $\begin{array}{l}\text { - Unidades de orientación para seguimiento y apoyo de jóvenes desescolarizados, entre } 16 \text { y } \\
24 \text { años, a través de los centros de educación de adultos y corporaciones locales para } \\
\text { favorecer su reincorporación al sistema. } \\
\text { - Convenios de colaboración con entidades y otras instituciones para la realización de } \\
\text { proyectos específicos (aulas de actividades lúdico-deportivas y de ocio saludable, talleres } \\
\text { pre-laborales, etc.) en zonas de mayor riesgo de exclusión social y abandono escolar, que } \\
\text { favorezcan la captación de estos jóvenes y su reinserción en el sistema educativo. }\end{array}$ \\
\hline ación \\
\hline $\begin{array}{l}\text { - Programas de escolarización compartida mediante acuerdos con el sector empresarial, que } \\
\text { faciliten la formación y cualificación profesional de jóvenes trabajadores con baja } \\
\text { cualificación o sin ella. } \\
\text { - Programas presenciales de formación reglada que contemplen la flexibilización y } \\
\text { adecuación de la organización escolar para favorecer la permanencia y/o continuidad en los } \\
\text { estudios de jóvenes temporales o discontinuos, financiando el sobrecoste que suponga } \\
\text { respecto a los programas ordinarios. }\end{array}$ \\
\hline
\end{tabular}

Fuente: Página web del Ministerio de Educación, Cultura y Deporte ${ }^{36}$

El montante transferido desde el Ministerio hacia las comunidades autónomas ${ }^{37}$ venía determinado por el tamaño de la población objetivo que, en este

${ }^{35}$ Estas recomendaciones se sintetizan en el informe "Reducing early school leaving: key messages and policy support" realizado por el grupo de trabajo temático en abandono escolar temprano de la Comisión Europea (European Commission, 2013a).

${ }^{36} \mathrm{http}: / /$ www.mecd.gob.es/educacion-mecd/areas-educacion/comunidadesautonomas/programas-cooperacion/programa-abandono/lineas.html 
caso, se representaba mediante un indicador que hacía referencia al producto de dos variables: el número de individuos de entre 18 y 24 años, y el diferencial entre la tasa de abandono escolar temprano de cada comunidad y el objetivo fijado por la Estrategia Europa $2020(10 \%)^{38}$.

Por comunidades autónomas, han sido numerosas las iniciativas, programas y medidas que se han planteado en este sentido, siendo competencia de éstas el desarrollo de las mismas, dentro del marco que establece el programa de cooperación territorial. Así pues, cada comunidad ha diseñado y desarrollado sus propias medidas atendiendo a sus circunstancias específicas del entorno económico, social y cultural.

El PNR de 2012 (Ministerio de la Presidencia, 2012) seguía estando enmarcado en un contexto de crisis generalizada, caracterizado por un alto nivel de desempleo, deterioro de las finanzas públicas y una priorización de las medidas para dar cumplimiento a las exigencias requeridas en el marco del Pacto de Estabilidad y Crecimiento. Cabe también destacar que esta edición del PNR se produce en un contexto de cambio de gobierno, tras la victoria del Partido Popular en las elecciones generales de noviembre de 2011. El PNR de 2012 recoge el cambio de tendencia registrado en el gasto educativo, que presenta una reducción del presupuesto asignado de entre un $25 \%$ y un $30 \%$ según cada comunidad autónoma. Este recorte del gasto ha afectado a distintos aspectos de la educación como son los costes relacionados con el personal docente o con los recursos materiales, y se ha efectuado bajo la premisa de que el notorio aumento del gasto educativo en los últimos años no se había traducido en una mejora perceptible de los resultados educativos.

En la edición de 2013, el PNR (Ministerio de la Presidencia, 2013) sigue estando contextualizado en un entorno de crisis generalizada y recesión, vertebrando las medidas y reformas hacia la reducción del déficit público. Destaca la introducción de medidas de ajuste del gasto, de mejora de la disciplina presupuestaria de las

\footnotetext{
${ }^{37}$ Para consultar las cantidades transferidas a las distintas comunidades autónomas, ver Cuadro Al.3 del Anexo I.

${ }^{38}$ Para el cálculo de la tasa de abandono escolar temprano, se tuvieron en cuenta los promedios de los cinco últimos años.
} 
administraciones y de moderación de precios para impulsar la competitividad. En el ámbito educativo, destacaba la elaboración de la Ley Orgánica de Mejora de la Calidad Educativa (LOMCE), aprobada en el transcurso del año 2013 en el parlamento y que planteaba cinco actuaciones para conseguir el objetivo de reducción del abandono escolar temprano:

- Introducción de evaluaciones finales al término de la educación primaria con el objetivo de la detección precoz del alumnado con dificultades de aprendizaje.

- Evaluación final diferenciada a la finalización de la ESO, en función de la orientación del alumnado hacia las salidas de FP o bachillerato.

- Adelanto de la edad en la que el alumnado comienza un itinerario diferenciado.

- Incremento de la presencia de competencias clave en la carga lectiva.

- Aumentar la autonomía de los centros educativos para desarrollar y ejecutar métodos pedagógicos específicos.

Si bien es cierto que la LOMCE recalca la necesidad de que el alumnado disponga de la elección de trayectoria educativa de una forma más temprana, se abandona la idea de suprimir el cuarto curso de la ESO por un curso propedéutico de Bachillerato. Otra de las medidas o actuaciones encaminadas a reducir el abandono escolar temprano a través de la reforma del sistema educativo son aquellas dirigidas a impulsar la formación profesional y a mejorar así los índices de empleabilidad del alumnado. En este sentido, se plantea la introducción de un nuevo curso de FP Básica, ampliándose por tanto de uno a dos cursos, modificando los requisitos de acceso, no siendo necesaria la superación de la ESO y garantizando un título profesional a aquellos que abandonan la ESO. Por otro lado, la LOMCE también reforma el resto de programas de FP, incluyendo nuevas materias específicas de cada campo en los grados medios.

Estas medidas se suman a las ya planteadas e iniciadas en el PNR de 2012, a las que se atribuye la reducción del indicador de abandono escolar temprano del $26,5 \%$ en 
2011 al 24,9\% de 2012, y que tuvieron una dotación presupuestaria de 100 millones de euros.

La Tabla 2.17, por su parte, muestra los progresos obtenidos en los indicadores de seguimiento para el caso español durante los últimos años de aplicación del marco estratégico ET 2020. Destaca especialmente la evolución favorable en la reducción de la proporción de alumnado con bajo nivel de competencias en el estudio PISA, especialmente en el caso de Ciencias, que registra un descenso de 2,5 puntos, y que supone un contraste frente al indicador a nivel europeo. En cuanto a enseñanza superior, España presenta una evolución ligeramente negativa y a casi cuatro puntos del objetivo planteado para 2020, pese a que nos encontramos por encima del objetivo europeo. En aprendizaje permanente el indicador permanece en un 10,8\%, en contraste con la Unión Europea $(+1,6 \%)$, mientras que en escolarización la subida del $0,4 \%$ roza el objetivo del $100 \%$ planteado, superando sobradamente el objetivo europeo (95\%). 
Tabla 2.17. Progreso de los indicadores de seguimiento del marco estratégico ET 2020 en España

\begin{tabular}{|l|c|c|c|c|}
\hline \multicolumn{1}{|c|}{ Indicador } & $\begin{array}{c}\text { Situación } \\
\mathbf{2 0 1 0}\end{array}$ & Último dato & Progreso & $\begin{array}{c}\text { Objetivo } \\
\mathbf{2 0 2 0}\end{array}$ \\
\hline $\begin{array}{l}\text { Aprendizaje permanente: \% de } \\
\text { población de entre } 25 \text { y } 64 \text { años que } \\
\text { participa en actividades de educación } \\
\text { y formación. }\end{array}$ & $10,8 \%$ & $10,8 \%^{2}$ & $=$ & $>15 \%$ \\
$\begin{array}{l}\text { Competencias básicas: \% de jóvenes } \\
\text { de } 15 \text { años con bajo rendimiento en: } \\
\text { - Matemáticas. }\end{array}$ & $23,7 \%^{3}$ & $23,6 \%^{4}$ & $-0,1 \%$ & \\
- Comprensión lectora. & $19,6 \%^{3}$ & $18,3 \%^{4}$ & $-1,3 \%$ & $<15 \%$ \\
- Ciencias. & $18,2 \%^{3}$ & $15,7 \%^{4}$ & $-2,5 \%$ & \\
$\begin{array}{l}\text { Enseñanza superior: \% de población de } \\
\text { entre 30 y 34 años con un nivel } \\
\text { educativo completado de educación } \\
\text { superior }{ }^{1} \text {. }\end{array}$ & $40,6 \%$ & $40,4 \%^{2}$ & $-0,2 \%$ & $44 \%$ \\
$\begin{array}{l}\text { Abandono escolar temprano. } \\
\text { Escolarización infantil: \% de niños de } \\
\text { entre 4 años y la edad de } \\
\text { escolarización obligatoria que están } \\
\text { escolarizados }\end{array}$ & $99,4 \%$ & $99,8 \%^{4}$ & $+0,4 \%$ & $100 \%$ \\
\hline
\end{tabular}

Fuente: Eurostat, Consejo Europeo (2009) y OECD (2010a y 2014a)

(1) Niveles CINE 5 y 6. (2) Dato provisional. Año 2013. (3) Datos correspondientes al año 2009. (4) Datos correspondientes al año 2012.

Por último, se registra un descenso de 4,3 puntos porcentuales en el indicador de abandono escolar temprano entre los años 2010 y 2013, que sin embargo, representa el dato más alto del conjunto de la Unión Europea (24,1\%). En este sentido, España tiene previsto reducir su tasa de abandono escolar temprano hasta el $23 \%$ en el año $2015^{39}$ y hasta el 15\% para el año 2020.

\subsection{Resumen y conclusiones}

En este segundo capítulo se resume de forma sucinta la formulación y el desarrollo de los programas de reformas estructurales de la Unión Europea desde el año 2000. En ellos, la preocupación por el papel de los sistemas de educación y

${ }^{39}$ Para el año 2014, Eurostat ofrece de forma provisional el dato de abandono escolar temprano de España, que asciende al 21,9\%, por lo que se encuentra por debajo del objetivo intermedio de reducirlo hasta el $23 \%$. 
formación como instrumentos indispensables para alcanzar el objetivo final de conseguir una economía basada en el conocimiento es permanente. Por ello, el objetivo de reducir el abandono escolar temprano constituye un objetivo prioritario para la formulación de las políticas.

En este sentido, cabe resaltar que la implantación de las diferentes medidas encaminadas a la creación de un capital humano más cualificado y la preocupación en general por la educación y la formación no tiene precedentes en la historia reciente de la Unión Europea, teniendo su fundamentación en las necesidades de un entorno globalizado en el que la inversión en estos ámbitos constituye no sólo una garantía para asegurar la sostenibilidad del modelo económico, sino un eje vertebrador que promueve una sociedad civil más participativa y con una mayor cohesión social. No obstante, la mayor parte de los objetivos planteados no han sido alcanzados, especialmente durante la Estrategia de Lisboa.

Por otra parte, es necesario señalar el cambio de contexto producido como consecuencia de la crisis económica, que ha supuesto un condicionante a la hora de precisar los objetivos de cara al horizonte 2020. En este sentido, se aprecia una formulación más realista de los objetivos y más coherente con el contexto en el caso de la Estrategia Europa 2020 frente a la Estrategia de Lisboa.

Por último, las medidas encaminadas a reducir el abandono escolar temprano en el caso español han tenido un alcance limitado, habida cuenta del reducido progreso registrado en los hasta el momento catorce años de aplicación de las dos estrategias europeas. No obstante, los últimos datos del indicador, junto con los efectos esperados de las medidas puestas en marcha en los últimos años, pueden repercutir en la mejora de los resultados de este indicador. 

Capítulo 3 : El concepto y los factores explicativos del abandono escolar temprano 



\subsection{Introducción}

Conocer y entender la complejidad del abandono escolar temprano es una cuestión fundamental antes de comenzar con el análisis empírico de los factores que explican sus diferencias regionales. A este respecto, este capítulo se centra en el abandono escolar temprano, en su definición, características y factores contextuales que lo generan.

El tercer capítulo se divide en dos grandes epígrafes: el primero de ellos se centra en conceptualizar el abandono escolar temprano a través del estudio de la definición estándar utilizada en la Unión Europea, además de explorar varias alternativas utilizadas por otros organismos, países o investigaciones; explicando, además, las metodologías de cálculo empleadas y las críticas y limitaciones del indicador. Por otro lado, se analiza la relación del concepto de abandono escolar temprano con otros indicadores, de forma que sirva de herramienta para discernir entre los distintos conceptos empleados en la literatura existente. Por su parte, el segundo realiza una revisión de los factores contextuales educativos, económicos, sociales e institucionales que la literatura nacional e internacional ha utilizado para explicar el abandono escolar temprano, desde una perspectiva económica, pero teniendo también en consideración trabajos de otras disciplinas y estudios que han seleccionado otros indicadores similares o relacionados con el mismo.

\subsection{Definiciones, acepciones y metodología de cálculo del abandono escolar temprano}

La presente investigación utiliza la definición, proporcionada por Eurostat, que es la referencia en el ámbito de aplicación de la Unión Europea, aunque es necesario profundizar en las especificaciones técnicas del indicador para conocer las posibles diferencias pragmáticas que se puedan hallar a la hora de analizar estudios y resultados provenientes de países que utilizan otros indicadores, ya que ello dificulta la realización de comparaciones a este nivel. 
Conviene señalar que, anteriormente a la promulgación de indicadores consistentes y homogéneos como el formulado por Eurostat, se utilizaba el término de abandono escolar temprano para explicar el fenómeno de distintas formas. Russell (1972) acotó el concepto de abandono escolar temprano o prematuro, estableciendo que la inclusión del término "temprano" o "prematuro" en la definición del concepto suponía la introducción de dos tipos de premisas. Por un lado, una de tipo normativa, por la cual el concepto englobaba aquellas personas que habían abandonado el sistema educativo antes de completar un periodo obligatorio, delimitado legalmente; por otro lado, existía una premisa social, según la cual el abandono se producía previamente a la consecución de un nivel educativo socialmente deseable.

\subsubsection{El indicador de Eurostat}

El abandono escolar temprano es también conocido por el término de abandono escolar prematuro o abandono educativo temprano, aunque en la actualidad los documentos oficiales emitidos por los organismos pertenecientes a la Unión Europea denominan a este fenómeno como "abandono temprano de la educación y la formación" (early leavers from education and training en inglés). Pese a ello, el término de "abandono escolar temprano" es el que con mayor frecuencia se utiliza en las distintas investigaciones tanto en el ámbito nacional como en el ámbito internacional (con el término anglosajón de early school leaving). Por ello, en este trabajo se utiliza generalmente el término de abandono escolar temprano.

En el caso español, el fenómeno se concreta en un indicador estadístico que sigue las indicaciones y metodología de cálculo de Eurostat. Además, en nuestro caso, el indicador de abandono escolar temprano forma parte del sistema estatal de indicadores de la educación del Instituto Nacional de Evaluación Educativa (INEE), organismo dependiente del Ministerio de Educación, Cultura y Deporte (MECD), encargado de la evaluación del sistema educativo español, así como de la monitorización del progreso de los objetivos del marco estratégico "Educación y Formación 2020". 
En lo que al indicador se refiere, se define como la proporción de personas de entre 18 y 24 años que cumple las siguientes condiciones, en relación al total de individuos de ese rango de edad:

- El nivel de educación alcanzado por el individuo ha de ser como máximo el de educación secundaria primera etapa, que en el sistema educativo español se correspondería con la Educación Secundaria Obligatoria ${ }^{40}$ (ESO), equivalente o inferior, es decir, aquellas personas que poseen un nivel educativo alcanzado correspondiente a los niveles CINE $^{41}$ (Clasificación Internacional Normalizada de Educación) 0, 1, 2 o los niveles 3c-244 y 3c-254.

- El individuo ha declarado no haber recibido ningún tipo de educación o formación en las cuatro semanas previas a la realización de la Encuesta de Población Activa.

En la práctica, este indicador emana de los datos suministrados por la EU Labor Force Survey, que en el caso español se articula a través de la conocida Encuesta de Población Activa (EPA) que realiza el Instituto Nacional de Estadística (INE), y que se caracteriza por contar con un muestreo estratificado en dos etapas y cumplir con los estándares técnicos internacionales exigidos (Instituto Nacional de Estadística, 2009). De esta forma, dentro del módulo $F$ del cuestionario, dedicado a enseñanza y formación, se tienen en cuenta las respuestas de las personas, que se encuentran dentro del rango de edad señalado, en las siguientes dos preguntas (Instituto Nacional de Estadística, 2005):

\footnotetext{
${ }^{40}$ Para conocer la estructura del sistema educativo español, consultar Cuadro All.1 del Anexo II.

${ }^{41}$ Los niveles CINE (Clasificación Internacional Normalizada de Educación, en inglés ISCED) son un sistema estandarizado de la UNESCO para definir los niveles educativos (UNESCO Institute for Statistics, 2012). Los niveles CINE 0, 1 y 2 se corresponden con la educación infantil, primaria y secundaria primera etapa (obligatoria) respectivamente, mientras que los niveles CINE 3c-244 y CINE 3c-254 se corresponden con programas postobligatorios de educación secundaria con una duración menor a los 2 años, y que Eurostat supone que no incrementa el nivel de formación. A efectos de garantizar la comparabilidad del indicador a lo largo del tiempo, ambos niveles CINE 3c-244 y CINE 3c-254 se corresponden con el anterior nivel CINE 3c-short recogido en el sistema de clasificación de 1997.
} 
- ¿Ha realizado durante las últimas cuatro semanas algún tipo de estudio o formación incluido en los planes oficiales de estudios?

- ¿Ha realizado durante las últimas cuatro semanas algún tipo de formación fuera de los planes oficiales de estudios? (Comprende cursos impartidos por academias, cursos en el centro de trabajo, cursos dirigidos a los desempleados, seminarios, conferencias, clases particulares recibidas, etc.).

- ¿Cuál es el mayor nivel de estudios que ha terminado y en qué especialidad?

Así pues, la tasa de abandono escolar temprano (TAET) se concreta en la siguiente especificación:

$$
T A E T=\frac{A}{N}
$$

, donde " $A$ " es el número de personas de 18 a 24 años que tienen como estudios máximos educación secundaria básica o un nivel inferior, y que en la actualidad no reciben ningún tipo de información: y " $N$ " representa el total de personas de ese rango de edad ${ }^{42}$.

Desde que se puso en marcha esta definición, el indicador ha sufrido modificaciones que cabe reseñar. En primer lugar, en el año 1998 se realizó un cambio metodológico por el que el nivel educativo CINE 3c, de estudios de duración menor a dos años no se consideraba ya como educación secundaria superior, sino educación secundaria obligatoria o básica, con la consecuente afectación a los datos del índice, que en el caso de España se vieron modificados a partir del año 2005.

También en el año 1998, la regulación 577/1998 (European Council, 1998) redefinía la metodología de elaboración de la EU Labour Force Survey, que pasaba de realizarse en base a los datos obtenidos en el segundo trimestre del año (dado que se consideraba que era representativo de todo el año), a hacerse de forma continua, teniendo en cuenta los cuatro trimestres del año. Este cambio en la forma de recabar datos se realizó entre 1998 y 2004, dependiendo de cada país, y no fue hasta 2008

\footnotetext{
${ }^{42}$ En el denominador se excluye aquellos individuos que no responden a las preguntas "nivel más alto alcanzado de educación o formación" y "participación en educación y formación".
} 
cuando Eurostat decidió emplear los datos continuos en el caso del indicador de abandono escolar temprano, siendo éste el promedio de los indicadores obtenidos en los cuatro trimestres del año.

\subsubsection{Limitaciones técnicas}

El indicador de abandono escolar temprano comúnmente utilizado no está, sin embargo, exento de críticas. En este sentido, y recogiendo las apreciaciones planteadas en el trabajo de Fernández Macías, Muñoz de Bustillo Llorente, Braña Pino y Antón Pérez (2010), se presentan una serie de deficiencias que esconde el indicador y que conviene tener en cuenta.

En primer lugar, se denota una falta de precisión en el hecho de que en el numerador se excluya a aquellas personas que no han terminado su formación inicial pero se encuentran recibiendo algún tipo de formación en el momento de realización de la encuesta, lo cual parece razonable, pero que sin embargo reduce artificialmente la tasa de abandono escolar temprano. Esto sucede al excluirse a este grupo de población en el denominador. Por ello, esta opción incorpora un pequeño grado de indeterminación, en la medida en que no es posible calcular qué proporción de los jóvenes que están recibiendo formación en la actualidad la finalizarán con éxito y cuántos la abandonarán antes de obtener una titulación de educación secundaria superior $^{43}$.

Una segunda reflexión muestra que en el cálculo de la tasa de abandono escolar temprano se excluye del numerador tanto a los jóvenes que cursan formación reglada en las últimas cuatro semanas como a aquellos que cursan formación no reglada, de modo que se reduce la tasa de abandono escolar temprano sin existir un motivo para ello, ya que la formación no reglada no conduce a la adquisición de títulos educativos oficiales y por tanto, aquellos que cursan algún tipo de formación no

\footnotetext{
${ }^{43}$ Como apuntan acertadamente Fernández Macías et al. (2010), la probabilidad de que estos individuos abandonen antes de finalizar con éxito los estudios es alta, debido a que estaríamos recogiendo información de alumnos repetidores al tomar en cuenta la franja de edad comprendida entre los 18 y los 24 años.
} 
reglada no pueden, al finalizar esta titulación, superar el umbral del abandono escolar temprano.

Las dos cuestiones anteriormente formuladas tienen su contrastación empírica en el citado trabajo de Fernández Macías et al. (2010), que demuestra que las tasas de abandono escolar temprano (y de fracaso escolar) serían ligeramente superiores si se excluyese los grupos objetivo comentados.

Por último, otra limitación del indicador se refiere a la contabilización de la población inmigrante que llegó a España con unos estudios finalizados que eran inferiores a la titulación equivalente de Educación Secundaria Obligatoria (ESO), por lo que se estaría atribuyendo al sistema educativo español un aumento de la tasa de abandono escolar temprano de la que en realidad no es responsable. Ello no quiere decir que se deba aislar el efecto de la inmigración sobre la tasa de abandono escolar temprano, ya que constituye una parte más del problema social, pero supone dificultades a la hora de evaluar la eficacia del sistema educativo español y las medidas implementadas en la reducción de la tasa de abandono escolar temprano.

Recogiendo el argumento anterior, y en contraposición a lo ocurrido durante la fase expansiva de la economía española, es también posible que la cada vez mayor emigración de la población joven registrada durante los últimos años suponga una distorsión a la baja o al alza, dependiendo de la estructura de la población que emigra en base al nivel formativo alcanzado. Paralelamente, se ha registrado también un efecto retorno de inmigrantes hacia sus respectivos países de origen.

Además de las críticas formuladas por Fernández Macías et al. (2010), el informe elaborado por el GHK (2005) también remarca la lógica pérdida de precisión que supone trabajar con datos muestrales en lugar de contar con datos censales. Complementariamente, este mismo informe (GHK, 2005) propone establecer otro indicador, similar al "event dropout rate" utilizado en Estados Unidos ${ }^{44}$, que suministre información de la cantidad de nuevos abandonos registrados cada año.

\footnotetext{
${ }^{44}$ En el epígrafe 3.2.3. del presente capítulo se explica el indicador con mayor profundidad.
} 
En otro sentido, Sánchez-Pascuala Neira (2011) señala también los problemas de atribución de responsabilidades que genera el indicador, debido a que en él confluyen expectativas familiares, factores laborales y sociales; y en el que más fielmente se refleja el valor social que ostenta la educación.

En definitiva, si bien el indicador de abandono escolar temprano propuesto por Eurostat es el que más certeramente puede aportar una información realista sobre el fenómeno en cuestión, hay que tener en cuenta sus limitaciones técnicas.

\subsubsection{Los indicadores de la OCDE}

La OCDE ha realizado numerosas publicaciones y estudios que analizan el abandono escolar temprano, caracterizándose la mayoría de ellos por tener un enfoque comparado. Por ello, son diversos los indicadores que ha utilizado en sus estudios. Así pues, en un primer momento, la OCDE estableció las siguientes tres alternativas para definir conceptualmente el abandono escolar temprano (OECD, 1998b):

- La proporción de jóvenes que no están estudiando a la edad obligatoria que marca la legislación de cada país.

- La proporción de jóvenes que no se encuentran estudiando a los 17 años, edad a la que se supone que deberían estar cursando la educación secundaria postobligatoria.

- La proporción de jóvenes que no están estudiando en el año en que se supone que han terminado la etapa de educación secundaria postobligatoria.

Como puede observarse, el indicador de la OCDE difiere al utilizado por Eurostat. Por un lado, no define un indicador determinado, sino que engloba tres, y todos ellos son indicadores de escolarización a diferentes edades. Además, en algunos casos, este indicador presenta problemas de comparabilidad, dado que el criterio de edad obligatoria de escolarización y los criterios que definen los distintos sistemas educativos de los países integrantes de la OCDE es diferente. 
Más adelante, la OCDE definió el concepto de abandono (dropout) como aquel que englobaba a los estudiantes que dejan un nivel educativo específico sin haber obtenido una cualificación básica (OECD, 2002). Asimismo, la OCDE ha empleado también un indicador de "nuevos abandonos escolares" o new school leavers, para reflejar a aquellos estudiantes de educación obligatoria que, estando escolarizados en el curso anterior, en el momento que se realiza la encuesta no lo están, y por tanto, se consideran que han abandonado el sistema educativo (OECD, 1998b).

Por otro lado, en otros informes la OCDE (OECD, 2004b) define el alumnado que ha abandonado prematuramente el sistema educativo como aquel joven, de entre 20 y 24 años, con un nivel de formación inferior a la educación secundaria superior y que no se encuentra realizando ningún programa de educación o formación. Más adelante, en un informe sobre las medidas preventivas destinadas a reducir el abandono escolar temprano (Lyche, 2010), la OCDE se refería a este concepto como la no finalización de los estudios de educación secundaria de nivel CINE 3, con independencia de si ésta era de carácter obligatorio.

Como veremos más adelante, estos indicadores están más asociados al concepto de fracaso escolar, dado que suponen un output directo que representa la escolarización en diferentes momentos. Además, los documentos de la OCDE utilizan una terminología en la que se manejan indistintamente los términos de "early school leaving" y "early school dropout", sin precisar las diferencias que connotan ambos conceptos.

En cuanto a la obtención de datos, la OCDE recaba la información sobre el abandono escolar temprano, a partir de la base de datos construida a través del proyecto INES (Indicators of Education Systems), germen del actual estudio PISA.

\subsubsection{Los indicadores de Estados Unidos}

En Estados Unidos el abandono escolar temprano es más comúnmente conocido por el término early school dropout, que contrasta con el término de early school leaving, utilizado con mayor frecuencia en Europa. 
Dentro del concepto, se utilizan distintos indicadores que captan rangos de edad dispares, y con criterios diferenciados. De forma general, se puede hablar de tres tipos de indicadores (Laird, DeBell y Chapman, 2006; Stillwell, 2010; Lamb y Markussen, 2011):

- Event dropout rate: se refiere al porcentaje de estudiantes de educación secundaria de entre los cursos $10^{\circ}$ y $12 \circ$ que abandonaron los estudios en el curso anterior sin haber obtenido ningún certificado académico.

- Status dropout rate: Porcentaje de individuos de entre 16 y 24 años que no están escolarizados y no poseen ningún certificado académico.

- Cohort dropout rate: Referido al porcentaje de individuos que ha abandonado el sistema educativo y que pertenecen a un determinado grupo de edad.

Así pues, el event dropout rate sería un indicador de la cantidad de alumnado que se pierde en los últimos años de la educación secundaria, sin importar su edad; mientras que el status y cohort dropout rate se basarían en el criterio de rango de edad, siendo comparable al indicador utilizado por Eurostat, aunque utiliza un rango de edad dos años más amplio en el caso del primer indicador.

\subsubsection{Otras definiciones e indicadores de abandono escolar temprano}

Además de la existencia de indicadores homogéneos y comparables internacionalmente, han sido numerosas las definiciones de abandono escolar temprano que han producido diversas instituciones y autores, especialmente con anterioridad a la difusión de indicadores estandarizados como el de Eurostat.

En este sentido, se puede citar el ejemplo de Cullen (2000), que definió este fenómeno como aquel referido a los jóvenes que abandonan sus estudios antes de la edad legal de escolarización, o que lo hacen con una formación limitada o no formal. Esta definición del concepto de abandono tenía su base en la definición legal que marcaba la Ley de Educación irlandesa, que en el año 2000, definía el indicador como el abandono por parte del alumnado antes de los 16 años, o antes de haber completado tres años de educación posterior a la educación primaria (Combat Poverty Agency, 2001). Además, en ese mismo informe de la Combat Poverty Agency (2001), se 
propuso una redefinición del indicador de abandono escolar, adaptándolo al sistema educativo irlandés, y concretándolo en el abandono del sistema educativo sin haber obtenido un mínimo de cinco aprobados en el certificado de educación secundaria ${ }^{45}$.

Asimismo, otros países como Bélgica, Hungría, Finlandia, Suecia, Francia o Países Bajos han contado con indicadores de abandono escolar temprano que, aún siendo análogos, tienen características diferenciadas, y están construidos para adaptarse a sus sistemas educativos concretos (GHK, 2005; European Commission, 2013b).

De la misma forma, otros indicadores de abandono ad-hoc se han definido con cierta arbitrariedad a la hora de realizar distintas investigaciones. Tal es el caso, por ejemplo, del estudio realizado por el Instituto Vasco de Evaluación e Investigación Educativa (2007), que define el abandono escolar como aquel correspondiente al alumnado que, estando matriculado en el centro al inicio del curso, no había acudido ningún día a clase.

Por otro lado, el estudio sobre la transición entre el sistema educativo y la inserción laboral realizado por Albert Verdú, Davia Rodríguez y Toharia Cortés (2008) considera como abandono escolar temprano al conjunto de jóvenes de entre 16 y 24 años que no han conseguido ningún título de educación postobligatoria, rebajando en dos años el espectro de población que recoge el indicador (al igual que el indicador de status dropout rate norteamericano), no teniendo en cuenta los individuos que a pesar de no haber obtenido el título se encuentran recibiendo formación.

Además, tal y como señalan Jugovic y Doolan (2013), en la literatura existe una rica variedad de acepciones similares que incluyen términos complementarios como abandono (early dropout, early leaving, early departure), no finalización (noncompletion), o salida o retirada (push out, ease out, fade out, opt out, pull out).

\footnotetext{
${ }^{45}$ Este certificado, denominado Leaving Certificate, es un examen realizado al finalizar la etapa de educación secundaria del sistema educativo irlandés.
} 
A modo de síntesis, el estudio realizado por el GHK (2005) señala que todas las definiciones de abandono escolar abarcan algunas de las siguientes conceptualizaciones:

- Fracaso en la finalización de la educación secundaria superior y no asistencia a programas de educación o formación en la actualidad.

- Fracaso en la finalización de la educación obligatoria.

- Fracaso en la obtención de certificaciones académicas concretas.

- No participación en programas de educación o formación a una determinada edad.

- Fracaso en la obtención de certificaciones académicas necesarias para acceder a educación superior.

- Fracaso en la obtención de certificaciones académicas necesarias para acceder a un mayor rango de oportunidades en el mercado laboral.

\subsubsection{La relación conceptual del abandono escolar temprano con otros}

\section{indicadores educativos}

En numerosas ocasiones, existe cierta confusión a la hora de emplear correctamente el término de abandono escolar temprano, siendo utilizado conjuntamente con términos que representan un marco conceptual relacionado pero diferente, como serían los de fracaso escolar, éxito escolar, o absentismo. Esta confusión puede tener una explicación en la dificultad que de hecho existe para discernir cuál es el sentido de la causalidad entre el abandono escolar temprano y otros fenómenos que tienen que ver con él.

En primer lugar, conviene aclarar que el abandono escolar temprano no es un hecho puntual que ocurre en la vida de las personas, sino que constituye un proceso que desemboca en el abandono por parte del estudiante de la enseñanza de forma temprana; esto es, antes de finalizar su titulación de educación secundaria postobligatoria o superior. Es en este proceso pues, en el que influyen un conglomerado de factores educativos, circunstancias individuales y condiciones socioeconómicas. En este sentido, Cabus y De Witte (2013) hablan de un proceso de 
desgaste con factores subyacentes asociados, que se van acumulando hasta finalizar en el abandono final por parte del alumnado.

En segundo lugar, cabe desatacar que en el desarrollo del abandono escolar temprano intervienen diferentes agentes o actores, como son el propio alumno, sus compañeros de clase, el profesorado, la familia, el centro escolar o el sistema educativo, por lo que depende de la confluencia del comportamiento y dinámica de una variedad de agentes.

Conviene señalar, además, la asociación que en muchos trabajos se realiza entre los factores que inciden en el fracaso escolar como causantes también del abandono escolar. De este modo, los trabajos de Fernández, Mena y Riviere (2010) y de Mena Martínez, Fernández Enguita y Riviere Gómez (2010) manifiestan que es obvio que el abandono de hecho, es decir, el absentismo continuado, suele conducir al fracaso, y que el fracaso puede conducir a su vez al absentismo y al abandono. De la misma forma, el estudio PISA, en su edición de 2012, establece que los sistemas educativos que cuentan con un mayor grado de absentismo escolar presentan peores resultados en los test de competencia (OECD, 2014b). Por consiguiente, es preciso reseñar la diferencia conceptual que esconden ambos indicadores.

En este sentido, el fracaso escolar es la contraposición al concepto de éxito escolar, esto es, el porcentaje de personas que no se gradúan en Educación Secundaria Obligatoria, teniendo como referencia el número de personas que se deberían de graduar a la edad teórica de finalización de los estudios obligatorios, es decir, a los 16 años ${ }^{46}$.

Por un lado, mientras que el fracaso escolar es un indicador de output, puesto que indica un resultado inmediato y relacionado más directamente con el sistema educativo; el abandono escolar temprano es un indicador mucho más complejo, debido a que esconde algo más allá de los outputs directos, muestra los resultados que el sistema educativo obtiene en la estructura económica y social (Sánchez-Pascuala Neira, 2011).

${ }^{46} \mathrm{El}$ indicador de fracaso escolar se puede calcular restando a 1 la tasa bruta de graduación a los 16 años. 
Por otro lado, mientras que el fracaso escolar se refiere al alumnado que no se ha graduado en la Educación Secundaria Obligatoria, el abandono escolar temprano se centra en los alumnos que, aún teniendo esta titulación, no consiguen obtener un título de educación superior o postobligatoria, como el bachillerato o un ciclo de formación profesional de grado medio. En este sentido, los individuos que forman parte del indicador de fracaso escolar estarían englobados dentro del indicador de abandono escolar temprano si tienen una edad comprendida entre los 18 y los 24 años y no se encuentran recibiendo formación.

Además, el absentismo representa un fenómeno que puede constituir una señal indicativa del futuro abandono. Sin embargo, se considera un hecho previo, y del que no se recogen datos agregados, por lo que, como apunta el informe GHK (2005), sería también útil contar con un proceso de estandarización de estos datos para su aprovechamiento desde el punto de vista de las políticas de lucha contra el abandono.

En términos generales, podemos afirmar que el abandono escolar temprano es un término más amplio y que abarca mayores dimensiones que el resto de indicadores educativos. Según Ross y Leathwood (2013), el concepto de abandono escolar temprano supone una simplificación que enmascara, al mismo tiempo, la naturaleza de las trayectorias educativas y la relación entre la educación y el mercado de trabajo. Cabe añadir que no evalúa únicamente el éxito o el desempeño educativo, sino que posee una dimensión evaluadora del valor de la formación continua y el aprendizaje a lo largo de la vida.

No obstante, es necesario remarcar la idoneidad de tomar en consideración otros indicadores educativos que ayuden a profundizar en el análisis del abandono escolar temprano. En este sentido, el Consejo de Ministros de la Unión Europea decidió incorporar, a instancia de España, la consideración de otros indicadores como las tasas de matrícula y graduación en Educación Secundaria superior para mejorar la valoración de la efectividad de las políticas educativas adoptadas con el objetivo de reducir el abandono escolar temprano. 


\subsection{Los factores explicativos del abandono escolar temprano. Una revisión de la literatura}

En este epígrafe se presenta una selección de las investigaciones que principalmente desde el punto de vista de la literatura económica - se han realizado acerca de la influencia de los factores que inciden en el abandono escolar temprano. No obstante, la multidimensionalidad del fenómeno objeto de estudio en esta tesis doctoral hace que, tal y como señalan Dickson y Harmon (2011), sea necesario analizar y tomar en consideración estudios que ofrecen perspectivas de otras disciplinas académicas, fundamentalmente provenientes de la sociología y las ciencias de la educación.

En términos generales, se puede hacer una división práctica de los trabajos que analizan los factores del abandono escolar temprano en base al enfoque que ofrecen sobre este fenómeno. Por un lado, la academia ha provisto de un gran número de trabajos que versan sobre los factores o causas desencadenantes del abandono escolar temprano, siendo este un campo de estudio prolífico y presentando unos resultados generalmente discutidos. Por otro lado, existen estudios que se centran en el impacto económico o el coste que el abandono escolar temprano puede representar para la economía. La presente tesis doctoral se centra en los primeros, es decir, en los que analizan las causas o factores del abandono escolar temprano.

En este sentido, hasta la actualidad, la práctica totalidad de las investigaciones realizadas sobre abandono escolar temprano coinciden en reconocer la multidimensionalidad de las causas que provocan y los factores que intervienen en la generación de este fenómeno (GHK, 2005; Hammond, Linton, Smink y Drew, 2007; Muñoz de Bustillo Llorente, Antón Pérez, Braña Pino y Fernández Macías, 2009; Lyche, 2010; Dale, 2010; Rumberger, 2011; Serrano, Soler y Hernández , 2013; Cabus y De Witte, 2013).

De esta forma, podemos afirmar que no existe una razón única por la que el alumnado decida abandonar prematuramente sus estudios, ya que se trata de una decisión compleja y en la que intervienen varios agentes (Bridgeland et al., 2006). Esta 
multicausalidad lleva además intrínseco un cierto grado de dificultad a la hora de separar los diferentes factores, para establecer un análisis preciso del grado de afectación de cada una de las causas que inciden sobre el abandono escolar temprano, y establecer así una atribución más o menos exacta.

Dentro de este epígrafe, se relacionan los factores que con frecuencia se apuntan a la hora de explicar el abandono temprano de la educación, comentando sucintamente los resultados de las principales investigaciones que han trabajado en cada uno de ellos. Pese a la existencia limitada de estudios que analicen el peso de los distintos factores contextuales sobre el abandono escolar temprano, existe una gran cantidad de ellos que utilizan otros indicadores educativos de rendimiento $y$ escolarización para estudiar esta influencia, y que están estrechamente relacionados con el abandono escolar temprano (Marks y Fleming, 1999), por lo que se tienen en cuenta en el presente epígrafe.

Con el objetivo de establecer una organización clara e intuitiva, se ha optado por realizar una división funcional de los distintos factores contextuales del abandono escolar temprano, que se engloban en las siguientes tres dimensiones:

- Factores del contexto educativo: Hace referencia a variables que tienen que ver con los recursos que se dedican al sistema educativo y el diseño institucional del mismo.

- Factores del contexto económico: Utiliza medidas de riqueza y analiza la influencia del entorno laboral.

- Factores del contexto cultural y social: Se relaciona con un conjunto amplio de fenómenos sociales como la inmigración, las características familiares o el nivel instructivo de las mismas.

\subsubsection{Factores del contexto educativo}

En primer lugar se va a estudiar una serie de factores o variables que tienen que ver con el volumen de recursos que se canalizan al sistema educativo y las prioridades de gasto educativo que la literatura existente ha analizado y que dependen, principalmente, de la acción de la política educativa de los distintos 
gobiernos. Por otro lado, se estudian también variables relacionadas con la configuración de las diferentes estructuras del sistema educativo, como la comprensividad del modelo educativo, la autonomía de los centros, o el grado de concertación de los mismos.

\subsubsection{Gasto público en educación}

El gasto público en educación es una de las cuestiones más estudiadas a la hora de explicar los resultados educativos obtenidos, ya que evidencia el esfuerzo inversor que los gobiernos otorgan a la educación. En la literatura existe una notable divergencia de resultados e interpretaciones, así como una cantidad ingente de trabajos que tratan una multitud de variables que tienen que ver con el gasto educativo.

En este contexto, es necesario señalar que son numerosos los estudios que establecen que las variables de gasto público en educación no son determinantes o carecen de significación a la hora de explicar los resultados educativos (Marchesi Ullastres, 2003; Calero, Choi y Waisgrais, 2010).

En la literatura internacional, Hanushek (2003) destaca el enfoque erróneo planteado por numerosos gobiernos, que han tomado como base para sus políticas la cantidad de recursos que el sistema implementa, ignorando otras variables, como los incentivos o la estructura institucional del sistema educativo. Además, pone de relieve la dificultad de discernir en qué situaciones el incremento de recursos económicos en el sistema educativo ofrece resultados significativos. En este sentido, Hanushek (2003) critica la tendencia de generalización de numerosos investigadores y legisladores, que extrapolan - en ausencia de un criterio científico - estudios realizados en países o regiones de las que es difícil establecer comparaciones por diversas circunstancias.

El estudio PISA (OECD, 2010b) matiza las conclusiones anteriores, estableciendo que la canalización de mayores recursos económicos hacia el sistema educativo no tiene un efecto sistemático en la mejora de los resultados académicos. En este sentido, Duru-Bellat y Suchaut (2005) observan que la débil relación entre gasto educativo y rendimiento académico se da, principalmente, entre los países desarrollados. Estos 
resultados vendrían a confirmar lo que ya se recoge en el capítulo primero de la presente tesis, que pone de relieve la existencia de un determinado umbral de inversión en educación o stock de capital humano, por debajo del cual sí que existe dicha asociación, y por encima del cual incrementos adicionales en el gasto en educación no mejoran por sí mismos los resultados educativos (Azariadis y Drazen, 1990; Lau et al., 1996; Carabaña, 2009).

No obstante, también existen otras investigaciones que contradicen la versión crítica liderada por Hanushek (1989, 1996, 1997 y 2003). En este sentido, la investigación llevada a cabo por Papke (2005) en el estado norteamericano de Michigan, utilizando datos de los resultados de las pruebas realizadas entre 1992 y 1998, muestra que los aumentos en el gasto en educación tienen un efecto positivo y significativo - especialmente en el caso de la prueba de matemáticas - y que además, éstos son aún más patentes en el caso de los colegios con resultados inicialmente más desfavorables.

Otro trabajo que contradice las revisiones realizadas por Hanushek (1989) es la investigación realizada por Ferguson (1991), que aduce problemas con las fuentes de datos utilizadas en estudios previos, y pone de relieve que la dotación de mayores recursos en ámbitos como la calidad del profesorado tiene efectos positivos y significativos sobre los resultados académicos.

Burtless (1996), por su parte, apunta otra línea que cuestiona las investigaciones llevadas a cabo por Hanushek, al señalar la interpretación de la relación entre resultados y políticas de financiación compensatoria, según las cuáles, se destina una cantidad mayor de recursos a aquellos centros educativos que presentan peores resultados, por lo que estos ostentan una mayor proporción de recursos disponibles, y cuyo análisis puede establecer un sesgo, ya que sus resultados son consecuencia de un conglomerado de factores de contexto que son exógenos al sistema educativo y que la política de aumento de gasto intenta paliar.

Por su parte, De Witte, Nicaise, Lavrijsen, Van Landeghem, Lamote y Van Damme (2013) realizan un estudio aplicado a los países europeos en el que utilizan el porcentaje de gasto en educación sobre el PIB como variable de gasto para explicar el 
efecto en el abandono escolar temprano. Para realizar la estimación, utilizan dos variables dependientes. Por un lado, el propio indicador de abandono temprano de la educación y la formación, y por otro, un indicador de abandono que recoge la proporción de jóvenes que han abandonado la educación formal pero que continúan formándose en escuelas de segunda oportunidad o en programas de educación no formal. ${ }^{47}$ Tras realizar las estimaciones, De Witte et al. (2013) encuentran que el gasto en educación resulta significativo para explicar el primer indicador de abandono, mientras que para el caso del indicador de abandono de la educación formal no resulta significativo.

Por otro lado, Holmlund, McNally y Viarengo (2010) muestran que un incremento de 1.000 dólares en el gasto por alumno incrementa significativamente los resultados en los test de competencia lectora, matemática y científica.

En el trabajo de Alegre Canosa y Benito Pérez (2010), se toman como variables explicativas del nivel de abandono escolar en la Unión Europea el gasto en educación por alumno, el gasto en educación en relación al PIB, y la proporción del gasto destinado a becas y ayudas al estudio en relación al gasto total en educación. Si bien todas ellas resultan ser no significativas, los autores realizan el mismo análisis tomando como variable dependiente la tasa de desescolarización a los 18 años, encontrando que, en el caso de la variable becas y ayudas al estudio, esta sí resulta ser significativa, aportando una bondad de ajuste del $23,4 \%$ en un análisis de regresión simple.

En el caso español se pone de manifiesto, además, que existe un cierto déficit en el grado de consecución de resultados educativos en relación a los recursos empleados (Miró i Ardèvol, 2010). Por su parte, Mora, Escardíbul y Espasa (2010) examinan el efecto que un eventual aumento del gasto por alumno en educación no universitaria tendría en la tasa de abandono escolar temprano y en el porcentaje de alumnos que abandonan el sistema educativo a la edad de 16 años, encontrando que,

\footnotetext{
${ }^{47}$ Este segundo indicador está calculado como la diferencia entre la tasa de abandono escolar temprano tradicional (early leaving from education and training) y la tasa de abandono escolar de la educación formal (early leaving from formal education).
} 
si bien éstos serían beneficiosos en términos de reducción del abandono escolar, su impacto sería limitado.

El estudio realizado por Pérez-Esparrells y Morales Sequera (2012a) muestra, sin embargo, que el nivel de gasto educativo en educación secundaria mantiene una relación negativa y significativa con resultados educativos como el porcentaje de alumnos que no se titulan en ESO, de forma que, para el caso de las comunidades autónomas españolas, cuanto mayor es el gasto público por alumno, menor es el porcentaje de alumnado que no consigue superar el umbral de la Educación Secundaria Obligatoria. En la misma línea, Utrilla de la Hoz y Mitxelena Camiruaga (2007) establecen que, en términos generales, se constata la relación negativa entre el gasto por alumno y por profesor, y los resultados en términos de abandono y tasas de idoneidad.

Según San Segundo (2009), los análisis estadísticos realizados en la última década, junto con experimentos sociales (proyecto $\mathrm{STAR}^{48}$ ) y normativos (reformas de modelos de financiación) señalan que los recursos asignados al sistema educativo tienen un papel relevante y significativo.

La última edición del informe PISA (OECD, 2014b) muestra que el aumento de gasto en educación, por sí mismo, no ha sido una variable influyente en la mejora de resultados de los países participantes. Sin embargo, en otra edición, las conclusiones del estudio PISA señalan que "los resultados del sistema educativo no dependen, únicamente, de los recursos, prácticas y políticas educativas, sino que también influyen en ellos la situación global - económica y social - y las características institucionales inherentes a los Estados" (OECD, 2010b).

En definitiva, los recursos asignados al sistema educativo son un factor que incide de forma determinante en los resultados educativos, y del que no se puede tener una mera observación cuantitativa, sino que se ha de examinar teniendo en consideración la importancia de cada nivel de recursos y la dinámica que estos

\footnotetext{
${ }^{48}$ El proyecto STAR (for Student/Teacher Achievement Ratio) es un experimento de carácter longitudinal llevado a cabo en el estado norteamericano de Tennessee para estudiar los efectos de la reducción de la ratio de alumnos en el aula.
} 
presentan con variables exógenas. En este sentido, es necesario señalar que, hasta la realización de los estudios PISA, no se ha contado con unas bases de datos fiables y comparables a nivel internacional, que recojan información sistemática de la que poder extraer conclusiones robustas. Por ello, muchos de los estudios analizados presentan problemas de fiabilidad de datos, y sesgos en la metodología empleada y en las interpretaciones realizadas. No obstante, alguno de los últimos estudios realizados (De Witte et al., 2013) pone de manifiesto la relación significativa entre el gasto en educación y el abandono escolar temprano, por lo que es preciso incluir este tipo de variables en el análisis de este problema.

\subsubsection{Tamaño de la clase}

Uno de los factores al que se recurre con frecuencia para explicar las diferencias en los resultados educativos es el tamaño de la clase, que aparece reflejado como un indicador clave de la calidad del sistema educativo y de los recursos que se encuentran disponibles en él (Averett y McLennan, 2004).

Dentro de este factor hay que tomar en consideración la variable utilizada, ya que mientras que algunos estudios toman como referencia el número de alumnos por aula, es decir, el tamaño de la clase, otros hacen lo propio con el número de alumnos por profesor.

La revisión realizada por Rumberger y Lim (2008) destaca, en este sentido, que dos de los seis análisis revisados revelan la relación positiva, entre el ratio de alumnos por profesor y la probabilidad de abandono temprano del sistema educativo (Rumberger y Thomas, 2000; McNeal, 1997).

El informe publicado por GHK (2005) no detecta una correlación significativa entre el ratio de alumnos por aula ni el ratio de alumnos por profesor y la tasa de abandono escolar temprano, aunque reconoce el impacto de estas variables en la literatura existente. En otro sentido, un estudio en el que se mide el nivel de impacto de distintas variables sobre la probabilidad de obtener un nivel $1^{49}$ en el test de

${ }^{49}$ El nivel 1 representa el nivel más bajo de los seis niveles de competencia en los que se distribuyen los resultados obtenidos por el alumnado. 
ciencias de PISA indica, mediante un modelo de regresiones logísticas multinivel, que el impacto de las variables "ratio de alumnos por profesor" y "tamaño de la clase" es nulo (Calero et al., 2010).

No obstante, la reducción del tamaño de la clase es apuntada como una medida clave para garantizar la reducción del fracaso y abandono escolar (Marchesi, 2003; Dale, 2010), especialmente en el caso del alumnado de bajo rendimiento o que está en riesgo (Finn, 1998). De la misma forma, los trabajos realizados por Hedges, Laine y Greenwald (1994), Hedges y Greenwald (1996) y Krueger (2002) formulan una crítica a las revisiones de la literatura realizadas por Hanushek (1989, 1996, 1997 y 2003), que consideran sesgada debido al incorrecto peso otorgado a estudios que apuntan a la no significatividad de la relación entre recursos - y entre ellos, el tamaño de la clase - y resultados educativos. Además, Krueger (2002) realiza un cálculo propio según el cual, los beneficios económicos aportados por la reducción del número de alumnos por aula es mayor a los costes que genera.

Por otra parte, Krueger y Whitmore (2001) demuestran, a través de la evidencia encontrada en el proyecto STAR, que los alumnos que asistieron a clases más pequeñas tienen una mayor posibilidad de acceder a la educación universitaria, mientras que Finn, Gerber y Boyd-Zaharias (2005), utilizando también los resultados del proyecto STAR, obtienen que las probabilidades de completar la educación secundaria eran un ochenta por ciento más altas en el caso de los estudiantes que habían estado durante el experimento en clases de menor tamaño. En otro sentido, Fredriksson, Björn y Oosterbeek (2013) observan en un estudio aplicado al caso sueco, que la reducción del tamaño de la clase, además de presentar efectos cognitivos positivos, tiene un impacto sobre el salario futuro obtenido por el alumnado.

Uno de los estudios más citados en este campo es el realizado por Angrist y Lavy (1999) para el caso israelí, en el que demuestran que el efecto del tamaño de la clase en los resultados de los test de matemáticas y lectura es significativo, aunque tiene un menor impacto que los resultados obtenidos por el programa STAR.

Los argumentos anteriores siguen la idea intuitiva apuntada por la teoría formulada por Lazear (2001), que arguye que, en general, los estudiantes que asisten a 
clases de menor tamaño experimentan menos interrupciones en el proceso educativo y pueden disfrutar de una atención más personalizada y, por tanto, aprenderán más y estarán más motivados. Este resultado es matizado por el propio autor, ya que aquellas clases compuestas por un alumnado más problemático necesitarán un menor tamaño óptimo, al contrario que ocurriría con las clases que cuentan con un alumnado más disciplinado. De esta manera, los colegios reducirían su proporción de alumnos por aula hasta llegar al punto en que reducciones adicionales igualen el coste que plantea la propia reducción.

De la misma forma, los estudios de Lee y Burkam (2003) y Dustmann y Van Soest (2007) también incluyen en su investigación el impacto del tamaño del colegio o centro educativo, descubriendo que también tiene una relación en la proporción de jóvenes que abandonan los estudios, por lo que cuanto menor es el tamaño del centro educativo en términos de número de alumnos, menor será la probabilidad de que el alumnado abandone.

Por su parte, Hoxby (2000) demuestra, para el caso del estado norteamericano de Connecticut, que no hay una relación significativa entre resultados educativos y tamaño de la clase, apuntando que las políticas que se basan en un incremento de los recursos son menos eficaces que aquellas que ligan los recursos con sistemas de incentivos y/o evaluaciones de los resultados obtenidos.

En el caso español, Mora et al. (2010) encuentran que el incremento de la ratio de alumnos por profesor aumenta el abandono escolar temprano, especialmente en el caso de las mujeres; aunque el tamaño de la clase se revela como una variable no significativa.

En definitiva, y tal y como apuntan Averett y McLennan (2004), no hay una respuesta absoluta sobre las cuestiones relativas a la implicación del tamaño de las clases en los resultados académicos, y hay que considerar otros factores educativos tales como la calidad docente o el método de enseñanza, como señalan autores de otras disciplinas como las ciencias de la educación (Smeyers, 2006).

No obstante, de la revisión de la literatura existente también se deduce que el alumnado perteneciente a clases de tamaño reducido tiende a coincidir con aquel que 
desarrolla un mejor desempeño académico y que introducir reducciones del tamaño de la clase es - en términos generales - una inversión económica razonable (Schanzenbach, 2007).

\subsubsection{Gasto en profesorado}

Otro aspecto a considerar es el gasto en profesorado. En este sentido, trabajos como los de Chubb y Moe (1990), Pirog y Magee (1997) y Rumberger y Palardy (2005) no muestran una asociación significativa de esta variable con el abandono o las tasas de graduación.

Por el contrario, el trabajo de Warren, Jenkins y Kulick (2006), demuestra que esta relación sí que existe. De la misma forma, el trabajo de Loeb y Page (2000) utiliza como variable independiente los salarios de los profesores, para constatar que existe una relación negativa y significativa con los resultados educativos. En concreto, encuentran que un aumento del $10 \%$ en el salario de los profesores, reduciría la tasa de abandono del alumnado entre un 3\% y un 4\%. Ferguson (1991), por su parte, demuestra en su trabajo que un aumento en el presupuesto destinado al gasto en profesorado en los centros educativos, manteniendo el número de estudiantes constante, puede mejorar los resultados académicos medios obtenidos por estos.

La última edición del estudio PISA (OECD, 2014b) muestra que los países que obtienen rendimientos educativos más satisfactorios son aquellos que tienden a priorizar el establecimiento de salarios relativamente altos dentro de sus partidas de gasto.

\subsubsection{Gasto en becas y ayudas al estudio}

Las becas y ayudas al estudio son un instrumento de financiación que cubre parcial o totalmente los gastos de matrícula y gastos asociados a la actividad del estudiante. Además, constituye un incentivo económico al estudio, ya que reduce el coste de oportunidad de estar estudiando. En este sentido, el estudio realizado por Mediavilla (2013) indica que estos instrumentos de financiación incrementan, en más de un $20 \%$, las posibilidades de finalizar con éxito la segunda etapa de la educación secundaria a la edad que corresponde, a pesar de contrastarse la presencia de efectos 
diferenciales para colectivos específicos, como es el caso de las mujeres o el de los alumnos provenientes de hogares desfavorecidos. Este impacto positivo se incrementa hasta más del $40 \%$ en otro estudio más reciente realizado por el mismo autor (Mediavilla, 2014), lo que supone que las becas pueden constituir un instrumento relevante a la hora de reducir el abandono escolar temprano.

Como hemos podido observar, la relación que tienen los recursos asignados al sistema educativo en cualquiera de las formas que ha sido objeto de análisis (gasto bruto, profesorado y becas y ayudas al estudio) con los resultados educativos a largo plazo no es concluyente. Ello se debe a la confluencia de estas variables con un conglomerado de factores - que son objeto de análisis a continuación - y que distorsionan la relación input-output, además de presentar problemas metodológicos y de comparabilidad.

Por consiguiente, tal y como apuntaban Chubb y Moe (1990), los recursos económicos deben ser parte de cualquier análisis equilibrado sobre las causas del rendimiento educativo y constituyen una herramienta fundamental para la implementación de cualquier política destinada a mejorar los resultados de rendimiento educativo y escolarización.

\subsubsection{Titularidad de los centros educativos}

Uno de los temas objeto de debate en la actualidad es el análisis de la estructura institucional de los sistemas educativos según el grado de participación en el mismo de los centros de titularidad privada. Es decir, hasta qué punto la existencia de un cierto grado de centros educativos de titularidad privada (concertada o no concertada) tiene una relación significativa con los resultados académicos.

En este sentido, destacan las investigaciones realizadas por Alegre Canosa y Subirats i Humet (2013), Fuchs y Wößmann (2006) y West y Woessmann (2010), que señalan que los centros educativos privados presentan unos resultados notablemente mejores que los públicos en el informe PISA, algo ya apuntado en la literatura con anterioridad por Chubb y Moe (1990). Hanushek y Woessmann (2014) realizan una revisión en la que concluyen que los beneficios de la enseñanza privada son 
significativos si estos centros cuentan con la autonomía suficiente en términos de decisión sobre el presupuesto del colegio y directrices sobre el currículo. Desde el punto de vista de la demanda educativa, el trabajo de Roselló Villalonga y Oliver Rullán (2014) para el caso de Baleares muestra que el alumnado de centros concertados presenta una mayor predisposición a cursar estudios de Bachillerato en comparación con el de los centros públicos.

El trabajo de Alegre Canosa y Benito Pérez (2010) aplicado al ámbito europeo, muestra que, si bien el peso que ostenta el sector privado en la educación secundaria postobligatoria no es determinante en la explicación de las diferencias de las tasas de abandono escolar, la proporción que ocupa el sector privado no concertado sí lo es.

Sin embargo, las investigaciones realizadas por Calero y Escardíbul (2007) y Mancebón, Calero, Choi y Ximénez-de-Embún (2012), también aplicadas al estudio PISA en sus ediciones de 2003 y 2006 respectivamente, revelan que este efecto pierde toda su significatividad cuando se controlan variables como el estatus socioeconómico y cultural del centro y sus alumnos, y que no se deben a la titularidad del centro educativo, cuestión que ha sido también señalada por los informes del propio estudio PISA (OECD, 2010b y 2014c). En este sentido, para el caso español, Mancebón Torrubia y Pérez Ximénez-De-Embún (2010) revelan que existen grandes diferencias entre el alumnado perteneciente a centros privados y públicos, registrándose una sobrerrepresentación de alumnos procedentes de entornos socioeconómicos desfavorables en el segundo caso.

En cuanto a la caracterización de los centros, tal y como señalan Chubb y Moe (1990), los colegios que presentan mejores resultados son aquellos que tienen objetivos educativos claros, estándares académicos rigurosos, un claro liderazgo de la dirección del centro, a la vez que una participación activa de los profesores en el proceso de toma de decisiones, mayor implicación de los padres en la vida escolar, y aquellos centros que también promueven valores como el orden y la disciplina. Todo lo anterior es característico, en el caso de Estados Unidos, en colegios predominantemente católicos y que gozan de un mayor grado de autonomía, factor clave para el éxito del proceso educativo. 
Sin embargo, Gamoran (1996) en su análisis sobre la efectividad de los distintos tipos de colegios estadounidenses, encuentra infundado el argumento de que los colegios católicos presenten - por su condición - mejores resultados académicos. Por otro lado, Dronkers y Robert (2008) utilizan los datos del estudio PISA para analizar las diferencias en el rendimiento entre colegios públicos y privados, encontrando que si bien en los segundos se presentan mejores resultados, ello se debe a la conjunción de otros factores ya apuntados, como la composición social del alumnado.

\subsubsection{Autonomía}

Para el caso de Inglaterra, el estudio de Clark (2009) apunta que los colegios con mayor autonomía tienden a presentar mejores resultados y un control más eficaz sobre el profesorado. Según Machin y Vernoit (2011), la introducción de una mayor autonomía otorga la posibilidad de una mejor y más flexible gobernanza, que permite adaptar la estructura del colegio a las necesidades docentes, lo que finalmente redunda en una enseñanza de mayor calidad y en la obtención de un mejor rendimiento académico.

La autonomía también es recogida por el informe PISA, que en su última edición refleja que, en términos generales, los países que otorgan a sus centros educativos mayor autonomía en materia de decisión de contenidos curriculares y evaluación, tienden a obtener mejores resultados (OECD, 2014c). No obstante, el mismo informe señala que la relación entre resultados y autonomía en materia de gestión de recursos no es significativa. Por otro lado, el reciente trabajo de Hanushek, Link y Wößmann (2014) demuestra, en un caso aplicado al estudio PISA, que la descentralización del poder de decisión tiene efectos ambivalentes dependiendo del rendimiento del sistema educativo, ya que en el caso de los países en desarrollo y de bajo rendimiento educativo, la mayor autonomía produce efectos negativos sobre los resultados educativos, mientras que el efecto es inverso cuando se trata de sistemas educativos de alto rendimiento o pertenecientes a países desarrollados.

La elección de centro educativo ha sido otro tema de análisis, aunque no se han obtenido unos resultados concluyentes. Alegre Canosa y Subirats i Humet (2013) investigan la cuestión de la autonomía del centro a través del nivel de discrecionalidad 
de los centros para elegir a su alumnado, señalando que los sistemas educativos caracterizados por delegar un mayor poder de decisión a los colegios no presentan unos mejores resultados educativos.

Existen otros estudios que analizan la elección de centro desde el punto de vista de los padres. En este sentido, se presentan distintos problemas, como la información que tienen los padres sobre los potenciales colegios que pueden elegir, o la aparición de efectos como la segregación en base a criterios étnicos o socioeconómicos (OECD, 2014c), así como consecuencias negativas en términos de inequidad.

\subsubsection{Comprensividad del sistema educativo}

Otro foco de debate lo constituye el grado de comprensividad del sistema educativo, esto es, hasta qué nivel de escolarización el sistema segrega al alumnado en base a criterios competenciales y a expectativas o los mantiene en un itinerario homogéneo.

Según Linnakylä, Roe y Lie (2003), los buenos resultados obtenidos por los países nórdicos, donde hay un alto grado de homogeneidad en los itinerarios educativos, son una evidencia de un óptimo equilibrio entre eficiencia y equidad en la medida que proveen al alumnado no sólo de los conocimientos y herramientas necesarias para continuar su educación superior, sino que también facilitan la participación de los individuos en la sociedad del conocimiento y la transición entre el sistema educativo y el mercado de trabajo. Sin embargo, el estudio elaborado por el GHK (2005) apunta a que ello se debe no a la comprensividad del sistema, sino a la confluencia en estos sistemas de otros factores explicativos, como son la mayor calidad del profesorado y el mayor nivel de inversión en educación.

Asimismo, los resultados del estudio PISA muestran que la diferenciación temprana del alumnado lleva aparejada una mayor disparidad de resultados académicos y está asociada a mayores diferencias socioeconómicas (OECD, 2004a y 2014c). Por su parte, Hanushek y Woessmann (2006) muestran indicios de que la diferenciación temprana en el alumnado tiene consecuencias negativas en términos de 
equidad. En este sentido, Woessmann, Luedemann, Schuetz y West (2009) señalan que la asociación entre resultados en los test de competencias del estudio PISA y el status socioeconómico del alumnado es significativamente menor cuanto más alta es la edad a la que se empieza a seleccionar o diferenciar al alumnado.

El trabajo de Alegre Canosa y Benito Pérez (2010) muestra que, para el caso europeo, no existe una asociación significativa entre la edad a la que se inician itinerarios diferenciados y las tasas de abandono escolar temprano y tasas de desescolarización a los 18 años que presentan los distintos sistemas educativos analizados. Por su parte, Felgueroso, Gutiérrez-Domènech y Jiménez-Martín (2013) evidencian, a través de un modelo probit, la afectación negativa que supuso la ampliación de la obligatoriedad de los 14 a los 16 años en detrimento de la antigua formación profesional de primer grado que se podía cursar en esa misma franja edad, arguyendo que la ausencia de una vía menos académica ha tenido un efecto negativo en el abandono escolar temprano, al no disponer de alternativas el alumnado fundamentalmente masculino - que no tiene voluntad de continuar el itinerario general.

\subsubsection{Evaluación y rendición de cuentas}

Otra característica señalada en la literatura internacional como relevante a la hora de explicar el rendimiento del alumnado es la existencia de evaluaciones, así como la publicación de resultados del rendimiento del alumnado. En primer lugar, la existencia de exámenes o pruebas externas al finalizar una determinada etapa educativa ha sido objeto de debate en numerosas ocasiones. En este sentido, Hanushek y Woessmann (2014) realizan una revisión de diferentes estudios que concluyen que en aquellos países donde se realizan pruebas externas, el alumnado obtiene mejores puntuaciones en los test internacionales de competencias. Ello puede deberse a que la existencia de estas pruebas supone un incentivo para el estudiante a la vez que un instrumento para monitorizar el desempeño académico de los mismos.

Por último, existen, como es obvio, otros factores de carácter educativo que, aunque no han tenido una consideración tan amplia en la literatura existente, también tienen un cierto grado de influencia, como es el caso del tiempo de duración de los 
cursos escolares (Eren y Millimet, 2006), el tiempo dedicado a tareas escolares en el hogar y actividades extraescolares (OECD, 2014c), el impacto de la implantación de pruebas evaluadoras externas al finalizar una determinada etapa educativa (Fuchs y Wößmann, 2006), la composición del currículum escolar (Plank, Deluca y Estacion, 2008), la importancia de la calidad del profesorado (Rivkin, Hanushek y Kain (2005), el material educativo e infraestructuras (OECD, 2014c), el nivel de repetición de curso (Jimerson, Anderson y Whipple, 2002; Benito, 2007; Jacob y Lefgren, 2009; Mora et al., 2010), el establecimiento de la edad mínima de escolarización obligatoria (GHK, 2005; Alegre Canosa y Benito Pérez, 2010; Cabus y De Witte, 2011), el nivel de escolarización en educación infantil (OECD, 2014c), o el denominado peer effect o "efecto compañero" (Willms, 2006).

\subsubsection{Factores del contexto económico}

El segundo bloque de factores que son objeto de análisis hacen referencia a aquellas variables relacionadas con el contexto económico y que, a pesar del carácter exógeno al sistema educativo, la revisión de la literatura las ha incluido en las investigaciones para medir el grado de influencia que presentan sobre los resultados educativos en general y sobre el abandono escolar en particular.

\subsubsection{La riqueza}

La riqueza de un país, generalmente medida a través del PIB, es un determinante evidente del nivel de gasto social que el Estado puede disponer y sirve también de referencia para medir la posición relativa que cada partida ocupa respecto a la riqueza que un país genera. Sin embargo, los resultados del estudio PISA (OECD, 2014c) muestran que la cantidad de gasto invertido en educación posee cierta variabilidad entre países, aún cuando éstos presentan niveles de riqueza similares. Es necesario considerar, además, la inevitable presencia de impactos indirectos que éste factor genera sobre otras variables que pueden incidir a su vez en el rendimiento académico del alumnado o en el patrón de escolarización del mismo.

Los trabajos de Alegre Canosa y Benito Pérez (2010 y 2014), aplicados a los países de la Unión Europea, muestran como el PIB per cápita no presenta una relación 
significativa ni con el abandono escolar temprano ni con las tasas de desescolarización a los 18 años. Sin embargo, la investigación llevada a cabo por Duru-Bellat y Suchaut (2005) utilizando datos del estudio PISA, sugiere que existe una relación por la cual, cuanto más rico es un país en términos de PIB, mejores son sus niveles medios de rendimiento en el estudio PISA. No obstante, estos autores encuentran casos atípicos que sesgan las estimaciones, como es el caso de Luxemburgo, que presenta unos resultados educativos demasiado bajos en comparación con su nivel de $\mathrm{PIB}^{50}$.

Sin embargo, al igual que ocurre con la inversión educativa, alcanzado un determinado nivel de riqueza, existen dudas sobre la influencia de este factor sobre el rendimiento educativo del alumnado. Así pues, uno de los informes del estudio PISA en su edición de 2009 (OECD, 2010b), apunta a que el PIB per cápita posee una influencia que se limita a explicar el $6 \%$ de las diferencias en el rendimiento medio de los alumnos y enfatiza que los pobres resultados que obtienen algunos países no son una consecuencia insalvable de su nivel de riqueza.

En otro sentido, Cabus y De Witte (2013) identifican otro efecto macroeconómico, según el cual un mayor nivel de PIB reduce el número de abandonos escolares, al estar asociado con un mayor desarrollo económico, y percibir por tanto los individuos la necesidad de una mayor participación en etapas educativas postobligatorias.

Desde una perspectiva micro, la clase socioeconómica del alumnado es otra de las causas que inciden en el rendimiento académico de los alumnos. En este sentido, Fernández et al. (2010) apuntan que la clase social de pertenencia del alumnado es el atributo con más peso en el proceso de salida de éste del sistema educativo. Rumberger (2011), por su parte, señala que el entorno socioeconómico de la familia del alumnado, que se conforma en base al nivel de ingresos familiares, al nivel educativo de los padres y a la estructura familiar, es el factor contextual más importante a la hora de influir en los resultados académicos de los alumnos.

\footnotetext{
${ }^{50}$ Este problema lo resuelven aplicando logaritmos, obteniendo una estimación en la que el PIB explica el $67 \%$ de la varianza de los resultados educativos.
} 
El análisis realizado por Dalton, Gennie y Ingels (2009) estima que casi la mitad de los abandonos del sistema educativo lo constituyen alumnos que provienen del primer cuartil de la distribución de estatus socioeconómico, calculada en base a un índice que agrupa variables como el estatus ocupacional de los padres, los ingresos familiares y la educación de los padres. El trabajo de Chubb y Moe (1990), que compara la distribución de los institutos norteamericanos en función de los resultados educativos, establece que las familias de los estudiantes que pertenecen a colegios situados en el primer cuartil de la distribución ganan un 35\% más que las familias cuyo alumnado se encuentra en los centros educativos pertenecientes al último cuartil.

Otro estudio para el caso norteamericano señala el rol determinante que ocupa dicho estatus socioeconómico sobre la decisión de abandonar los estudios y también sobre la decisión de retomarlos una vez abandonados (Chuang, 1997). Taubman (1989) revisa varias investigaciones previas con las que concluye que tanto el nivel de ingresos como el nivel de educación de los padres constituyen un factor determinante en el rendimiento educativo y en la demanda de educación por parte de los alumnos. Por su parte, Blue y Cook (2004) muestran que los estudiantes que se ubican en hogares de ingresos bajos tienen, como mínimo, el doble de posibilidades de abandonar el sistema educativo de forma prematura, conclusión también es obtenida por la investigación realizada por Cataldi, Laird, KewalRamani y Chapman (2009).

Otro estudio que analiza el caso estadounidense, realizado por Ratcliffe y McKernan (2010), utiliza las tasas de pobreza como indicador predictor, afirmando que los individuos que a la edad de tres años estaban por debajo del umbral de pobreza tenían el triple de posibilidades de no completar la educación secundaria.

Asimismo, varios de los informes del estudio PISA (OECD, 2004b, 2010b y 2014c) señalan que, en términos generales, los países que cuentan con un alumnado que presenta más ventajas desde el punto de vista de su entorno socioeconómico tienden a obtener unos mejores resultados en los test de competencias.

Otro de los aspectos que examina el estudio citado anteriormente es el nivel de equidad de los sistemas educativos, concluyendo que las diferencias entre países en la distribución de las características socioeconómicas explican una pequeña parte de las 
diferencias en la calidad y equidad de los sistemas educativos (OECD, 2010b). En este sentido, los análisis muestran que aunque un país tenga una distribución de ingresos altamente desigual, se puede alcanzar equidad en cuanto a igualdad de oportunidades educativas.

Es evidente que la riqueza económica tiene una influencia en los resultados académicos del alumnado, bien por el efecto que supone la necesidad de adquirir una mayor formación para obtener un determinado nivel esperado de ingresos, bien porque ésta se asocia a un entorno más favorable para el correcto desempeño académico del mismo en el sistema educativo, como así lo han señalado los múltiples trabajos citados en este epígrafe.

\subsubsection{El entorno laboral}

Recogiendo el argumento de De Witte et al. (2013), parece racional que los individuos tomen decisiones relativas a su continuidad en el sistema educativo atendiendo a los potenciales beneficios y costes de oportunidad que conlleva esta decisión de demanda de educación cuya fundamentación se ubica en la teoría del capital humano y sus teorías complementarias, recogidas en el primer capítulo de la presente tesis doctoral.

En este sentido, el principal coste de oportunidad de los individuos que se encuentran en la franja de edad que contempla el abandono escolar es la participación en el mercado de trabajo, de forma que el comportamiento del mercado de trabajo esto es, su estructura, su nivel de demanda y oferta salarial - supone un aspecto clave a la hora de estudiar la permanencia del alumnado en el sistema educativo.

Así pues, el nivel de desempleo puede ser un determinante que atrae o repele la incorporación del alumnado al mercado laboral. Micklewright, Pearson y Smith (1990) diferencian tres tipos de efectos en este sentido. Por un lado, el nivel actual de la tasa de desempleo de la población joven, que produce un efecto disuasorio del abandono del sistema educativo en caso de ser alto; por otro, el nivel futuro de desempleo esperado, que en caso de ser elevado puede producir dos efectos de carácter ambivalente: reduciría las tasas de retorno económico de la educación, y por 
tanto su demanda, al percibir el individuo un desincentivo para incrementar su formación, a la vez que podría aumentar la demanda educativa, al animar a los individuos a formarse para presentar menores oportunidades de sufrir estas altas tasas de desempleo esperado. También hay que considerar el efecto del desempleo de los padres, que además de constituir un fenómeno cercano al alumnado, incide en la cantidad de recursos económicos disponibles de la familia, determinando la cantidad de educación que puede ser demandada.

No obstante, Micklewright et al. (1990) se muestran escépticos sobre la vinculación entre el aumento de la tasa de desempleo y la caída en el abandono escolar en el análisis que realizan para el caso británico, al igual que el estudio que hace Kodde (1988) para el caso holandés.

El estudio de Clark (2011) analiza la influencia de las tasas de desempleo en Inglaterra sobre las decisiones de los individuos de demanda de educación, demostrando que esta relación entre desempleo joven y escolarización es positiva y fuerte, y que las incertidumbres presentadas en estudios anteriores se deben a que no utilizan datos de desempleo de población joven y a cambios en las series de modelos de escolarización. De la misma forma, Tumino y Taylor (2013) estudian estas relaciones entre desempleo y escolarización usando un panel de datos, y corroboran los resultados del estudio anteriormente citado (Clark, 2011).

Por su parte, Dellas y Sakellaris (2003) ponen de relieve el carácter contracíclico de la escolarización, mediante la aplicación de un análisis con datos de la encuesta continua de población de los Estados Unidos (Current Population Survey), los individuos tienden a demandar más educación durante las recesiones, cuando el coste de oportunidad de no trabajar es menor, bien sea por las menores posibilidades de participar en este, o bien por la existencia de unos salarios menos atractivos. De la misma forma, ambas variables resultan ser un factor de expulsión cuando el ciclo económico se encuentra en su parte álgida, es decir, cuando los salarios y la cantidad demandada de trabajo es más alta.

Los procesos expansionistas de determinados sectores intensivos en mano de obra poco cualificada también producen un efecto notable sobre las decisiones de 
escolarización. En este sentido, el estudio de Black, McKinnish y Sanders (2005) analiza los efectos del boom y posterior declive de la industria del carbón en los estados norteamericanos de Kentucky y Pensilvania, determinando que un aumento del $10 \%$ en los salarios de los trabajadores de este sector, basado en mano de obra de baja cualificación, produjo un decremento de entre el $5 \%$ y el $7 \%$ en las tasas de escolarización. Ello se debe a que la reducción de la brecha salarial entre los trabajadores no graduados y graduados redujo los retornos esperados de la inversión en educación.

Neumark y Wascher (1995), también utilizando la CPS (Current Population Survey) estadounidense, estudian el papel del salario mínimo en las decisiones de escolarización, llegando a la conclusión de que un mayor nivel de salario mínimo produce un desplazamiento de alumnos desde el sistema educativo hasta el mercado de trabajo para ocupar puestos de trabajo poco cualificados, produciendo además como efecto secundario la sustitución de trabajadores con un menor grado de cualificación (sheepskin effect), haciendo que éstos presenten una mayor propensión a encontrarse en una situación de desempleo y desescolarización. Estos resultados también son contrastados para el caso canadiense en el estudio realizado por Montmarquette, Viennot-Briot y Dagenais (2007).

Por otro lado, la investigación realizada por Meschi, Swaffield y Vignoles (2011) matiza las conclusiones de anteriores trabajos que dan un rol determinante a las características del mercado laboral de cercanía del alumnado. De esta forma, Meschi et al. (2011) argumentan que, para el caso de Inglaterra, los factores principales de las decisiones de permanencia en el sistema educativo se centran en el desempeño académico del alumnado y las aspiraciones y expectativas de los progenitores, aunque existe un impacto de las condiciones laborales a través de las tasas de desempleo locales, impacto que en cualquier caso se da en los hombres, y con un carácter heterogéneo entre los distintos alumnos.

A su vez, Crofton, Anderson y Rawe (2009) estiman que el impacto del salario mínimo sobre el abandono del sistema educativo tiene significatividad en el caso de los estudiantes de raza hispana, en un estudio desarrollado en el estado 
norteamericano de Maryland, que estudia el efecto del salario sobre las decisiones de demanda educativa entre las poblaciones de diferentes razas y grupos sociales.

Además, existen otros trabajos como el de Warren y Hamrock (2010), que ponen en duda las conclusiones anteriores sobre el salario mínimo, arguyendo problemas metodológicos de estudios anteriores, cuyas correcciones, para el caso norteamericano, ponen de relieve la no existencia de un claro efecto de la subida de los salarios mínimos sobre las tasas de graduación de la educación secundaria.

En el caso español, es evidente que el boom del sector inmobiliario ha supuesto unas caídas bruscas de los rendimientos salariales de distintos niveles educativos. Ello ha producido un efecto expulsión del sistema educativo, ya que tanto la cantidad de trabajo que el sector de la construcción demandaba, como la existencia de unos salarios relativamente altos representaban un coste de oportunidad alto, como así lo apuntan distintos estudios que analizan el caso español (Aparicio, 2010; Lacuesta, Puente y Villanueva, 2012). En este sentido, Serrano y Soler (2014) señalan, a través de una encuesta realizada a personas de entre 18 y 30 años sobre los motivos de abandono de sus estudios, que un $26,2 \%$ de los entrevistados había abandonado sus estudios de educación secundaria (obligatoria o postobligatoria) por haber encontrado trabajo. Por otro lado, Felgueroso et al. (2013), muestran que los beneficios, en términos de prima salarial, de completar la educación secundaria son muy bajos, lo que ayuda a desincentivar la decisión de continuar con los mismos.

En el trabajo realizado por Fernández et al. (2010) se determina que un tercio de los alumnos entrevistados abandonaron de forma prematura sus estudios por incorporarse al mercado laboral. De esta forma, se corroboran las tesis que ya planteaban Petrongolo y San Segundo (2002), en un estudio en el que se evidenciaba que los estudiantes de educación secundaria toman sus decisiones relativas a continuar con sus estudios en función de las tasas de desempleo joven locales, si bien es cierto que otra de las conclusiones alcanzadas es que las tasas de desempleo de la población adulta tenían una relación negativa.

Este cierto poder de atracción del mercado de trabajo es más notorio, si cabe, cuando la demanda de trabajo que rodea al joven se caracteriza por ser de baja 
cualificación (Azevedo, 2003). Por su parte, Peraita y Pastor (1998) también precisan que las condiciones del mercado de trabajo local son determinantes en la decisión de abandonar prematuramente el sistema educativo. No obstante, el nivel de educación de los individuos es un determinante del éxito laboral en términos de salarios y actividad. En este sentido, el trabajo de López-Bazo y Motellón (2013) demuestra que las diferencias regionales en las comunidades autónomas españolas, en términos de dotación de educación, tienen efectos significativos sobre las diferencias en las tasas de actividad y salarios medios de las diferentes regiones.

Por otro lado, hay que tener en cuenta que el entorno laboral del alumnado es el local, y que esta influido notablemente por el de sus progenitores. A este respecto, el estudio de Fernández-Macías, Antón, Braña y Muñoz de Bustillo (2013) demuestra, aplicando un modelo logit para el caso español, que el trabajo del padre y el prestigio del mismo es un factor que influye significativamente sobre el riesgo de abandonar tempranamente el sistema educativo. Además, el modelo incluye dos dummies que permiten observar que los alumnos cuyos padres están empleados en el sector de la agricultura o de la construcción tienen un mayor riesgo de abandonar sus estudios.

En otro sentido, el estudio de Dustmann y Van Soest (2007) introduce una diferenciación de género en el trabajo a tiempo parcial entre los estudiantes, concluyendo que tienen un pequeño efecto sobre el rendimiento académico en el caso de los hombres, mientras que el mismo impacto en el caso de las mujeres es nulo, cuestión que también se manifiesta en el estudio de Aparicio (2010) sobre el efecto de la expansión del sector inmobiliario español. Montmarquette et al. (2007) también demuestran, para el caso canadiense, que las mujeres tienen mayor predisposición a permanecer en el sistema educativo, mientras que para el caso de los hombres estiman que la participación en trabajos a tiempo parcial que suponen un compromiso menor a las 15 horas semanales no afectan al desempeño académico.

Además de los efectos sobre la decisión de escolarización del alumnado, la ocupación de los padres es otro factor estrechamente relacionado con el desempeño académico del mismo. Así lo apuntan los diferentes informes del estudio PISA (OECD, $2001 b$ y 2004b), aunque las diferencias en los resultados del estudio PISA en función 
de la ocupación de los padres difieren entre los distintos países, en el caso español no son una excepción (Instituto Nacional de Evaluación Educativa, 2014a).

Queda patente pues que el mercado de trabajo produce efectos sobre las decisiones de escolarización de los individuos, y éstos pueden ser en ocasiones ambivalentes, como bien apunta el trabajo de Micklewright et al. (1990). En este sentido, es necesario estudiar qué efectos ha podido producir el comportamiento singular del mercado de trabajo español, dada la excesiva proliferación de puestos de trabajo de baja cualificación y la gran sensibilidad de éstos a la dinámica del ciclo económico.

\subsubsection{Factores del contexto socio-cultural}

El tercer apartado de este epígrafe recoge aquellos aspectos relacionados con las características sociales y culturales del entorno que la literatura ha estudiado para explicar el abandono escolar temprano y otros fenómenos educativos relacionados. Entre otros factores, se toma en consideración el nivel educativo del entorno del alumnado (donde cobra especial importancia el de los padres), la estructura familiar, los fenómenos migratorios o el género.

\subsubsection{Nivel instructivo del entorno familiar y social}

En el trabajo de Alegre Canosa y Benito Pérez (2010), se determina que el déficit instructivo de la población explica el $72,6 \%$ de la variabilidad en los niveles de abandono escolar temprano de los países de la Unión Europea, importancia que también es avalada por el estudio PISA, que precisa que el nivel de estudios de los padres - especialmente el de la madre - es una variable de gran influencia (OECD, 2001b, 2010b).

El análisis realizado por Dalton et al. (2009) confirma también que los alumnos cuyos padres ostentan un título universitario tienen unas tasas de abandono escolar siete puntos inferiores al resto. Para el caso australiano, Marks y Fleming (1999) constatan que este efecto - el nivel educativo de los padres - es significativamente mayor que el peso que presenta la ocupación de los padres. En Países Bajos, el estudio realizado por Traag y Van der Velden (2008) afirma que por cada año adicional de 
estudios de los progenitores, la probabilidad de abandonar tempranamente el sistema educativo decrece en un $7 \%$.

El ya citado trabajo de Chubb y Moe (1990) encuentra que los padres de alumnos de los centros educativos que se encuentran en el primer cuartil de la distribución de resultados tienen en promedio un año y medio más de periodo de escolarización en el sistema educativo, frente a los padres cuyos hijos se encuentran en los centros con peores resultados académicos.

Para el caso español, Petrongolo y San Segundo (2002) estiman que el nivel de educación de los padres es el factor más determinante en la decisión de permanencia del alumnado en la etapa de educación secundaria superior. Serrano y Soler (2014), por su parte, exponen que el nivel formativo de los padres tiene un efecto significativo y creciente sobre la decisión de abandonar le sistema educativo prematuramente, siendo de 18 puntos menos la probabilidad de abandonar en el caso de que el padre cuente con estudios superiores, y de 22 puntos menos en el caso del nivel educativo alcanzado por la madre. De la misma forma, el estudio de Roselló Villalonga y Oliver Rullán (2014) para el caso de Baleares muestra que la existencia de progenitores con estudios aumenta la posibilidad de que sus hijos se decanten por continuar estudiando más allá de la etapa obligatoria.

Además del nivel educativo de los padres, el estudio PISA analiza el impacto de otros factores, como es el nivel cultural de la familia de procedencia del alumnado, que se mide a través de variables que tienen que ver con la cantidad de libros o piezas de arte que poseen en el hogar familiar (OECD, 2001b).

\subsubsection{Estructura familiar}

La estructura de la familia es otro factor al que se recurre con frecuencia para explicar el fracaso en la consecución de los objetivos educativos que el sistema tiene previsto para el alumnado, siendo los estudios de disciplinas como la psicología o la sociología los que realizado un mayor número de contribuciones en este sentido. Dentro de esta dimensión, son diversas las variables que pueden presentar un efecto en los resultados educativos. 
El tamaño de la familia es un ejemplo de las variables utilizadas en los estudios realizados. En el trabajo realizado por Fernández-Macías et al. (2013) para el caso español, se concluye que mientras que el número de hermanos o de integrantes de una familia no es explicativo de la decisión de abandonar el sistema educativo, la ausencia de uno de los progenitores - especialmente de la madre - reduce notablemente las posibilidades de finalizar la etapa de la educación secundaria.

No obstante, algunos estudios (Dustmann y Van Soest, 2007; Roselló Villalonga y Oliver Rullán, 2014) sí encuentran una influencia entre el tamaño familiar y el rendimiento académico, de modo que a mayor número de hermanos, más probabilidad de obtener peores resultados escolares y abandonar el sistema de forma prematura. Estos resultados también son estimados por Petrongolo y San Segundo (2002), que matizan que la existencia de hermanos con edad inferior a la del alumnado de referencia hace que éstos presenten más probabilidades de no continuar con la enseñanza postobligatoria, debido a la potencial presencia de mayores restricciones económicas. Por el contrario, el estudio de Roselló Villalonga y Oliver Rullán (2014) muestra que la existencia de hermanos escolarizados aumenta las posibilidades de continuar estudiando después de la etapa obligatoria.

Al igual que en el caso del estudio señalado de Fernández-Macías et al. (2013), son varias las investigaciones que han apuntado que los alumnos procedentes de familias monoparentales o desestructuradas presentan una mayor tendencia a encontrarse en los niveles inferiores de rendimiento educativo (Coleman, 1988; OECD, 2001b; Björklund y Chadwick, 2003; Bridgeland et al., 2006) y abandonar prematuramente el sistema educativo (Rumberger, 2011). Ello puede deberse, además de la situación estructural de la familia, a que éstas son más proclives a obtener unos ingresos más bajos y depender, en mayor medida, de la asistencia pública (Rumberger, 2011) al ofrecer una supervisión más laxa en cuestiones de apoyo a la escolarización (Astone y McLanahan, 1991).

Asimismo, los cambios en la estructura familiar pueden influir de manera negativa en el desempeño académico del alumnado, aunque este efecto depende del 
momento de escolarización en que éste se encuentre cuando se produce un cambio de este tipo (Garasky, 1995).

Merece también la pena señalar otros factores más estudiados por otras disciplinas, como es la importancia de la implicación parental en la vida escolar del alumnado (Chubb y Moe, 1990; Cooper, Chavira y Mena, 2005), la vinculación emocional entre los padres y los hijos (Duchesne y Larose, 2007), las expectativas de los padres sobre la carrera académica de sus hijos (Rumberger, 2011), la localización geográfica de la zona de residencia del alumnado (Rumberger, 2004), y la pertenencia a determinadas razas o etnias (Johnson, Crosnoe y Elder, 2001), entre otros.

\subsubsection{Fenómenos migratorios}

Los fenómenos migratorios son otro de los factores apuntados en varios estudios que pueden explicar el comportamiento de la tasa de abandono escolar temprano. En este sentido, es necesario recordar el pronunciado proceso inmigratorio registrado en España durante la primera década del presente siglo, motivado principalmente por la existencia de una alta demanda de trabajo de baja cualificación, y que ha tenido sus efectos también en los resultados del sistema educativo.

Como se ha reflejado con anterioridad en el presente capítulo, la existencia de una gran cantidad de población inmigrante puede distorsionar la valoración de las tasas de abandono escolar temprano, haciendo especialmente difícil el grado de atribución de responsabilidades del sistema educativo, al no ser éste responsable de aquellos individuos de origen inmigrante que pasaron a engrosar el indicador de abandono escolar temprano, pero cuyo paso por el sistema educativo se había dado en el país de origen.

En términos generales, se puede afirmar que el alumnado inmigrante muestra una predisposición superior a abandonar sus estudios que el alumnado nacional, como lo refleja el trabajo de Mora Corral (2010), o el realizado por Calero et al. (2010), que concluye que los alumnos de origen inmigrante tienen un mayor riesgo de fracasar en sus estudios. Ello puede ser debido a la estructura por nivel educativo de la población inmigrante, que se caracteriza por tener unas proporciones mayores de individuos con 
un nivel de escolarización menor, además de los problemas obvios de adaptación que se pueden presentar. Así pues, es posible que una parte de la tasa de abandono escolar temprano en el caso español, creciente entre los años 2000 y 2010, se debe a este fenómeno (Fernández-Macías et al., 2013). Por otro lado, Serrano y Soler (2014) señalan que ser extranjero aumenta las posibilidades de abandonar prematuramente el sistema educativo entre 11 y 18 puntos.

No obstante, el estudio de Levels, Dronkers y Kraaykamp (2008) revela, en una investigación que analiza los resultados de competencia matemática en el informe PISA 2003 de más de 7.000 alumnos inmigrantes, que el país de origen, el país de destino y los factores contextuales de ambos son determinantes a la hora de explicar las diferencias de resultados de los diferentes colectivos de inmigrantes.

\subsubsection{Género}

Otro factor frecuentemente utilizado para explicar fenómenos educativos como el fracaso o el abandono escolar es el género. Como apuntan multitud de informes y estudios, el desempeño académico de las mujeres es notablemente superior, lo que se ve traducido en un menor nivel de fracaso escolar y abandono escolar temprano (Marks y Fleming, 1999). En este sentido, Fernández-Macías et al. (2013) cuantifican en un $7 \%$ la influencia negativa de ser mujer sobre el hecho de abandonar prematuramente el sistema educativo, realizando un análisis logit para dos cohortes generacionales. Por otro lado, las perspectivas en el mercado laboral han jugado un papel también desigual en la decisión de continuar con los estudios. En este sentido, Felgueroso et al. (2013) afirman que la brecha en cuanto a oportunidades de empleo de las mujeres que continúan con los estudios y aquellas que abandonan es mucho más amplia que en el caso de los hombres.

Además, el género no solamente tiene un efecto significativo cuando éste se estudia desde el punto de vista del alumnado, sino que la influencia del nivel de estudios de los progenitores es más sensible al nivel de estudios alcanzado por la madre (Fernández-Macías et al., 2013). 
En definitiva, la influencia marcada por el nivel educativo del entorno de referencia del alumnado es reconocida por la práctica totalidad de las investigaciones, al igual que el género, mientras que no existe un consenso tan amplio sobre los efectos relacionados con el tamaño y estructura de la familia, y la inmigración, que, como señala la mayoría de trabajos analizados, está supeditada a otras variables como el nivel socioeconómico. Cabe reseñar, también, que los factores del contexto sociocultural se refieren a un ámbito predominantemente externo al ámbito de actuación de la política educativa, pero que es necesario tener en cuenta a la hora de diseñar cualquier estrategia de lucha contra el fenómeno que se estudia.

Tras el análisis de la literatura existente sobre los factores que condicionan el tiempo de escolarización del alumnado y los resultados educativos, queda patente la confluencia de una multitud de variables que intervienen. El trabajo de Fuchs y Wößmann (2006) evidencia este carácter multivariante, al demostrar, a través del estudio de los resultados del informe PISA, que las características individuales del alumnado, el entorno socioeconómico de la familia del estudiante, los ingresos, los recursos y profesores de los colegios y las instituciones, constituyen todos ellos factores determinantes a la hora de explicar las diferencias entre los distintos países participantes.

Otro ejemplo lo constituye el estudio de Croninger y Lee (2001), que construyen un indicador que combina variables que tienen que ver con la pertenencia a minorías étnicas y lingüísticas, pobreza en el entorno familiar, ausencia de progenitores y carencia de estudios entre los padres. De esta forma, los autores revelan que las posibilidades de abandonar de forma prematura el instituto eran de un $66 \%$ más para el caso de alumnos que presentaran características desfavorables en al menos uno de los indicadores.

Uno de los informes del último estudio PISA (OECD, 2014b) remarca que las sucesivas ediciones del programa PISA han constatado la influencia del entorno socioeconómico en los resultados que los distintos países obtienen en los test de competencia. Para alcanzar esta conclusión, el estudio PISA desarrolló un índice de estatus cultural, económico y social, basado en indicadores que reflejan el nivel 
educativo, ocupación laboral de los padres y los recursos económicos, entre otros, que permite comparar internacionalmente los distintos países participantes.

\subsection{Resumen y conclusiones}

A modo de resumen, el presente capítulo ha revisado las distintas definiciones, consideraciones técnicas y limitaciones del los distintos indicadores utilizados para concretar el abandono escolar temprano, así como los factores de los contextos educativo, económico y socio-cultural que la literatura ha empleado para explicarlo.

En primer lugar, ha quedado patente la necesidad de contar con un indicador homogéneo del fenómeno que garantice la comparabilidad y representatividad del mismo. En este sentido, han sido varios los indicadores que se han utilizado por diversas instituciones e investigadores, si bien el empleado por la Unión Europea es el que tiene una mayor aceptación y comparabilidad, por lo que es el que sirve de referencia en la presente tesis doctoral.

En segundo lugar, es necesario reconocer la multidimensionalidad del fenómeno que nos ocupa, contrastada en numerosas investigaciones, y que hacen de este, un problema complejo e interdisciplinar. Además, se ha contrastado la disparidad de resultados obtenidos en el estudio del grado de afectación de cuestiones propias del sistema educativo (como el gasto en educación, la autonomía o el grado de privatización del sistema), del entorno económico (mercado laboral), y entorno sociocultural (nivel instructivo, inmigración). Ello sirve de guía de referencia para la elección de variables cuyo efecto se testará en el capítulo quinto de la presente tesis doctoral, además de servir de fundamento teórico para la interpretación de los resultados obtenidos en ella.

En cuanto al nivel de recursos que se destinan al sistema educativo, se ha puesto de manifiesto una gran cantidad de problemas relacionados con los datos y la metodología empleada. Sin embargo, parece que, reconociendo la existencia de un efecto umbral, el gasto en educación tiene una relación significativa con los resultados educativos en general y con el abandono escolar temprano en particular. No obstante, hay tomar en consideración la distorsión que puede introducir interpretaciones 
meramente cuantitativas, como la señalada por Burtless (1996). Además, es necesario tomar en consideración otras variables que pueden ser reflejo de las prioridades de la política de gasto en educación, como el nivel salarial del profesorado, o la proporción de recursos destinados a becas y ayudas al estudio.

Según la literatura analizada, el contexto económico ejerce una gran influencia sobre los resultados educativos. En este sentido, se puede concluir que el origen socioeconómico es un factor determinante de los mismos, y que el comportamiento y características del mercado laboral es un condicionante de las decisiones de escolarización del alumnado, especialmente durante las etapas post-obligatorias.

Por otro lado, el contexto socio -cultural presenta también efectos sobre los resultados educativos en general y el abandono escolar temprano en particular. Uno de los factores sobre el que existe más consenso es el nivel educativo de los padres y el género. Por otro lado, otras variables como las relativas a fenómenos migratorios y la estructura y tamaño de la familia presentan resultados en general más discutidos. En definitiva, para analizar la posible influencia de los factores y variables señaladas en este capítulo en el nivel de abandono escolar temprano en el caso de las comunidades autónomas españolas, resulta necesario realizar un estudio pormenorizado de cada una de ellas. 
Capítulo 4 : Análisis de evolución y caracterización del abandono escolar temprano en las comunidades autónomas españolas 



\subsection{Introducción}

El cuarto capítulo de la presente tesis doctoral inicia la parte empírica de la investigación. Como punto de partida, resulta necesario estudiar sucintamente la evolución de la escolarización en España y el entorno europeo para tener en cuenta las posiciones de partida de ambos y establecer un análisis posterior fundamentado, ya que si consideramos el abandono escolar temprano como un problema de escolarización, podemos comprobar que éste se remonta varias décadas atrás, y que tiene precedentes en etapas de escolarización anteriores.

En este sentido, España ha presentado persistentemente una situación de desventaja respecto al entorno europeo; desventaja que algunos autores han atribuido a cuestiones religiosas (Easterlin, 1981), y de modernización económica (Nuñez, 1992).

Sin entrar en profundidad en la discusión sobre las causas de la desventaja de España en el terreno educativo, el Gráfico 4.1 ilustra las diferencias en escolarización en la etapa de educación primaria de España respecto a otras potencias europeas a lo largo del siglo XIX y los inicios del siglo XX. A excepción de Italia, que registra unos niveles de escolarización aún menores que los españoles, se puede comprobar como dicha desventaja se ha mantenido constante respecto a países como Francia o Alemania. Además, se denota el nulo progreso de la escolarización en esta etapa educativa a partir de finales del siglo XIX. 


\section{Gráfico 4.1. Escolarización en educación primaria (por cada 10.000 habitantes)}

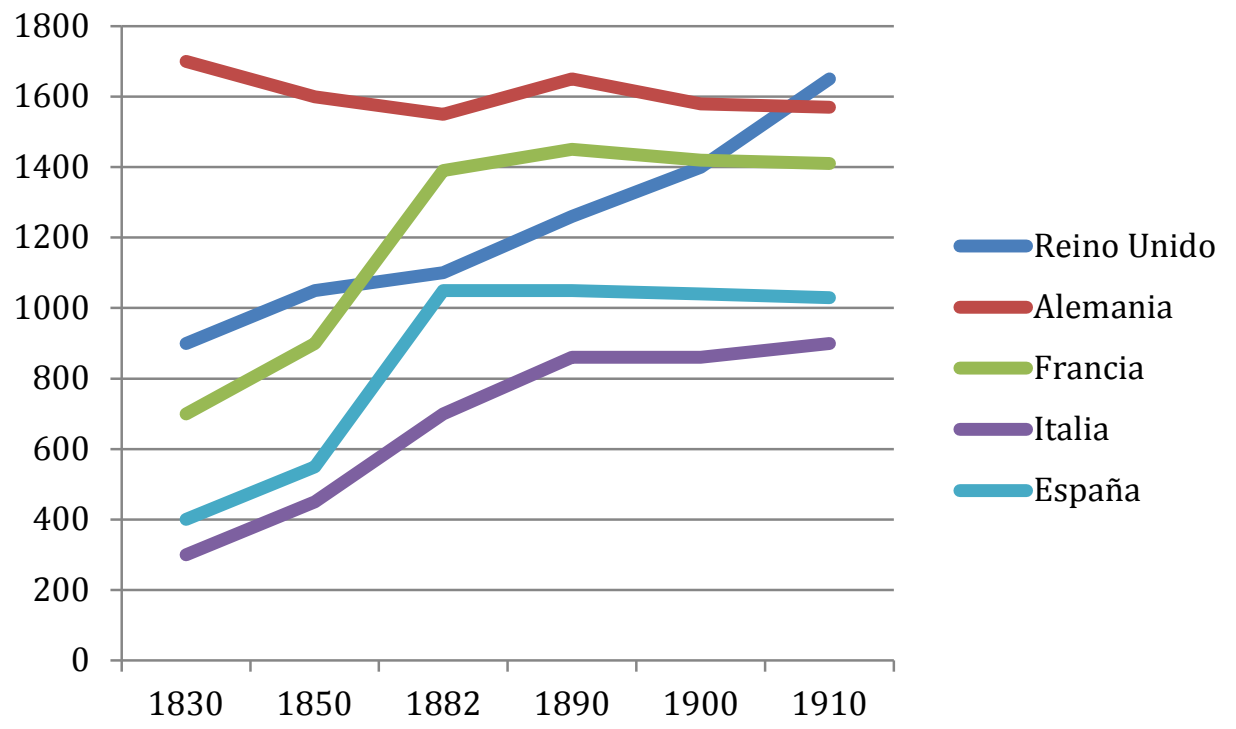

Fuente: Stevens y Weale (2004) a partir de datos de Easterlin (1981)

A pesar de lo anteriormente expuesto y centrándonos en el caso español, en un periodo temporal más próximo, las sucesivas leyes educativas introducidas desde hace más de 40 años en España han servido para que cada vez sean más altos los niveles de alfabetización y de escolarización en todas las edades. En el año 1970, la Ley General de Educación (LGE) abordó el objetivo de escolarización obligatoria hasta los 14 años, aunque no fue hasta 1990, año que se aprobó la Ley de Ordenación General del Sistema Educativo (LOGSE), cuando el tramo de edad de escolarización obligatoria se amplió hasta los 16 años. Ambas leyes tenían por objetivo reducir la brecha existente respecto a otros países del entorno europeo en términos de escolarización, junto a otros objetivos no menos importantes (Roca Cobo, 2010).

Como es lógico, además de ampliar la edad obligatoria de escolarización, las diferentes legislaciones aplicadas desde los años 70 sirvieron también para mejorar la escolarización de los estudiantes españoles en los niveles de educación postobligatoria. Prueba de ello son los datos recogidos en los siguientes gráficos, que muestran la distribución de la población activa según el nivel educativo alcanzado en el periodo 1964-2013 (Gráfico 4.2), y las tasas netas de escolarización de la población de 16, 17 y 18 años durante la década de los años 90 (Gráfico 4.3). 
Gráfico 4.2. Distribución de la población activa por nivel de estudios finalizados (1964-2013, \%)

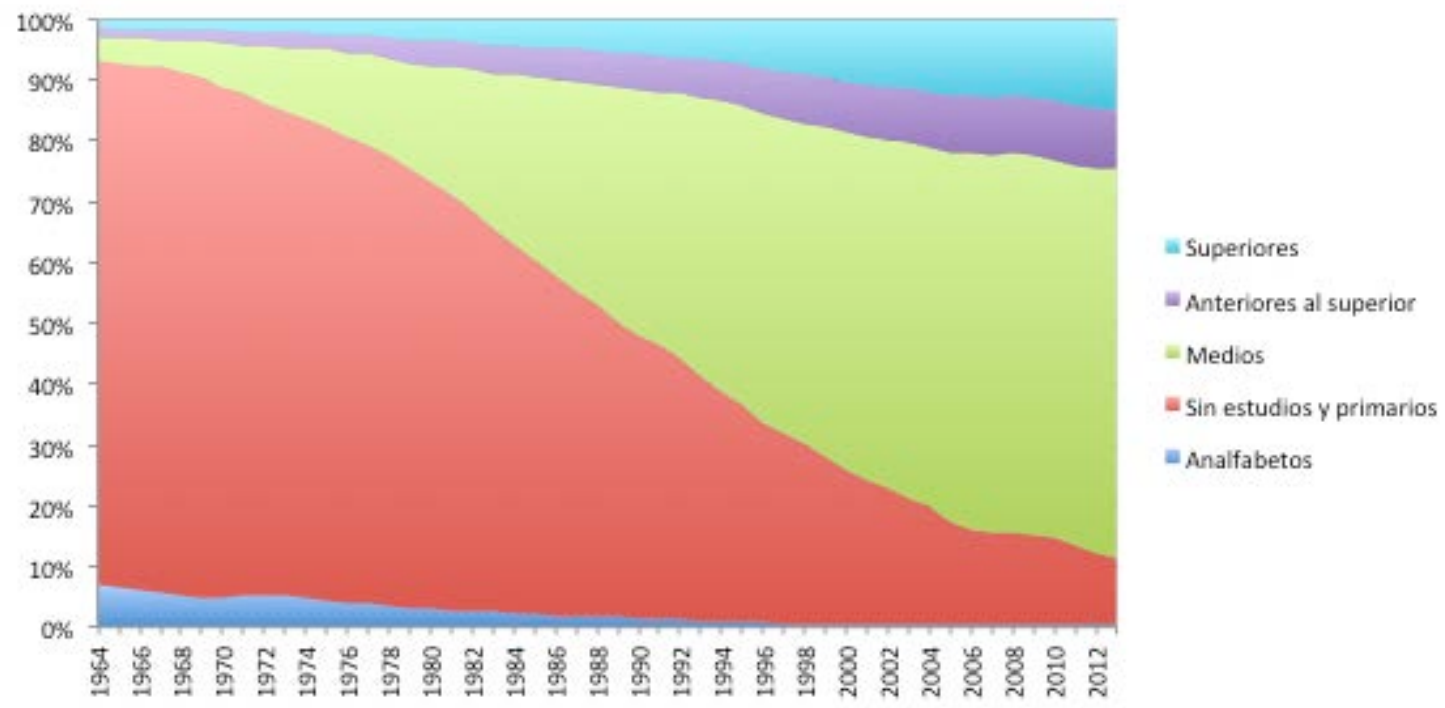

Fuente: Elaboración propia a partir de series de datos del IVIE (2014)

En el Gráfico 4.2 se puede observar la tendencia generalizada hacia una mayor escolarización de la población activa, produciéndose una inversión en la proporción de población sin estudios o con estudios primarios ${ }^{51}$, en favor de un mayor peso relativo de población con estudios medios y superiores, que aumenta significativamente a partir de la década de los años 80.

Por su parte, el Gráfico 4.3 refleja que el porcentaje de población escolarizada creció considerablemente entre los cursos 1991/92 y 1999/00, siendo de 10,3 puntos el incremento en la tasa de escolarización a los 16 años, y de un 8,3 puntos a los 17 años.

Estos datos de tendencia positiva no encuentran, sin embargo, la misma evolución en el caso de las tasas de escolarización a los 18 años, indicador que ha registrado una evolución irregular y que se encuentra muy por debajo (en torno a 30 puntos menos durante todo el periodo) de la tasa de escolarización de la población un año más joven (17 años). Si hasta el curso 1996/97 se produjo un incremento de 8,5 puntos, a partir de ese curso la escolarización a los 18 años descendió 4,4 puntos, por

${ }^{51}$ A pesar de la evolución positiva, en relación con el contexto europeo España continua presentando una situación de desventaja. Para el año 2014, España registra una proporción de población de entre 15 y 64 años con estudios secundarios de primera etapa, estudios primarios o sin estudios que asciende al $44,5 \%$, lo que supone más de 17 puntos más que el conjunto de la Unión Europea (27,4\%). 
lo que el incremento entre el curso 1991/92 y 1999/00 ha sido tan sólo de 4,1 puntos, manteniéndose esta tendencia hasta la actualidad.

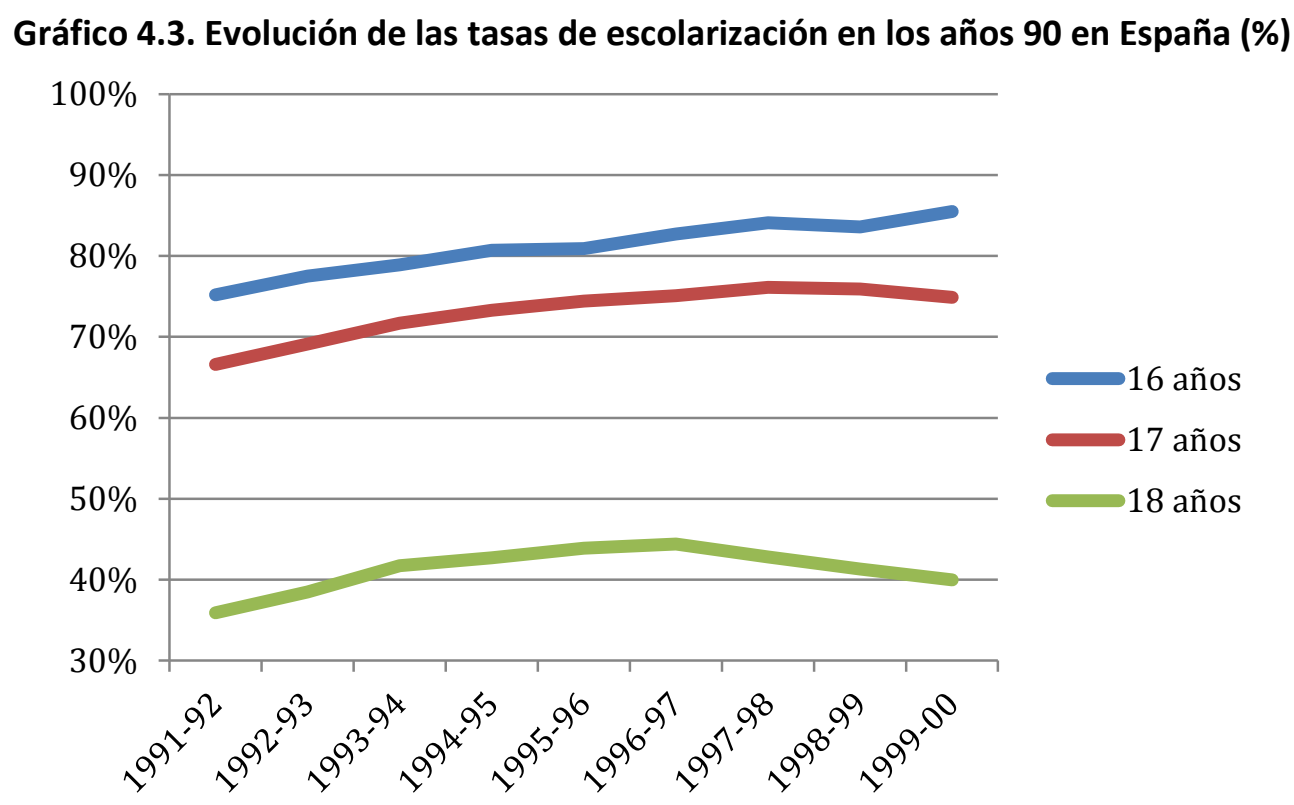

Fuente: Elaboración propia a partir de datos del Ministerio de Educación, Cultura y Deporte (MECD)

Así pues, el proceso de generalización de la enseñanza iniciado en los años 70 y desarrollado en los años 80 y 90 ha desplazado el problema del abandono de la educación hacia cohortes de edad más altas, posicionando este fenómeno como un problema de capital importancia para las políticas públicas. De este modo, se puede afirmar que los objetivos de las políticas de escolarización han ido evolucionando, pasando de la plena alfabetización y el acceso de la población menor de 16 años a la educación, al actual objetivo, que consiste en reducir el número de personas que abandonan la educación en edades posteriores a las que corresponden a la educación obligatoria, sin conseguir un título correspondiente a la educación secundaria postobligatoria o equivalente. Según Cullen (2000) el interés por este objetivo se vio acrecentado a partir de los años 80 , coincidiendo con la caída de los trabajos menos intensivos en conocimiento o que requerían una cualificación relativamente baja, en favor de trabajos con unas exigencias formativas más altas. 


\subsection{Evolución de las tasas de abandono escolar temprano}

Una vez contextualizado el problema de escolarización que ha ido evolucionando desde la alfabetización hasta las etapas postobligatorias, en este epígrafe se analiza cuál ha sido la evolución del abandono escolar temprano y su situación en las comunidades autónomas españolas.

La tasa de abandono escolar temprano en España presenta unos niveles que doblan prácticamente la media europea, con una evolución muy irregular. A este respecto, el Cuadro 4.1 muestra los niveles que presentaba el indicador en el año 2000, fecha en la que se planteó la Estrategia de Lisboa; en 2010, fin del horizonte temporal para la consecución de los objetivos establecidos en la citada estrategia e inicio de la Estrategia Europea 2020; y en 2013, que se refiere al último dato consolidado que está disponible. Por último, también se recoge el objetivo de cada país para el año $2020^{52}$.

${ }^{52}$ Para conocer los datos completos del periodo 2000 - 2013, consultar Cuadro Alll.1 del Anexo III. 
Cuadro 4.1. Tasas de abandono escolar temprano en la Unión Europea-28 (Años 2000, 2010, 2013 y objetivo (\%)

\begin{tabular}{|c|c|c|c|c|}
\hline & 2000 & 2010 & 2013 & Objetivo \\
\hline Austria & 10,2 & 8,3 & 7,3 & 9,5 \\
\hline Bélgica & 13,8 & 11,9 & 11,0 & 9,5 \\
\hline Bulgaria & $20,5^{*}$ & 13,9 & 12,5 & 11,0 \\
\hline Croacia & $8,0 *$ & 3,7 & 3,7 & 4,0 \\
\hline Chipre & 18,5 & 12,7 & 9,1 & 10,0 \\
\hline R. Checa & $5,7^{*}$ & 4,9 & 5,4 & 5,5 \\
\hline Dinamarca & 11,7 & 11,0 & 8,0 & 10,0 \\
\hline Estonia & 15,1 & 11,6 & 9,7 & 9,5 \\
\hline UE-28 & $16,9 *$ & 13,9 & 11,9 & 10,0 \\
\hline Finlandia & 9,0 & 10,3 & 9,3 & 8,0 \\
\hline Francia & 13,3 & 12,6 & 9,7 & 9,5 \\
\hline Alemania & 14,6 & 11,9 & 9,9 & 10,0 \\
\hline Grecia & 18,2 & 13,7 & 10,1 & 9,7 \\
\hline Hungría & 13,9 & 10,5 & 11,8 & 10,0 \\
\hline Irlanda & $14,6 *$ & 11,5 & 8,4 & 8,0 \\
\hline Italia & 25,1 & 18,8 & 17,0 & 16,0 \\
\hline Letonia & $16,9 *$ & 13,3 & 9,8 & 13,4 \\
\hline Lituania & 16,5 & 7,9 & 6,3 & 9,0 \\
\hline Luxemburgo & 16,8 & 7,1 & 6,1 & 10,0 \\
\hline Malta & 54,2 & 25,9 & 20,9 & 10,0 \\
\hline Países Bajos & 15,4 & 10,0 & 9,2 & 8,0 \\
\hline Polonia & $7,4^{*}$ & 5,4 & 5,6 & 4,5 \\
\hline Portugal & 43,6 & 28,7 & 19,2 & 10,0 \\
\hline Rumanía & 22,9 & 18,4 & 17,3 & 11,3 \\
\hline Eslovaquia & $6,7^{*}$ & 4,7 & 6,4 & 6,0 \\
\hline Eslovenia & $6,4^{*}$ & 5,0 & 3,9 & 5,0 \\
\hline España & 29,1 & 28,4 & 23,5 & 15,0 \\
\hline Suecia & 7,3 & 6,5 & 7,1 & 10,0 \\
\hline Reino Unido & 18,2 & 14,9 & 12,4 & $* *$ \\
\hline
\end{tabular}

Fuente: Elaboración propia a partir de datos de Eurostat

* Los datos de Bulgaria, Eslovenia y Polonia pertenecen al año 2001. Los datos de Eslovaquia, Irlanda, Letonia, República Checa, Croacia y la UE-28 pertenecen al año 2002.

** Dato no disponible.

Como se puede observar, España presenta la tasa de abandono escolar temprano más alta de la Unión Europea, con un valor que asciende al 23,5\% para el año 2013, distando en 8,5 puntos del objetivo español, en 13,5 del objetivo europeo, y en 11,6 de la media de la Unión Europea.

Si atendemos a la evolución del indicador, España ha registrado una reducción global de 5,3 puntos en los trece años que recoge el Cuadro 4.1, casi un 20\% menos de la tasa que registraba en el año 2000, que ascendía a un 29,1\%. De forma similar, el 
conjunto de países de la Unión Europea (UE-28) ha reducido su indicador en 5 puntos, lo que representa casi un $30 \%$ respecto a su situación de partida en promedio, por lo que España, a pesar de encontrarse con una de las tasas más altas, ha registrado una evolución desfavorable en términos comparativos.

Así pues, puede comprobarse como todos los países pertenecientes a la Unión Europea han conseguido disminuir su tasa de abandono escolar temprano, con la excepción de Finlandia, que presentaba ya en el año 2000 una tasa de abandono escolar temprano por debajo del objetivo europeo $(9,3 \%)$.

El Gráfico 4.4 ayuda a poner de relieve el comportamiento de la tasa de abandono escolar temprano en España, ya que se establece una comparación con aquellos países en los que el indicador estaba por encima del 20\% en el año 2000. Como se puede observar, España es el país que peor evolución ha registrado, en un periodo de diez años (2000 - 2009) en el que el indicador se ha mantenido en torno a un $30 \%$, con dos años (2004 y 2008) alcanzando el 32\%, y una evolución de 2,1 puntos de incremento en el indicador. Por el contrario, un segundo periodo, iniciado a partir del año 2010, se ha caracterizado por presentar sistemáticas aunque insuficientes reducciones en el indicador, llegando en el año 2013 a una tasa del 23,5\%, y una evolución en este sub-periodo de reducción de 4,9 puntos. 
Gráfico 4.4. Evolución de la tasa de abandono escolar temprano (varios países, 2000*-2013, \%)

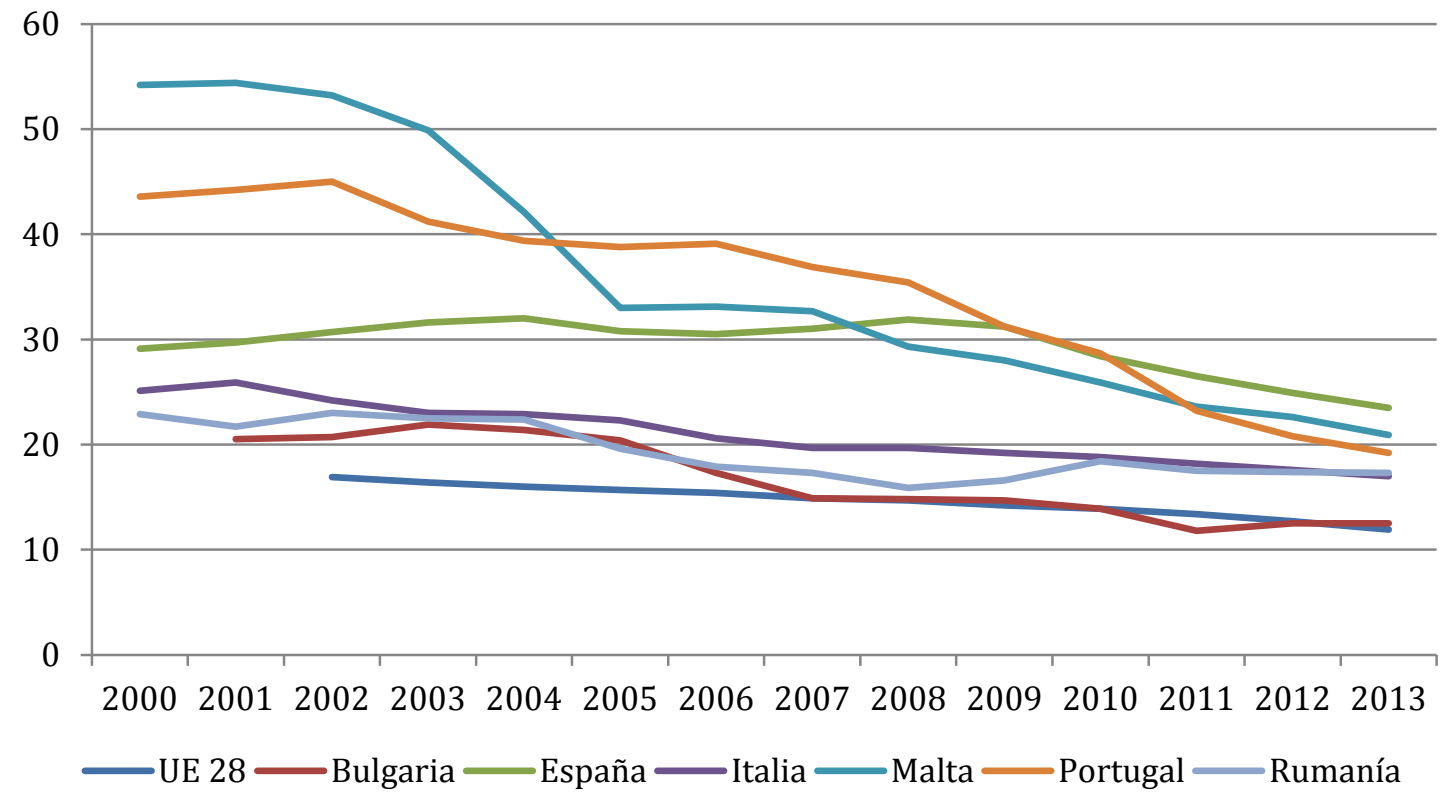

Fuente: Elaboración propia a partir de datos de Eurostat

* Debido a la falta de disponibilidad de datos de varios países, no hay dato promedio de la Unión Europea 28 hasta el año 2002 y dato de Bulgaria hasta el año 2001.

En el Gráfico 4.4 se puede identificar un cierto proceso de convergencia entre los países que presentaban peores tasas de abandono escolar temprano al inicio de la Estrategia de Lisboa, tendiendo en general a reducir notablemente su indicador. Sin embargo, son destacables las diferencias entre países. En este sentido, la evolución del indicador en Portugal y Malta se caracteriza por experimentar una pronunciada reducción, pasando de ostentar las tasas más altas en el año 2000 (43,6\% y 54,2\% respectivamente), a situarse ambas en torno a un $20 \%$, habiendo registrado un descenso de 24,4 y 33,3 puntos, respectivamente.

Por su parte, Italia, Rumanía y Bulgaria, que presentaban un punto de partida más ventajoso (entre el $20 \%$ y el $26 \%$ ), han mejorado su indicador hasta situarlo en torno a un $17 \%$ - en el caso de Italia y Rumanía - y un 12,5\% en el caso de Bulgaria, que se posiciona próximo a la media europea. España, como ya se ha comentado, ha registrado la peor evolución de este grupo de países, y, pese a que ha conseguido reducir su indicador desde el año 2009, ha pasado de ser el tercer país con la tasa de abandono escolar temprano de la Unión Europea más alta, a ser el primero. 
Las diferencias regionales en el nivel de abandono escolar temprano en la Unión Europea quedan reflejadas en el Gráfico 4.5, mostrando el promedio de cada país (línea negra) junto con la comunidad o región a nivel NUTS2 ${ }^{53}$ con mayor (rojo) y menor (verde) abandono escolar temprano, utilizando para ello un promedio del periodo 2010 - 2013 (ambos inclusive). Se observa la posición destacable de España, que además de ser el país con mayores niveles de abandono, también cuenta con las disparidades regionales más acusadas, lo que constituye un caso de especial singularidad que conviene estudiar.

\section{Gráfico 4.5. Diferencias regionales en las tasas de abandono escolar temprano en la Unión Europea (promedio de años 2010-2013, \%)}

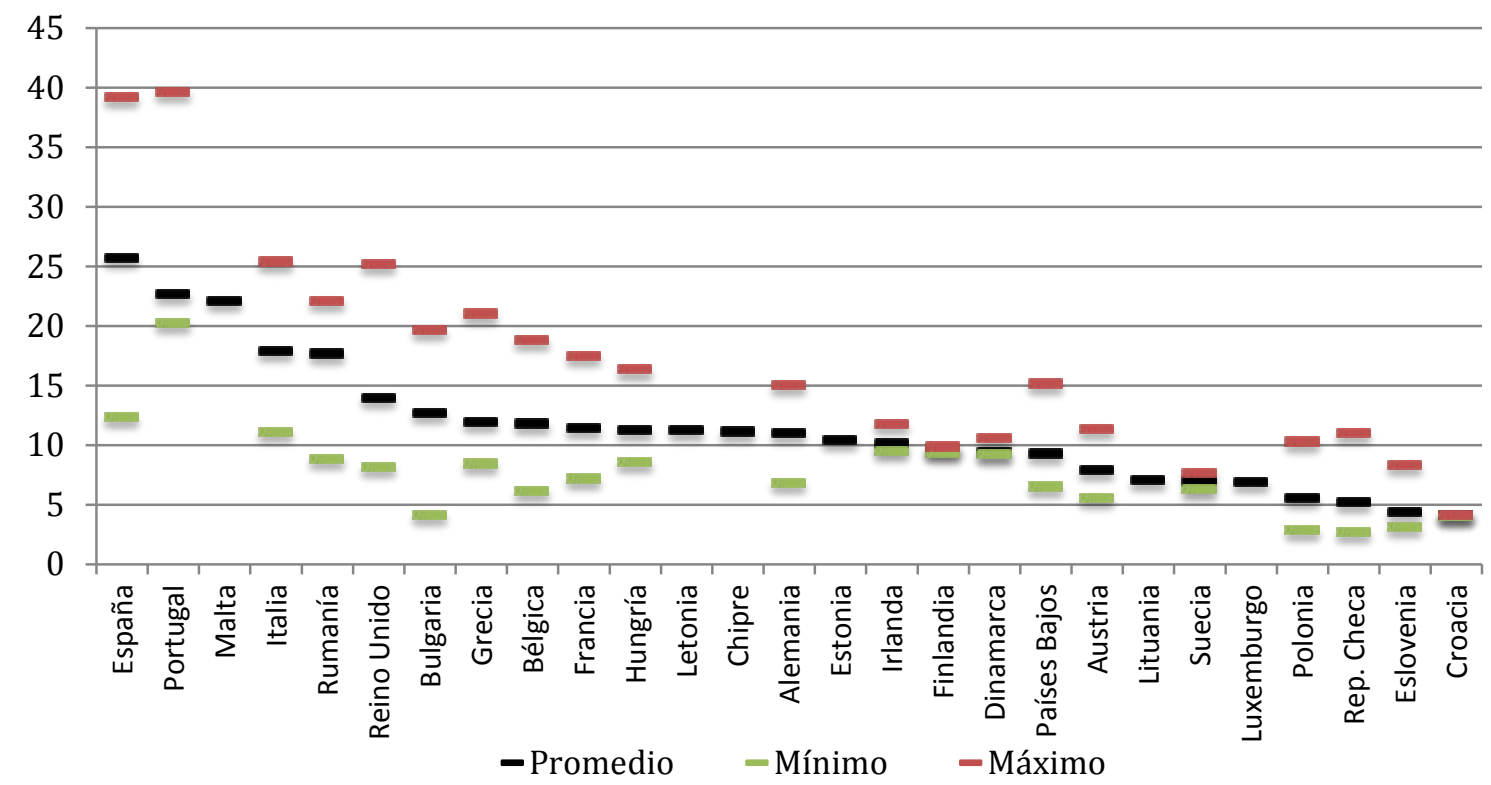

Fuente: Elaboración propia a partir de datos de Eurostat

Una vez presentados los datos de los países de referencia, conviene desgranar la información contenida en el indicador para observar que el comportamiento del mismo en nuestro país es de extraordinaria singularidad, debido a la ya comentada disparidad regional.

\footnotetext{
${ }^{53}$ Las NUTS o Nomenclatura de las Unidades Territoriales Estadísticas (de la traducción de las siglas en francés de Nomenclature des Unités Territoriales Statistiques) son un sistema jerárquico de nomenclatura creado por la Unión Europea para facilitar la recopilación, y análisis de estadísticas regionales. El nivel NUTS2 se corresponde con el nivel de desagregación de comunidades autónomas para el caso español.

${ }^{54}$ Para Malta, Letonia, Chipre, Estonia, Lituania y Luxemburgo no hay valores mínimos y máximos, ya que no cuentan con división en regiones de nivel NUTS2.
} 
Antes de comenzar con los análisis descriptivos, es necesario apuntar que se ha excluido de todos ellos el caso de las ciudades autónomas de Ceuta y Melilla, ya que constituyen unidades territoriales distintas al resto de las comunidades autónomas españolas, presentando, por ello, dificultades evidentes a la hora de establecer comparaciones. No obstante, cabe reseñar que ambas ciudades autónomas han presentado sistemáticamente las tasas de abandono escolar temprano más altas a nivel nacional ${ }^{55}$.

De esta forma, en el Gráfico 4.6 se puede observar el nivel de abandono escolar temprano de cada comunidad autónoma, así como el promedio de España y de la Unión Europea (UE-28) para 2013, último año con disponibilidad de datos consolidados.

Gráfico 4.6. Tasa de abandono escolar temprano en las CCAA españolas (año 2013, \%)

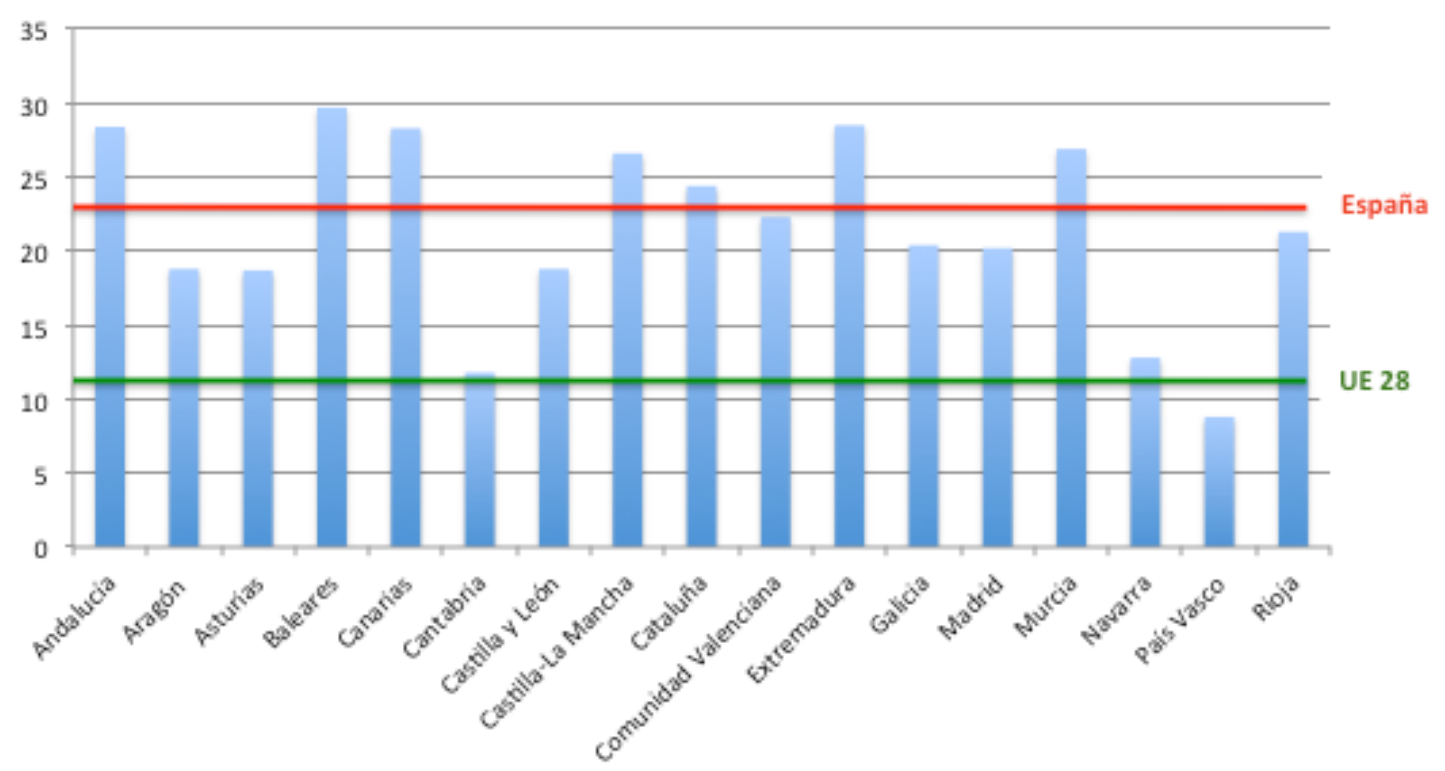

Fuente: Elaboración propia a partir de datos de Eurostat y MECD

Como se puede comprobar, las diferencias regionales entre las distintas comunidades autónomas son muy amplias. Por un lado, seis comunidades, coincidentes con la mitad sur de la península junto con las islas (Andalucía, Baleares, Canarias, Castilla La Mancha, Extremadura y Murcia), presentan una tasa de abandono superior al $25 \%$, mientras que Cataluña, con un $24,4 \%$ y Comunidad Valenciana, con un 22,3\%, se sitúan ligeramente por debajo de las mencionadas. Por otro lado, Aragón,

${ }^{55}$ Para el año 2013, Ceuta y Melilla han registrado, en promedio, una tasa de abandono escolar temprano que asciende al $34,2 \%$. 
Asturias, Castilla y León, Galicia y Madrid forman un grupo de regiones con tasas de entre el $18 \%$ y el $20,5 \%$. Por último, Navarra $(12,8 \%)$, Cantabria $(11,8 \%)$ y País Vasco $(8,8 \%)$ presentan las tasas de abandono escolar más bajas, situándose en torno al promedio europeo. Estas tres regiones, además, son las únicas que han cumplido con el objetivo nacional de situar la tasa de abandono escolar temprano en un $15 \%$ para el año 2020.

De igual forma, el Cuadro 4.2 ilustra las diferencias entre comunidades autónomas en cuanto a la evolución registrada, mostrando el nivel de abandono escolar temprano para los años 2000, 2008 y $2013^{56}$, así como las tasas de crecimiento medio anual acumulativo para los periodos 2000 - 2008 y 2009 - 2013, y un indicador de las diferencias regionales para el año 2013 tomando como referencia el promedio nacional (Dato España $=100$ ). La elección del corte entre los dos periodos en el año 2008 se justifica por el hecho de que es precisamente, en este año, en el que se produce un punto de inflexión, a partir del cual la tasa de abandono escolar temprano comienza a reducirse, además de suponer el inicio de un cambio de ciclo en la economía que, como se verá con posterioridad, establece patrones diferenciados en la evolución de diversas variables.

Como se puede observar, se constata, en la mayor parte de las comunidades autónomas, la diferencia de comportamiento entre los periodos $2000-2008$, de casi nulo descenso o ligero aumento del indicador, y 2009 - 2013, en el que todas las regiones han registrado una evolución más favorable.

${ }^{56}$ Para conocer los datos completos del periodo 2000 - 2013, consultar Cuadro Alll.2 del Anexo III. 
Cuadro 4.2. Tasas de abandono escolar temprano por CCAA (\%)

\begin{tabular}{|c|c|c|c|c|c|c|c|}
\hline & \multirow{2}{*}{2000} & \multirow{2}{*}{2008} & \multirow{2}{*}{2013} & \multicolumn{3}{|c|}{$\begin{array}{c}\text { Tasa de Crecimiento Medio } \\
\text { Anual Acumulativo }\end{array}$} & \multirow{2}{*}{$\begin{array}{c}\text { Diferencial } \\
\text { interregional } \\
\text { (España }=100\end{array}$} \\
\hline & & & & $\begin{array}{c}2000- \\
2008 \\
\end{array}$ & $\begin{array}{c}2009- \\
2013\end{array}$ & Total & \\
\hline España & 29,1 & 31,7 & 23,6 & $1,08 \%$ & $-6,52 \%$ & $-1,60 \%$ & 100,00 \\
\hline Andalucía & 35,5 & 37,9 & 28,7 & $0,82 \%$ & $-6,28 \%$ & $-1,62 \%$ & 121,61 \\
\hline Aragón & 21,9 & 25,8 & 18,9 & $2,07 \%$ & $-6,75 \%$ & $-1,13 \%$ & 80,08 \\
\hline Asturias & 21,8 & 20,0 & 19,1 & $-1,07 \%$ & $-2,69 \%$ & $-1,01 \%$ & 80,93 \\
\hline Baleares & 42,0 & 42,5 & 29,8 & $0,15 \%$ & $-7,27 \%$ & $-2,61 \%$ & 126,27 \\
\hline Canarias & 34,1 & 34,1 & 27,5 & $0,00 \%$ & $-2,71 \%$ & $-1,64 \%$ & 116,53 \\
\hline Cantabria & 22,8 & 22,9 & 12,1 & $0,05 \%$ & $-15,91 \%$ & $-4,76 \%$ & 51,27 \\
\hline Castilla y León & 21,6 & 26,4 & 19,2 & $2,54 \%$ & $-8,08 \%$ & $-0,90 \%$ & 81,36 \\
\hline Castilla-La Mancha & 35,8 & 38,4 & 27,4 & $0,88 \%$ & $-5,67 \%$ & $-2,04 \%$ & 116,10 \\
\hline Cataluña & 29,1 & 32,9 & 24,7 & $1,55 \%$ & $-6,19 \%$ & $-1,25 \%$ & 104,66 \\
\hline C. Valenciana & 32,7 & 32,6 & 21,7 & $-0,04 \%$ & $-9,18 \%$ & $-3,11 \%$ & 91,95 \\
\hline Extremadura & 41,0 & 33,8 & 29,2 & $-2,38 \%$ & $-3,80 \%$ & $-2,58 \%$ & 123,73 \\
\hline Galicia & 29,2 & 23,6 & 20,2 & $-2,63 \%$ & $-5,93 \%$ & $-2,79 \%$ & 85,59 \\
\hline Madrid & 19,6 & 27,1 & 19,7 & $4,13 \%$ & $-6,88 \%$ & $0,04 \%$ & 83,47 \\
\hline Murcia & 39,2 & 40,6 & 26,3 & $0,44 \%$ & $-8,06 \%$ & $-3,02 \%$ & 111,44 \\
\hline Navarra & 16,4 & 18,8 & 12,9 & $1,72 \%$ & $-8,86 \%$ & $-1,83 \%$ & 54,66 \\
\hline País Vasco & 14,7 & 14,8 & 9,9 & $0,08 \%$ & $-12,12 \%$ & $-3,00 \%$ & 41,95 \\
\hline Rioja & 26,1 & 37,0 & 21,7 & $4,46 \%$ & $-9,18 \%$ & $-1,41 \%$ & 91,95 \\
\hline
\end{tabular}

Fuente: Elaboración propia a partir de datos de Eurostat y MECD

En cuanto al primer periodo, caracterizado por un aumento medio anual del 1,08\% para el conjunto nacional, La Rioja y Madrid fueron las comunidades que aumentaron sus tasas de abandono escolar temprano a un ritmo mayor, de un 4,46\% y 4,13\% medio anual respectivamente. En contraste, Extremadura y Galicia redujeron sus indicadores en más de un $2 \%$ anual.

El segundo periodo está caracterizado por presentar reducciones en la tasa de abandono escolar temprano en todas las comunidades autónomas, a un ritmo medio del 6,52\% anual. Por regiones destacan especialmente Cantabria, que ha conseguido reducir su indicador más de diez puntos, registrando en el año 2013 un 12,1\% de abandono escolar temprano; y País Vasco, que cuenta con un 9,9\%, después de haber reducido su indicador a razón de un 12,12\% medio anual, siendo estas dos comunidades las que presentan mejores datos de abandono escolar temprano a nivel nacional, tal como se ha puesto de manifiesto en líneas precedentes.

El Gráfico 4.7 refleja la evolución de la amplitud de las diferencias registradas entre comunidades autónomas, que se ha reducido en el periodo 2000-2013, pasando 
de una diferencia de 27,3 puntos entre la región con tasa de abandono escolar temprano más alta y más baja en el año 2000, a una diferencia de 20,9 puntos para el año 2013.

Gráfico 4.7. Evolución de las diferencias regionales en las tasas de abandono escolar temprano en las CCAA españolas (años 2000-2013, \%)

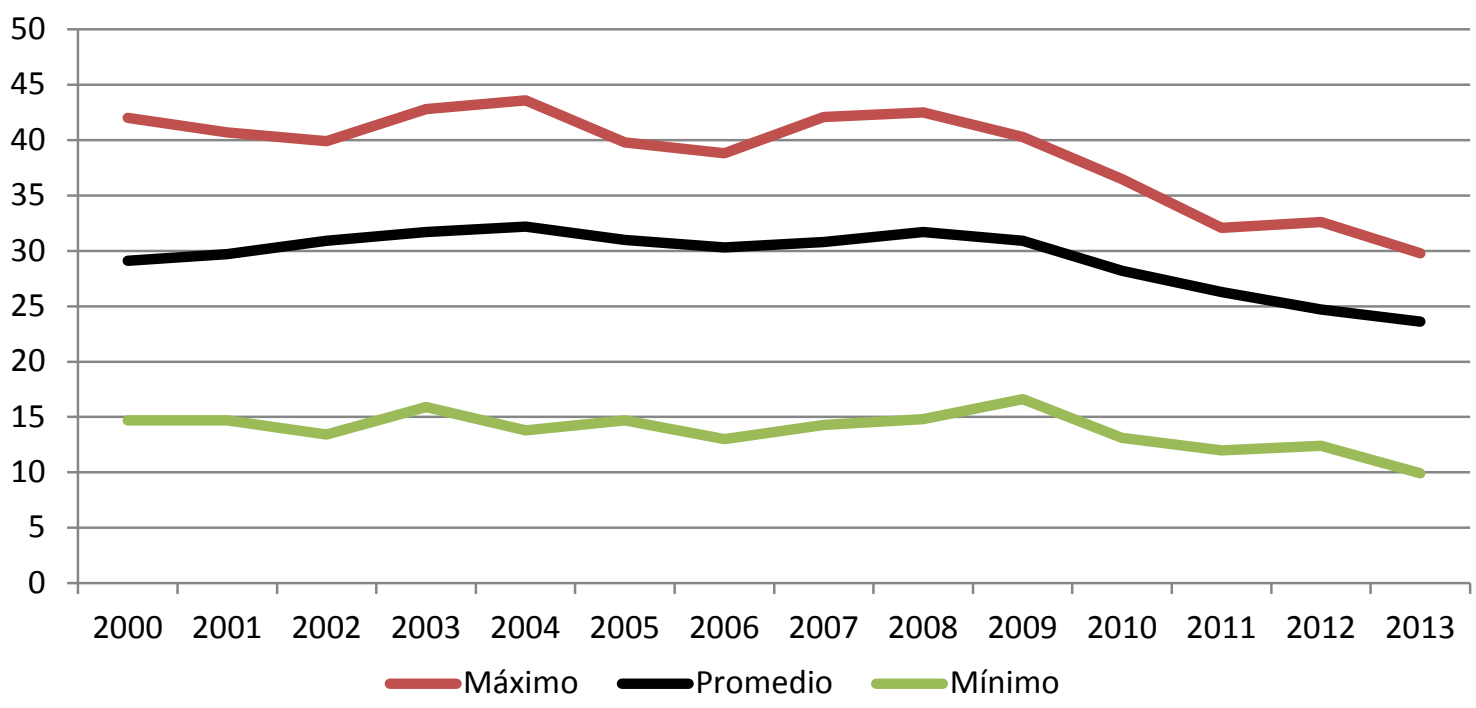

Fuente: Elaboración propia a partir de datos de Eurostat y MECD

Por último, el Gráfico 4.8 ayuda a poner de relieve el comportamiento del abandono escolar temprano a nivel regional, ya que muestra la relación entre el nivel de abandono escolar temprano en las comunidades autónomas españolas en el año 2000 y en el año 2013. Como se puede observar, se mantiene, en términos generales, un equilibrio en cuanto a la posición de cada comunidad autónoma respecto a su nivel de abandono escolar temprano de origen, siendo evidente el descenso registrado en el indicador para todas las regiones. La región que más destaca es Cantabria, que es la comunidad que más se aleja de la tendencia general, habiendo reducido su nivel de abandono escolar temprano hasta casi la mitad. 
Gráfico 4.8. Abandono escolar temprano en las CCAA españolas (año 2000 versus 2013, \%)

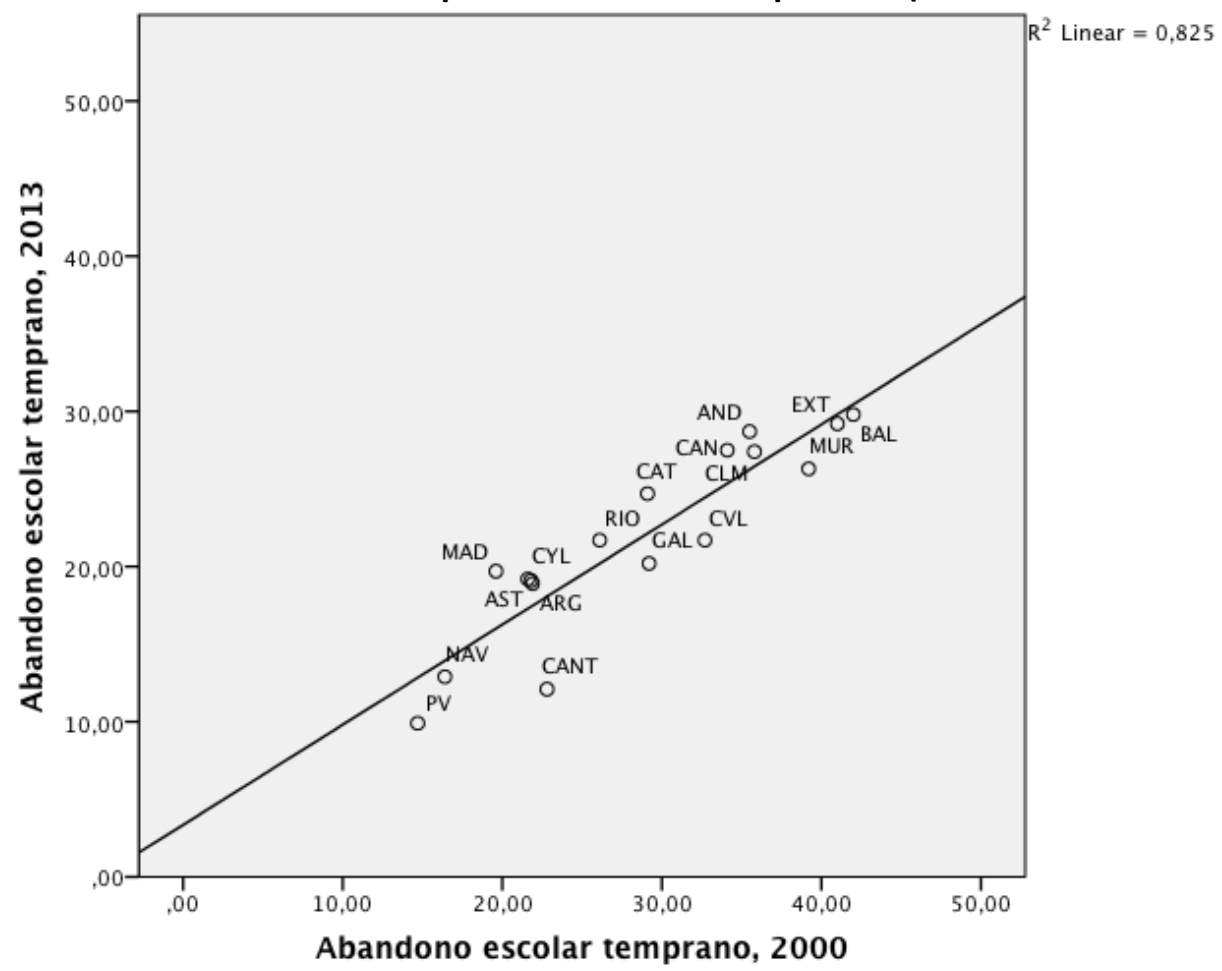

Fuente: Elaboración propia a partir de datos de Eurostat y MECD

De esta forma, queda patente la gran disparidad registrada, tanto en los datos de abandono escolar temprano como en su evolución; por lo que es pertinente realizar un análisis acerca de cuáles son los factores que han incidido en el comportamiento desigual de las tasas de abandono escolar temprano en las diferentes comunidades autónomas de nuestro país, tomando como referencia las variables que se han revisado en la literatura, de cara a establecer conclusiones relevantes para la implementación de la política económica.

\subsection{Caracterización de la tasa de abandono escolar temprano}

Antes de iniciar el análisis regional de los factores de entorno que intervienen en la generación del abandono escolar temprano, conviene desglosar la máxima información posible que se esconde tras el indicador. Con este objeto, se desarrolla a continuación un análisis descriptivo de la tasa de abandono escolar temprano categorizada por sexo, edad, ocupación y nacionalidad, con datos provenientes de la explotación de las variables educativas de la Encuesta de Población Activa (EPA) 
disponible en la base de datos "Educa Base" del Ministerio de Educación, Cultura y Deporte (MECD). ${ }^{57}$

En primer lugar, el Gráfico 4.9 ilustra la diferencia, ya apuntada en la revisión de la literatura (Marks y Fleming, 1999; Felgueroso et al, 2013; Fernández-Macías et al., 2013), de las tasas de abandono escolar temprano entre hombres y mujeres. Como se puede observar, la evolución del abandono escolar temprano en hombres y mujeres es similar, aunque las diferencias entre ambos se han reducido notablemente, pasando de una distancia de casi 13 puntos en el año 2002 a 7 puntos aproximadamente en el año 2013, produciéndose prácticamente toda la disminución de diferencias a partir del año 2009.

Gráfico 4.9. Evolución de las tasas de abandono escolar temprano según género (años 20022013, \%)

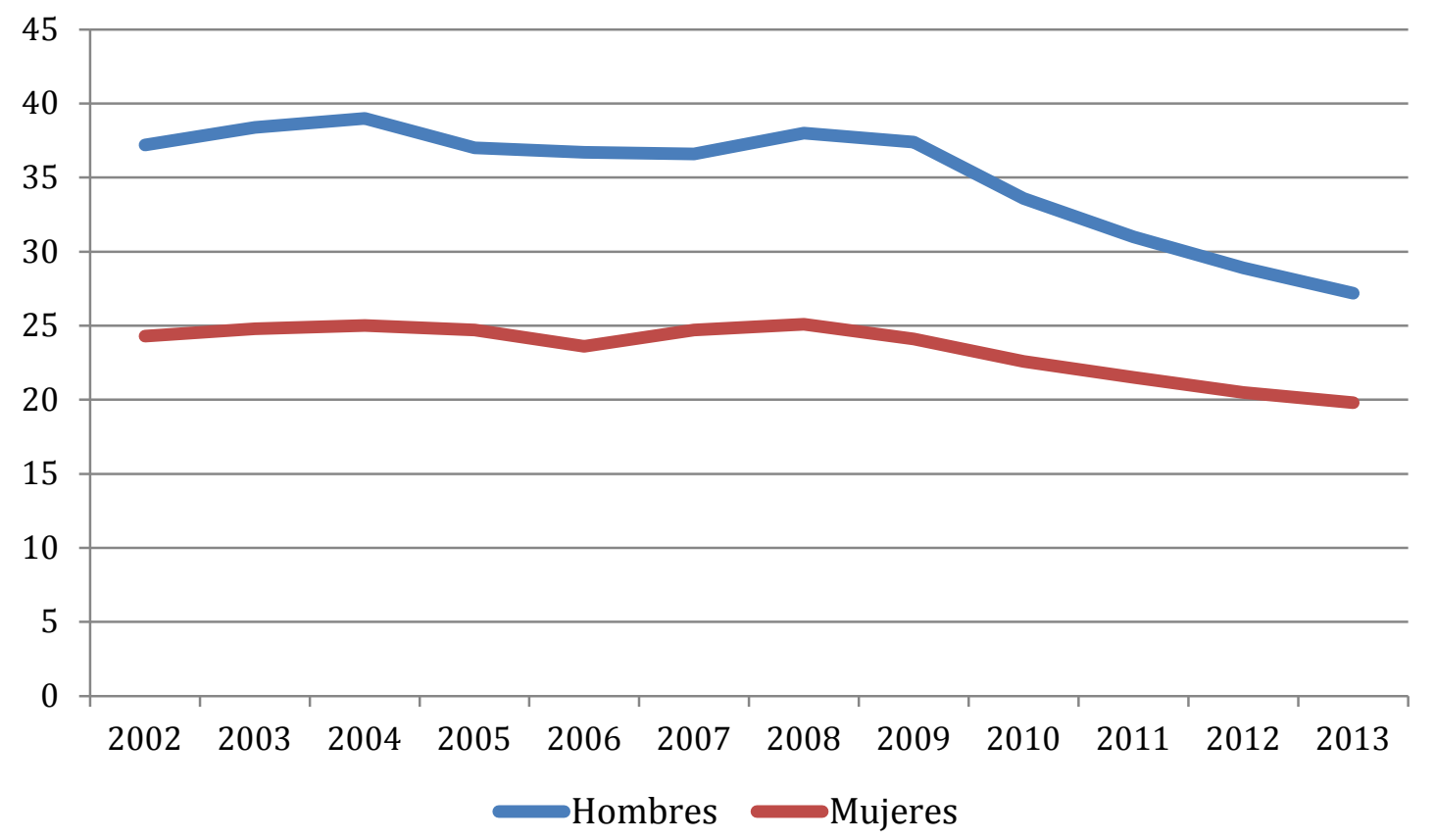

Fuente: Elaboración propia a partir de datos de MECD

En segundo lugar, el Gráfico 4.10 muestra la evolución de las tasas de abandono escolar temprano en su promedio nacional según las diferentes edades que recoge el indicador. Como se puede observar, en términos generales se mantiene un patrón por el cual a mayor edad, mayor tasa de abandono escolar, si bien entre los

$57 \quad$ Disponible en: http://www.mecd.gob.es/servicios-al-ciudadanomecd/estadisticas/educacion/mercado-laboral/epa.html 
años 2005 y 2009 se registra una menor variabilidad en el comportamiento de la tasa. A partir del año 2009, el indicador se reduce notablemente, especialmente para el grupo de edad correspondiente a los 18 años, que en el año 2013 se sitúa en un 14,6\%. Para el grupo de edad de 24 años el indicador se sitúa por encima del 30\% para todo el periodo, aumentando sensiblemente en el último año.

Gráfico 4.10. Evolución de las tasas de abandono escolar temprano según edad (años 20022013, \%)

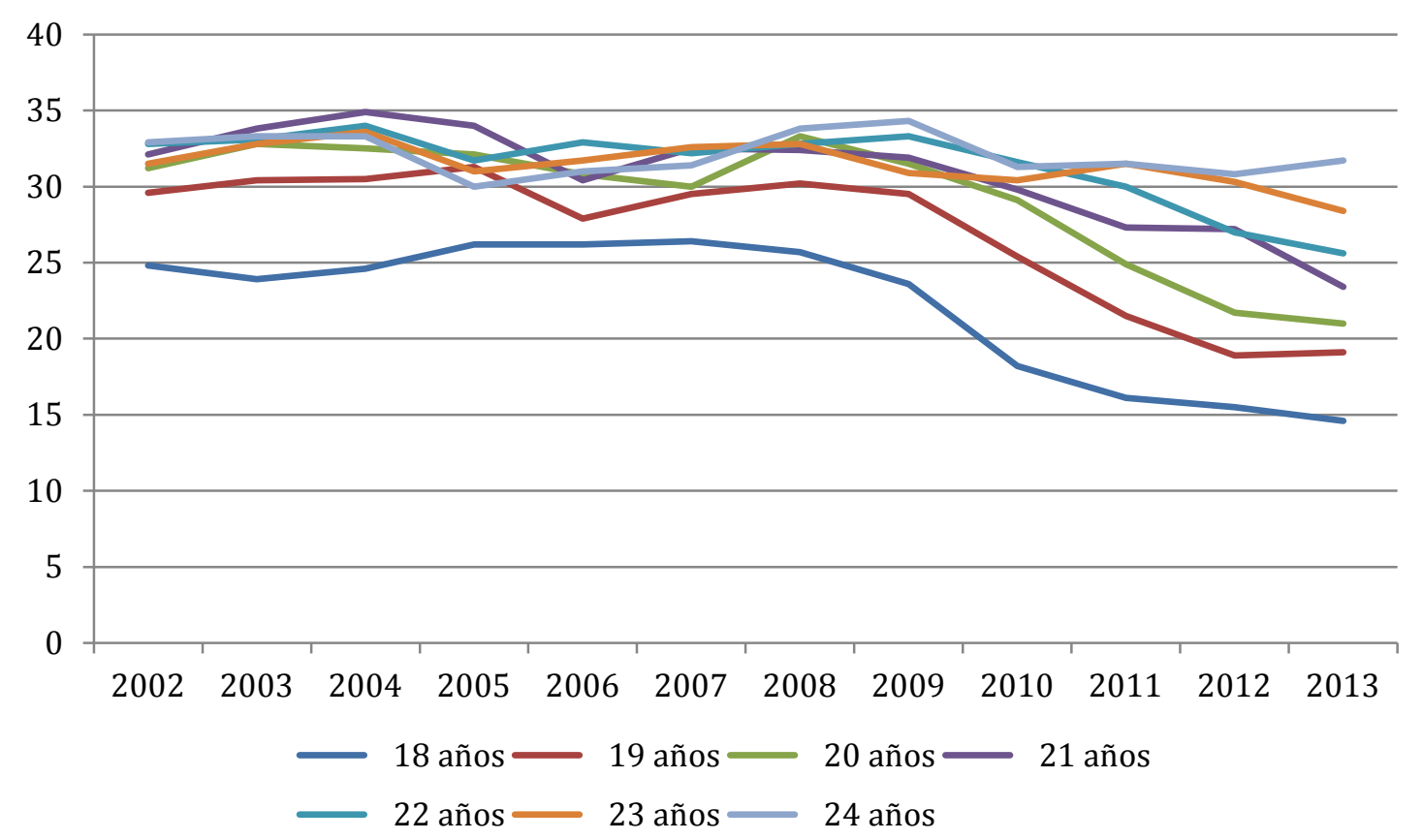

Fuente: Elaboración propia a partir de datos de MECD

La tendencia que apuntan los datos es lógica, puesto que a los 18 años hay una mayor proporción de alumnado escolarizado, ya que coincide con la edad teórica de finalización de la educación secundaria no obligatoria, tanto en la modalidad de bachillerato como del ciclo de formación profesional de grado medio, además del alumnado que se encuentre a esa edad aún finalizando la Educación Secundaria Obligatoria. De esta forma, es lógico que a los 19 años se produzca un salto en la tasa de abandono escolar temprano, como reflejo del alumnado que ha desistido de proseguir sus estudios, aún contando con la Educación Secundaria Obligatoria.

Sin embargo, en el siguiente Gráfico 4.11 se puede comprobar como el alumnado que abandona el sistema educativo después de haber obtenido la ESO se ha reducido de forma considerable, resultando en un proceso de convergencia respecto a los que abandonaban sin alcanzar la titulación de ESO, cuya representación en el 
indicador ha aumentado en todo el periodo. De esta forma, parece que durante el periodo 2002 - 2008, en la que la evolución general del indicador se mantuvo constante, en valores muy altos (en torno al 30\%), sí que existían dos tendencias diferenciadas, mientras que a partir del año 2009 la tasa de abandono escolar temprano viene registrando descensos proporcionales para ambos grupos.

Gráfico 4.11. Evolución de las tasas de abandono escolar temprano según titulación alcanzada (años 2002-2013, \%)

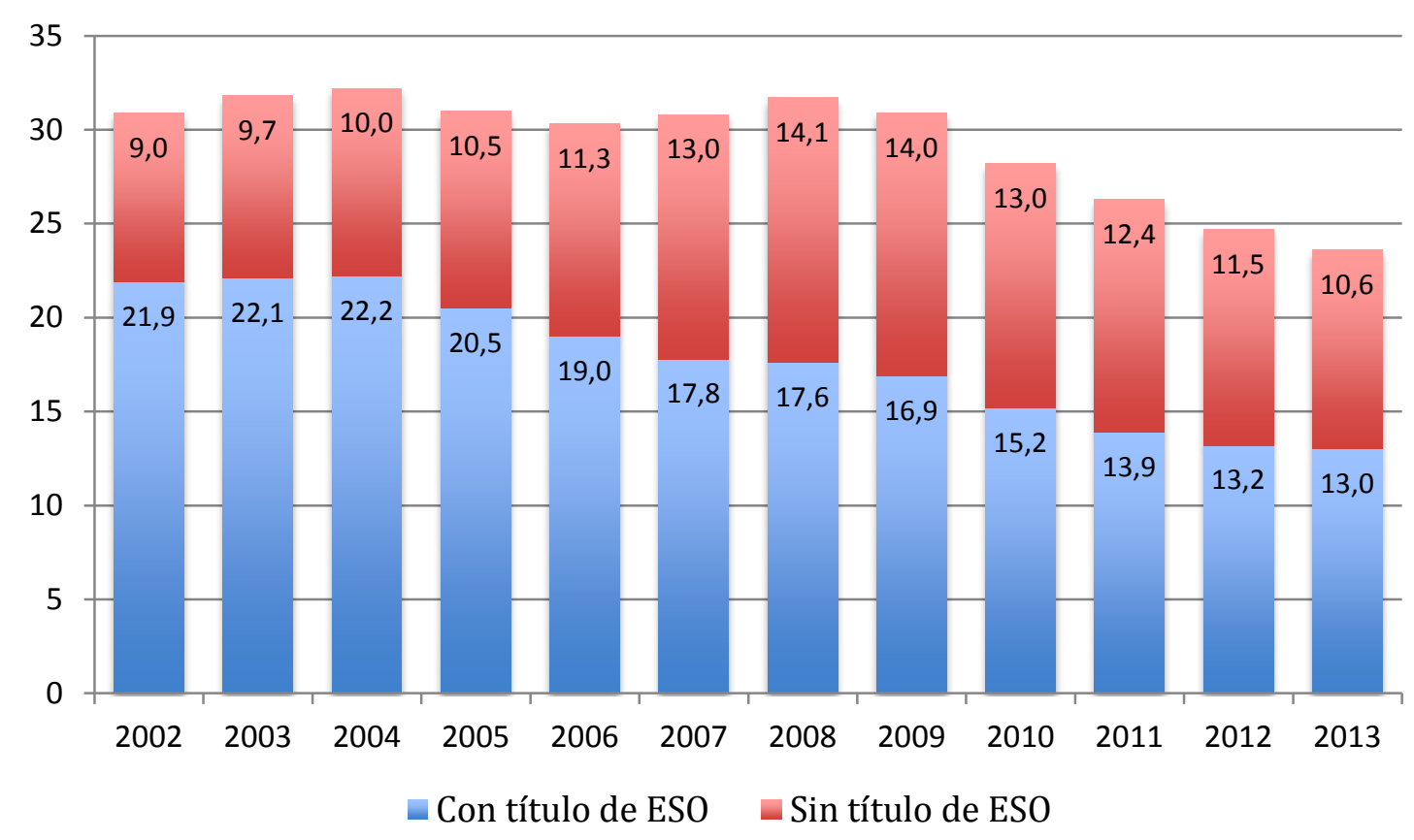

Fuente: Elaboración propia a partir de datos de MECD

Este comportamiento esconde un hecho preocupante, ya que evidencia que el grueso del descenso del indicador de abandono escolar temprano lo ha protagonizado el alumnado titulado en ESO, mientras que los que no han alcanzado dicha titulación, y que por tanto engrosan también el indicador de fracaso escolar, no han experimentado una evolución tan favorable, ya que aún se encuentra por encima de los niveles del año 2002. Es decir, como bien recoge el análisis realizado por Felgueroso (2015), si bien en los últimos años se ha conseguido aumentar la proporción de individuos que tras conseguir el título de ESO prosigue estudiando, esta relación ha permanecido prácticamente inalterable para el caso de los que no han alcanzado la titulación de ESO.

Desagregando la información anterior por edades se pueden observar diferencias, especialmente en el caso de los individuos no titulados, cuya evolución 
aparece reflejada en el siguiente Gráfico 4.12 Como se puede comprobar, el comportamiento es desigual e irregular para las distintas edades. Por un lado, en los primeros años se da una ordenación inversa a la anteriormente apuntada, según la cual las categorías de edad más jóvenes presentan un mayor nivel de abandono escolar temprano. Se trata de un comportamiento carente de lógica a priori, al que es necesario dar respuesta. Como se analizará en el siguiente capítulo, es posible que durante este primer periodo el mercado laboral haya ejercido de factor de expulsión del sistema educativo, y que ese poder de atracción haya tomado una mayor dimensión en la población más joven.

\section{Gráfico 4.12. Evolución de las tasas de abandono escolar temprano de los individuos no titulados en ESO, según edad (años 2002-2013, \%)}

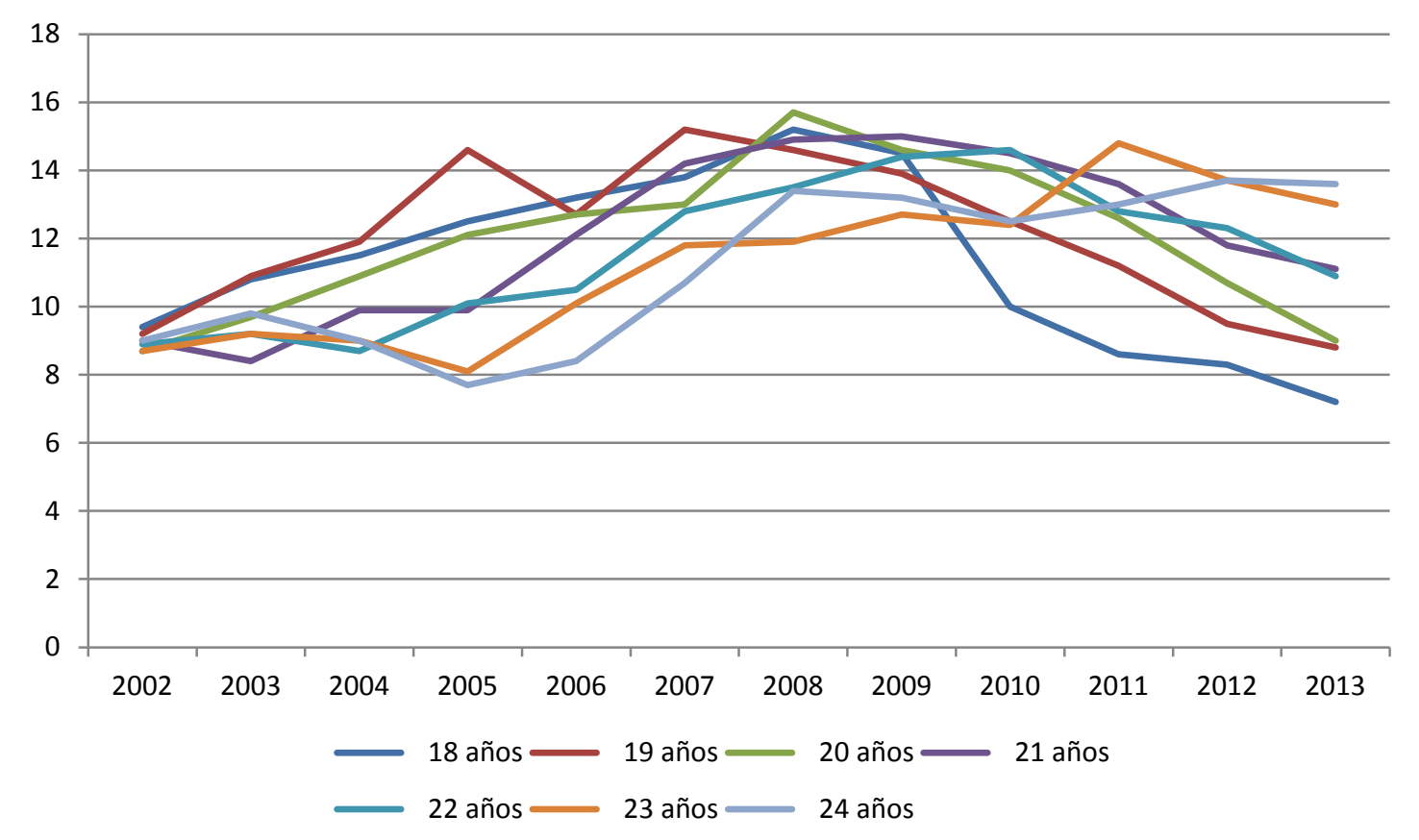

Fuente: Elaboración propia a partir de datos de MECD

A partir del año 2009 esta ordenación se invierte, siendo los más jóvenes sin titular los que presentan comparativamente unas menores tasas de abandono escolar temprano respecto a los individuos de mayor edad. Esta ordenación es más coherente con las tasas del indicador global. De la misma forma, para el caso de los alumnos titulados, la ordenación es similar (ver Gráfico 4.13), sin cambios notables salvo los ya apuntados con anterioridad. 
Gráfico 4.13. Evolución de las tasas de abandono escolar temprano de los individuos titulados en ESO, según edad (años 2002-2013, \%)

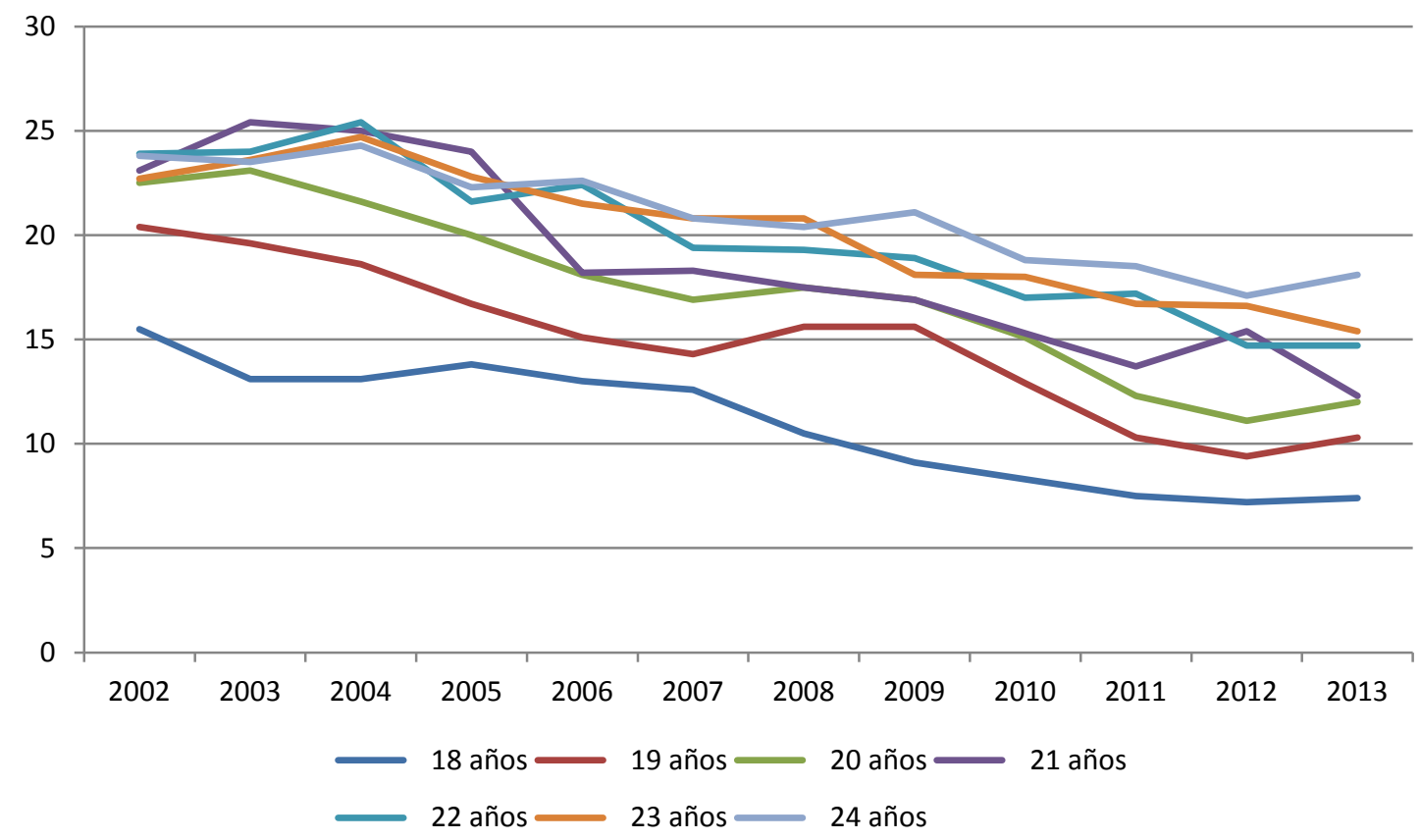

Fuente: Elaboración propia a partir de datos de MECD

En cuanto a las diferencias entre ocupados y no ocupados, en el Gráfico 4.14 se puede comprobar que han presentado dos evoluciones notablemente dispares. Por un lado, el nivel de abandono escolar temprano de los ocupados se ha mantenido constante y por encima del $20 \%$ hasta el año 2008 , momento en el que el indicador comienza a descender pronunciadamente hasta niveles inferiores al $10 \%$. Por otro lado, los no ocupados han registrado unas tasas de abandono escolar temprano en torno al $10 \%$ hasta el 2007 , año en el que se produce un notable aumento hasta alcanzar el 15\% en el 2009, manteniéndose en niveles similares hasta el año 2013. 
Gráfico 4.14. Evolución de las tasas de abandono escolar temprano según su ocupación (años 2002-2013, \%)

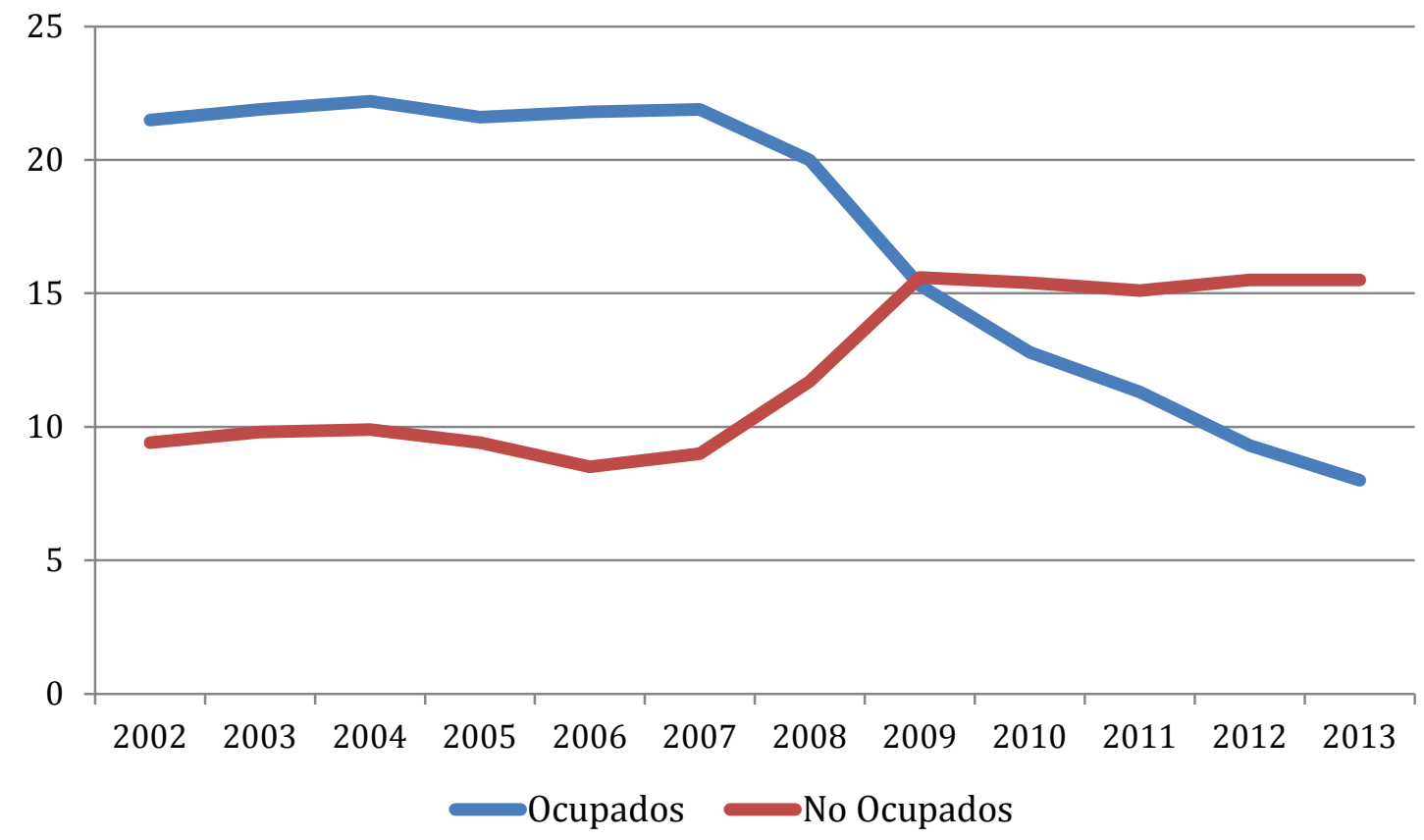

Fuente: Elaboración propia a partir de datos de MECD

Estos comportamientos en principio singulares esconden cierta lógica, ya que hasta el año 2008, la alta demanda de empleo no cualificado ha podido incidir en el hecho de que los ocupados sean los que mayores tasas de abandono escolar temprano registraban, ya que el continuar estudiando presentaba un coste de oportunidad mayor; mientras que los no ocupados, al no disponer de trabajo, tienen, además de un menor coste de oportunidad a la hora de formarse, un incentivo para cualificarse y acceder posteriormente al mercado de trabajo.

En el segundo periodo, a partir de 2008, la inversión de las tendencias puede explicarse, en parte, por la recesión económica, que ha supuesto la destrucción de numerosos puestos de trabajo, especialmente en sectores poco intensivos en mano de obra cualificada. Este hecho ha podido incidir en la motivación para continuar formándose de los jóvenes ocupados, que perciben que es necesaria una formación más allá de la Educación Secundaria Obligatoria. En el caso de los no ocupados, es probable que el aumento de abandonos registrados, a partir del año 2008, responda a un intercambio de flujo de los ocupados, es decir, que aquellos que antes de la crisis se englobaban dentro del abandono escolar temprano, a partir del 2008 se hayan quedado sin ocupación y no hayan retomado ningún tipo de estudios o formación. 
Otro de los elementos que permite observar la desagregación de datos son las diferencias en la tasa de abandono escolar temprano, según la nacionalidad de los individuos, cuya evolución aparece reflejada en el Gráfico 4.15. Como se puede comprobar, la evolución de los individuos de nacionalidad española y extranjera es muy similar, con una diferencia notable y constante en el tiempo, estando de esta forma la tasa de abandono escolar temprano veinte puntos por encima en el caso de los jóvenes de nacionalidad extranjera, en consonancia con los resultados obtenidos por otros trabajos como el realizado por Mora Corral (2010), Calero et al. (2010) o Serrano y Soler (2014).

Gráfico 4.15. Evolución de las tasas de abandono escolar temprano según su nacionalidad (años 2002-2013, \%)

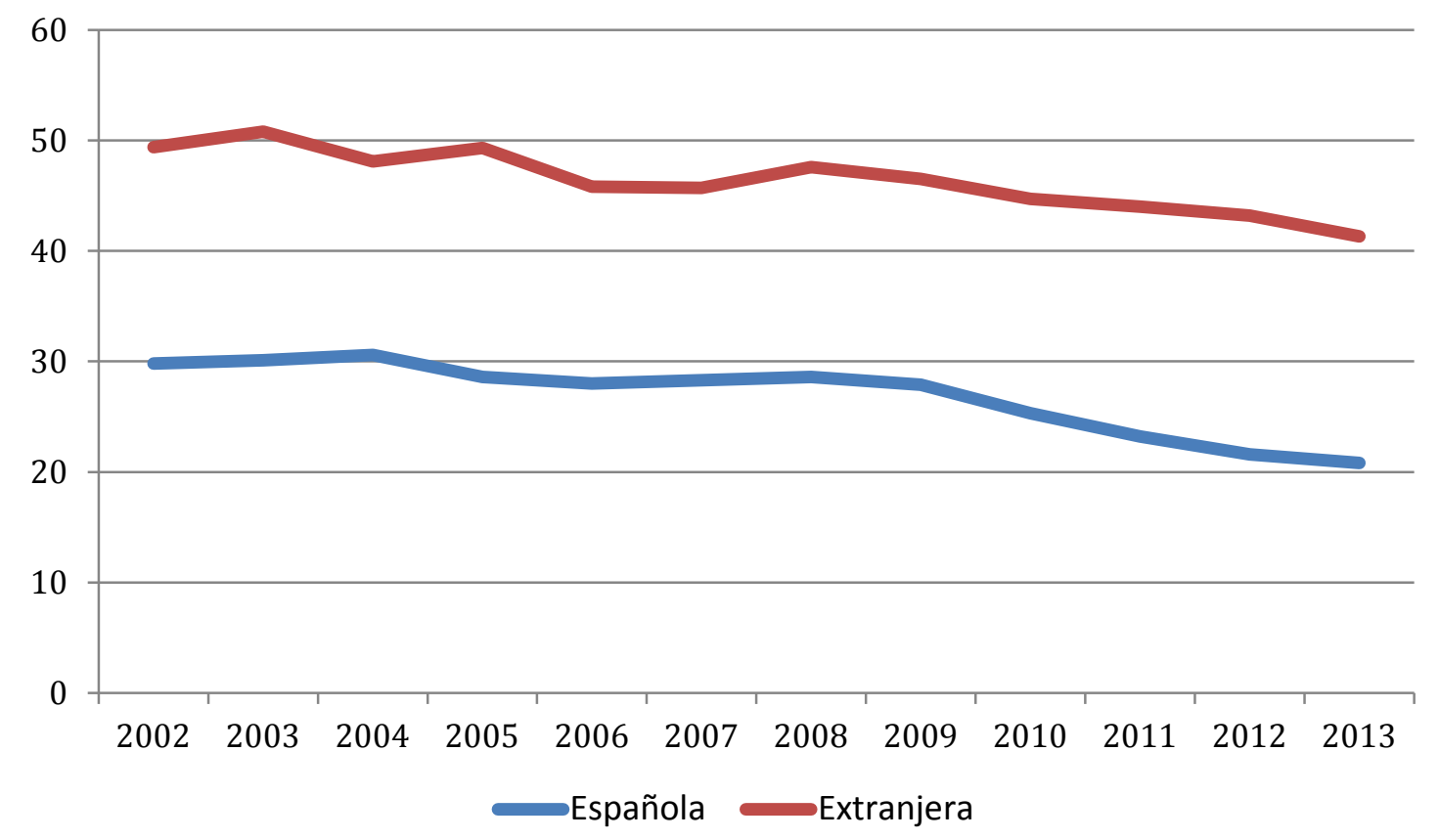

Fuente: Elaboración propia a partir de datos de MECD

Por último, la desagregación estadística ofrecida por el MECD permite diferenciar la tasa de abandono escolar temprano de los jóvenes, según el nivel de titulación máxima alcanzada por la madre. Así pues, el Gráfico 4.16 muestra la evolución del indicador según los estudios de la madre en el periodo 2002 - 2013. La evolución de cada categoría es relativamente estable, sin embargo son muy destacables las diferencias entre cada categoría, de forma que para cada nivel de titulación alcanzado por la madre se produce un salto notable con respecto al anterior. 


\section{Gráfico 4.16. Evolución de las tasas de abandono escolar temprano según nivel de estudios máximos alcanzados por la madre (años 2002-2013, \%)}

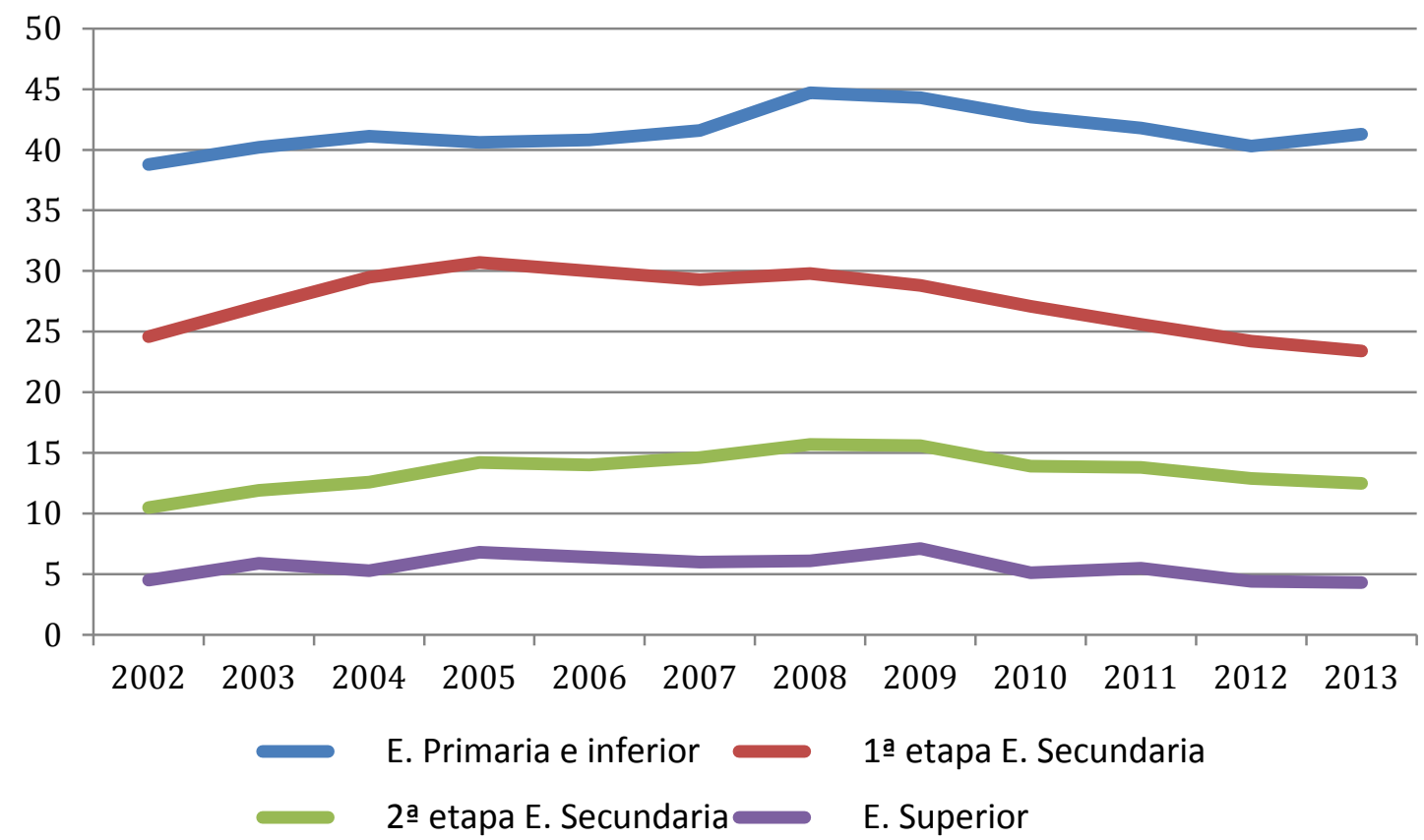

Fuente: Elaboración propia a partir de datos de MECD

Como se puede observar, mientras que en el caso de los individuos cuya madre había alcanzado estudios superiores, la tasa de abandono escolar temprano ha oscilado en torno al $5 \%$ durante todo el periodo; en el caso de los individuos con madres con estudios de educación secundaria de segunda etapa, estos se encontraban con tasas de abandono de entre el $10 \%$ y el $15 \%$. Los jóvenes con madres con estudios de educación secundaria de primera etapa han registrado tasas de abandono escolar de entre el $25 \%$ y el $30 \%$; y por último, los individuos cuyas madres no tenían estudios o como máximo habían completado la educación primaria, presentan unos niveles de abandono escolar temprano de más del $40 \%$. Estos resultados están en consonancia con la mayoría de estudios de la literatura, entre los que hay un consenso amplio en cuanto a la influencia del nivel educativo de la madre (Calero et al., 2010; García Gracia, Casal Bataller, Merino Pareja y Sánchez Gelabert, 2013).

En definitiva, este análisis de la tasa de abandono escolar temprano permite establecer una radiografía del fenómeno estudiado que puede ser útil de cara a la focalización de las políticas de reducción del abandono escolar temprano. De esta forma, los sucesivos gráficos presentados denotan grandes diferencias en el indicador, que reflejan la mayor predisposición de sufrir abandono escolar de los hombres, de los 
jóvenes de nacionalidad extranjera, y de aquellos cuyas madres poseen estudios primarios o inferiores. Además, se pone de manifiesto que la proporción de abandonos entre los individuos que no poseen el título de Educación Secundaria Obligatoria no se ha visto reducida y que la dinámica del mercado laboral ha podido jugar un papel importante en la distribución de las tasas de abandono escolar temprano.

\subsection{La relación del abandono escolar temprano con otros fenómenos educativos}

En este último epígrafe del capítulo se realiza un análisis de la situación, la evolución y la relación que tienen diversos indicadores educativos con el abandono escolar temprano, con el objeto de estudiar la endogeneidad, apuntada en la revisión de la literatura realizada en el capítulo tercero de esta investigación (Fernández et al., 2010; Mena Martínez et al., 2010; Cabus y De Witte, 2013; Ross y Leathwood, 2013), que define el abandono escolar temprano como el resultado de un proceso que da señales previas, como puede ser el absentismo, el fracaso escolar, o los resultados académicos del alumnado, que conviene tener en cuenta, de forma previa al análisis de factores de entorno externos que se realiza en el siguiente capítulo. Es decir, el presente epígrafe trata de analizar hasta qué punto el indicador de abandono escolar temprano se relaciona con otros indicadores educativos que han sido señalados como complementarios al mismo.

\subsubsection{Tasas de escolarización}

Como indica Roca Cobo (2010), las tasas de escolarización y matriculación son uno de los indicadores más cercanos al abandono escolar temprano, puesto que constituyen un indicador directo de escolaridad. En concreto, representan la relación porcentual entre el alumnado de una edad determinada que está escolarizado en cualquier nivel educativo, y el total de la población de esa edad (Instituto Nacional de Evaluación Educativa, 2014b). De la misma forma, la investigación realiza por Alegre Canosa y Benito Pérez (2010) utiliza como variable complementaria al abandono 
escolar temprano la tasa de desescolarización a los 18 años $^{58}$. En este caso, el Cuadro 4.3 muestra las tasas de escolarización a los 17 años en el curso 2000/01, 2007/08 y 2012/13, así como la evolución registrada en los periodos 2000/01 - 2007/08 y 2008/09 - 2012/13, y el diferencial de cada comunidad autónoma respecto al promedio nacional $^{59}$.

Cuadro 4.3. Tasas de escolarización a los 17 años por CCAA (\%)

\begin{tabular}{|c|c|c|c|c|c|c|c|}
\hline & \multirow{2}{*}{$2000 / 01$} & \multirow{2}{*}{$2007 / 08$} & \multirow[b]{2}{*}{$2012 / 13$} & \multicolumn{3}{|c|}{$\begin{array}{c}\text { Tasa de Crecimiento Medio } \\
\text { Anual Acumulativo }\end{array}$} & \multirow{2}{*}{$\begin{array}{c}\text { Diferencial } \\
\text { interregional } \\
(\text { España }=100)\end{array}$} \\
\hline & & & & $\begin{array}{c}2000 / 01 \\
- \\
2007 / 08\end{array}$ & $\begin{array}{c}2008 / 09 \\
- \\
2012 / 13\end{array}$ & Total & \\
\hline España & 74,8 & 81,3 & 91,8 & $1,20 \%$ & $4,21 \%$ & $1,72 \%$ & 100 \\
\hline Andalucía & 72,1 & 76,0 & 97,5 & $0,75 \%$ & $6,52 \%$ & $2,54 \%$ & 106,21 \\
\hline Aragón & 79,0 & 85,5 & 88,9 & $1,14 \%$ & $2,31 \%$ & $0,98 \%$ & 96,83 \\
\hline Asturias & 88,5 & 92,6 & 90,6 & $0,65 \%$ & $0,86 \%$ & $0,19 \%$ & 98,69 \\
\hline Baleares & 64,6 & 70,2 & 78,6 & $1,20 \%$ & $5,55 \%$ & $1,64 \%$ & 85,62 \\
\hline Canarias & 74,5 & 83,5 & 86,0 & $1,64 \%$ & $3,16 \%$ & $1,20 \%$ & 93,66 \\
\hline Cantabria & 82,0 & 91,0 & 89,8 & $1,50 \%$ & $0,72 \%$ & $0,76 \%$ & 97,91 \\
\hline Castilla y León & 86,5 & 90,4 & 92,9 & $0,64 \%$ & $1,79 \%$ & $0,59 \%$ & 101,20 \\
\hline Castilla-La Mancha & 68,4 & 81,0 & 89,5 & $2,44 \%$ & $4,13 \%$ & $2,26 \%$ & 97,49 \\
\hline Cataluña & 68,8 & 78,6 & 90,6 & $1,92 \%$ & $3,86 \%$ & $2,32 \%$ & 98,76 \\
\hline C. Valenciana & 66,6 & 76,7 & 88,8 & $2,03 \%$ & $5,46 \%$ & $2,43 \%$ & 96,77 \\
\hline Extremadura & 71,9 & 84,6 & 89,4 & $2,35 \%$ & $3,69 \%$ & $1,83 \%$ & 97,38 \\
\hline Galicia & 81,1 & 90,2 & 93,0 & $1,53 \%$ & $3,33 \%$ & $1,15 \%$ & 101,37 \\
\hline Madrid & 80,4 & 83,2 & 92,6 & $0,48 \%$ & $4,48 \%$ & $1,18 \%$ & 100,90 \\
\hline Murcia & 67,5 & 76,5 & 86,3 & $1,81 \%$ & $3,70 \%$ & $2,06 \%$ & 94,00 \\
\hline Navarra & 81,1 & 85,4 & 91,1 & $0,75 \%$ & $1,18 \%$ & $0,97 \%$ & 99,27 \\
\hline País Vasco & 90,3 & 98,8 & 98,2 & $1,29 \%$ & $0,70 \%$ & $0,70 \%$ & 107,02 \\
\hline Rioja & 78,5 & 81,9 & 91,9 & $0,60 \%$ & $5,25 \%$ & $1,32 \%$ & 100,17 \\
\hline C.V..$^{60}$ & 0,104 & 0,086 & 0,049 & & & & \\
\hline
\end{tabular}

Fuente: Elaboración propia a partir de datos de MECD

Como se puede observar, en los trece cursos que se recogen se ha registrado un aumento medio de la tasa de escolarización a los 17 años del 1,72\% medio anual

${ }^{58}$ La tasa de desescolarización a los 18 años es la proporción de jóvenes que a esa edad se encuentran fuera del sistema educativo. En el trabajo citado, se utiliza este indicador como variable independiente, de forma que se utilizan las mismas variables explicativas para el abandono escolar temprano y las tasas de desescolarización a los 18 años, estableciendo una comparativa entre las mismas, dada su proximidad conceptual.

${ }^{59}$ Para reflejar las diferencias regionales, se ha realizado un índice con base 100 (Dato España $=100$ ). Para ver los datos del periodo 2000/01 - 2012/13 al completo ir al Cuadro Alll.3 del Anexo III.

${ }^{60}$ Coeficiente de variación de Pearson. 
para el conjunto de España, siendo este aumento más intenso durante el segundo periodo 2008/09 - 2012/13. Para el último curso escolar para el que existen datos disponibles (2012/13), la tasa de escolarización a los 17 años alcanza el 91,8\%, aunque existen diferencias regionales.

País Vasco y Andalucía presentan las tasas de escolarización a los 17 años más altas (98,2\% y $97,5 \%$ respectivamente), siendo esta última la región que ha registrado una evolución más favorable en todo el periodo estudiado. Por el contrario, Canarias y Murcia son las comunidades con tasas de escolarización a esta edad más bajas, pese a que han conseguido también mejorar el indicador, de forma sensible, especialmente en el segundo periodo considerado. Conviene señalar que es necesario tomar con cierta cautela estos datos, puesto que pueden esconder realidades muy diferentes, ya que, como apuntan Fernández et al. (2010), una parte de los alumnos que se encuentran escolarizados lo están porque llevan retraso académico, por lo que es necesario complementar este indicador junto a otros como las tasas de idoneidad o de graduación.

En cuanto a la relación de las tasas de escolarización con el abandono escolar temprano, el Gráfico 4.17 revela que existe cierta relación entre ambos indicadores, aunque la capacidad explicativa de la regresión lineal se limita al 34\%. Para realizar la regresión, se ha tenido en cuenta el último año con información disponible y consolidada sobre abandono escolar temprano (2013) y la tasa de escolarización a los 17 años para el curso 2011/12, de forma que la variable explicativa se incluye con un retardo de un año, puesto que captura el indicador a los 17 años, que es la edad un año menor a la mínima que recoge la franja del indicador de abandono escolar temprano (18 - 24 años). Se observa que aquellas comunidades que tienen mayores tasas de escolarización a los 17 años, tienden a presentar menores tasas de abandono escolar temprano. 
Gráfico 4.17. Tasa de abandono escolar temprano versus tasa de escolarización a los 17 años

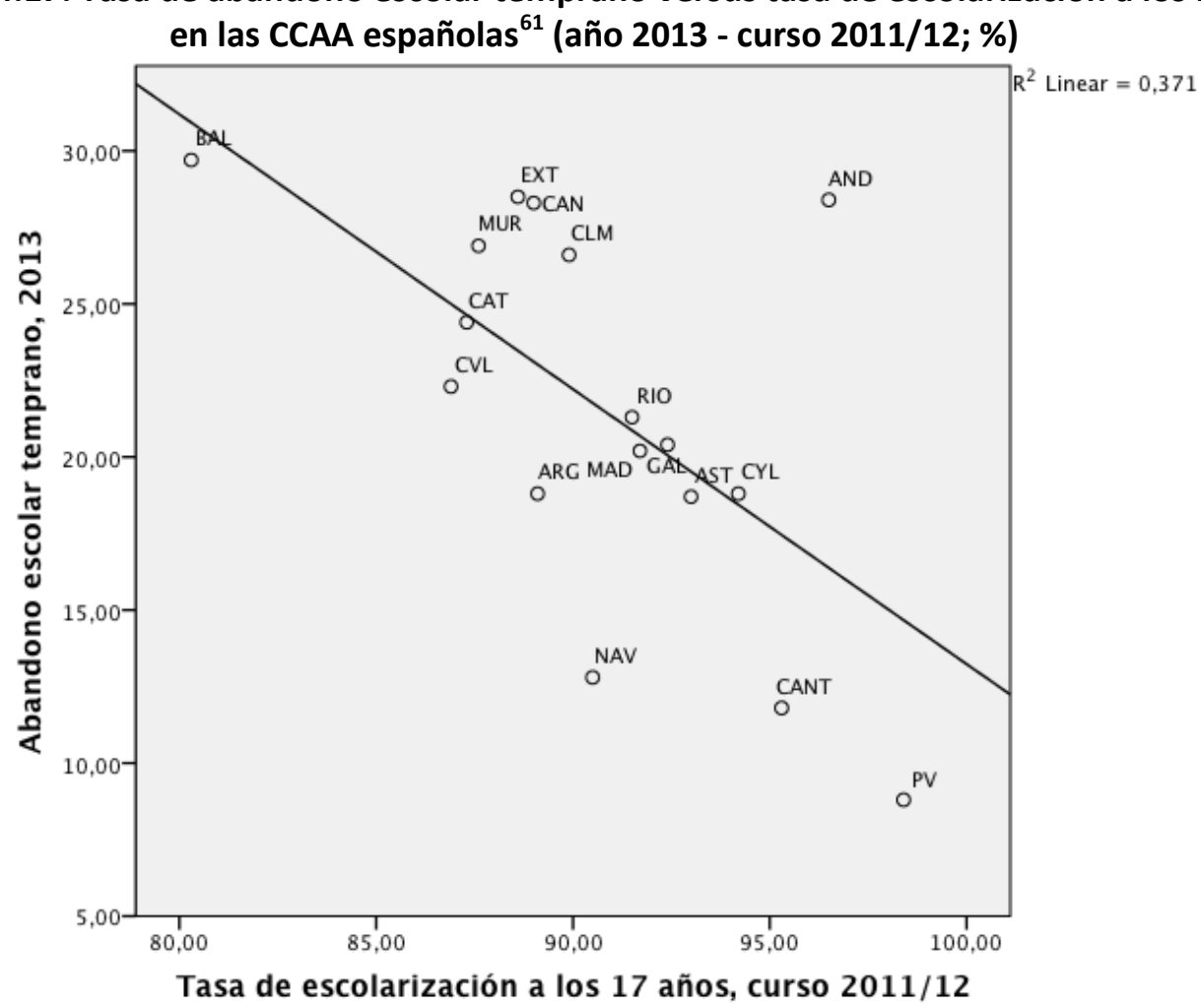

Fuente: Elaboración propia a partir de datos de MECD

\subsubsection{Esperanza de vida escolar}

La esperanza de vida escolar es un indicador que estima, a la edad de seis años, el número de años que, previsiblemente, los individuos van a estar escolarizados en el sistema educativo en todas sus etapas ${ }^{62}$. Es por tanto, un indicador que suministra información sobre el tiempo que se espera que los individuos permanezcan en el sistema educativo, independientemente del nivel educativo que estos alcancen.

El Cuadro 4.4 muestra la evolución y diferencias regionales en el indicador de la esperanza de vida escolar a los seis años. Como se puede apreciar, en los trece cursos

\footnotetext{
${ }^{61}$ La descripción de las siglas de las distintas comunidades autónomas se relacionan en la sección de Abreviaturas de la página 375.

${ }^{62}$ Para realizar el cálculo, se divide por 100 la suma de las tasas de escolarización del alumnado de entre 6 a 24 años matriculado. Se consideran las enseñanzas de régimen general universitarias y no universitarias, los ciclos formativos de artes plásticas y diseño, las enseñanzas artísticas superiores y las enseñanzas deportivas de régimen especial (Instituto de Evaluación, 2011).
} 
contemplados $^{63}$, el indicador ha pasado de 14,6 años en el curso 2000/01 a 17 años en el curso 2012/13, lo cual se traduce en que, en promedio, es previsible que un alumno de seis años de edad permanezca escolarizado hasta los 23 años, edad a la que, teóricamente, el alumnado se encuentra cursando estudios superiores. No obstante, el indicador no ofrece información acerca del grado de éxito o fracaso del alumnado, por lo que hay que tomar con precaución estos datos.

\begin{tabular}{|c|c|c|c|c|c|c|c|}
\hline & \multirow[b]{2}{*}{$2000 / 01$} & \multirow[b]{2}{*}{$2007 / 08$} & \multirow[b]{2}{*}{$2012 / 13$} & \multicolumn{3}{|c|}{$\begin{array}{c}\text { Tasa de Crecimiento Medio } \\
\text { Anual Acumulativo }\end{array}$} & \multirow{2}{*}{$\begin{array}{c}\text { Diferencial } \\
\text { interregional } \\
(\text { España = 100) }\end{array}$} \\
\hline & & & & \begin{tabular}{|c|}
$2000 / 01$ \\
- \\
$2007 / 08$ \\
\end{tabular} & $\begin{array}{c}2008 / 09 \\
- \\
2012 / 13\end{array}$ & Total & \\
\hline España & 14,6 & 15,9 & 17,0 & $1,20 \%$ & $4,10 \%$ & $1,28 \%$ & 100 \\
\hline Andalucía & 14,3 & 15,4 & 16,7 & $1,11 \%$ & $4,06 \%$ & $1,31 \%$ & 98,17 \\
\hline Aragón & 14,9 & 15,5 & 16,8 & $0,64 \%$ & $3,64 \%$ & $1,01 \%$ & 98,58 \\
\hline Asturias & 15,3 & 16,1 & 17,1 & $0,77 \%$ & $3,55 \%$ & $0,94 \%$ & 100,43 \\
\hline Baleares & 13,0 & 13,7 & 14,5 & $0,78 \%$ & $4,56 \%$ & $0,97 \%$ & 85,52 \\
\hline Canarias & 14,1 & 15,5 & 16,2 & $1,30 \%$ & $4,78 \%$ & $1,17 \%$ & 95,49 \\
\hline Cantabria & 14,5 & 15,3 & 16,7 & $0,75 \%$ & $3,77 \%$ & $1,18 \%$ & 98,06 \\
\hline Castilla y León & 15,6 & 16,8 & 18,1 & $1,04 \%$ & $4,05 \%$ & $1,25 \%$ & 106,39 \\
\hline Castilla-La Mancha & 13,6 & 14,5 & 15,6 & $0,93 \%$ & $3,76 \%$ & $1,21 \%$ & 92,03 \\
\hline Cataluña & 14,3 & 15,3 & 16,9 & $1,01 \%$ & $4,10 \%$ & $1,44 \%$ & 99,54 \\
\hline C. Valenciana & 14,3 & 15,4 & 17,2 & $1,10 \%$ & $5,08 \%$ & $1,53 \%$ & 100,88 \\
\hline Extremadura & 14,0 & 15,4 & 16,0 & $1,37 \%$ & $3,55 \%$ & $1,16 \%$ & 94,34 \\
\hline Galicia & 15,0 & 16,1 & 17,2 & $0,98 \%$ & $3,87 \%$ & $1,15 \%$ & 101,08 \\
\hline Madrid & 15,4 & 16,4 & 18,2 & $0,86 \%$ & $4,97 \%$ & $1,40 \%$ & 107,04 \\
\hline Murcia & 14,0 & 15,0 & 16,7 & $0,97 \%$ & $4,32 \%$ & $1,46 \%$ & 98,27 \\
\hline Navarra & 14,6 & 15,7 & 16,7 & $1,03 \%$ & $2,77 \%$ & $1,13 \%$ & 98,27 \\
\hline País Vasco & 15,4 & 17,3 & 18,2 & $1,64 \%$ & $4,16 \%$ & $1,40 \%$ & 107,22 \\
\hline Rioja & 14,3 & 14,8 & 18,4 & $0,49 \%$ & $7,66 \%$ & $2,10 \%$ & 108,13 \\
\hline C.V. & 0,049 & 0,054 & 0,059 & & & & \\
\hline
\end{tabular}

Fuente: Elaboración propia a partir de datos de MECD

Madrid, País Vasco y La Rioja son las comunidades con una esperanza de vida escolar a los seis años más alta, ya que se encuentran por encima de los 18 años, siendo La Rioja además la comunidad que mejor evolución ha experimentado, pasando de los 14,3 años en el curso 2000/01 a los 18,4 años del curso 2012/13. Por el contrario, Baleares destaca al presentar tan sólo 14,5 años en este indicador para el curso 2012/13, además de registrar la peor evolución.

${ }^{63}$ Para conocer los datos para el periodo completo (cursos 2000/01 - 2012/13), ver Cuadro Alll.4 del Anexo III. 
El Gráfico 4.18 refleja la importante relación que presentan el abandono escolar temprano y la esperanza de vida escolar a los seis años. En este caso, se ha utilizado un retardo mucho mayor, puesto que el segundo indicador está calculado a la edad teórica de seis años ${ }^{64}$. Como se puede observar, la bondad del ajuste alcanza el $49 \%$, quedando patente que las comunidades autónomas que en el curso escolar 2000/01 presentaban una esperanza de vida escolar a los seis años más alta tienden, en el año 2013, a registrar menores tasas de abandono escolar temprano.

Gráfico 4.18. Tasa de abandono escolar temprano versus esperanza de vida escolar a los seis años en las CCAA españolas (año 2013 - curso 2000/01; \%)

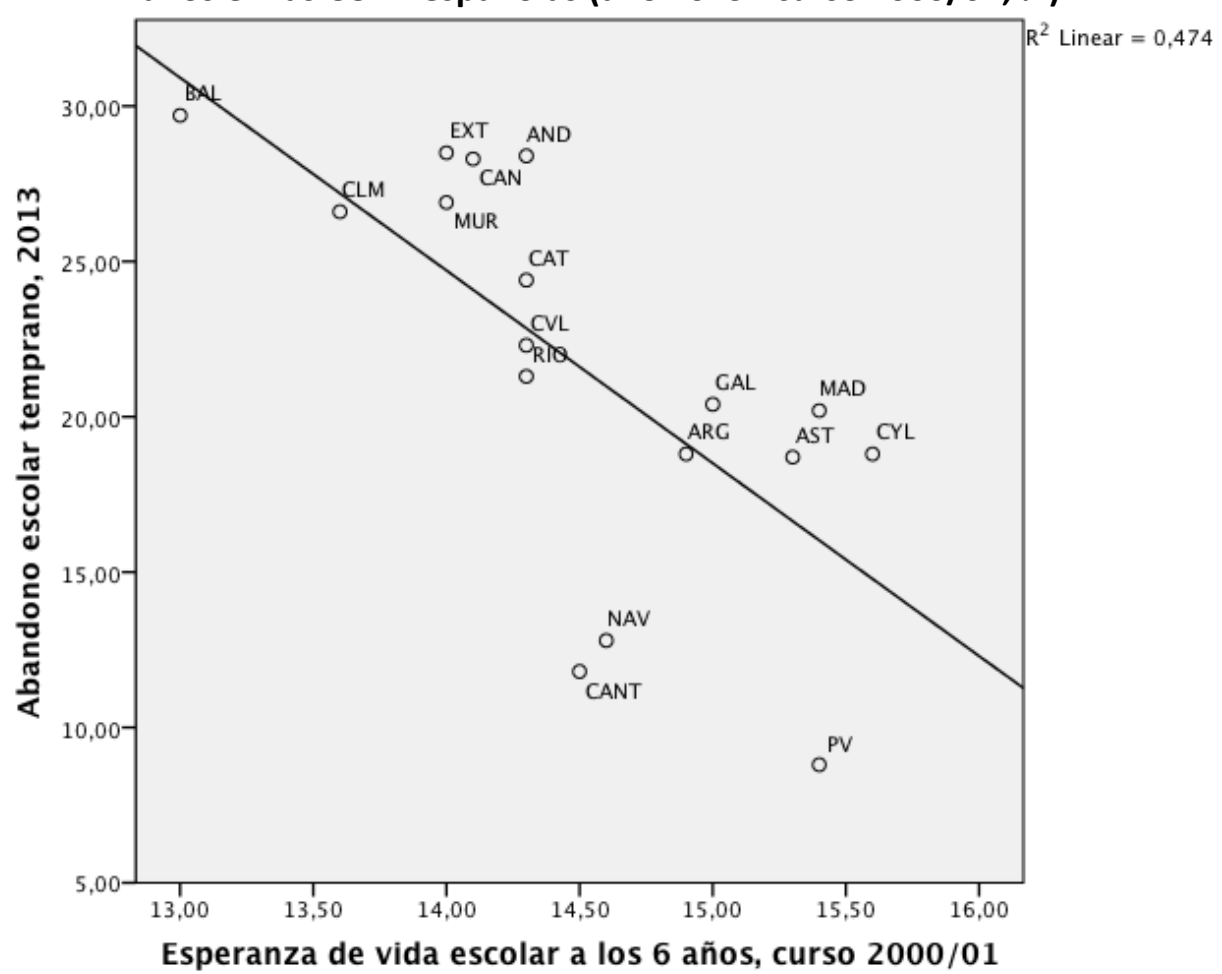

Fuente: Elaboración propia a partir de datos de MECD

De este resultado se puede derivar que el abandono escolar temprano puede tener su reflejo o dar señales previas en un periodo muy prematuro, como es la etapa de educación primaria. En este sentido, Fernández et al. (2010) apuntan que los problemas relacionados con el fracaso y el abandono escolar comienzan a manifestarse durante las primeras etapas de escolarización. No obstante, es necesario tomar en consideración que para el cálculo de este indicador se tienen en cuenta las

\footnotetext{
${ }^{64}$ El retardo es de 12 cursos en la variable explicativa.
} 
tasas de escolarización de diversas cohortes de edad (de 6 a 24 años), por lo que no es posible determinar si existe un efecto diferencial a una edad teórica determinada.

Por otro lado, Prats et al. (2005) señalan que, en el conjunto de sistemas educativos europeos, existe una estrecha relación entre la esperanza de vida en el sistema educativo y las características socio-culturales del entorno del alumnado. Como se comprueba en el capítulo cinco de la presente investigación, esta relación también está presente si se utiliza el abandono escolar temprano como variable dependiente.

\subsubsection{Tasas de idoneidad}

Las tasas de idoneidad representan la proporción de alumnado que se encuentra matriculado en el curso que le corresponde a la edad teórica que se considere (Instituto Nacional de Evaluación Educativa, 2014b), por lo que, además de medir grado de escolarización, también incorpora una medición del grado de éxito escolar, puesto que refleja el grado de repetición del alumnado, concepto que está estrechamente ligado con el fracaso y abandono escolar (Cordero Ferrera, Manchón López y Simancas Rodríguez, 2014).

En el Cuadro 4.5 se refleja la evolución y situación regional de la tasa de idoneidad a los quince años, edad a la que teóricamente el alumnado se debe de encontrar cursando el cuarto curso de la ESO, segundo de BUP (Bachillerato Unificado Polivalente) o segundo de FPI (Formación Profesional Inicial), según el régimen de estudios que se considere.

En el promedio nacional, se ha registrado una diferencia de tendencia entre los dos periodos de tiempo considerados, que tiene su punto de inflexión en el curso 2007/08, momento en el que la tasa de idoneidad a los quince años comienza a crecer, después de haberse reducido a un ritmo de 1,29\% medio anual acumulativo entre los cursos 2000/01 y 2007/08. De esta forma, en el curso 2012/13 la tasa de idoneidad a los quince años se sitúa en el $62,5 \%$, lo que supone que un $37,5 \%$ del alumnado de esa edad no se encuentra escolarizado en el curso que teóricamente le corresponde. Como apuntan Fernández et al. (2010), ello se debe a que el alumnado acumula un 
importante grado de repetición desde la educación primaria. Conviene señalar también que España es uno de los países de la OCDE con mayor tasa de repetición en su alumnado (OECD, 2014c).

\begin{tabular}{|c|c|c|c|c|c|c|c|}
\hline \multicolumn{8}{|c|}{ Cuadro 4.5. Tasas de idoneidad a los quince años por CCAA $(\%)^{65}$} \\
\hline & \multirow[b]{2}{*}{ 2000/01 } & \multirow[b]{2}{*}{$2007 / 08$} & \multirow[b]{2}{*}{$2012 / 13$} & \multicolumn{3}{|c|}{$\begin{array}{l}\text { Tasa de Crecimiento Medio } \\
\text { Anual Acumulativo }\end{array}$} & \multirow{2}{*}{$\begin{array}{c}\text { Diferencial } \\
\text { interregional } \\
(\text { España }=100)\end{array}$} \\
\hline & & & & \begin{tabular}{|c|}
$2000 / 01$ \\
- \\
$2007 / 08$ \\
\end{tabular} & \begin{tabular}{|c|}
$2008 / 09$ \\
- \\
$2012 / 13$ \\
\end{tabular} & Total & \\
\hline España & 63,2 & 57,7 & 62,5 & $-1,29 \%$ & $1,57 \%$ & $-0,10 \%$ & 100 \\
\hline Andalucía & 57,3 & 51,1 & 58,0 & $-1,62 \%$ & $1,93 \%$ & $0,10 \%$ & 92,81 \\
\hline Aragón & 63,4 & 57,4 & 60,3 & $-1,41 \%$ & $1,23 \%$ & $-0,42 \%$ & 96,50 \\
\hline Asturias & 65,4 & 59,2 & 66,7 & $-1,41 \%$ & $1,21 \%$ & $0,17 \%$ & 106,83 \\
\hline Baleares & 53,2 & 54,0 & 56,3 & $0,21 \%$ & $2,10 \%$ & $0,47 \%$ & 90,09 \\
\hline Canarias & 58,4 & 49,5 & 57,4 & $-2,33 \%$ & $2,36 \%$ & $-0,14 \%$ & 91,92 \\
\hline Cantabria & 60,3 & 57,6 & 63,3 & $-0,65 \%$ & $1,63 \%$ & $0,40 \%$ & 101,27 \\
\hline Castilla y León & 59,3 & 56,8 & 61,7 & $-0,61 \%$ & $1,66 \%$ & $0,34 \%$ & 98,83 \\
\hline Castilla-La Mancha & 56,6 & 53,5 & 56,8 & $-0,80 \%$ & $1,21 \%$ & $0,03 \%$ & 90,88 \\
\hline Cataluña & 83,5 & 69,4 & 73,7 & $-2,61 \%$ & $1,48 \%$ & $-1,04 \%$ & 117,97 \\
\hline C. Valenciana & 61,1 & 55,3 & 59,1 & $-1,41 \%$ & $1,10 \%$ & $-0,27 \%$ & 94,66 \\
\hline Extremadura & 56,6 & 50,9 & 57,8 & $-1,50 \%$ & $1,76 \%$ & $0,18 \%$ & 92,53 \\
\hline Galicia & 57,7 & 59,6 & 63,0 & $0,46 \%$ & $1,34 \%$ & $0,73 \%$ & 100,80 \\
\hline Madrid & 62,0 & 60,2 & 63,1 & $-0,42 \%$ & $1,50 \%$ & $0,15 \%$ & 101,08 \\
\hline Murcia & 56,8 & 52,8 & 55,6 & $-1,04 \%$ & $1,16 \%$ & $-0,18 \%$ & 89,02 \\
\hline Navarra & 72,6 & 66,9 & 68,9 & $-1,16 \%$ & $0,67 \%$ & $-0,43 \%$ & 110,34 \\
\hline País Vasco & 71,8 & 70,6 & 72,8 & $-0,24 \%$ & $0,37 \%$ & $0,11 \%$ & 116,48 \\
\hline Rioja & 63,8 & 57,3 & 59,1 & $-1,52 \%$ & $0,71 \%$ & $-0,63 \%$ & 94,68 \\
\hline C.V. & 0,121 & 0,108 & 0,090 & & & & \\
\hline
\end{tabular}

Fuente: Elaboración propia a partir de datos de MECD

Las comunidades cuyo alumnado presenta mejores tasas de idoneidad son, para el curso 2012/13, Cataluña y País Vasco, ya que un $73,7 \%$ y $72,8 \%$ respectivamente de su alumnado de quince años se encuentra cursando el nivel de estudios que teóricamente le corresponde. No obstante, es preciso señalar que Cataluña ha registrado una evolución irregular con comportamientos dispares entre los dos periodos recogidos, mientras que País Vasco ha mantenido estable su tasa de idoneidad a los quince años con valores de entre el $70 \%$ y el $73 \%$. Por el contrario, las comunidades autónomas de Andalucía, Baleares, Canarias, Castilla-La Mancha,

${ }^{65}$ Para conocer los datos para el periodo completo (cursos 2000/01 - 2012/13), ver Cuadro Alll.5 del Anexo III. 
Extremadura y Murcia se encuentran, todas ellas, por debajo del $93 \%$ en la tasa de idoneidad a los quince años.

Al igual que ocurre con el resto de indicadores hasta ahora estudiados, la tasa de idoneidad a los quince años también presenta una relación estrecha y negativa con el abandono escolar temprano (con una bondad de ajuste del $52,1 \%$ ), como se puede comprobar en el Gráfico $4.19^{66}$, de forma que las comunidades autónomas en las que se registra una mayor tasa de idoneidad tienden a presentar una menor tasa de abandono escolar temprano.

Gráfico 4.19. Tasa de abandono escolar temprano versus tasa de idoneidad a los quince años en las CCAA españolas (año 2013 - curso 2009/10; \%)

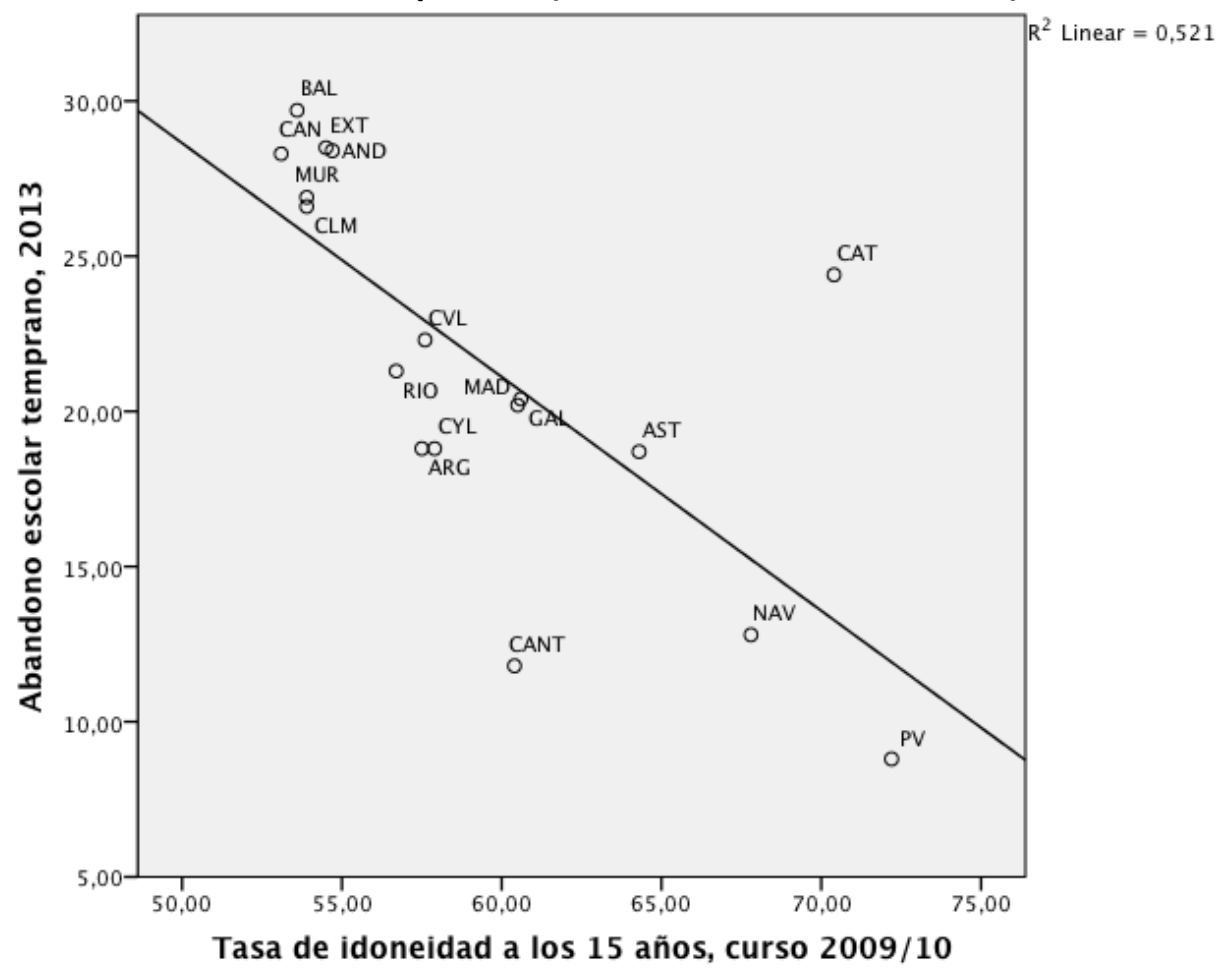

Fuente: Elaboración propia a partir de datos de MECD

Estos resultados apoyan la hipótesis de que el abandono escolar temprano da señales previas, ya que existe una importante proporción de alumnado que a los quince años ha repetido en alguna ocasión, lo que supone que los malos resultados académicos se empiezan a fraguar con cierta antelación y a una edad en la que los condicionamientos externos que puede suponer el mercado laboral son, en principio,

${ }^{66}$ En este caso, se ha utilizado un retardo de tres años, que es la diferencia entre el primer año de la franja que captura el indicador de abandono escolar temprano (los 18 años) y la edad teórica a la que está calculada la tasa de idoneidad (15 años). 
menores. Además, la tasa de idoneidad refleja un alto grado de repetición entre el alumnado, hecho que el informe PISA ha señalado como práctica costosa y poco eficaz de cara a combatir el fracaso y abandono escolar (OECD, 2014c).

\subsubsection{Tasas de graduación}

Las tasas de graduación constituyen otro indicador que muestra el grado de éxito educativo, puesto que refleja la relación de alumnado que consigue graduarse en un determinado nivel educativo, independientemente de su edad, respecto a la población total de la franja de edad teórica a la que se debería conseguir el mismo. Es por tanto, un indicador que puede anticipar una mayor o menor tendencia a abandonar de forma temprana el sistema educativo y que está también estrechamente relacionado con las tasas de idoneidad. Como señalan Rumberger y Lim (2008), la mayoría de estudios concluyen que las tasas de graduación tienen un efecto significativo sobre el abandono escolar temprano.

En este caso, se utiliza la tasa bruta de graduación en ESO, que se define como la relación entre el alumnado que termina con éxito esta etapa educativa, independientemente de su edad, y el total de población de 15 años, edad teórica de comienzo del último curso (Instituto Nacional de Evaluación Educativa, 2014b), cuyos datos se reflejan en el Cuadro $4.6 .^{67}$

${ }^{67}$ Para conocer los datos para el periodo completo (cursos 2000/01 - 2012/13), ver Cuadro Alll.6 del Anexo III. 
Cuadro 4.6. Tasas brutas de graduación en ESO por CCAA (\%)

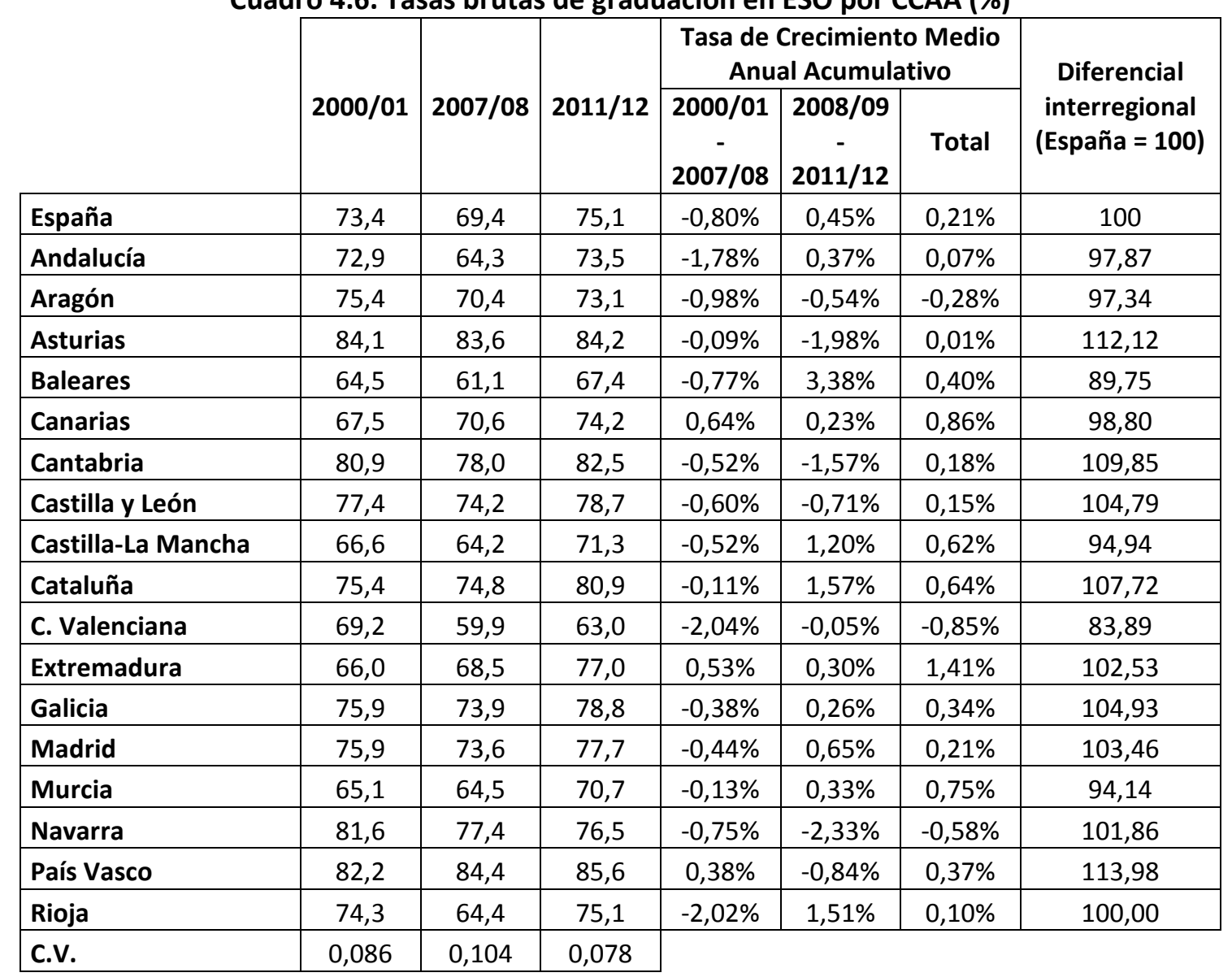

Fuente: Elaboración propia a partir de datos de MECD

País Vasco, con un $85,6 \%$ y Asturias, con un $84,2 \%$, son las regiones con mejores resultados en la tasa bruta de graduación en ESO para el curso 2011/12, último con datos disponibles, habiendo destacado por presentar una evolución estable. Por su parte, Comunidad Valenciana sobresale al registrar una tasa de graduación muy por debajo del promedio nacional (63\% frente a $75,1 \%)$.

El Gráfico 4.20 muestra la relación entre la tasa bruta de graduación en ESO y el abandono escolar temprano ${ }^{68}$. Como se puede observar, la relación es negativa, puesto que aquellas comunidades con mejores resultados en graduación en ESO tienden a registrar tasas de abandono escolar temprano más bajas, siendo Comunidad Valenciana una de las tres regiones que ha reducido este indicador respecto a la

${ }^{68} \mathrm{Al}$ igual que en el caso de la tasa de idoneidad a los 15 años, se ha utilizado un retardo de tres años, que es la diferencia entre el primer año de la franja que captura el indicador de abandono escolar temprano (los 18 años) y la edad teórica a la que está calculada la tasa bruta de graduación en ESO (15 años). 
situación del curso 2000/01, junto a Aragón y Navarra, que sin embargo presentan una situación mucho más favorable. La bondad de ajuste, por otro lado, asciende a casi el $60 \%$.

Gráfico 4.20. Tasa de abandono escolar temprano versus tasa bruta de graduación en ESO en las CCAA españolas (año 2013 - curso 2009/10; \%)

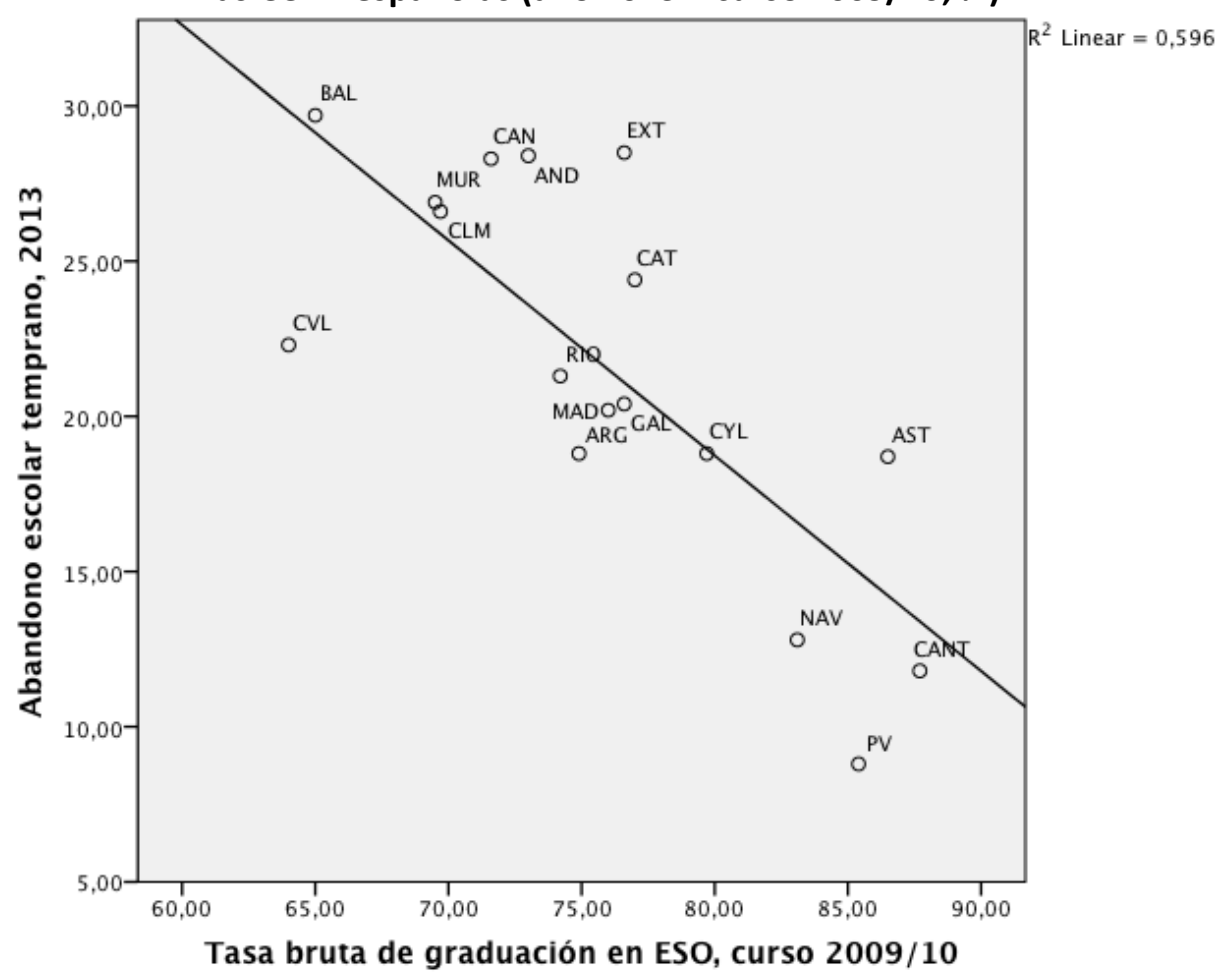

Fuente: Elaboración propia a partir de datos de MECD

\subsubsection{Resultados de los test de competencias}

En este epígrafe, se analiza la situación y posible relación de los resultados de los test de competencias por excelencia, que son la Evaluación General de Diagnóstico (EGD), desarrollada por el Instituto Nacional de Evaluación Educativa y el MECD, y el estudio PISA, realizado por la OCDE. Ambas tienen por objeto evaluar el grado de adquisición de competencias por parte del alumnado en diferentes disciplinas, con el fin de proporcionar resultados comparables que sean útiles en la formulación y aplicación de políticas educativas.

En primer lugar, la EGD se centra en evaluar las competencias en el alumnado de cuarto curso de Educación Primaria y en el segundo curso de la ESO. De forma similar al informe PISA, para la obtención de las puntuaciones se elabora una escala de rendimiento para cada una de las competencias evaluables, asociando a cada pregunta 
una puntuación en una escala de media 500 y desviación típica 100, agrupándose las puntuaciones mediante el cálculo de promedios para cada individuo y para cada comunidad autónoma.

El Cuadro 4.7 muestra las puntuaciones de la evaluación realizada en el año 2010, correspondiente al segundo curso de $\mathrm{ESO}^{69}$, en la que se medía el grado de adquisición de las competencias en comunicación lingüística, matemática, competencia en el conocimiento y la interacción con el mundo físico, y competencia social y ciudadana. Asimismo, aparece reflejado el promedio de las puntuaciones de las cuatro competencias como indicador global de cada comunidad autónoma.

\begin{tabular}{|c|c|c|c|c|c|c|}
\hline \multicolumn{7}{|c|}{$\begin{array}{r}\text { Cuadro 4.7. Resultados de la Evaluación General de } \\
\text { (puntuaciones medias) }\end{array}$} \\
\hline & $\begin{array}{c}\text { Competencia } \\
\text { en } \\
\text { Comunicación } \\
\text { Lingüística }\end{array}$ & $\begin{array}{l}\text { Competencia } \\
\text { Matemática }\end{array}$ & $\begin{array}{c}\text { Competencia } \\
\text { en el } \\
\text { conocimiento } \\
\text { y la interacción } \\
\text { con el mundo } \\
\text { físico }\end{array}$ & $\begin{array}{c}\text { Competencia } \\
\text { social y } \\
\text { ciudadana }\end{array}$ & Promedio & $\begin{array}{l}\text { Diferencial } \\
\text { interregional } \\
\text { (España = } \\
100)\end{array}$ \\
\hline España & 500 & 500 & 500 & 500 & 500,0 & 100 \\
\hline Andalucía & 482 & 486 & 482 & 486 & 484,0 & 96,80 \\
\hline Aragón & 514 & 520 & 511 & 510 & 513,8 & 102,75 \\
\hline Asturias & 527 & 510 & 514 & 511 & 515,5 & 103,10 \\
\hline Baleares & 497 & 494 & 503 & 491 & 496,3 & 99,25 \\
\hline Canarias & 488 & 468 & 475 & 489 & 480,0 & 96,00 \\
\hline Cantabria & 519 & 510 & 517 & 507 & 513,3 & 102,65 \\
\hline Castilla y León & 528 & 526 & 528 & 529 & 527,8 & 105,55 \\
\hline Castilla-La Mancha & 511 & 497 & 504 & 515 & 506,8 & 101,35 \\
\hline Cataluña & 502 & 487 & 513 & 494 & 499,0 & 99,80 \\
\hline C. Valenciana & 490 & 491 & 494 & 495 & 492,5 & 98,50 \\
\hline Extremadura & 485 & 486 & 494 & 485 & 487,5 & 97,50 \\
\hline Galicia & 487 & 502 & 506 & 515 & 502,5 & 100,50 \\
\hline Madrid & 530 & 521 & 525 & 529 & 526,3 & 105,25 \\
\hline Murcia & 511 & 500 & 504 & 508 & 505,8 & 101,15 \\
\hline Navarra & 531 & 546 & 534 & 519 & 532,5 & 106,50 \\
\hline País Vasco & 511 & 525 & 504 & 498 & 509,5 & 101,90 \\
\hline Rioja & 522 & 525 & 524 & 528 & 524,8 & 104,95 \\
\hline c.v. & 0,034 & 0,039 & 0,031 & 0,030 & 0,031 & \\
\hline
\end{tabular}

Fuente: Elaboración propia a partir de datos de MECD

${ }^{69}$ En este caso, no se cuenta con información temporal, ya que la de 2010 fue la primera evaluación general de diagnóstico para el segundo curso de la ESO. No obstante, conviene señalar que se realizó una evaluación general de diagnóstico para el alumnado del cuarto curso de la Educación Primaria en el año 2009. 
Las regiones que obtienen mejores puntuaciones son Navarra (532,5 puntos), Castilla y León (527,8 puntos) y Madrid (526,3 puntos), mientras que Andalucía (484 puntos) y Canarias (480 puntos) registran las peores puntuaciones promedio en estos test de competencia. Por otra parte, cabe destacar que en los resultados de cada comunidad no existen grandes diferencias entre los resultados de los distintos test realizados.

En cuanto a la relación de los resultados de los test de competencias con el abandono escolar temprano, el Gráfico 4.21 refleja que ésta es relativamente fuerte, ya que las regiones con mejores resultados en los test presentan tasas de abandono escolar temprano más reducidas, con una bondad de ajuste que asciende al 43,5\%.

Gráfico 4.21. Tasa de abandono escolar temprano versus puntuación media en la Evaluación General de Diagnóstico 2010 en las CCAA españolas (año 2013 - 2010; \%, puntuación media)

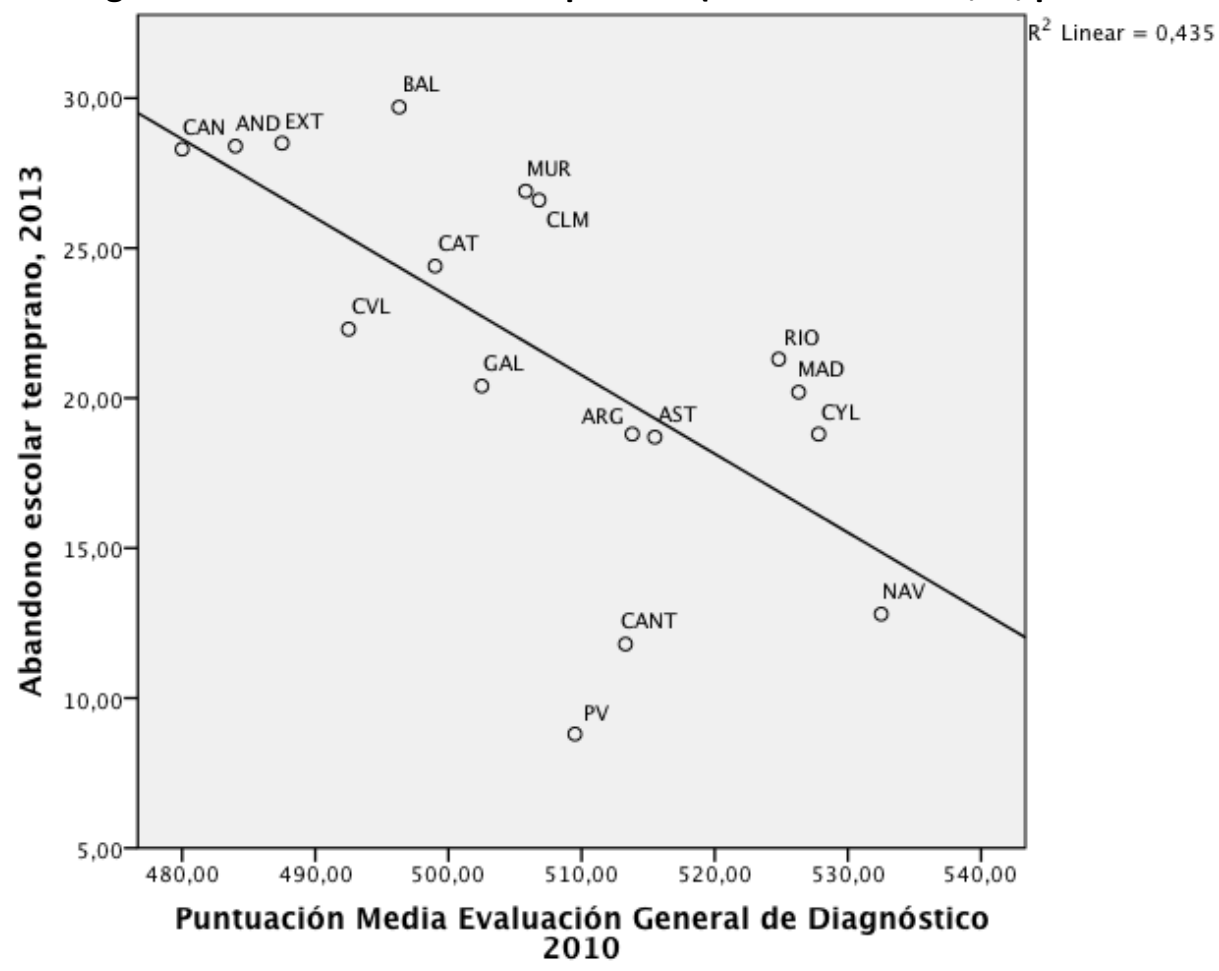

Fuente: Elaboración propia a partir de datos de MECD

Por otro lado, el informe PISA, de forma similar a lo apuntado sobre la EGD, recoge, entre otros muchos indicadores ${ }^{70}$, los resultados de competencias en

\footnotetext{
${ }^{70}$ Pese a que los resultados de competencias constituyen el núcleo central y más mediático del estudio PISA, este recoge y presenta una gran cantidad y variedad de información relativa a los sistemas educativos, los procesos de enseñanza - aprendizaje y el estatus socioeconómico y cultural del alumnado.
} 
comprensión lectora, matemáticas y ciencias, del alumnado de 15 años para el conjunto de países de la OCDE. El Cuadro 4.8 muestra las puntuaciones obtenidas por las distintas comunidades autónomas españolas, con la excepción de Canarias, CastillaLa Mancha y Comunidad Valenciana, que no realizaron ampliación de muestra en la edición de $2012^{71}$ del estudio, por lo que no es posible disponer de datos desagregados a nivel regional.

Cuadro 4.8. Resultados del Estudio PISA 2012 por CCAA (puntaciones medias)

\begin{tabular}{|l|c|c|c|c|c|}
\cline { 2 - 6 } & $\begin{array}{c}\text { Comprensión } \\
\text { lectora }\end{array}$ & Matemáticas & Ciencias & Promedio & $\begin{array}{l}\text { Diferencial } \\
\text { interregional } \\
\text { (España }=100)\end{array}$ \\
\hline España & 488 & 484 & 496 & 489,4 & 100,0 \\
\hline Andalucía & 477 & 472 & 486 & 478,3 & 97,7 \\
\hline Aragón & 493 & 496 & 504 & 497,8 & 101,7 \\
\hline Asturias & 504 & 500 & 517 & 506,9 & 103,6 \\
\hline Baleares & 476 & 475 & 483 & 478,0 & 97,7 \\
\hline Canarias* & - & - & - & - & - \\
\hline Cantabria & 485 & 491 & 501 & 492,6 & 100,7 \\
\hline Castilla y León & 505 & 509 & 519 & 510,9 & 104,4 \\
\hline Castilla-La Mancha* & - & - & - & - & - \\
\hline Cataluña & 501 & 493 & 492 & 495,2 & 101,2 \\
\hline C. Valenciana* & - & - & - & - & - \\
\hline Extremadura & 457 & 461 & 483 & 467,2 & 95,5 \\
\hline Galicia & 499 & 489 & 512 & 499,8 & 102,1 \\
\hline Madrid & 511 & 504 & 517 & 510,6 & 104,3 \\
\hline Murcia & 462 & 462 & 479 & 467,6 & 95,6 \\
\hline Navarra & 509 & 517 & 514 & 513,3 & 104,9 \\
\hline País Vasco & 498 & 505 & 506 & 503,2 & 102,8 \\
\hline Rioja & 490 & 503 & 510 & 501,1 & 102,4 \\
\hline C.V. & 0,035 & 0,035 & 0,029 & 0,032 & \\
\hline Fuente: Elabora & & & & \\
\hline
\end{tabular}

Fuente: Elaboración propia a partir de datos de MECD

*Datos no disponibles al no existir ampliación de muestra para presentar resultados a nivel regional.

En este caso, el promedio de España se mueve en torno a los 490 puntos, en relación a las puntuaciones obtenidas para el total de países participantes en el estudio a nivel internacional. Por comunidades, vuelven a destacar las mismas

\footnotetext{
${ }^{71}$ Se ha escogido el año 2012 ya que es el último con datos disponibles. No se ha tenido en cuenta la evolución temporal debido a que se disponen de pocas observaciones, ya que la evaluación se realiza cada tres años, y existen varias comunidades autónomas que no cuentan con una ampliación de la muestra para que los resultados sean representativos a nivel regional.
} 
regiones que en el caso de la Evaluación General de Diagnóstico, Navarra, Castilla y León y Madrid, con puntuaciones medias de 513, 511 y 510 puntos respectivamente. Murcia y Extremadura, por el contrario, obtienen los peores resultados, con valores en torno a los 467 puntos.

Pese a no contar con las observaciones de tres comunidades autónomas, el Gráfico 4.22 refleja la relación entre resultados de competencias del estudio PISA, en su edición de 2012, y la tasa de abandono escolar temprano, de forma similar a como ocurre en el caso de la Evaluación General de Diagnóstico 2010.

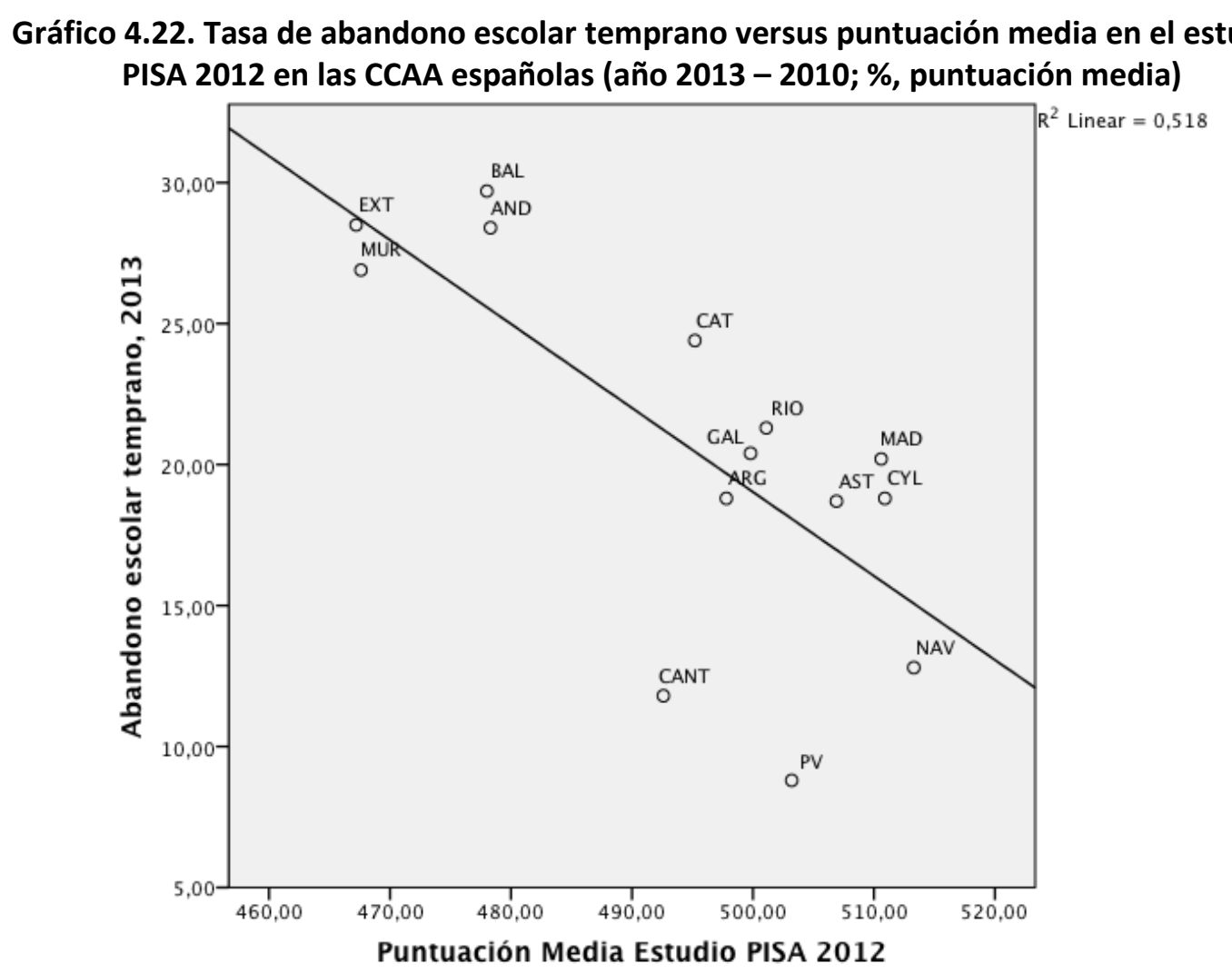

Fuente: Elaboración propia a partir de datos de MECD

A la vista de los resultados obtenidos, se puede concluir que los resultados de las competencias adquiridas por el alumnado son también un buen predictor de fenómenos educativos como el abandono escolar temprano. Al igual que ocurre con otras variables, es posible que los resultados de los test de competencias tengan su origen en etapas escolares precedentes, y que por tanto, como demuestran Choi y Jerrim (2015), las diferencias regionales y el desfase de España frente al resto de países europeos y de la OCDE se produzca con anterioridad. 


\subsection{Resumen y conclusiones}

El presente capítulo ha puesto de relieve la evolución de los problemas de escolarización que España ha presentado históricamente, y que en los últimos años se han centrado en el abandono escolar temprano. Una de las singularidades del problema en el caso español es que, además de presentar la tasa de abandono escolar temprano más alta de toda la Unión Europea, ésta se caracteriza por presentar también las diferencias regionales más acusadas.

Además, se ha analizado la caracterización del indicador en base a la información interna del mismo, proporcionada por el MECD, destacando la mayor tendencia a sufrir abandono escolar temprano por parte de los hombres en comparación con las mujeres, de los alumnos extranjeros respecto a los nacionales y de aquellos cuyas madres no tienen un nivel educativo medio o superior.

Por último, se ha contrastado la relación de distintos fenómenos educativos que han sido apuntados por la literatura con el abandono escolar temprano, de forma que se evidencia el carácter endógeno de esta relación, destacando que todos los indicadores probados - tasas de escolarización, esperanza de vida escolar, tasas de idoneidad, nivel de formación de la población joven, tasas de graduación y resultados de los test de competencias - están estrechamente relacionados con el abandono escolar temprano.

Los resultados obtenidos sugieren, por otro lado, que el panorama regional en muchos de los indicadores analizados se origina en las primeras etapas de escolarización, como señalan Fernández et al. (2010), Mena Martínez et al. (2010) y Choi y Jerrim (2015), lo que conviene tener en cuenta a la hora de diseñar medidas de prevención de este problema, que ha de ser concebido como el resultado de un largo proceso. 

Capítulo 5 : Análisis de los factores explicativos del abandono escolar temprano en las comunidades autónomas españolas 



\subsection{Introducción}

Tras examinar los factores que la literatura ha utilizado para explicar el abandono escolar temprano, así como observar su amplia diferencia interregional y estudiar la relación endógena que presenta con otros fenómenos educativos, el quinto capítulo de esta tesis doctoral se centra en analizar los factores de contexto que contribuyen a explicar las diferencias regionales en el nivel de abandono escolar temprano.

Para ello, en el presente capítulo se realiza un extenso análisis descriptivo de las variables que se pueden extraer de la revisión de la literatura realizada a través de su evolución, su situación regional, y su relación con el abandono escolar temprano. De este modo, se realiza una primera aproximación a los factores de contexto, a través de la observación descriptiva de su evolución. La pertinencia del enfoque de la investigación bajo el prisma regional se fundamenta en las divergencias descritas en el capítulo anterior. En el mismo sentido, estudios como el desarrollado por el Instituto Valenciano de Investigaciones Económicas (IVIE) (Serrano et al., 2013) recalca, a través de las estimaciones de un modelo probit, la persistencia de efectos estructurales diferenciados de entorno por regiones en el caso español.

La elección de las variables que se utilizan responde a un doble criterio, en función de la relación con los factores apuntados en la literatura y de disponibilidad de datos, teniendo en cuenta, para todas las variables, el último dato y su evolución a partir del año 2000 o primer dato disponible a partir de ese año. Asimismo, se analiza de forma transversal la evolución de las mismas a lo largo de dos sub-periodos (año inicial - 2008, y 2009 - último año ${ }^{72}$ ), para estudiar el posible efecto de la crisis económica en la evolución de las variables, que tiene su punto de inflexión, generalmente, en el año 2008. Además, se analizan las diferencias regionales de las distintas variables a través de un índice con base 100 para el último año o curso con datos disponibles (Dato España $=100$ ).

${ }^{72}$ En el caso de variables referidas a cursos escolares, se utilizan los periodos curso inicial curso 2007/08 y curso 2008/09 - último curso. 
Por otro lado, cabe señalar que para establecer las relaciones de las variables con el abandono escolar temprano, se utilizarán retardos en algunas de ellas, puesto que su influencia no tiene un efecto inmediato sobre el abandono escolar. Ello es debido a que la franja de edad que captura el indicador de abandono escolar temprano (18 a 24 años) hace que muchos fenómenos, especialmente los educativos y los que tienen que ver con el contexto familiar y social, ejerzan una influencia desde mucho antes de que el abandono se produzca efectivamente.

En cuanto a la estructura, al igual que en la revisión de la literatura, se ha dividido en tres grandes categorías: contexto educativo, que contiene variables referidas a gasto en educación y características institucionales del sistema educativo; contexto económico, con variables de riqueza económica y mercado laboral; y contexto socio-cultural, con variables relativas a nivel educativo de contexto e inmigración.

Conviene señalar además, que todas las variables que están cuantificadas en euros aparecen en términos constantes, para lo que se han utilizado los índices de volúmenes encadenados de cada región con referencia 2008 de la estadística de la Contabilidad Regional de España del Instituto Nacional de Estadística (INE).

\subsection{Análisis de los factores del contexto educativo}

\subsubsection{Factores de gasto en educación}

\subsubsection{Gasto público en educación no universitaria}

El primer aspecto al que se ha hecho referencia en la revisión de la literatura es el gasto público en educación. Por tanto, la primera variable considerada es el gasto público en educación no universitaria por alumno ${ }^{73}$. La elección de este indicador se

\footnotetext{
${ }^{73}$ El gasto por alumno está calculado como el cociente entre el gasto público en educación no universitaria y el número de alumnos de educación no universitaria de régimen general. Este dato lo recoge el Ministerio de Educación, Cultura y Deporte, utilizando como fuente el presupuesto liquidado de la Estadística del Gasto Público en Educación. Los datos están en términos constantes, utilizando los índices de volumen encadenados de cada región con referencia 2008 de la estadística de Contabilidad Regional de España del Instituto Nacional de Estadística.
} 
justifica en el hecho de que tiene en cuenta el gasto invertido en función de las necesidades, a diferencia del indicador de gasto en educación en relación al PIB, que es indicativo del esfuerzo de gasto relativo en función de la riqueza (Pastor, Raymond, Roig y Serrano, 2009; Morales Sequera, 2010).

El Cuadro 5.1 muestra los datos para los cursos 2000/01; 2007/08 y 2011/12, así como la evolución registrada en los periodos 2000/01 - 2007/08 y 2008/09 2011/12, y el diferencial de cada comunidad autónoma respecto al promedio nacional $^{74}$. Como se puede observar, en los once cursos que se recogen se ha registrado un aumento medio del gasto público por alumno en educación no universitaria del 2,88\% anual para el conjunto de España, pasando de 3.435,7 $€ /$ alumno a 4694,4,8 $€$ /alumno, si bien es cierto que hay dos periodos diferenciados en el comportamiento de esta variable.

${ }^{74}$ Para conocer los datos del periodo 2000/01 - 2011/12 al completo, ver Cuadro AIV.1 del Anexo IV. 
Cuadro 5.1. Gasto público por alumno en educación no universitaria por CCAA ( $€$ /alumno)

\begin{tabular}{|c|c|c|c|c|c|c|c|}
\hline & \multirow{2}{*}{$\begin{array}{l}\text { Curso } \\
\text { 2000/01 }\end{array}$} & \multirow{2}{*}{$\begin{array}{l}\text { Curso } \\
2007 / 08\end{array}$} & \multirow{2}{*}{$\begin{array}{l}\text { Curso } \\
2011 / 12\end{array}$} & \multicolumn{3}{|c|}{$\begin{array}{l}\text { Tasa de Crecimiento Medio } \\
\text { Anual Acumulativo }\end{array}$} & \multirow{2}{*}{$\begin{array}{c}\text { Diferencial } \\
\text { interregional } \\
\text { (España }= \\
100)\end{array}$} \\
\hline & & & & $\begin{array}{l}2001- \\
2008\end{array}$ & $\begin{array}{l}2009- \\
2012\end{array}$ & Total & \\
\hline España & $3.435,7$ & $4.534,8$ & $4.694,4$ & $4,04 \%$ & $-1,89 \%$ & $2,88 \%$ & 100 \\
\hline Andalucía & $2.668,8$ & $3.585,5$ & $3.972,7$ & $4,31 \%$ & $0,49 \%$ & $3,68 \%$ & 84,63 \\
\hline Aragón & $3.514,5$ & $4.136,7$ & $4.266,9$ & $2,36 \%$ & $-1,95 \%$ & $1,78 \%$ & 90,89 \\
\hline Asturias & $3.451,2$ & $5.157,1$ & $5.030,8$ & $5,91 \%$ & $-3,42 \%$ & $3,49 \%$ & 107,16 \\
\hline Baleares & $2.827,4$ & $4.281,4$ & $4.684,2$ & $6,11 \%$ & $-1,12 \%$ & $4,70 \%$ & 99,78 \\
\hline Canarias & $3.448,6$ & $4.042,7$ & $3.786,7$ & $2,30 \%$ & $-4,62 \%$ & $0,85 \%$ & 80,66 \\
\hline Cantabria & $3.346,8$ & $4.955,6$ & $5.211,7$ & $5,77 \%$ & $-1,05 \%$ & $4,11 \%$ & 111,02 \\
\hline Castilla y León & $3.407,9$ & $4.688,7$ & $4.609,3$ & $4,66 \%$ & $-3,63 \%$ & $2,78 \%$ & 98,19 \\
\hline Castilla-La Mancha & $3.285,7$ & $4.635,1$ & $5.384,1$ & $5,04 \%$ & $0,48 \%$ & $4,59 \%$ & 114,69 \\
\hline Cataluña & $2.868,2$ & $3.976,3$ & $4.066,3$ & $4,78 \%$ & $-2,18 \%$ & $3,22 \%$ & 86,62 \\
\hline C. Valenciana & $3.077,6$ & $3.997,7$ & $4.374,0$ & $3,81 \%$ & $-2,43 \%$ & $3,25 \%$ & 93,17 \\
\hline Extremadura & $2.948,7$ & $4.453,0$ & $5.006,7$ & $6,07 \%$ & $-0,09 \%$ & $4,93 \%$ & 106,65 \\
\hline Galicia & $3.708,9$ & $4.918,1$ & $4.947,9$ & $4,11 \%$ & $-2,65 \%$ & $2,65 \%$ & 105,40 \\
\hline Madrid & $2.635,6$ & $3.244,3$ & $3.041,0$ & $3,01 \%$ & $-3,14 \%$ & $1,31 \%$ & 64,78 \\
\hline Murcia & $3.052,5$ & $3.740,4$ & $4.419,4$ & $2,95 \%$ & $0,09 \%$ & $3,42 \%$ & 94,14 \\
\hline Navarra & $4.684,8$ & $5.013,7$ & $5.630,9$ & $0,97 \%$ & $-0,22 \%$ & $1,69 \%$ & 119,95 \\
\hline País Vasco & $4.737,5$ & $5.950,8$ & $6.382,5$ & $3,31 \%$ & $-1,02 \%$ & $2,75 \%$ & 135,96 \\
\hline Rioja & $3.595,4$ & $4.456,2$ & $4.301,8$ & $3,11 \%$ & $-3,85 \%$ & $1,64 \%$ & 91,64 \\
\hline c.v. & 0,178 & 0,150 & 0,167 & & & & \\
\hline
\end{tabular}

Fuente: Elaboración propia a partir de datos del MECD.

En el primer periodo, comprendido entre los cursos 2000/01 y 2007/08, el crecimiento promedio del gasto público por alumno fue de un 4,04\% anual. Una parte de este crecimiento viene dado por las fluctuaciones demográficas, tal y como apuntan Utrilla de la Hoz y Mitxelena Camiruaga (2006), Pastor et al. (2009) y Pérez-Esparrells y Morales Sequera (2012b). San Segundo (2009) por su parte, hace hincapié también en la afluencia de población inmigrante, que ha supuesto un aumento del alumnado en edad escolar. Sin embargo, en este periodo, la tasa de crecimiento medio anual acumulativa del gasto público en educación $(4,8 \%)$ es más alta que la del número de alumnos $(0,73 \%)^{75}$. Por comunidades, existe una gran diferencia en la evolución; un primer grupo, formado por las regiones de Extremadura (6,07\%), Asturias (5,91\%),

${ }^{75}$ Para ver los datos de evolución y crecimiento del gasto público en educación y el número de alumnos, ver el Cuadro AIV.2 y el Cuadro AIV.3 del Anexo IV respectivamente. 
Cantabria (5,77\%), Castilla y León $(4,66 \%)$ y Galicia $(4,11 \%)$, registran unos incrementos anuales en gasto público por alumno por encima de la media $(4,04 \%)$, si bien este hecho viene, en parte, explicado por el descenso del número de alumnos en educación no universitaria ${ }^{76}$.

En segundo lugar, un gran número de comunidades, formado por Comunidad Valenciana (3,81\%), País Vasco (3,31\%), La Rioja (3,11\%), Madrid (3,01\%), Murcia (2,95\%), Aragón (2,36\%) y Navarra (0,97\%), han experimentado unos crecimientos medios anuales inferiores a la media (aunque todos ellos positivos), a la vez que han registrado aumentos del número de alumnos. En tercer lugar Baleares (6,11\%), Castilla-La Mancha (5,04\%), Cataluña (4,78\%) y Andalucía $(4,31 \%)$ se caracterizan por haber simultaneado crecimientos anuales superiores a la media junto con un aumento del número de alumnos. Por último, Canarias $(2,30 \%)$ es la única región que ha registrado incrementos inferiores al promedio nacional junto con un descenso en el número de alumnos.

El periodo 2008/09 - 2011/12, en contraste con el anterior, se caracteriza por registrar una tasa de crecimiento negativo, del -1,91\% anual en el promedio nacional. Al estancamiento del gasto (la tasa de crecimiento del gasto público en educación es del $0,18 \%$ anual), se le suma un crecimiento de un $2,1 \%$ en este periodo del número de alumnos (ver el Cuadro AIV.2 y el Cuadro AIV.3 del Anexo IV respectivamente), lo que se ha traducido en un descenso paulatino del gasto en educación por alumno. Como en otros países de nuestro entorno, la incidencia de la crisis financiera iniciada en 2008 ha producido recortes en el gasto público en educación, aunque estos han tenido una mayor incidencia en los cursos más recientes para los que aún no hay datos disponibles (Eurydice, 2013; Instituto Nacional de Evaluación Educativa, 2013).

Por regiones, Andalucía (0,49\%), Castilla La-Mancha $(0,48 \%)$, y Murcia $(0,09 \%)$ son las únicas comunidades autónomas que presentan un crecimiento medio anual positivo, aunque notablemente menor que en el primer periodo analizado; por su parte, Extremadura (-0,09\%), Navarra (-0,22\%), País Vasco (-1,02\%), Cantabria $(-1,05 \%)$

\footnotetext{
${ }^{76}$ Para consultar los datos de la evolución de alumnos durante el periodo analizado, ver el Cuadro AIV.3 del Anexo IV).
} 
y Baleares $(-1,12 \%)$ registran descensos inferiores a la media, mientras que el resto de comunidades presentan los descensos más notables (Aragón, -1,95; Cataluña, -2,18\%; Comunidad Valenciana, -2,43\%; Galicia, -2.65\%; Madrid, -3,14\%; Asturias, -3,42\%; Castilla y León, $-3,63 \%$; La Rioja, $-3,85 \%$ y Canarias, $-4,62 \%)$. Este cambio de tendencia observado en este periodo tiene su fundamentación en el descenso del gasto público destinado a educación iniciado en el curso 2009/10, en consonancia con los datos agregados aportados por Eurydice (2013), así como el aumento, en todas las comunidades, del número de alumnos en educación no universitaria. De este modo, el nivel de gasto educativo por alumno ha tenido su techo en el curso 2009/10, en el que se alcanzaron los $5.135 €$ /alumno, habiendo descendido en dos cursos hasta los $4.694,4 €$ /alumno.

Por otro lado, la última fila del Cuadro 5.1 muestra el coeficiente de variación (CV) de los tres cursos seleccionados, mostrando una cierta convergencia entre los cursos 2000/01 y 2007/08, en contraste con el segundo periodo en el que las diferencias se han acentuado. Además, la última columna muestra las diferencias regionales para el último curso con datos disponibles (2011/12) tomando como referencia en base 100 el dato de España. Como se puede observar, existen unas diferencias interregionales sustanciales, con comunidades como Madrid y Canarias, con un casi un $35 \%$ y $20 \%$ menos de gasto por alumno que el promedio nacional respectivamente, frente a regiones como País Vasco o Navarra, con un $36 \%$ y $20 \%$ más de gasto dedicado a educación no universitaria. El tipo de modelo de financiación autonómica y el porcentaje de gasto dedicado a conciertos con la enseñanza privada (Pastor et al., 2009; Pérez-Esparrells y Morales Sequera, 2012b) por un lado, y la dispersión geográfica de la población, el tamaño de los centros educativos y el coste añadido del bilingüismo (San Segundo, 2001) por otro, son algunos de los factores más relevantes que pueden ayudar a explicar estas diferencias.

En cuanto a la relación del gasto público en educación con el abandono escolar temprano, el Gráfico 5.1 muestra que ésta es negativa, de modo que aquellas regiones con mayor cantidad de gasto invertido en educación no universitaria por alumno tienden a registrar tasas de abandono escolar menores $\left(R^{2}=37,9 \%\right)$, con casos 
atípicos en la serie, como la Comunidad de Madrid, cuyo nivel de gasto se correspondería con una tasa de abandono considerablemente más alta, o Baleares y Extremadura, en el otro extremo, que poseen unas tasas de abandono escolar temprano sustancialmente superiores a las esperadas dado su nivel de gasto en educación por alumno.

Gráfico 5.1. Tasa de abandono escolar temprano versus gasto público en educación no universitaria por alumno en las CCAA españolas ${ }^{77}$ (año 2013 - curso 2010/11; \%, €/alumno)

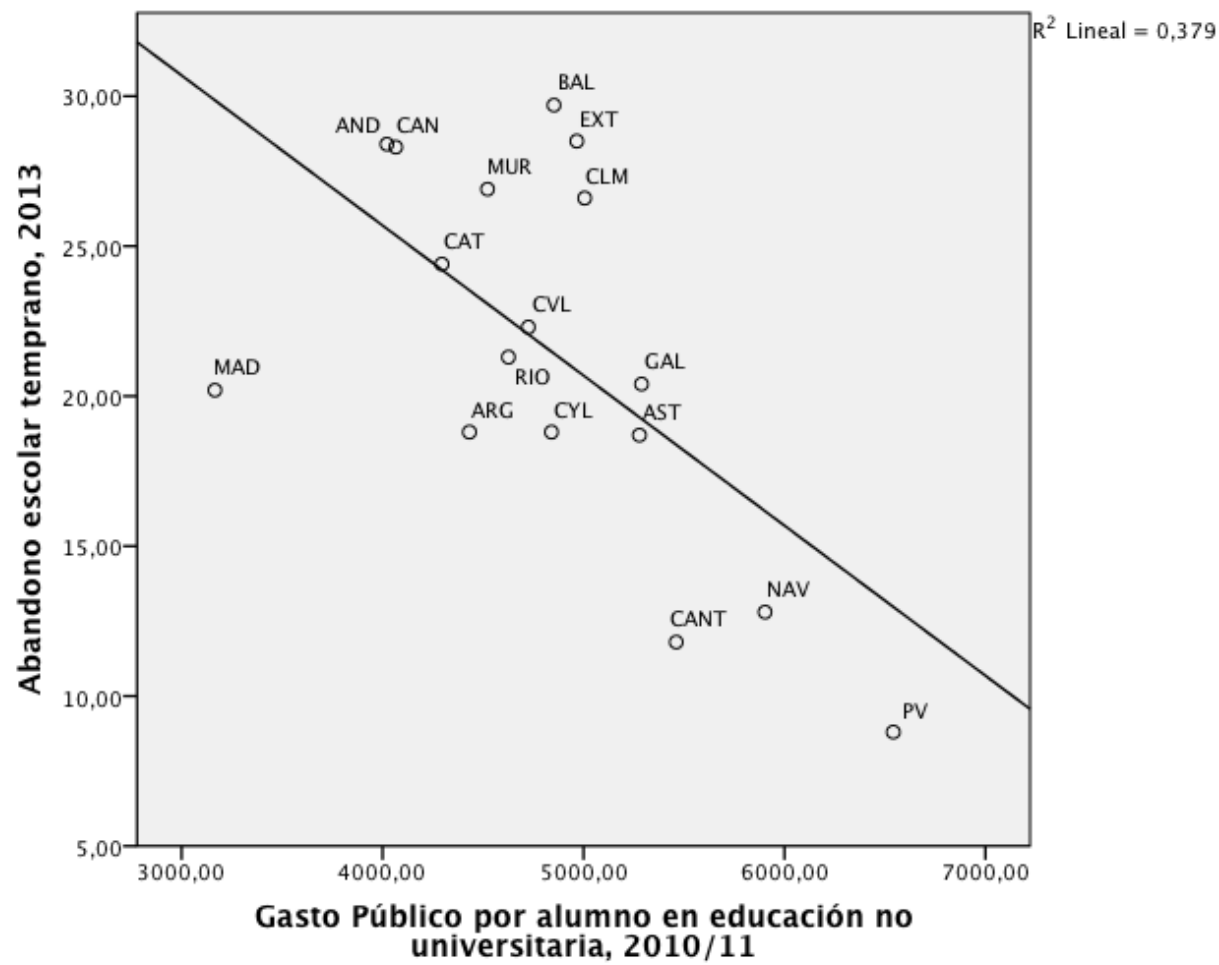

Fuente: Elaboración propia a partir de datos del MECD y el Instituto Nacional de Evaluación Educativa (INEE).

Así pues, estos resultados vendrían a corroborar los resultados de estudios como el de De Witte et al. (2013) y Pérez-Esparrells y Morales Sequera (2012b), que utilizan como variable dependiente la tasa de graduación en la Educación Secundaria Obligatoria; o el de Utrilla de la Hoz y Mitxelena Camiruaga (2007) que utilizan tasas de idoneidad y de abandono.

\footnotetext{
${ }^{77}$ Las abreviaturas de las distintas comunidades autónomas se relacionan en la página 375 de la presente tesis doctoral.
} 


\subsubsection{Tamaño de la clase}

La segunda de las variables relativas al contexto educativo es el tamaño de la clase, para la que el Cuadro 5.2 refleja los datos de el número medio de alumnos por clase en Educación Secundaria Obligatoria (ESO).

Cuadro 5.2. Número medio de alumnos por grupo en ESO por CCAA (alumnos/grupo)

\begin{tabular}{|c|c|c|c|c|c|c|c|}
\hline & \multirow{2}{*}{$\begin{array}{c}\text { Curso } \\
2000 / 01\end{array}$} & \multirow{2}{*}{$\begin{array}{c}\text { Curso } \\
2007 / 08\end{array}$} & \multirow{2}{*}{$\begin{array}{c}\text { Curso } \\
2011 / 12\end{array}$} & \multicolumn{3}{|c|}{$\begin{array}{c}\text { Tasa de Crecimiento } \\
\text { Medio Anual } \\
\text { Acumulativo }\end{array}$} & \multirow{2}{*}{$\begin{array}{c}\text { Diferencial } \\
\text { interregional } \\
(\text { España }=100)\end{array}$} \\
\hline & & & & $\begin{array}{l}2001- \\
2008 \\
\end{array}$ & $\begin{array}{c}2009- \\
2012 \\
\end{array}$ & Total & \\
\hline España & 25,6 & 24,4 & 24,5 & $-0,66 \%$ & $0,26 \%$ & $-0,40 \%$ & 100 \\
\hline Andalucía & 27,4 & 26,1 & 25,9 & $-0,71 \%$ & $0,02 \%$ & $-0,52 \%$ & 105,78 \\
\hline Aragón & 24,7 & 24,0 & 23,4 & $-0,40 \%$ & $-0,59 \%$ & $-0,49 \%$ & 95,61 \\
\hline Asturias & 24,6 & 22,2 & 22,3 & $-1,42 \%$ & $0,06 \%$ & $-0,88 \%$ & 91,00 \\
\hline Baleares & 26,2 & 23,2 & 24,7 & $-1,70 \%$ & $2,10 \%$ & $-0,54 \%$ & 100,74 \\
\hline Canarias & 24,1 & 23,5 & 23,9 & $-0,36 \%$ & $0,70 \%$ & $-0,10 \%$ & 97,47 \\
\hline Cantabria & 24,4 & 21,3 & 22,0 & $-1,90 \%$ & $1,01 \%$ & $-0,90 \%$ & 90,06 \\
\hline Castilla y León & 24,2 & 22,5 & 22,3 & $-1,01 \%$ & $0,01 \%$ & $-0,74 \%$ & 91,12 \\
\hline Castilla-La Mancha & 25,4 & 22,7 & 22,4 & $-1,60 \%$ & $-0,29 \%$ & $-1,14 \%$ & 91,67 \\
\hline Cataluña & 26,0 & 27,8 & 27,7 & $0,95 \%$ & $-0,11 \%$ & $0,57 \%$ & 113,15 \\
\hline C. Valenciana & 24,9 & 24,0 & 24,6 & $-0,51 \%$ & $1,61 \%$ & $-0,10 \%$ & 100,55 \\
\hline Extremadura & 25,4 & 21,9 & 21,3 & $-2,09 \%$ & $-0,37 \%$ & $-1,58 \%$ & 87,11 \\
\hline Galicia & 24,7 & 20,6 & 20,1 & $-2,56 \%$ & $-0,75 \%$ & $-1,89 \%$ & 81,97 \\
\hline Madrid & 26,6 & 25,6 & 25,6 & $-0,55 \%$ & $0,23 \%$ & $-0,34 \%$ & 104,76 \\
\hline Murcia & 25,6 & 25,8 & 25,4 & $0,07 \%$ & $-0,79 \%$ & $-0,08 \%$ & 103,81 \\
\hline Navarra & 24,0 & 22,3 & 22,9 & $-1,03 \%$ & $-0,66 \%$ & $-0,42 \%$ & 93,48 \\
\hline País Vasco & 21,7 & 19,7 & 20,4 & $-1,35 \%$ & $1,20 \%$ & $-0,55 \%$ & 83,52 \\
\hline Rioja & 25,7 & 25,1 & 24,2 & $-0,33 \%$ & $1,51 \%$ & $-0,52 \%$ & 98,93 \\
\hline C.V. & 0,051 & 0,091 & 0,087 & & & & \\
\hline
\end{tabular}

Fuente: Elaboración propia a partir de datos del MECD

Como se puede observar, la evolución en términos generales ha sido de una reducción muy limitada, con una tasa de crecimiento medio anual del $-0,4 \%$ en el periodo total, pasando de 25,6 alumnos por grupo en el curso 2000/01 a 24,5 en el 2011/12. Por tanto, se trata de una variable con una evolución temporal muy constante, tal y como recoge también el Sistema Estatal de Indicadores de la Educación (Instituto Nacional de Evaluación Educativa, 2014b). El primer sub-periodo 2000/01 - 2007/08 se caracteriza por presentar una reducción del -0,66\% anual. En este contexto, Galicia $(-2,56 \%)$, Extremadura $(-2,09 \%)$ y Cantabria $(-1,90 \%)$ fueron las comunidades que más intensamente redujeron esta proporción, si bien se 
encontraban por debajo de la media nacional (25,6 alumnos grupo), en contraste con Cataluña $(0,95 \%)$ y Murcia $(0,07 \%)$, que aumentaron ligeramente el ratio, a pesar de encontrarse igual, o incluso por encima del promedio nacional. El resto de comunidades registran, en este periodo, descensos de entre el $0,33 \%$ y el $1,7 \%$ anuales.

El segundo sub-periodo (cursos 2008/09 - 2011/12), se caracteriza por presentar una evolución creciente pero aún más moderada (tasa de crecimiento medio anual acumulativo del $0,26 \%$ en el promedio nacional). Murcia, que en el periodo anterior era de las pocas regiones que registraba aumentos en este indicador, pasa en este a liderar la bajada de alumnos por grupo (-0,79\%), seguido por Galicia $(-0,75 \%)$, que es la región que mejora más este indicador en el periodo total. Por el contrario, Baleares (2,1\%), La Rioja (1,51\%) y Comunidad Valenciana $(1,61 \%)$ son las comunidades que más aumentan el ratio alumnos/grupo en este segundo sub-periodo. Así pues, la evolución de este indicador ha estado marcada por dos periodos en los que tanto la reducción como el aumento del ratio de número de alumnos por grupo ha sido muy reducida. Además, al igual que en la variable anterior, hay que tener en cuenta que las fluctuaciones de la cantidad de alumnado han jugado un papel relevante, tal y como han apuntado varias investigaciones previas (Pérez-Esparrells y Morales Sequera, 2012b).

En cuanto a las diferencias regionales del curso 2011/12, aunque no son tan acusadas como en el caso del gasto público por alumno, destacan Galicia y País Vasco por poseer 18,03 y 16,48 puntos menos de alumnos por grupo en ESO que el promedio nacional respectivamente, mientras que Cataluña tiene un 13,15 puntos más, siendo la comunidad con el ratio más alto ${ }^{78}$ (27,7 alumnos por grupo en ESO).

Por otro lado, en el Gráfico 5.2 se representa la relación del número medio de alumnos por grupo en la ESO con el abandono escolar temprano, donde se puede comprobar que aunque la relación es limitada, el número medio de alumnos por grupo

\footnotetext{
${ }^{78}$ De hecho, Cataluña, que redujo su ratio en un alumno por grupo entre los cursos 2000/2001 y 2004/2005, es, desde el curso 2005/2006 la comunidad que presenta datos más altos en este indicador (Ver Cuadro AIV.4 del Anexo IV).
} 
explica el $30,5 \%$ de la variabilidad de las diferencias registradas en la tasa de abandono escolar temprano en las diferentes comunidades autónomas españolas.

\section{Gráfico 5.2. Tasa de abandono escolar temprano versus número medio de alumnos por grupo en ESO en las CCAA españolas (año 2013 - curso 2010/11; \%, alumnos/grupo)}

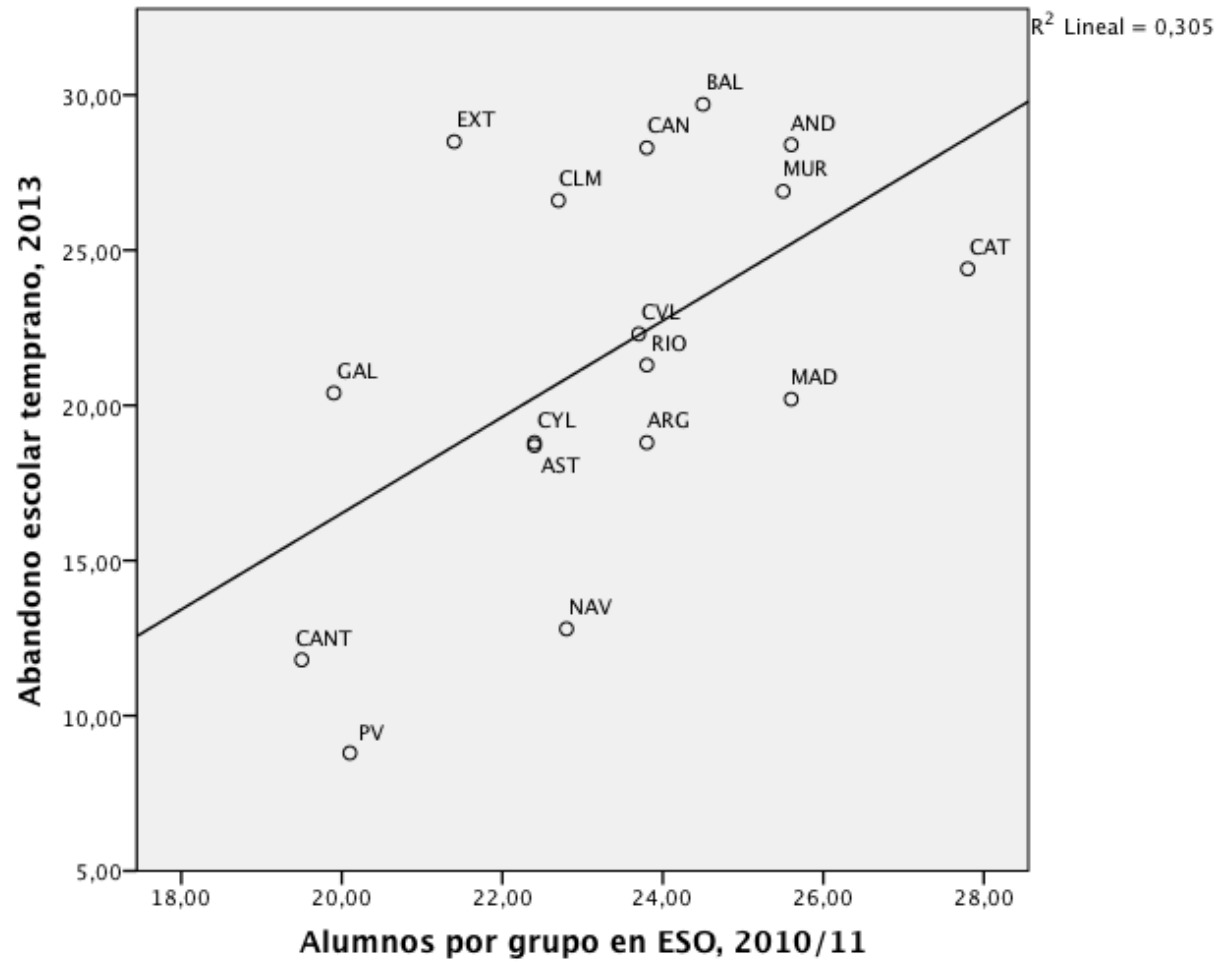

Fuente: Elaboración propia a partir de datos del MECD y el INEE

La relación es además positiva, de forma que aquellas comunidades que en promedio concentran a más alumnos por grupo, tienden a registrar mayores tasas de abandono escolar temprano. Así pues, estos primeros resultados van en consonancia con lo ya apuntado por otras investigaciones como las de Krueger y Whitmore (2001) o Mora et al. (2010).

\subsubsection{Becas y ayudas al estudio}

Otro de los aspectos señalados en la revisión de la literatura es el impacto de las becas y ayudas al estudio, del que es preciso realizar varias consideraciones previas. En primer lugar, conviene señalar que las etapas de educación primaria y secundaria son enteramente gratuitas en la enseñanza pública, y que por tanto, tal y como describen Pérez-Esparrells y Morales Sequera (2012b), las becas y ayudas al estudio programadas para estas etapas de escolarización se centran en proporcionar ayuda para sufragar los costes complementarios de la enseñanza (transporte, comedor, 
material escolar, etc.), si bien es cierto que las becas de la etapa no obligatoria de la enseñanza secundaria tienen por objeto atenuar el coste de oportunidad que constituye la incorporación al mercado laboral.

En segundo lugar, hay que subrayar que la política de becas y ayudas al estudio en España es desarrollada de forma centralizada por el Ministerio de Educación, Cultura y Deporte con un objetivo redistributivo, aunque esta política es complementada por las distintas comunidades autónomas. Por último, también es necesario señalar que estas partidas han registrado en todo el periodo incrementos en sus asignaciones presupuestarias, como ya han señalado otros estudios (Tiana Ferrer, 2008; San Segundo, 2009; Pérez-Esparrells y Morales Sequera, 2012b).

En el presente análisis, se ha analizado la relación del abandono escolar temprano con tres variables que muestran el nivel de gasto educativo en becas $^{79} \mathrm{y}$ ayudas al estudio para tres niveles educativos distintos. En primer lugar, el Cuadro 5.3 muestra los datos de gasto en becas y ayudas al estudio por alumno en educación primaria, cuya etapa engloba a los alumnos de entre 6 y 12 años $^{80}$, y que se caracteriza por ser una etapa de itinerario único, ya que posee un currículo homogéneo para todo el alumnado. En los dos periodos analizados se han registrado crecimientos, si bien en el sub-periodo 2000/01 - 2007/8 éste se ha producido con mayor intensidad (tasa de crecimiento medio anual acumulativo del $7,41 \%$ frente al $3,17 \%$ del segundo subperiodo ${ }^{81}$ ).

\footnotetext{
${ }^{79}$ Todos los datos de gasto en becas por alumno están expresados en términos constantes, tomando como referencia los índices de volumen encadenados de cada región con base 2008 de la estadística de la Contabilidad Regional de España del INE.

${ }^{80}$ Para conocer la estructura del sistema educativo y sus diferentes itinerarios, ver Cuadro All.1 del Anexo II.

${ }^{81}$ En el segundo sub-periodo 2008/09 - 2011/12 el crecimiento del gasto desciende debido, principalmente, a la caída del crecimiento anual del gasto en esta partida (baja del $8,11 \%$ del primer periodo al $4,85 \%$ ) y al mayor aumento del número de alumnos de educación primaria (1,63\% anual). Para consultar los datos del gasto en becas y el número de alumnos en educación primaria, ver Cuadro AIV.6 y Cuadro AIV.7del Anexo IV.
} 
Cuadro 5.3. Gasto público en becas y ayudas al estudio en Educación Primaria por CCAA

(€/alumno)

\begin{tabular}{|c|c|c|c|c|c|c|c|}
\hline & \multirow{3}{*}{$\begin{array}{c}\text { Curso } \\
2000 / 01\end{array}$} & & \multirow{3}{*}{$\begin{array}{c}\text { Curso } \\
2011 / 12\end{array}$} & \multirow{2}{*}{\multicolumn{3}{|c|}{$\begin{array}{c}\text { Tasa de Crecimiento Medio } \\
\text { Anual Acumulativo }\end{array}$}} & \\
\hline & & \multirow{2}{*}{$\begin{array}{l}\text { Curso } \\
2007 / 08\end{array}$} & & & & & \multirow{2}{*}{$\begin{array}{c}\text { Diferencial } \\
\text { interregional } \\
\text { (España = } \\
\text { 100) }\end{array}$} \\
\hline & & & & $\begin{array}{c}2001- \\
2008\end{array}$ & $\begin{array}{c}2009- \\
2012 \\
\end{array}$ & Total & \\
\hline España & 40,6 & 67,0 & 87,8 & $7,41 \%$ & $3,17 \%$ & $7,26 \%$ & 100 \\
\hline Andalucía & 19,5 & 62,9 & 111,3 & $18,21 \%$ & $8,61 \%$ & $17,16 \%$ & 126,73 \\
\hline Aragón & 23,0 & 15,8 & 26,9 & $-5,21 \%$ & $1,75 \%$ & $1,42 \%$ & 30,64 \\
\hline Asturias & 11,2 & 72,4 & 54,6 & $30,62 \%$ & $-15,14 \%$ & $15,53 \%$ & 62,17 \\
\hline Baleares & 42,4 & 51,9 & 38,1 & $2,92 \%$ & $-15,64 \%$ & $-0,97 \%$ & 43,40 \\
\hline Canarias & 96,7 & 22,2 & 63,6 & $-18,95 \%$ & $39,15 \%$ & $-3,73 \%$ & 72,47 \\
\hline Cantabria & 12,1 & 78,1 & 116,8 & $30,56 \%$ & $49,02 \%$ & $22,91 \%$ & 133,04 \\
\hline Castilla y León & 13,3 & 135,6 & 149,8 & $39,31 \%$ & $-1,64 \%$ & $24,61 \%$ & 170,50 \\
\hline Castilla-La Mancha & 16,8 & 36,4 & 60,9 & $11,71 \%$ & $10,74 \%$ & $12,45 \%$ & 69,37 \\
\hline Cataluña & 36,8 & 33,3 & 36,8 & $-1,42 \%$ & $-2,34 \%$ & $0,00 \%$ & 41,92 \\
\hline C. Valenciana & 63,2 & 114,1 & 101,1 & $8,82 \%$ & $-5,85 \%$ & $4,37 \%$ & 115,11 \\
\hline Extremadura & 31,5 & 64,8 & 93,6 & $10,86 \%$ & $0,26 \%$ & $10,42 \%$ & 106,62 \\
\hline Galicia & 10,9 & 6,8 & 88,3 & $-6,54 \%$ & $103,92 \%$ & $20,92 \%$ & 100,56 \\
\hline Madrid & 80,6 & 88,3 & 107,7 & $1,32 \%$ & $0,43 \%$ & $2,68 \%$ & 122,66 \\
\hline Murcia & 33,1 & 63,3 & 61,2 & $9,70 \%$ & $-3,72 \%$ & $5,75 \%$ & 69,69 \\
\hline Navarra & 11,6 & 36,4 & 7,3 & $17,71 \%$ & $-38,54 \%$ & $-4,14 \%$ & 8,31 \\
\hline País Vasco & 89,0 & 166,0 & 196,7 & $9,30 \%$ & $1,37 \%$ & $7,47 \%$ & 223,91 \\
\hline Rioja & 8,6 & 35,0 & 37,5 & $22,12 \%$ & $2,13 \%$ & $14,27 \%$ & 42,70 \\
\hline C.V. & 0,831 & 0,676 & 0,608 & & & & \\
\hline
\end{tabular}

Fuente: Elaboración propia a partir de datos del MECD

La primera conclusión que se extrae de los datos presentados es la desigual e irregular evolución del gasto en esta partida entre las diferentes regiones, con crecimientos exponenciales como el registrado por Castilla y León, que ha aumentado más de once veces la cantidad que destina por alumno de educación primaria a becas y ayudas al estudio (pese a que presenta ligeros descensos a partir del curso 2009/10). No obstante, es País Vasco, una vez más, la región mejor situada en el indicador, con un montante que asciende a 196,7 €/alumno en becas de educación primaria, frente a los 149,8 €/alumnos aportados por Castilla y León, que registra el segundo dato más alto. Otro hecho que confirma el pronunciado crecimiento de la desigualdad es la diferencia de amplitud entre las regiones con mayor y menor gasto dedicado a becas en educación primaria, que era de 87,4 euros por alumno en el curso 2000/01, mientras que para el curso 2011/12 asciende a 156,6 euros por alumno. 
En el otro extremo, se encuentran comunidades como Navarra y Aragón, cuya dotación en este apartado es, aproximadamente, un 92\% y un 70\% menor que el promedio nacional, respectivamente; siendo Navarra la región que peor evolución ha registrado, reduciendo un 4,14\% anual la dotación por alumno, con un importe que se limita a 7,3 euros por alumno en el curso 2011/12. Cabe concluir, por tanto, que la evolución registrada es muy $\operatorname{irregular}^{82}$ y que no se puede extraer un patrón de comportamiento preciso, debido, principalmente, a que las becas en esta etapa son reducidas en comparación con otras etapas educativas, y responden fundamentalmente a la implementación de programas de ayudas a la adquisición de libros y material escolar, o ayudas de comedor y transporte escolar.

En la siguiente etapa educativa, correspondiente con la primera etapa de la educación secundaria, y que comprende los cuatro cursos de la ESO, se comprueba que la dotación de becas y ayudas al estudio ha registrado un aumento aún mayor en comparación con la educación primaria, llegando a multiplicar por más del triple los recursos asignados (ver Cuadro 5.4), aunque tomando en consideración los datos de todo el periodo analizado (ver Cuadro AIV.8 del Anexo IV), esta evolución se ha caracterizado también por ser muy irregular. Asimismo, el primer sub-periodo presenta una tasa de crecimiento medio anual mayor que el segundo $(13,69 \%$ frente a $5,44 \%)$ en el promedio nacional. ${ }^{83}$

\footnotetext{
82 Por ejemplo, la cantidad destinada en Galicia en el curso 2006/07 a becas en esta etapa fue nula, mientras que a partir de ese curso, se fueron introduciendo ayudas hasta llegar a los 88,3 euros por alumno en el curso 2011/12. Para conocer los datos del periodo 2000/01-2011/12 al completo, ver Cuadro AIV.5 del Anexo IV.

${ }^{83}$ Para consultar los datos de las variables gasto público en becas y número de alumnos en ESO de forma separada, ver Cuadros Cuadro AIV.9 y Cuadro AIV.10 del Anexo IV.
} 
Cuadro 5.4. Gasto público en becas y ayudas al estudio en ESO por CCAA (€/alumno)

\begin{tabular}{|c|c|c|c|c|c|c|c|}
\hline & \multirow{3}{*}{$\begin{array}{c}\text { Curso } \\
2000 / 01\end{array}$} & \multirow{3}{*}{$\begin{array}{l}\text { Curso } \\
2007 / 08\end{array}$} & \multirow{3}{*}{$\begin{array}{c}\text { Curso } \\
2011 / 12\end{array}$} & \multirow{2}{*}{\multicolumn{3}{|c|}{$\begin{array}{c}\text { Tasa de Crecimiento Medio } \\
\text { Anual Acumulativo }\end{array}$}} & \multirow{3}{*}{$\begin{array}{c}\text { Diferencial } \\
\text { interregional } \\
(\text { España }=100)\end{array}$} \\
\hline & & & & & & & \\
\hline & & & & $\begin{array}{l}2001- \\
2008\end{array}$ & \begin{tabular}{|c|}
$2009-$ \\
2012 \\
\end{tabular} & Total & \\
\hline España & 15,6 & 38,2 & 48,4 & $13,69 \%$ & $5,44 \%$ & $10,87 \%$ & 100 \\
\hline Andalucía & 19,0 & 25,6 & 25,8 & $4,36 \%$ & $7,48 \%$ & $2,84 \%$ & 53,28 \\
\hline Aragón & 6,9 & 5,6 & 3,7 & $-2,86 \%$ & $-13,39 \%$ & $-5,56 \%$ & 7,58 \\
\hline Asturias & 10,2 & 89,7 & 64,3 & $36,38 \%$ & $-16,90 \%$ & $18,19 \%$ & 132,80 \\
\hline Baleares & 7,3 & 16,5 & 15,9 & $12,24 \%$ & $-6,02 \%$ & $7,28 \%$ & 32,83 \\
\hline Canarias & 12,0 & 18,3 & 16,9 & $6,18 \%$ & $-8,49 \%$ & $3,16 \%$ & 34,98 \\
\hline Cantabria & 10,4 & 82,0 & 98,8 & $34,34 \%$ & $132,64 \%$ & $22,73 \%$ & 204,02 \\
\hline Castilla y León & 11,1 & 104,1 & 99,5 & $37,75 \%$ & $-5,28 \%$ & $22,11 \%$ & 205,56 \\
\hline Castilla-La Mancha & 7,5 & 13,8 & 4,6 & $9,18 \%$ & $-33,54 \%$ & $-4,26 \%$ & 9,57 \\
\hline Cataluña & 11,8 & 22,6 & 29,5 & $9,78 \%$ & $2,95 \%$ & $8,71 \%$ & 60,87 \\
\hline C. Valenciana & 13,9 & 52,8 & 73,4 & $21,01 \%$ & $4,14 \%$ & $16,34 \%$ & 151,58 \\
\hline Extremadura & 33,8 & 49,9 & 89,1 & $5,73 \%$ & $6,70 \%$ & $9,22 \%$ & 184,08 \\
\hline Galicia & 11,7 & 5,4 & 66,7 & $-10,48 \%$ & $107,03 \%$ & $17,16 \%$ & 137,69 \\
\hline Madrid & 10,6 & 46,4 & 67,3 & $23,45 \%$ & $11,08 \%$ & $18,26 \%$ & 138,92 \\
\hline Murcia & 14,8 & 22,5 & 45,0 & $6,16 \%$ & $30,75 \%$ & $10,63 \%$ & 93,02 \\
\hline Navarra & 8,9 & 47,3 & 9,2 & $26,95 \%$ & $-39,03 \%$ & $0,26 \%$ & 18,93 \\
\hline País Vasco & 58,8 & 124,5 & 145,5 & $11,32 \%$ & $0,43 \%$ & $8,59 \%$ & 300,50 \\
\hline Rioja & 8,9 & 0,6 & 5,0 & $-32,41 \%$ & $64,66 \%$ & $-4,98 \%$ & 10,42 \\
\hline C.V. & 0,850 & 0,870 & 0,827 & & & & \\
\hline
\end{tabular}

Fuente: Elaboración propia a partir de datos del MECD

Una vez más, País Vasco es la región que más recursos dedica a esta partida (145,5 €/alumno) seguida de Castilla y León (99,5 €/alumno) y Cantabria (98, $€$ /alumno), habiendo registrado estas dos últimas comunidades la mejor evolución del periodo objeto de estudio, con aumentos anuales de más del $22 \%$. Por el contrario, hay comunidades con una evolución negativa, como es el caso de Aragón, que ha reducido esta dotación a un ritmo anual del $-5,56 \%$, contando tan sólo con 3,7 €/alumno; o La Rioja, cuya reducción ha sido de casi un 5\% anual, situándose en 5 €/alumno, lo que supone una asignación de recursos a este tipo de becas casi un $90 \%$ inferior al promedio nacional aproximadamente.

Por último, el Cuadro 5.5 representa el gasto por alumno en becas destinadas a las etapas educativas de la segunda etapa de la educación secundaria, que agrupa los estudios de bachillerato y los ciclos formativos de grado medio. Paradójicamente, en esta ocasión es País Vasco la región que menos gasto en becas realiza en esta etapa, 
con una dotación de 109,4 €/alumno en el curso 2011/12 (aproximadamente 72 puntos menos que el promedio nacional), en contraste con comunidades como Andalucía, que dobla el promedio nacional (812,8 frente a 395,2 €/alumno) o Extremadura, con $658 €$ /alumno.

Cuadro 5.5. Gasto público en becas y ayudas al estudio en la segunda etapa de la educación secundaria por CCAA ( $€$ /alumno)

\begin{tabular}{|c|c|c|c|c|c|c|c|}
\hline & \multicolumn{6}{|c|}{ 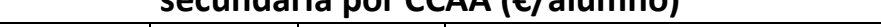 } & \multirow{3}{*}{$\begin{array}{c}\text { Diferencial } \\
\text { interregional } \\
(\text { España }=100)\end{array}$} \\
\hline & \multirow{2}{*}{$\begin{array}{c}\text { Curso } \\
2002 / 03\end{array}$} & \multirow{2}{*}{$\begin{array}{c}\text { Curso } \\
2007 / 08\end{array}$} & \multirow{2}{*}{$\begin{array}{c}\text { Curso } \\
2011 / 12\end{array}$} & \multicolumn{3}{|c|}{$\begin{array}{c}\text { Tasa de Crecimiento Medio } \\
\text { Anual Acumulativo }\end{array}$} & \\
\hline & & & & $\begin{array}{l}2001- \\
2008\end{array}$ & $\begin{array}{l}2009- \\
2012 \\
\end{array}$ & Total & \\
\hline España & 109,0 & 176,4 & 395,2 & $10,11 \%$ & $10,61 \%$ & $15,39 \%$ & 100 \\
\hline Andalucía & 206,4 & 330,1 & 812,8 & $9,84 \%$ & $14,28 \%$ & $16,45 \%$ & 205,69 \\
\hline Aragón & 62,0 & 95,8 & 217,3 & $9,07 \%$ & $13,94 \%$ & $14,95 \%$ & 54,99 \\
\hline Asturias & 90,7 & 144,6 & 295,7 & $9,78 \%$ & $4,12 \%$ & $14,03 \%$ & 74,83 \\
\hline Baleares & 28,4 & 49,8 & 150,3 & $11,89 \%$ & $12,72 \%$ & $20,34 \%$ & 38,04 \\
\hline Canarias & 139,0 & 215,1 & 448,1 & $9,12 \%$ & $4,82 \%$ & $13,89 \%$ & 113,39 \\
\hline Cantabria & 85,1 & 113,6 & 315,7 & $5,94 \%$ & $14,38 \%$ & $15,68 \%$ & 79,88 \\
\hline Castilla y León & 97,6 & 173,0 & 297,7 & $12,14 \%$ & $4,26 \%$ & $13,19 \%$ & 75,33 \\
\hline Castilla-La Mancha & 150,0 & 243,7 & 404,7 & $10,20 \%$ & $3,89 \%$ & $11,66 \%$ & 102,42 \\
\hline Cataluña & 36,2 & 54,3 & 159,7 & $8,46 \%$ & $15,32 \%$ & $17,93 \%$ & 40,41 \\
\hline C. Valenciana & 80,3 & 145,8 & 422,5 & $12,68 \%$ & $16,32 \%$ & $20,27 \%$ & 106,91 \\
\hline Extremadura & 282,1 & 438,5 & 658,0 & $9,22 \%$ & $2,17 \%$ & $9,87 \%$ & 166,51 \\
\hline Galicia & 130,9 & 241,9 & 348,7 & $13,06 \%$ & $1,38 \%$ & $11,50 \%$ & 88,25 \\
\hline Madrid & 38,6 & 62,3 & 198,3 & $10,05 \%$ & $13,49 \%$ & $19,95 \%$ & 50,19 \\
\hline Murcia & 105,9 & 144,5 & 423,5 & $6,41 \%$ & $14,25 \%$ & $16,65 \%$ & 107,17 \\
\hline Navarra & 77,3 & 119,1 & 176,3 & $9,02 \%$ & $-2,06 \%$ & $9,59 \%$ & 44,61 \\
\hline País Vasco & 72,4 & 101,8 & 109,4 & $7,04 \%$ & $-4,26 \%$ & $4,69 \%$ & 27,69 \\
\hline Rioja & 84,0 & 69,4 & 174,5 & $-3,76 \%$ & $13,12 \%$ & $8,47 \%$ & 44,16 \\
\hline C.V. & 0,617 & 0,651 & 0,571 & & & & \\
\hline
\end{tabular}

Fuente: Elaboración propia a partir de datos del MECD

Atendiendo a la evolución, se comprueba que entre los cursos 2002/03 ${ }^{84}$ y 2011/12 el gasto dedicado a becas en bachillerato y ciclos formativos de grado medio se ha multiplicado por más de tres en el promedio nacional, sin una diferencia significativa entre los periodos $2002 / 03$ - 2007/08 y 2008/09 - 2011/12, en los que existen sin embargo amplias diferencias regionales. En este sentido, Madrid, Baleares y

${ }^{84}$ En este caso, se utiliza como curso base el 2002/03 al no disponer de datos desagregados de importe de becas y ayudas al estudio en ciclos formativos de grado medio para los cursos 2000/01 y 2001/02. Para conocer los datos de evolución completos, ver Cuadro AIV.11 del Anexo IV. Para ver los datos de gasto en becas y ayudas al estudio y número de alumnos, ver Cuadro AIV.12 y Cuadro AIV.13 respectivamente. 
Comunidad Valenciana son las comunidades que han registrado una evolución más favorable, incrementando sus recursos presupuestados destinados a esta partida a un ritmo del $20 \%$ anual aproximadamente, mientras que País Vasco, a pesar de haber aumentado a una tasa media del $5 \%$ anual aproximadamente su dotación en este tipo de becas, presenta la evolución más desfavorable.

En cuanto a la relación de las variables de gasto en becas con el abandono escolar temprano, el Gráfico 4.8 muestra las regresiones simples aplicadas, tomando como variables independientes los indicadores de gasto público por alumno en becas y ayudas al estudio correspondientes a las etapas educativas comentadas con anterioridad. Aunque la bondad de ajuste es similar, ya que explica en torno a una cuarta parte de las diferencias en el nivel de abandono escolar, hay una contraposición en el coeficiente entre la regresión aplicada a las etapas de educación primaria y secundaria primera etapa, por un lado, y las correspondientes a la educación secundaria segunda etapa, por otro lado. 
Gráfico 5.3. Tasa de abandono escolar temprano versus gasto público en becas y ayudas al estudio por etapas educativas en las CCAA españolas (año 2013 - cursos 2006/07, 2010/11 y 2011/12; \%, €/alumno)

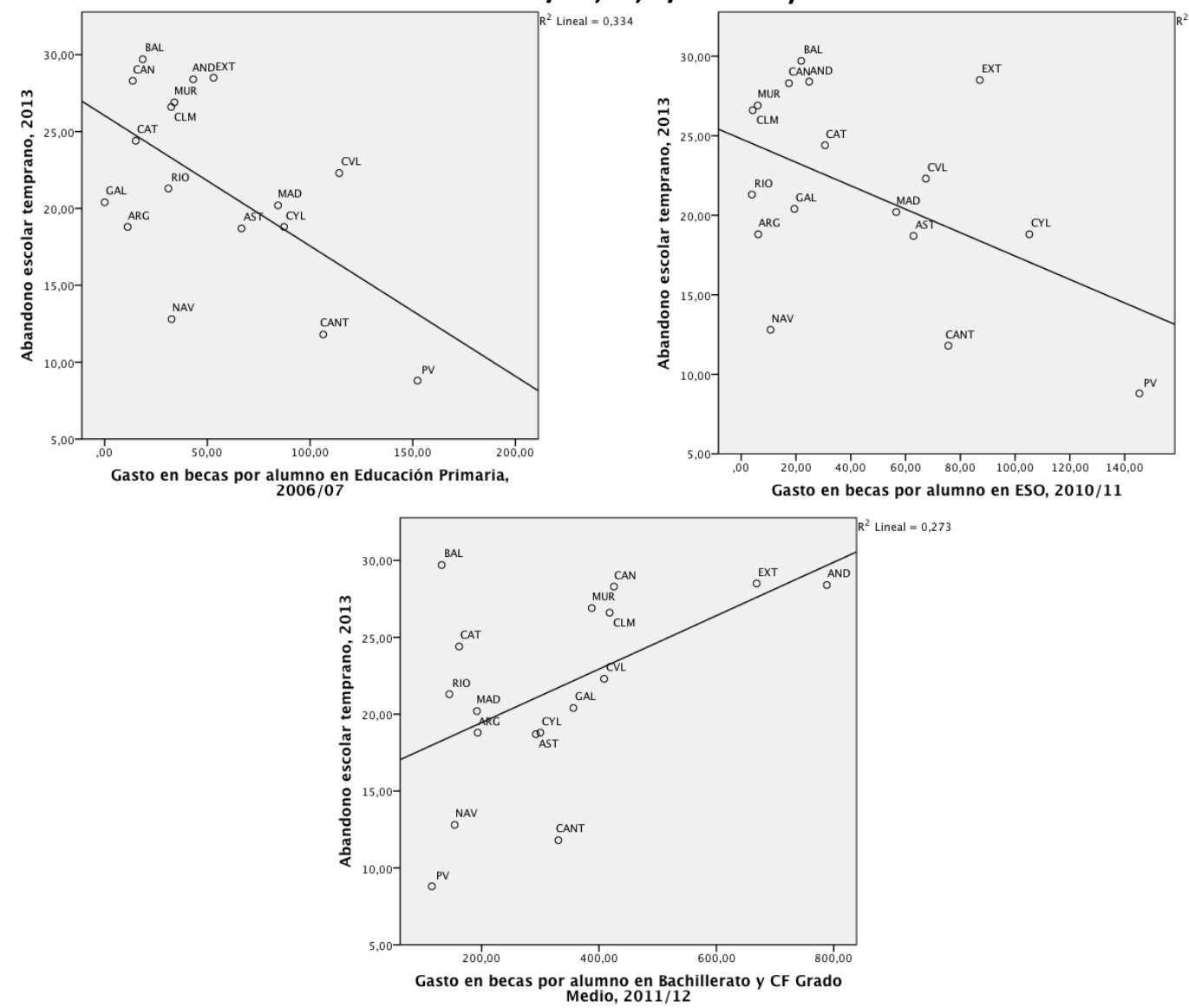

Fuente: Elaboración propia a partir de datos del MECD y el INEE

Así pues, se puede observar como en el caso de las enseñanzas obligatorias (educación primaria y Educación Secundaria Obligatoria), las regiones con un mayor nivel de gasto en becas se corresponden con aquellas que presentan un menor nivel de abandono escolar temprano (como es el caso de País Vasco y Cantabria). Por el contrario, en el caso de la segunda etapa de la educación secundaria, el signo de la regresión es el contrario, esto es, las regiones que más gastan en becas, como por ejemplo Andalucía y Extremadura, registran las tasas de abandono escolar temprano más altas.

Para explicar esta disparidad en los resultados, es necesario matizar que la finalidad de las becas en las distintas etapas responde a objetivos diferentes. Mientras que en el caso de las etapas de educación primaria y ESO, ambas obligatorias, la cantidad destinada es significativamente menor $(87,8$ y 48,4 $€$ /alumno respectivamente), en el caso de la segunda etapa de la educación secundaria, primera 
etapa de escolarización no obligatoria, esta cantidad asciende a 395,2 €/alumno. Ello puede responder al hecho de que la segunda etapa de la educación secundaria se corresponda con el primer periodo de no obligatoriedad y que por tanto, cursarla suponga un coste de oportunidad de no estar trabajando, por lo que la política de becas puede ayudar, en buena parte, a mitigar este coste e incentivar la permanencia del alumnado en el sistema educativo, más allá de la etapa obligatoria. Por el contrario, durante la etapa de escolarización obligatoria, la dotación de becas y ayudas al estudio está más asociada al principio de igualdad de oportunidades en el acceso a la educación, por lo que las diferencias en las cantidades dotadas pueden estar también ligadas a la distribución de la renta en cada región.

En otro sentido, recogiendo el argumento de Burtless (1996), una posible explicación podría venir del hecho de que exista un sesgo en la interpretación, y que las regiones con mayor dotación de recursos asignados para becas en la etapa postobligatoria sean precisamente las que mayores tasas de abandono escolar temprano registren, al tener éstas una mayor necesidad de recursos para hacer frente a este problema, que puede estar sujeto a factores externos (como puede ser el mercado laboral) que ejerzan un efecto expulsión del sistema educativo que en otras comunidades no existe con tanta intensidad o se produce más tarde.

\subsubsection{Factores institucionales}

La dimensión institucional engloba aquellas variables que representan los factores del diseño institucional del sistema educativo. Sin embargo, carece de sentido analizar las diferencias regionales en ciertos aspectos, ya que algunos de los apuntados en la revisión de la literatura, como la autonomía escolar, o la comprensividad del sistema, son idénticos en todo el territorio nacional, ya que están supeditados a las normas homogéneas y regulación del Ministerio de Educación, Cultura y Deporte.

No obstante, uno de los aspectos en los que sí se pueden detectar diferencias es en la titularidad de los centros educativos, dado que en España existe una gran tradición de concertación de la enseñanza. 


\subsubsection{Grado de concertación de la enseñanza}

El Cuadro 5.6 muestra la distribución porcentual de alumnado de ESO perteneciente a la enseñanza privada concertada, esto es, aquellos centros que, aunque son de titularidad privada, son cofinanciados mediante fondos públicos.

La evolución general ha sido de estabilidad en el promedio nacional, con una concertación en cuanto a número de alumnos del 31\% aproximadamente, que apenas ha variado en los últimos diez $\operatorname{años}^{85}$. A nivel regional, la evolución también ha sido estable, destacando Canarias, que ha aumentado su proporción de alumnado concertado a un ritmo medio anual acumulativo del $1,77 \%$. No obstante, tomando el último curso con datos disponibles, 2011/12, se puede comprobar que sí existen diferencias entre comunidades autónomas.

\footnotetext{
${ }^{85}$ Para conocer la evolución completa, ver Cuadro AIV.14 del Anexo IV.
} 
Cuadro 5.6. Distribución porcentual del alumnado de ESO en enseñanza privada concertada por CCAA (\%)

\begin{tabular}{|c|c|c|c|c|c|c|c|}
\hline & \multirow{2}{*}{$\begin{array}{c}\text { Curso } \\
2001 / 02\end{array}$} & \multirow{2}{*}{$\begin{array}{c}\text { Curso } \\
2007 / 08\end{array}$} & \multirow{2}{*}{$\begin{array}{c}\text { Curso } \\
2011 / 12\end{array}$} & \multicolumn{3}{|c|}{$\begin{array}{c}\text { Tasa de Crecimiento } \\
\text { Medio Anual } \\
\text { Acumulativo }\end{array}$} & \multirow{2}{*}{$\begin{array}{c}\text { Diferencial } \\
\text { interregional } \\
\text { (España }=100)\end{array}$} \\
\hline & & & & $\begin{array}{c}2002- \\
2008 \\
\end{array}$ & \begin{tabular}{|c|}
$2009-$ \\
2012 \\
\end{tabular} & Total & \\
\hline España & 31,2 & 30,5 & 30,7 & $-0,38 \%$ & $0,16 \%$ & $-0,15 \%$ & 100 \\
\hline Andalucía & 23,2 & 21,7 & 22,1 & $-1,11 \%$ & $0,29 \%$ & $-0,49 \%$ & 71,85 \\
\hline Aragón & 37,5 & 34,0 & 32,8 & $-1,62 \%$ & $-0,67 \%$ & $-1,32 \%$ & 106,79 \\
\hline Asturias & 31,9 & 32,5 & 32,4 & $0,31 \%$ & $-0,32 \%$ & $0,15 \%$ & 105,34 \\
\hline Baleares & 40,8 & 36,1 & 34,9 & $-2,02 \%$ & $-0,08 \%$ & $-1,55 \%$ & 113,57 \\
\hline Canarias & 17,1 & 19,9 & 20,4 & $2,56 \%$ & $-0,03 \%$ & $1,77 \%$ & 66,30 \\
\hline Cantabria & 37,7 & 37,5 & 35,0 & $-0,09 \%$ & $-1,94 \%$ & $-0,75 \%$ & 113,77 \\
\hline Castilla y León & 33,5 & 35,7 & 36,3 & $1,07 \%$ & $0,26 \%$ & $0,80 \%$ & 118,02 \\
\hline Castilla-La Mancha & 19,0 & 18,2 & 17,7 & $-0,71 \%$ & $-0,53 \%$ & $-0,70 \%$ & 57,62 \\
\hline Cataluña & 43,2 & 38,7 & 36,6 & $-1,82 \%$ & $-0,85 \%$ & $-1,63 \%$ & 119,20 \\
\hline C. Valenciana & 32,4 & 30,6 & 31,0 & $-0,95 \%$ & $1,04 \%$ & $-0,42 \%$ & 101,00 \\
\hline Extremadura & 22,0 & 22,6 & 22,9 & $0,45 \%$ & $0,56 \%$ & $0,39 \%$ & 74,43 \\
\hline Galicia & 25,7 & 28,2 & 28,3 & $1,56 \%$ & $-0,02 \%$ & $0,96 \%$ & 92,01 \\
\hline Madrid & 33,5 & 35,4 & 37,5 & $0,92 \%$ & $0,53 \%$ & $1,13 \%$ & 121,94 \\
\hline Murcia & 26,0 & 26,7 & 28,1 & $0,44 \%$ & $0,49 \%$ & $0,78 \%$ & 91,45 \\
\hline Navarra & 41,7 & 39,5 & 38,6 & $-0,90 \%$ & $-0,41 \%$ & $-0,76 \%$ & 125,62 \\
\hline País Vasco & 57,3 & 55,1 & 53,1 & $-0,65 \%$ & $-0,53 \%$ & $-0,75 \%$ & 172,87 \\
\hline Rioja & 37,1 & 34,8 & 36,4 & $-1,06 \%$ & $0,57 \%$ & $-0,19 \%$ & 118,46 \\
\hline C.V. & 0,309 & 0,279 & 0,265 & & & & \\
\hline
\end{tabular}

Fuente: Elaboración propia a partir de datos del MECD

Según Fernández Llera y Muñiz Pérez (2012), existen perfiles diferenciados a nivel regional en el patrón de concertación de la enseñanza. Además, estos autores encuentran que, por encima de la supuesta mejora en la calidad educativa, uno de los factores determinantes en la demanda de educación en centros concertados es la preferencia de los progenitores por las características socioeconómicas del alumnado. De esta forma, País Vasco destaca por encima del resto de regiones, con una proporción de concertación que alcanza el 53,1\%, a una gran distancia de la segunda región en concertación, Navarra, que ostenta un 38,6\%, y Madrid, que cuenta con un $37,5 \%$ en este tipo de centros educativos. Por el contrario, Castilla-La Mancha $(17,7 \%)$ junto a Canarias $(20,4 \%)$ son las comunidades que menos proporción de alumnos concertados en la etapa de ESO tienen respecto al total. 
Atendiendo a la relación de esta variable con el abandono escolar temprano, el Gráfico 5.4 muestra que esta relación es negativa y fuerte, es decir, aquellas comunidades autónomas que se caracterizan por tener una mayor proporción de alumnado de ESO en centros de enseñanza concertada son aquellas que registran tasas de abandono escolar más bajas, alcanzando la bondad de ajuste de la regresión simple el $58,4 \%$.

Gráfico 5.4. Tasa de abandono escolar temprano versus distribución porcentual de alumnado de ESO en la enseñanza privada concertada en las CCAA españolas (año 2013 - curso

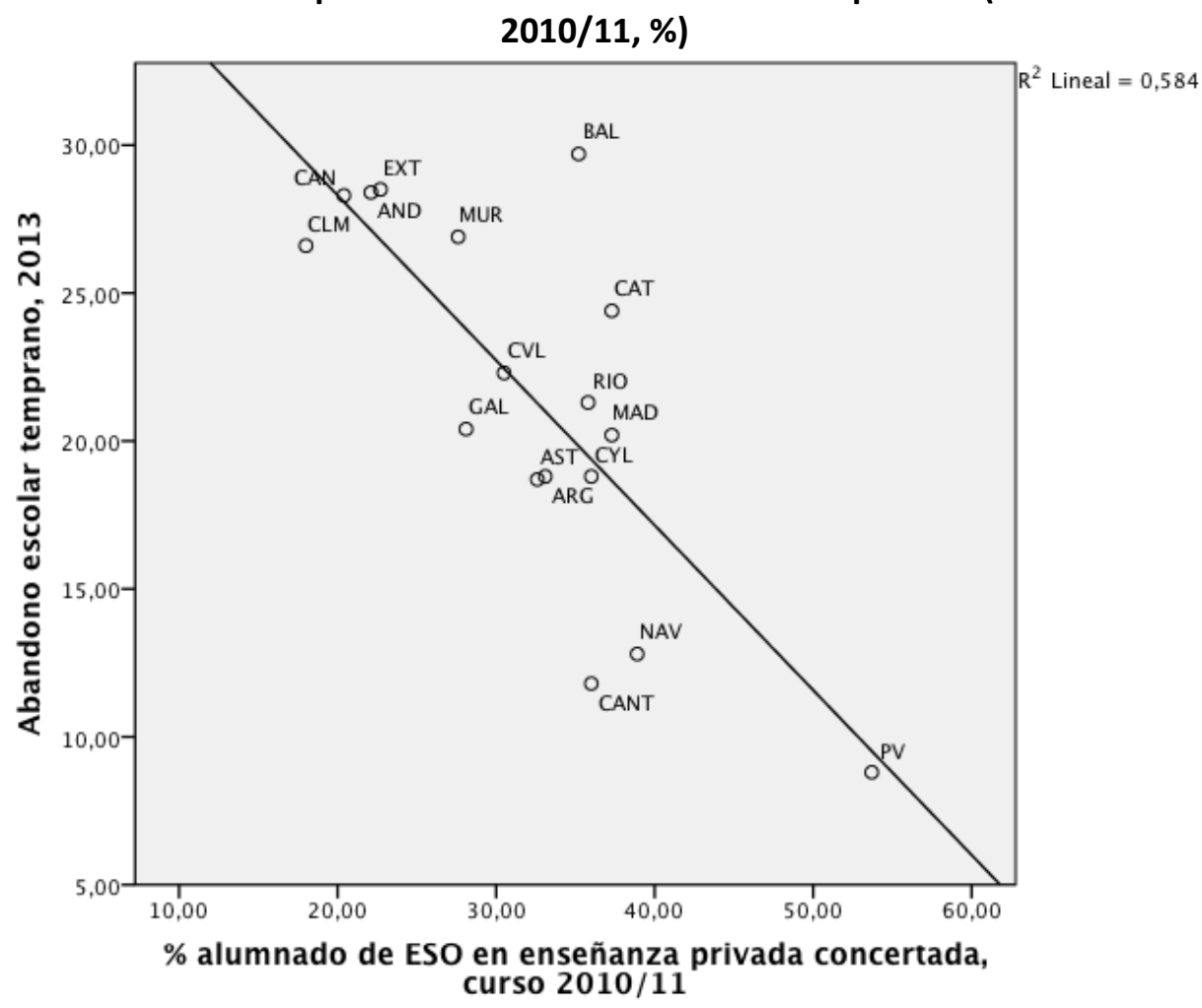

Fuente: Elaboración propia a partir de datos del MECD

Otro indicador que puede dar cuenta del grado de concertación de la enseñanza es la proporción del gasto público en educación no universitaria en conciertos y subvenciones a la enseñanza privada, que aparece representado en el Cuadro 5.7. En este sentido, la evolución ha sido relativamente estable, con una ligera subida desde el año 2008 y un promedio del peso de los conciertos en el gasto público del $16,5 \%$ para el año $2011^{86}$. No obstante, las diferencias entre los dos sub-periodos recogidos es más amplia, ya que en el primero de ellos se produce un descenso del

\footnotetext{
${ }^{86}$ Para conocer los datos del periodo 2001 - 2011, ver Cuadro AIV.16 del Anexo IV.
} 
$1,02 \%$ medio anual acumulativo, mientras que en el segundo (que únicamente recoge el periodo 2009-2011) se registra un cambio de tendencia, siendo el aumento del 2,52\% medio anual acumulativo.

Cuadro 5.7. Distribución porcentual del gasto público de educación no universitaria en conciertos y subvenciones a la enseñanza privada por CCAA (\%)

\begin{tabular}{|c|c|c|c|c|c|c|c|}
\hline & \multirow[t]{2}{*}{2000} & \multirow[t]{2}{*}{2008} & \multirow[t]{2}{*}{2011} & \multicolumn{3}{|c|}{$\begin{array}{c}\text { Tasa de Crecimiento } \\
\text { Medio Anual } \\
\text { Acumulativo }\end{array}$} & \multirow{2}{*}{$\begin{array}{c}\text { Diferencial } \\
\text { interregional } \\
(\text { España }=100)\end{array}$} \\
\hline & & & & $\begin{array}{c}2000- \\
2008 \\
\end{array}$ & $\begin{array}{c}2009- \\
2011 \\
\end{array}$ & Total & \\
\hline España & 15,2 & 14,0 & 16,5 & $-1,02 \%$ & $2,52 \%$ & $0,75 \%$ & 100 \\
\hline Andalucía & 12,4 & 10,9 & 13,4 & $-1,60 \%$ & $-0,74 \%$ & $0,71 \%$ & 81,21 \\
\hline Aragón & 17,5 & 16,1 & 17,1 & $-1,04 \%$ & $1,80 \%$ & $-0,21 \%$ & 103,64 \\
\hline Asturias & 13,3 & 11,9 & 13,6 & $-1,38 \%$ & $4,73 \%$ & $0,20 \%$ & 82,42 \\
\hline Baleares & 23,5 & 19,5 & 20,3 & $-2,31 \%$ & $-0,25 \%$ & $-1,32 \%$ & 123,03 \\
\hline Canarias & 7,0 & 7,8 & 9,8 & $1,36 \%$ & $6,13 \%$ & $3,11 \%$ & 59,39 \\
\hline Cantabria & 19,1 & 15,5 & 17,7 & $-2,58 \%$ & $2,64 \%$ & $-0,69 \%$ & 107,27 \\
\hline Castilla y León & 15,4 & 15,5 & 18,6 & $0,08 \%$ & $4,91 \%$ & $1,73 \%$ & 112,73 \\
\hline Castilla-La Mancha & 9,1 & 7,7 & 7,9 & $-2,07 \%$ & $-3,59 \%$ & $-1,28 \%$ & 47,88 \\
\hline Cataluña & 25,2 & 18,7 & 21,0 & $-3,66 \%$ & $-0,24 \%$ & $-1,64 \%$ & 127,27 \\
\hline C. Valenciana & 17,0 & 16,5 & 19,6 & $-0,37 \%$ & $4,06 \%$ & $1,30 \%$ & 118,79 \\
\hline Extremadura & 7,5 & 8,5 & 9,9 & $1,58 \%$ & $2,63 \%$ & $2,56 \%$ & 60,00 \\
\hline Galicia & 11,5 & 12,0 & 13,3 & $0,53 \%$ & $3,15 \%$ & $1,33 \%$ & 80,61 \\
\hline Madrid & 18,8 & 21,0 & 28,0 & $1,39 \%$ & $7,34 \%$ & $3,69 \%$ & 169,70 \\
\hline Murcia & 12,7 & 12,6 & 17,3 & $-0,10 \%$ & $7,75 \%$ & $2,85 \%$ & 104,85 \\
\hline Navarra & 22,0 & 19,7 & 21,6 & $-1,37 \%$ & $0,70 \%$ & $-0,17 \%$ & 130,91 \\
\hline País Vasco & 28,3 & 27,8 & 29,3 & $-0,22 \%$ & $1,22 \%$ & $0,32 \%$ & 177,58 \\
\hline Rioja & 17,7 & 15,8 & 18,9 & $-1,41 \%$ & $3,63 \%$ & $0,60 \%$ & 114,55 \\
\hline C.V. & 0,375 & 0,350 & 0,336 & & & & \\
\hline
\end{tabular}

Fuente: Elaboración propia a partir de datos del MECD.

A nivel regional, las diferencias responden en cierto modo al nivel de demanda (cantidad de alumnos) de este tipo de enseñanza, siendo País Vasco y Madrid (que ha aumentado en casi un $3,7 \%$ medio anual acumulativo la cantidad de recursos que destina a esta partida) las comunidades que más peso otorgan en el gasto público a la enseñanza privada. Por el contrario, Castilla-La Mancha, Extremadura y Canarias son las regiones que menos gasto dedican a esta partida, pese a que en las dos últimas se han producido consecutivos incrementos presupuestarios, en este sentido.

Por otra parte, en el Gráfico 5.5 se puede comprobar como, a pesar de que el gasto en conciertos y subvenciones a la enseñanza privada sigue estando relacionado 
con las tasas de abandono escolar temprano, la regresión en este caso pierde capacidad explicativa frente a la variable relativa a la proporción de alumnos $(32,5 \%$ frente a $58,4 \%)$.

Gráfico 5.5. Tasa de abandono escolar temprano versus distribución porcentual del gasto de educación no universitaria en conciertos y subvenciones a la enseñanza privada en las CCAA

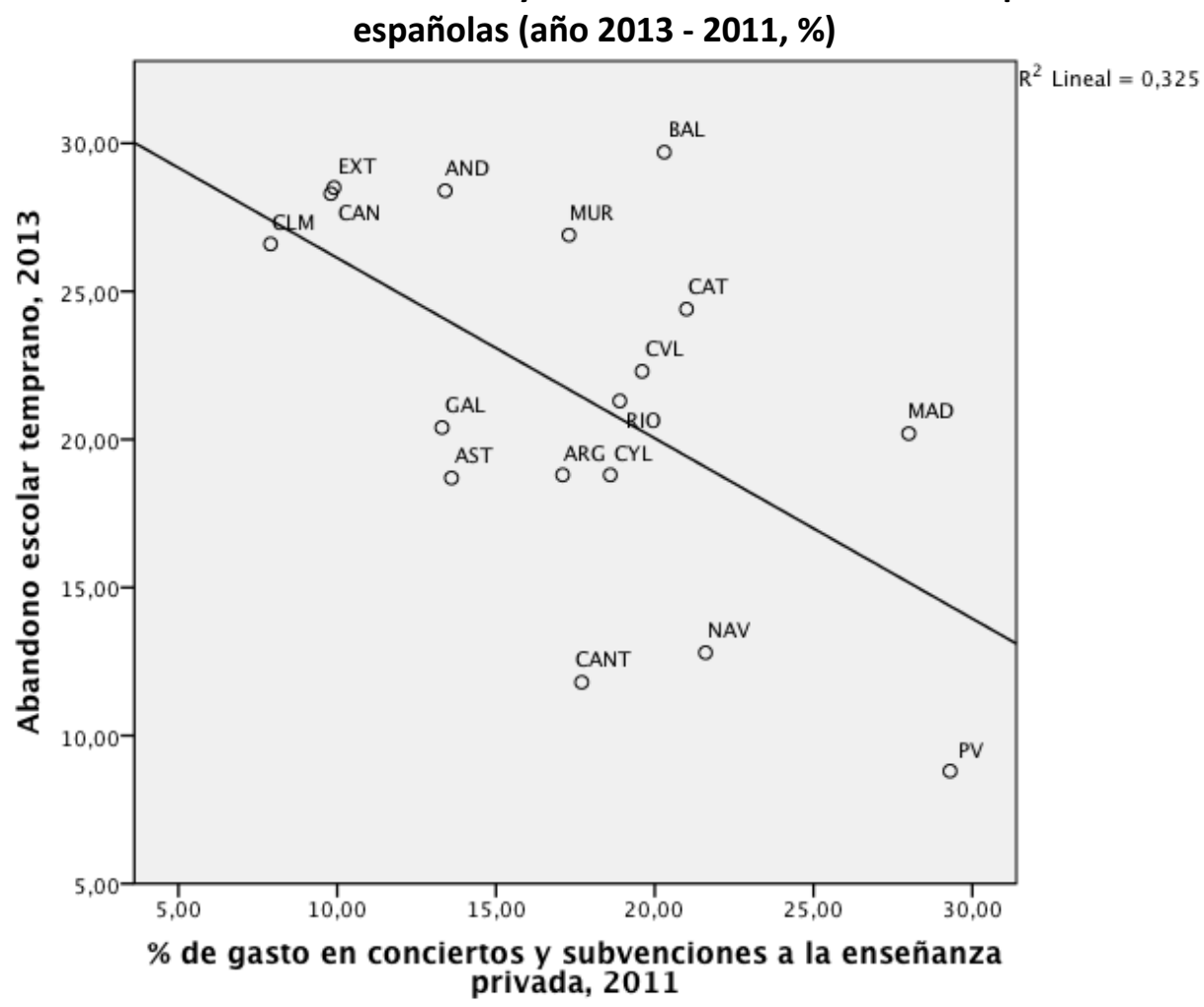

Fuente: Elaboración propia a partir de datos del MECD

Estos resultados están en consonancia con los obtenidos en estudios previos que analizan la relación entre titularidad del centro educativo y resultados académicos (Fuchs y Wößmann, 2006; West y Woessmann, 2010; Alegre Canosa y Subirats i Humet, 2013) y que señalan que los centros educativos privados tienen mejores resultados. No obstante, esta estrecha relación podría deberse a que el alumnado perteneciente a centros privados presenta otras características determinantes que tienen que ver con el estatus socioeconómico, como así lo apuntan las investigaciones realizadas por Calero y Escardíbul (2007), Mancebón et al. (2012) y los informes PISA (OECD, 2010b y 2014c).

En otro sentido, Alegre Canosa y Benito Pérez (2010 y 2014) apuntan que pese a que la proporción de enseñanza privada concertada no es significativa para explicar las diferencias de abandono escolar temprano en el ámbito europeo, esta relación se 
torna relevante si se utiliza la enseñanza privada no concertada. No obstante, este tipo de enseñanza se caracteriza, en el caso español, por tener una escasa presencia $(3,5 \%$ de alumnado de ESO en el promedio nacional), concentrándose principalmente en la Comunidad de Madrid $(11,1 \%)^{87}$, y no guardando relación significativa con las diferencias de abandono entre comunidades autónomas (ver Cuadro AV.1 del Anexo V).

Así pues, es necesario atender a la conjunción de otras variables para definir la importancia de cada una de ellas. Parece preciso señalar que el grado de concertación de la enseñanza ayuda a explicar las diferencias regionales en la tasa de abandono escolar temprano, si bien es cierto que la proporción de alumnos tiene una mayor capacidad explicativa que el gasto que se dedica a esta partida.

Por último, es necesario señalar que no se han incluido en el análisis variables que también forman parte de la dimensión educativa, como son aquellas que tienen que ver con la definición de la etapa de escolarización obligatoria o el gasto en profesorado, debido a que los patrones son comunes, o no existen diferencias significativas entre las comunidades autónomas españolas.

\subsection{Análisis de los factores del contexto económico}

\subsubsection{La riqueza económica}

El segundo bloque de factores hace referencia a variables que tienen que ver con el entorno económico y laboral. En primer lugar, se analiza la potencial influencia del PIB sobre el abandono escolar temprano. A este efecto, el Cuadro 5.8 muestra los datos de evolución y de dispersión entre regiones, utilizando para ello el indicador de PIB per cápita a precios constantes ${ }^{88}$.

Como se puede observar, el PIB per cápita ha presentado entre los años 2000 y 2013 una tasa de crecimiento medio anual acumulativo de casi el 4\%, si bien ésta ha

\footnotetext{
${ }^{87}$ Para conocer los datos del periodo 2001/02 - 2011/12, ver Cuadro AIV.15 del Anexo IV.

${ }^{88}$ Para deflactar el indicador, se toman como referencia los índices de volumen encadenados de cada región con base 2008 de la estadística de la Contabilidad Regional de España del INE. Para conocer los datos del periodo 2000 - 2013, ver Cuadro AIV.17 del Anexo IV.
} 
registrado dos periodos bien diferenciados. Así pues, entre 2000 y 2008 España registró unas tasas de crecimiento del PIB per cápita del 8,58\% medio anual acumulativo; por el contrario, el segundo periodo (2009 - 2013) estuvo caracterizado por unas caídas del 1,59\%.

En el primer periodo, Galicia (10,76\%), Castilla-La Mancha $(10,12 \%)$ y Murcia $(9,97 \%)$ fueron las regiones que registraron una evolución más favorable, en contraste con las comunidades autónomas insulares, que presentaron la evolución más desfavorable, con unas tasas de crecimiento del PIB per cápita del 5,94\% para Baleares y del 7,2\% para Canarias, aunque estos datos se ven también acompañados de un crecimiento de la población por encima de la media ${ }^{89}$. A pesar de que en el presente análisis se recoge como año de inicio el 2000, cabe mencionar que el periodo de crecimiento se inicia en 1996 (Mancha Navarro y Garrido Yserte, 2009).

En el segundo periodo, todas las comunidades autónomas presentan evoluciones negativas. Paradójicamente, dos de las regiones que registraban las evoluciones más favorables (Castilla-La Mancha y Murcia) presentan en este periodo dos de los descensos más pronunciados (-2,68\% y -2,75\% respectivamente) junto con Extremadura (-2,84\%), que es la región que peor evolución registra, Andalucía $(-2,6 \%)$ y Comunidad Valenciana $(-2,1 \%)$. Estas cinco comunidades han sido las que han sufrido un mayor impacto de la crisis económica, tal y como recogen también los datos expuestos por Bandrés y Gadea (2013) ${ }^{90}$. Por el contrario, País Vasco (-0,61\%), Galicia $(-0,74 \%)$, Cataluña $(-0,77 \%)$ y Navarra $(-0,78 \%)$ son las comunidades autónomas que mejor resisten el impacto de la crisis.

Como apunta Cuadrado-Roura (2012), el comportamiento de las economías regionales no se ha debido únicamente al "efecto país" de la crisis, sino también a las estructuras productivas regionales, que han marcado la heterogeneidad del

\footnotetext{
${ }^{89}$ Para comprobar los datos de evolución del PIB total y del número de habitantes, ver Cuadro AIV.18 y Cuadro AIV.19 del Anexo IV. En el Cuadro AIV.20 se resume el comportamiento de las tasas de crecimiento medio anual acumulativo tanto del PIB per cápita como del PIB total y el número de habitantes.

${ }^{90}$ El citado trabajo no incluye sin embargo a Extremadura, pudiéndose deber este hecho a la elección de un periodo temporal diferente al utilizado en el presente trabajo.
} 
comportamiento de las mismas frente a la crisis. Bandrés y Gadea (2013) señalan, en este sentido, que las regiones con mayor peso industrial, mejor dotación de capital humano y más apertura hacia el comercio exterior tienden a atenuar el impacto de la crisis. Así pues, el impacto de la crisis ha provocado una mayor desigualdad entre regiones en términos de PIB, rompiendo de esta forma el proceso de convergencia regional registrado hasta el inicio de la crisis (Cuadrado-Roura y Maroto-Sánchez, 2014).

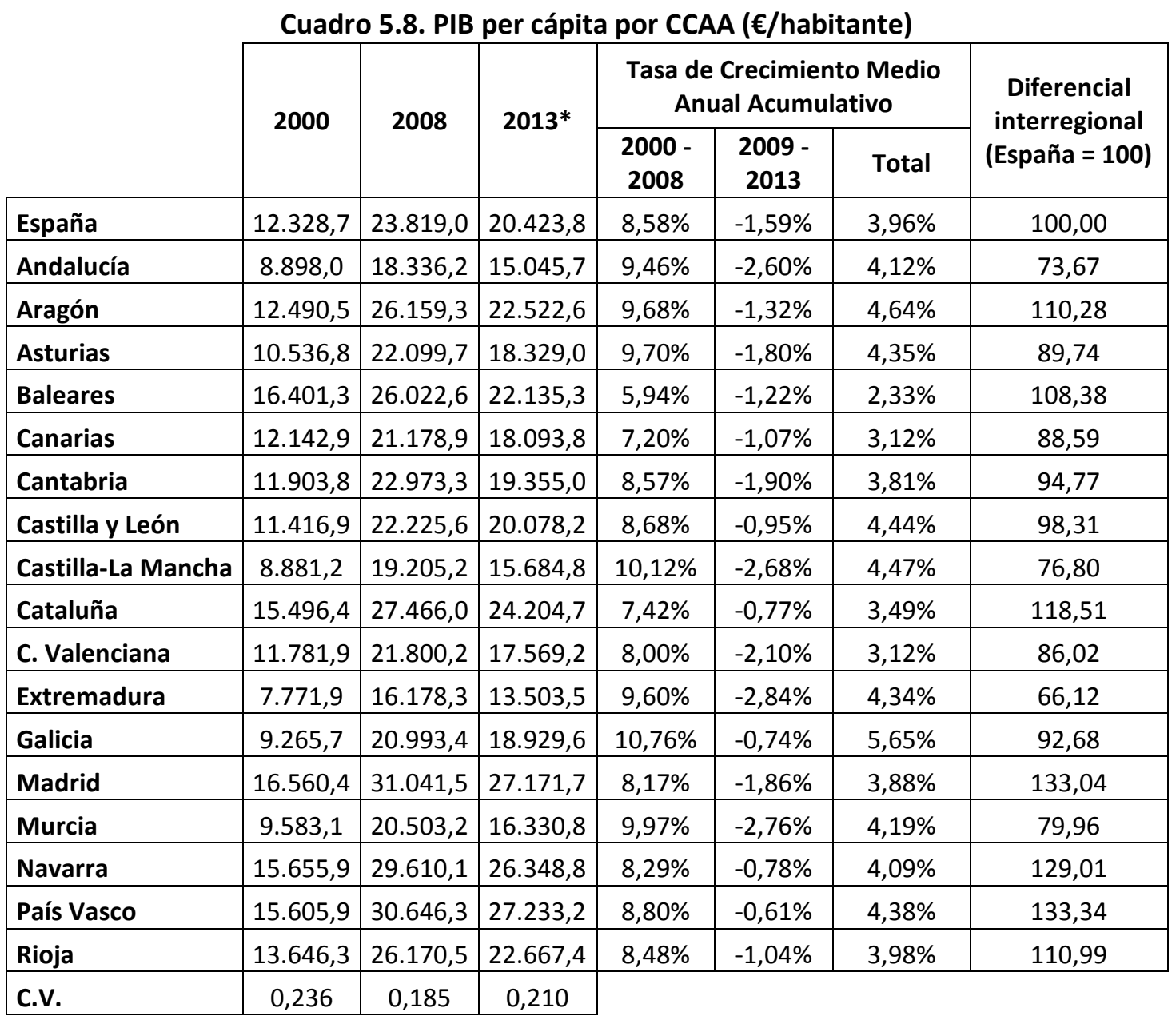

Fuente: Elaboración propia a partir de datos del Instituto Nacional de Estadística (INE)

* Primera estimación

En cuanto a las diferencias entre comunidades autónomas, País Vasco, Navarra y Madrid presentan los mejores datos de PIB per cápita, pasando la barrera de los 25.000 € per cápita para el año 2013, mientras que Extremadura (13.503 €) y Andalucía (15.045 €) son las regiones más pobres en estos términos. Según apunta Mancha Navarro y Garrido Yserte (2009), una explicación de las desigualdades entre regiones en cuanto a riqueza se debe, junto al fenómeno inmigratorio, a que en la 
última etapa de crecimiento registrada (1996-2006) se ha producido, de forma paralela, un proceso de concentración productiva en los ejes de crecimiento de la economía española (Mediterráneo, eje del Ebro País Vasco-Cataluña y Madrid). En este sentido, Villaverde (2006) expone las diferencias en la productividad y las tasas de ocupación como factores explicativos de las diferencias regionales en cuanto a riqueza (en este caso, medida a través del valor añadido bruto).

Atendiendo a la relación con el abandono escolar temprano, el Gráfico 5.6 muestra que el PIB per cápita tiene una capacidad explicativa que asciende al 37,6\%, con un coeficiente negativo. Ello se traduce en que las regiones con un nivel de riqueza más alto en términos de PIB per cápita tienden a ser aquellas que presentan unas tasas de abandono escolar temprano más bajas.

De esta forma, los resultados están en la línea de las conclusiones apuntadas por Cabus y De Witte (2013), según las cuales, un mayor nivel de PIB estaría asociado a un menor nivel de abandono escolar, puesto que los individuos perciben la necesidad de adquirir más educación para poder integrarse en una economía más intensiva en conocimiento, y que por tanto presenta unas exigencias formativas más altas. 
Gráfico 5.6. Tasa de abandono escolar temprano versus PIB per cápita en las CCAA españolas (año 2011; \%, €)

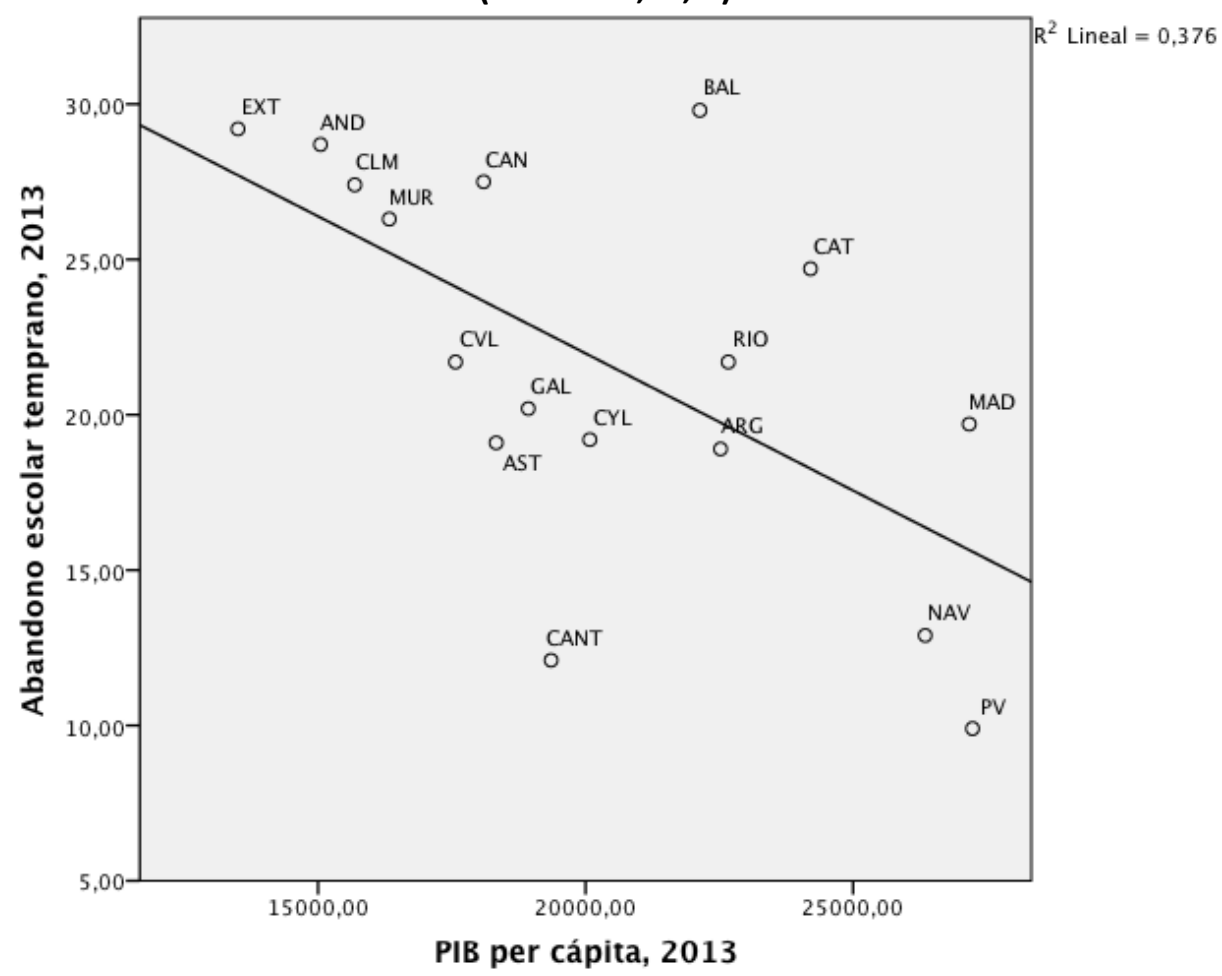

Fuente: Elaboración propia a partir de datos del INE y del MECD

Por otro lado, la pobreza es otra variable apuntada en la literatura como factor predictor del abandono escolar temprano (Ratcliffe y McKernan, 2010). El Cuadro 5.9 muestra de forma resumida el comportamiento del indicador de tasa de riesgo de pobreza en los últimos años. La tasa de riesgo de pobreza refleja la proporción de población que percibe unos ingresos equivalentes inferiores al $60 \%$ de los ingresos medios, por lo que es un indicador relativo de riqueza que a su vez suministra información sobre desigualdad.

Como se puede observar, entre los años 2004 y 2013, primer y último año en los que hay estadísticas disponibles, la tasa de riesgo de pobreza se ha incrementado a un ritmo medio acumulativo del 0,98\% anual. En el primer sub-periodo (2004-2008) se produjo a nivel nacional una ligera reducción media anual acumulativa del 0,5\%, siendo Navarra $(-12,63 \%)$ la región que mejor evolución registró, en contraste con Madrid (8,02\%), Aragón (6,87\%) y Rioja (5,6\%) que fueron las comunidades con evolución más desfavorable, pese a que todas ellas se encontraban por debajo del promedio nacional tanto en el año 2004 como en el 2008. 
Según Herrero, Soler y Villar (2013), el impacto de la crisis sobre la pobreza ha supuesto un desequilibrio territorial que marcará la salida de la crisis, y que, al igual que ocurre con el PIB per cápita, tiene sus raíces en la estructura productiva y la dotación de capital humano. De este modo, a partir del año 2008 y hasta el 2013 se registra un cambio de tendencia (ver Cuadro AIV.21 del Anexo IV), aumentando la tasa de riesgo de pobreza a una tasa de crecimiento medio anual acumulativo del $2,74 \%$, con un máximo en el año 2012, en el que este indicador alcanzó el 28,2\%. Ello se puede deber a que, además del considerable descenso en el nivel de renta de la población, se ha añadido una peor redistribución de la misma (Fundación FOESSA, 2014). Por regiones, Cantabria (11,96\%) y Aragón (10,25\%) fueron las que presentaron aumentos más pronunciados en el indicador, mientras que Castilla y León $(-2,69 \%)$ y La Rioja $(-2,03 \%)$ han sido las que han experimentado una evolución más favorable.

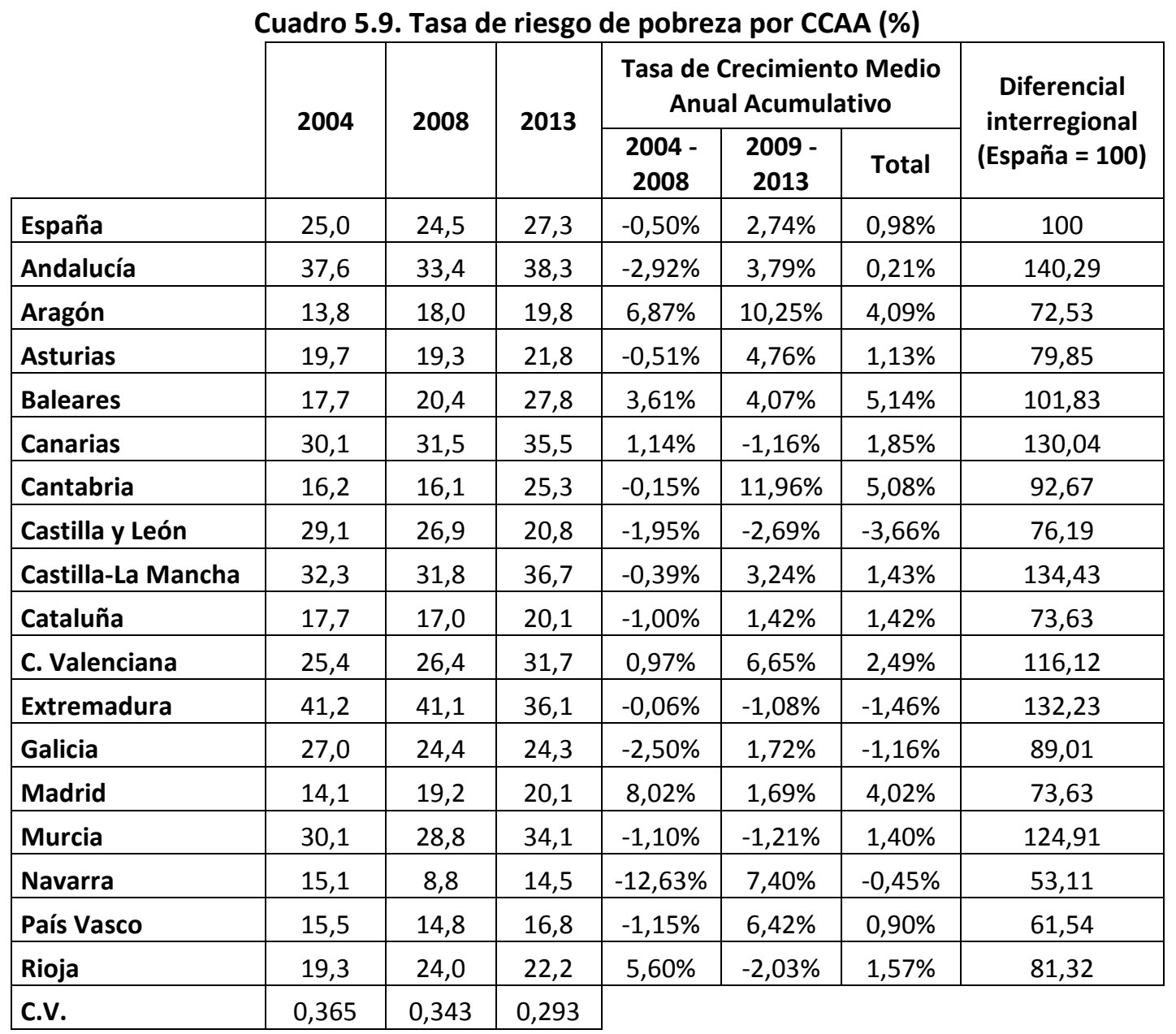

Fuente: Elaboración propia a partir de datos de Eurostat 
Se puede observar que, teniendo en cuenta las diferencias interregionales para el año 2013, existe una clara división norte-sur según la posición relativa de cada región respecto al promedio nacional, división que ha sido constante para largos periodos de tiempo (Pérez Mayo, 2013). Si tomamos este año (2013) como referencia, vemos como Andalucía, Castilla-La Mancha y Extremadura se sitúan entre las regiones más pobres ya que, pese a no haber registrado evoluciones significativamente peores al resto de comunidades, partían de una situación ya desfavorable (estas tres comunidades eran también las más pobres en el año 2004). Por el contrario, Navarra y País Vasco presentan una tasa de riesgo de pobreza 46,89 y 38,46 puntos más bajas que el promedio nacional, respectivamente.

No obstante, cabe mencionar la investigación realizada por Rubiera, Lasarte y Fernández (2013) en la que se reestiman los umbrales de pobreza teniendo en cuenta los costes de vida, que apunta que la incidencia de la pobreza después de introducir esta revisión para el periodo 2006-2011 es aún mayor. De forma análoga, Lafuente Lechuga y Faura Martínez (2013) establecen una división espacial de las comunidades autónomas españolas en función de la proporción de población vulnerable a la exclusión social, detectando diferencias regionales similares a las aquí planteadas con el indicador de tasa de riesgo de pobreza.

El Gráfico 5.7 ilustra la estrecha relación que tiene la tasa de riesgo de pobreza con el abandono escolar temprano, ya que la bondad de ajuste en la regresión simple asciende a casi el $60 \%$, por lo que puede ser un factor explicativo importante a la hora de analizar las diferencias regionales en el indicador de abandono escolar temprano. Se puede observar pues, que existe un numeroso grupo de comunidades con altas tasas de riesgo de pobreza que se ajustan con mucha precisión al valor de abandono escolar temprano esperado. 


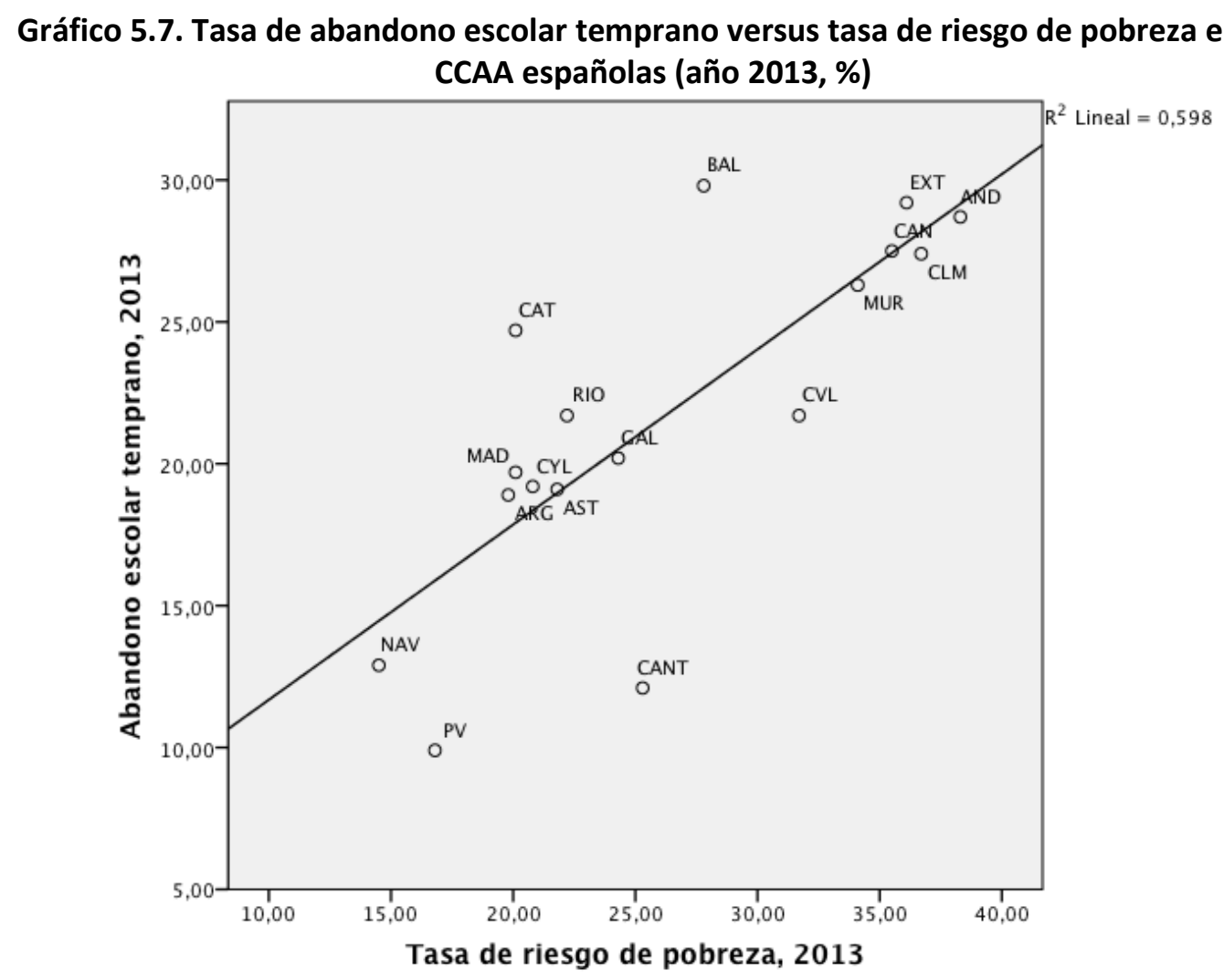

Fuente: Elaboración propia a partir de datos de Eurostat y del MECD

\subsubsection{El mercado laboral}

En el capítulo anterior se han revisado los diversos y ambivalentes efectos que puede suponer el comportamiento y características del mercado de trabajo sobre las decisiones de escolarización de la población, por lo que en el presente epígrafe se van a utilizar distintas variables para comprobar el comportamiento de las mismas y su grado de influencia en el abandono escolar temprano para el caso de las comunidades autónomas españolas.

En primer lugar se toma en consideración la tasa de paro de la población total, representada en el Cuadro $5.10^{91}$, en el que se observa un notable contraste entre los dos sub-periodos recogidos, ya que el impacto de la crisis se ha manifestado en incrementos notables de la tasa de paro a partir del año 2007 (Ver Cuadro AIV.22 del Anexo IV). Así pues, en el segundo sub-periodo 2009-2013 se ha registrado un crecimiento medio acumulativo de casi el $10 \%$ anual, mientras que en el primer

${ }^{91}$ La tasa está calculada a partir del promedio de los datos trimestrales de la tasa de paro obtenida de la Encuesta de Población Activa (EPA). 
periodo la tasa de crecimiento medio acumulativo era del $-0,30 \%$ anual. Por regiones, la evolución regional ha sido también dispar. En este sentido, en el primer sub-periodo hubo regiones con notables descensos, como País Vasco, Galicia y Asturias, que registraron tasas de crecimiento medio anual acumulativo por encima del $-5 \%$, mientras que Canarias destacó por presentar la peor evolución (su tasa de paro creció a un $7,64 \%$ medio anual acumulativo).

En el segundo sub-periodo todas las regiones incrementaron sustancialmente sus tasas de paro. Asturias y Cantabria fueron las que peores evoluciones registraron, si bien es cierto que este deterioro se inicia ya en el año 2008 (Ver Cuadro AIV.22 del Anexo IV). Por el contrario, Baleares fue la comunidad autónoma que menos aumentó sus tasas de paro en el segundo sub-periodo, a pesar de acumular un crecimiento medio anual acumulativo que asciende al 5,59\%. Se trata pues, de una variable que también presenta un patrón norte - sur, en el que, a pesar de las evoluciones dispares, se dan unas distribuciones de desempleo regionales con desigualdades persistentes en el tiempo, como también apunta el trabajo de Buendía Azorín y Sánchez de la Vega (2013). 


\begin{tabular}{|c|c|c|c|c|c|c|c|}
\hline \multicolumn{8}{|c|}{ Cuadro 5.10. Tasa de paro por CCAA (\%) } \\
\hline & \multirow{2}{*}{2002} & \multirow{2}{*}{2008} & \multirow{2}{*}{2013} & \multicolumn{3}{|c|}{$\begin{array}{c}\text { Tasa de Crecimiento Medio } \\
\text { Anual Acumulativo }\end{array}$} & \multirow{2}{*}{$\begin{array}{c}\text { Diferencial } \\
\text { interregional } \\
(\text { España }=100)\end{array}$} \\
\hline & & & & $\begin{array}{l}2002- \\
2008\end{array}$ & $\begin{array}{c}2009- \\
2013\end{array}$ & Total & \\
\hline España & 11,5 & 11,2 & 26,1 & $-0,30 \%$ & $9,95 \%$ & $7,78 \%$ & 100 \\
\hline Andalucía & 19,5 & 17,7 & 36,2 & $-1,59 \%$ & $9,45 \%$ & $5,79 \%$ & 138,81 \\
\hline Aragón & 5,8 & 7,3 & 21,4 & $3,73 \%$ & $13,13 \%$ & $12,51 \%$ & 81,94 \\
\hline Asturias & 9,8 & 8,5 & 24,1 & $-2,35 \%$ & $15,80 \%$ & $8,53 \%$ & 92,46 \\
\hline Baleares & 7,6 & 10,2 & 22,3 & $4,97 \%$ & $5,59 \%$ & $10,28 \%$ & 85,59 \\
\hline Canarias & 11,1 & 17,2 & 33,7 & $7,64 \%$ & $6,72 \%$ & $10,65 \%$ & 129,26 \\
\hline Cantabria & 10,0 & 7,2 & 20,4 & $-5,46 \%$ & $14,25 \%$ & $6,69 \%$ & 78,36 \\
\hline Castilla y León & 10,5 & 9,6 & 21,7 & $-1,41 \%$ & $11,69 \%$ & $6,88 \%$ & 83,34 \\
\hline Castilla-La Mancha & 9,5 & 11,7 & 30,0 & $3,44 \%$ & $12,25 \%$ & $10,98 \%$ & 114,84 \\
\hline Cataluña & 10,2 & 8,9 & 23,1 & $-2,23 \%$ & $9,27 \%$ & $7,75 \%$ & 88,60 \\
\hline C. Valenciana & 10,8 & 12,0 & 28,1 & $1,72 \%$ & $7,81 \%$ & $9,05 \%$ & 107,49 \\
\hline Extremadura & 19,0 & 15,4 & 33,9 & $-3,53 \%$ & $13,19 \%$ & $5,37 \%$ & 129,79 \\
\hline Galicia & 12,1 & 8,6 & 22,0 & $-5,53 \%$ & $15,38 \%$ & $5,57 \%$ & 84,47 \\
\hline Madrid & 7,3 & 8,6 & 19,8 & $2,77 \%$ & $9,28 \%$ & $9,48 \%$ & 75,73 \\
\hline Murcia & 11,3 & 12,4 & 29,0 & $1,61 \%$ & $9,27 \%$ & $8,94 \%$ & 111,06 \\
\hline Navarra & 5,8 & 6,8 & 17,9 & $2,66 \%$ & $13,43 \%$ & $10,74 \%$ & 68,71 \\
\hline País Vasco & 9,6 & 6,6 & 16,6 & $-5,94 \%$ & $9,96 \%$ & $5,13 \%$ & 63,51 \\
\hline Rioja & 7,1 & 7,9 & 20,0 & $1,90 \%$ & $12,19 \%$ & $9,96 \%$ & 76,78 \\
\hline C.V. & 0,367 & 0,340 & 0,241 & & & & \\
\hline
\end{tabular}

Fuente: Elaboración propia a partir de datos de la EPA

Tomando como referencia el año 2013, Canarias (33,7\%), Extremadura (33,9\%) y Andalucía $(36,2 \%)$ representan los peores datos de tasas de paro (entre 30 y 28 puntos más que el promedio nacional), mientras que País Vasco $(16,6 \%)$ y Navarra $(17,9 \%)$ son las mejor situadas, con tasas de paro de más de 30 puntos inferiores al promedio nacional.

En el análisis de regresión simple representado en el Gráfico 5.8 se puede comprobar que la tasa de paro total ${ }^{92}$ tiene una relación estrecha, que llega a explicar el $75,2 \%$ de la variabilidad registrada en el nivel de abandono escolar temprano a nivel regional. Así pues, en este caso, se corrobora el efecto apuntado por Micklewright et al. (1990), según el cual el desempleo general produce un desincentivo sobre las decisiones de escolarización.

${ }^{92}$ En este caso, la tasa de paro se ha seleccionado con un retardo de 2 años, puesto que de esta manera se recoge mejor la posible influencia del efecto del desempleo esperado. 
Gráfico 5.8. Tasa de abandono escolar temprano versus tasa de paro en las CCAA españolas

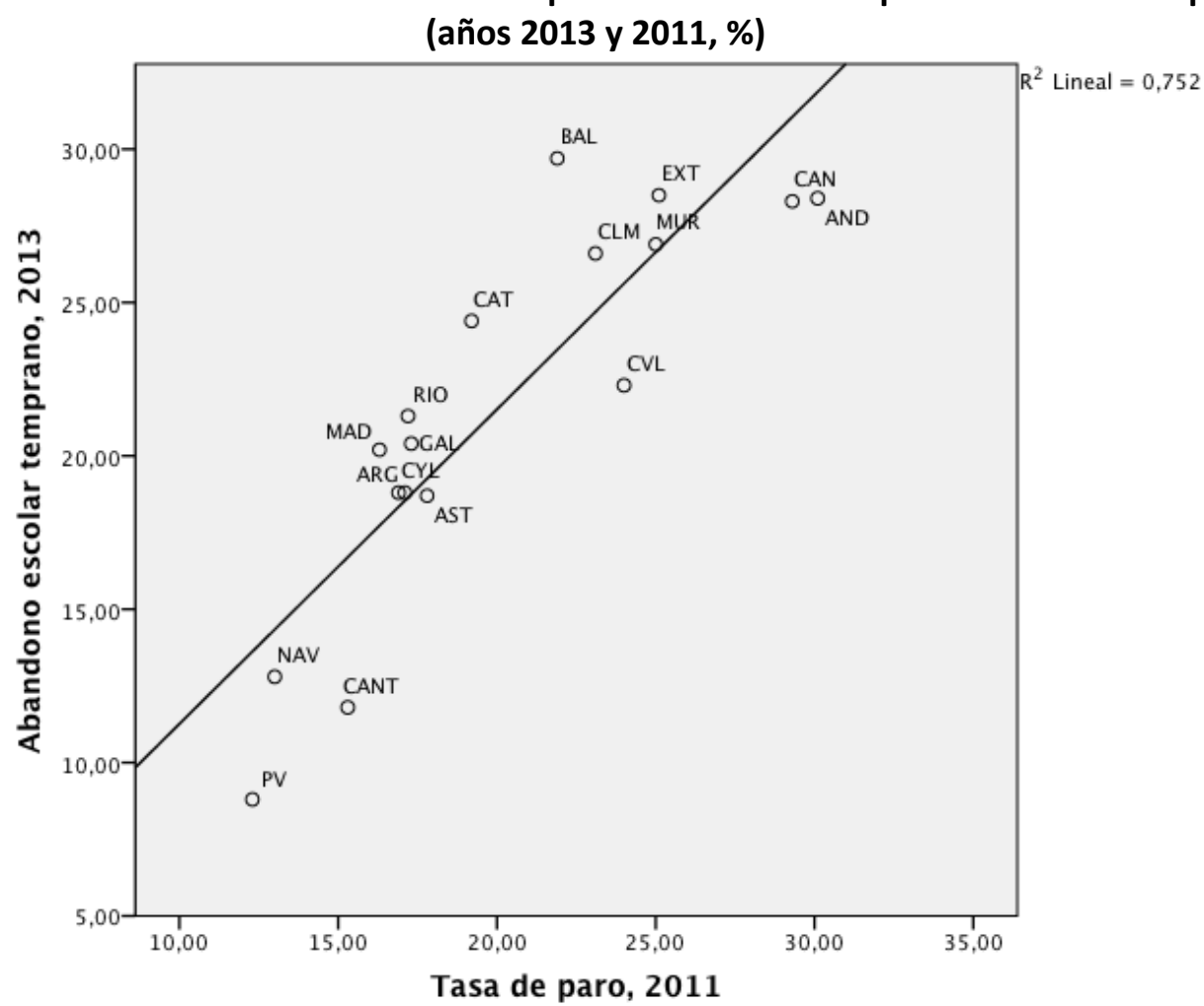

Fuente: Elaboración propia a partir de datos de la EPA y el MECD

De la misma forma, si se repite el análisis tomando como referencia el año 2006, anterior a la crisis económica, para la variable dependiente, se puede comprobar como la relación pierde capacidad explicativa, ya que la bondad de ajuste desciende hasta el 22,6\%, siendo el p-valor ligeramente superior (0,054, ver Cuadro AIV.1 del Anexo IV) al criterio para poder rechazar la hipótesis nula, por lo que es necesario esperar al análisis de panel de datos realizado en el capítulo sexto para extraer conclusiones con un mayor grado de precisión.

En segundo lugar se ha tenido en cuenta la tasa de paro de la población menor de 25 años $^{93}$, observándose (ver Cuadro 5.11) un comportamiento aún más desfavorable que la tasa de paro general, con un incremento medio anual acumulativo del $8,68 \%$ entre los años 2002 y 2013 . En el primer sub-periodo se ha registrado un aumento moderado (1,63\%), mientras que, en el segundo, el incremento del indicador para esta franja de edad se dispara, con un crecimiento medio anual acumulativo del

${ }^{93}$ La tasa está calculada a partir del promedio de los datos trimestrales de la tasa de paro de la población menor de 25 años. Para ver los datos completos del periodo $2002-2013$, consultar Cuadro AIV.23 del Anexo IV. 
10,11\% anual, alcanzando en el año 2013 la alarmante cifra del 55,5\% en el promedio nacional.

Este incremento ha sido desigual a nivel regional, con comunidades como Castilla-La Mancha, Aragón, Navarra o La Rioja, que han aumentado su tasa de paro entre la población menor de 25 años a un ritmo medio acumulativo superior al $12 \%$ anual, si bien es cierto que las tres últimas se encontraban por debajo del promedio nacional. El patrón norte-sur se vuelve a repetir en esta ocasión, con las excepciones de Baleares, que se encuentra con una tasa de paro joven 17,5 puntos inferior al promedio nacional, y Murcia, que con una tasa de paro joven del 53,5\% se sitúa 3,6 puntos por debajo del promedio.

Cuadro 5.11. Tasa de paro de la población menor de 25 años por CCAA (\%)

\begin{tabular}{|c|c|c|c|c|c|c|c|}
\hline & \multirow{2}{*}{2002} & \multirow{2}{*}{2008} & \multirow{2}{*}{2013} & \multicolumn{3}{|c|}{$\begin{array}{c}\text { Tasa de Crecimiento Medio } \\
\text { Anual Acumulativo }\end{array}$} & \multirow{2}{*}{$\begin{array}{c}\text { Diferencial } \\
\text { interregional } \\
(\text { España }=100)\end{array}$} \\
\hline & & & & $\begin{array}{c}2002- \\
2008\end{array}$ & $\begin{array}{c}2009- \\
2013\end{array}$ & Total & \\
\hline España & 22,2 & 24,5 & 55,5 & $1,63 \%$ & $10,11 \%$ & $8,68 \%$ & 100 \\
\hline Andalucía & 31,3 & 31,2 & 66,0 & $-0,09 \%$ & $10,00 \%$ & $7,01 \%$ & 118,89 \\
\hline Aragón & 14,0 & 19,8 & 50,3 & $5,95 \%$ & $12,19 \%$ & $12,33 \%$ & 90,59 \\
\hline Asturias & 23,0 & 21,7 & 55,0 & $-1,01 \%$ & $11,89 \%$ & $8,23 \%$ & 99,18 \\
\hline Baleares & 14,6 & 24,2 & 45,8 & $8,76 \%$ & $9,11 \%$ & $10,94 \%$ & 82,51 \\
\hline Canarias & 19,4 & 31,9 & 65,3 & $8,62 \%$ & $8,12 \%$ & $11,65 \%$ & 117,64 \\
\hline Cantabria & 23,3 & 19,3 & 52,5 & $-3,12 \%$ & $14,89 \%$ & $7,66 \%$ & 94,70 \\
\hline Castilla y León & 24,8 & 22,5 & 49,8 & $-1,65 \%$ & $11,62 \%$ & $6,53 \%$ & 89,67 \\
\hline Castilla-La Mancha & 17,6 & 23,0 & 61,4 & $4,54 \%$ & $14,08 \%$ & $12,04 \%$ & 110,72 \\
\hline Cataluña & 20,7 & 20,1 & 50,2 & $-0,54 \%$ & $8,01 \%$ & $8,39 \%$ & 90,56 \\
\hline C. Valenciana & 20,7 & 26,1 & 56,3 & $3,98 \%$ & $9,28 \%$ & $9,54 \%$ & 101,45 \\
\hline Extremadura & 31,7 & 29,1 & 61,3 & $-1,44 \%$ & $10,31 \%$ & $6,17 \%$ & 110,43 \\
\hline Galicia & 24,5 & 21,1 & 49,9 & $-2,46 \%$ & $13,22 \%$ & $6,70 \%$ & 89,99 \\
\hline Madrid & 15,0 & 20,8 & 48,8 & $5,63 \%$ & $9,30 \%$ & $11,36 \%$ & 87,97 \\
\hline Murcia & 20,8 & 23,3 & 53,5 & $1,91 \%$ & $12,09 \%$ & $8,95 \%$ & 96,41 \\
\hline Navarra & 12,4 & 19,0 & 48,1 & $7,29 \%$ & $12,09 \%$ & $13,08 \%$ & 86,69 \\
\hline País Vasco & 21,9 & 19,5 & 46,5 & $-1,92 \%$ & $10,15 \%$ & $7,10 \%$ & 83,83 \\
\hline Rioja & 13,6 & 21,8 & 47,7 & $8,11 \%$ & $9,52 \%$ & $12,07 \%$ & 86,05 \\
\hline C.V. & 0,278 & 0,176 & 0,121 & & & & \\
\hline
\end{tabular}

Fuente: Elaboración propia a partir de datos de la EPA

Si atendemos a la relación de la tasa de paro de la población menor de 25 años con el abandono escolar temprano, se comprueba que existe cierto patrón por el cual las comunidades con mayor desempleo en esta franja de edad, presentan también 
unas tasas de abandono escolar temprano elevadas. Sin embargo, el $p$-valor asociado a la hipótesis nula de que el coeficiente no es significativo lleva a descartar la significatividad de esta variable en el presente análisis de regresión (ver resultados en Cuadro AV.1 del Anexo V) ${ }^{94}$, por lo no es posible extraer conclusiones precisas de la misma.

Una vez analizada la influencia del mercado laboral en general, merece la pena profundizar en fenómenos como el boom inmobiliario, que ha podido influir en las decisiones de abandono prematuro del sistema educativo. Como señala García Montalvo (2013), la caída del sector construcción iniciada en el año 2008 ha tenido unos efectos devastadores no sólo en términos de PIB, sino que ha afectado de manera especial al empleo, siendo además este efecto heterogéneo entre comunidades autónomas. Así pues, el Cuadro 5.12 muestra el porcentaje de población ocupada en el sector construcción, aunque en este caso, los datos disponibles elaborados a través de la Encuesta de Población Activa se inician en el año 2008, por lo que no se dispone de un año base anterior a la crisis, como ocurre en el resto de variables analizadas. Por consiguiente, se puede observar un brusco descenso de la participación en este sector productivo fruto del impacto de la crisis.

De este modo, en el periodo $2008-2013^{95}$ se ha producido en promedio unos descensos del 12,91\% medio anual acumulativo, siendo el porcentaje de ocupados en el sector construcción el 6\% para el año 2013. Las regiones del sur (Murcia, Andalucía, Castilla-La Mancha, Comunidad Valenciana, Baleares y Canarias) han sido las más afectadas, con unos descensos por encima de la media, si bien es cierto que todas ellas se encontraban por encima del promedio nacional en el año 2008, pasando Andalucía, Canarias, Comunidad Valenciana y Murcia a situarse en valores inferiores al $6 \%$ en el año 2013. No obstante, Baleares y Castilla-La Mancha siguen presentando las mayores proporciones de ocupados en este sector, siendo en torno a 30 y 23 puntos más altas

\footnotetext{
${ }^{94}$ El p-valor asociado es 0,20 tomando como referencia el año 2013. Repitiendo el análisis para el año 2006, el p-valor arroja un valor de 0,454 que sigue sin permitir rechazar la hipótesis nula.

${ }^{95}$ Para ver los datos completos del periodo 2008 - 2013, consultar el Cuadro AIV.24 del Anexo IV.
} 
que en el conjunto nacional respectivamente. Por el contrario, Madrid, Andalucía son las comunidades que menos proporción de ocupados en este sector registran, siendo entre 12 y 17 puntos inferiores al promedio nacional aproximadamente.

\begin{tabular}{|c|c|c|c|c|}
\hline & \multirow[t]{2}{*}{2008} & \multirow[t]{2}{*}{2013} & $\begin{array}{c}\text { Tasa de Crecimiento } \\
\text { Medio Anual } \\
\text { Acumulativo }\end{array}$ & \multirow[t]{2}{*}{$\begin{array}{c}\text { Diferencial } \\
\text { interregional } \\
(\text { España }=100)\end{array}$} \\
\hline & & & 2008-2013 & \\
\hline España & 12,0 & 6,0 & $-12,91 \%$ & 100 \\
\hline Andalucía & 13,2 & 5,3 & $-16,87 \%$ & 87,14 \\
\hline Aragón & 11,1 & 6,0 & $-11,54 \%$ & 99,59 \\
\hline Asturias & 11,6 & 6,4 & $-11,28 \%$ & 105,39 \\
\hline Baleares & 15,9 & 7,8 & $-13,17 \%$ & 129,88 \\
\hline Canarias & 12,5 & 5,7 & $-14,62 \%$ & 93,78 \\
\hline Cantabria & 13,1 & 7,3 & $-11,10 \%$ & 120,75 \\
\hline Castilla y León & 11,8 & 7,2 & $-9,39 \%$ & 119,09 \\
\hline Castilla-La Mancha & 15,9 & 7,5 & $-14,01 \%$ & 123,65 \\
\hline Cataluña & 11,4 & 6,2 & $-11,46 \%$ & 102,49 \\
\hline C. Valenciana & 13,2 & 5,9 & $-14,80 \%$ & 98,34 \\
\hline Extremadura & 13,6 & 6,9 & $-12,75 \%$ & 114,11 \\
\hline Galicia & 11,2 & 6,9 & $-9,26 \%$ & 114,11 \\
\hline Madrid & 10,0 & 5,1 & $-12,77 \%$ & 83,82 \\
\hline Murcia & 13,9 & 5,5 & $-17,11 \%$ & 90,46 \\
\hline Navarra & 11,1 & 5,6 & $-12,91 \%$ & 92,12 \\
\hline País Vasco & 9,2 & 6,5 & $-6,76 \%$ & 107,88 \\
\hline Rioja & 11,7 & 6,3 & $-11,57 \%$ & 104,56 \\
\hline C.V. & 0,147 & 0,129 & & \\
\hline
\end{tabular}

Fuente: Elaboración propia a partir de datos de la EPA

El Gráfico 5.9 muestra la relación relativamente alta que presenta el porcentaje de ocupados en el sector de la construcción a nivel regional con el abandono escolar temprano para el año $2008^{96}$. Ello vendría a corroborar las conclusiones planteadas en trabajos anteriores (Black et al., 2005; Aparicio, 2010), que revelan que los procesos expansionistas de sectores basados en el empleo de mano de obra no cualificada producen efectos de desincentivación de la demanda educativa, y que por tanto, estos fenómenos a nivel agregado pueden explicar una parte de las diferencias regionales en el nivel de abandono escolar temprano.

${ }^{96}$ Se ha seleccionado el año 2008 para realizar la regresión puesto que es el año con una mayor proporción de ocupados en el sector construcción. 
Gráfico 5.9. Tasa de abandono escolar temprano versus porcentaje de ocupados en el sector

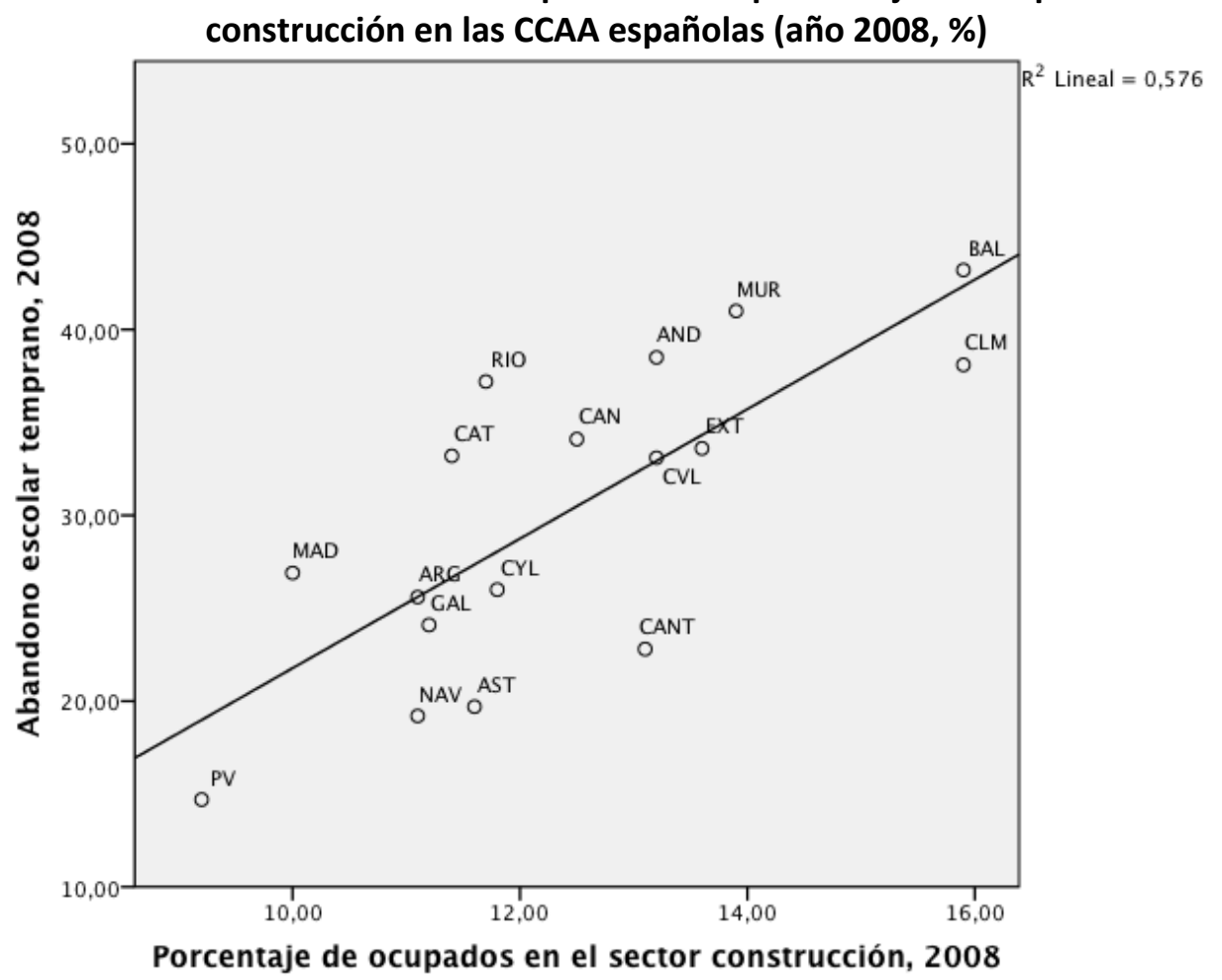

Fuente: Elaboración propia a partir de datos de la EPA y el MECD

Otra característica que puede suponer un efecto atracción hacia el mercado laboral son los salarios, especialmente entre la población más joven. Si se observan los datos del salario medio de la población menor de 25 años, representados en el Cuadro $5.13^{97}$, se puede concluir que el ascenso registrado en el primer sub-periodo (20042008) es similar a la caída que se produce en el segundo (2009-2012), estando en torno al 5\% medio anual acumulativo tanto el incremento como el descenso.

En el periodo de crecimiento, Navarra, Castilla-La Mancha y Extremadura fueron las regiones que más incrementaron este indicador, con tasas de crecimiento medio anual acumulativo de entre el $8 \%$ y el $11 \%$ aproximadamente, aunque desde puntos de partida desfavorables respecto al promedio nacional. En el periodo de crisis, Asturias, Baleares, Comunidad Valenciana y Murcia fueron las comunidades en las que decrecieron más pronunciadamente los salarios medios entre la población menor de

${ }^{97}$ Los datos, extraídos de la Encuesta de Estructura Salarial del INE, están únicamente disponibles para el periodo 2004-2012. Los datos están en términos constantes, tomando como referencia los índices de volumen encadenados de cada región con base 2008 de la estadística de Contabilidad Regional de España del INE. 
25 años, cayendo en todas ellas en más de un 7\% medio anual acumulativo. Para el año 2012, último con datos disponibles, País Vasco y Navarra, con un $22 \%$ y $26 \%$ respectivamente por encima del promedio nacional, se sitúan como las regiones con mejores salarios medios para la población de este tramo de edad, mientras que Canarias y Comunidad Valenciana son las comunidades peor situadas en este indicador.

\begin{tabular}{|c|c|c|c|c|c|c|c|}
\hline Cuadro 5. & \multirow{2}{*}{2004} & \multirow{2}{*}{2008} & \multirow{2}{*}{2012} & \multicolumn{3}{|c|}{$\begin{array}{c}\text { Tasa de Crecimiento Medio } \\
\text { Anual Acumulativo }\end{array}$} & \multirow{2}{*}{$\begin{array}{c}\text { Diferencial } \\
\text { interregional } \\
(\text { España }=100)\end{array}$} \\
\hline & & & & $\begin{array}{c}2004- \\
2008\end{array}$ & $\begin{array}{c}2009- \\
2012\end{array}$ & Total & \\
\hline España & $10.556,2$ & $12.953,6$ & $10.462,2$ & $5,25 \%$ & $-4,69 \%$ & $-0,11 \%$ & 100 \\
\hline Andalucía & $10.220,4$ & $12.599,9$ & $9.778,6$ & $5,37 \%$ & $-5,28 \%$ & $-0,55 \%$ & 93,47 \\
\hline Aragón & $10.722,7$ & $13.923,1$ & $10.553,4$ & $6,75 \%$ & $-5,86 \%$ & $-0,20 \%$ & 100,87 \\
\hline Asturias & $10.486,7$ & $13.056,2$ & $10.123,4$ & $5,63 \%$ & $-7,40 \%$ & $-0,44 \%$ & 96,76 \\
\hline Baleares & $11.299,3$ & $13.570,1$ & $10.096,1$ & $4,68 \%$ & $-7,91 \%$ & $-1,40 \%$ & 96,50 \\
\hline Canarias & $9.924,3$ & $11.306,4$ & $9.405,5$ & $3,31 \%$ & $-3,89 \%$ & $-0,67 \%$ & 89,90 \\
\hline Cantabria & $10.414,7$ & $13.785,7$ & $10.733,5$ & $7,26 \%$ & $-2,05 \%$ & $0,38 \%$ & 102,59 \\
\hline Castilla y León & $9.928,0$ & $12.944,1$ & $11.303,9$ & $6,86 \%$ & $-3,25 \%$ & $1,64 \%$ & 108,05 \\
\hline Castilla-La Mancha & $9.227,3$ & $13.061,0$ & $11.298,2$ & $9,08 \%$ & $-3,25 \%$ & $2,56 \%$ & 107,99 \\
\hline Cataluña & $11.467,2$ & $13.371,9$ & $10.755,4$ & $3,92 \%$ & $-4,24 \%$ & $-0,80 \%$ & 102,80 \\
\hline C. Valenciana & $10.395,8$ & $12.572,4$ & $9.072,3$ & $4,87 \%$ & $-7,36 \%$ & $-1,69 \%$ & 86,72 \\
\hline Extremadura & $8.721,3$ & $12.082,4$ & $9.464,3$ & $8,49 \%$ & $-5,95 \%$ & $1,03 \%$ & 90,46 \\
\hline Galicia & $9.436,3$ & $11.705,6$ & $9.611,9$ & $5,54 \%$ & $-5,11 \%$ & $0,23 \%$ & 91,87 \\
\hline Madrid & $10.733,7$ & $12.870,5$ & $11.156,8$ & $4,64 \%$ & $-2,45 \%$ & $0,48 \%$ & 106,64 \\
\hline Murcia & $10.405,5$ & $12.663,7$ & $9.947,6$ & $5,03 \%$ & $-7,16 \%$ & $-0,56 \%$ & 95,08 \\
\hline Navarra & $10.433,6$ & $15.524,7$ & $13.241,9$ & $10,45 \%$ & $-4,63 \%$ & $3,02 \%$ & 126,57 \\
\hline País Vasco & $12.175,3$ & $15.405,9$ & $12.767,7$ & $6,06 \%$ & $-5,57 \%$ & $0,60 \%$ & 122,04 \\
\hline Rioja & $10.575,7$ & $13.303,2$ & $10.415,2$ & $5,90 \%$ & $-6,69 \%$ & $-0,19 \%$ & 99,55 \\
\hline C.V. & 0,080 & 0,084 & 0,107 & & & & \\
\hline
\end{tabular}

Fuente: Elaboración propia a partir de datos de la Encuesta de Estructura Salarial

En el Gráfico 5.10 se representa el análisis de regresión realizado utilizando como variable dependiente el salario medio por trabajador menor de 25 años para el año $2008^{98}$, de pleno auge de la burbuja inmobiliaria y con un índice de abandono escolar temprano que superaba el $30 \%$ en el promedio nacional.

\footnotetext{
98 Únicamente existen datos de la serie desde el año 2004. Para ver los datos completos del periodo 2004 - 2012, consultar el Cuadro AIV.25 del Anexo IV.
} 
Gráfico 5.10. Tasa de abandono escolar temprano versus salario medio anual por trabajador

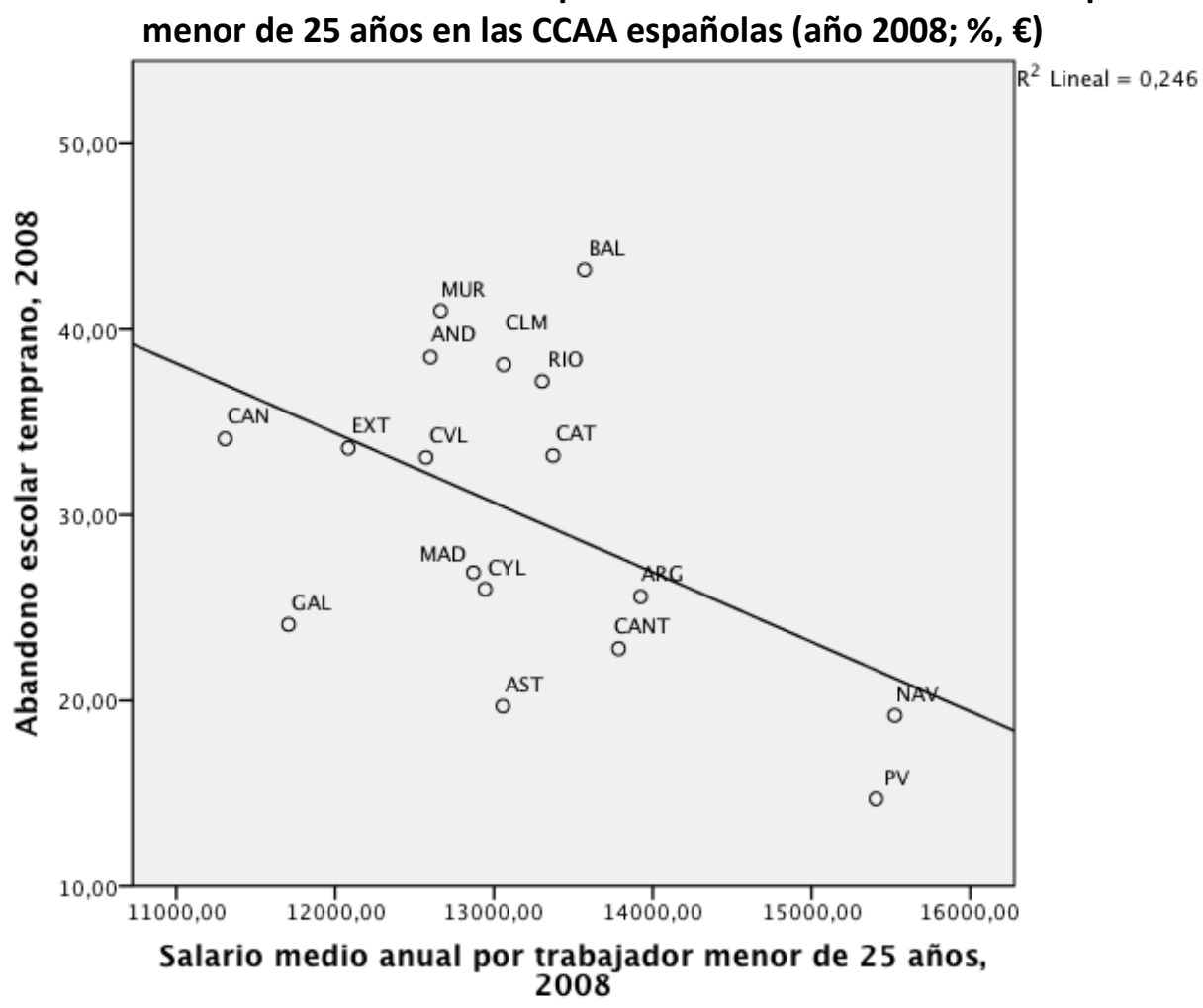

Fuente: Elaboración propia a partir de datos de la Encuesta de Estructura Salarial y del MECD

Como puede observarse, la relación de esta variable con el abandono escolar temprano, que presenta una bondad de ajuste del $24,6 \%$, es de coeficiente negativo, de forma que las comunidades con salarios más altos para los jóvenes menores de 25 años registran las tasas de abandono escolar más bajas, por lo que este resultado, a priori, contradice las conclusiones apuntadas por estudios anteriores como los de Neumark y Wascher (1995), Aparicio (2010) o Lacuesta et al. (2012). Ello puede ser, por otra parte, una señal de que, a nivel agregado, los salarios más altos para este tramo de edad se concentran en aquellas regiones con una estructura productiva basada en sectores de alto valor añadido. Como apunta López-Bazo y Motellón (2013), los salarios medios tienden a ser más altos en las regiones que cuentan con un mayor nivel de cualificación entre sus trabajadores. No obstante, estos datos deben tomarse con precaución, puesto que varias observaciones de la variable dependiente corresponden a cifras estadísticas no significativas ${ }^{99}$.

\footnotetext{
${ }^{99}$ Para ver las observaciones estadísticamente no significativas, ir a Cuadro AIV.25 del Anexo IV.
} 
Así pues, parece que la cantidad de trabajo demanda ha tenido un mayor peso que el salario en la explicación de las diferencias regionales del efecto expulsión que ejerce el mercado de trabajo sobre la escolarización. No obstante, cabe matizar el posible sesgo del análisis de los salarios de la población joven, ya que las diferencias regionales de esta variable pueden venir determinadas por factores exógenos como la negociación colectiva, además de que conviene tener en cuenta los también dispares niveles del coste de vida de las diferentes comunidades autónomas españolas.

Otro de los aspectos que se pueden analizar del mercado de trabajo es la exigencia formativa de la fuerza laboral, ya que diferencias en el nivel de formación de la población ocupada pueden explicar el efecto expulsión hacia el mercado de trabajo entre las diferentes comunidades autónomas. Por ello, el Cuadro 5.14 muestra los datos correspondientes a un índice de descualificación de la población ocupada, que ha sido calculado como la proporción de población ocupada que posee un nivel educativo inferior a la educación secundaria segunda etapa ${ }^{100}$.

Como puede observarse, el índice de descualificación ha caído a un ritmo del $3,11 \%$ medio anual acumulativo entre los años 2002 y $2013^{101}$, pasando de ser prácticamente la mitad de la población ocupada la que no disponía de estudios más allá de la primera etapa de la educación secundaria (ESO o equivalente) en el año 2002 a un $35,4 \%$ para el año 2013. Este descenso, al contrario que otras variables, ha sido paulatino y constante, sin hallarse diferencias significativas entre los dos sub-periodos analizados.

${ }^{100}$ Calculado como el promedio anual de la proporción de población ocupada que es analfabeta, o cuenta con estudios de educación primaria o educación secundaria primera etapa.

${ }^{101}$ Para ver los datos del periodo $2002-2013$ al completo, ver el Cuadro AIV.26 del Anexo IV. 


\begin{tabular}{|c|c|c|c|c|c|c|c|}
\hline & \multirow[t]{2}{*}{2002} & \multirow[t]{2}{*}{2008} & \multirow[t]{2}{*}{2013} & \multicolumn{3}{|c|}{$\begin{array}{c}\text { Tasa de Crecimiento } \\
\text { Medio Anual } \\
\text { Acumulativo }\end{array}$} & \multirow{2}{*}{$\begin{array}{c}\text { Diferencial } \\
\text { interregional } \\
\text { (España = 100) }\end{array}$} \\
\hline & & & & $\begin{array}{c}2002- \\
2008\end{array}$ & $\begin{array}{c}2009- \\
2013\end{array}$ & Total & \\
\hline España & 50,1 & 42,0 & 35,4 & $-2,91 \%$ & $-3,05 \%$ & $-3,11 \%$ & 100 \\
\hline Andalucía & 56,1 & 49,6 & 41,7 & $-2,03 \%$ & $-2,84 \%$ & $-2,66 \%$ & 117,80 \\
\hline Aragón & 48,3 & 37,9 & 33,2 & $-3,99 \%$ & $-1,58 \%$ & $-3,37 \%$ & 93,64 \\
\hline Asturias & 47,2 & 38,3 & 30,2 & $-3,42 \%$ & $-4,25 \%$ & $-3,99 \%$ & 85,17 \\
\hline Baleares & 52,6 & 48,9 & 39,2 & $-1,20 \%$ & $-4,50 \%$ & $-2,64 \%$ & 110,66 \\
\hline Canarias & 53,2 & 47,3 & 40,3 & $-1,92 \%$ & $-1,69 \%$ & $-2,48 \%$ & 113,84 \\
\hline Cantabria & 49,1 & 38,3 & 29,2 & $-4,05 \%$ & $-6,15 \%$ & $-4,63 \%$ & 82,34 \\
\hline Castilla y León & 50,3 & 42,6 & 34,4 & $-2,73 \%$ & $-4,44 \%$ & $-3,39 \%$ & 97,18 \\
\hline Castilla-La Mancha & 59,7 & 52,7 & 43,9 & $-2,07 \%$ & $-2,84 \%$ & $-2,76 \%$ & 123,94 \\
\hline Cataluña & 48,1 & 41,2 & 35,8 & $-2,53 \%$ & $-2,44 \%$ & $-2,63 \%$ & 101,20 \\
\hline C. Valenciana & 57,4 & 45,1 & 39,4 & $-3,94 \%$ & $-2,47 \%$ & $-3,36 \%$ & 111,30 \\
\hline Extremadura & 58,9 & 54,3 & 47,9 & $-1,35 \%$ & $-2,23 \%$ & $-1,86 \%$ & 135,24 \\
\hline Galicia & 57,7 & 45,6 & 40,3 & $-3,84 \%$ & $-2,53 \%$ & $-3,20 \%$ & 113,91 \\
\hline Madrid & 38,1 & 29,3 & 23,3 & $-4,29 \%$ & $-4,95 \%$ & $-4,37 \%$ & 65,82 \\
\hline Murcia & 55,7 & 50,3 & 44,5 & $-1,70 \%$ & $-2,09 \%$ & $-2,03 \%$ & 125,64 \\
\hline Navarra & 42,1 & 34,6 & 28,7 & $-3,25 \%$ & $-4,11 \%$ & $-3,42 \%$ & 81,14 \\
\hline País Vasco & 38,9 & 29,4 & 24,4 & $-4,54 \%$ & $-2,75 \%$ & $-4,15 \%$ & 68,86 \\
\hline Rioja & 51,6 & 41,2 & 34,5 & $-3,69 \%$ & $-1,48 \%$ & $-3,59 \%$ & 97,39 \\
\hline C.V. & 0,131 & 0,176 & 0,198 & & & & \\
\hline
\end{tabular}

Fuente: Elaboración propia a partir de datos de la EPA

Por comunidades, Cantabria, Madrid y País Vasco son las que más han reducido este indicador (en más de un $4 \%$ medio anual acumulativo) mientras que Extremadura ha registrado la reducción más limitada con un $1,86 \%$, contando con una proporción de población ocupada de baja cualificación que asciende al 47,9\%, la máxima nacional. En el otro extremo se encuentran Madrid y País Vasco, que poseen las proporciones de ocupados descualificados más bajas ( $23,3 \%$ y $24,4 \%$ respectivamente). Como apuntan López-Bazo y Motellón (2013), la adquisición de mayores niveles educativos ejerce un efecto positivo sobre la probabilidad de estar activo y ocupado, de lo que puede deducirse, que estos descensos han podido producirse al destruirse más empleos de baja cualificación.

El Gráfico 5.11 revela, por otra parte, la estrecha relación que tiene el índice de descualificación de la población ocupada con el abandono escolar temprano, por el cual a mayor índice, es decir, menor nivel de instrucción formativa del mercado laboral 
de una comunidad autónoma, ésta presenta un mayor nivel de abandono escolar temprano. En este sentido, la capacidad explicativa de esta variable asciende al $66,7 \%$ para el año 2013 , siendo incluso mayor $(69,4 \%)$ para el año 2006 , antes del inicio de la crisis económica.

Gráfico 5.11. Tasa de abandono escolar temprano versus índice de descualificación de la población ocupada en las CCAA españolas (años 2006 y 2013, \%)
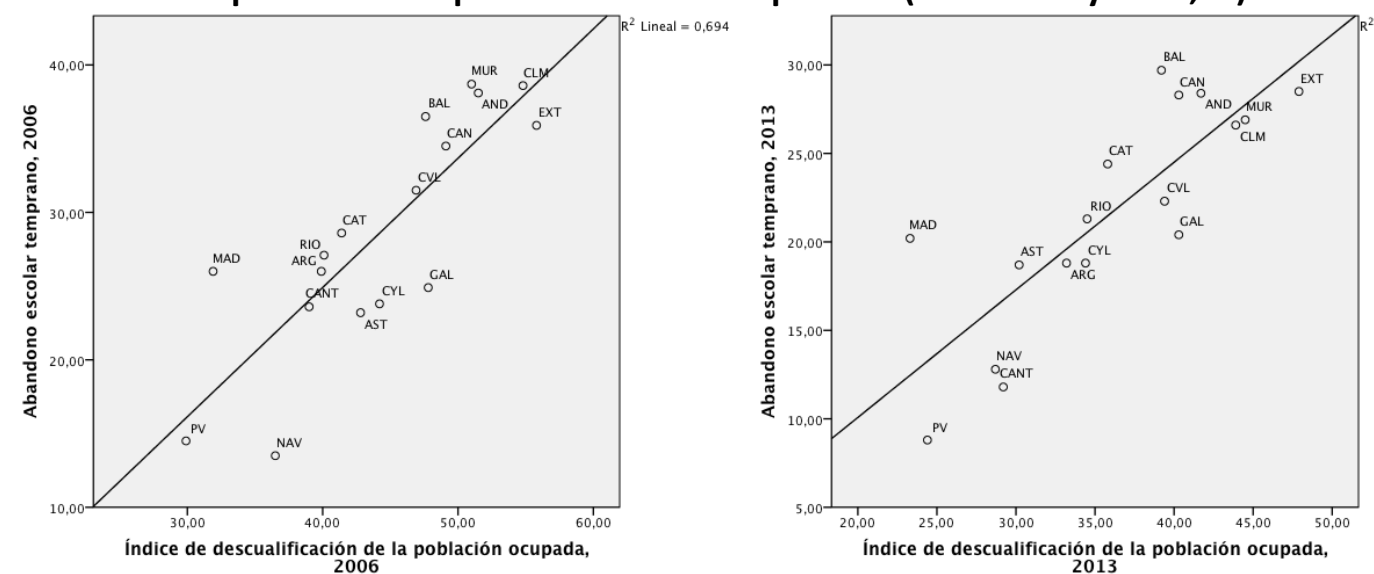

Fuente: Elaboración propia a partir de datos de la EPA

\subsection{Análisis de los factores del contexto socio-cultural}

\subsubsection{Nivel educativo de la población adulta}

En este sub-epígrafe se emplean dos variables relacionadas con el entorno cultural y social que se extraen de la revisión de la literatura. El primer aspecto señalado, a este respecto, fue el nivel instructivo del entorno familiar y social del alumnado. En este sentido, se utiliza un indicador similar al índice de descualificación de la población ocupada, pero referido a la población total, como una medida del nivel de instrucción del contexto general.

El Cuadro 5.15 muestra la también decreciente evolución del índice de descualificación de la población adulta, que se refiere a la proporción de la población de entre 18 y 64 años que cuenta con un nivel de estudios inferior a la educación secundaria segunda etapa ${ }^{102}$. Como señala Cabrera Rodríguez (2013), la evolución de las tasas de escolarización en educación superior ha sido dispar a nivel regional y ello ha perpetuado las desigualdades interregionales en términos de demanda educativa.

${ }^{102}$ Para ver los datos del periodo 2000 - 2012 al completo, ver el Cuadro AIV.27 del Anexo IV. 
Aplicado al indicador aquí utilizado, se puede observar que Madrid y País Vasco presentan la población mejor formada a nivel nacional, siendo inferior al $32 \%$ la proporción de población que tiene como máximo la ESO completada, registrando además la mejor evolución a nivel regional. Por el contrario, Extremadura, Castilla-La Mancha, Murcia y Andalucía son las regiones con peores resultados en este indicador, superando el $50 \%$ la proporción de población que no posee estudios postobligatorios (presentando también una evolución relativamente desfavorable).

Cuadro 5.15. Índice de descualificación de la población adulta por CCAA (\%)

\begin{tabular}{|c|c|c|c|c|c|c|c|}
\hline & \multirow{2}{*}{2000} & \multirow{2}{*}{2008} & \multirow{2}{*}{2013} & \multicolumn{3}{|c|}{$\begin{array}{c}\text { Tasa de Crecimiento Medio } \\
\text { Anual Acumulativo }\end{array}$} & \multirow{2}{*}{$\begin{array}{c}\text { Diferencial } \\
\text { interregional } \\
(\text { España = 100) }\end{array}$} \\
\hline & & & & $\begin{array}{c}2000- \\
2008\end{array}$ & $\begin{array}{c}2009- \\
2012 \\
\end{array}$ & Total & \\
\hline España & 63,0 & 48,8 & 45,6 & $-3,14 \%$ & $-1,82 \%$ & $-2,65 \%$ & 100 \\
\hline Andalucía & 69,1 & 57,4 & 54,2 & $-2,29 \%$ & $-1,14 \%$ & $-2,01 \%$ & 118,73 \\
\hline Aragón & 62,1 & 43,2 & 40,5 & $-4,44 \%$ & $-1,01 \%$ & $-3,50 \%$ & 88,70 \\
\hline Asturias & 63,7 & 47,0 & 42,2 & $-3,74 \%$ & $-2,76 \%$ & $-3,38 \%$ & 92,43 \\
\hline Baleares & 66,1 & 52,3 & 47,1 & $-2,87 \%$ & $-3,00 \%$ & $-2,79 \%$ & 103,15 \\
\hline Canarias & 65,4 & 54,0 & 51,1 & $-2,36 \%$ & $-0,80 \%$ & $-2,04 \%$ & 111,93 \\
\hline Cantabria & 59,7 & 44,7 & 38,6 & $-3,55 \%$ & $-5,29 \%$ & $-3,57 \%$ & 84,58 \\
\hline Castilla y León & 62,0 & 48,5 & 43,2 & $-3,02 \%$ & $-3,34 \%$ & $-2,97 \%$ & 94,66 \\
\hline Castilla-La Mancha & 73,3 & 58,9 & 54,2 & $-2,68 \%$ & $-1,73 \%$ & $-2,48 \%$ & 118,78 \\
\hline Cataluña & 59,3 & 47,2 & 45,6 & $-2,80 \%$ & $-1,40 \%$ & $-2,16 \%$ & 99,98 \\
\hline C. Valenciana & 66,1 & 50,6 & 47,7 & $-3,30 \%$ & $-1,78 \%$ & $-2,69 \%$ & 104,44 \\
\hline Extremadura & 72,4 & 62,2 & 61,1 & $-1,87 \%$ & $-0,07 \%$ & $-1,40 \%$ & 133,93 \\
\hline Galicia & 69,9 & 51,8 & 48,6 & $-3,67 \%$ & $-1,87 \%$ & $-2,99 \%$ & 106,48 \\
\hline Madrid & 52,0 & 34,9 & 31,3 & $-4,89 \%$ & $-3,82 \%$ & $-4,14 \%$ & 68,67 \\
\hline Murcia & 64,8 & 56,3 & 53,4 & $-1,73 \%$ & $-1,15 \%$ & $-1,60 \%$ & 117,04 \\
\hline Navarra & 57,1 & 40,9 & 37,9 & $-4,09 \%$ & $-1,77 \%$ & $-3,36 \%$ & 83,04 \\
\hline País Vasco & 52,6 & 36,2 & 31,9 & $-4,57 \%$ & $-3,17 \%$ & $-4,10 \%$ & 69,83 \\
\hline Rioja & 63,3 & 45,6 & 40,6 & $-4,02 \%$ & $-1,76 \%$ & $-3,63 \%$ & 88,96 \\
\hline C.V. & 0,096 & 0,157 & 0,180 & & & & \\
\hline
\end{tabular}

Fuente: Elaboración propia a partir de datos del MECD

Al igual que ocurría para el caso de la población ocupada, se comprueba, en el Gráfico 5.12, que el índice de descualificación de la población adulta tiene una gran capacidad explicativa, con un nivel de bondad de ajuste que alcanza el 68,3\%. 


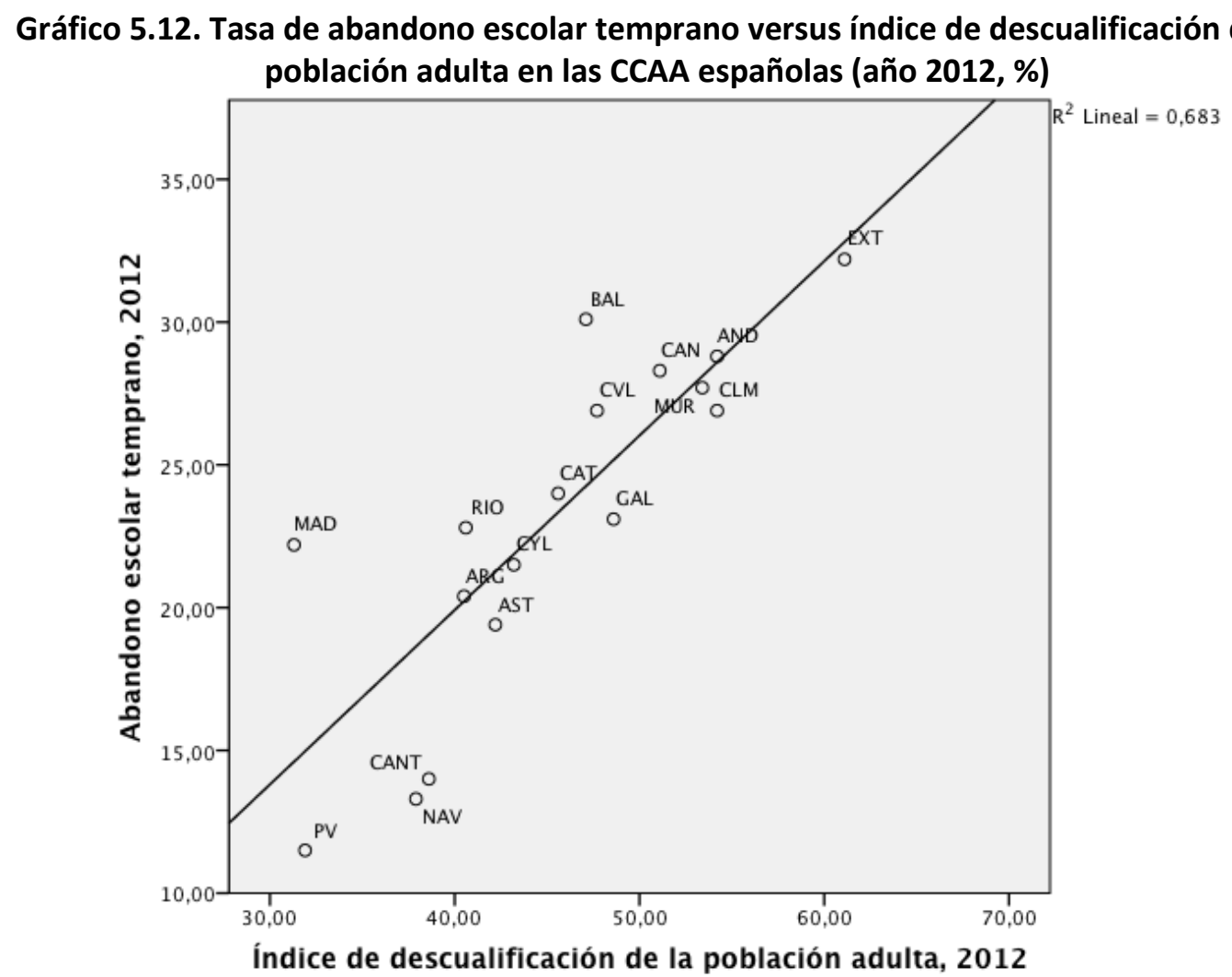

Fuente: Elaboración propia a partir de datos del MECD

Esta relación positiva y significativa entre ambos indicadores es similar a la obtenida por Alegre Canosa y Benito Pérez (2010 y 2014), que utilizan el mismo indicador para el caso de los países de la Unión Europea. Asimismo, la variable utilizada puede servir de proxy para representar el nivel educativo de los padres, por lo que estos resultados estarían también relacionados con los obtenidos por estudios previos como los de Dalton et al. (2009), Petrongolo y San Segundo (2002) o Marks y Fleming (1999), que establecieron que el nivel educativo de los progenitores de los alumnos está estrechamente relacionado con las decisiones de permanencia del alumnado en el sistema educativo.

\subsubsection{Nivel de inmigración}

La condición de inmigrante es otro de los factores apuntados en la literatura para explicar el abandono escolar temprano (Mora Corral, 2010; Calero et al., 2010). De esta forma, a priori, si existen diferencias en la cantidad de inmigrantes que residen en las comunidades autónomas, éstas podrían, en parte, explicar las diferencias en el indicador de abandono escolar temprano. Así pues, el Cuadro 5.16 muestra las cifras 
de la proporción de población inmigrante joven, que es calculada como el cociente de la población inmigrante de entre 15 y 24 años entre el total de población de esa franja de edad. Como puede observarse, el aumento de población inmigrante entre los años 2000 y 2011 ha sido exponencial, pasando de un 2,3\% a un 12,2\%, aunque se observa, a partir del año 2008 una desaceleración en la afluencia de inmigración e incluso un leve descenso en algunas comunidades autónomas ${ }^{103}$. Así pues, es muy notable la diferencia entre el primer sub-periodo, en el que la proporción de población inmigrante joven se incrementa a un ritmo medio acumulativo del $22,3 \%$ anual, mientras que en el segundo sub-periodo se registra un estancamiento general. En este sentido, el efecto de la crisis ha podido jugar un importante papel, al ejercer de factor de expulsión en aquellas regiones que han registrado una peor respuesta ante la recesión (Minondo Uribe-Etxeberria, Requena Silvente y Serrano Domingo, 2013). Por otro lado, hay que tener en cuenta que la crisis también ha traído un significativo aumento de las migraciones exteriores en los tramos de población activa más joven, invirtiéndose la dinámica hasta llegar a saldos migratorios negativos (Reher, Requena y Sanz, 2011; Alba Monteserin, Fernández Asperilla y Martínez Vega, 2013).

${ }^{103}$ Para ver los datos del periodo 2000 - 2011 al completo, consultar el Cuadro AIV.28 del Anexo IV. 


\begin{tabular}{|c|c|c|c|c|c|c|c|}
\hline & \multirow{2}{*}{2000} & \multirow{2}{*}{2008} & \multirow{2}{*}{2011} & \multicolumn{3}{|c|}{$\begin{array}{c}\text { Tasa de Crecimiento Medio } \\
\text { Anual Acumulativo }\end{array}$} & \multirow{2}{*}{$\begin{array}{c}\text { Diferencial } \\
\text { interregional } \\
(\text { España }=100)\end{array}$} \\
\hline & & & & $\begin{array}{l}2000- \\
2008 \\
\end{array}$ & $\begin{array}{c}2009- \\
2011\end{array}$ & Total & \\
\hline España & 2,3 & 11,4 & 12,2 & $22,30 \%$ & $0,45 \%$ & $16,46 \%$ & 100 \\
\hline Andalucía & 1,8 & 7,6 & 8,7 & $20,06 \%$ & $3,27 \%$ & $15,60 \%$ & 71,12 \\
\hline Aragón & 1,0 & 11,7 & 12,7 & $35,78 \%$ & $-0,27 \%$ & $25,90 \%$ & 104,35 \\
\hline Asturias & 0,7 & 3,8 & 4,7 & $22,82 \%$ & $3,62 \%$ & $18,36 \%$ & 38,23 \\
\hline Baleares & 6,5 & 20,8 & 21,8 & $15,71 \%$ & $0,28 \%$ & $11,68 \%$ & 178,92 \\
\hline Canarias & 4,5 & 13,7 & 14,4 & $14,90 \%$ & $0,42 \%$ & $11,18 \%$ & 118,46 \\
\hline Cantabria & 0,8 & 5,7 & 6,6 & $27,85 \%$ & $0,77 \%$ & $21,10 \%$ & 53,90 \\
\hline Castilla y León & 0,7 & 6,1 & 6,8 & $30,04 \%$ & $1,59 \%$ & $22,26 \%$ & 55,37 \\
\hline Castilla-La Mancha & 0,8 & 10,1 & 11,0 & $37,26 \%$ & $0,69 \%$ & $26,91 \%$ & 90,24 \\
\hline Cataluña & 2,9 & 15,0 & 15,7 & $22,79 \%$ & $-0,57 \%$ & $16,62 \%$ & 129,04 \\
\hline C. Valenciana & 3,8 & 16,9 & 17,2 & $20,50 \%$ & $-0,72 \%$ & $14,75 \%$ & 141,18 \\
\hline Extremadura & 0,8 & 3,2 & 3,8 & $18,83 \%$ & $5,47 \%$ & $14,98 \%$ & 30,84 \\
\hline Galicia & 0,9 & 3,4 & 4,0 & $17,56 \%$ & $1,82 \%$ & $13,94 \%$ & 32,40 \\
\hline Madrid & 3,2 & 16,0 & 16,5 & $22,41 \%$ & $-0,63 \%$ & $16,11 \%$ & 134,95 \\
\hline Murcia & 2,3 & 15,8 & 16,4 & $27,40 \%$ & $0,21 \%$ & $19,63 \%$ & 134,37 \\
\hline Navarra & 1,7 & 10,5 & 11,2 & $25,62 \%$ & $-0,22 \%$ & $18,71 \%$ & 91,47 \\
\hline País Vasco & 1,0 & 5,4 & 6,7 & $23,43 \%$ & $4,24 \%$ & $18,69 \%$ & 54,55 \\
\hline Rioja & 1,7 & 13,8 & 14,3 & $30,32 \%$ & $-0,90 \%$ & $21,65 \%$ & 117,56 \\
\hline C.V. & 0,790 & 0,515 & 0,477 & & & & \\
\hline
\end{tabular}

Fuente: Elaboración propia a partir de datos del INE

Por regiones, Baleares es la comunidad que más población inmigrante joven registra, con un 21,8\%, seguida de Comunidad Valenciana (17.2\%), Madrid (16,5\%) y Murcia $(16,4 \%)$, mientras que es en Extremadura (3,8\%) y Galicia $(4 \%)$ donde esta proporción es menor. En cuanto a la evolución, destaca la gran disparidad registrada, si bien es cierto que todas las comunidades autónomas han presentado aumentos muy notables en su población inmigrante joven. Tanto es así, que Canarias, que es la región que menos ha incrementado este indicador, ha multiplicado por más de tres su proporción de población inmigrante joven, mientras que Aragón y Castilla-La Mancha han multiplicado su proporción por más de doce.

Sin embargo, en esta ocasión la variable escogida no guarda relación con el abandono escolar temprano, a la luz de la limitada capacidad explicativa $(9,8 \%)$ y la carencia de significatividad estadística ( $p$-valor de 0,221, ver Cuadro AV.1 del Anexo V) de la regresión simple representada en el Gráfico 5.13. 


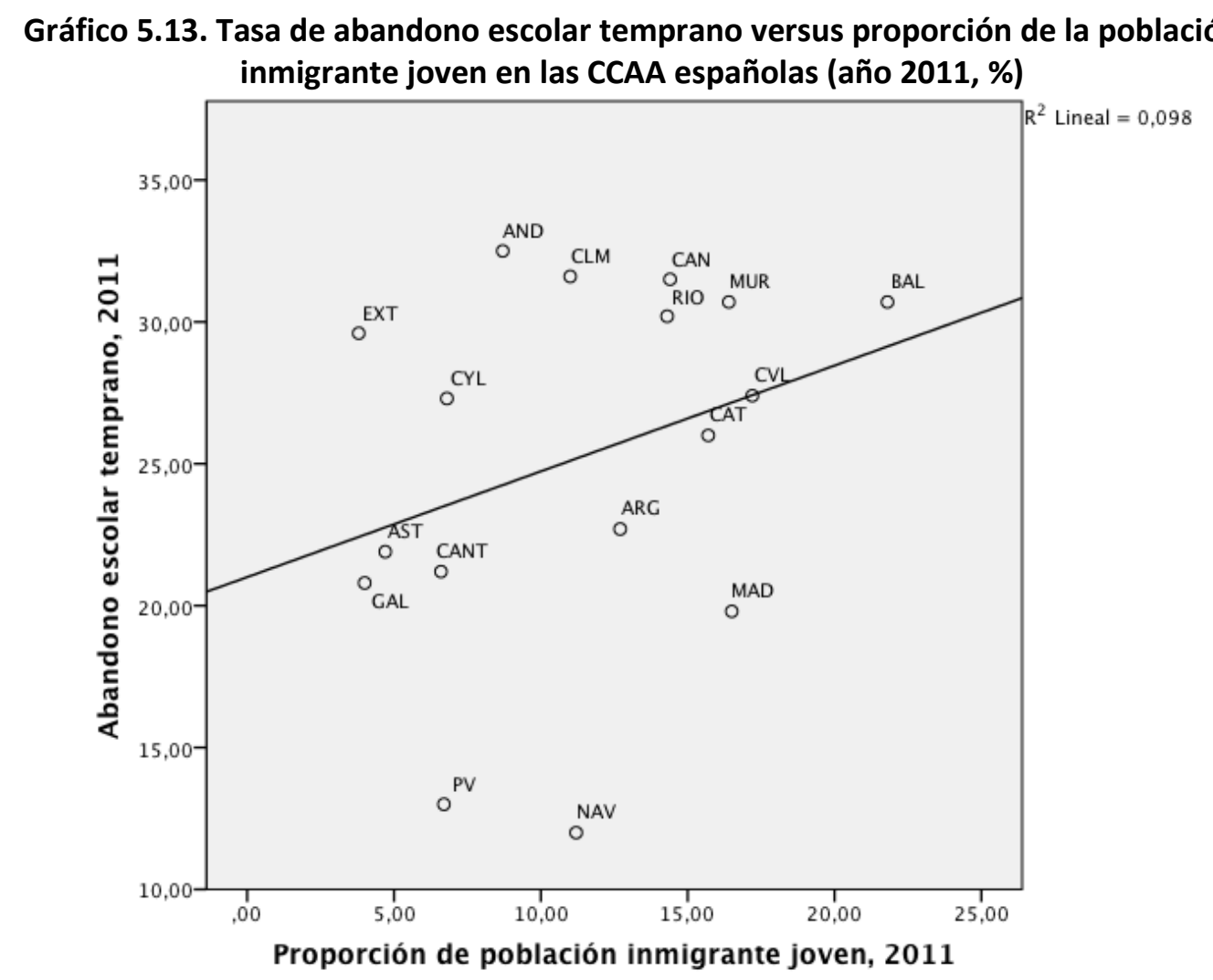

Fuente: Elaboración propia a partir de datos del INE y MECD

En la revisión de la literatura se ha apuntado además al género como factor explicativo del abandono escolar temprano (Fernández-Macías et al., 2013). Sin embargo, a un nivel agregado no existen diferencias significativas entre comunidades autónomas que puedan explicar este fenómeno. Para comprobarlo, se ha construido un índice de masculinidad de la población de 15 a 24 años para el año 2013, comprobando que las diferencias apreciables son muy reducidas, y que no guardan relación alguna - a nivel agregado - con la tasa de abandono escolar temprano (la regresión simple arroja una bondad de ajuste del $2,1 \%)^{104}$.

De la misma forma, se ha construido un indicador para reflejar el efecto que pueden representar las diferencias en el tamaño familiar, ya que algunos estudios esgrimen que a mayor número de hermanos existen mayores probabilidades de obtener peores resultados académicos y abandonar prematuramente el sistema educativo (Dustmann y Van Soest, 2007); aunque este indicador ha resultado no ser

\footnotetext{
${ }^{104}$ Para construir el indicador se ha utilizado la siguiente fórmula: Índice de masculinidad = 100 * ( $\mathrm{n}$ - hombres 15-24 años/no mujeres 15-24 años). Para comprobar el cálculo y consultar los datos, ver el Cuadro AIV.29 del Anexo IV.
} 
relevante a la hora de explicar de forma agregada las diferencias en el indicador de abandono escolar temprano entre comunidades autónomas (la regresión simple da una bondad de ajuste del $13,9 \%$ y carece de significatividad estadística). Asimismo, las diferencias agregadas de la proporción de familias monoparentales, variable recogida en la literatura para explicar el déficit en resultados educativos (Björklund y Chadwick, 2003; Bridgeland et al., 2006), ha resultado ser también no significativa (con una bondad de ajuste del 1,7\%, ver Cuadro AV.1 del Anexo V) ${ }^{105}$.

\subsection{Resumen y conclusiones}

En este capítulo se ha realizado un análisis descriptivo pormenorizado de una relación de variables que ha permitido poner de relieve la composición de la casuística relativa a las diferencias regionales en el nivel de abandono escolar temprano. De esta forma, se ha podido comprobar que factores educativos como el número de alumnos por grupo o el gasto en educación tienen una gran relevancia, aunque dentro del gasto educativo es precisamente el que se realiza en educación primaria el que tiene una mayor capacidad explicativa. Por su parte, tanto la proporción de alumnado como de gasto destinado a la enseñanza concertada ha revelado que tiene una capacidad explicativa notable.

En cuanto a los factores económicos, hemos comprobado que en su mayoría tienen una alta capacidad explicativa, tanto los que tienen que ver con riqueza (PIB per cápita, tasa de riesgo de pobreza), como los asociados al mercado laboral, denotando la especial relación del abandono escolar temprano con la proliferación de trabajo de baja cualificación. Por su parte, las variables relativas al entorno socio-cultural presentan, en su mayoría, limitaciones, y se caracterizan por contar con una capacidad explicativa relativamente baja.

Por consiguiente, es necesario realizar un análisis de carácter multivariante que tenga además en cuenta la evolución de las variables aquí presentadas para discernir,

\footnotetext{
${ }^{105}$ Para ver el cálculo de los indicadores de la proporción de hogares con tres o más hijos y hogares monoparentales, así como sus diferencias regionales, ver el Cuadro AIV.30 del Anexo IV.
} 
con mayor precisión, los efectos de las mismas sobre el abandono escolar temprano. Para ello, el estudio de evolución y desigualdad regional de las variables aquí realizado es útil para seleccionar las variables a incorporar en el modelo, así como para intuir los efectos que estas puedan presentar. 
Capítulo 6 : Un análisis de panel de datos de los factores explicativos del abandono escolar temprano 



\subsection{Introducción}

Tras haber analizado detalladamente la evolución y la desigualdad regional de las variables de contexto educativo, económico y social que condicionan el abandono escolar temprano, el presente capítulo, último de esta tesis doctoral, tiene por objeto realizar un modelo multivariante que explique las diferencias de abandono escolar temprano en las comunidades autónomas españolas.

Así pues, se utilizan estimaciones de modelos de panel de datos, con una selección de variables explicativas, para poder analizar con mayor precisión y robustez la dinámica que las variables presentan en su relación con el abandono escolar temprano.

Después de esta introducción, el segundo epígrafe resume las características principales de la técnica del panel de datos, así como su justificación de uso en este análisis. El tercer epígrafe, de especificación del modelo, expone las variables utilizadas para, en el cuarto, resumir las distintas estimaciones realizadas. Por último, el quinto epígrafe resume los resultados obtenidos, tomando en consideración, además de los resultados de la estimaciones de panel de datos, los análisis realizados en el capítulo cuarto.

\subsection{La técnica de panel de datos}

El panel de datos es un tipo de técnica econométrica muy extendida en el campo de la investigación económica. Según Marco Crespo y Ortiz Serrano (2006), este tipo de análisis tiene su origen en el estudio de funciones de producción agraria a principios de los años 60, siendo el análisis del mercado laboral, veinte años después, su campo de aplicación más destacado.

La técnica de panel de datos posee varias ventajas, ya que al trabajar con datos longitudinales, además de transversales, se aumenta el número de observaciones, por lo que se puede poner de relieve los posibles cambios en la dependencia de las variables explicativas y estudiar la dinámica de las mismas. De este modo, el análisis de panel de datos analiza la relación existente entre una variable dependiente y varias 
variables independientes o predictores, de forma que las ponderaciones de los predictores indican su contribución relativa a la predicción conjunta, a lo largo de un periodo de tiempo acotado y para un número determinado de individuos, de los que se dispone de información en el tiempo.

Por otro lado, el análisis de panel de datos permite controlar aquellos factores que no son observables y que afectan a la heterogeneidad individual de las comunidades autónomas, o aquellos fenómenos que son homogéneos a las mismas pero que cambian en el tiempo (efectos temporales).

\subsection{Especificación del modelo}

En la presente investigación, se ha tratado de seleccionar un conjunto de variables representativas de las tres dimensiones de contexto estudiadas - contexto educativo, económico y socio-cultural - en función de su significatividad y relevancia mostrada en los análisis realizados en el capítulo quinto, además de la disponibilidad de datos. Por consiguiente, el panel de datos mediría el grado en el que las variables de contexto indicen en el comportamiento regional de la tasa de abandono escolar temprano, lo que ayudaría a explicar las notables diferencias apuntadas. De esta forma, las diferentes estimaciones de panel de datos seguirían una especificación de referencia como la que muestra se muestra en la Ecuación 6.1.

$$
Y_{i t}=\alpha_{i}+\beta_{1} X_{1 i t}+\beta_{2} X_{2 i t}+\cdots+\beta_{n} X_{n i t}+\varepsilon_{i t}
$$

, donde " $\alpha_{i}$ " representa el intercepto, " $\mathrm{i}$ " hace referencia a la unidad espacial " $\mathrm{t}$ " a los periodos de tiempo, " $Y$ " representa la variable dependiente, las " $X$ " conforman el conjunto de factores que se incluirán en el análisis, las " $\beta$ " representan los coeficientes de cada una de las variables independientes $y$ " $\varepsilon$ " es el término de error o perturbación.

La variable dependiente " $\gamma$ " representa el abandono escolar temprano, cuya definición conviene recordar, es el número de personas de entre 18 y 24 años que ha 
finalizado como nivel educativo máximo la primera etapa de la educación secundaria y que no sigue recibiendo ningún tipo de formación. La fuente de los datos es Eurostat.

La Tabla 6.1 relaciona el conjunto de variables explicativas seleccionadas para la aplicación del modelo

Tabla 6.1. Relación de variables explicativas

\begin{tabular}{|l|c|c|}
\hline \multicolumn{1}{|c|}{ Sigla } & Variable & Fuente \\
\hline GPA & Gasto público por alumno en educación no universitaria & MECD \\
APG & Alumnos por grupo en ESO & MECD \\
PACC & Porcentaje de alumnado de ESO en educación privada concertada & MECD \\
GPC & Proporción de gasto pública en educación no universitaria destinado a & MECD \\
& conciertos y subvenciones a la enseñanza privada & \\
PIB & PIB per cápita a precios constantes & INE \\
TPARO & Tasa de paro & EPA \\
IDESPA & Índice de descualificación de la población adulta & EPA \\
PPIJ & Proporción de población inmigrante joven & INE \\
\hline
\end{tabular}

Fuente: Elaboración propia

A continuación, se desarrollan las características de cada una de las variables explicativas referenciadas en la Tabla 6.1:

- GPA: Gasto público por alumno en educación no universitaria. Está calculado como el cociente entre el gasto público en educación no universitaria y el número de alumnos de educación no universitaria de régimen general. La fuente es el Ministerio de Educación, Cultura y Deporte (MECD), utilizando los datos de presupuesto liquidado de la Estadística del Gasto Público en Educación. Los datos están en términos constantes, para lo que se han empleado los índices de volumen encadenado a nivel regional con referencia 2008 de la estadística de Contabilidad Regional de España del INE. Esta variable se incluye en el modelo con un retardo de un año, dado que el alumnado al que afecta el gasto agruparía como edad teórica máxima los 18 años, edad mínima de cálculo de la franja de abandono escolar temprano.

- APG: Número medio de alumnos por grupo en ESO. Se trata de una variable relativa al tamaño de la clase. La fuente es el MECD y dado que está referida a la etapa de ESO, lleva un retardo de 3 años, puesto que es el tiempo que le quedaría al alumnado de la edad teórica de inicio del último curso de la ESO 
para alcanzar la edad mínima correspondiente a la franja de edad que mide el abandono escolar temprano.

- PACC: Es el porcentaje de alumnado de ESO en educación privada concertada. Incluye un retardo de 3 años porque, al igual que la variable anterior, está referida a la etapa de la ESO. La fuente de datos es el MECD.

- GPC: Es la proporción de gato público en educación no universitaria destinado a conciertos y subvenciones a la enseñanza privada. Al estar referida a la educación no universitaria y no a la etapa concreta de la ESO, en este caso incorpora, al igual que la variable de gasto público por alumno, un retardo de un año. La fuente de datos es el MECD.

- PIB: Es el PIB per cápita a precios constantes, para lo que, al igual que en el caso del gasto público, se ha tomado como referencia los índices de volumen encadenados de cada región con base 2008 de la estadística de la Contabilidad Regional de España del INE. La fuente de datos es el INE.

- TPARO: Es la tasa de paro, calculada a partir del promedio de los datos trimestrales obtenidos por la Encuesta de Población Activa (EPA). Esta variable incorpora un retardo de dos años, puesto que con ello se recoge el hecho de que es a los 16 años, dos años antes de la edad mínima de la franja de cálculo del abandono escolar temprano, cuando la escolarización deja de ser obligatoria, además de constituir la edad legal para comenzar a trabajar. Es decir, es la edad teórica en la que comienza a existir un coste de oportunidad en términos de percepción de renta asociado a las decisiones de escolarización.

- IDESPA: Es el índice de descualificación de la población adulta. Calculado a partir de datos de la EPA, es la proporción de individuos de entre 18 y 64 años de cada comunidad autónoma que tiene como estudios máximos la primera etapa de la educación secundaria, es decir, la ESO, o anteriores niveles educativos.

- PPIJ: Es la proporción de población inmigrante joven, calculada a partir de datos del INE como el cociente de población inmigrante de entre 15 y 24 años entre el total de población de esa franja de edad. 
Para la realización del modelo, se ha tenido en cuenta el periodo temporal comprendido entre el año 2001 y 2011, ambos incluidos, por lo que se cuenta con once periodos temporales, con 17 individuos (comunidades autónomas) para cada corte transversal, que permiten contar con 187 observaciones en total. Antes de comenzar con las estimaciones de los distintos modelos de panel de datos, es útil observar una panorámica general de los datos que se van a utilizar. En este sentido, el Cuadro 6.1 muestra los estadísticos descriptivos de cada una de las variables en el modelo.

Cuadro 6.1. Estadísticas descriptivas de las variables del modelo

\begin{tabular}{|c|c|c|c|c|c|}
\hline Variable & & Media & $\begin{array}{c}\text { Desviación } \\
\text { típica }\end{array}$ & Mínimo & Máximo \\
\hline \multirow{3}{*}{ AET } & Overall & \multirow{3}{*}{28,879} & 7,624 & 12,000 & 43,200 \\
\hline & between & & 7,416 & 14,245 & 39,564 \\
\hline & within & & 2,468 & 20,015 & 35,297 \\
\hline \multirow{3}{*}{ GPA } & Overall & \multirow{3}{*}{$4.182,152$} & 849,582 & $2.635,624$ & $6.972,814$ \\
\hline & between & & 649,935 & $3.105,003$ & $5.793,026$ \\
\hline & within & & 567,525 & $2.957,609$ & $5.401,281$ \\
\hline \multirow{3}{*}{ APG } & Overall & \multirow{3}{*}{24,402} & 1,822 & 19,722 & 27,798 \\
\hline & between & & 1,518 & 20,901 & 26,798 \\
\hline & within & & 1,067 & 21,430 & 27,653 \\
\hline \multirow{3}{*}{ PIB } & Overall & \multirow{3}{*}{$19.343,950$} & $5.021,500$ & $8.447,173$ & $31.041,470$ \\
\hline & between & & $3.769,526$ & $12.969,180$ & $25.619,260$ \\
\hline & within & & $3.430,755$ & $11.635,450$ & $25.147,660$ \\
\hline \multirow{3}{*}{ TPARO } & Overall & \multirow{3}{*}{10,736} & 4,530 & 4,100 & 26,000 \\
\hline & between & & 3,399 & 6,045 & 18,545 \\
\hline & within & & 3,096 & 4,791 & 23,055 \\
\hline \multirow{3}{*}{ IDESPA } & Overall & \multirow{3}{*}{52,217} & 8,545 & 31,891 & 72,565 \\
\hline & between & & 7,091 & 39,036 & 64,821 \\
\hline & within & & 5,043 & 44,211 & 64,441 \\
\hline \multirow{3}{*}{ PPIJ } & Overall & \multirow{3}{*}{8,162} & 5,220 & 1,010 & 21,900 \\
\hline & between & & 4,379 & 2,499 & 16,697 \\
\hline & within & & 3,017 & $-0,155$ & 13,365 \\
\hline \multirow{3}{*}{ PACC } & Overall & \multirow{3}{*}{32,030} & 9,529 & 13,615 & 57,700 \\
\hline & between & & 9,647 & 18,117 & 56,334 \\
\hline & within & & 1,657 & 24,619 & 35,784 \\
\hline \multirow{3}{*}{ GPC } & Overall & \multirow{3}{*}{16,480} & 5,722 & 7,000 & 30,700 \\
\hline & between & & 5,768 & 7,982 & 29,191 \\
\hline & within & & 1,125 & 12,688 & 21,180 \\
\hline
\end{tabular}

Fuente: Elaboración propia 
Como se puede comprobar, existe una mayor variabilidad en las observaciones entre comunidades autónomas (between) que entre periodos temporales (within) de una comunidad autónoma, tanto para el abandono escolar temprano como para la totalidad de variables explicativas utilizadas.

\subsection{Estimación del modelo}

Una vez especificado el modelo, en este epígrafe se presentan distintas estimaciones realizadas bajo el enfoque de la metodología de panel de datos. En primer lugar, se presenta la estimación más sencilla del modelo, en la que se considera que las observaciones de las distintas comunidades autónomas a lo largo del tiempo no tienen correlación, y que el término de error tiene una distribución normal independiente entre los individuos y en el tiempo. Este modelo recibe el nombre de regresión agrupada (pooled) y bajo este supuesto, se realiza una estimación por mínimos cuadrados ordinarios (MCO) sin tener en cuenta las dos dimensiones de los datos, el tiempo y el espacio. De este modo, siguiendo la especificación del modelo de panel de datos mostrada en la Ecuación 6.2, el modelo inicial que se plantea sería el siguiente:

$$
\begin{aligned}
& A E T_{i t}=\alpha+\beta_{1} G P A_{i t-1}+\beta_{2} A P G_{i t-3}+\beta_{3} G P B_{i t-1}+\beta_{4} P I B_{i t}+ \\
& \beta_{5} \text { Tparo }_{i t-2}+\beta_{6} I D E S P A_{i t}+\beta_{7} P A C C_{i t-3}+\beta_{8} P P I J_{i t}+\varepsilon_{i t} \\
& \text {, donde " } \mathrm{i} \text { " representaría las } 17 \text { comunidades autónomas españolas y " } \mathrm{t} \text { " los }
\end{aligned}
$$
años comprendidos en el periodo 2001 - 2011. Los resultados de la estimación se presentan en el siguiente Cuadro $6.2^{106}$ :

\footnotetext{
${ }^{106}$ Para ver los resultados completos de la estimación, ir a Cuadro AV.2 del Anexo V.
} 
Cuadro 6.2. Resultados de la estimación agrupada por MCO

\begin{tabular}{|l|c|c|}
\hline \multicolumn{1}{l|}{} & \multicolumn{1}{c|}{$\mathbf{R}^{\mathbf{2}}$} & $\mathbf{p}$-valor \\
\cline { 2 - 3 } Modelo: MCO pooled & 0,82990 & 0,000 \\
\hline Variable & Coeficiente & $\mathbf{p}$-valor \\
\hline Gasto público por alumno & $-0,00220$ & 0,000 \\
\hline Alumnos por grupo & $-0,15682$ & 0,556 \\
\hline Proporción de alumnos en centros concertados & 0,20355 & 0,040 \\
\hline Proporción de gasto en conciertos & $-0,49871$ & 0,001 \\
\hline PIB per cápita & 0,00045 & 0,001 \\
\hline Índice de descualificación & 0,87430 & 0,000 \\
\hline Tasa de paro & $-0,04635$ & 0,497 \\
\hline Índice de descualificación & 0,87430 & 0,000 \\
\hline Proporción de población inmigrante joven & 0,82322 & 0,000 \\
\hline
\end{tabular}

Fuente: Elaboración propia

Como se puede observar, la bondad de ajuste es relativamente alta $(82,9 \%)$, y las variable de gasto público por alumno, proporción de alumnos en centros concertados y gasto en conciertos, PIB per cápita, índice de descualificación y proporción de la población inmigrante joven aparecen significativas. No obstante, el uso de métodos de estimación para panel de datos permite controlar aquellas características singulares de cada comunidad autónoma que son difíciles de cuantificar y que son invariantes en el tiempo mediante el término intercepto " $\alpha_{i}$ ".

Según los supuestos que se consideren sobre " $\alpha_{i}$ ", se pueden estimar distintos modelos. Por un lado, el modelo de efectos fijos, que supone que las diferencias no observadas entre las distintas comunidades autónomas son constates, es decir, " $\alpha_{i}$ " es fijo y se estima junto con el resto de parámetros. En este modelo, las variables dependiente y explicativas se expresan como desviaciones de sus valores medios, restando los valores individuales de cada variable, obteniendo valores corregidos por la media, que se estiman después por MCO. Entre otras características, este modelo permite la existencia de correlación entre las variables incluidas en el modelo y la heterogeneidad individual no observada recogida en " $\alpha_{i}$ ", sin necesidad de especificar la forma concreta de esa correlación. La especificación del modelo de efectos fijos sería la siguiente:

$$
\begin{gathered}
A E T_{i t}=\alpha_{i}+\beta_{1} G P A_{i t-1}+\beta_{2} A P G_{i t-3}+\beta_{3} G P B_{i t-1}+\beta_{4} P I B_{i t}+ \\
\beta_{5} \text { Tparo }_{i t-2}+\beta_{6} I D E S P A_{i t}+\beta_{7} P A C C_{i t-3}+\beta_{8} P P I J_{i t}+\varepsilon_{i t}
\end{gathered}
$$


, es decir, este modelo supone que las diferencias entre comunidades autónomas son fijas o constantes, por lo que son invariantes en el tiempo. En cuanto a los resultados de la estimación, se muestran en el Cuadro $6.3^{107}$. Para verificar que el modelo de efectos fijos es preferible al modelo restringido (pooled), se realiza la prueba $F$, cuya hipótesis nula es que todas las variables dicotómicas (de las comunidades autónomas) son iguales a cero. En este caso, el p-valor de la prueba $(0,000)$, permite rechazar la hipótesis nula (ver el Cuadro AV.3 del Anexo V), por lo que se descarta el modelo de regresión agrupada frente al de efectos fijos.

Cuadro 6.3. Resultados de la estimación del modelo de efectos fijos

\begin{tabular}{|c|c|c|c|c|}
\hline & \multicolumn{3}{|c|}{$\mathbf{R}^{2}$} & \multirow{2}{*}{ p-valor } \\
\hline & Within & Between & Total & \\
\hline Modelo: Efectos fijos & 0,4603 & 0,4552 & 0,4132 & 0,000 \\
\hline Variable & \multicolumn{3}{|c|}{ Coeficiente } & p-valor \\
\hline Gasto público por alumno & \multicolumn{3}{|c|}{$-0,00273$} & 0,000 \\
\hline Alumnos por grupo & \multicolumn{3}{|c|}{$-0,08432$} & 0,747 \\
\hline Proporción de alumnos en centros concertados & \multicolumn{3}{|c|}{0,35206} & 0,002 \\
\hline Proporción de gasto en conciertos & \multicolumn{3}{|c|}{$-0,53669$} & 0,001 \\
\hline PIB per cápita & \multicolumn{3}{|c|}{0,00020} & 0,098 \\
\hline Tasa de paro & \multicolumn{3}{|c|}{$-0,29183$} & 0,000 \\
\hline Índice de descualificación & \multicolumn{3}{|c|}{0,25334} & 0,019 \\
\hline Proporción de población inmigrante joven & \multicolumn{3}{|c|}{0,28493} & 0,016 \\
\hline
\end{tabular}

Fuente: Elaboración propia

Por otro lado, en el modelo de efectos aleatorios se considera que las diferencias no observadas entre comunidades autónomas son aleatorias, de forma que " $\alpha_{i}=\alpha+\mathrm{u}_{i}$ ", por lo que el término intercepto tiene un componente aleatorio con una distribución condicional a los regresores, es decir, suponemos que el intercepto es una variable aleatoria con media " $\alpha$ " y desviación aleatoria " $u_{i}$ ".

El modelo de efectos aleatorios es más eficiente, puesto que la varianza es menor, pero resulta menos consistente que el de efectos fijos. Los resultados de la estimación del modelo utilizando efectos aleatorios se representa en el Cuadro $6.4^{108}$.

\footnotetext{
${ }^{107}$ Para ver los resultados completos de la estimación, ir a Cuadro AV.3 del Anexo V.

${ }^{108}$ Para ver los resultados completos de la estimación, ir a Cuadro AV.4 del Anexo V.
} 
Cuadro 6.4. Resultados de la estimación del modelo de efectos aleatorios

\begin{tabular}{|c|c|c|c|c|}
\hline & \multicolumn{3}{|c|}{$\mathbf{R}^{2}$} & \multirow{2}{*}{ p-valor } \\
\hline & Within & Between & Total & \\
\hline Modelo: Efectos aleatorios & 0,3972 & 0,8398 & 0,7831 & 0,000 \\
\hline Variable & \multicolumn{3}{|c|}{ Coeficiente } & p-valor \\
\hline Gasto público por alumno & \multicolumn{3}{|c|}{$-0,00302$} & 0,000 \\
\hline Alumnos por grupo & \multicolumn{3}{|c|}{$-0,48949$} & 0,058 \\
\hline Proporción de alumnos en centros concertados & \multicolumn{3}{|c|}{0,16783} & 0,087 \\
\hline Proporción de gasto en conciertos & \multicolumn{3}{|c|}{$-0,60663$} & 0,000 \\
\hline PIB per cápita & \multicolumn{3}{|c|}{0,00283} & 0,026 \\
\hline Tasa de paro & \multicolumn{3}{|c|}{$-0,28256$} & 0,000 \\
\hline Índice de descualificación & \multicolumn{3}{|c|}{0,56780} & 0,000 \\
\hline Proporción de población inmigrante joven & \multicolumn{3}{|c|}{0,66185} & 0,000 \\
\hline
\end{tabular}

Fuente: Elaboración propia

De forma similar al modelo de efectos fijos, es necesario comprobar si el modelo de efectos aleatorios es preferible al modelo de regresión agrupado o pooled. A este efecto, la prueba de Breusch y Pagan para efectos aleatorios realiza un contraste bajo la hipótesis nula de que la varianza del error es igual a cero. En el Cuadro 6.5, que muestra los resultados de esta prueba, se comprueba que se rechaza la hipótesis nula, por lo que es preferible el modelo de efectos aleatorios al modelo agrupado.

\section{Cuadro 6.5. Resultados de la prueba de Breusch y Pagan para efectos aleatorios}

Breusch and Pagan Lagrangian multiplier test for random effects

$$
\begin{aligned}
& \mathrm{AET}[\text { comunidad, } \mathrm{t}]=\mathrm{Xb}+\mathrm{u}[\text { comunidad }]+\mathrm{e}[\text { comunidad, } \mathrm{t}] \\
& \text { Estimated results: } \\
& \begin{array}{r|cc} 
& \text { Var } & \text { sd }=\text { sqrt }(\text { Var }) \\
\text { AET } & 58,13008 & 7,624308 \\
\text { e } & 3,775417 & 1,943043 \\
\text { u } & 3,370378 & 1,835859
\end{array} \\
& \text { Test: } \quad \operatorname{var}(u)=0 \\
& \begin{array}{l}
\operatorname{chibar} 2(\odot 1)=129,65 \\
\text { Prob }>\text { chibar2 }=0,000 \odot
\end{array}
\end{aligned}
$$

Fuente: Elaboración propia. Salida de resultados de STATA

Una vez constatada la preferencia de los modelos de efectos fijos y aleatorios frente al modelo de datos agrupados, es necesario escoger el modelo que mejor se aproxima a la estimación que se ha realizado. Para ello, el test de Hausman (1978) establece en su hipótesis nula que no existe correlación entre el componente de error individual y las variables explicativas del modelo, a través de la diferencia entre los 
coeficientes de efectos fijos y aleatorios. Los resultados del test se presentan en el Cuadro 6.6.

Cuadro 6.6. Resultados del test de Hausman

\begin{tabular}{|c|c|c|c|c|}
\hline & $\begin{array}{l}\text { (b) } \\
\text { EFijos }\end{array}$ & $\begin{array}{l}\text { Coefficien } \\
\text { (B) } \\
\text { EAleatorios }\end{array}$ & $\begin{array}{c}(b-B) \\
\text { Difference }\end{array}$ & 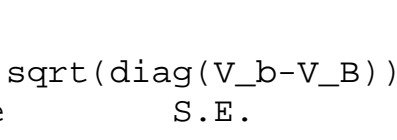 \\
\hline GPA &,$- 0 \odot 27337$ & - , 0030177 &, $0 \odot \odot 284$ & , $\odot \odot \odot 1755$ \\
\hline APG & - , 0843166 & - , 4894878 & 4051711 & 0364591 \\
\hline PIB & , $\odot \odot \odot 2 \odot 27$ & , $\odot \odot \odot 2831$ & - ,, $0 \odot \odot 804$ & . \\
\hline Tparo & -, 2918252 & -, 2825578 &,- 0092674 & \\
\hline DESPA & 2533419 & 5678027 &,- 3144608 &, 0503957 \\
\hline PPI J & 2849341 & 6618456 & - , 3769115 & , 0697922 \\
\hline PACC &, 3520596 & 1678341 & 1842256 & , $05 \odot 859$ \\
\hline GPC &,- 5366859 &,- 6066326 & 0699467 & 0482643 \\
\hline
\end{tabular}

$\mathrm{b}=$ consistent under $\mathrm{Ho}$ and $\mathrm{Ha}$; obtained from xtreg

$\mathrm{B}=$ inconsistent under $\mathrm{Ha}$, efficient under Ho; obtained from xtreg

Test: Ho: difference in coefficients not systematic

$$
\begin{aligned}
& \operatorname{chi2}(8)=(b-B)^{\prime}\left[\left(V_{-} b-V_{-} B\right)^{\wedge}(-1)\right](b-B) \\
& \text { Prob }>\text { chi2 }=\quad 0,0000 \\
& \text { ( } V \_b-V \_B \text { is not positive definite) }
\end{aligned}
$$

Fuente: Elaboración propia. Salida de resultados de STATA

El resultado de la prueba lleva a rechazar la hipótesis nula, por lo que el modelo de efectos fijos es preferible al de efectos aleatorios, ya que las diferencias de los coeficientes de las estimaciones son significativamente distintas, en cuyo caso se prefiere el modelo más consistente (efectos fijos), puesto que se considera que continúa existiendo correlación entre el componente de error y los regresores.

Además de incluir la heterogeneidad transversal (entre comunidades autónomas), se puede también incorporar a las estimaciones los denominados efectos temporales, que representan aquellos hechos que han afectado por igual a todas las comunidades autónomas durante el periodo de tiempo analizado, lo que permite reducir sesgos en la estimación. Además, conviene tener en cuenta que es muy probable que para el periodo temporal escogido para el análisis, 2001 - 2011, existan hechos no observables en el modelo que hayan afectado homogéneamente al conjunto de comunidades autónomas, como puede ser la crisis económica iniciada en 2008. 
Continuando con el modelo de efectos fijos reflejado en la ecuación 6.2, los efectos temporales estarían representados en un vector de variables dicotómicas para cada año denominado " $\eta_{t}$ ", como se observa en la siguiente ecuación:

$$
\begin{gathered}
A E T_{i t}=\alpha_{i}+\eta_{t}+\beta_{1} G P A_{i t-1}+\beta_{2} A P G_{i t-3}+\beta_{3} G P B_{i t-1}+\beta_{4} P I B_{i t}+ \\
\beta_{5} \text { Tparo }_{i t-2}+\beta_{6} I D E S P A_{i t}+\beta_{7} P A C C_{i t-3}+\beta_{8} P P I J \\
i t
\end{gathered}
$$

De esta forma, los resultados de la estimación de efectos fijos incorporando efectos temporales aparecen en el siguiente Cuadro $6.7^{109}$ :

\begin{tabular}{|c|c|c|c|c|}
\hline & \multicolumn{3}{|c|}{$\mathbf{R}^{2}$} & \multirow{2}{*}{ p-valor } \\
\hline & Within & Between & Total & \\
\hline Modelo: Efectos fijos con efectos temporales & 0,5414 & 0,0025 & 0,0029 & 0,000 \\
\hline Variable & \multicolumn{3}{|c|}{ Coeficiente } & p-valor \\
\hline Gasto público por alumno & \multicolumn{3}{|c|}{$-0,00285$} & 0,006 \\
\hline Alumnos por grupo & \multicolumn{3}{|c|}{$-0,07793$} & 0,757 \\
\hline Proporción de alumnos en centros concertados & \multicolumn{3}{|c|}{0,47128} & 0,001 \\
\hline Proporción de gasto en conciertos & \multicolumn{3}{|c|}{$-0,57204$} & 0,002 \\
\hline PIB per cápita & \multicolumn{3}{|c|}{0,00089} & 0,000 \\
\hline Tasa de paro & \multicolumn{3}{|c|}{$-0,22674$} & 0,020 \\
\hline Índice de descualificación & \multicolumn{3}{|c|}{0,25817} & 0,041 \\
\hline Proporción de población inmigrante joven & \multicolumn{3}{|c|}{0,36020} & 0,021 \\
\hline
\end{tabular}

Cuadro 6.7. Resultados de la estimación del modelo de efectos fijos con efectos temporales

Fuente: Elaboración propia

Como puede observarse, la bondad de ajuste total y para el caso intracomunidades (within) aumenta notablemente respecto al modelo sin efectos temporales, mientras que algunas variables explicativas como el PIB per cápita ganan en significatividad. No obstante, es necesario comprobar la significatividad conjunta de los efectos temporales, para lo que se realiza una prueba $F$, cuyos resultados aparecen en el Cuadro 6.8.

\footnotetext{
${ }^{109}$ Para ver los resultados completos de la estimación, ir a Cuadro AV.5 del Anexo V.
} 


\section{Cuadro 6.8. Resultados de la prueba $F$ de efectos temporales}

$$
\begin{aligned}
& \text { (1) _Iyear_2002 }=0 \\
& \text { (2) -Iyear_2003 }=0 \\
& \text { (3) Iyear_2004 }=0 \\
& \text { (4) -Iyear_2005 }=0 \\
& \text { (5) _Iyear_2006 }=0 \\
& \text { (6) Iyear_2007 = } 0 \\
& \text { (7) -Iyear_2008 }=0 \\
& \text { (8) -Iyear_2009 }=0 \\
& \text { (9) Iyear_2010 = } 0 \\
& \text { (10) } \text {-Iyear_2011 = } 0
\end{aligned}
$$

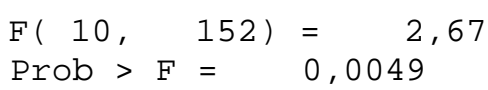

Fuente: Elaboración propia. Salida de resultados de STATA

Los efectos temporales resultan ser conjuntamente significativos, ya que el pvalor permite rechazar la hipótesis nula de que sean iguales a cero (Ho: $\eta_{2002}=\eta_{2003}=$ $\left.\ldots=\eta_{2011}=0\right)$, por lo que es preciso mantenerlos en el modelo.

Una vez escogido un modelo previo, se ha de proceder a verificar los potenciales problemas de especificación que puede contener. En primer lugar, se ha verificado la existencia de autocorrelación, que implica que los términos de error " $\varepsilon_{i t}$ " no son independientes, en este caso en su dimensión temporal, lo cual supone una violación del modelo clásico de regresión lineal, que hace que los estimadores no sean eficientes (Gujarati y Porter, 2010). La presencia de autocorrelación se comprueba a través del test de Wooldridge para paneles de datos, cuyos resultados se muestran en el Cuadro $6.9^{110}$

\footnotetext{
${ }^{110} \mathrm{El}$ p-valor asociado al estadístico $\mathrm{F}(1,16)=22,376$ arroja un resultado de 0,0002 que lleva a rechazar la hipótesis nula de que no existe correlación.
} 


\section{Cuadro 6.9. Resultados del test de Wooldridge para paneles de datos}

$\begin{array}{rr}\text { Linear regression } & \text { Number of obs }=170 \\ & F(8,16)=15,02 \\ & \text { Prob }>F=0,0000 \\ \text { R-squared }=0,3308 \\ \text { Root MSE }=2,131\end{array}$

Std. Err. adjusted for 17 clusters in comunidad)

\begin{tabular}{|c|c|c|c|c|c|c|}
\hline D. AET । & Coef. & $\begin{array}{l}\text { Robust } \\
\text { Std. Err. }\end{array}$ & $\mathrm{t}$ & $P>|t|$ & [95\% Conf. & Interval] \\
\hline \multicolumn{7}{|l|}{ GPA } \\
\hline D1. & - , 0020309 & , ๑७९८०५८ & $-2,52$ & $\odot, 023$ & - , 0037391 & - , 0003227 \\
\hline \multicolumn{7}{|l|}{ APG } \\
\hline D1. &,- 1061847 &, 3435228 & $-0,31$ & 0,761 &,- 8344205 & , 6220511 \\
\hline \multicolumn{7}{|l|}{ PIB } \\
\hline D1. &, 0002842 &, 0001647 & 1,73 & 0,104 &,- 0000649 &, 0006334 \\
\hline \multicolumn{7}{|l|}{ Tparo } \\
\hline D1. & - , 2339276 & , 0879556 & $-2,66$ & 0,017 &,- 420385 & - ,, 0474702 \\
\hline \multicolumn{7}{|l|}{ IDESPA } \\
\hline D1. &, 5011334 &, 1335211 & 3,75 & $\odot, \odot \odot 2$ & , 2180813 &, 7841854 \\
\hline \multicolumn{7}{|l|}{ PPIJ } \\
\hline D1. & , 4169539 &, 2117754 & 1,97 & $\odot, 067$ & - , 0319899 & , 8658976 \\
\hline \multicolumn{7}{|l|}{ PACC } \\
\hline D1. &, 5567054 &, 1364432 & 4,08 & $\odot, 0 \odot 1$ &, 2674587 & , 8459521 \\
\hline \multicolumn{7}{|l|}{ GPC } \\
\hline D1. &,- 5772088 & , 1599159 & $-3,61$ & 0,002 & - , 9162153 & - , 2382022 \\
\hline
\end{tabular}

Wooldridge test for autocorrelation in panel data

$\mathrm{HO}$ : no first-order autocorrelation

$$
\begin{array}{rc}
\mathrm{F}(1,16)= & 22,376 \\
\text { Prob }>\mathrm{F}= & 0,0002
\end{array}
$$

Fuente: Elaboración propia. Salida de resultados de STATA

Como se puede observar, el p-valor asociado al estadístico $F(1,16)=22,376$ arroja un resultado de 0,0002, por lo que se rechaza la hipótesis nula de que no exista correlación. Este resultado es esperado ya que muchas observaciones de variables como el gasto público por alumno o el número de alumnos por grupo están asociadas en el tiempo.

Para corregir este fenómeno, una posible solución consiste en introducir un término autorregresivo " $\rho$ " de grado 1 para controlar la dependencia de los periodos 
" $\mathrm{t}$ " respecto a " $\mathrm{t}-1$ ", de forma que el nuevo modelo vendría representado mediante la ecuación 6.4, pero el término de error presentaría la siguiente especificación:

$$
\varepsilon_{i t}=\rho \varepsilon_{i, t-1}
$$

En este caso, la estimación con término autorregresivo seguiría la siguiente especificación:

$$
\begin{gathered}
A E T_{i t}=\alpha_{i}+\eta_{t}+\beta_{1} G P A_{i t-1}+\beta_{2} A P G_{i t-3}+\beta_{3} G P B_{i t-1}+\beta_{4} P I B_{i t}+ \\
\beta_{5} \text { Tparo }_{i t-2}+\beta_{6} I D E S P A_{i t}+\beta_{7} P A C C_{i t-3}+\beta_{8} P P I J_{i t}+\rho \varepsilon_{i t}
\end{gathered}
$$

Los resultados de esta estimación, denominada AR1, aparecen en el siguiente Cuadro 6.10.

\begin{tabular}{|c|c|c|c|c|}
\hline & \multicolumn{3}{|c|}{$\mathbf{R}^{2}$} & \multirow{2}{*}{ p-valor } \\
\hline & Within & Between & Total & \\
\hline Modelo: Efectos fijos con efectos temporales AR1 & 0,4981 & 0,1257 & 0,1662 & 0,000 \\
\hline Variable & \multicolumn{3}{|c|}{ Coeficiente } & p-valor \\
\hline Gasto público por alumno & \multicolumn{3}{|c|}{$-0,00338$} & 0,01 \\
\hline Alumnos por grupo & \multicolumn{3}{|c|}{$-0,13050$} & 0,668 \\
\hline Proporción de alumnos en centros concertados & \multicolumn{3}{|c|}{0,41792} & 0,078 \\
\hline Proporción de gasto en conciertos & \multicolumn{3}{|c|}{$-0,48674$} & 0,037 \\
\hline PIB per cápita & \multicolumn{3}{|c|}{0,00074} & 0,019 \\
\hline Tasa de paro & \multicolumn{3}{|c|}{$-0,12682$} & 0,259 \\
\hline Índice de descualificación & \multicolumn{3}{|c|}{0,37439} & 0,012 \\
\hline Proporción de población inmigrante joven & \multicolumn{3}{|c|}{0,34938} & 0,24 \\
\hline
\end{tabular}

Cuadro 6.10. Resultados de la estimación del modelo de efectos fijos con efectos temporales y término autorregresivo de orden $1^{111}$

Fuente: Elaboración propia

Otro de los problemas presentes en la estimación del modelo es la existencia de heterocedasticidad, es decir, la varianza de los errores no es constante, por lo que se viola el principio de homocedasticidad. Para comprobar la existencia de heterocedasticidad, se ha utilizado el test modificado de Wald para paneles de datos sobre el modelo de la ecuación 6.4, cuyos resultados aparecen en el siguiente Cuadro 6.11.

\footnotetext{
${ }^{111}$ Para ver los resultados completos de la estimación, ir a Cuadro AV.6 del Anexo V.
} 


\section{Cuadro 6.11. Resultados del test modificado de Wald para paneles de datos}

Modified Wald test for groupwise heteroskedasticity

in fixed effect regression model

HO: $\operatorname{sigma}(i)^{\wedge} 2=\operatorname{sigma}^{\wedge} 2$ for all $i$

$$
\begin{array}{lr}
\text { chi2 }(17)= & 95,15 \\
\text { Prob }>\text { chi2 }= & 0,0000
\end{array}
$$

Fuente: Elaboración propia. Salida de resultados de STATA

Como se puede observar, el $p$-valor asociado al estadístico $x^{2}=95,15$ permite rechazar la hipótesis nula (Ho: $\sigma_{i}^{2}=\sigma^{2}$ ), por lo que además de autocorrelación, el modelo también presenta heterocedasticidad.

Por último, es necesario comprobar si el modelo presenta correlación contemporánea, es decir, si existen observaciones de determinadas comunidades autónomas que están correlacionadas con las observaciones de otras comunidades para el mismo periodo de tiempo a través de sus términos de error. Para identificar este problema, se ha llevado a cabo el test de Frees $(1995,2004)^{112}$, que prueba hipótesis nula de no existencia de correlación contemporánea, y cuyos resultados aparecen en el Cuadro 6.12.

Pese a que es más común el test de Breusch y Pagan (1980), no se ha realizado debido a que su uso es desaconsejable cuando el número de periodos temporales es inferior al número de observaciones transversales (De Hoyos y Sarafidis, 2006), como es el caso del panel de la presente investigación.

\section{Cuadro 6.12. Resultados del Test $Q$ de Frees}

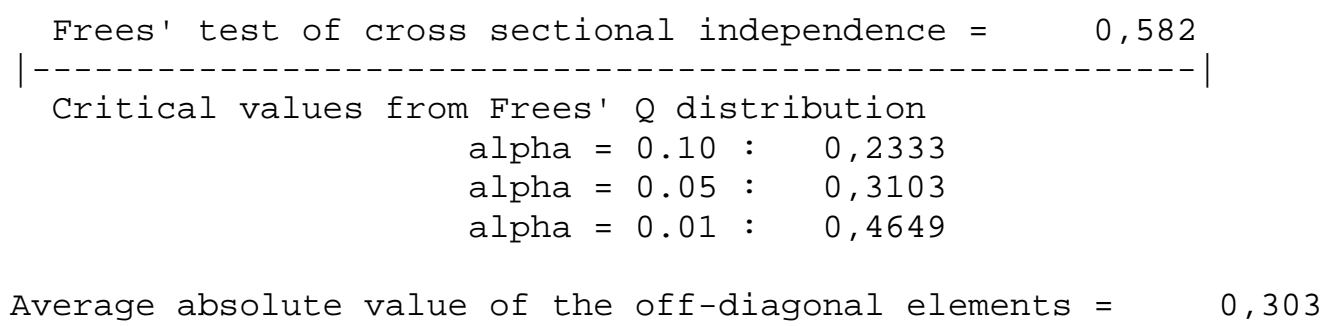

Fuente: Elaboración propia. Salida de resultados de STATA

${ }^{112}$ De la misma forma, se han descartado los test de Pesaran (2004) y Friedman (1937), ya que no proporcionan resultados concluyentes al trabajar con paneles de datos con efectos temporales incorporados. 
Los resultados del test no permiten rechazar la hipótesis nula de independencia transversal para ninguno de los niveles de significación. Por lo tanto, el modelo de efectos fijos con efectos temporales incorporados que se utiliza presenta problemas de autocorrelación y heterocedasticidad que es necesario corregir.

Para solucionar estos problemas hay dos posibilidades, que consisten en utilizar estimadores de mínimos cuadrados generalizados factibles (MCGF) o bien estimadores con errores estándar corregidos para panel (EECP), metodología más precisa propuesta por Beck y Katz (1995), que supone realizar la estimación MCO de los coeficientes del modelo, corrigiendo los errores estándar para que expresen la variabilidad de los estimadores teniendo en cuenta los problemas apuntados, obteniendo la estimación de la matriz de varianzas y covarianzas corregidas por heterocedasticidad y correlación serial. Los resultados de estas dos últimas estimaciones, MCGF y EECP se muestran en los siguientes Cuadro 6.13 y Cuadro $6.14^{113}$ :

Cuadro 6.13. Resultados de la estimación de mínimos cuadrados generalizados factibles para panel del modelo de efectos fijos con efectos temporales

\begin{tabular}{|l|c|c|}
\cline { 2 - 3 } \multicolumn{1}{c|}{} & $\mathbf{R}^{\mathbf{2}}$ & p-valor \\
\hline Modelo: Efectos Fijos (MCGF) con efectos temporales & & 0,000 \\
\hline Variable & Coeficiente & p-valor \\
\hline Gasto público por alumno & $-0,00372$ & 0,000 \\
\hline Alumnos por grupo & $-0,15999$ & 0,462 \\
\hline Proporción de alumnos en centros concertados & 0,27828 & 0,030 \\
\hline Proporción de gasto en conciertos & $-0,60796$ & 0,000 \\
\hline PIB per cápita & 0,000791 & 0,000 \\
\hline Tasa de paro & $-0,17962$ & 0,026 \\
\hline Índice de descualificación & 0,27632 & 0,009 \\
\hline Proporción de población inmigrante joven & 0,10255 & 0,445 \\
\hline
\end{tabular}

Fuente: Elaboración propia

${ }^{113}$ Para ver los resultados completos de la estimación, ir a Cuadro AV.7 y Cuadro AV.8 del Anexo V. 


\begin{tabular}{|c|c|c|}
\hline & $\mathbf{R}^{2}$ & p-valor \\
\hline Modelo: Efectos Fijos (EECP) con efectos temporales & 0,9353 & 0,000 \\
\hline Variable & Coeficiente & p-valor \\
\hline Gasto público por alumno & $-0,00302$ & 0,002 \\
\hline Alumnos por grupo & $-0,10247$ & 0,680 \\
\hline Proporción de alumnos en centros concertados & 0,47038 & 0,002 \\
\hline Proporción de gasto en conciertos & $-0,57671$ & 0,000 \\
\hline PIB per cápita & 0,00090 & 0,000 \\
\hline Tasa de paro & $-0,19594$ & 0,039 \\
\hline Índice de descualificación & 0,29010 & 0,017 \\
\hline Proporción de población inmigrante joven & 0,30525 & 0,047 \\
\hline
\end{tabular}

Fuente: Elaboración propia

Como se puede comprobar, los resultados de ambas estimaciones son similares, sin presentar grandes cambios en los coeficientes. Sin embargo, la estimación de errores estándar corregidos para panel presentaría las estimaciones más consistentes, ya que además de haber realizado las pruebas pertinentes para descartar tanto el modelo de efectos aleatorios como el modelo de datos agrupados; se han corregido los problemas de heterocedasticidad y autocorrelación que inicialmente se presentaban.

\subsection{Discusión de resultados}

Una vez realizadas las distintas estimaciones, se puede realizar una interpretación de los resultados que han arrojado los distintos modelos. Para ello, y aunque el modelo que mejor representa los resultados es el modelo EECP, se tendrán en cuenta los distintos modelos que se han estimado, para tener una visión amplia de la dinámica de los coeficientes y el proceso de elección y mejora de modelo.

De este modo, el Cuadro 6.15 resume los resultados de las estimaciones que se han realizado en el epígrafe anterior: mínimos cuadrados ordinarios (1), efectos fijos (2), efectos aleatorios (3), efectos fijos con efectos temporales incorporados (4), modelo con término autorregresivo de grado 1 (5), modelo de mínimos cuadrados generalizados factibles (6) y modelo de errores estándar corregidos para panel (7). En el modelo (5) (AR1) está corregido el problema de autocorrelación, mientras que en los 
modelos (6) y (7) - MCGF y EECP - están corregidos los problemas de autocorrelación y heterocedasticidad. 


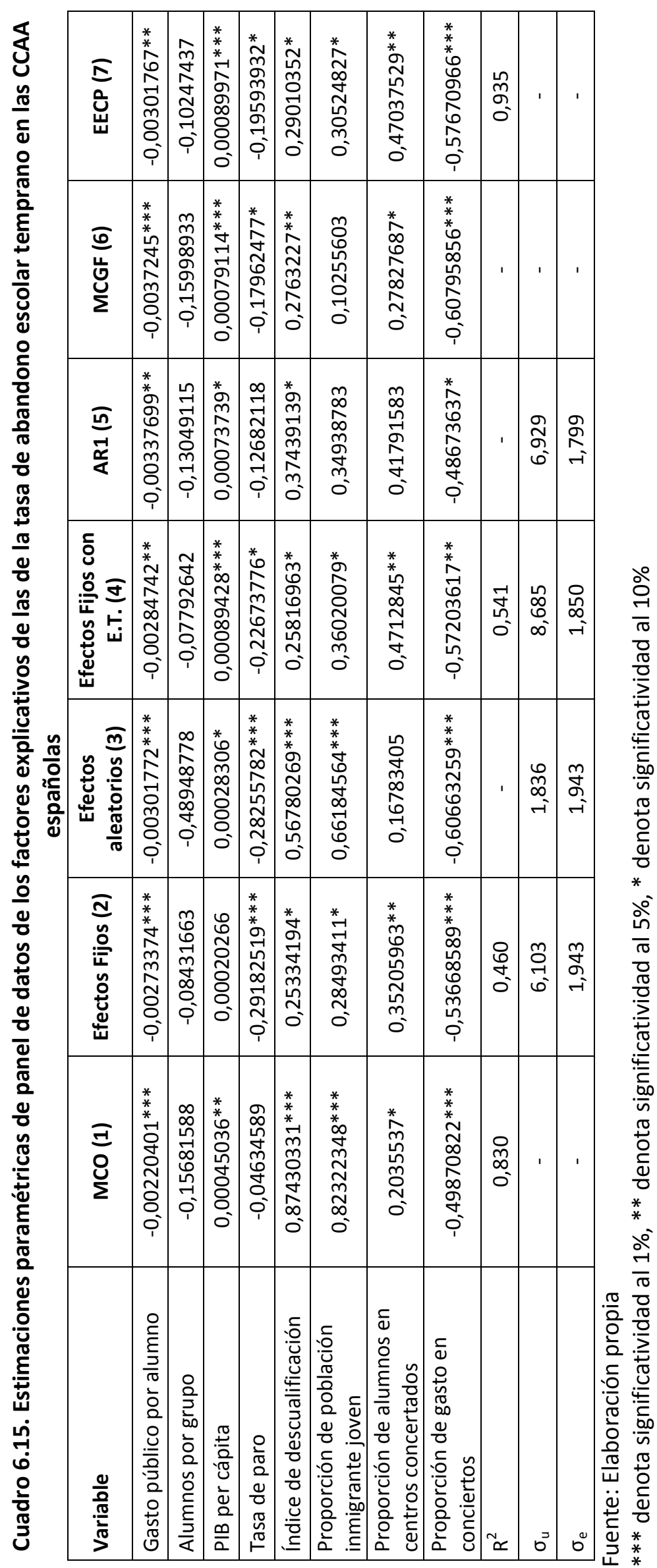


Como puede observarse, en términos generales, se da cierta homogeneidad en cuanto al signo de los coeficientes y las variables explicativas que resultan significativas entre las diferentes estimaciones realizadas. Cabe reseñar que la robustez de los resultados es mucho mayor que en los análisis preliminares realizados en el capítulo quinto, puesto que los modelos de panel de datos abarcan un periodo de tiempo amplio, en el que están incluidas la totalidad de comunidades autónomas españolas.

En primer lugar, se observa como la variable gasto público por alumno resulta ser significativa en todas las estimaciones y presenta una relación negativa con el nivel de abandono escolar temprano. En la estimación por EECP (7) se deduce que por cada euro de gasto por alumno en educación no universitaria adicional por parte de cualquier comunidad autónoma, la tasa de abandono escolar temprano se reduciría en 0,3 puntos aproximadamente.

Por tanto, el gasto público dedicado a la educación se muestra por sí sólo como un factor relevante a la hora de explicar las diferencias regionales del indicador, con un resultado similar al de investigaciones previas de otros trabajos como el de PérezEsparrells y Morales (2012b) o el de De Witte et al. (2013), que utiliza sin embargo un indicador de gasto en educación en relación al PIB. Por otro lado, este resultado muestra la significatividad de la variable relativa al gasto público, en contradicción con otros estudios previos (Alegre Canosa y Benito Pérez, 2010 y 2014), en los que esta variable no ha resultado ser significativa.

En cuanto a la variable "número medio de alumnos por grupo en ESO" (APG), no se muestra significativa en ninguna de las estimaciones realizadas, pese a que mantiene el signo negativo en todos los casos. Ello no supone que su reducción no sea una medida eficaz, sino que esta variable no es significativa a la hora de explicar las diferencias regionales de la tasa de abandono escolar temprano. Una posible causa de ello puede encontrarse en el hecho de que es la variable con menor variabilidad del modelo, tanto entre comunidades autónomas como entre años, como se ha podido apreciar en el Cuadro 6.1 en el epígrafe de especificación del modelo, y en el Cuadro 5.2 , en el que se muestra que el ratio de alumnos por grupo ha descendido en el 
periodo comprendido entre el curso 2000/1 y 2011/12 en menos de un alumno por grupo, y que es una de las variables más constantes dentro del modelo.

Las variables relativas al grado de concertación de la enseñanza muestran, en principio, resultados ambivalentes. En primer lugar, en cuanto a la variable referida a la distribución porcentual de alumnado que acude a la enseñanza concertada en ESO (PACC), el análisis muestra que cada punto porcentual adicional en la proporción de alumnos de ESO en centros privados concertados de cualquier comunidad se traduce en un incremento de 0,47 puntos en el indicador de abandono escolar temprano.

No obstante, la variable relativa a la distribución del gasto público en conciertos y subvenciones a la enseñanza privada muestra un efecto contrario. En este sentido, por cada punto porcentual de gasto público en educación que se destina a este tipo de educación en cualquier comunidad autónoma, el abandono escolar temprano se reduciría en 0,58 puntos, aproximadamente.

Las principales investigaciones aducen que, en términos generales los centros privados presentan mejores resultados educativos (Fuchs y Wößmann, 2006; West y Woessmann, 2010; Alegre Canosa y Subirats i Humet, 2013), por tanto, hay que tomar con cautela los resultados aquí presentados, ya que las dos variables resultan significativas aunque de signo contrario.

Una posible explicación a este resultado se puede encontrar en el hecho de que las comunidades como País Vasco o Navarra, con los mejores resultados de abandono escolar temprano a nivel nacional, han reducido sensiblemente su proporción de alumnos en centros concertados de forma paralela a la reducción de su indicador de abandono escolar temprano, a pesar de ser las dos regiones con más concertación en términos relativos de alumnado y gasto.

EI PIB per cápita es la variable más significativa en las estimaciones por MCGF (6) y EECP (7), manteniendo en cada una de ellas una relación positiva con el indicador de abandono, de forma que un incremento de un euro en el PIB per cápita de una comunidad autónoma explicaría el aumento de la tasa de abandono escolar temprano de 0,09 puntos aproximadamente. 
Así pues, este resultado evidencia una relación positiva entre riqueza económica y abandono escolar temprano que contradice los resultados obtenidos en el análisis de regresión simple aplicados en el epígrafe 5.3.1. , tanto para el PIB (año 2013) como para la tasa de pobreza (2013). Esta contradicción podría tener su explicación en el hecho de que, desde un punto de vista estático, aquellas regiones más ricas (en términos de PIB y tasa de pobreza) tienden a presentar menores tasas de abandono escolar temprano. Sin embargo, teniendo en cuenta el periodo de tiempo recogido, la dinámica de las comunidades ha tenido una relación positiva con el abandono, por lo que se puede deducir que los incrementos en el PIB de las comunidades con más abandono durante la fase expansiva, en la que sectores poco intensivos en mano de obra cualificada han sido la fuerza tractora de la economía como es el caso del sector construcción - han contribuido a obtener esta relación entre riqueza y abandono escolar temprano.

Estos resultados contradicen las lógicas extraídas de investigaciones previas que aducen que la riqueza económica va asociada a la mejora de los resultados educativos, y que la falta de la misma produce desincentivos para demandar educación (Duru-Bellat y Suchaut, 2005; Cabus y De Witte, 2013). Por lo tanto, este sorprendente resultado puede evidenciar que el crecimiento económico registrado en España se ha podido fundamentar en un empleo de mano de obra no cualificada, que ha supuesto un desincentivo para permanecer en el sistema educativo y que los individuos, lejos de percibir la necesidad de estar formados para participar en la economía del conocimiento, han experimentado un efecto de atracción de sectores no intensivos en conocimiento, lo que ha llevado a un fuerte efecto expulsión del sistema educativo hacia el mercado laboral.

Estas conclusiones se refrendan con los resultados de la variable de la tasa de paro, también significativa en prácticamente todas las estimaciones (salvo para la estimación agrupada (1) y la AR1 (5)) y con una relación negativa con la tasa de abandono escolar temprano, de forma que por cada punto de aumento de la tasa de paro en una comunidad autónoma, el abandono escolar temprano se reduciría en 0,196 puntos aproximadamente. Así pues, se confirma un efecto expulsión del sistema 
educativo, en línea con las conclusiones apuntadas por Dellas y Sakellaris (2003), que ponen de manifiesto el carácter contracíclico de la escolarización con el mercado laboral; y Black et al. (2005), que constatan los efectos que los procesos expansionistas de sectores intensivos en mano de obra poco cualificada tienen sobre la escolarización, que en el caso español se evidencia a través del sobredimensionamiento del sector construcción (Aparicio, 2010; Lacuesta et al., 2012).

Estos resultados pueden parecer en principio contradictorios a los obtenidos en la regresión simple representada en el Gráfico 5.8 del capítulo quinto, en la que la relación entre tasa de paro y abandono escolar es positiva, aunque en este caso había dudas sobre la validez de las regresiones, puesto que en una segunda regresión para el año 2006 el resultado no era significativo. Por otro lado, es posible que para un año concreto la relación sea positiva, ya que la estructura económica de aquellas comunidades especializadas en sectores de baja cualificación hace que en época de recesión se haya expulsado del mercado laboral a aquellos individuos con menor preparación. Sin embargo, aplicando la técnica de panel de datos, la dinámica por la que las altas tasas de abandono se han producido en comunidades en las que se ha experimentado un proceso de expansión económica basado en el sector construcción, con una posterior destrucción de empleo, ha producido un efecto determinante en los cambios en las tasas de abandono escolar temprano, que han empezado a reducirse a la par que la tasa de paro aumentaba considerablemente.

Por consiguiente, tanto los resultados de las variables PIB per cápita como los relativos a la tasa de paro ponen de manifiesto que el aumento de la actividad económica ha llevado aparejado un aumento de las tasas de abandono escolar temprano. Por ello, la crisis económica, que ha tenido unas nefastas consecuencias en términos de destrucción de empleo, se ha caracterizado por registrar mejoras en los resultados de la tasa de abandono escolar temprano.

En relación al contexto socio-cultural, la variable "índice de descualificación de la población adulta" (IDESPA) se muestra significativa en todas las estimaciones y con una relación positiva a la hora de explicar las diferencias regionales del abandono escolar temprano. Atendiendo a la estimación por EECP (7), por cada punto porcentual 
adicional en la proporción de individuos con un nivel de estudios inferior a la etapa de educación secundaria segunda etapa, una comunidad autónoma registra 0,29 puntos porcentuales más en su tasa de abandono escolar temprano. De este modo, estos resultados van en consonancia con los obtenidos en los estudios de Alegre Canosa y Benito Pérez (2010 y 2014) para el caso europeo y coinciden también con las conclusiones apuntadas por Dalton et al. (2009) y Petrongolo y San Segundo (2002) que utilizan el nivel educativo de los progenitores para explicar el rendimiento académico del alumnado.

Por último, la proporción de alumnado inmigrante joven (PPIJ) juega también un papel significativo en las diferencias regionales del abandono escolar temprano, ya que por cada punto adicional en la proporción de este grupo de población, la tasa de abandono escolar se incrementaría en 0,31 puntos aproximadamente, por lo que se confirmaría lo que otros estudios han apuntado (Mora, 2010; Calero et al., 2010; Fernández-Macías et al., 2013), que el alumnado inmigrante se ha caracterizado por registrar unas proporciones mayores de individuos con menores niveles de escolarización.

\subsection{Resumen y conclusiones.}

En este capítulo se han realizado distintas estimaciones con técnicas de panel de datos, con el objetivo de obtener un modelo multivariante que explique con mayor robustez la afectación de los factores de contexto más relevantes en el nivel abandono escolar temprano de las comunidades autónomas españolas, que ya ha sido aproximada en el capítulo cuarto.

El panel de datos construido consta con ocho variables explicativas, 17 comunidades autónomas en el corte transversal y los 11 datos temporales que recogen el periodo 2001-2011.

Los resultados de las distintas estimaciones sugieren que el modelo de crecimiento en España en el periodo analizado, fundamentado en sectores con exigencias formativas bajas, cuyo núcleo ha sido el sector de la construcción, ha tenido como consecuencia un efecto expulsión del sistema educativo hacia el mercado 
laboral, que es capaz de explicar, en buena medida, las diferencias en abandono escolar temprano de las diferentes comunidades autónomas españolas.

Por otro lado, se ha constatado que el gasto público en educación juega un papel fundamental y que su evolución está asociada también a las diferencias regionales en la tasa de abandono escolar temprano, de forma que en las regiones donde se ha invertido más por alumno, se ha registrado una tasa de abandono escolar temprano más baja. Sin embargo, las variables relativas al grado de concertación de la enseñanza muestran resultados contradictorios, por lo que es necesario tomar con cautela las posibles interpretaciones a este respecto.

Por último, los factores del contexto social y cultural incluidos - nivel de instrucción de la población adulta y proporción de población inmigrante joven - han resultado tener un efecto notorio sobre la evolución del indicador de abandono escolar temprano en el periodo analizado. 

Conclusiones 

En esta última parte, se sintetizan las principales conclusiones y aportaciones que se extraen de la investigación realizada, que se enumeran a continuación:

1. La gran mayoría de las investigaciones analizadas ponen de relieve que, a pesar de los problemas econométricos derivados de la falta de datos fiables, el capital humano, tradicionalmente medido a través de los años de escolarización, tiene un impacto positivo en la renta percibida por los individuos y en el crecimiento económico de los países. Este impacto no se limita al terreno económico, sino que produce un conjunto de externalidades positivas, en términos de salud y fomento de valores cívicos.

2. Los objetivos en educación y formación recogidos en los marcos estratégicos “Education and Training" 2010 y 2020, englobados en la Estrategia de Lisboa y la Estrategia Europa 2020, en buena medida no se han cumplido, a pesar de la importancia otorgada a ambos.

- Destaca la divergencia de objetivos planteados entre los distintos países, que pone de relieve un panorama del abandono escolar temprano en la Unión Europea muy dispar. El objetivo global de reducir el abandono escolar temprano por debajo del 10\% para el año 2020 resulta, no obstante, factible, dada la evolución positiva del indicador en los últimos años, y el conjunto de programas y medidas aplicados para combatir este problema.

- En el caso español, el objetivo para el año 2020 supone reducir el indicador de abandono escolar temprano hasta el $15 \%$, con un objetivo intermedio de situarlo, como máximo, en el 23\% para el año 2015, objetivo ya cumplido según los últimos datos del indicador (21,9\% para el año 2014).

3. La definición de abandono escolar temprano de Eurostat, a pesar de ser la más empleada, no está exenta de limitaciones. Por ello, es aconsejable utilizar, en la medida de lo posible, otros indicadores que complementen la información suministrada por la tasa de abandono escolar temprano, que 
ayuden a identificar las características propias de los colectivos con más riesgo de sufrir este problema.

4. En la literatura sobre abandono escolar temprano existe un amplio consenso sobre el carácter multidimensional de los factores explicativos del mismo, lo que supone que el enfoque para analizar este fenómeno ha de ser holístico.

- Existe un fuerte debate que se remonta varias décadas sobre el efecto que tiene la dotación de recursos en los resultados educativos. Hay cierto consenso acerca de la existencia de un efecto umbral por el que, alcanzado un determinado nivel de recursos, nuevos incrementos no se traducen, sistemáticamente, en mejores resultados educativos. No obstante, el nivel de gasto educativo se muestra relevante en un gran número de investigaciones, por lo que es necesario tener en cuenta esta variable a la hora de abordar cualquier análisis.

- El entorno económico también juega un papel muy importante en la generación del abandono escolar temprano. La riqueza económica ha sido utilizada con frecuencia para explicar un gran número de indicadores educativos, aunque los resultados obtenidos en la literatura son ambiguos, dada la diversidad de datos y técnicas econométricas utilizadas. Varios estudios demuestran que el entorno laboral del alumnado ha supuesto, en muchos casos, un aliciente para abandonar el sistema educativo de forma temprana.

- En cuanto al contexto socio-cultural, existe un amplio consenso sobre la importancia del nivel de estudios de los padres del alumnado. Fenómenos como la inmigración han sido analizados como factores de riesgo, aunque existe una importante línea de estudios que muestran que el efecto de la inmigración se diluye cuando se tiene en cuenta el origen socioeconómico del alumnado.

5. Históricamente, España ha presentado una desventaja persistente respecto al entorno europeo en sus indicadores de escolarización. Por ello, en 
cualquier análisis sobre este tipo de problemas debe tomarse en consideración el punto de partida y la evolución de estos indicadores, que en el caso de España ha sido positiva.

- La población ha registrado una continua progresión en cuanto al nivel de estudios alcanzado, habiéndose eliminado prácticamente por completo el analfabetismo y trasladándose la preocupación hacia etapas post obligatorias.

- El nivel de abandono escolar temprano se ha mantenido en niveles muy altos (en torno al 30\%) entre los años 2000 y 2008, sin haber registrado ninguna mejora hasta 2009, año en el que el indicador ha comenzado a disminuir.

- A pesar de la evolución positiva registrada en los últimos años, la tasa de abandono escolar temprano de España continua siendo la más alta de la Unión Europea. Una de las singularidades de la misma son sus diferencias regionales, que son las más amplias de la Unión Europea.

6. El abandono escolar temprano presenta una estrecha relación con otros indicadores educativos como las tasas de escolarización, la esperanza de vida escolar, las tasas de idoneidad, las tasas de graduación o los resultados de los test de competencia, lo que indica que se trata de un problema que se manifiesta en anteriores etapas educativas. Por consiguiente, es necesario incidir en la priorización de las medidas de diagnóstico y prevención desde las primeras etapas de escolarización, con el objetivo de anticipar la intervención en el alumnado que presenta problemas.

7. Los datos del indicador de abandono escolar temprano muestran que existe una mayor predisposición a sufrir este problema por parte de los hombres, de los jóvenes de nacionalidad extranjera, y de aquellas personas cuyas madres poseen únicamente estudios primarios o inferiores, lo que hace necesario que la intervención para afrontar este problema vaya enfocada hacia la población con estas características. 
8. El análisis de las variables de contexto educativo, económico y socio-cultural muestra que tanto la situación como la evolución de las distintas variables estudiadas se caracteriza por registrar unas profundas diferencias regionales. Las diferencias en el nivel de gasto público destinado a la educación no universitaria, el desigual grado de concertación de la enseñanza, el dispar nivel de PIB per cápita o el comportamiento del mercado de trabajo han incidido de forma muy distinta en el nivel de abandono escolar temprano registrado por las diferentes comunidades autónomas españolas.

9. En cuanto a los resultados tanto del modelo como de los análisis individuales realizados en el capítulo quinto, el gasto público por alumno tiene una relación negativa y significativa con la tasa de abandono escolar temprano a la hora de explicar las diferencias regionales del indicador. Este resultado pone de relieve la importancia del nivel de gasto que se destina a la educación, y sugiere que ha de ser un factor muy a tener en cuenta a la hora de afrontar este problema, en contra del criterio adoptado en los últimos años, caracterizado por la racionalización y los recortes en el presupuesto educativo.

10. El tamaño de la clase, medido a través del número de alumnos por aula, no ha resultado significativo en ninguna de las estimaciones y análisis realizados. Sin embargo, ello puede deberse a la escasa variabilidad del indicador, tanto en el periodo de análisis considerado como en sus diferencias entre comunidades autónomas.

11. En cuanto a las becas y ayudas al estudio, no parecen presentar una relación clara con el abandono escolar temprano, caracterizándose por registrar unas disparidades regionales muy pronunciadas. Es necesario señalar, además, la distinta función de este instrumento según el nivel educativo que se considere, puesto que en la etapa post-obligatoria, las becas y ayudas al estudio tienen la función de paliar el coste de oportunidad que representa el no acceder al mercado laboral. En este sentido, es necesario realizar estudios 
y evaluaciones sobre la relación entre estas medidas y las decisiones de abandono prematuro del sistema educativo.

12. El grado de concertación de la enseñanza es también otro elemento de debate, ya que se han obtenido unos resultados ambiguos. Por un lado, el estudio individual de las variables relativas a la proporción de alumnado en centros concertados y la proporción de gasto destinado a este tipo de enseñanza está en concordancia con las principales investigaciones que indican que la enseñanza concertada tiende a generar mejores resultados educativos, y por tanto, registrar un menor abandono escolar temprano. Sin embargo, los resultados del análisis de panel de datos evidencian que la primera de las variables muestra un efecto contrario en el periodo considerado, por lo que hay que tomar con cautela esta interpretación, y tener en cuenta el posible efecto de comunidades como Navarra o País Vasco, que han reducido sensiblemente su proporción de alumnado concertado de forma paralela a la disminución del indicador de abandono escolar temprano.

13. El PIB en términos per cápita es la variable con mayor significatividad en el análisis de panel de datos, presentando una relación positiva con el abandono escolar temprano, es decir, los aumentos del PIB per cápita durante el periodo 2001-2011 han estado asociados a incrementos en el nivel de abandono escolar temprano. Sin embargo, a nivel estático, las regresiones simples realizadas en el capítulo cinco evidencian una relación inversa, de forma que sugiere una interpretación según la cual aquellas comunidades autónomas con mayor PIB tienden, en términos generales, a registrar menores tasas de abandono escolar temprano. No obstante, la relación positiva entre la evolución del PIB y el abandono escolar temprano revela que el crecimiento de la economía española se ha basado en sectores de uso intensivo de mano de obra poco cualificada, lo que ha supuesto un efecto expulsión del sistema educativo. 
14. La tasa de paro muestra un comportamiento similar pero de menor intensidad con el abandono escolar temprano, de forma que las comunidades autónomas que han reducido su tasa de paro han aumentado la tasa de abandono escolar temprano, confirmando el efecto expulsión comentado previamente.

15. Por tanto, queda patente que el aumento de la actividad económica ha llevado aparejado un incremento de las tasas de abandono escolar temprano. Se puede interpretar que el descenso registrado en el indicador en los últimos años se puede atribuir, en buena medida, al declive de sectores como la construcción, que han llevado asociado el descenso de una oferta de empleo eminentemente de baja cualificación. De cara al diseño de políticas que traten de reducir el abandono escolar temprano, este resultado se traduce en la necesidad de identificar medidas que reduzcan el coste de oportunidad que supone no acceder al mercado laboral por permanecer en el sistema educativo.

16. El entorno socio-cultural también ha ejercido un peso destacado en las diferencias regionales de la tasa de abandono escolar temprano. Las dos variables contrastadas en el modelo de panel de datos, el índice de descualificación de la población adulta y el peso de la población inmigrante joven, han resultado ser significativas, de la misma forma que en los análisis individuales del capítulo cinco y de acuerdo a los resultados que la literatura ha señalado. Por lo tanto, a la hora de diseñar medidas hay que tener en cuenta el entorno social y cultural del alumnado, por lo que sería necesaria una priorización de la intervención en aquellas zonas que se caracterizan por presentar un alto grado de inmigración o un bajo grado de cualificación o estudios alcanzados entre su población.

17. Por último, es necesario señalar que el panorama del abandono escolar temprano en España, caracterizado por registrar unas profundas diferencias regionales, que se asocian a los también diferentes contextos educativos, económicos y socio-culturales, hace imprescindible contar con una 
intervención pública más coordinada por parte del Ministerio de Educación, Cultura y Deporte, que tenga en cuenta la situación de cada región y establezca, en consecuencia, una priorización de las intervenciones a realizar para afrontar este problema. Además, la interconexión del abandono escolar temprano con las variables del entorno socio-cultural requiere una coordinación más estrecha de la política educativa con la política social. 

Referencias bibliográficas 

Abramovitz, M. (1956). Resource and output trends in the United States since 1870. American Economic Review, 46(2), 5-23.

Acemoglu, D. (2009). Introduction to modern economic growth. Princeton: Princeton University Press.

Alba Monteserin, S., Fernández Asperilla, A., y Martínez Vega, U. (2013). Crisis económica y nuevo panorama migratorio en España. (Colección Estudios, no 65). Madrid: Centro de Documentación de las Migraciones de la Fundación 10 de Mayo.

Albert Verdú, C., Davia Rodríguez, M. A., y Toharia Cortés, L. (2008). Exclusión social y pobreza: transición educativo - formativa e inserción laboral de la población joven. Madrid: Ministerio de Trabajo e Inmigración.

Alegre Canosa, M. A., y Benito Pérez, R. (2010). Los factores del abandono educativo temprano. España en el marco europeo. Revista De Educación, no extraordinario 2010, 65-92.

Alegre, M. A., y Benito, R. (2014). Youth education attainment and participation in Europe: the role of contextual factors and the scope of education policy. European Journal of Education 49(1), 127-143.

Alegre Canosa, M. A., y Subirats i Humet, J. (2013). Sistemas y políticas educativas comparadas: transformaciones, convergencias y divergencias en los países occidentales. En E. Del Pino, y J. Rubio (Eds.), Los estados de bienestar en la encrucijada. Políticas sociales en perspectiva comparada (pp. 262-290). Madrid: Tecnos.

Angrist, J. D., y Lavy, V. (1999). Using Maimonides' rule to estimate the effect of class size on scholastic achievement. The Quarterly Journal of Economics, 114(2), 533575.

Aparicio, A. (2010). High-school dropouts and transitory labor market shocks: the case of the Spanish housing boom. (IZA Discussion Paper Series No. 5139). Bonn: IZA.

Arrow, K. (1973). Higher education as a filter. Journal of Public Economics, 2, 193-216.

Astone, N. M., y McLanahan, S. S. (1991). Family structure, parental practices and high school completion. American Sociological Review, 56(3), 309-320.

Averett, S. L., y McLennan, M. C. (2004). Exploring the effect of class size on student achievement: what have we learned over the past two decades? En G. Johnes, y J. Johnes (Eds.), International handbook on the economics of education (pp. 329367). Cheltenham y Northampton: Edward Elgar Publishing Ltd.

Azariadis, C., y Drazen, A. (1990). Threshold externalities in economic development. Quarterly Journal of Economics, 105(2), 501-526.

Azevedo, J. (2003). Entre la escuela y el mercado de trabajo. Una mirada crítica sobre las transiciones. En A. Marchesi, y C. Hernández Gil (Eds.), El fracaso escolar. Una perspectiva internacional (pp. 203-225). Alianza Editorial.

Banco de España. (2009). Informe anual 2008. Madrid.

Banco de España. (2011). Informe anual 2010. Madrid. 
Bandrés, E., y Gadea, M. D. (2013). Crisis económica y ciclos regionales en España. Papeles De Economía Española, 138, 2-30.

Barro, R. J. (1991). Economic growth in a cross section of countries. Quarterly Journal of Economics, 106(2), 407-443.

Barro, R. J. (1996). Determinants of economic growth: A cross-country empirical study. (NBER Working Paper 5698). Cambridge: National Bureau of Economic Research.

Barro, R. J. (2013). Education and economic growth. Annals of Economics and Finance, 14(2), 301-328.

Barro, R. J., y Lee, J. W. (1993). International comparisons of educational attainment. Journal of Monetary Economics, 32(3), 363-394.

Barro, R. J., y Lee, J. W. (1996). International measures of schooling years and schooling quality. American Economic Review, 86(2), 218-223.

Barro, R. J., y Lee, J. W. (2000). International data on educational attainment, updates and implications. (NBER Working Paper, no 7911). Cambridge: National Bureau of Economic Research.

Beck, N., y Katz, J. N. (1995). What to do (and not to do) with time-series cross-section data. The American Political Science Review, 89(3), 634-647.

Becker, G. S. (1962). Investment in human capital: a theoretical analysis. Journal of Political Economy, 70, 22-49.

Becker, G. S. (1964). Human capital: a theoretical and empirical analysis, with special references to education. New York: National Bureau of Economic Research.

Belfield, C. R., y Levin, H. M. (2007). The price we pay: economic and social consequences of inadequate education. Washington, DC: Brookings Institute Press.

Benhabib, J., y Spiegel, M. (1994). The role of human capital in economic development: evidence from aggregate cross-country data. Journal of Monetary Economics, 34, 143-173.

Benito, A. (2007). La LOE ante el fracaso, la repetición y el abandono escolar. Revista Iberoamericana De Educación, 43(7), 1-11.

Bernstein, B. (1977). Class, codes and control: a theoretical and empirical analysis, with special reference to education. London: Routledge \& Kegan Paul.

Björklund, A., y Chadwick, L. (2003). Intergenerational income mobility in permanent and separated families. Economics Letters, 80, 239-246.

Black, D. A., McKinnish, T. G., y Sanders, S. G. (2005). Tight labor markets and the demand for education: evidence from the coal boom and bust. Industrial and Labor Relations Review, 59(1), 1-16.

Blaug, M. (1982). Introducción a la economía de la educación. México, DF: Aguilar.

Blue, D. B., y Cook, J. E. (2004). High school dropouts: can we reverse the stagnation in school graduation? Study of High School Restructuring, 1(2), 1-11.

Bowles, S., y Gintis, H. (1975). The problem with human capital theory: a Marxian critique. American Economic Review, 65, 74-82. 
Bowles, S., y Gintis, H. (1976). Schooling in capitalist America: educational reform and the contradiction of economic life. New York: Basic Books.

Bowles, S., y Gintis, H. (2002). The inheritance of inequality. Journal of Economic Perspectives, 16(3), 3-30.

Breusch, T., y Pagan, A. (1980). The Lagrange multiplier test and its application to model specification in econometrics. Review of Economic Studies, 47, 239-253.

Bridgeland, J. M., Dilulio, J. J., y Morrison, K. B. (2006). The silent epidemic: Perspectives of high school dropout. Washington, DC: Civil Enterprises.

Brown, S., y Sessions, J. G. (2004). Signalling and screening. En G. Johnes, y J. Johnes (Eds.), International handbook on the economics of education (pp. 58-100). Cheltenham y Northampton: Edward Elgar Publishing Ltd.

Buendía Azorín, J. D., y Sánchez de la Vega, M. M. (2013). La distribución del desempleo en las provincias españolas: un análisis con datos de panel mediante el filtrado espacial. Investigaciones Regionales, 27, 143-154.

Burtless, G. (1996). Introduction and summary. En G. Burtless (Ed.), Does money matter? The effect of school resources on student achievement and adult success (pp. 1-42). Washington, DC: Brookings Institution Press.

Cabrera Rodríguez, L. J. (2013). Desigualdad social, rendimiento y logro educativos en España (1990-2012): los desequilibrios regionales aumentan. Revista De Estudios Regionales, 98, 15-49.

Cabus, S. J., y De Witte, K. (2011). Does school time matter? - On the impact of compulsory education age on school dropout. Economics of Education Review, 30, 1384-1398.

Cabus, S. J., y De Witte, K. (2013). Why do students leave education early? - Theory and evidence on high school dropout rates. Tier Working Paper Series, 13/01. Tier.

Calero, J., Choi, A., y Waisgrais, S. (2010). Determinantes del riesgo de fracaso escolar en España: una aproximación a través de un análisis logístico multinivel aplicado a PISA-2006. Revista De Educación, no extraordinario 2010, 225-256.

Calero, J., y Escardíbul, J. O. (2007). Evaluación de servicios educativos: el rendimiento en los centros públicos y privados medido en PISA-2003. Hacienda Pública Española, 183(4), 33-66.

Caneda González, A., y Fernández-Jardón Fernández, C. M. (2000). El nivel educativo de los trabajadores como factor de crecimiento económico. análisis comparativo entre Galicia y España. Vigo: Servicio de Publicacións da Universidad de Vigo.

Carabaña, J. (2009). Las diferencias entre países y regiones en las pruebas PISA. (Documento de Trabajo n2). Colegio Libre de Eméritos, Universidad Complutense de Madrid.

Carnoy, M., Miller, L. C., y Luschei, T. F. (2005). Economía de la educación. Barcelona: Universidad Abierta de Cataluña.

Cataldi, E. F., Laird, J., KewalRamani, A., y Chapman, C. (2009). High school dropout and completion rates in the United States: 2007. (Compendium Report, NCES 2009- 
064). Washington, DC: National Center for Education Statistics, Institute of Education Sciences, U.S. Department of Education.

Chapman, C., Laird, J., Ifill, N., y KewalRamani, A. (2011). Trends in high school dropout and completion rates in the United States: 1972 - 2009. (NCES 2012-006). Washington, DC: National Center for Education Statistics, Institute of Education Sciences, U.S. Department of Education.

Choi, A., y Jerrim, J. (2015). The use (and misuse) of PISA in guiding policy reform: the case of Spain. (IEB Working Paper N. 2015/06). Barcelona: Institut d'Economia de Barcelona.

Chuang, H. (1997). High school youth's dropout and re-enrolment behaviour. Economics of Education Review, 16(2), 171-186.

Chubb, J. E., y Moe, T. M. (1990). Politics, markets, and America's schools. Washington, D.C.: Brookings Institution.

Clark, D. (2009). The performance and competitive effects of school autonomy. Journal of Political Economy, 117(4), 745-783.

Clark, D. (2011). Do recessions keep students in school? The impact of youth unemployment on enrolment in post-compulsory education in England. Economica, 78, 523-545.

Cohen, D., y Soto, M. (2007). Growth and human capital: good data, good results. Journal of Economic Growth, 12(1), 51-76.

Coleman, J. S. (1988). Social capital in the creation of human capital. The American Journal of Sociology, 94(Supplement: Organizations and Institutions: Sociological and Economic Approaches to the Analysis of Social Structure), 95-120.

Combat Poverty Agency. (2001). Submission on early school leavers and youth unemployment to the national economic and social forum. (Policy Submission). Dublin.

Comisión Europea. (2000). Indicadores estructurales. (Comunicación de la Comisión, $\operatorname{COM}(2000) 594$ final). Bruselas.

Comisión Europea. (2001). Futuros objetivos precisos de los sistemas educativos. (Informe de la Comisión, $\operatorname{COM(2001)~} 59$ final). Bruselas.

Comisión Europea. (2011a). Abordar el abandono escolar prematuro: una contribución clave a la agenda Europa 2020. (Comunicación de la Comisión al Parlamento Europeo, al Consejo, al Comité Económico y Social Europeo y al Comité de las Regiones, $\operatorname{COM(2011)~} 18$ final). Bruselas.

Comisión Europea. (2011b). Propuesta de Recomendación del Consejo relativa a las políticas para reducir el abandono escolar prematuro. (SEC(2011) 98 final, SEC(2011) 97 final, SEC(2011) 96 final). Bruselas.

Consejo Europeo. (2000). Consejo Europeo de Lisboa: Conclusiones de la presidencia. Lisboa.

Consejo Europeo. (2005). Consejo Europeo de Bruselas: Conclusiones de la presidencia. Bruselas. 
Consejo Europeo. (2009). Conclusiones del Consejo de 12 de mayo de 2009 sobre un marco estratégico para la cooperación europea en el ámbito de la educación y la formación "ET 2020". (2009/C119/02).

Cooper, C. R., Chavira, G., y Mena, D. D. (2005). From pipelines to partnerships: a synthesis of research on how diverse families, schools and communities support children's pathways through school. Journal of Education for Students Placed at Risk, 10(4), 407-430.

Cordero Ferrera, J. M., Manchón López, C., Simancas Rodríguez, R. (2014). La repetición de curso y sus factores condicionantes en España. Revista de Educación, 365, 12-37.

Corugedo, I., García Pérez, E., y Martínez Pagés, J. (1990). Un análisis coste-beneficio de la educación no universitaria en España. Revista De Educación, 293, 67-108.

Corugedo de las Cuevas, I., García, E., y Martínez, J. (1991). Un análisis coste-beneficio de la enseñanza media en España. Madrid; Centro de Publicaciones del Ministerio de Educación y Ciencia, CIDE.

Corugedo, I., García Pérez, E., y Martínez Pagés, J. (1992). Educación y rentas: una aplicación a la enseñanza media en España. Una nota. Investigaciones Económicas, 16(2), 299-304.

Crofton, S. O., Anderson, W. L., y Rawe, E. C. (2009). Do higher real minimum wages lead to more high school dropouts? Evidence from Maryland across races, 19932004. American Journal of Economics and Sociology, 68(2), 445-464.

Croninger, R. G., y Lee, V. E. (2001). Social capital and dropping out of high school: benefits to at-risk students of teacher's support and guidance. Teachers College Record, 103(4), 548-581.

Cuadrado Roura, J. R., Mancha, T., Villena, J. E., Casares, J., González, M., Marín, J. M., y Peinado, M. L. (2010). Política económica: elaboración, objetivos e instrumentos (4a Edición). Madrid: McGraw-Hill.

Cuadrado-Roura, J. R. (2012). La crisis económica actual y sus efectos regionales. panorama general, perspectivas y posibles salidas. Cuadernos De Ciencias Económicas y Empresariales, 63, 113-136.

Cuadrado-Roura, J. R., y Maroto-Sánchez, A. (2014). Unbalanced regional impact of the crisis in Spain. An explorative analysis through structural changes, sectoral specialization and productivity. (54th European Regional Science Association Congress). St. Petersburg.

Cullen, B. (2000). Evaluating integrated responses to educational disadvantage. (Children's Research Centre). Dublin: Combat Poverty Agency.

Dale, R. (2010). Early school leaving. Lessons from research for policy makers. (An independent expert report submitted to the European Commission). Network of Experts in Social Sciences of Education and Training.

Dalton, B., Gennie, E., e Ingels, S. J. (2009). Late high school dropouts: characteristics, experiences, and changes across cohorts. (Descriptive Analysis Report, NCES 2009- 
307). Washington, DC: National Centre for Education Statistics, Institute of Education Sciences, US Department of Education.

De Hoyos, R. E., y Sarafidis, V. (2006). Testing for cross-sectional dependence in paneldata models. The Stata Journal, 6(4), 482-496.

De la Fuente, A. (2002). Capital humano y crecimiento: nuevas series de escolarización y algunos resultados para la OCDE. Economía Industrial, 348(VI), 41-52.

De la Fuente, A. (2004). Educación y crecimiento: un panorama. Revista Asturiana De Economía, 31, 7-49.

De la Fuente, A., y Doménech, R. (2002). Human capital growth regressions: how much difference does data quality make? An update and further results. (UFAE and IAE Working Papers, No. 537.02). Unitat de Fonaments e l'Anàlisi Econòmica e Institut d'Anàlisi Econòmica.

De la Fuente, A., y Doménech, R. (2006). Human capital in growth regressions: how much difference does data quality make? Journal of the European Economic Association, 4(1), 1-36.

De la Rica, S., e Iza, A. (1999). Capital humano, productividad y crecimiento: teorías y contrastes. Ekonomiaz, 45, 266-283.

De Witte, K., Nicaise, I., Lavrijsen, J., Van Landeghem, G., Lamote, C., y Van Damme, J. (2013). The impact of institutional context, education and labour market policies on early school leaving: a comparative analysis of EU countries. European Journal of Education, 48(3, Special Issue: Problematising the Issue of Early School Leaving in the European Context), 331-345.

Dellas, H., y Sakellaris, P. (2003). On the cyclicality of schooling: theory and evidence. Oxford Economic Papers, 55(I), 148-172.

Denison, E. F. (1962). The sources of economic growth in the US and the alternatives before us. Washington DC: The Brookings Institution.

Dickson, M., y Harmon, C. (2011). Economic returns to education: What we know, what we don't know, and where we are going-some brief pointers. Economics of Education Review, 30(6), 1118-1122.

Doeringer, P. B., y Piore, M. J. (1971). Internal labor markets and manpower analysis. Lexington: D.C. Heath.

Dolado, J. J., Felgueroso, F., y Jimeno, J. F. (2000). Youth labour markets in Spain: education, training, and crowding-out. European Economic Review, 44, 943-956.

Domar, E. D. (1946). Expansion, rate of growth and employment. Econometrica, 14(2), 137-147.

Dronkers, J., y Robert, P. (2008). Differences in scholastic achievement of public, private government-dependent, and private independent schools. A crossnational analysis. Educational Policy, 22, 541-577.

Duchesne, S., y Larose, S. (2007). Adolescent parental attachment and academic motivation and performance in early adolescence. Journal of Applied Social Psychology, 37(7), 1501-1521. 
Duncan, G., y Hoffman, S. (1981). The incidence and wage effects of overeducation. Economics of Education Review, 1(1), 75-86.

Duru-Bellat, M., y Suchaut, B. (2005). Organisation and context, efficiency and equity of educational systems: what PISA tell us. European Educational Research Journal, 4(3), 181-194.

Dustmann, C., y Van Soest, A. (2007). Part-time work, school success and school leaving. Empirical Economics, 32, 277-299.

Easterlin, R. (1981). Why isn't the whole world developed? Journal of Economic History, 41, 1-19.

Eren, O., y Millimet, D. L. (2006). Time to learn? The organizational structure of schools and student achievement. En C. Dustmann, B. Fitzenberger y S. Machin (Eds.), The economics of education and training (pp. 47-78). Springer.

European Commission. (1993). Growth, competitiveness, employment. The challenges and ways forward into the 21st century. (Brussels White Paper COM(93) 700). Brussels.

European Commission. (1995). Teaching and learning - towards the learning society. (White paper on education and training $\operatorname{COM}(95)$ 590). Brussels.

European Commission. (2003). Education \& Training 2010 - The success of the Lisbon strategy hinges on urgent reforms. (Communication from the Commission $\operatorname{COM}(2003) 685$ final). Brussels.

European Commission. (2006). Member States autumn 2006 reports on the implementation of their National Reform Programmes. Brussels.

European Commission. (2008). Regions 2020. An assessment of future challenges for EU regions. (Commission Staff Working Document SEC(2008). Brussels.

European Commission. (2010a). Lisbon Strategy evaluation document. (Commission Staff Working Document SEC(2010) 114 final). Brussels.

European Commission. (2010b). Europe 2020 - A strategy for smart, sustainable and inclusive growth. (Commission's communication COM(2010) 2020). Brussels.

European Commission. (2013a). Reducing early school leaving: Key messages and policy support. (Final report of the Thematic Working Group on Early School Leaving). Brussels.

European Commission. (2013b). Data collection on and monitoring of early school leaving. (Draft analysis of the results from the mapping exercise on data collection and monitoring of ESL). Brussels: Thematic Working Group on Early School Leaving.

European Council. (1998). Council Regulation on the organisation of a labour force sample survey in the Community. (Council Regulation 577/1998 of 9 March 1998). Brussels.

European Council. (2001). The concrete future objectives of education and training systems. (Education Council Report 5980/01). 
European Council. (2002). Detailed work programme on the follow-up of the objectives of education and training systems in Europe. (Education Council report 2002/C143/01).

European Council. (2003a). The promotion of enhanced European cooperation in vocational education and training. (Council Resolution of 19 December 2002, $\mathrm{C} 13 / 2-\mathrm{C} 13 / 4)$.

European Council. (2003b). Reference levels of European average performance in education and training (benchmarks). (Council conclusions of 5 May 2003, C134/02).

European Council. (2011). Policies to reduce early school leaving. (Council Recommendation of 28 June 2011, C191/1 - C191/6).

European Parliament. (2002). Report on the Commission communication on the draft detailed work programme for the follow-up of the report on the concrete objectives of education and training systems (COM(2001) 501 - C5-0601/2001 2001/2251(COS)). (Session Document A5-0017/2002). Committee on Culture, Youth, Education, the Media and Sport.

Eurydice. (2013). Funding of education in Europe 2000-2012: the impact of the economic crisis. (Eurydice Report). Luxembourg: Publication Office of the European Union, European Commission.

Felgueroso, F. (2015). El retroceso del abandono escolar temprano. (NeG Visual y Básico 23/05/2015). Nada es Gratis.

Felgueroso, F., Gutiérrez-Domènech, M., y Jiménez-Martín, S. (2013). ¿Por qué el abandono escolar se ha mantenido tan elevado en España en las últimas dos décadas? El papel de la ley de educación (LOGSE). (Colección Estudios Económicos 02-2013). Fundación de Estudios de Economía Aplicada.

Ferguson, R. F. (1991). Paying for public education: new evidence on how and why money matters. Harvard Journal on Legislation, 28, 465-498.

Fernández Llera, R., y Muñiz Pérez, M. (2012). Colegios concertados y selección de escuela en España: un círculo vicioso. Presupuesto y Gasto Público, 67, 97-118.

Fernández, M., Mena, L., y Riviere, J. (2010). Fracaso y abandono escolar en España. (Colección de Estudios Sociales, No. 29). Barcelona: Obra Social Fundación "La Caixa".

Fernández Macías, E., Muñoz de Bustillo Llorente, R., Braña Pino, F. J., y Antón Pérez, J. I. (2010). Algunas apreciaciones aritméticas sobre el fracaso y el abandono escolar en España. Revista De Educación, no extraordinario 2010, 307-324.

Fernández-Macías, E., Antón, J. I., Braña, F. J., y Muñoz de Bustillo, R. (2013). Early school-leaving in Spain: evolution, intensity and determinants. European Journal of Education, 48(1), 150-164.

Finn, J. D. (1998). Class size and students at risk. what is known? What is next? (Report no AR-98-7104). National Institute on the Education of At-Risk Students. Office of Educational Research and Improvement. US Department of Education. 
Finn, J. D., Gerber, S. B., y Boyd-Zaharias, J. (2005). Small classes in the early grades, academic achievement, and graduating from high school. Journal of Educational Psychology, 97, 214-223.

Fredriksson, P., Björn, Ö., y Oosterbeek, H. (2013). Long-term effects of class size. The Quarterly Journal of Economics, 128(1), 249-285.

Frees, E. W. (1995). Assessing cross-sectional correlations in panel data. Journal of Econometrics, 64(393), 414.

Frees, E. W. (2004). Longitudinal and panel data: analysis and applications in the social sciences. Cambridge: Cambridge University Press.

Freire-Serén, M. J. (2001). Human capital accumulation and economic growth. Investigaciones Económicas, XXV(3), 585-602.

Freire-Serén, M. J. (2002). On the relationship between human capital accumulation and economic growth. Applied Economic Letters, 9(12), 805-808.

Friedman, M. (1937). The use of ranks to avoid the assumption of normality implicit in the analysis of variance. Journal of the American Statistical Association, 32, 675701.

Fuchs, T., y Wößmann, L. (2006). What accounts for international differences in student performance? A re-examination using PISA data. En C. Dustmann, B. Fitzenberg y S. Machin (Eds.), The economics of education and training (pp. 209240) Springer.

Fundación FOESSA. (2014). VII informe sobre exclusión y desarrollo social en España. Madrid: Fundación Fomento de Estudios Sociales y de Sociología Aplicada.

Gamoran, A. (1996). Student achievement in public magnet, public comprehensive, and private city high schools. Educational Evaluation and Policy Analysis, 18, 1-18.

Garasky, S. (1995). The effects of family-structure on educational-attainment. do the effects vary by the age of the child? American Journal of Economics and Sociology, 54, 89-105.

García Gracia, M., Casal Bataller, J., Merino Pareja, R., Sánchez Gelabert, A. (2013). Itinerarios de abandono escolar y transiciones tras la Educación Secundaria Obligatoria. Revista de Educación, 361, 65-94.

García Montalvo, J. (2013). Dimensiones regionales del ajuste inmobiliario en España. Papeles De Economía Española, 138, 62-79.

Gautier, P. A., Van der Berg, G. J., Van Ours, J. C., y Ridder, G. (2002). Worker turnover at the firm level and crowding out of lower educated workers. European Economic Review, 46(3), 523-538.

GHK. (2005). Study on access to education and training, basic skills and early school leavers. (Lot 3: Early School Leavers Final Report, DG EAC 38/04). London: European Commission DG EAC.

Gorostiaga, A. (1999). ¿Cómo afectan el capital público y el capital humano al crecimiento? Un análisis para las regiones españolas en el marco neoclásico. Investigaciones Económicas, 23, 95-114. 
Gottschalk, P., y Hansen, M. (2003). Is the proportion of college workers in noncollege jobs increasing? Journal of Labor Economics, 21(2), 409-448.

Groot, W., y Oosterbeek, H. (1994). Earnings effects of different components of schooling: human capital versus screening. Review of Economics and Statistics, 76(2), 317-321.

Gujarati, D. N., y Porter, D. C. (2010). Econometría (5a ed.). México, DF: McGrawHill.

Hammond, C., Linton, D., Smink, J., y Drew, S. (2007). Dropout risk factors and exemplary programs. (Technical Report). Cemson, SC: National Dropout Prevention Center y Communities in Schools, Inc.

Hanushek, E. A. (1989). The impact of differential expenditures on school performance. Educational Researcher, 18, 45-62.

Hanushek, E. A. (1996). School resources and student performance. En G. Burtless (Ed.), Does money matter? The effect of school resources on student achievement and adult success (pp. 43-73). Washington, DC: Brookings Institution Press.

Hanushek, E. A. (1997). Assessing the effects of school resources on student performance: an update. Educational Evaluation and Policy Analysis, 19(2), 141164.

Hanushek, E. A. (2003). The failure of input-based schooling policies. The Economic Journal, 113, 64-98.

Hanushek, E. A., y Kimko, D. (2000). Schooling, labor-force quality and the growth of nations. American Economic Review, 90(5), 1184-1208.

Hanushek, E. A., Link, S., y Wößmann, L. (2014). Does school autonomy make sense everywhere? Panel estimates from PISA. Journal of Development Economics, 104, 212-232.

Hanushek, E. A., y Woessmann, L. (2006). Does educational tracking affect performance and inequality? Differences-in-differences evidence across countries. Economic Journal, 116(510), C63-C76.

Hanushek, E. A., y Woessmann, L. (2014). Institutional structures of the education system and student achievement: a review of cross-country economic research. En R. Strietholt, W. Bos, J. E. Gustafsson y M. Rosen (Eds.), Educational policy evaluation through international comparative assessments (pp. 145-175). Munster, Germany: Waxman.

Harrod, R. F. (1939). An essay in dynamic theory. The Economic Journal, 49(193), 1433.

Hausman, J. A. (1978). Specification test in econometrics. Econometrica, 46, 12511272.

Heckman, J., y Klenow, P. (1997). Human capital policy. Mimeo.

Hedges, L. V., y Greenwald, R. (1996). Have times changed? The relation between school resources and student performance. En G. Burtless (Ed.), Does money matter? The effect of school resources on student achievement and adult success (pp. 74-92). Washington, DC: Brookings Institution Press. 
Hedges, L. V., Laine, R. D., y Greenwald, R. (1994). Does money matter? A metaanalysis of studies of the effects of differential school inputs on student outcomes. Educational Researcher, 23, 5-14.

Herrero, C., Soler, A., y Villar, A. (2013). Desarrollo y pobreza en España y sus comunidades autónomas: el impacto de la crisis. Papeles De Economía Española, 138, 98-113.

Heywood, J. S. (1994). How widespread are sheepskin returns to education in the US? Economics of Education Review, 13(3), 227-234.

Holmlund, H., McNally, S., y Viarengo, M. (2010). Does money matter for schools? Economics of Education Review, 29, 1154-1164.

Horowitz, S. P., y Sherman, A. (1980). A direct measure of the relationship between human capital and productivity. Journal of Human Resources, 15, 67-76.

Hoxby, C. M. (2000). The effects of class size on student achievement: new evidence from population variation. Quarterly Journal of Economics, 115(4), 1239-1285.

Hungerford, T., y Solon, G. (1987). Sheep-skin effects in the returns to education. Review of Economics and Statistics, 69(1), 175-177.

Instituto de Evaluación. (2011). Objetivos educativos europeos y españoles. Estrategia educación y formación 2020. (Informe español 2010-2011). Secretaría de Estado de Educación y Formación Profesional, Ministerio de Educación.

Instituto de Estadística de la UNESCO. (2011). Clasificación Internacional Normalizada de la Educación CINE 2011. UNESCO.

Instituto Nacional de Estadística. (2005). Cuestionario encuesta de población activa 2005.

Instituto Nacional de Estadística. (2009). Encuesta de población activa. Diseño de la encuesta y evaluación de la calidad de los datos. (Informe Técnico). Madrid:

Instituto Nacional de Evaluación Educativa. (2013). ¿Cuál es el impacto de la crisis económica en el gasto público en educación? (Education Indicators in Focus n18).

Instituto Nacional de Evaluación Educativa. (2014a). Ocupaciones de los padres y PISA 2012: el caso de las CCAA. EducaINEE no2.

Instituto Nacional de Evaluación Educativa. (2014b). Sistema estatal de indicadores de la educación. Subdirección General de Estadística y Estudios, Ministerio de Educación, Cultura y Deporte.

Instituto Valenciano de Investigaciones Económicas. (2014). Series de capital humano (1964-2013).

Instituto Vasco de Evaluación e Investigación Educativa. (2007). Abandono escolar. segundo ciclo de ESO. Bilbao: Departamento de Educación, Universidades e Investigación, Gobierno Vasco.

Islam, N. (1995). Growth empirics: a panel data approach. Quarterly Journal of Economics, 110, 1127-1170.

Jacob, B., y Lefgren, L. (2009). The effect of grade retention on high school completion. American Economic Journal of Applied Economics, 1(3), 33-58. 
Jimerson, S. R., Anderson, G. E., y Whipple, A. D. (2002). Winning the battle and losing the war: examining the relation between grade retention and dropping out of high school. Psychology in the Schools, 39(4), 441-457.

Johnson, M. K., Crosnoe, R., y Elder, G. H. (2001). Students' attachment and academic engagement: The role of race and ethnicity. Sociology of Education, 74(4), 318340.

Jorgenson, D. W., y Griliches, Z. (1967). The explanation of productivity change. Review of Economic Studies, 34, 249-284.

Jugovic, I., y Doolan, K. (2013). Is there anything specific about early school leaving in southeast Europe? A review of research and policy. European Journal of Education, 48(3, Special Issue: Problematising the Issue of Early School Leaving in the European Context), 363-377.

Keesing, D. B. (1965). Labor skills and international trade: evaluating many trade flows with a single measuring device. Review of Economics and Statistics, 47(3), 287294.

Keesing, D. B. (1966). Labor skills and comparative advantage. American Economic Review, 56, 249-258.

Khalifa, S. (2010). Job competition, crowding out, and unemployment fluctuations. Fullerton: California State University.

Kodde, D. (1988). Unemployment expectations and human capital formation. European Economic Review, 32, 1645-1660.

Kodde, D., y Ritzen, J. (1984). Integrating consumption and investment motives in a neoclassical model of demand for education. Kyklos, International Review for Social Sciences, 37(4), 598-606.

Kok, W. (2003). Enlarging the European union. Achievements and challenges. (Report of Wim Kok to the European Commission). European University Institute, Robert Schuman Centre for Advanced Studies.

Kok, W., Bausch, R., Fitzgerald, N., Gutiérrez, A., Hutton, W., Idrac, A. M., LundbyWedin, W., Mirow, T., Moldan, B., Paganetto, L., Rosati, D., Sundbäck, V., y Verzetnitsch, F. (2004). Hacer frente al desafío. Ia Estrategia de Lisboa para el crecimiento y el empleo. (Informe del Grupo de Alto Nivel presidido por Wim Kok).

Krueger, A. (2002). Understanding the magnitude and effect of class size on student achievement. En L. Mishel, y R. Rothstein (Eds.), The class size debate (pp. 7-36). Washington, DC: Economic Policy Institute.

Krueger, A., y Lindahl, M. (2001). Education for growth: why and for whom? Journal of Economic Literature, XXXIX, 1101-1136.

Krueger, A., y Whitmore, D. (2001). The effect of attending a small class in the early grades on college-test taking and middle school test results: evidence from project STAR. The Economic Journal, 111(January), 1-28.

Kyriacou, G. (1991). Level and growth effect of human capital: a cross-country study of the convergence hypothesis. (Economic Research Reports). New York: New York University, C.V. Starr Center for Applied Economics. 
Lacuesta, A., Puente, S., y Villanueva, E. (2012). The schooling response to a sustained increase in low-skill wages: evidence from Spain 1989 - 2009. (Documento de Trabajo No. 1208). Banco de España.

Lafuente Lechuga, M., y Faura Martínez, U. (2012). Estudio de la vulnerabilidad a la exclusión social por comunidades autónomas en España (2005-2009). Investigaciones Regionales, 23, 105-126.

Laird, J., DeBell, M., y Chapman, C. (2006). Dropout rates in the United States: 2004. (NCES 2007-024). Washington, DC: National Center for Education Statistics, U.S. Department of Education.

Lamb, S., y Markussen, E. (2011). School dropout and completion: an international perspective. En S. Lamb, E. Markussen, R. Teese, N. Sandberg y J. Polesel (Eds.), School dropout and completion: International comparative studies in theory and policy (pp. 1-18). Springer.

Landeras, P., y Pérez de Villareal, J. M. (2003). La educación como filtro imperfecto. Economía de la Educación AEDE XII, 393-403.

Lassibille, G., y Navarro Gómez, M. L. (2004). Manual de economía de la educación: teoría y casos prácticos. Madrid: Pirámide.

Lassibille, G., y Navarro Gómez, M. L. (2012). Un compendio de investigaciones en economía de la educación. Presupuesto y Gasto Público, 67, 9-28.

Lau, L., Bhalla, S., y Louat, F. (1991). Human and physical capital stock in developing countries: Construction of data and trends. (Mimeo).

Lau, L., Jamison, D., Liu, S., y Rivlin, S. (1996). Education and economic growth: Some cross-sectional evidence. En N. Birdsall, y R. H. Sabot (Eds.), Education in Brazil (pp. 83-116). Washington, DC.: Inter-American Development Bank.

Lau, L., Jamison, D., y Louat, F. (1991). Education and productivity in developing countries: An aggregate production function approach. (Working Papers Series $\mathrm{n}$ 612). Policy, Research, and External Affairs, The World Bank.

Layard, P. R. G., y Psacharopoulos, G. (1974). The screening hypothesis and the returns to education. Journal of Political Economy, 82, 985-998.

Lazear, E. (2001). Educational production. The Quarterly Journal of Economics, 116(3), 777-803.

Lee, V. E., y Burkam, D. T. (2003). Dropping out of high school: the role of school organization and structure. American Educational Research Journal, 40(2), 353393.

Leontaridi, M. R. (1998). Segmented labour markets: theory and evidence. Journal of Economic Surveys, 12(1), 63-101.

Leontaridi, M. R. (2002). Career, experience and returns to human capital: is the dual labour market hypothesis relevant for the UK? Research in Economics, 56, 399426.

Leuven, E., y Oosterbeek, H. (2011). Overeducation and mismatch in the labor market. (IZA Discussion Paper Series, 5523). Bonn: IZA. 
Levels, M., Dronkers, J., y Kraaykamp, G. (2008). Immigrant children's educational achievement in western countries: origin, destination, and community effects on mathematical performance. American Sociological Review, 73, 835-853.

Levin, H. M. (2009). The economic payoff to investing in educational justice. Educational Researcher, 38(1), 5-20.

Linnakylä, P., Roe, A., y Lie, A. (2003). Future challenges to Nordic education. En S. Lie, P. Linnakylä y A. Roe (Eds.), Northern lights on PISA. Unity and diversity in the Nordic countries in PISA 2000 (pp. 159-165). Oslo: Department of Teacher Education and School Development, University of Oslo.

Lleras-Muney, A. (2005). The relationship between education and adult mortality in the United States. Review of Economic Studies, 72, 189-221.

Lochner, L., y Moretti, E. (2004). The effect of education on criminal activity: evidence from prison inmates, arrests, and self-reports. American Economic Review, 94(1), 155-189.

Loeb, S., y Page, M. E. (2000). Examining the link between teacher wages and student outcomes: the importance of alternative labor market opportunities and nonpecuniary variation. Review of Economics and Statistics, 82, 393-408.

López-Bazo, E., y Moreno, R. (2012). Profitability of investments in education. Evidence from Spanish regions. Regional Studies, 46(10), 1333-1346.

López-Bazo, E., y Motellón, E. (2013). Disparidades en los mercados de trabajo regionales. El papel de la educación. Papeles De Economía Española, 135, 46-61.

Lucas, R. E. (1988). On the mechanics of economic development. Journal of Monetary Economics, 22(1), 3-42.

Lucas, R. E. (1993). Making a miracle. Econometrica, 61(2), 251-272.

Lyche, C. (2010). Taking on the completion challenge: A literature review on policies to prevent dropout and early school leaving. (OECD Education Working Papers, 53). OECD Publishing.

Machin, S., y Vernoit, J. (2011). Changing school autonomy: academy schools and their introduction to England's education. (CEE Discussion Paper 123). London: Centre for the Economics of Education, London School of Economics.

Mancebón Torrubia, M. J., y Pérez Ximénez-De-Embún, D. (2010). Una valoración del grado de segregación socioeconómica existente en el sistema educativo español. Un análisis por comunidades autónomas a partir de PISA 2006. Regional and Sectoral Economic Studies, 10(3), 129-148.

Mancebón, M. J., Calero, J., Choi, A., y Ximenez-de-Embun, D. P. (2012). The efficiency of public and publicly subsidized high schools in Spain: evidence from PISA-2006. Journal of the Operational Research Society, 63(11), 1516-1533.

Mancha Navarro, T., y Garrido Yserte, R. (2009). Las desigualdades regionales en España (1955-2006): Pasado, presente y futuro. Foreign Affairs, 9(1), 87-98.

Mankiw, N. G., Romer, D., y Weil, D. N. (1992). A contribution to the empirics of economic growth. Quarterly Journal of Economics, 107(2), 407-437. 
Marchesi Ullastres, A. (2003). El fracaso escolar en España. (Documento de Trabajo 11/2003). Fundación Alternativas.

Marco Crespo, R., y Ortiz Serrano, S. (2006). Los fondos de inversión a examen. Un análisis empírico con datos de panel. Madrid: Vision Net Editorial.

Marks, G., y Fleming, N. (1999). Early school leaving in Australia: findings from the 1995 year 9 LSAY cohort. (LSAY Research Reports, no 11). Victoria: Australian Council for Educational Research.

Martín, C., y Velázquez, F. J. (2002). Determinants of net trade flows in the OECD: new evidence with special emphasis on the case of the former communist members. Review of International Economics, 10(1), 129-139.

Martín, C., Velázquez, F. J., Sanz, I., Crespo, J., Perales, F. J., y Turrión, J. (2000). Capital humano y bienestar económico. la necesaria apuesta de España por la educación de calidad. Madrid: Círculo de Empresarios.

Matías Clavero, G. (2005). La estrategia de Lisboa sobre la sociedad del conocimiento: la nueva economía. Información Comercial Española, ICE: Revista De Economía, 820, 169-194.

Mazzonna, F. (2014). The long-lasting effects of family background: a European crosscountry comparison. Economics of Education Review, 40, 25-42.

McMahon, W. W. (2004). The social and external benefits of education. En G. Johnes, y J. Johnes (Eds.), International handbook on the economics of education (pp. 211259). Cheltenham y Northampton: Edward Elgar Publishing Ltd.

McNeal, R. B. (1997). High school dropouts: A closer examination of school effects. Social Sciences Quarterly, 78(1), 209-222.

Mediavilla, M. (2013). Heterogeneidad en el impacto de la política de becas en la escolaridad secundaria postobligatoria en España: un análisis por subgrupos poblaciones. Estudios De Economía, 40(1), 97-120.

Mediavilla, M. (2014). ¿Son efectivas las becas en España? Una evaluación de impacto para el nivel secundario postobligatorio. Revista Iberoamericana De Evaluación Educativa, 7(1), 121-139.

Mena Martínez, L., Fernández Enguita, M., y Riviere Gómez, J. (2010). Desenganchados de la educación: procesos, experiencias, motivaciones y estrategias del abandono y del fracaso escolar. Revista de Educación, no extraordinario 2010, 119-145.

Meschi, E., Swaffield, J., y Vignoles, A. (2011). The relative importance of local labour market conditions and pupil attainment on post-compulsory schooling decisions. (Discussion Paper Series No. 6143). Bonn: IZA.

Micklewright, J., Pearson, M., y Smith, S. (1990). Unemployment and early school leaving. The Economic Journal, 100, 163-169.

Mincer, J. (1974). Schooling, experience and earnings. Washington DC: National Academy of Education.

Ministerio de Educación. (2011). Objetivos educativos europeos y españoles. Estrategia Educación y Formación 2020. Informe español 2010-2011. Madrid: Secretaría de Estado de Educación y Formación Profesional, Conferencia de Educación. 
Ministerio de Educación, Cultura y Deporte. (2013). Objetivos educativos europeos y españoles. Estrategia Educación Formación 2020. Informe español 2013. Madrid: Secretaría de Estado de Educación, Formación Profesional y Universidades. Conferencia de Educación.

Ministerio de la Presidencia. (2005). Convergencia y Empleo. Programa nacional de reformas de España. Madrid: Secretaria General Técnica.

Ministerio de la Presidencia. (2006). Programa nacional de reformas de España. Informe anual de progreso 2006. Madrid.

Ministerio de la Presidencia. (2007). Programa nacional de reformas de España. Informe anual de progreso 2007. Madrid.

Ministerio de la Presidencia. (2008). Programa nacional de reformas de España. Informe anual de progreso 2008. Madrid.

Ministerio de la Presidencia. (2009). Programa nacional de reformas de España. Informe anual de progreso 2009. Madrid.

Ministerio de la Presidencia. (2011). Programa nacional de reformas de España 2011. Madrid.

Ministerio de la Presidencia. (2012). Programa nacional de reformas de España 2012. Madrid.

Ministerio de la Presidencia. (2013). Programa nacional de reformas. Reino de España 2013. Madrid.

Minondo Uribe-Etxeberria, A., Requena Silvente, F., y Serrano Domingo, G. (2013). Movimientos migratorios en España antes y después de 2008. Papeles De Economía Española, 138, 80-97.

Miró i Ardèvol, J. (2010). El rendimiento escolar. La anomalía española. Institut d'Estudis del Capital Social, Universitat Abat Oliva CEU.

Montmarquette, C., Viennot-Briot, N., y Dagenais, M. (2007). Dropout, school performance, and working while in school. The Review of Economics and Statistics, 89(4), 752-760.

Mora Corral, A. J. (2010). Determinantes del abandono escolar en Cataluña: Más allá del nivel socio-económico de las familias. Revista De Educación, no extraordinario 2010, 171-190.

Mora, T., Escardíbul, J. O., y Espasa, M. (2010). The effects of regional educational policies on school failure in Spain. Revista de Economía Aplicada, 18(54), 79-106.

Morales Sequera, S. (2010). La descentralización de la educación no universitaria en España: efectos sobre la convergencia regional desde la perspectiva del gasto público. (Tesis Doctoral). Universidad Autónoma de Madrid.

Muñoz de Bustillo Llorente, R., Antón Pérez, J. I., Braña Pino, J. I., y Fernández Macías, E. (2009). Abandono escolar y mercado de trabajo en España (Colección Informes y Estudios, Serie Empleo, nํ40). Madrid: Ministerio de Trabajo e Inmigración.

Murthy, N. R., y Chien, I. S. (1997). The empirics of economic growth for OECD countries: Some new findings. Economics Letters, 55(3), 425-429. 
Nehru, V., Swanson, E., y Dubey, A. (1995). A new database on human capital stocks in developing and industrial countries: sources, methodology and results. Journal of Development Economics, 46, 379-401.

Nelson, R., y Phelps, E. (1966). Investment in humans, technological diffusion and economic growth. American Economic Review, 56(2), 69-82.

Neumark, D., y Wascher, W. (1995). The effects of minimum wages on teenage employment and enrolment: evidence from matched CPS surveys. (NBER Working Paper № 5092). Cambridge: National Bureau of Economic Research.

Nonneman, W., y Vanhout, P. (1996). A further augmentation of the Solow model and the empirics of economic growth for OECD countries. The Quarterly Journal of Economics, 111(3), 943.

Nuñez, C. E. (1992). La fuente de la riqueza: Educación y desarrollo económico en la España contemporánea. Madrid: Alianza Universidad.

Nuñez, C. E. (2005). Educación. En A. Carreras, y X. Tafunell (Eds.), Estadísticas históricas de España: Siglos XIX y XX (pp. 155-244). Bilbao: Fundación BBV.

OCDE. (2004). Informe PISA 2003. Aprender para el mundo del mañana. Paris: OECD Publishing.

OCDE. (2010). PISA 2009: Informe español. Madrid: OECD Publishing.

OECD. (1998a). Education at a Glance - OECD Indicators. Paris: OECD.

OECD. (1998b). Overcoming failure at school. Paris: OECD Publishing.

OECD. (2001a). The well-being of nations: the role of human and social capital. Paris: OECD Publishing.

OECD. (2001b). Knowledge and skills for life: First results from PISA 2000. Paris: OECD Publishing.

OECD. (2002). Education at a glance. Paris: OECD Publishing.

OECD. (2004a). Learning for tomorrow's world. First results from PISA 2003. Paris: OECD Publishing.

OECD. (2004b). Education at a glance. OECD Indicators 2004. Paris: OECD Publishing.

OECD. (2007). Understanding the social outcomes of learning. Centre for Educational Research and Innovation, OECD Publishing.

OECD. (2010a). PISA 2009 results: what students know and can do - student performance in reading, mathematics and science. Volume I. Paris: OECD Publishing.

OECD. (2010b). PISA 2009 results: Overcoming social background - equity in learning opportunities and outcomes. Volume II. Paris: OECD Publishing.

OECD. (2014a). PISA 2012 results: what students know and can do - student performance in mathematics, reading and science. Volume I. Paris: OECD Publishing.

OECD. (2014b). PISA 2012 results: what makes schools successful? Resources, policies and practices. Volume IV. Paris: OECD Publishing. 
OECD. (2014c). PISA 2012 results: Excellence through equity. Giving every student the chance to succeed. Volume II. Paris: OECD Publishing.

Papke, L. E. (2005). The effects of spending on test pass rates: evidence from Michigan. Journal of Public Economics, 89, 821-839.

Pastor, J. M., Raymond, J. L., Roig, J. L., y Serrano, L. (2009). Gasto público en educación en las comunidades autónomas. 2000 - 2006. Papeles De Economía Española, 118, 220-237.

Pépin, L. (2006). The history of European cooperation in education and training. Europe in the making - an example. Luxembourg: Office Publications of the European Communities, European Commission.

Pépin, L. (2011). Education in the Lisbon Strategy: assessment and prospects. European Journal of Education, 46, 25-35.

Peraita, C., y Pastor, M. (1998). The primary school dropout in Spain: The influence of family background and labor market conditions. VII Jornadas De La Asociación De La Economía De La Educación, 211-218.

Pérez Mayo, J. (2013). Crisis económica y territorio: el impacto de la crisis sobre la desigualdad de rentas en las distintas regiones españolas. Papeles De Economía Española, 135, 36-49.

Pérez-Esparrells, C., y Morales Sequera, S. (2012a). El fracaso escolar en España: un análisis por comunidades autónomas. Revista De Estudios Regionales, 94, 39-69.

Pérez Esparrells, C., y Morales Sequera, S. (2012b). La descentralización de la enseñanza no universitaria en España: análisis de convergencia desde la perspectiva del gasto. Presupuesto y Gasto Público, 67, 137-160.

Pesaran, M. H. (2004). General diagnostic tests for cross section dependence in panels. Cambridge: University of Cambridge.

Petrongolo, B., y San Segundo, M. J. (2002). Staying-on at school at 16: the impact of labor market conditions in Spain. Economics of Education Review, 21(353), 353365.

Pirog, M. A., y Magee, C. (1997). High school completion: the influence of schools, families, and adolescent parenting. Social Sciences Quarterly, 78, 710-724.

Plank, S. B., Deluca, S., y Estacion, V. (2008). High school dropout and the role of career and technical education: a survival analysis of surviving high school. Sociology of Education, 81, 345-370.

Pleis, J. R., Ward, W. B., y Lucas, J. W. (2010). Summary health statistics for U.S. adults: National health interview survey, 2009. Vital Health Stat, 10(249), National Center for Health Statistics.

Prados de la Escosura, L., y Rosés, J. (2010). Human capital and economic growth in Spain, 1850-2000. Explorations in Economic History, 47, 520-532.

Prats, J., Raventós, F., Gasòliba, E., Cowen, R., Creemers, B. P. M., Gauthier, P. L., Maes, B., Schulte, B., y Standaert, R. (2005). Los sistemas educativos europeos. ¿Crisis o transformación?. (Colección de Estudios Sociales, nำ18). Barcelona: Fundación La Caixa. 
Pritchett, L. (2000). Where has all education gone? World Bank and Kennedy School of Government.

Psacharopoulos, G., y Patrinos, H. A. (2004). Human capital and rates of return. En G. Johnes, y J. Johnes (Eds.), International handbook on the economics of education (pp. 1-57). Cheltenham y Northampton: Edward Elgar Publishing Ltd.

Ratcliffe, C., y McKernan, S. M. (2010). Childhood poverty persistence: Facts and consequences. Washington, DC: The Urban Institute.

Reher, D., Requena, M., y Sanz, A. (2011). ¿España en la encrucijada? Consideraciones sobre el cambio migratorio. Revista Internacional De Sociología, 69(Monográfico), 9-44.

Riley, J. G. (1979). Testing the educational screening hypothesis. Journal of Political Economy, 87(5), 227-252.

Riley, J. G. (2001). Silver signals: twenty-five years of screening and signalling. Journal of Economic Literature, 34, 432-478.

Rivkin, S. G., Hanushek, E. A., y Kain, J. F. (2005). Teachers, schools, and academic achievement. Econometrica, 73(2), 417-458.

Roca Cobo, E. (2010). El abandono temprano de la educación y la formación en España. Revista De Educación, no extraordinario 2010, 31-62.

Romer, P. M. (1986). Increasing returns and long-run growth. Journal of Political Economy, 94(5), 1002-1037.

Romer, P. M. (1990). Endogenous technological change. Journal of Political Economy, 98(5), 71-102.

Roselló Villalonga, J., y Oliver Rullán, X. (2014). The determinants of non-compulsory education demand: an analysis from the students' perspective. Revista De Educación, 365, 202-236.

Rosenzweig, M. R., y Schultz, T. W. (1989). Schooling, information and non-market productivity: contraceptive use and its effectiveness. International Economic Review, 30(2), 457-477.

Ross, A., y Leathwood, C. (2013). Problematising early school leaving. European Journal of Education, 48(3, Special Issue: Problematising the Issue of Early School Leaving in the European Context), 405-418.

Rotchschild, M., y Stigliz, J. (1976). Equilibrium in competitive insurance markets: an essay on the economics of imperfect information. Quarterly Journal of Economics, $60,629-649$.

Rouse, C. E. (2005). The labor market consequences of an inadequate education. (Mimeo). Princeton University and National Bureau of Economic Research.

Rubiera, F., Lasarte, E., y Fernández, E. (2013). Efectos de los incrementos en el coste de vida sobre el mapa de la pobreza en España. Papeles De Economía Española, $138,114-128$. 
Rumberger, R. W. (2004). Why students drop out of school? En G. Orfied (Ed.), Dropouts in America: Confronting the graduation rate crisis (pp. 131-155). Harvard Education Press.

Rumberger, R. W. (2010). Education and the reproduction of economic inequality in the United States: an empirical investigation. Economics of Education Review, 29, 246-254.

Rumberger, R. W. (2011). Dropping out. Why students drop out of high school and what can be done about it. Cambridge, Massachusetts and London: Harvard University Press.

Rumberger, R. W., y Lim, S. (2008). Why students drop out of school: A review of 25 years of research. Santa Barbara: University of California.

Rumberger, R. W., y Palardy, G. J. (2005). Test scores, dropout rates, and transfer rates as alternative indicators of high school performance. American Educational Research Journal, 41, 3-42.

Rumberger, R. W., y Thomas, S. L. (2000). The distribution of dropout and turnover rates among urban and suburban high schools. Sociology of Education, 73(1), 3967.

Russell, B. (1972). Antecedents and consequences of early school leaving. Geneva: International Bureau of Education.

San Segundo, M. J. (2001). Economía de la educación. Madrid: Síntesis.

San Segundo, M. J. (2009). ¿Merece la pena elevar el gasto educativo? Papeles De Economía Española, 119, 208-227.

Sánchez-Pascuala Neira, F. (2011). Del éxito escolar a la reducción del abandono escolar temprano. Cuadernos De Pensamiento Político, 29, 143-165.

Schanzenbach, D. W. (2007). What have researchers learned from project STAR? Brookings Papers on Education Policy, 9, 205-228.

Schultz, T. W. (1960). Capital formation by education. Journal of Political Economy, 69, 571-583.

Schultz, T. W. (1961). Investment in human capital. American Economic Review, 51(1), 1-17.

Serrano, L. (1996). Indicadores de capital humano y productividad. Revista De Economía Aplicada, 10, 177-190.

Serrano, L., y Soler, A. (2014). Evaluación del programa de cooperación territorial para la reducción del abandono temprano de la educación. Instituto Valenciano de Investigaciones Económicas.

Serrano, L., Soler, A., y Hernández, L. (2013). El abandono educativo temprano: Análisis del caso español. Instituto Valenciano de Investigaciones Económicas.

Smeyers, P. (2006). The relevance of irrelevant research: the irrelevance of relevant research. En P. Smeyers, y M. Depaepe (Eds.), Educational research: why "what works" doesn't work (pp. 95-108). Dordrecht: Springer. 
Solow, R. M. (1956). A contribution to the theory of economic growth. Quarterly Journal of Economics, 70, 65-94.

Solow, R. M. (1957). Technical change and the aggregate production function. The Review of Economics and Statistics, 39(3), 312-320.

Spence, M. (1973). Job market signalling. Quarterly Journal of Economics, 87, 355-374.

Spence, M. (2002). Signalling in retrospect and the informational structure of markets. The American Economic Review, 92(3), 434-459.

Steedman, H. (1996). Measuring the quality of educational outputs: a note. (Discussion Paper $\mathrm{n}$ - 302). London: Centre for Economic Performance, London School of Economics and Political Science.

Stevens, P., y Weale, M. (2004). Education and economic growth. En G. Johnes, y J. Johnes (Eds.), International handbook on the economics of education (pp. 164188). Cheltenham y Northampton: Edward Elgar Publishing Ltd.

Stigliz, J. (1975). The theory of screening, education and the distribution of income. American Economic Review, 65, 283-300.

Stillwell, R. (2010). Public school graduates and dropouts from the common core of data: School year 2007-08. (NCES 2010-341). Washington, DC: National Center for Education Statistics, U.S. Department of Education.

Summers, R., y Heston, A. (1991). The Penn world table (mark 5): an expanded set of international comparisons, 1950-1988. Quarterly Journal of Economics, 106(2), 327-369.

Taubman, P. (1989). Role of parental income in educational attainment. The American Economic Review, 79(2), 57-61.

Temple, J. (1999). A positive effect of human capital on growth. Economics Letters, 65(1), 131-134.

Thurow, L. C. (1975). Generating inequality: mechanisms of distribution in the U.S. economy. New York: Basic Books.

Thurow, L. C., y Lucas, R. E. (1972). The American distribution of income: a structural problem. Washington, DC: United States Government Publishing Office.

Tiana Ferrer, A. (2008). La política de becas del Estado: Un balance del período 20042008. Presupuesto y Gasto Público, 50, 191-200.

Traag, T., y Van der Velden, R. K. W. (2008). Early school-leaving in the Netherlands. The role of student-, family- and school factors for early school-leaving in lower secondary education. Maastricht: Research Centre for Education and the Labour Market.

Tumino, A., y Taylor, M. (2013). The impact of local labour market conditions on school leaving decisions. (IZA Workshop on the Future of Labor: The Effects of the Economic Crisis on the Labor Market, Unemployment and Income Distribution) Bonn.

UNESCO. (2012). International standard classification of education ISCED 2011. Montreal: UNESCO Institute for Statistics. 
Utrilla de la Hoz, A., y Mitxelena Camiruaga, C. (2006). El gasto público en educación 2000-2004: un análisis por comunidades autónomas. (DT no 25/06). Observatorio de Financiación Autonómica y Políticas Públicas, Instituto de Estudios Fiscales.

Utrilla de la Hoz, A., y Mitxelena Camiruaga, C. (2007). Determinantes del gasto público en educación y resultados del sistema educativo por comunidades autónomas. Revista De Estudios Regionales, 78, 429-446.

Uzawa, H. (1965). Optimal technical change in an aggregative model of economic growth. International Economic Review, 6, 18-31.

Valiente García, A. (2003). La demanda de educación universitaria y el rendimiento privado de la educación en España. Valladolid: Universidad de Valladolid, Secretariado de Publicaciones e Intercambio Editorial.

Van Ours, J. C., y Ridder, G. (1995). Job matching and job competition: are lower educated workers at the back of job queues? European Economic Review, 39, 1717-1731.

Villaverde, J. (2006). El crecimiento de las comunidades autónomas: un análisis gráfico. Mediterráneo Económico, 10, 285-301.

Warren, J. R., y Hamrock, C. (2010). The effect of minimum wage rates on high school completion. Social Forces, 88(3), 1379-1392.

Warren, J. R., Jenkins, K. N., y Kulick, R. B. (2006). High school exit examinations and state-level completion and GED rates, 1975-2002. Educational Evaluation and Policy Analysis, 28, 131-152.

West, M. R., y Woessmann, L. (2010). Every catholic child in a catholic school: historical resistance to state schooling, contemporary school competition, and student achievement across countries. The Economic Journal, 120, 229-255.

Wiles, P. (1974). The correlation between education and earnings: the external testnot content hypothesis. Higher Education, 3, 43-58.

Willis, R., y Rosen, S. (1979). Education and self-selection. Journal of Political Economy, 87(5), 817-836.

Woessmann, L., Luedemann, E., Schuetz, G., y West, M. R. (2009). School accountability, autonomy, and choice around the world. Cheltenham, UK: Edward Elgar.

Wolpin, K. I. (1977). Education and screening. American Economic Review, 67(5), 949958. 


\section{ANEXO I: Tablas y gráficos adicionales del Capítulo 2}



Tabla Al.1. Clasificación simplificada de los niveles CINE (Clasificación Internacional Normalizada de la Educación)

\begin{tabular}{|c|c|}
\hline Código & Programa CINE \\
\hline 0 & Educación de la primera infancia \\
1 & Educación primaria \\
2 & Educación secundaria baja (primera etapa) \\
3 & Educación secundaria alta (segunda etapa) \\
4 & Educación postsecundaria no terciaria \\
5 & Educación terciaria de ciclo corto \\
6 & Grado en educación terciaria o educación equivalente \\
7 & Nivel de maestría, especialización o equivalente \\
8 & Nivel de doctorado o equivalente \\
\hline
\end{tabular}

Fuente: Instituto de Estadística de la UNESCO (2013)

Tabla Al.2. Directrices integradas para el crecimiento y el empleo (2005-2008)

\begin{tabular}{|l|}
\hline \multicolumn{1}{|c|}{ DIRECTRICES MACROECONÓMICAS } \\
\hline - Garantizar la estabilidad económica. \\
- Salvaguardar la sostenibilidad económica. \\
- Promover una asignación eficiente de los recursos. \\
- Promover una mayor coherencia entre las políticas macroeconómicas y estructurales. \\
- Garantizar una evolución de los salarios que contribuya a la estabilidad macroeconómica y \\
el crecimiento. \\
- Contribuir al dinamismo y el buen funcionamiento de la UEM. \\
\hline \multicolumn{1}{c|}{ DIRECTRICES MICROECONÓMICAS } \\
\hline - Ampliar y profundizar el mercado interior. \\
- Garantizar la apertura y la competitividad de los mercados. \\
- Crear un entorno empresarial más atractivo. \\
- Promover la iniciativa empresarial y crear un entorno favorable para las PYMEs. \\
prioritarios acordados. \\
- Incrementar y mejorar la inversión en I+D. \\
- Facilitar la innovación y la implantación de las tecnologías de la información y la \\
comunicación. \\
- Fomentar una utilización sostenible de los recursos y fortalecer las sinergias entre la \\
protección del medio ambiente y el crecimiento. \\
- Contribuir a crear una base industrial fuerte. \\
\hline \multicolumn{1}{c|}{ DIRECTRICES DE EMPLEO } \\
\hline - Aplicar políticas de empleo conducentes al pleno empleo, la mejora de la calidad. y la \\
productividad del trabajo y el fortalecimiento de la cohesión social y territorial. \\
- Promover un enfoque del trabajo basado en el ciclo de vida. \\
- Garantizar mercados de trabajo inclusivos con los solicitantes de empleo y las personas \\
desfavorecidas. \\
- Mejorar la adecuación a las necesidades del mercado de trabajo. \\
- Promover la flexibilidad combinada con la seguridad del empleo y reducir la segmentación \\
del mercado de trabajo. \\
- Velar para que los salarios y otros costes laborales evolucionen de manera favorable al \\
empleo. \\
- Ampliar y mejorar la inversión en capital humano. \\
- Adaptar los sistemas de educación y de formación en respuesta a las nuevas exigencias en \\
materia de competencias.
\end{tabular}

Fuente: Consejo Europeo (2005) 
Cuadro Al.1. Tasa de empleo en la Unión Europea. Años 2000 - 2013 (\%)

\begin{tabular}{|l|c|c|c|c|c|c|c|}
\cline { 2 - 7 } \multicolumn{1}{c|}{} & $\mathbf{2 0 0 0}$ & $\mathbf{2 0 0 1}$ & $\mathbf{2 0 0 2}$ & $\mathbf{2 0 0 3}$ & $\mathbf{2 0 0 4}$ & $\mathbf{2 0 0 5}$ & $\mathbf{2 0 0 6}$ \\
\hline UE - 15 & 63,4 & 64,1 & 64,3 & 64,5 & 64,8 & 65,3 & 66,1 \\
\hline UE - 27 & 62,2 & 62,6 & 62,4 & 62,6 & 62,9 & 63,4 & 64,4 \\
\hline UE - 28 & $*$ & $*$ & 62,3 & 62,5 & 62,9 & 63,4 & 64,3 \\
\hline UE - 15 & $\mathbf{2 0 0 7}$ & $\mathbf{2 0 0 8}$ & $\mathbf{2 0 0 9}$ & $\mathbf{2 0 1 0}$ & $\mathbf{2 0 1 1}$ & $\mathbf{2 0 1 2}$ & $\mathbf{2 0 1 3}$ \\
\hline UE - 27 & 66,8 & 67,1 & 65,7 & 65,3 & 65,4 & 65,1 & 65 \\
\hline UE - 28 & 65,3 & 65,8 & 64,5 & 64,2 & 64,2 & 64,1 & 64,2 \\
\hline
\end{tabular}

Fuente: Eurostat

* Dato no disponible

Cuadro Al.2. Inversión en I+D en la Unión Europea. Años 2000 - 2013 (\% del PIB)

\begin{tabular}{|l|c|c|c|c|c|c|c|}
\cline { 2 - 8 } \multicolumn{1}{c|}{} & $\mathbf{2 0 0 0}$ & $\mathbf{2 0 0 1}$ & $\mathbf{2 0 0 2}$ & $\mathbf{2 0 0 3}$ & $\mathbf{2 0 0 4}$ & $\mathbf{2 0 0 5}$ & $\mathbf{2 0 0 6}$ \\
\hline UE - 15 & 1,85 & 1,86 & 1,87 & 1,86 & 1,83 & 1,83 & 1,85 \\
\hline UE - 28 & 1,79 & 1,8 & 1,81 & 1,8 & 1,76 & 1,76 & 1,78 \\
\hline & $\mathbf{2 0 0 7}$ & $\mathbf{2 0 0 8}$ & $\mathbf{2 0 0 9}$ & $\mathbf{2 0 1 0}$ & $\mathbf{2 0 1 1}$ & $\mathbf{2 0 1 2}$ & $\mathbf{2 0 1 3}$ \\
\hline UE - 15 & 1,86 & 1,94 & 2,03 & 2,02 & 2,06 & 2,09 & 2,09 \\
\hline UE - 28 & 1,78 & 1,85 & 1,94 & 1,93 & 1,97 & 2,01 & 2,01 \\
\hline
\end{tabular}

Fuente: Eurostat

Tabla Al.3. Directrices integradas de la Estrategia Europa 2020

- Garantizar la calidad y la viabilidad de las finanzas públicas.

- Abordar los desequilibrios macroeconómicos.

- Reducir los desequilibrios dentro de la zona Euro.

- Optimizar el apoyo a la investigación, el desarrollo y la innovación, reforzar el triangulo de conocimiento y liberar el potencial de la economía digital.

- Mejorar la utilización eficiente de los recursos y reducir los gases de efecto invernadero.

- Mejorar el entorno empresarial y de los consumidores, modernizar y desarrollar la base industrial para garantizar el pleno funcionamiento del mercado interior.

- Aumentar la participación de mujeres y hombres en el mercado laboral, reducir el desempleo estructural y fomentar el empleo de calidad.

- Conseguir una población activa cualificada que responda a las necesidades del mercado laboral y promover el aprendizaje permanente.

- Mejorar la calidad y los resultados de los sistemas educativos y de formación en todos los niveles e incrementar la participación en la enseñanza superior o equivalente.

- Promover la inclusión social y luchar contra la pobreza.

Fuente: European Commission (2010b) 
Cuadro Al.3. Fondos aportados por el Ministerio de Educación, Cultura y Deporte al programa de reducción del abandono escolar temprano, por comunidad autónoma. Años $2007-2012$ (euros)

\begin{tabular}{|l|c|c|c|c|c|c|}
\cline { 2 - 7 } \multicolumn{1}{c|}{} & $\mathbf{2 0 0 7}$ & $\mathbf{2 0 0 8}$ & $\mathbf{2 0 0 9}$ & $\mathbf{2 0 1 0}$ & $\mathbf{2 0 1 1}$ & $\mathbf{2 0 1 2}$ \\
\hline España & 11.200 .000 & 20.000 .000 & 37.200 .000 & 48.600 .000 & 44.500 .000 & 40.500 .000 \\
\hline Andalucía & 3.016 .945 & 5.580 .170 & 10.007 .842 & 13.139 .106 & 12.074 .237 & 11.102 .638 \\
\hline Aragón & 197.307 & 496.560 & 722.736 & 950.242 & 910.783 & 848.175 \\
\hline Asturias & 93.417 & 250.034 & 480.048 & 541.139 & 425.841 & 419.081 \\
\hline Baleares & 363.036 & 585.581 & 1.358 .953 & 1.830 .498 & 1.646 .840 & 1.511 .959 \\
\hline Canarias & 594.369 & 1.242 .364 & 2.141 .806 & 2.839 .368 & 2.563 .599 & 2.374 .638 \\
\hline Cantabria & 76.466 & 162.304 & 336.065 & 390.991 & 334.481 & 317.339 \\
\hline Castilla y León & 427.180 & 742.977 & 1.213 .662 & 1.631 .314 & 1.598 .253 & 1.439 .471 \\
\hline Castilla-La Mancha & 629.821 & 1.351 .766 & 2.239 .503 & 2.980 .751 & 2.720 .162 & 2.510 .733 \\
\hline Cataluña & 936.044 & 2.558 .705 & 5.893 .869 & 7.624 .473 & 6.929 .550 & 6.167 .041 \\
\hline C. Valenciana & 1.303 .909 & 2.227 .124 & 4.478 .960 & 5.622 .313 & 5.106 .004 & 4.623 .254 \\
\hline Extremadura & 390.098 & 705.004 & 1.271 .782 & 1.646 .097 & 1.446 .915 & 1.305 .504 \\
\hline Galicia & 430.005 & 894.504 & 1.385 .597 & 1.773 .342 & 1.647 .887 & 1.507 .375 \\
\hline Madrid & 1.142 .283 & 2.067 .516 & 3.514 .573 & 4.821 .335 & 4.624 .484 & 4.107 .135 \\
\hline Murcia & 531.385 & 1.028 .168 & 1.900 .094 & 2.484 .092 & 2.182 .311 & 2.001 .783 \\
\hline Rioja & 67.735 & 107.222 & 254.510 & 324.939 & 288.653 & 263.874 \\
\hline Funte: Ministero
\end{tabular}

Fuente: Ministerio de Educación, Cultura y Deporte y Serrano y Soler (2014) 



\section{ANEXO II: Estructura del sistema educativo español}



Cuadro All.1. Esquema de la estructura del sistema educativo español
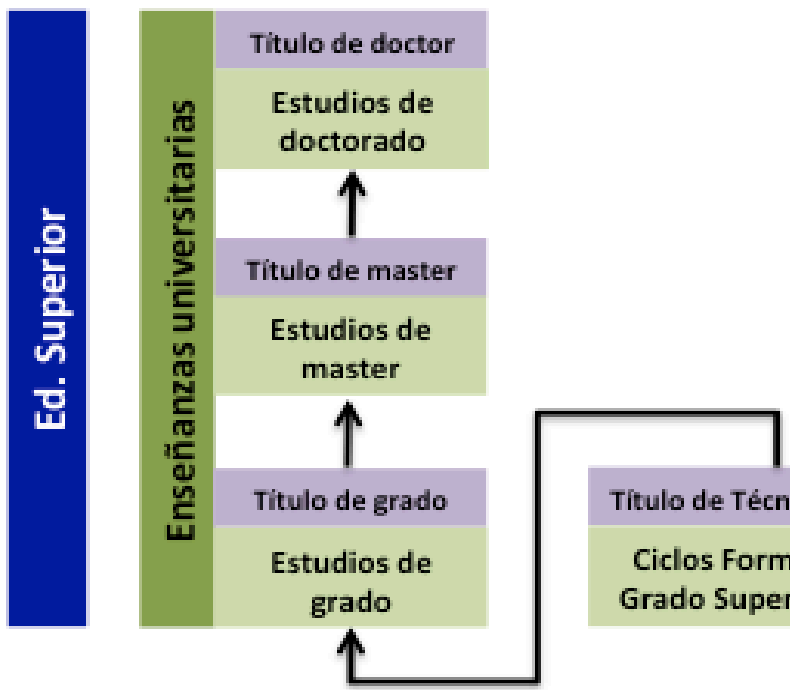

Título de Técnico Superior

Ciclos Formativos de

Grado Superior de F.P.

\section{Enseñanzas \\ artísticas \\ superiores}

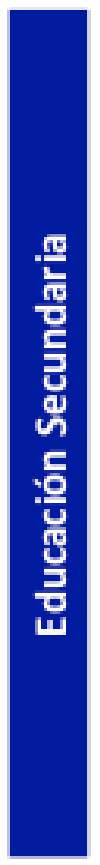

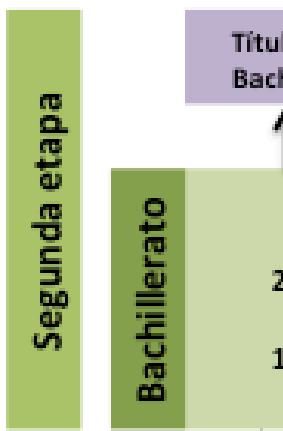

Título de

achiller<smiles>[CH]1CC1</smiles>

$2^{2}$

19

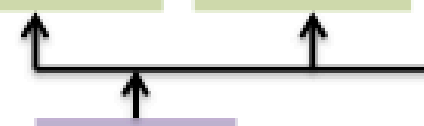

Formativos
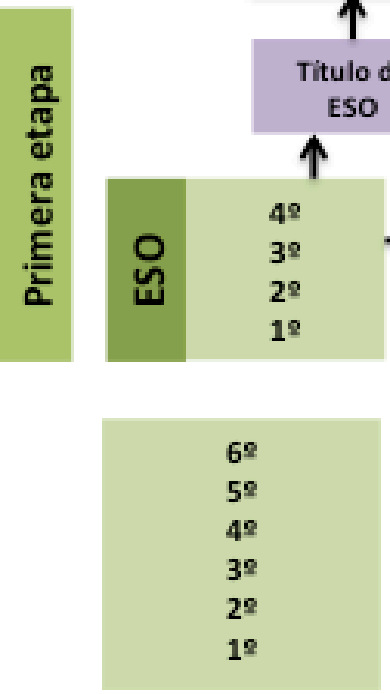

Segundo Ciclo

(3-6 años)

Primer Ciclo

(0-3 años)

Fuente: MECD

$\uparrow$

Ciclos

de Grado

Medio de

F.P.

\section{Enseñanzas \\ elementales de \\ música y danza} de AP y D

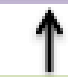

Ciclos

Formativos de

Grado Medio

de Artes

Plásticas y

Diseño

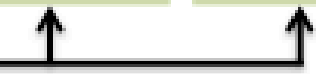

$\uparrow$

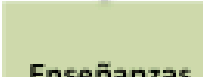

Deportivas

de Grado

Medio

$\begin{array}{cc}\text { Módulos } & \text { Módulos } \\ \text { voluntarios } & \text { profesionales }\end{array}$ y generales 



\section{ANEXO III: Estadísticas adicionales del Capítulo 4}





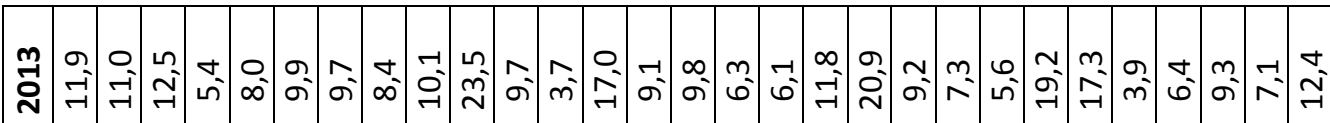

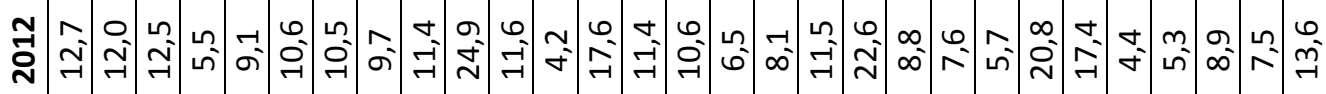

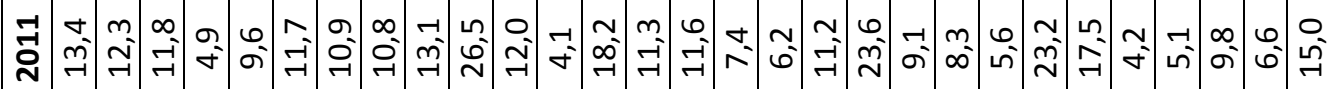

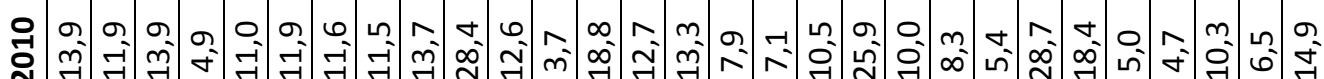

$\stackrel{m}{\circ}$

ठ্సి 迹

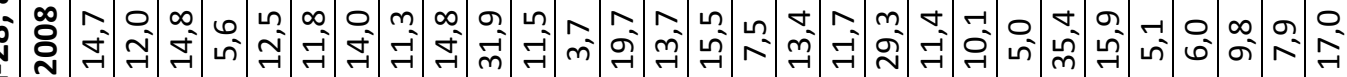

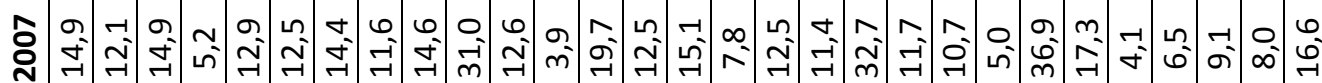

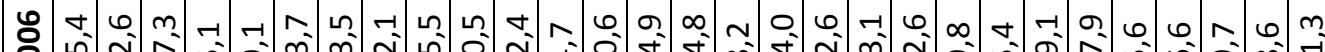

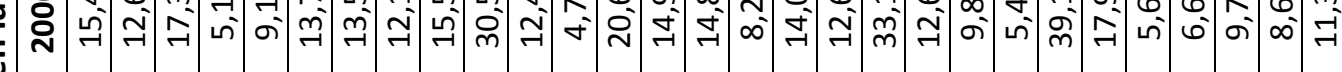

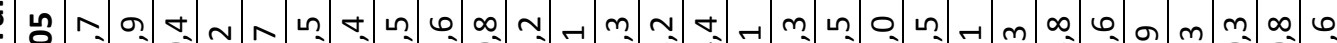

乌ి

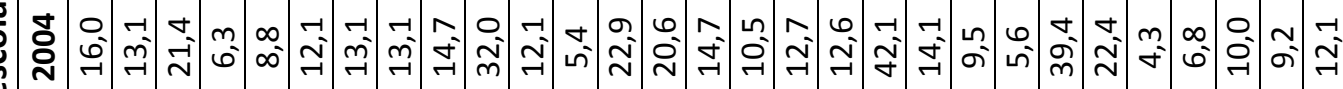

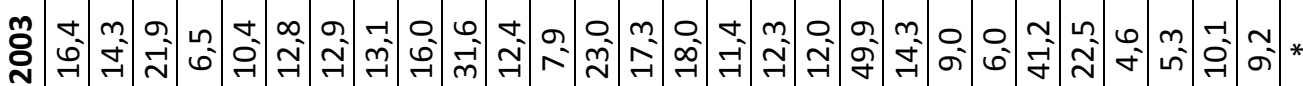

రิ

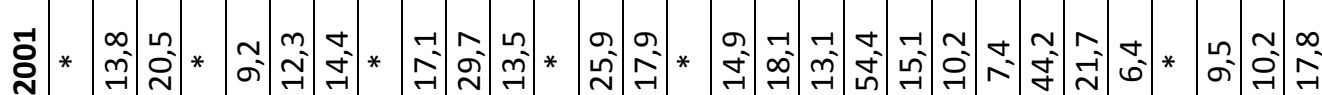

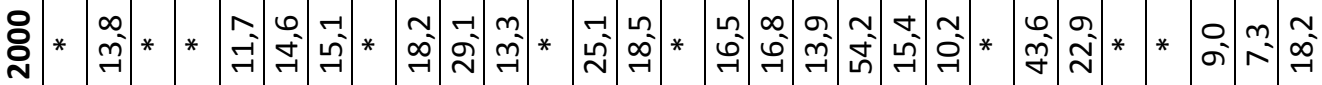

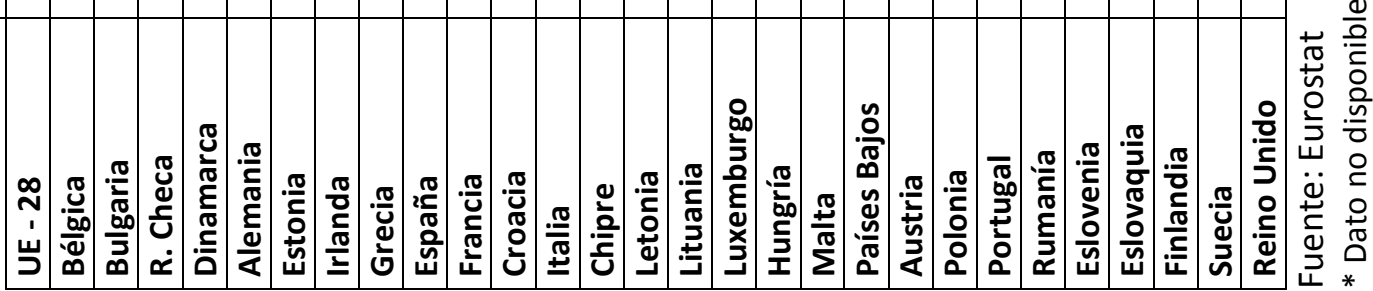




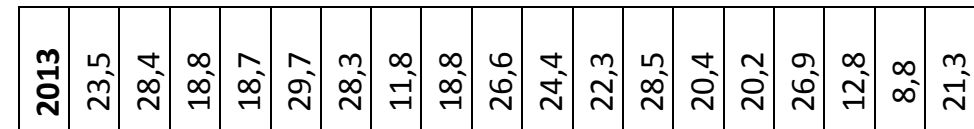

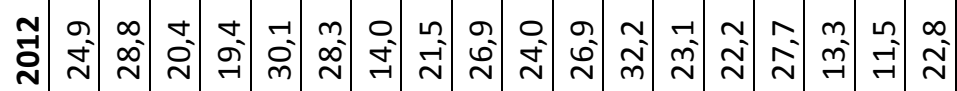

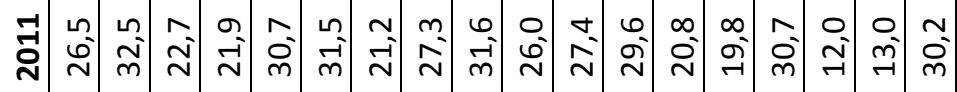

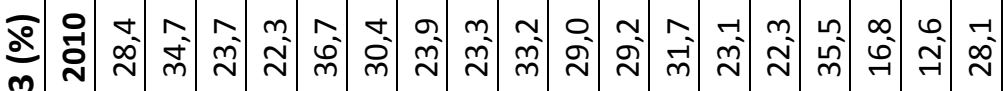

究

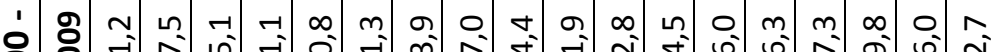

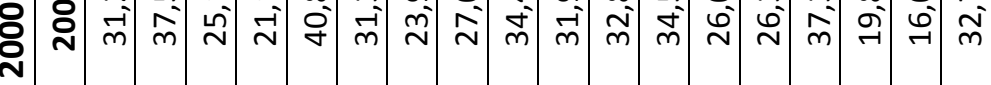

ठ্রে

\%

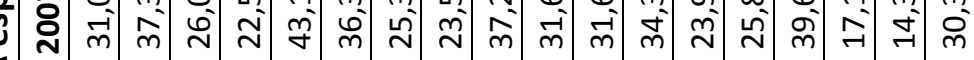

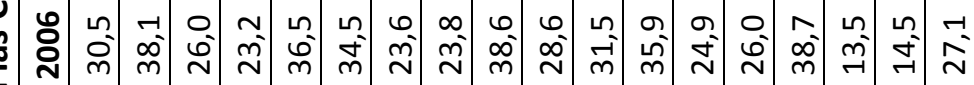

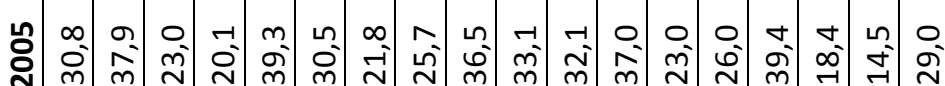

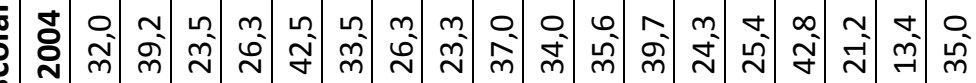

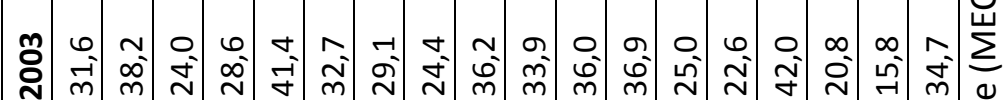

บับำ

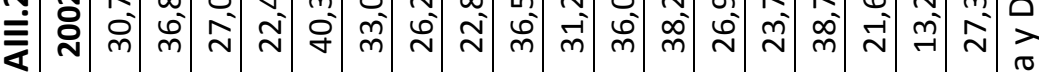

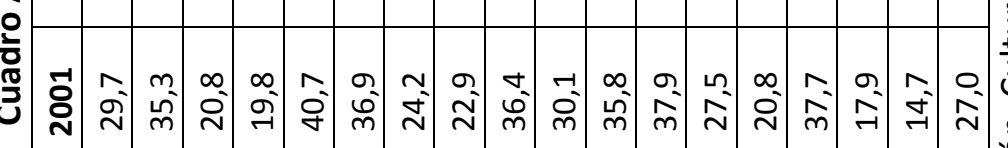

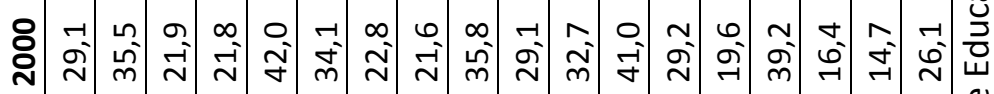

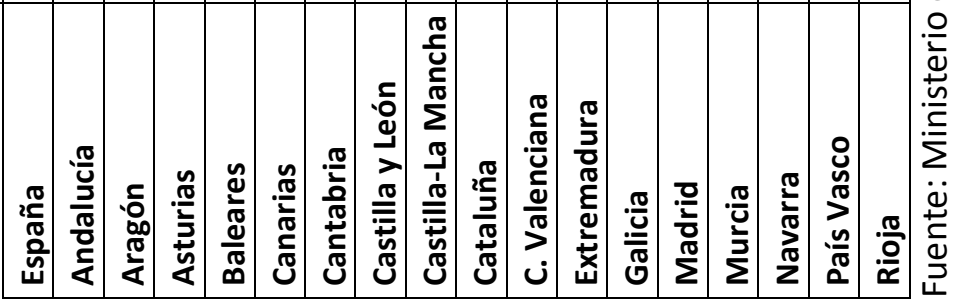




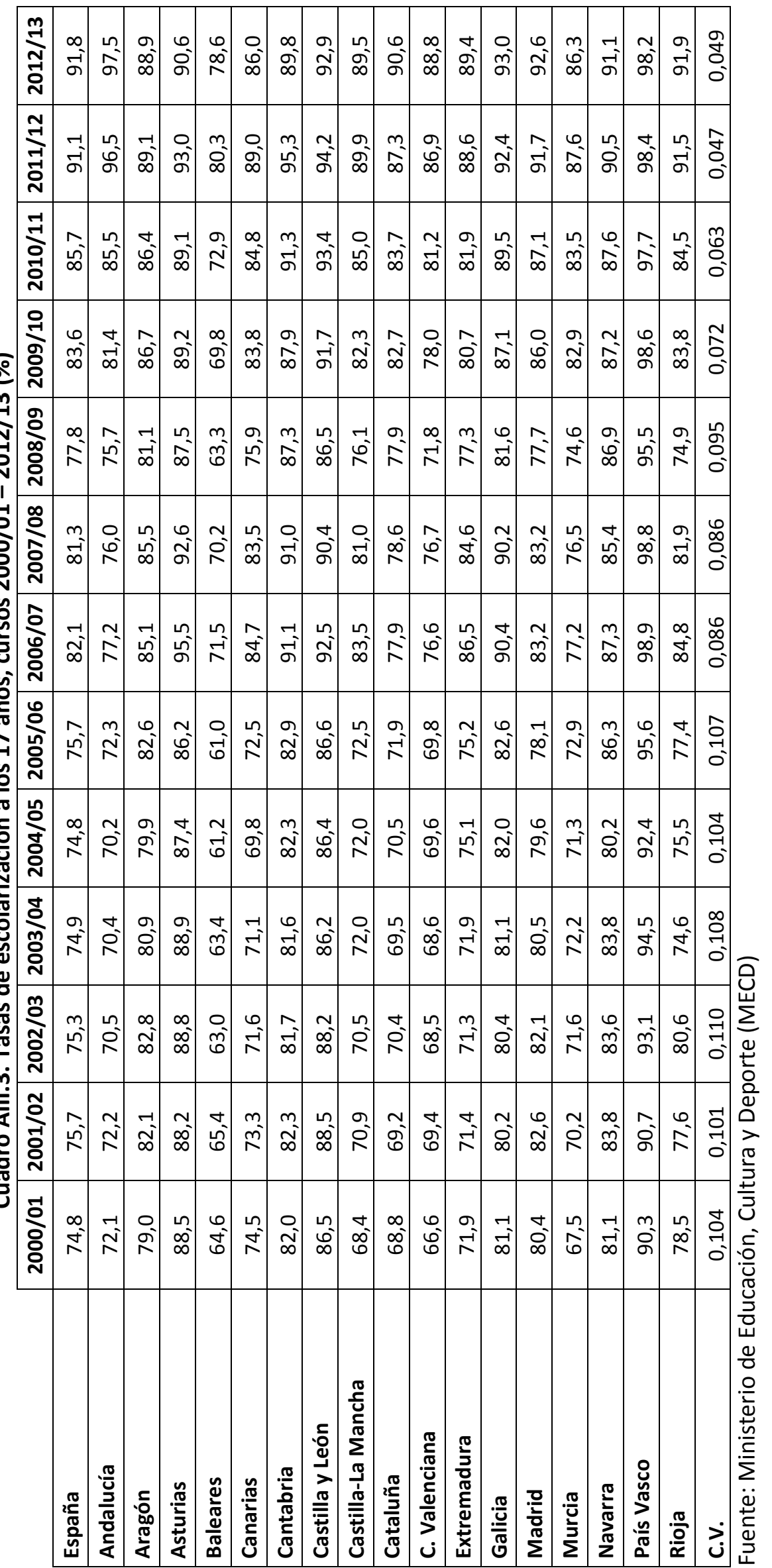




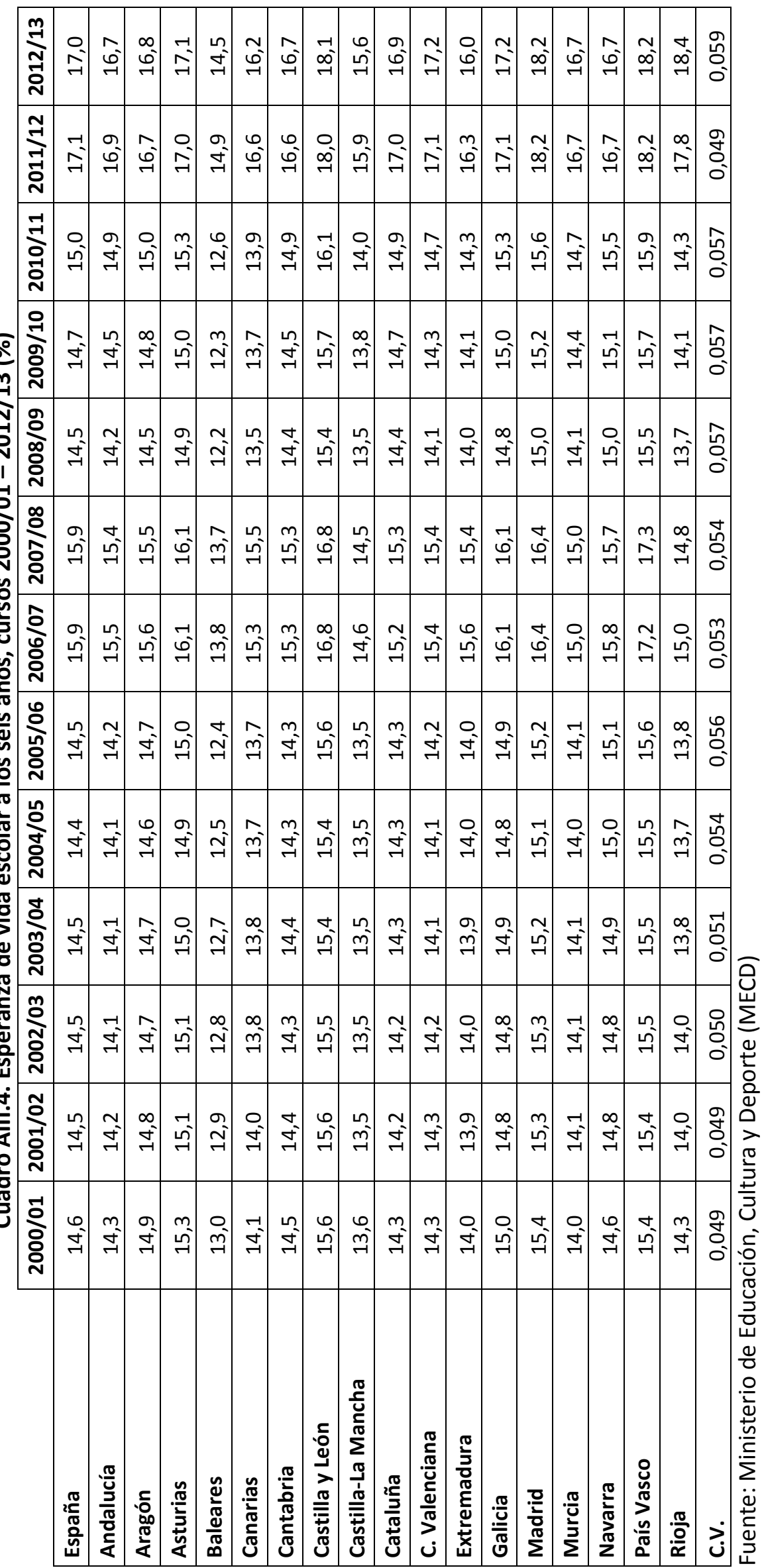




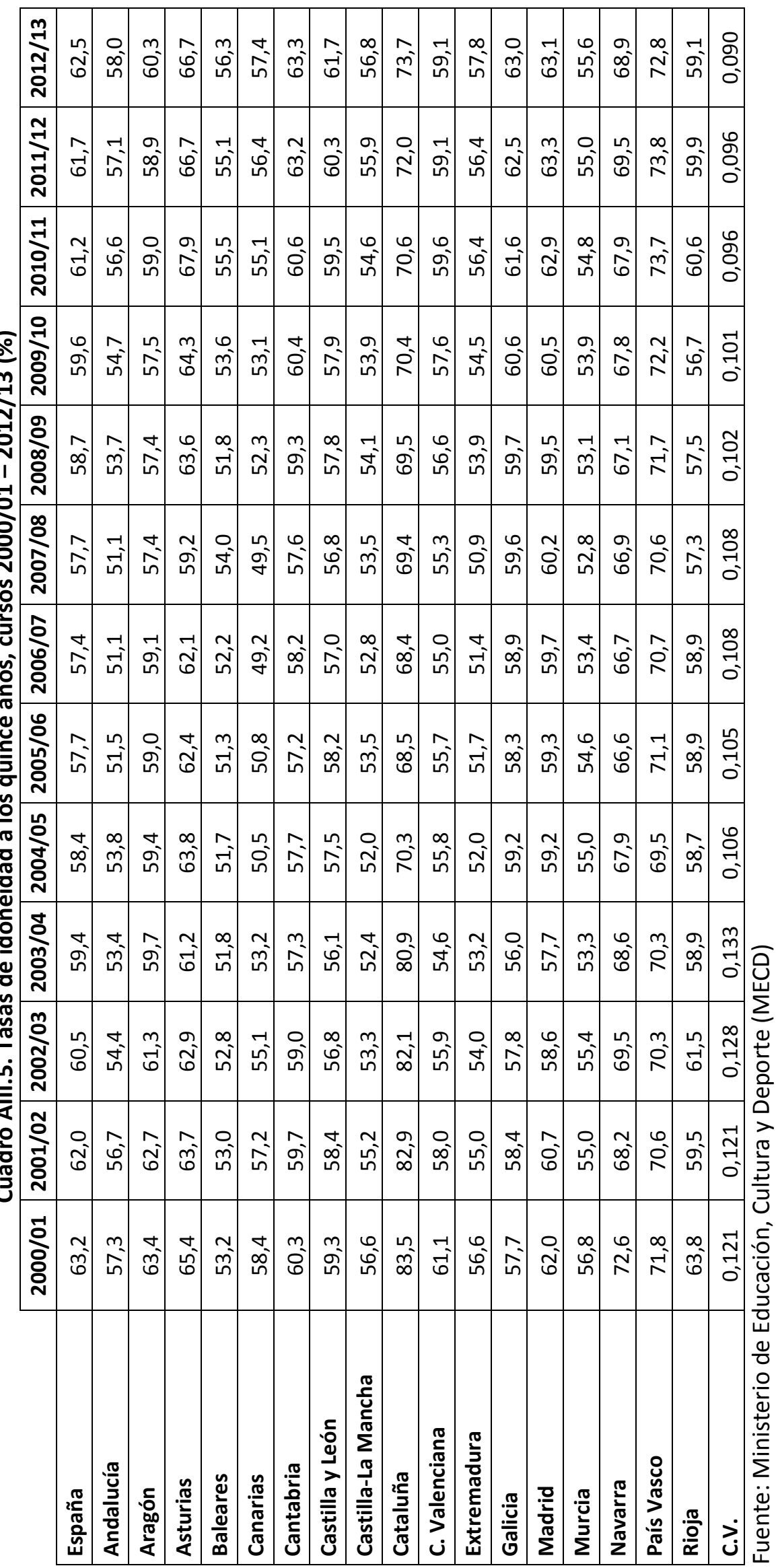




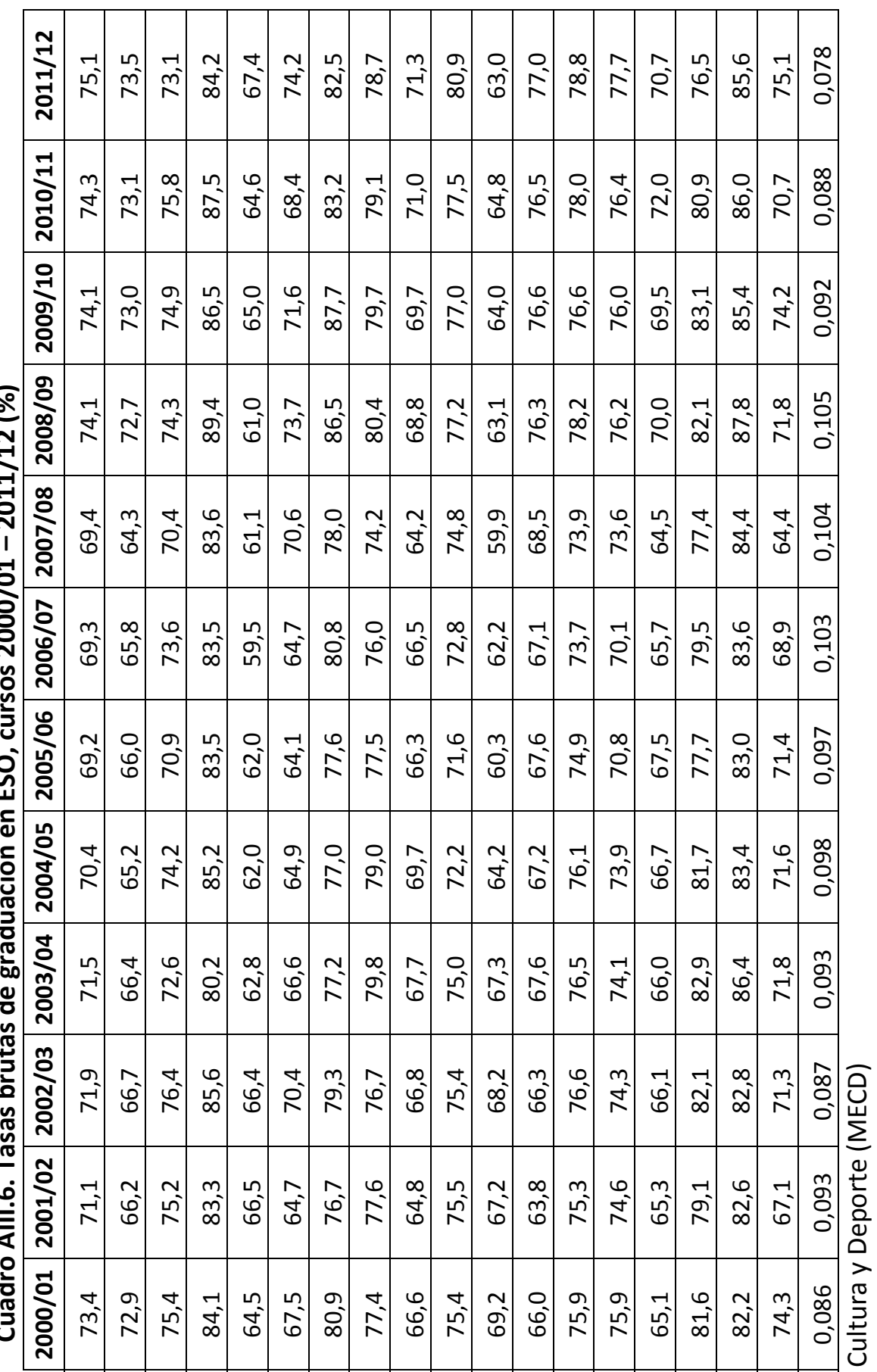

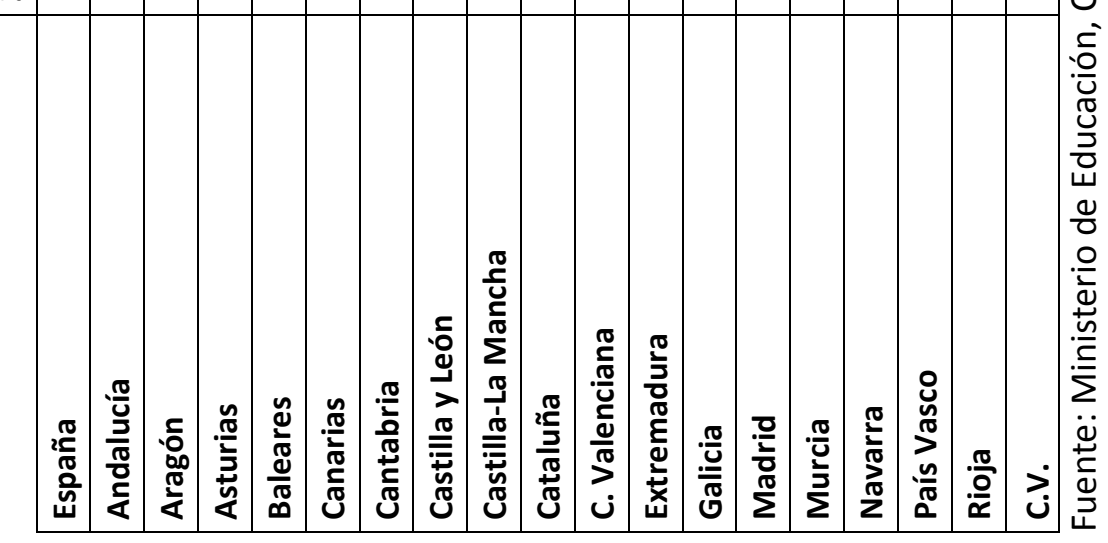




\section{ANEXO IV: Estadísticas adicionales del Capítulo 5}




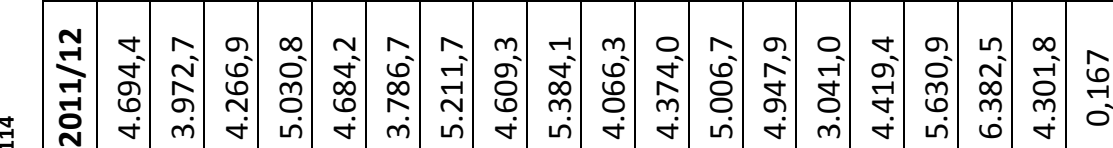

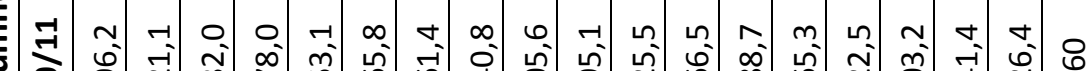

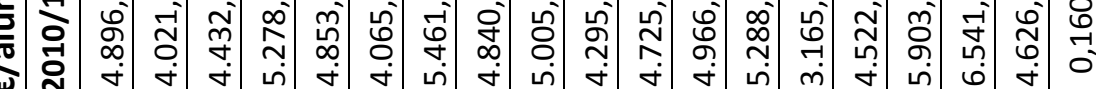

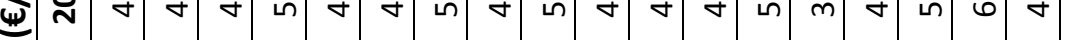

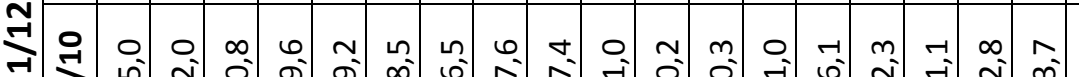

ఫิ

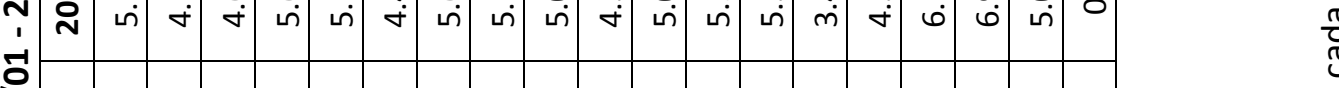

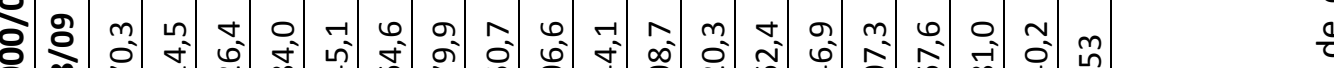

ర్సి

ติ

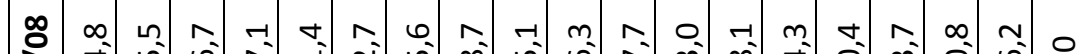

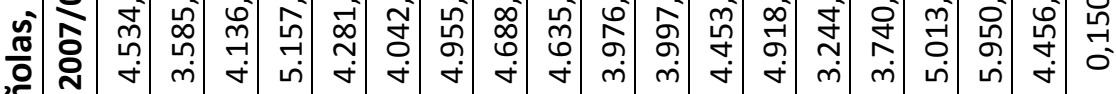

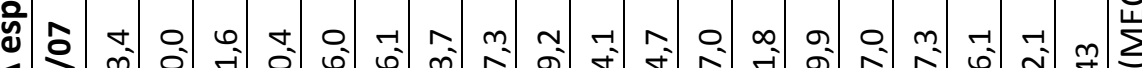

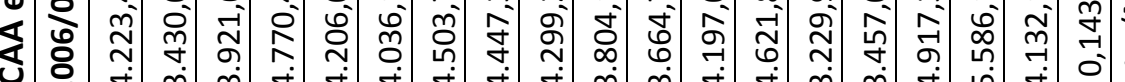

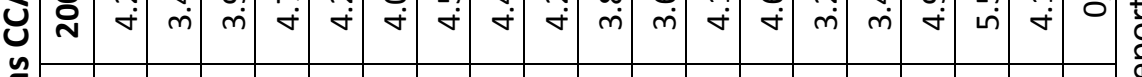

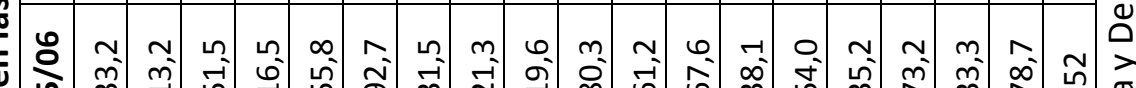

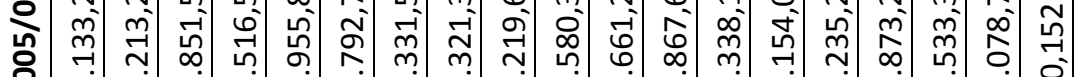

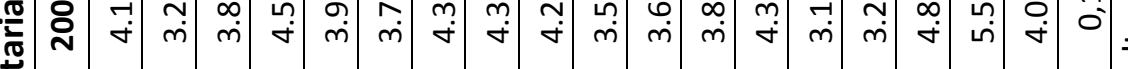

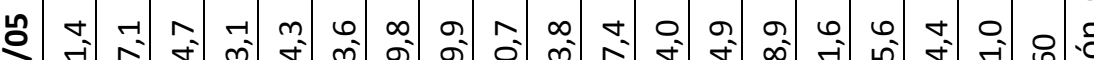

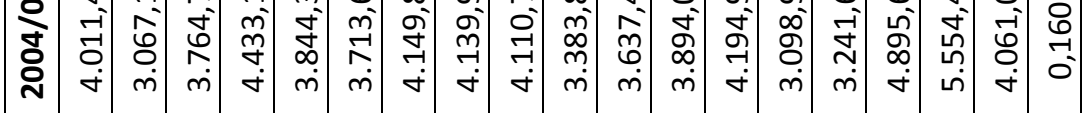

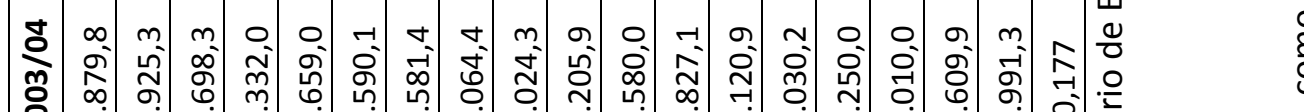

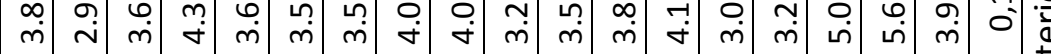

m

궁

¿

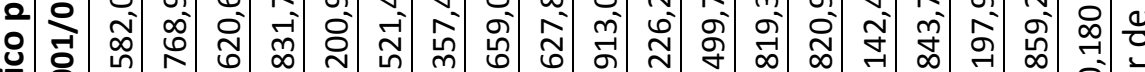

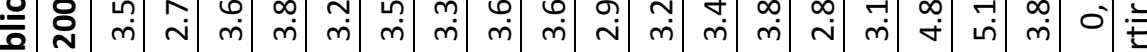

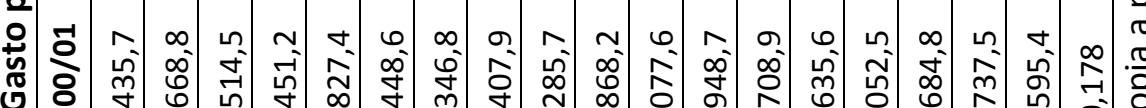

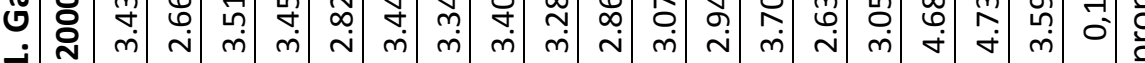

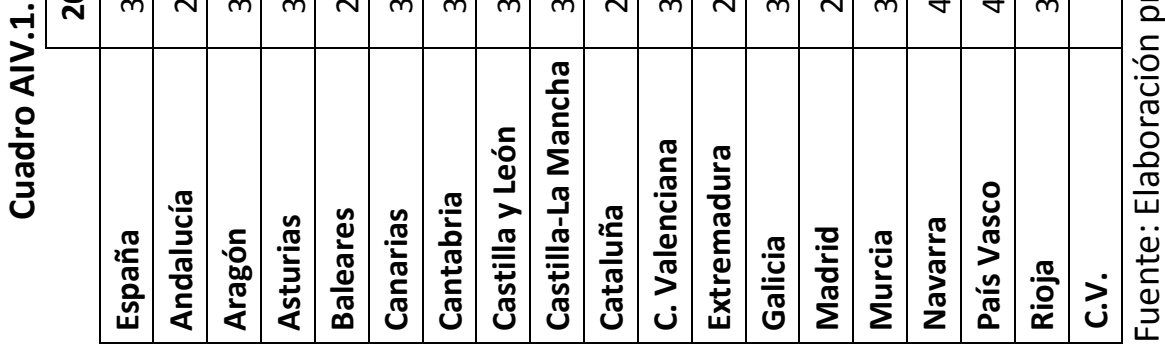

只

ญ్

ธั่

व

$\stackrel{0}{20}$

$\frac{\pi}{0}$

$\frac{1}{0}$

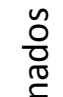

$\frac{0}{0}$

$\frac{\text { d }}{\frac{2}{3}}$

$\frac{1}{0}$

$\stackrel{u}{0}$

음

은

든 음

世ㄴ

일

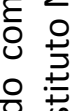

응 䒿

है

造 $\frac{2}{\pi}$

त

ஸे $\frac{0}{0}$

을음

ह઼

원

든

兵

पु

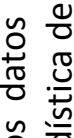

오 흠 


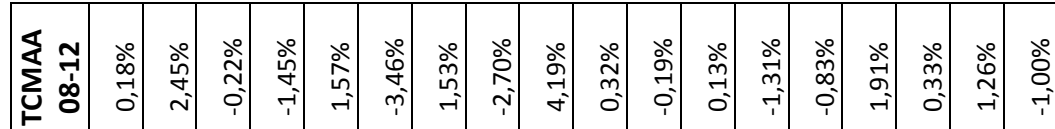

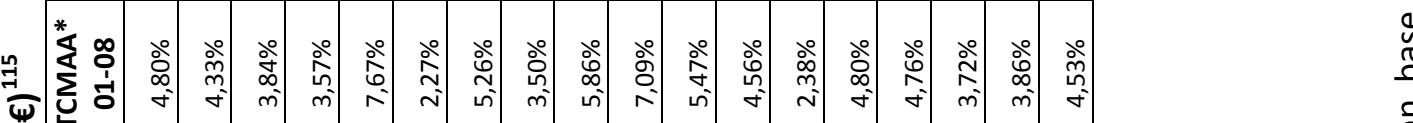

\&

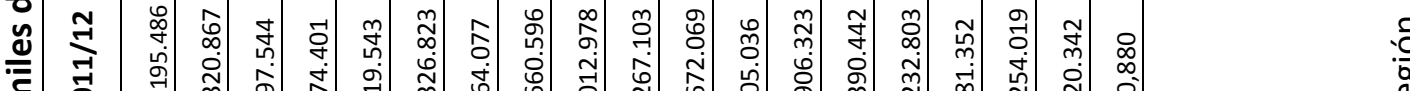

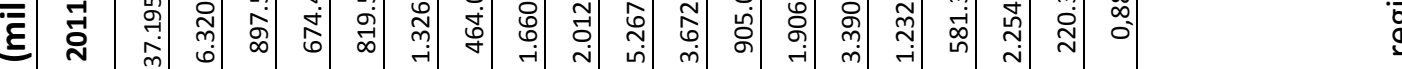

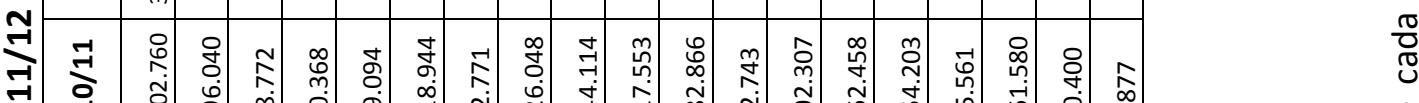

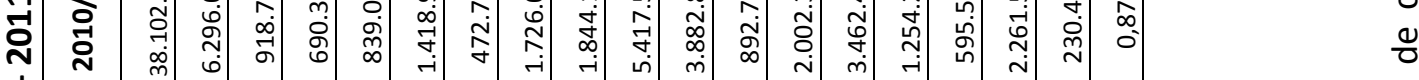

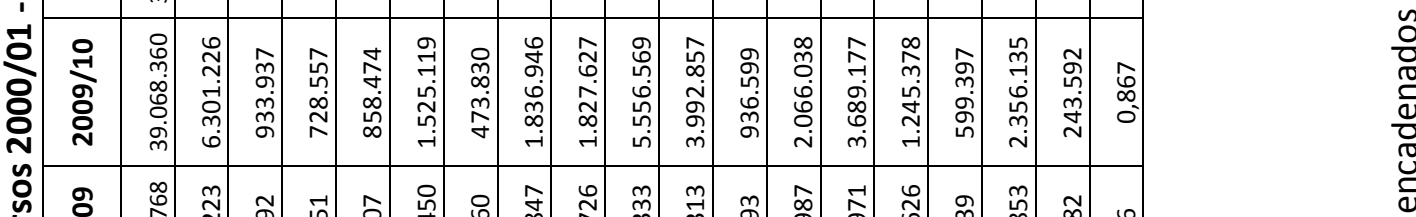

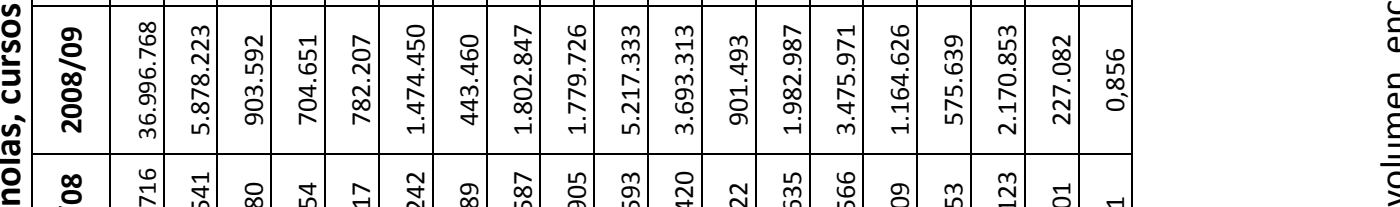

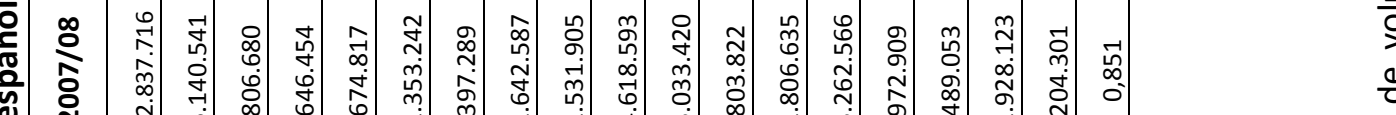

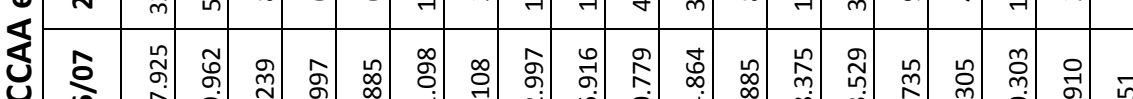

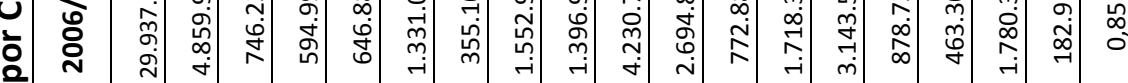

芯芯

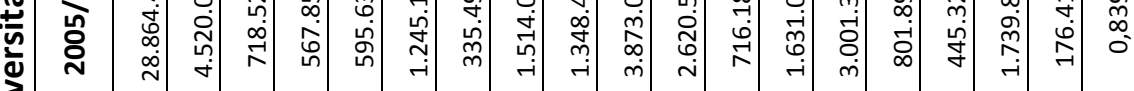

:

亏

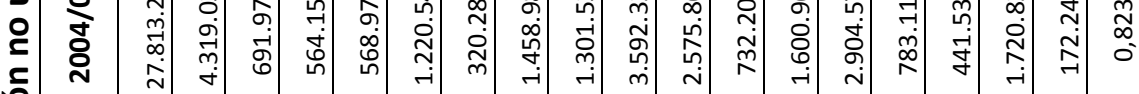

总

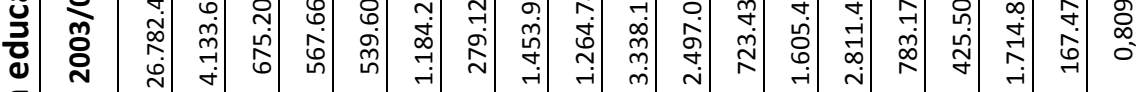

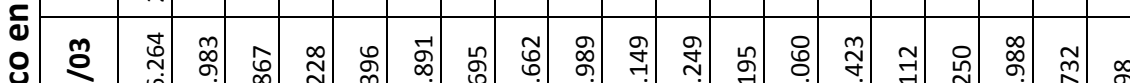

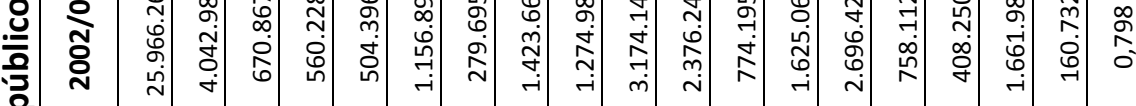

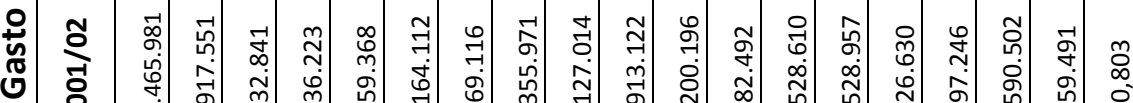

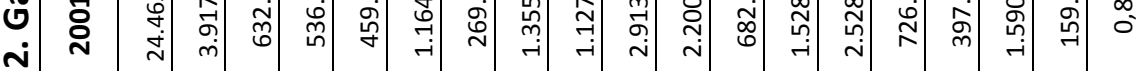

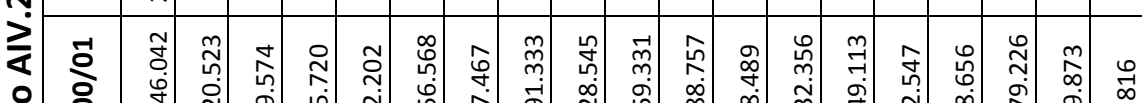

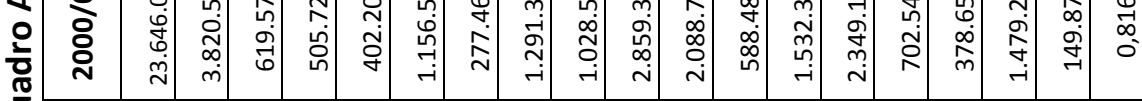

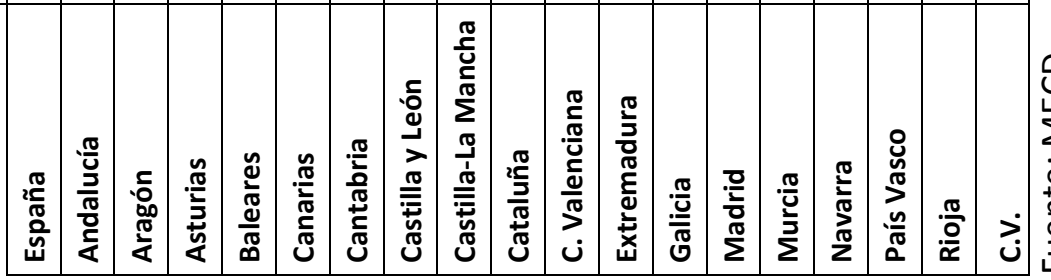

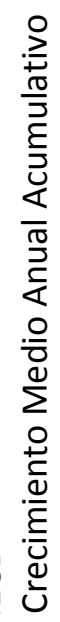

d્.

$\stackrel{. .}{\underline{y}}$

으 운

은

บับ

迹

율

ㄷํㅇㅇํㄴ

음

हิ $\frac{\overline{0}}{0}$

过

兵

등 $\frac{0}{0}$

음음

हิ ฯ

迹

등

苞

ปै

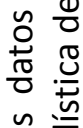




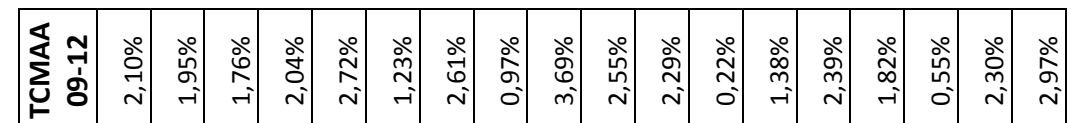

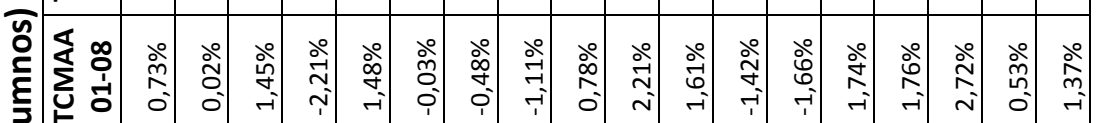

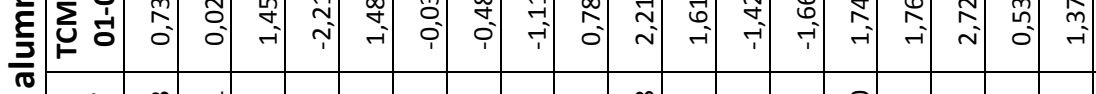

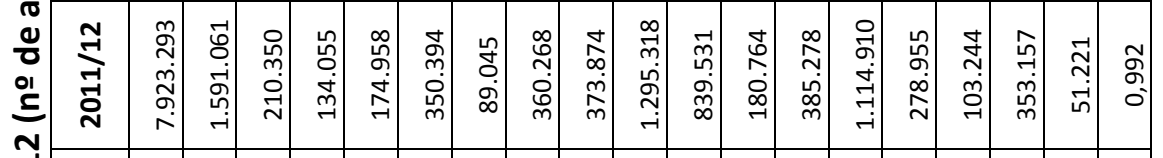

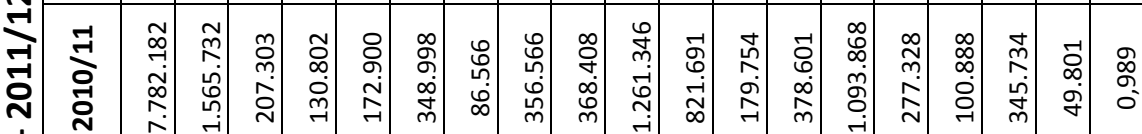

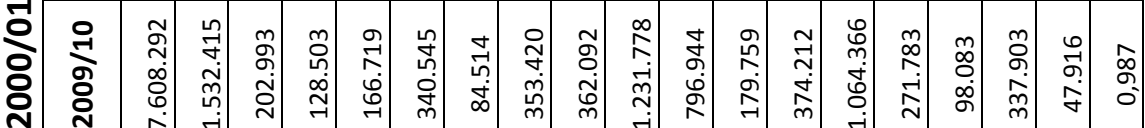

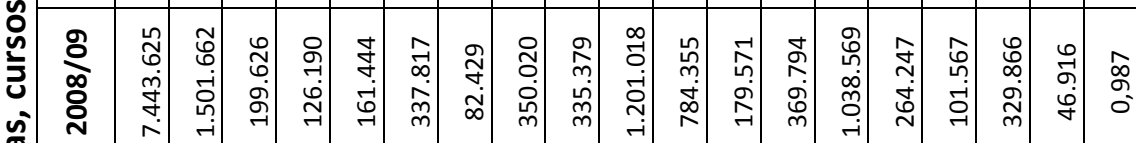

음

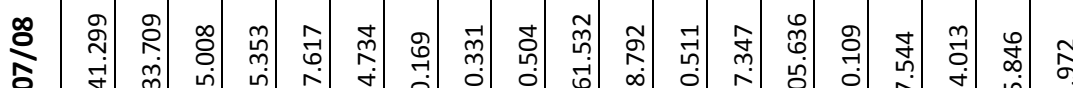

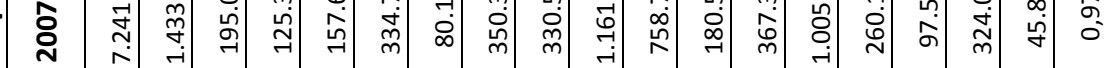

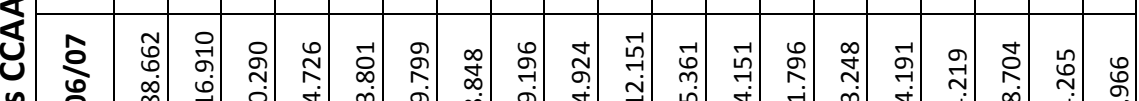

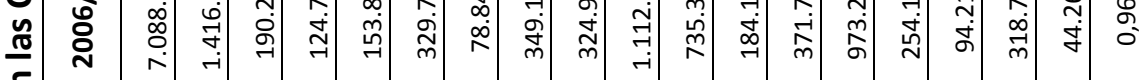

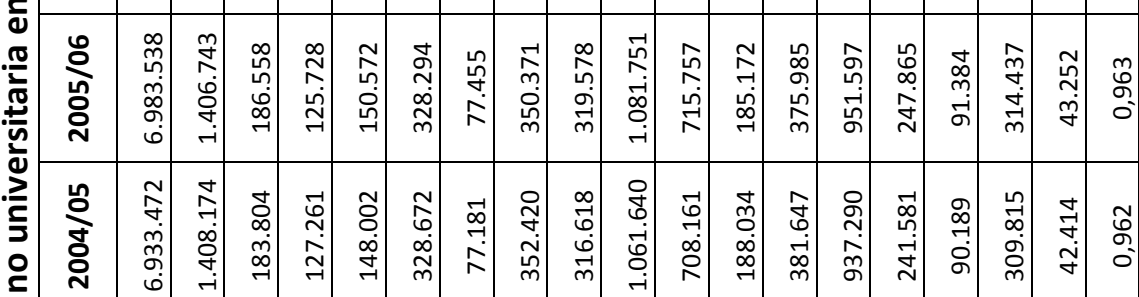

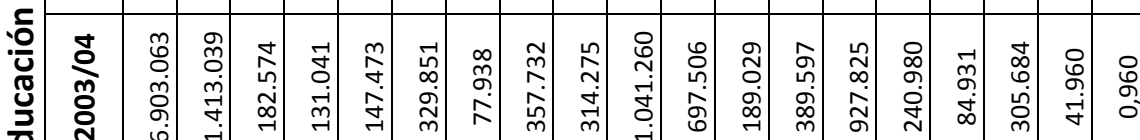

ะ

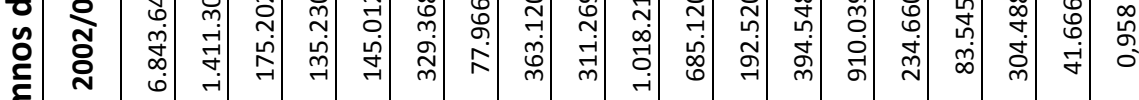

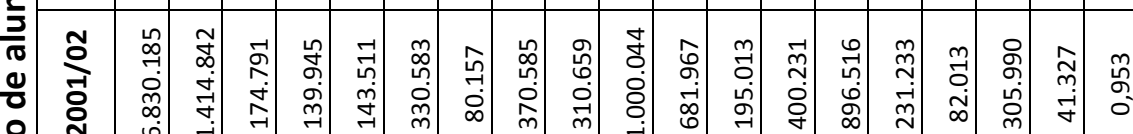

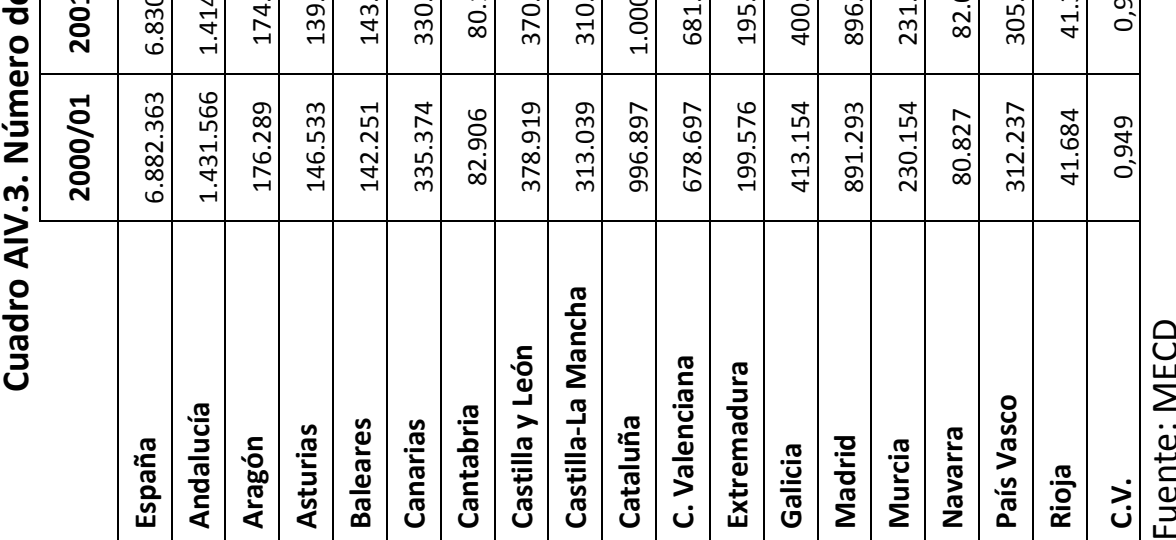




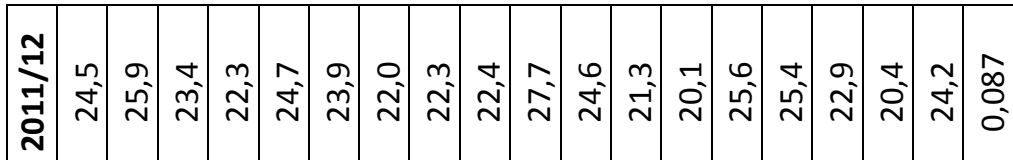

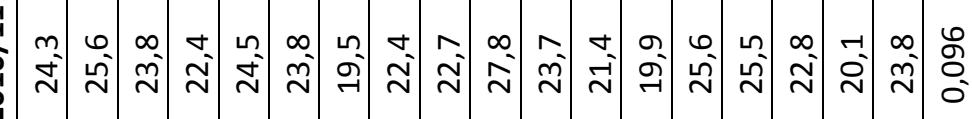

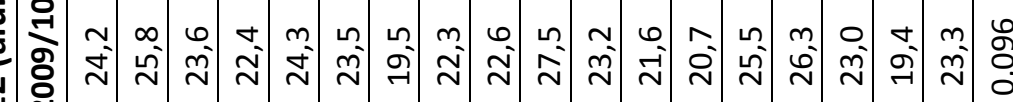

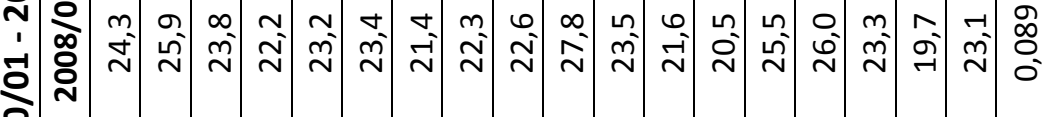

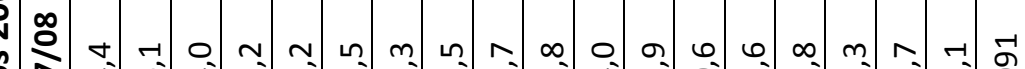

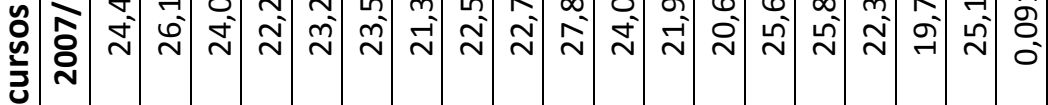

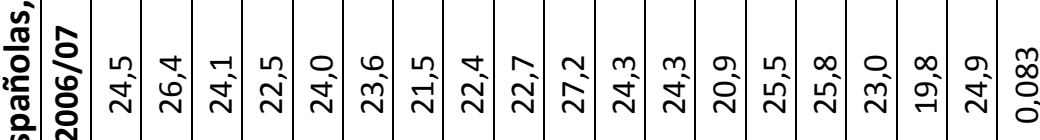

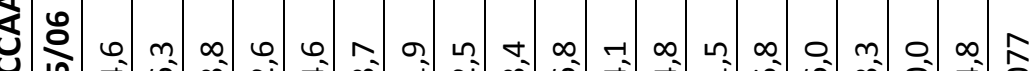

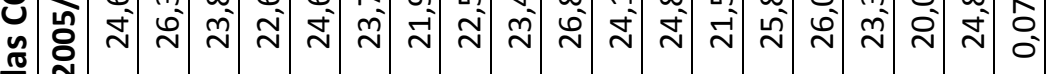
.

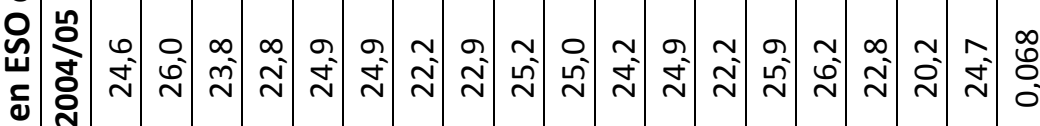

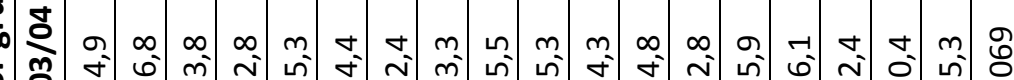

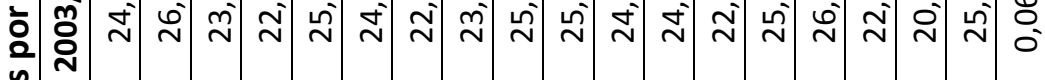

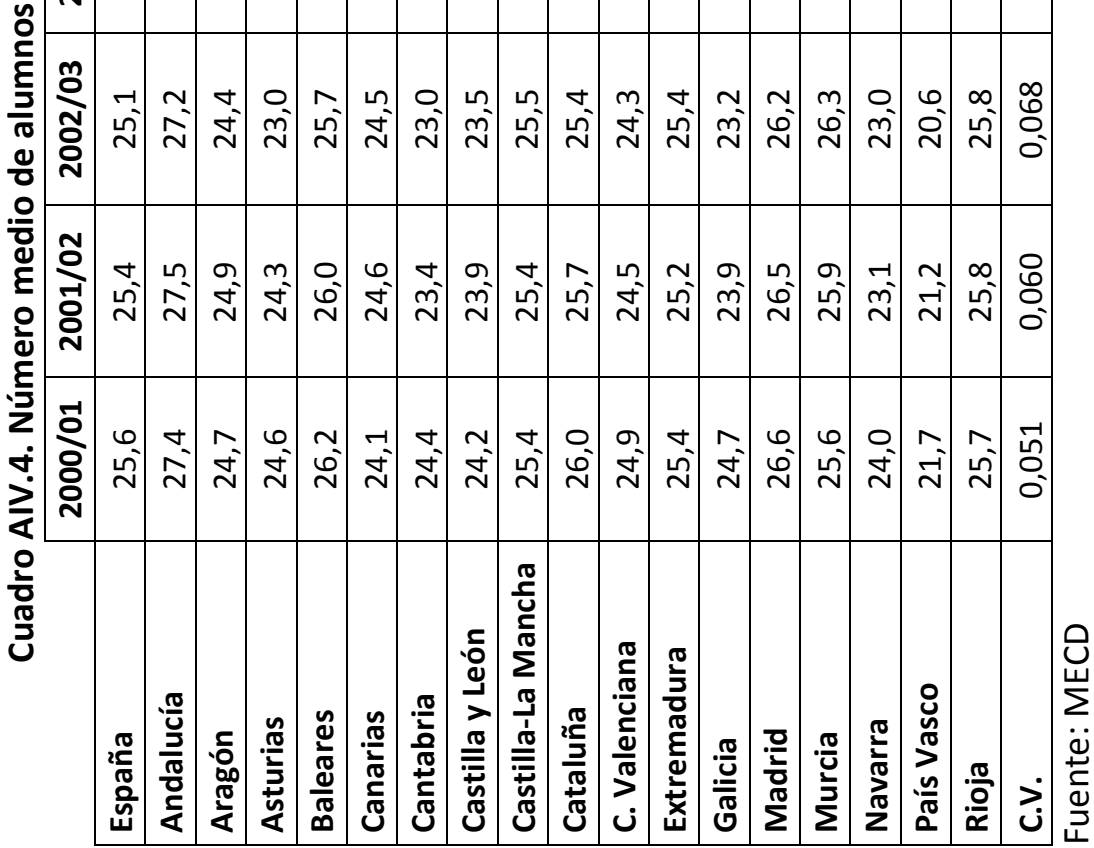




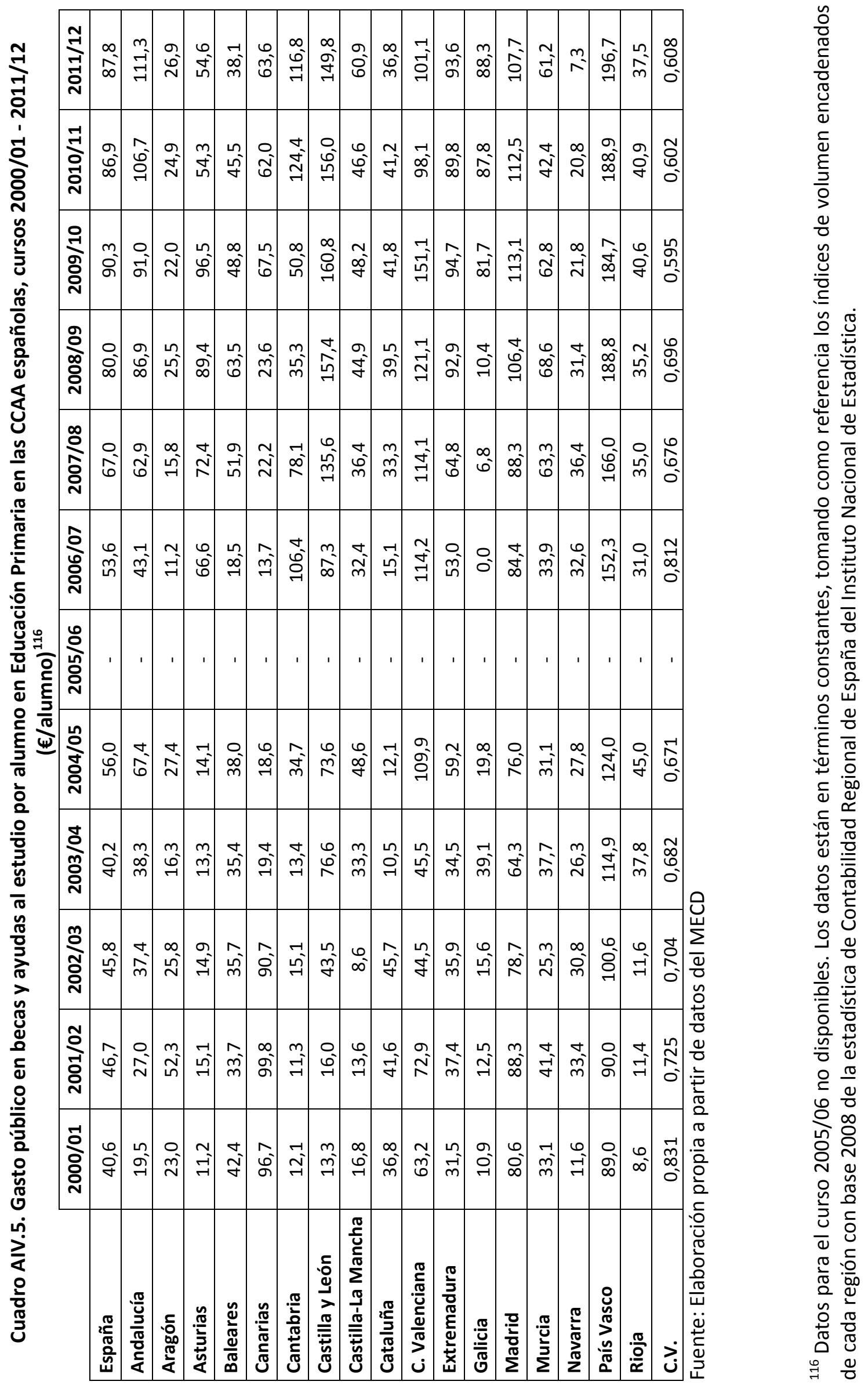




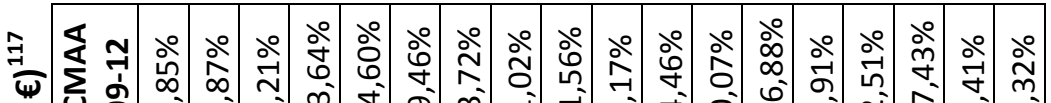

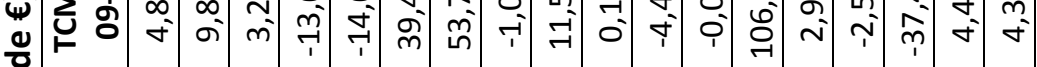

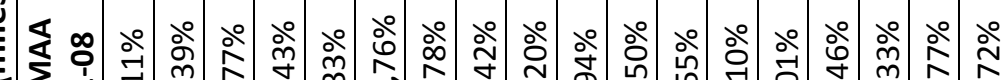
I

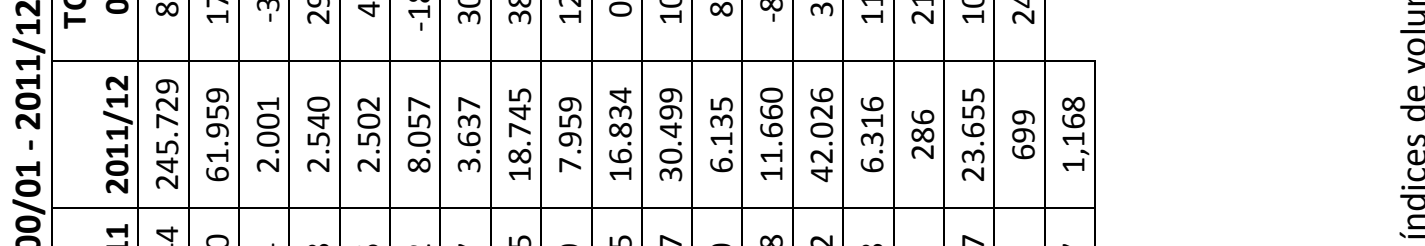

రำ

ô

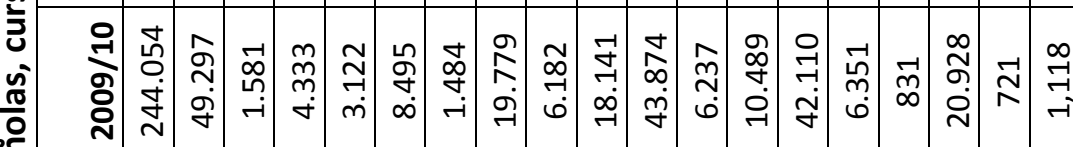

○ी

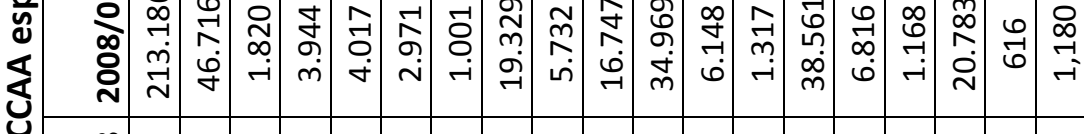

๘

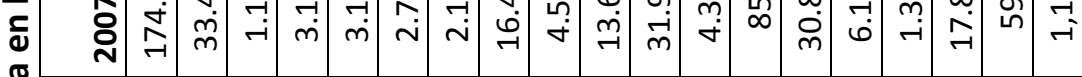

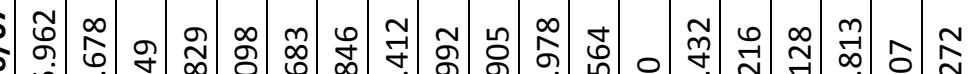

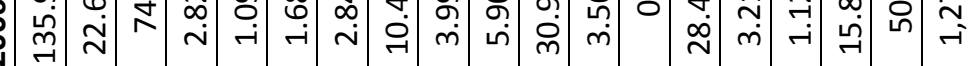

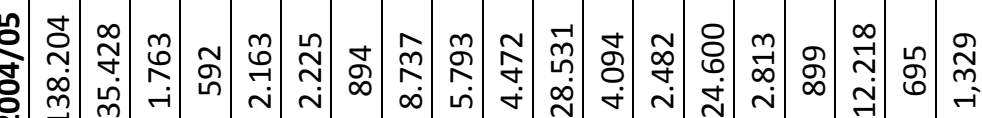

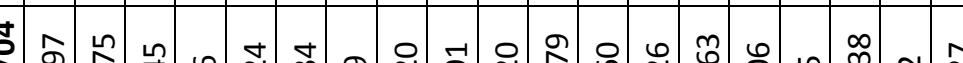

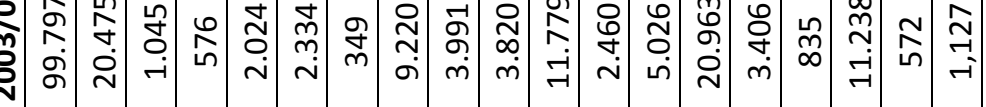

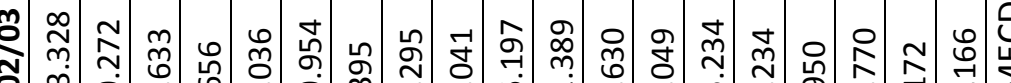

崩

₹ 娄

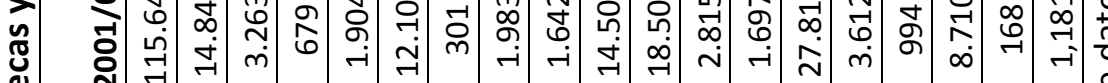

\begin{tabular}{lllllll}
$m$ & $\infty$ & & -1 & 0 \\
\hline
\end{tabular}

:

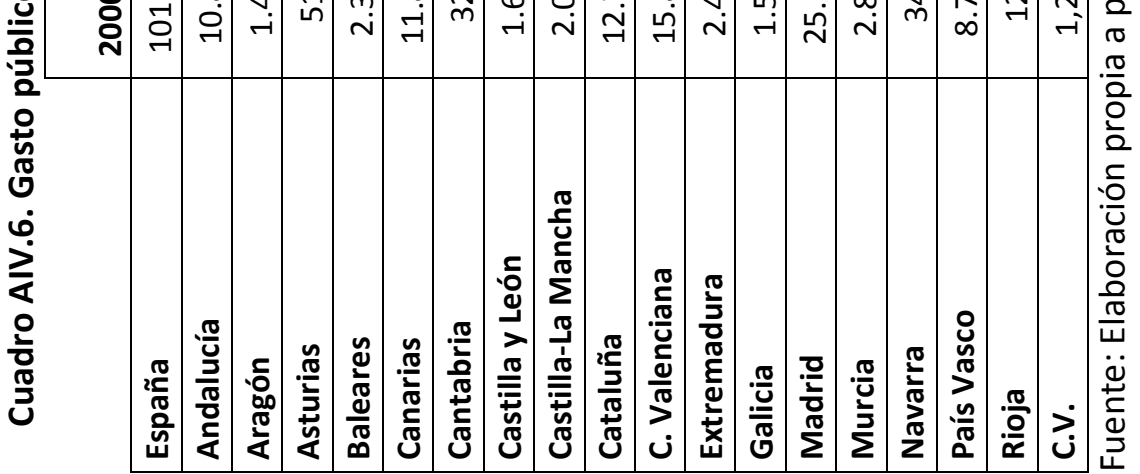

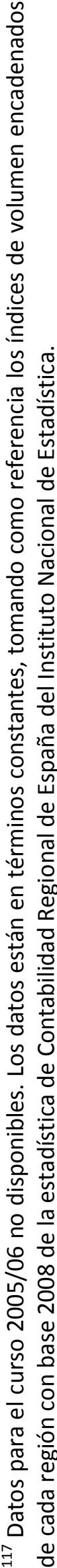




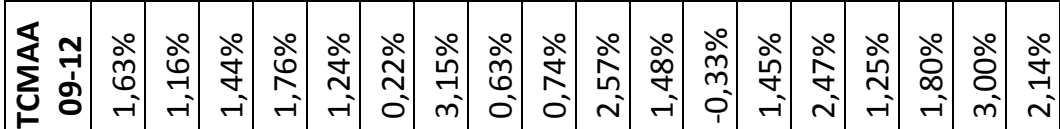

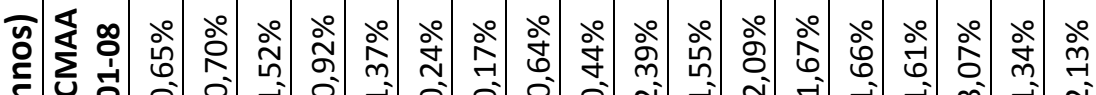

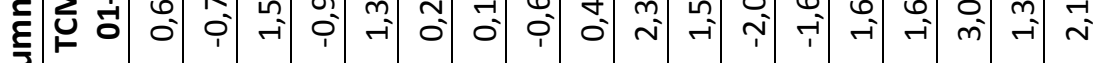

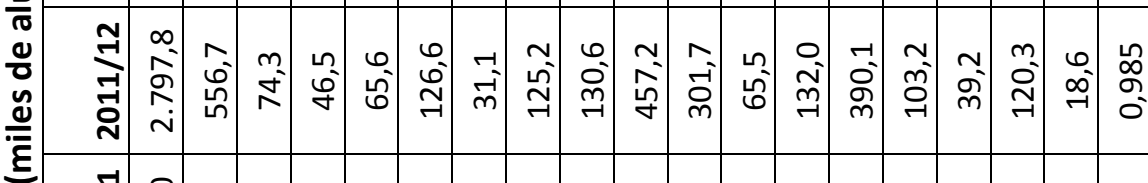

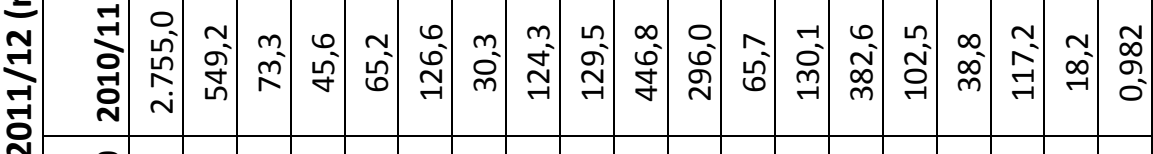

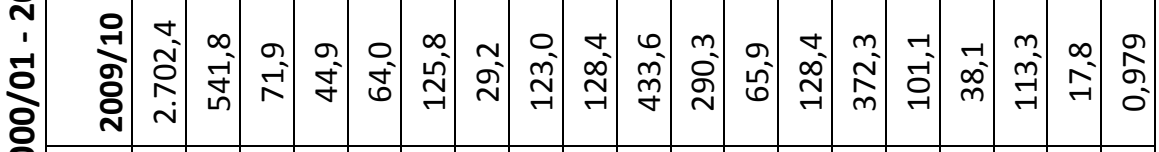

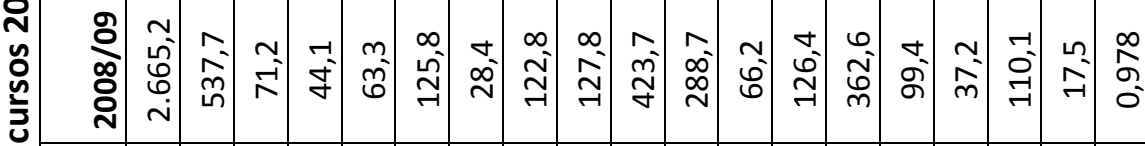

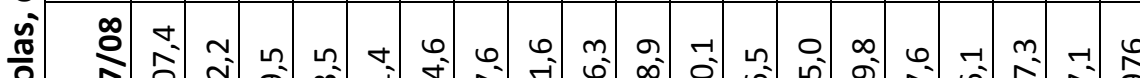

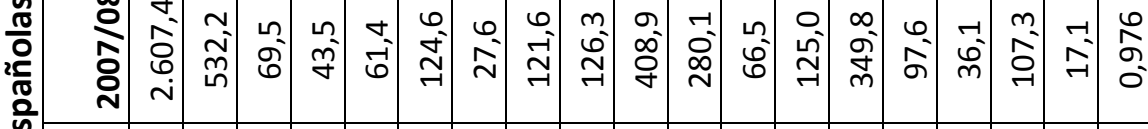

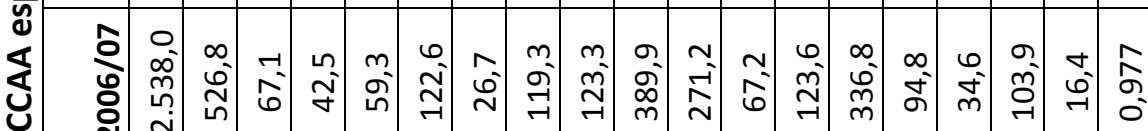

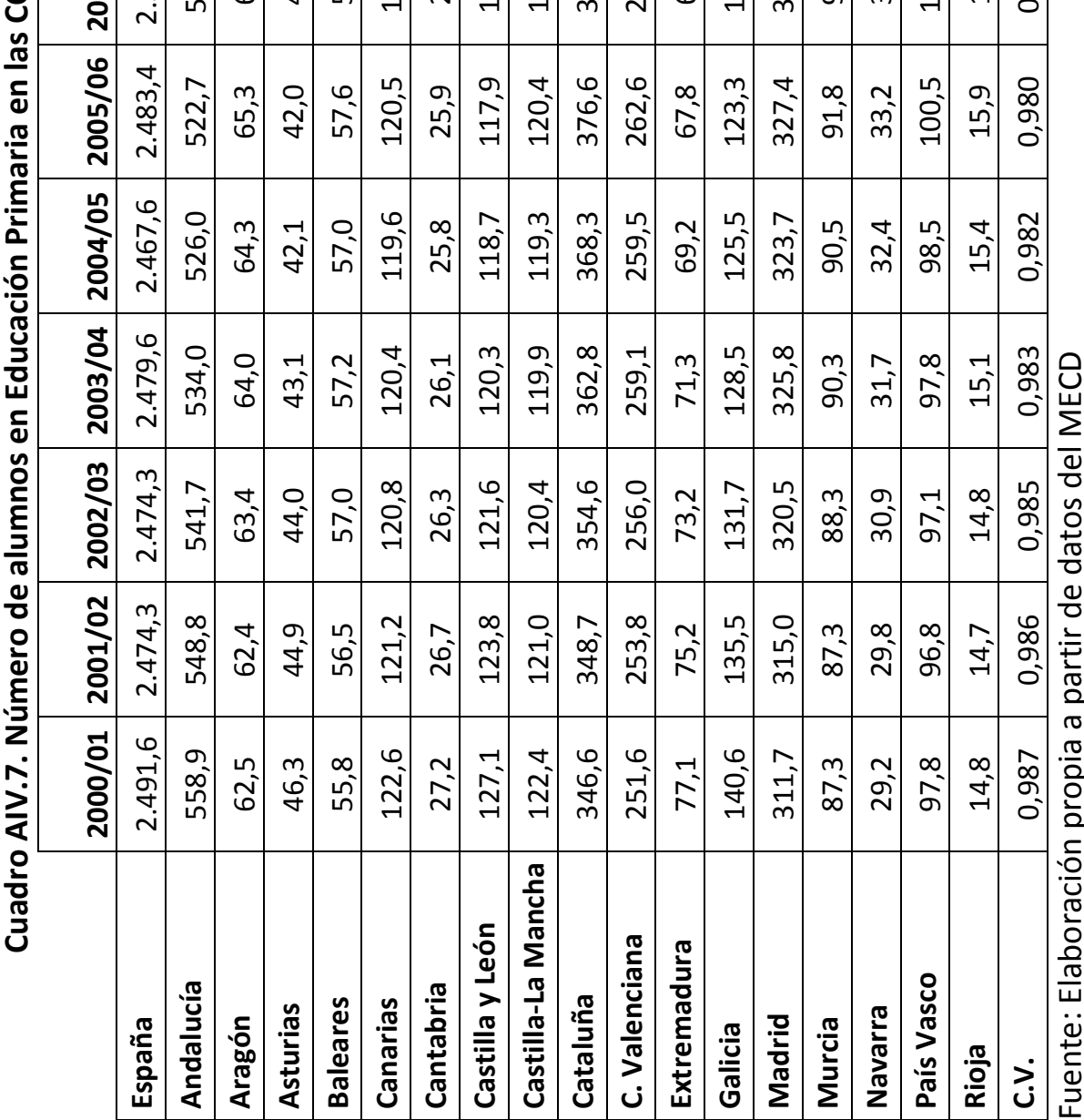




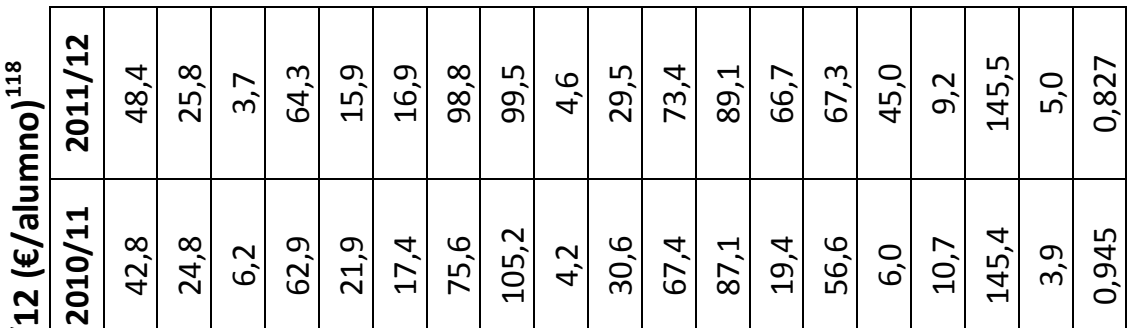

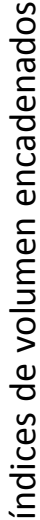

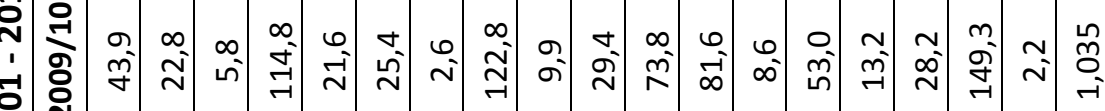

잉

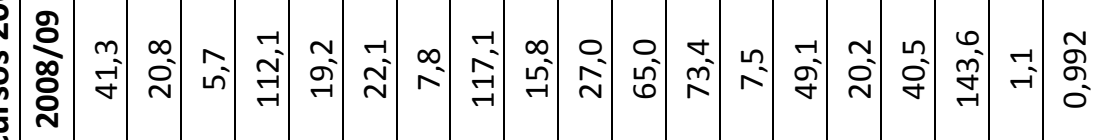

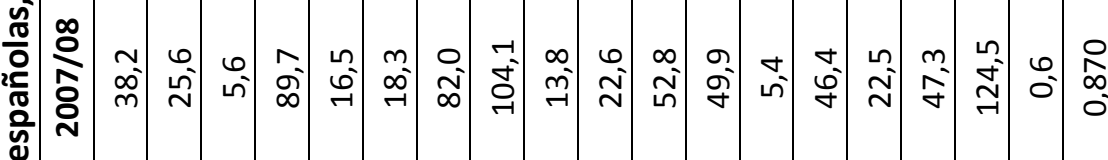

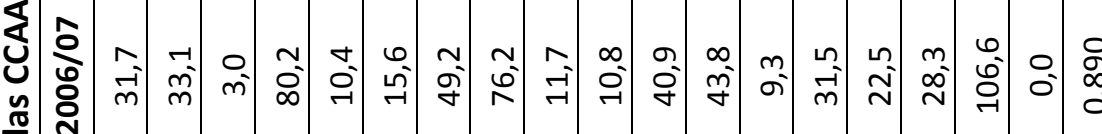

○ั

ฮั

ํำ

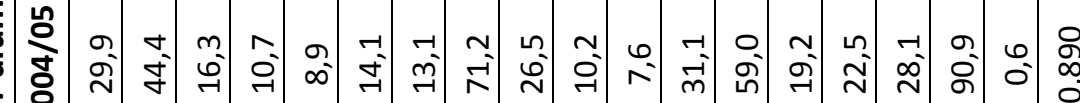
。

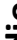

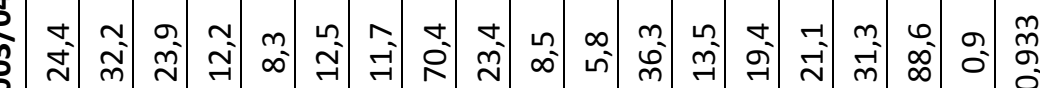

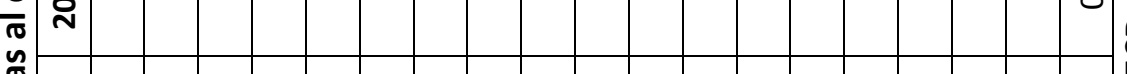

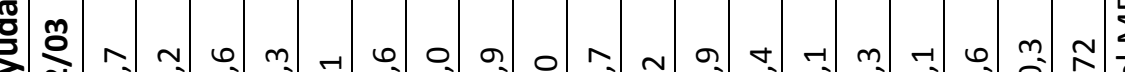

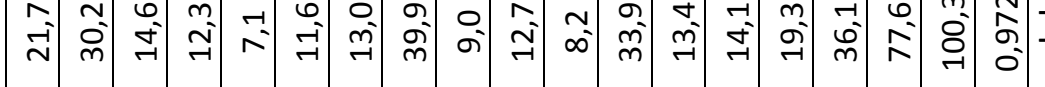

2.

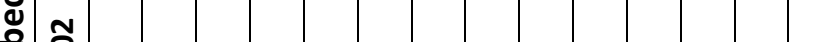

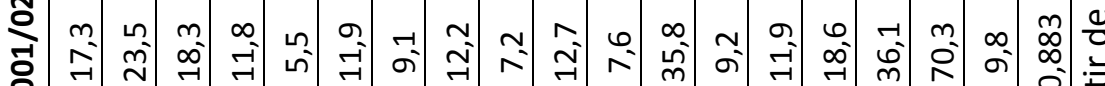

○)

을

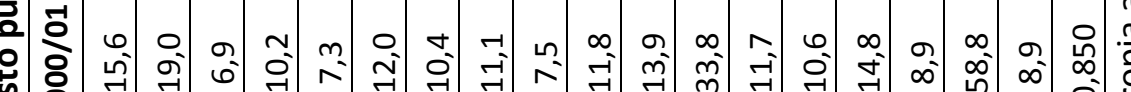

岕

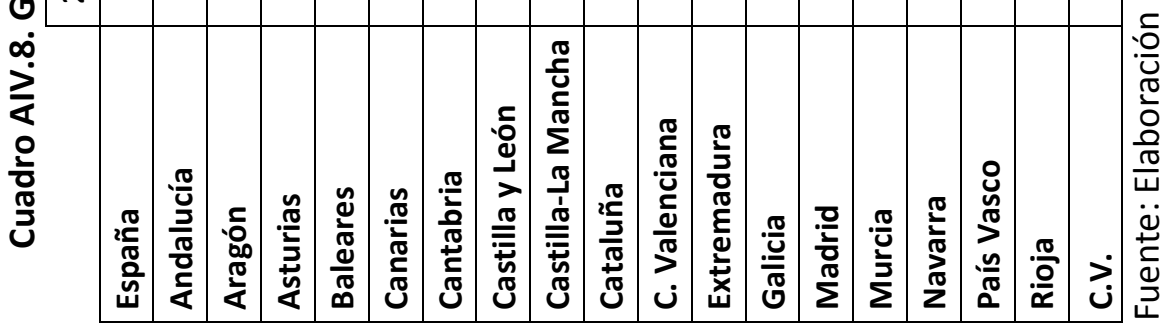

으. 윰

$\frac{\pi}{2}$

d

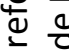

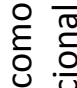

응 $\frac{\pi}{2}$

ํํํ율

空

岂

苍

ㄴำ

을

은

ฮ)

究

음

늉

气ิ

$\rightarrow$.

包

흥

으

ᄃ

ㅇํㅇㅇㅇ

8 ㅇำ

जิ

ปั

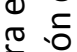

$\frac{\sqrt{2}}{\sqrt[\pi]{2}}$

옹 


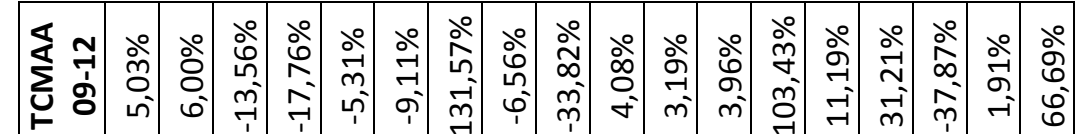
స్తి «

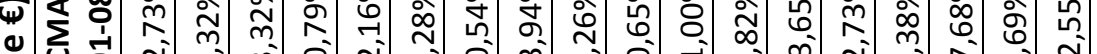

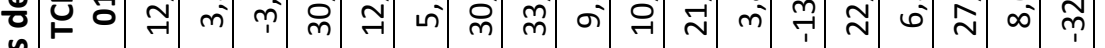

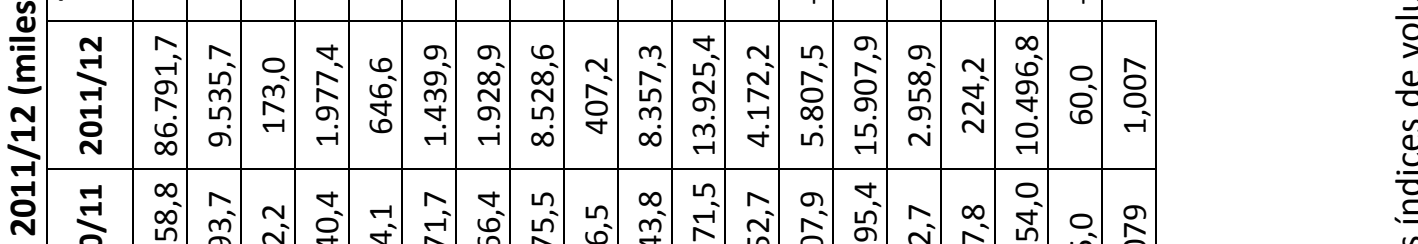

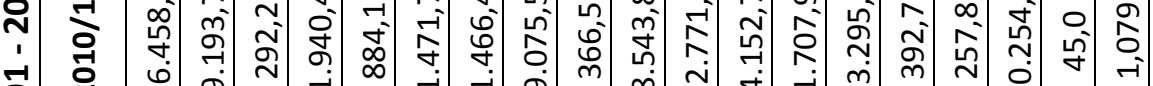

-1

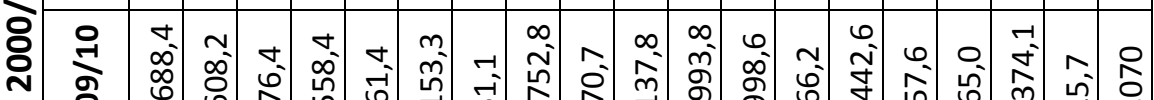

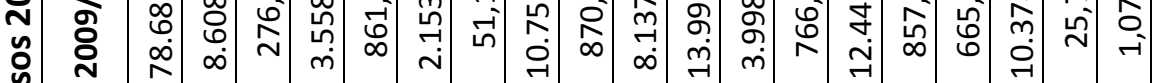

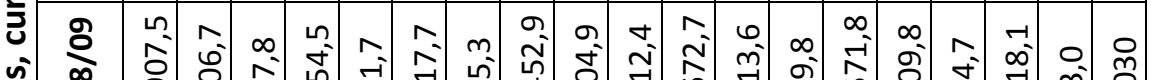

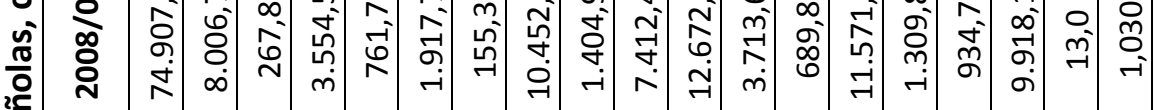

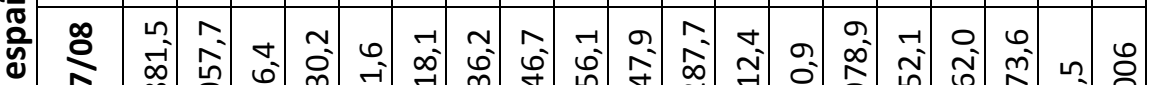

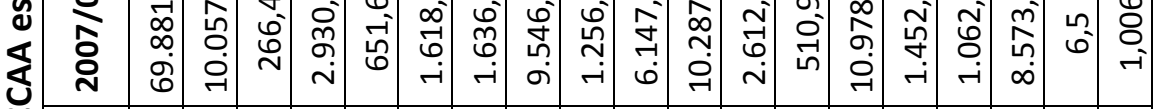

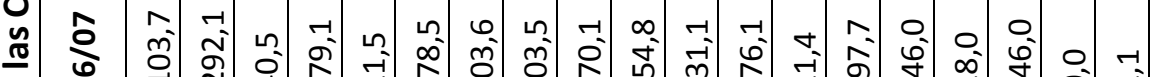

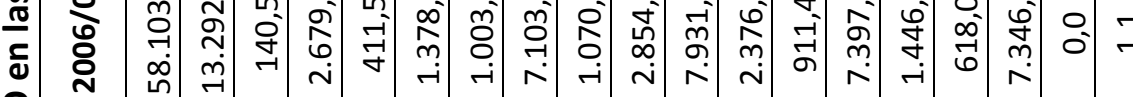

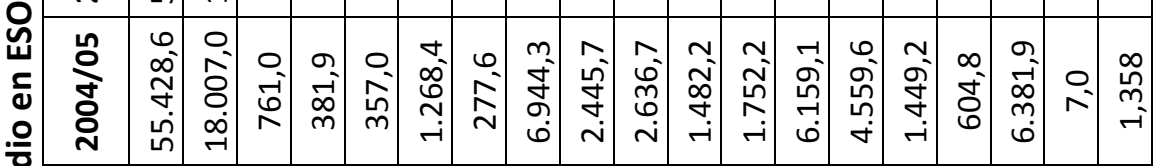

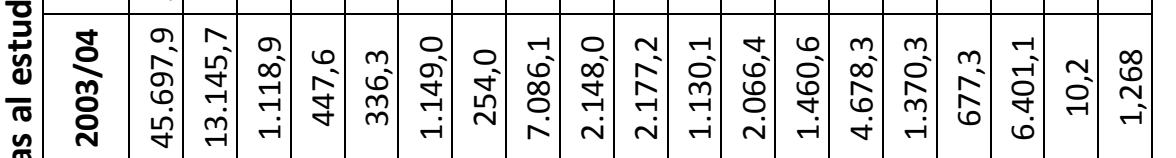

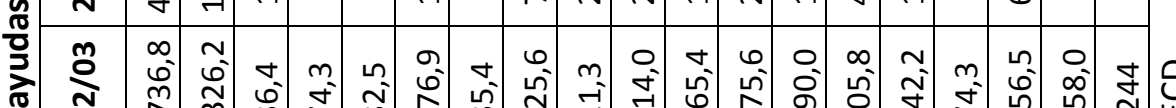

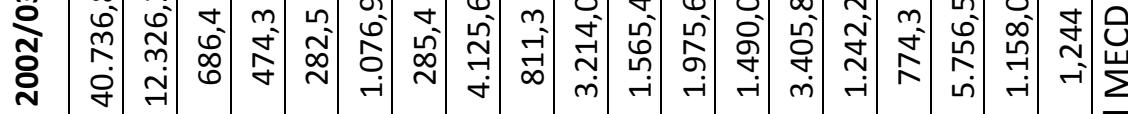

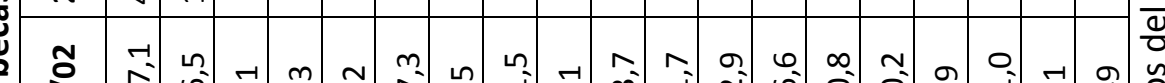

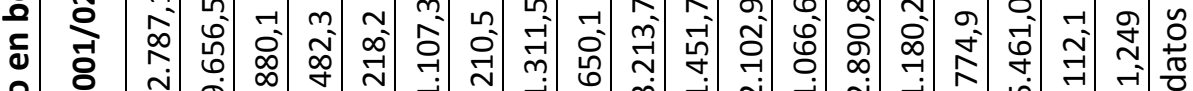

:

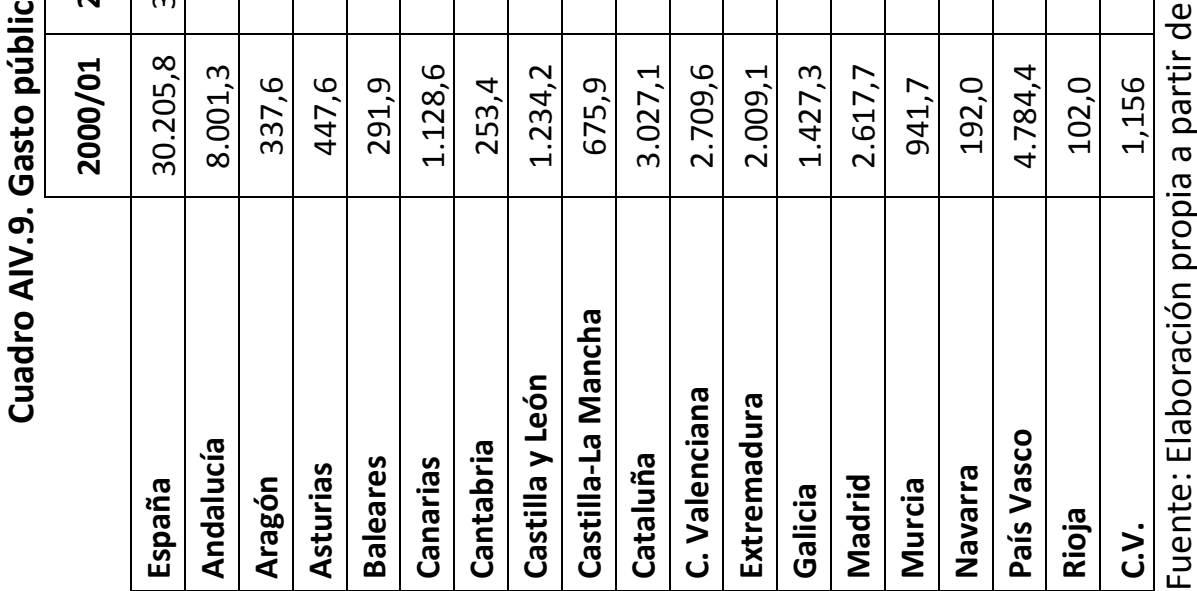

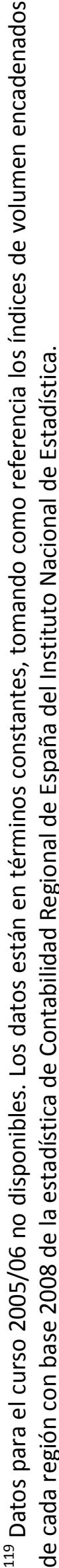




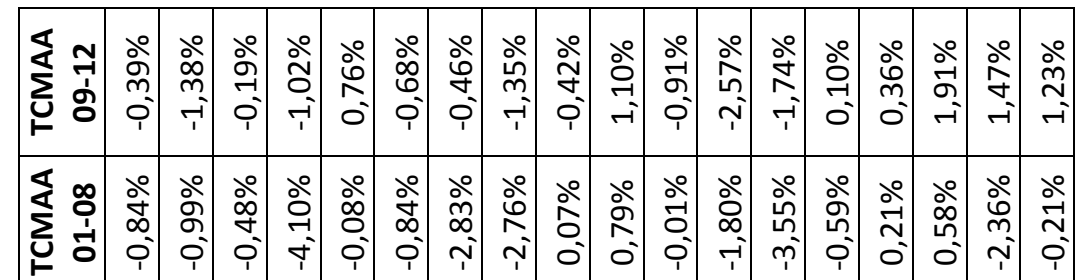

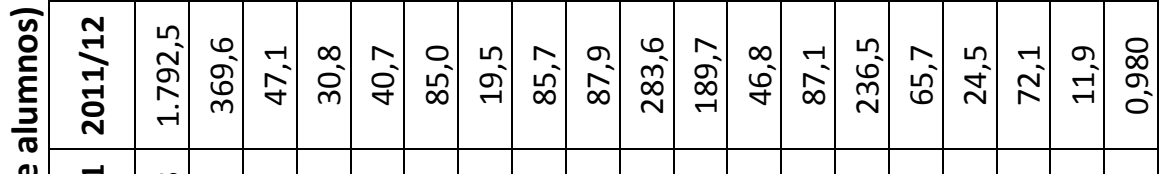

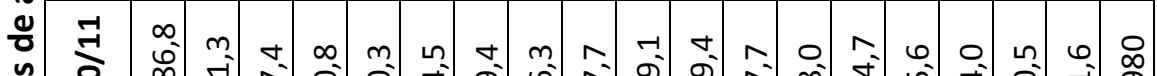

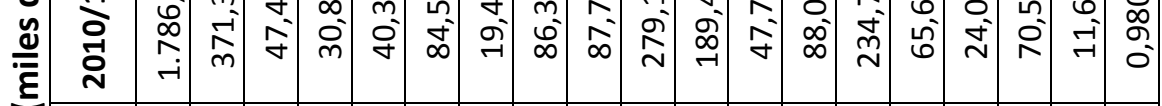

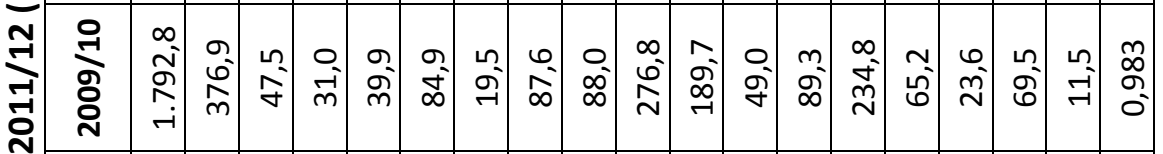

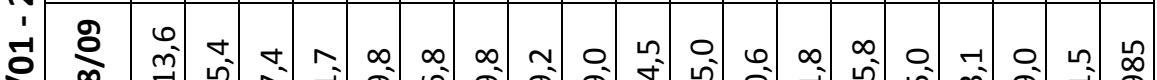

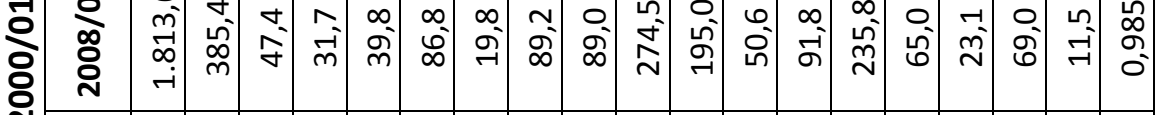

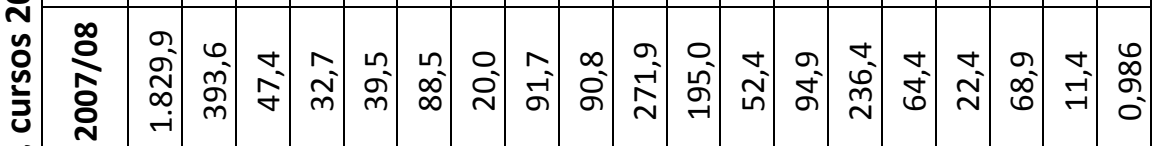

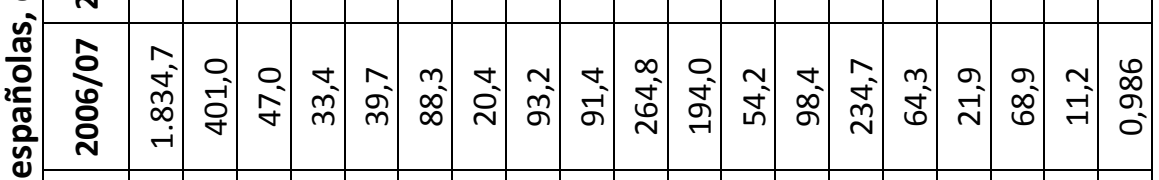

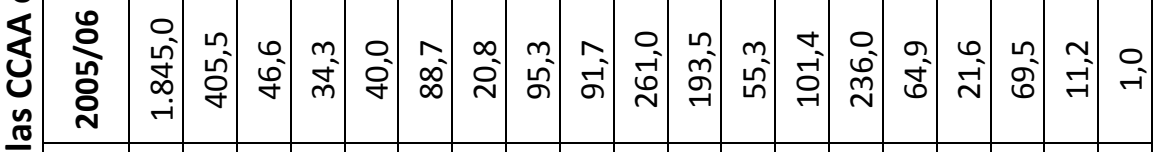

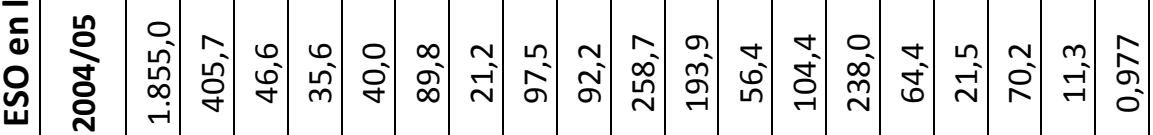

峁

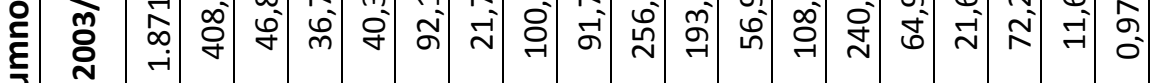

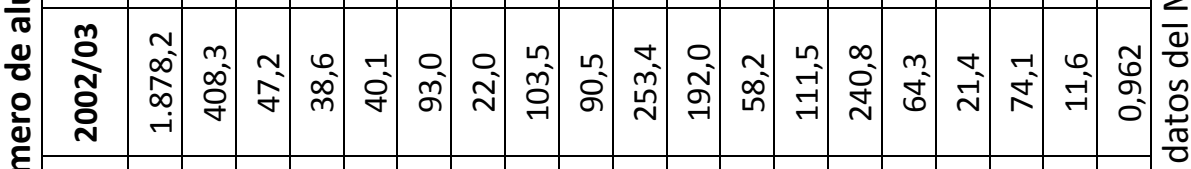

ร है

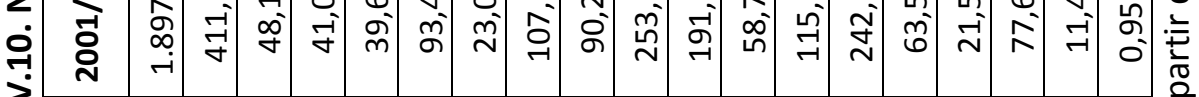

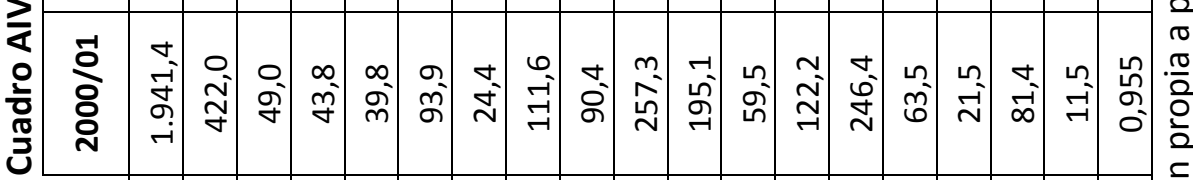

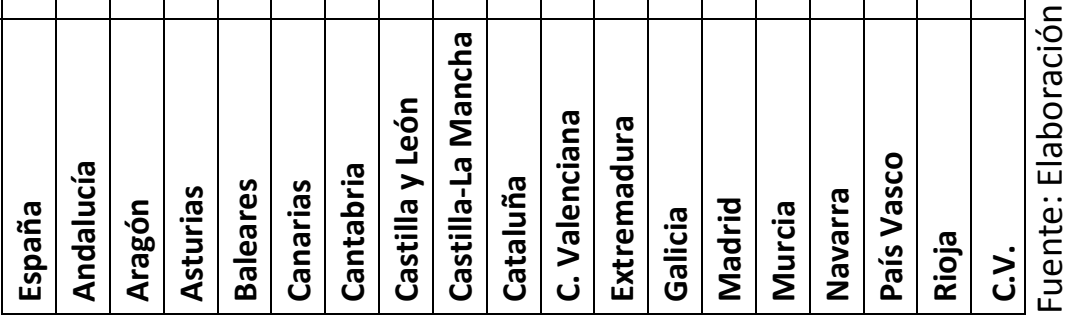




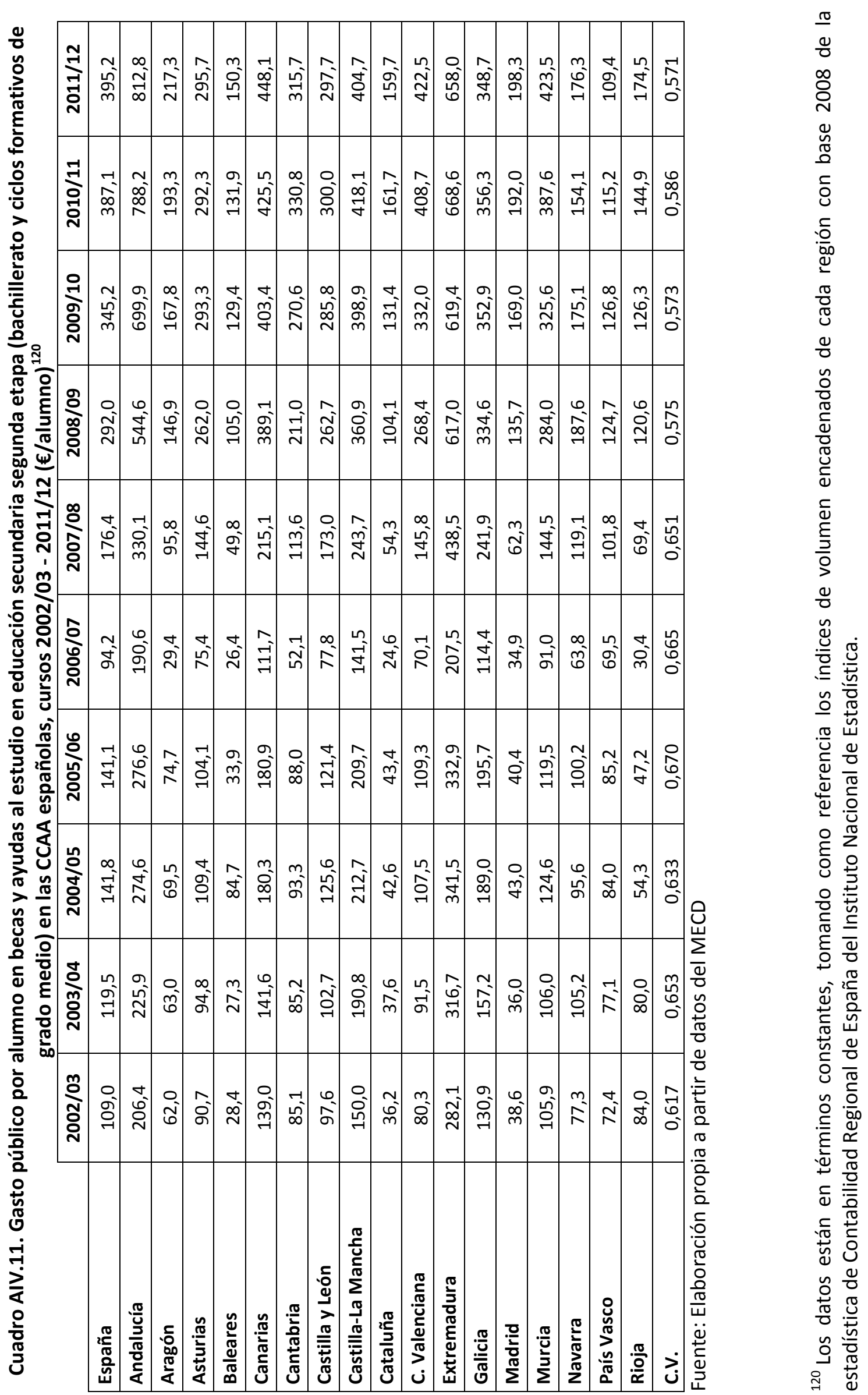




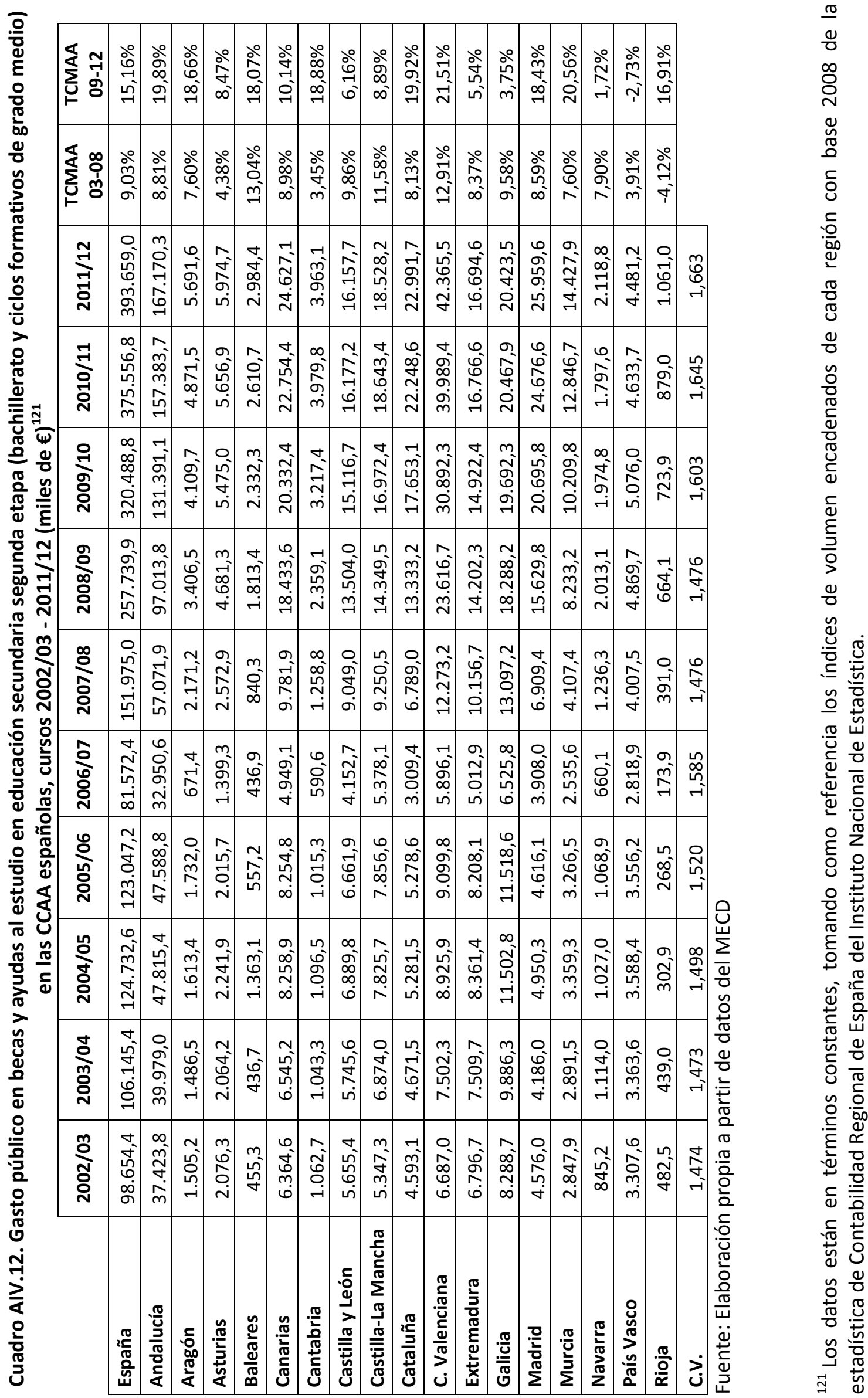




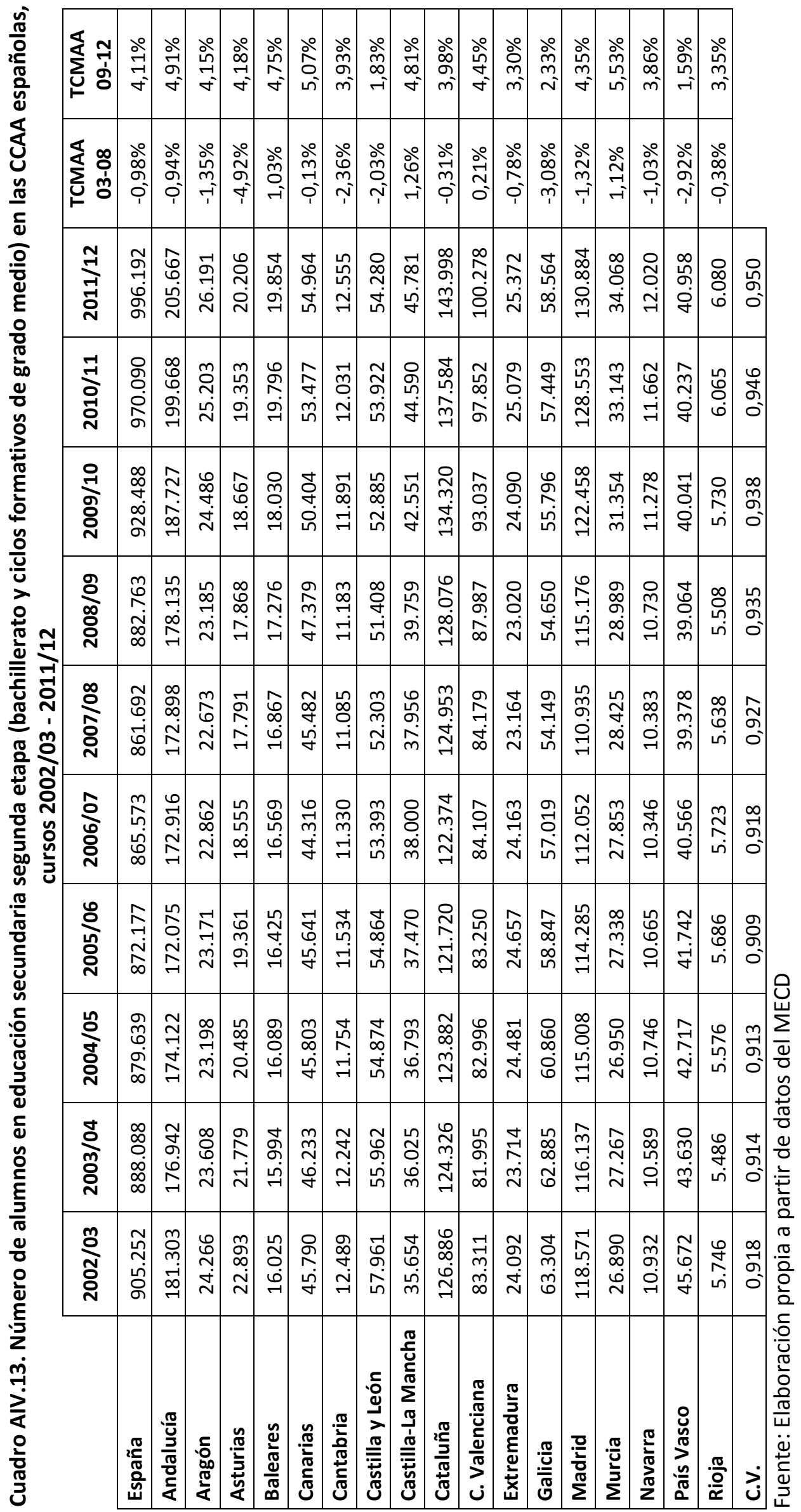




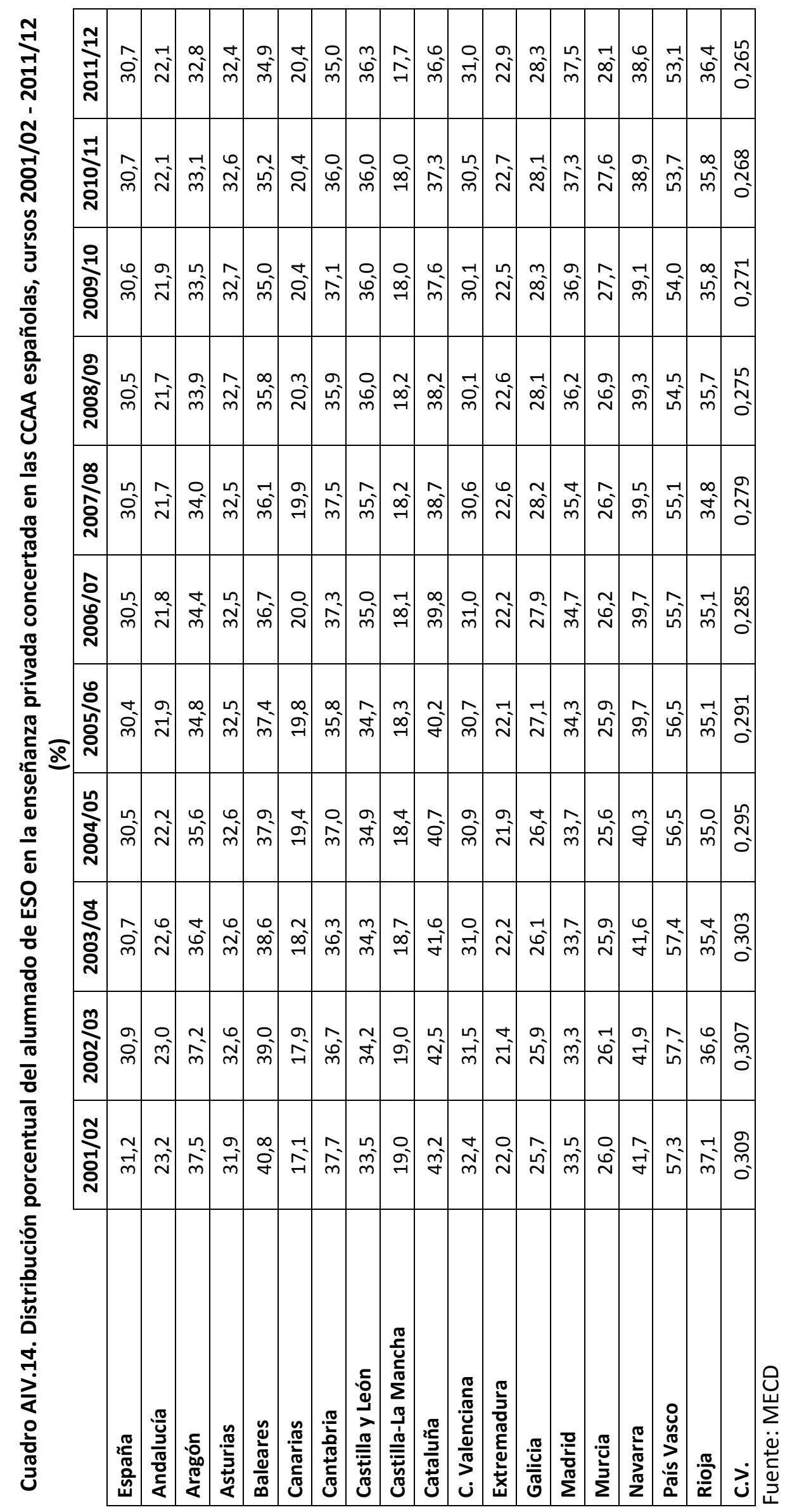




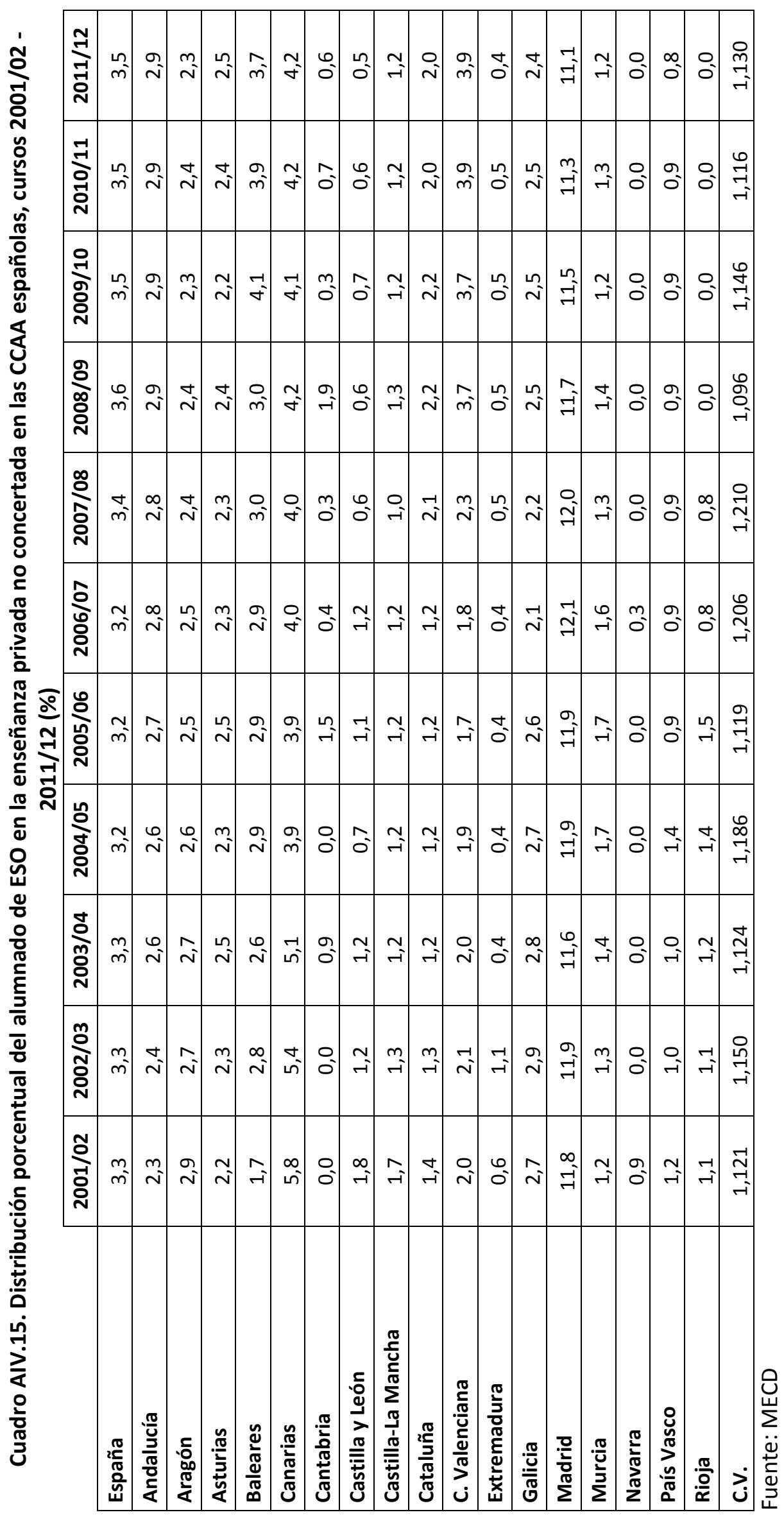




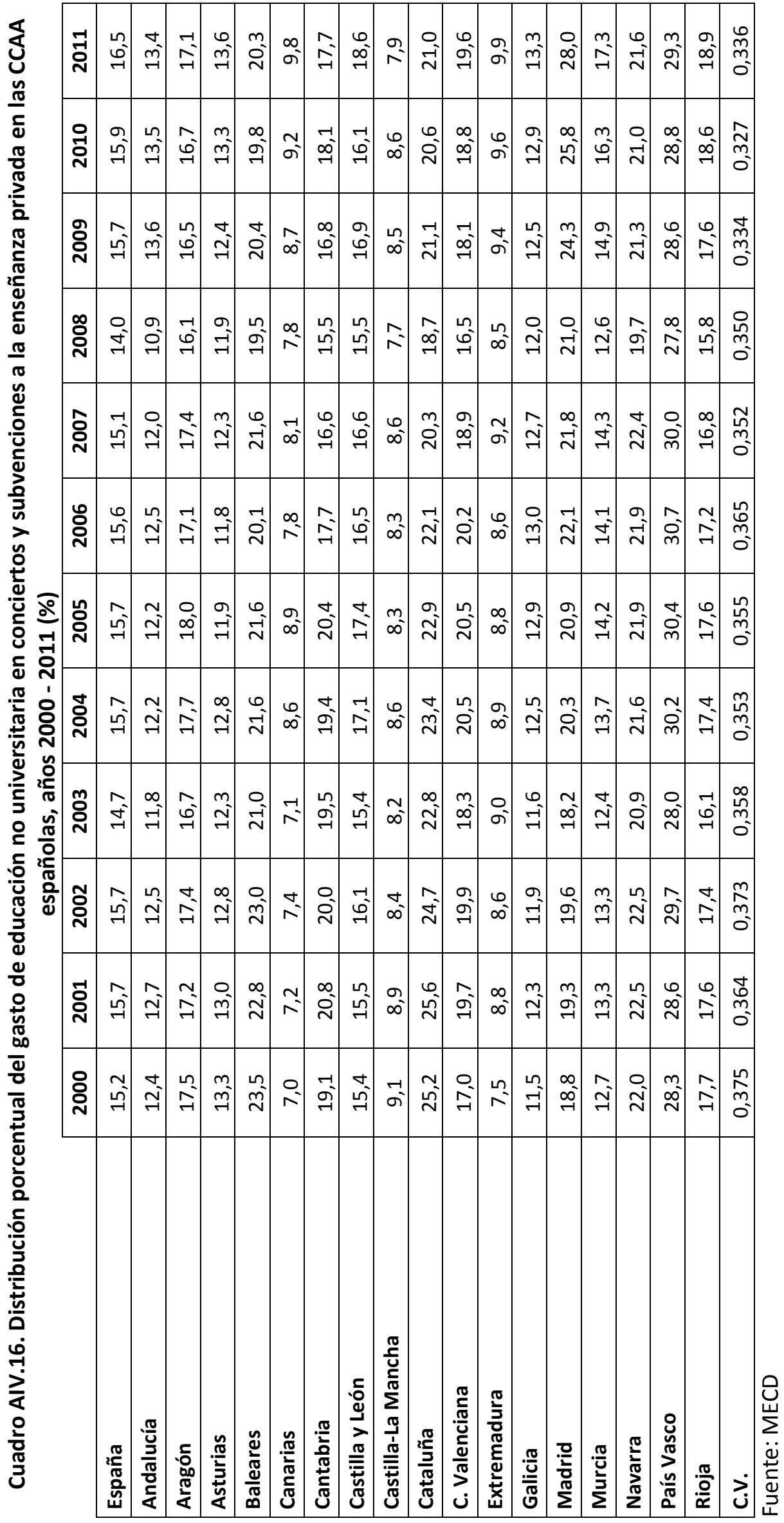




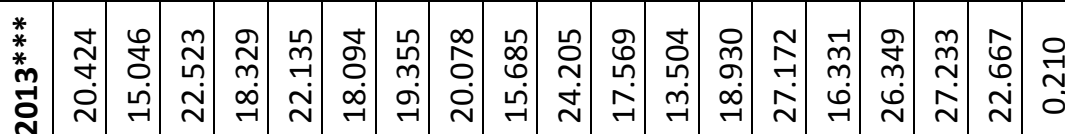

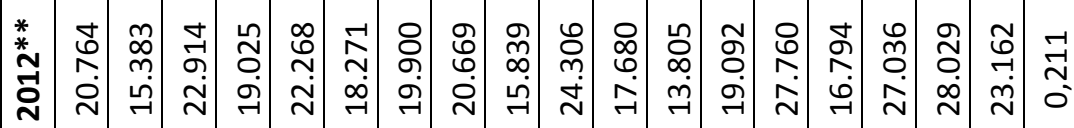

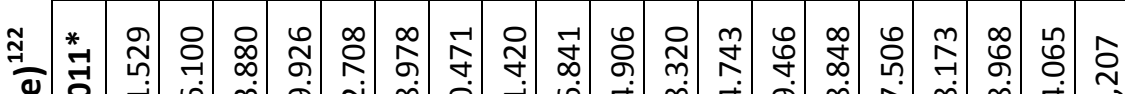
ฐ

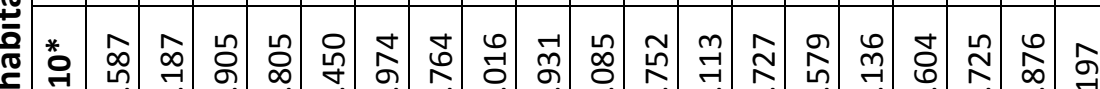

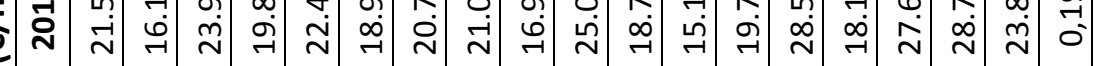

苛

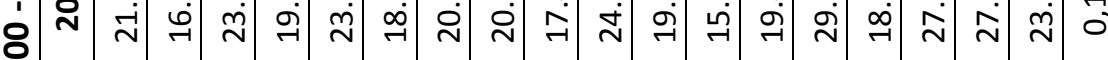

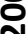

స్ ‘ 岳

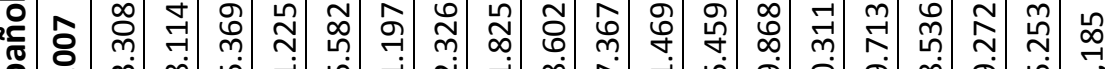

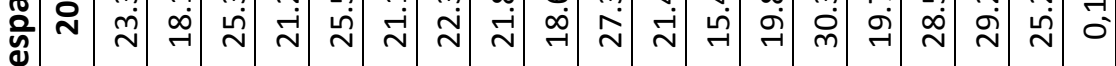
过

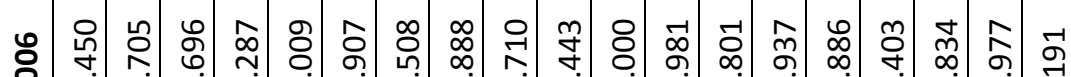
范

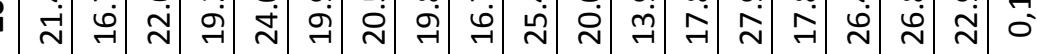

๘

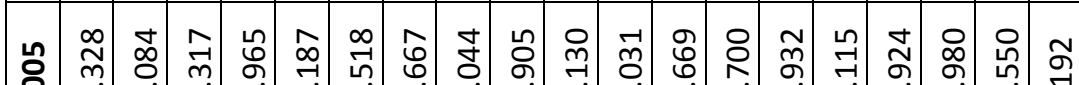
壳

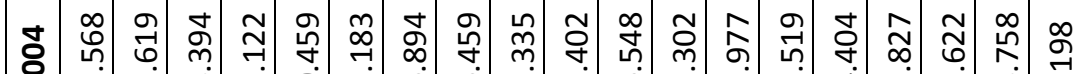

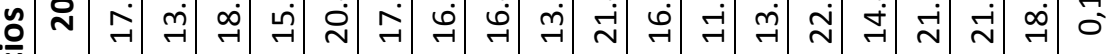
( 0 :

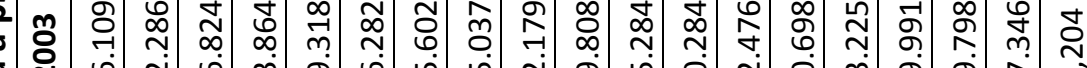
ஐ $\frac{2}{\sqrt{0}}$

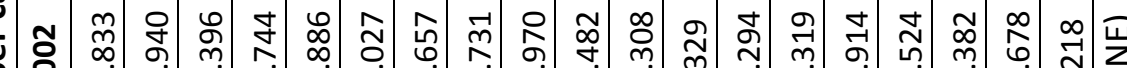
o

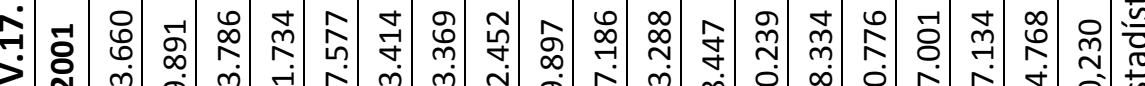
ऐ

๖ำ

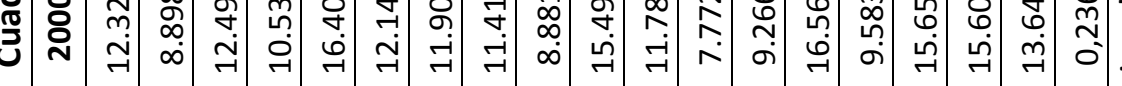

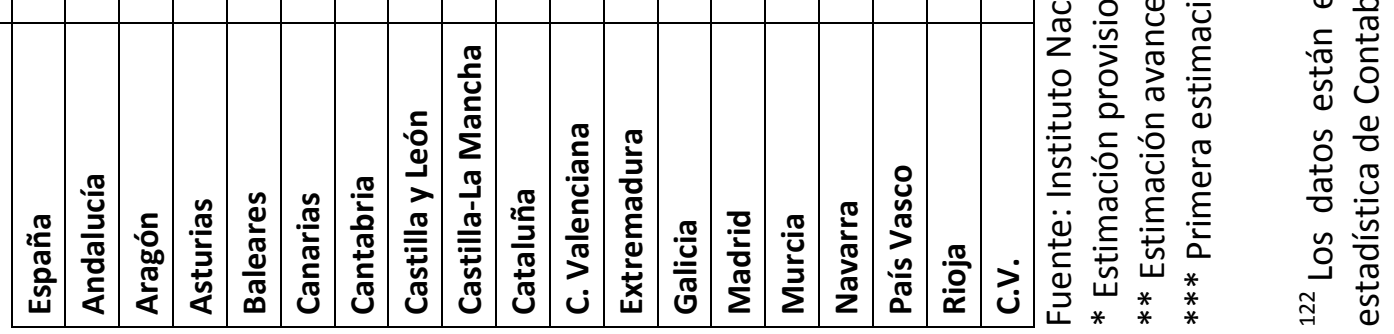




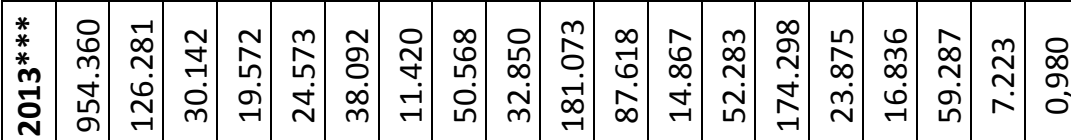

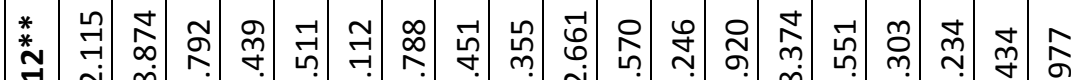

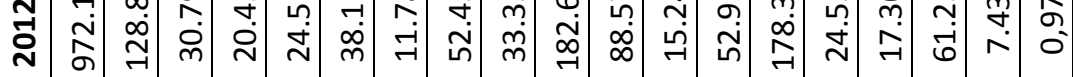

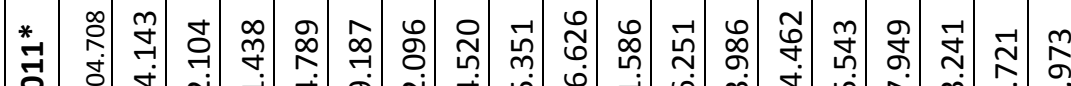

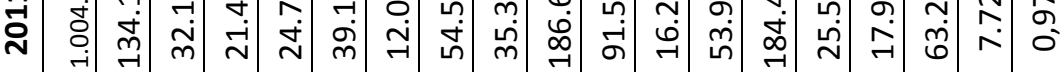

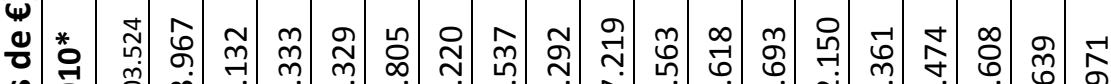
凹

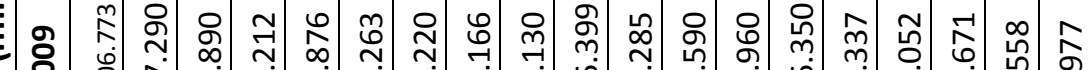

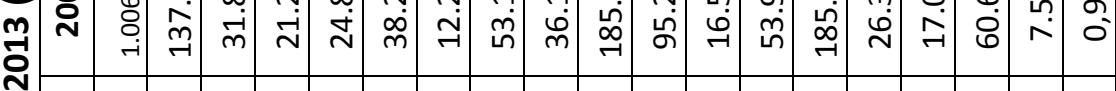

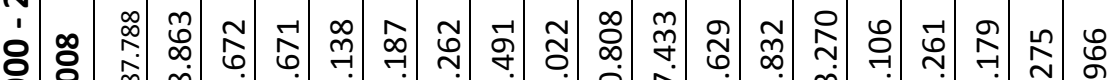

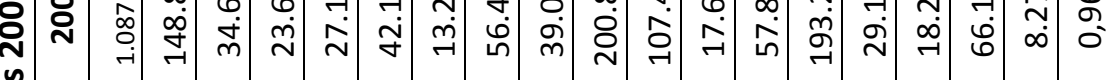

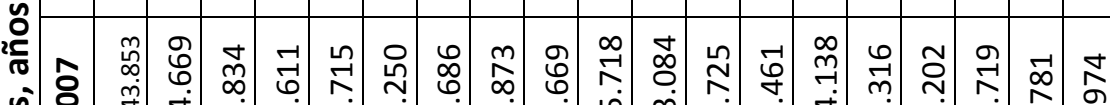

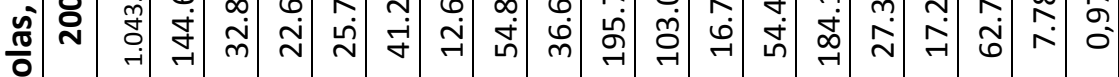

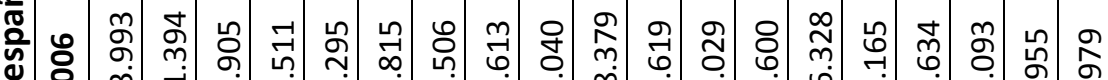

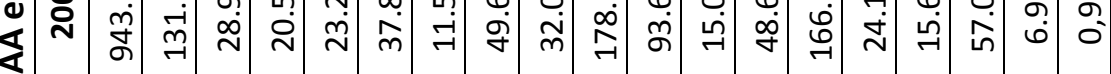

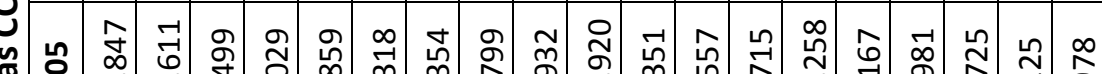

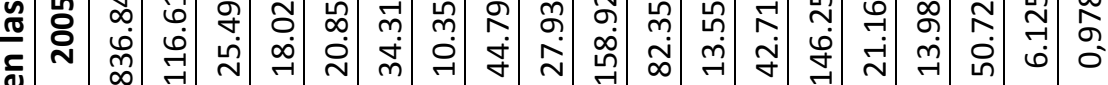

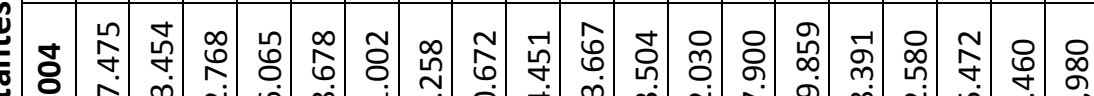

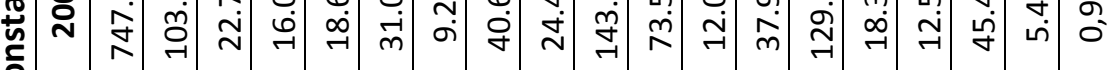

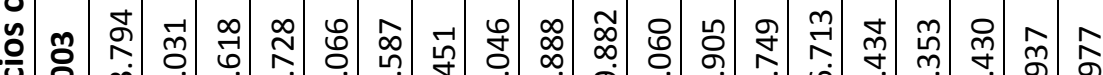

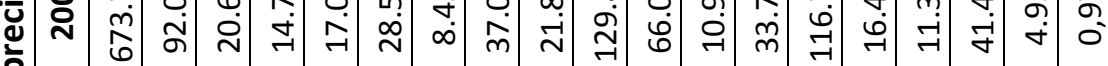

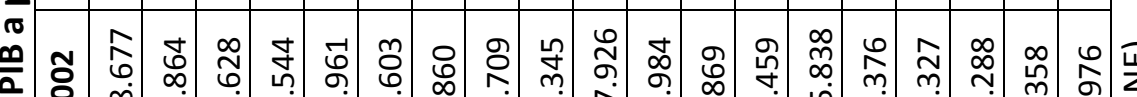

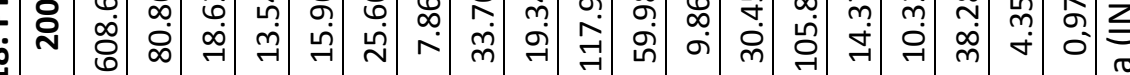

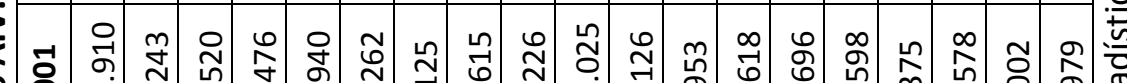

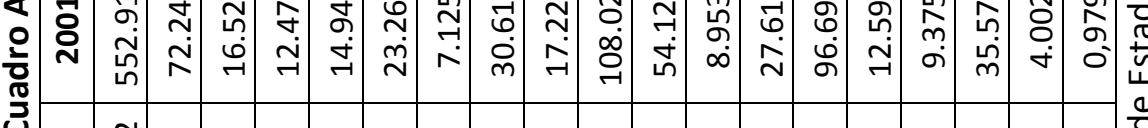

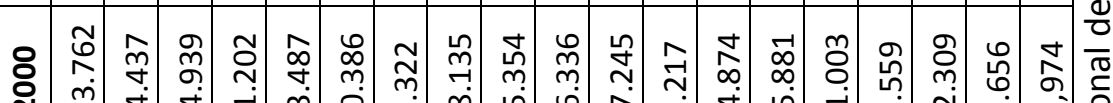

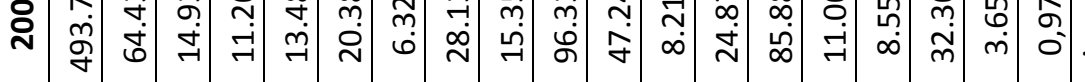

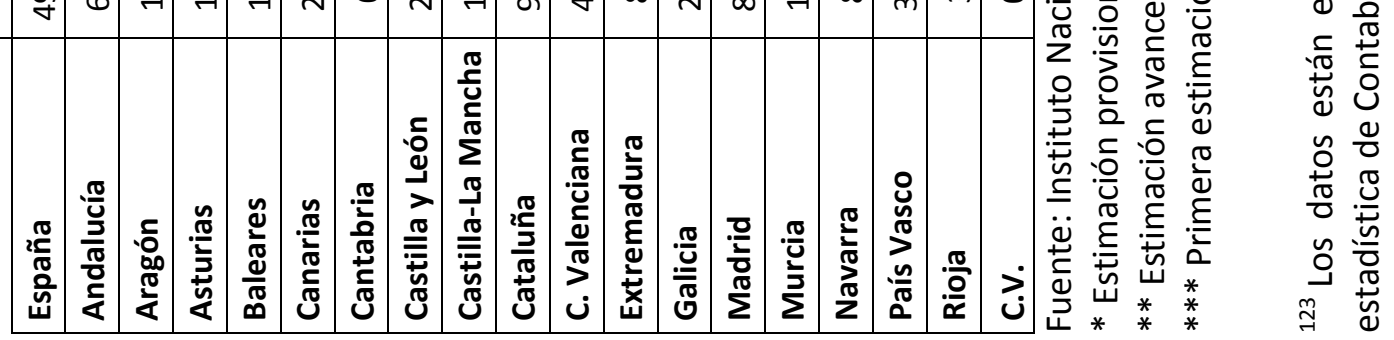




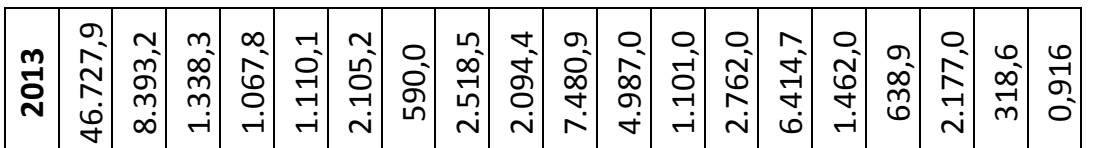

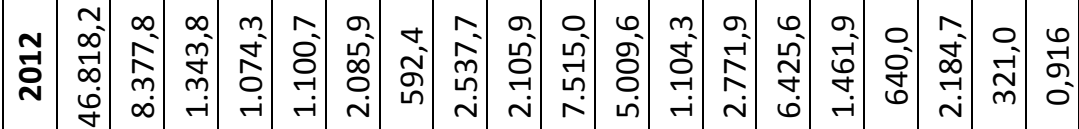

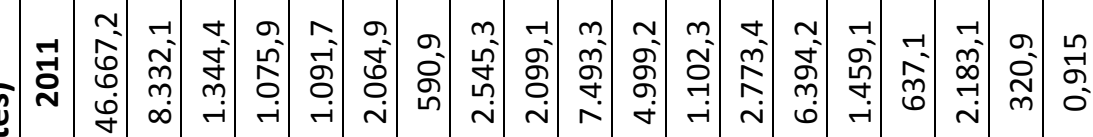

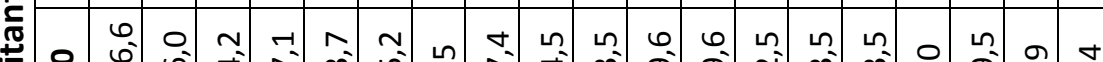

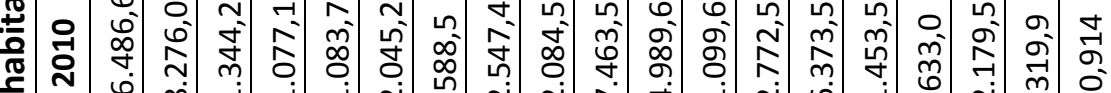

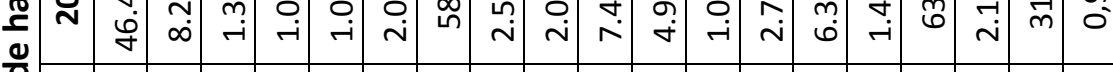

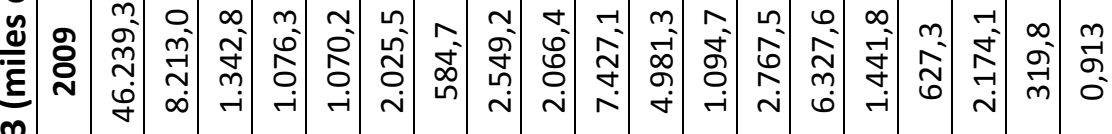

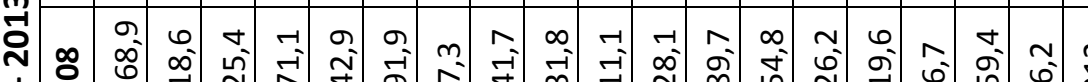

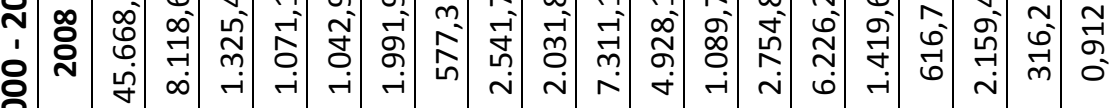

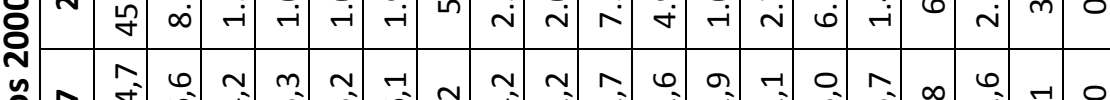

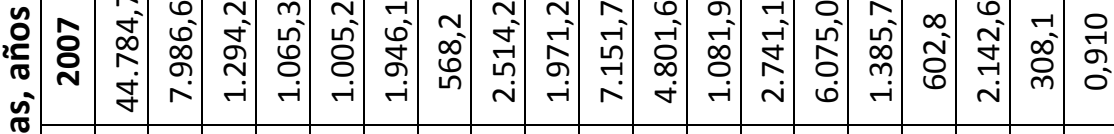

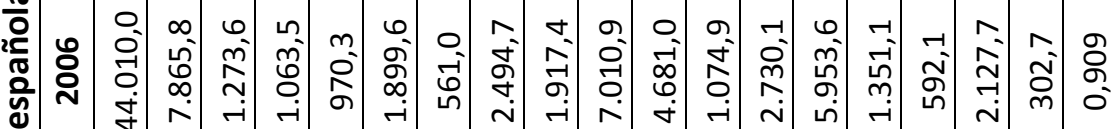
乐舟 员 ゙ָ

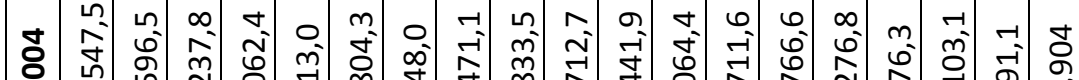

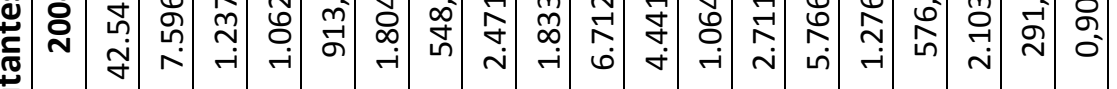

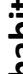

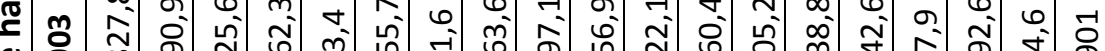

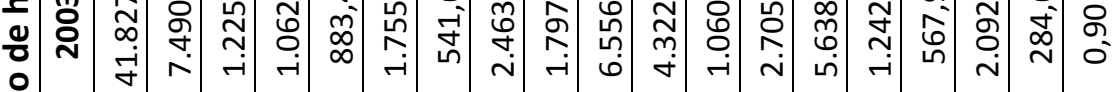

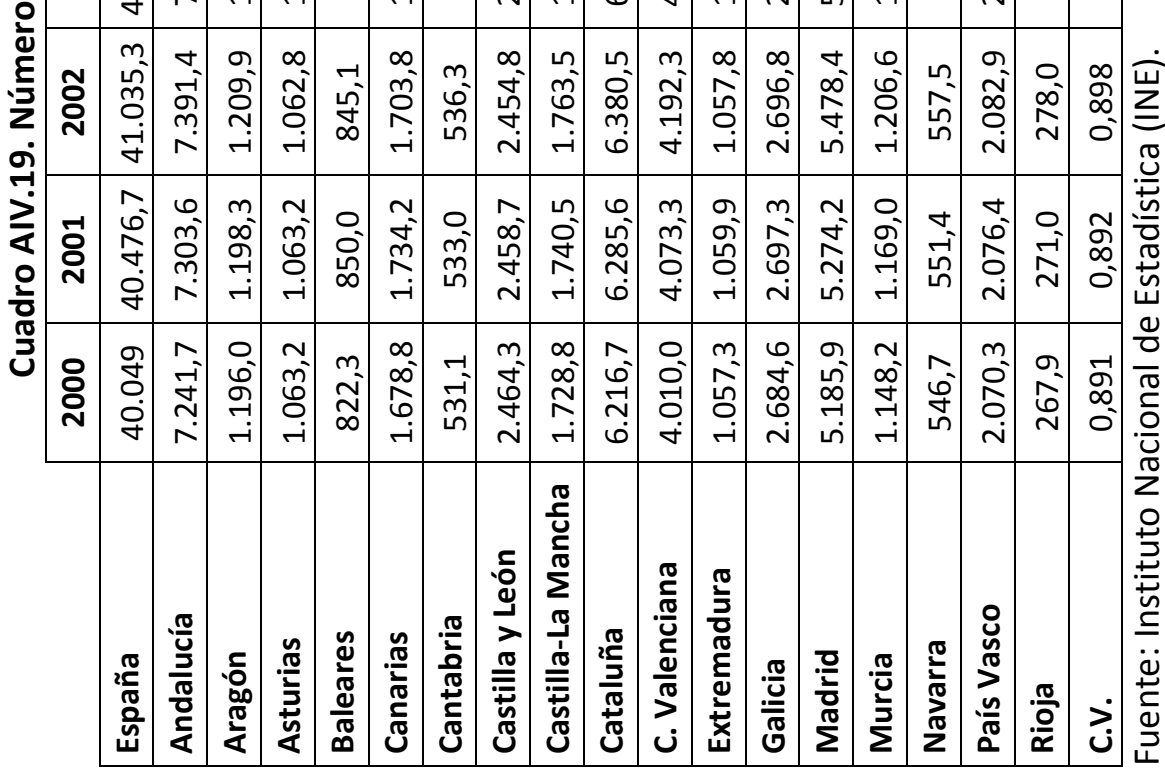




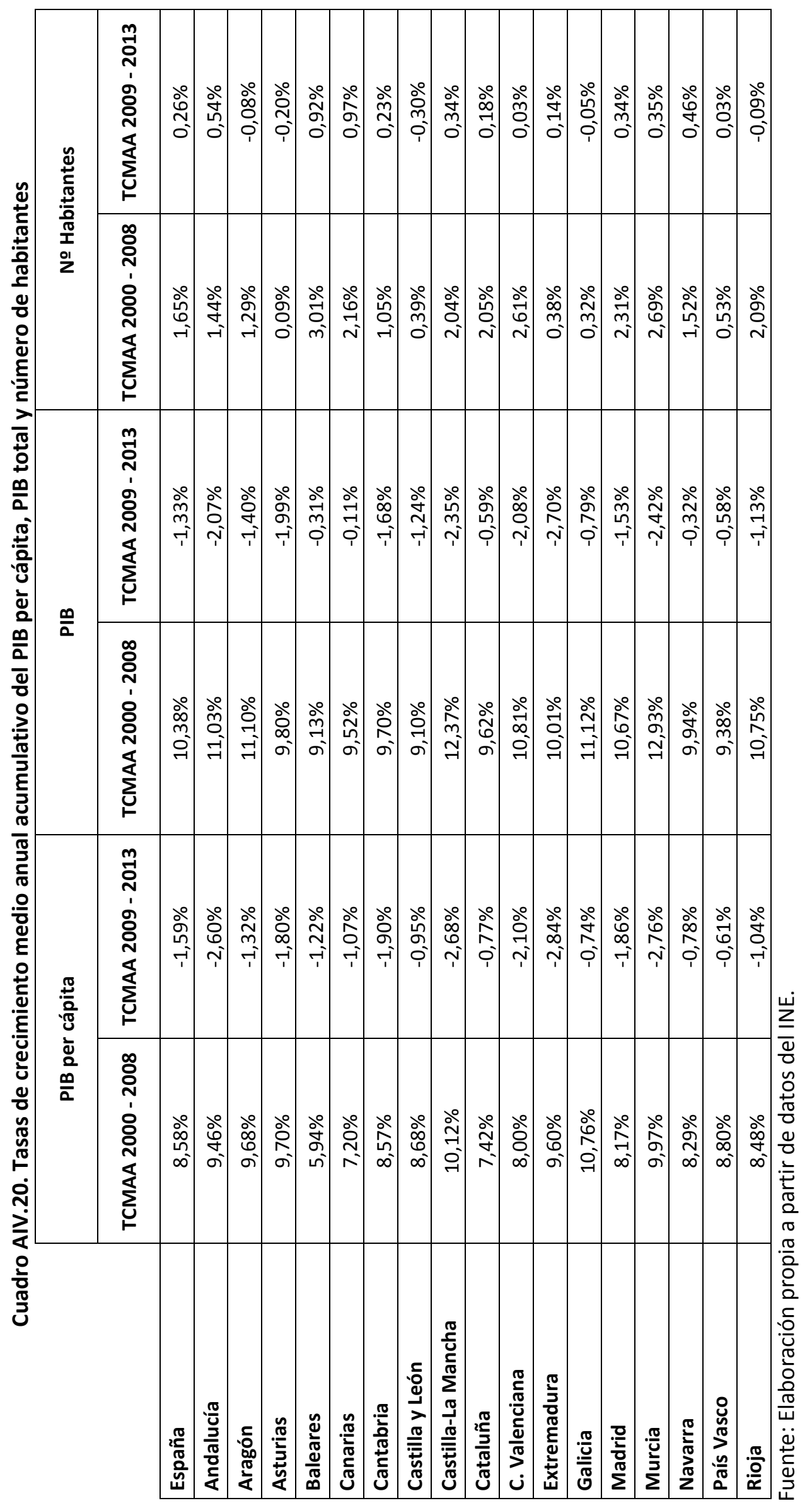




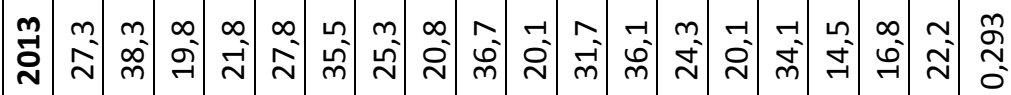

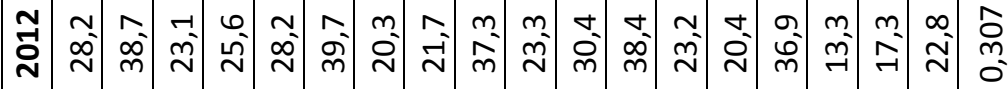

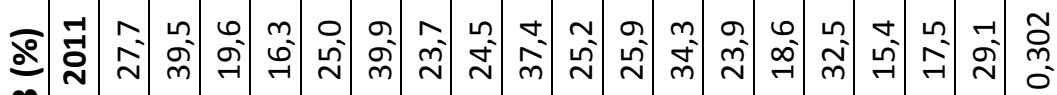

旁

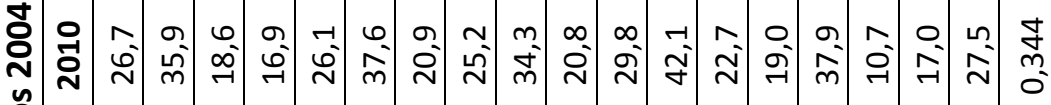
额

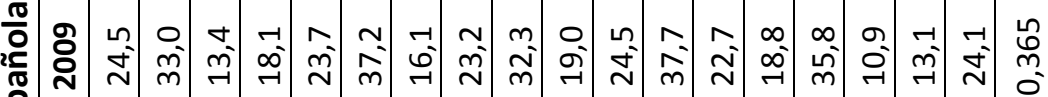

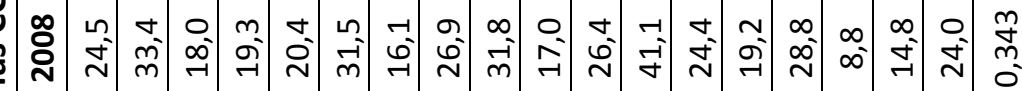

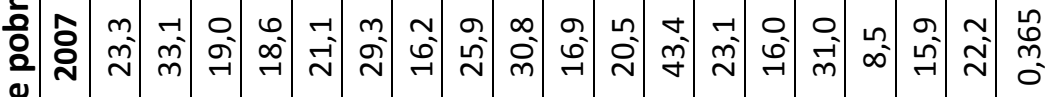

$\div$

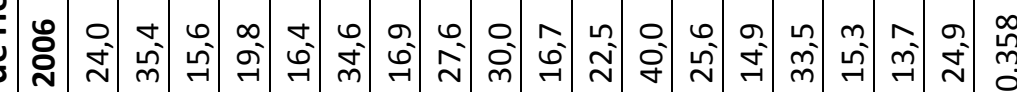

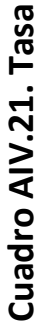

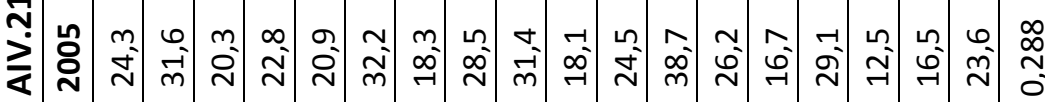

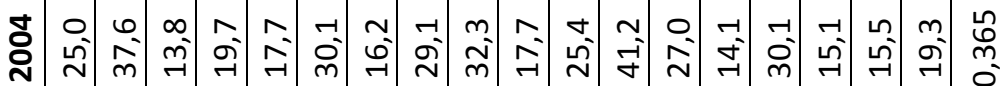

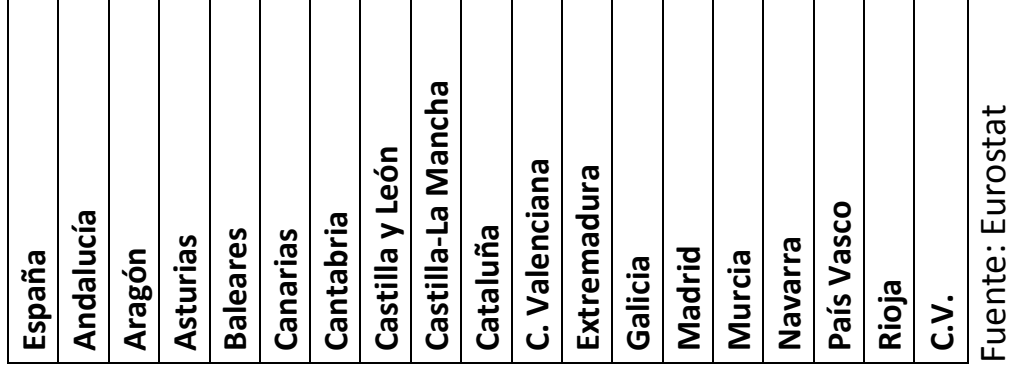




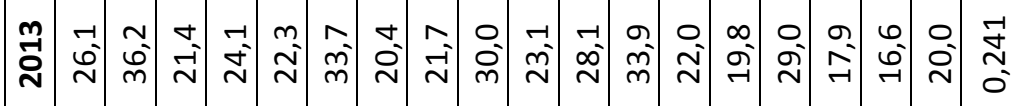

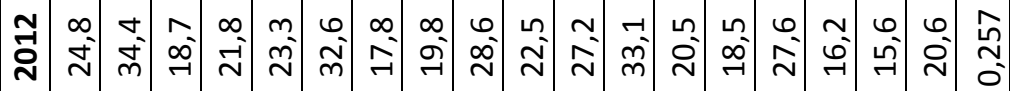

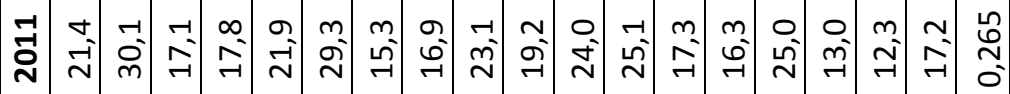

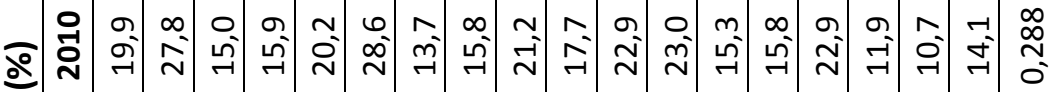

空

$\dot{\sim}$
$\delta$

产

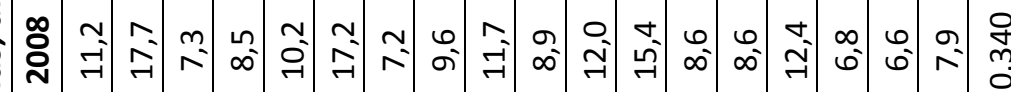

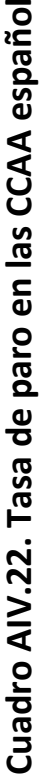

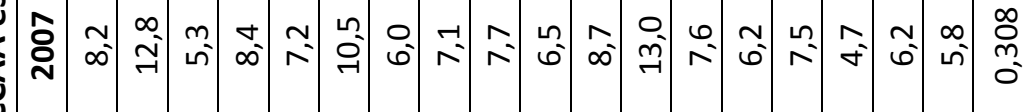

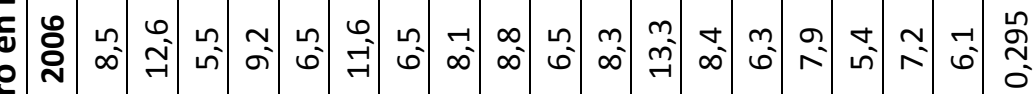

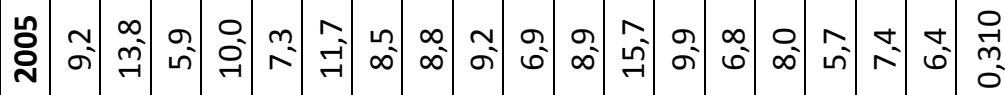

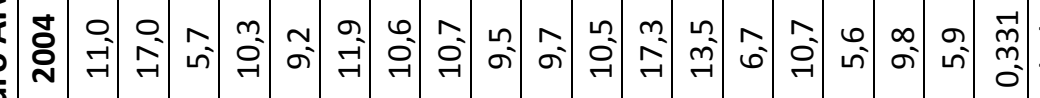

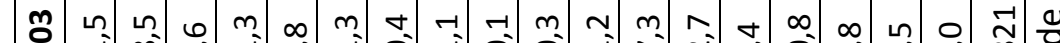

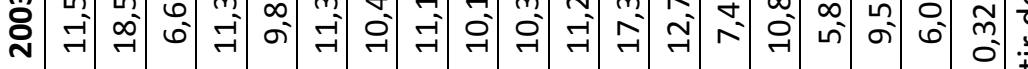

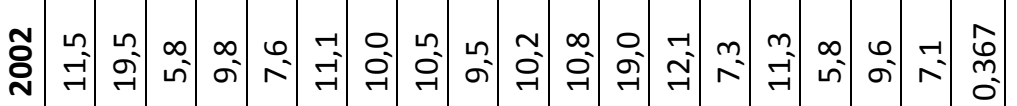

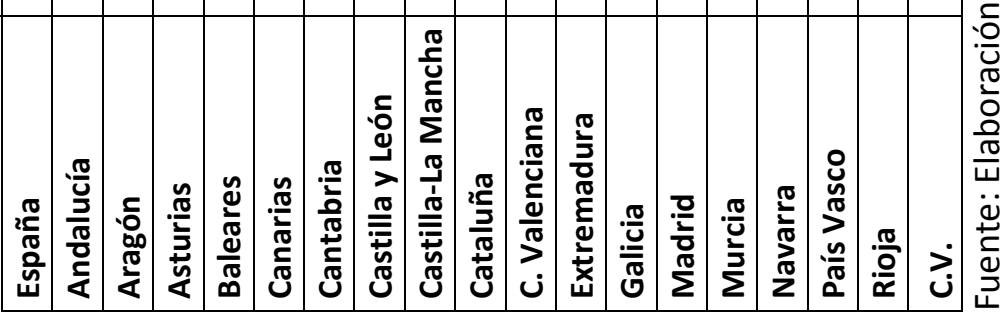




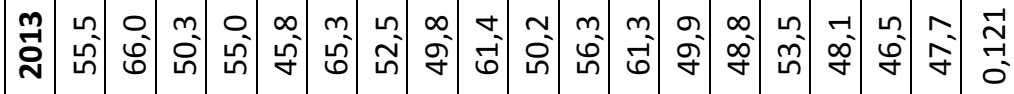

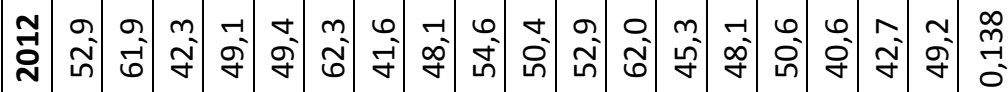

ฮำ

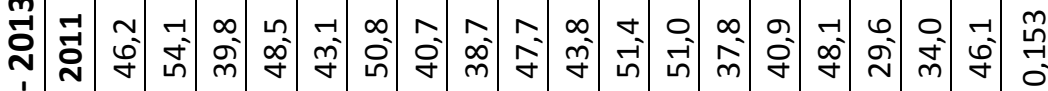

ช్

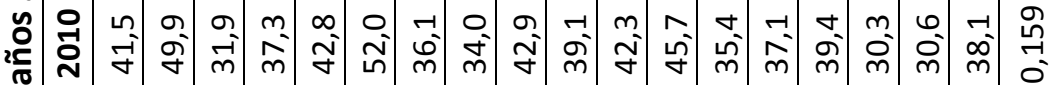

$\frac{5}{0}$

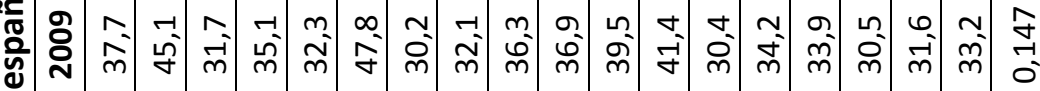

过

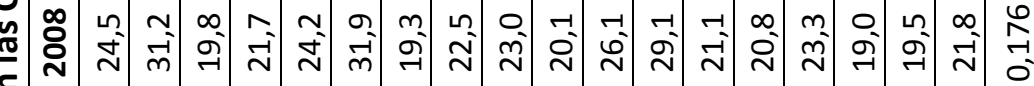

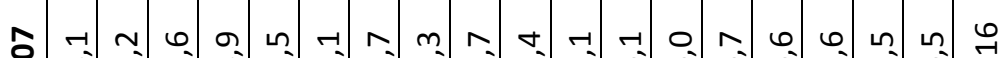

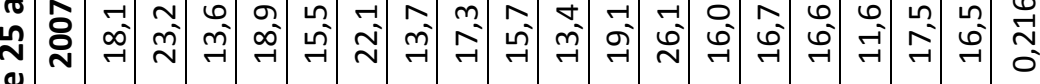

잉

है

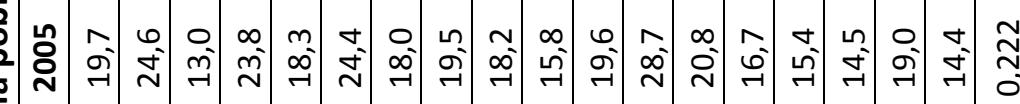

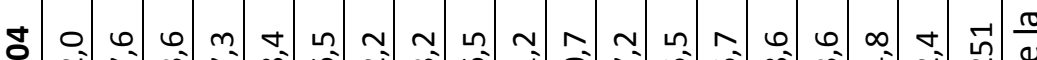

ठำ N

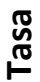
ᄁ̦

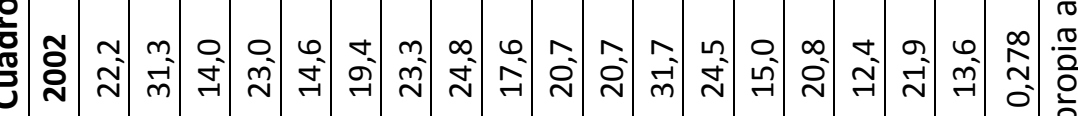

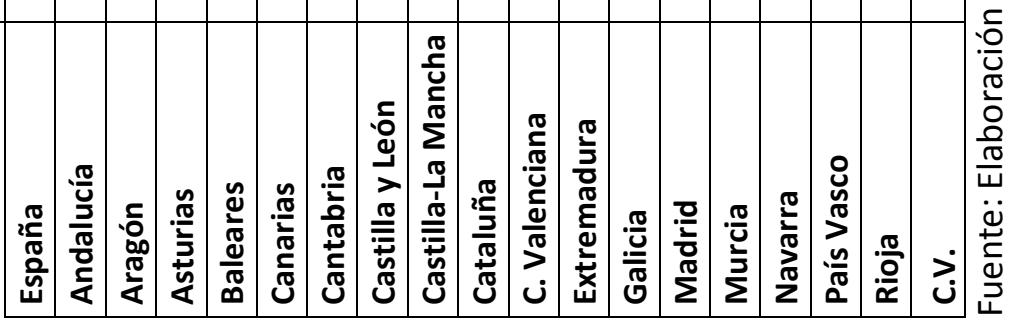




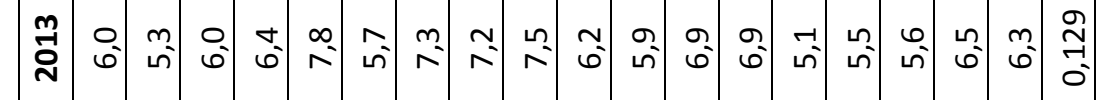

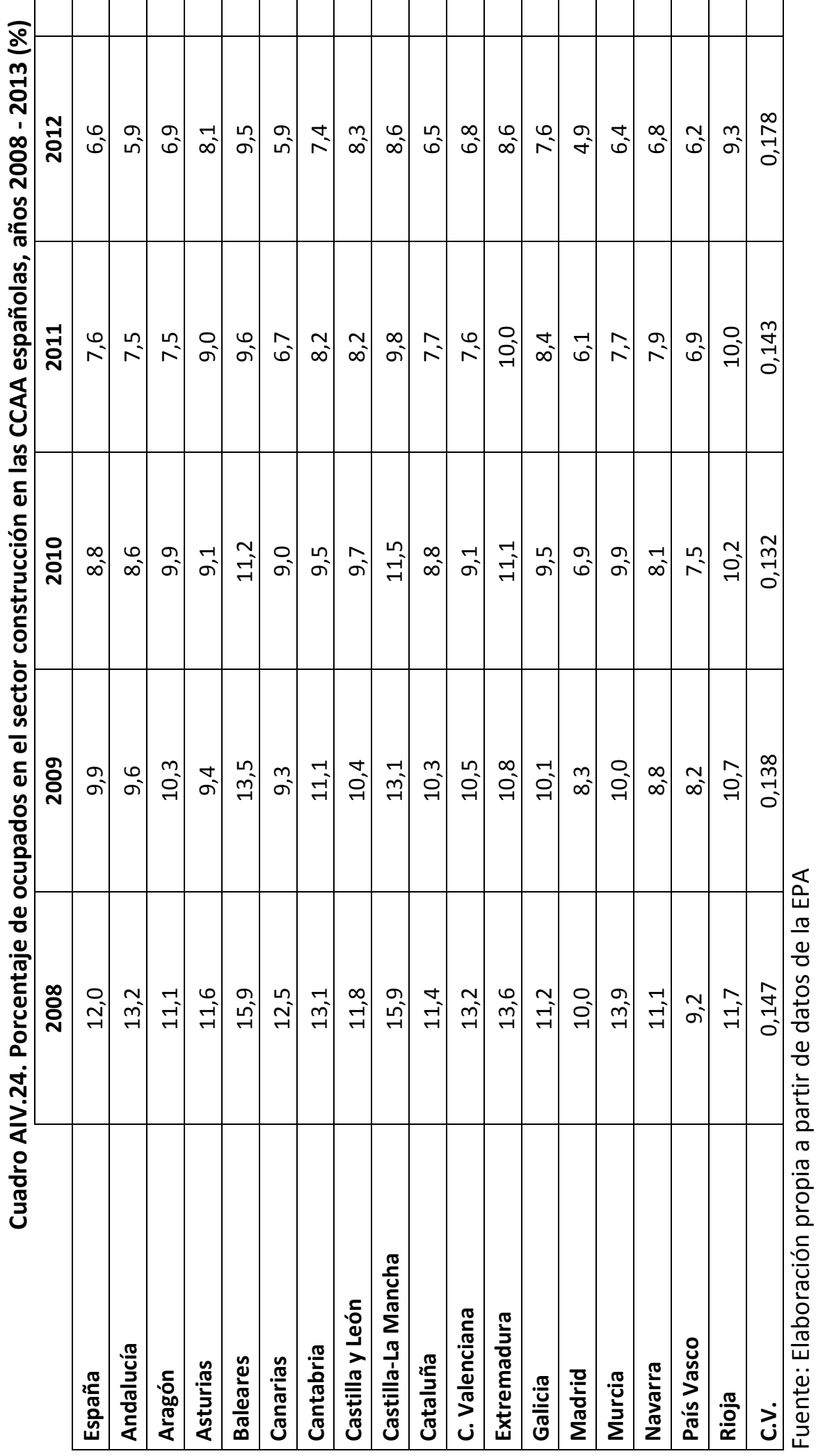




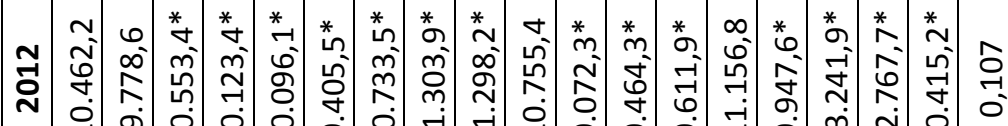

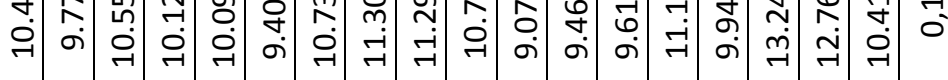

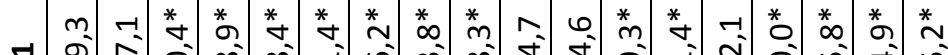

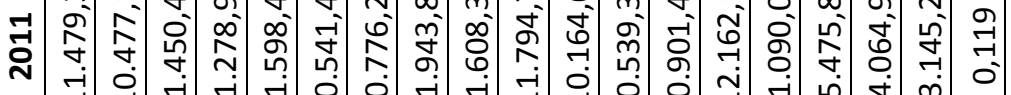

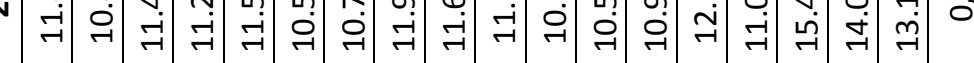

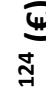

Ұ $0 m$ m

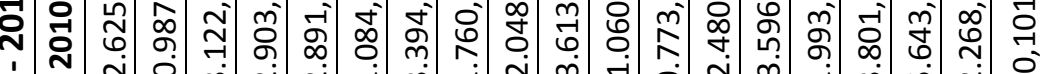

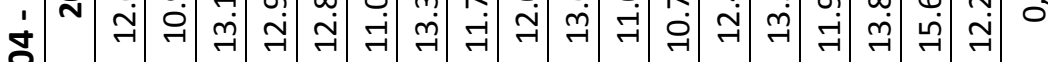

年

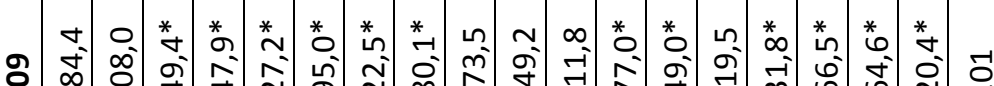
v.

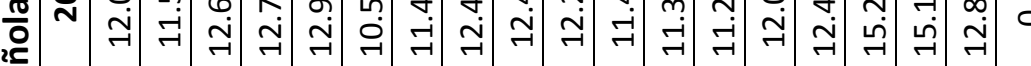
\%

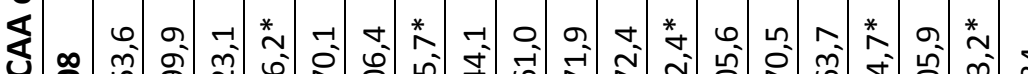
ठํ.

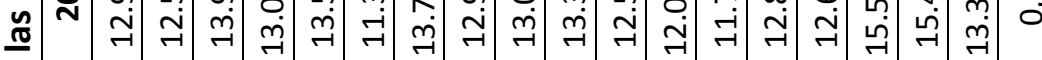
ฮ 参

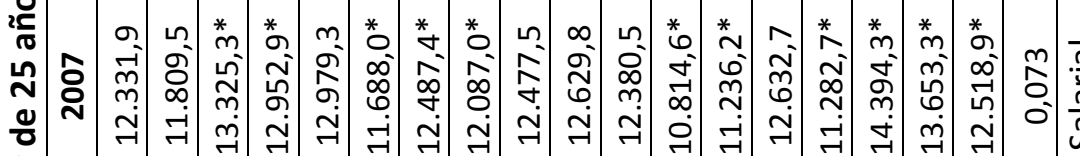

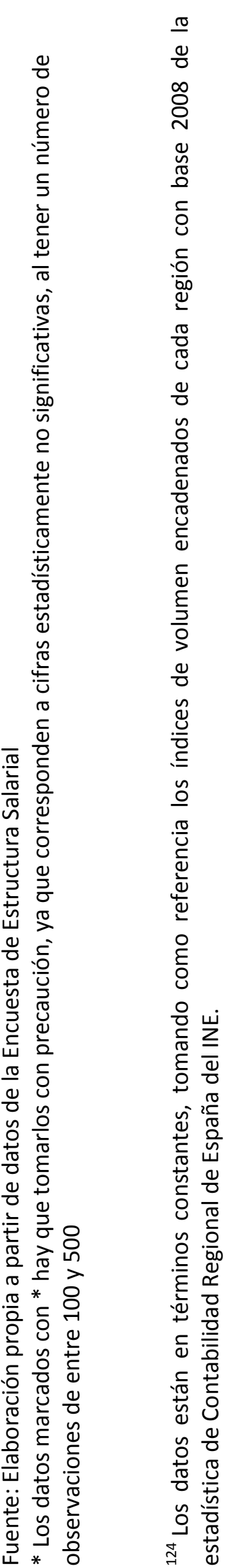

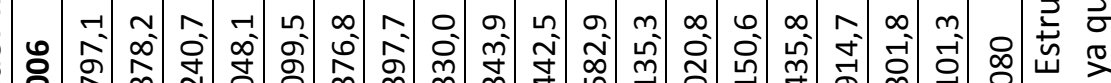

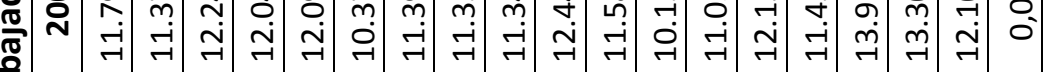

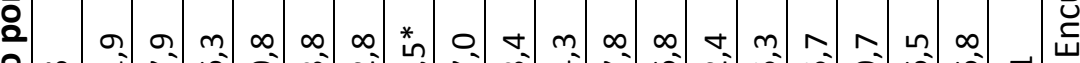

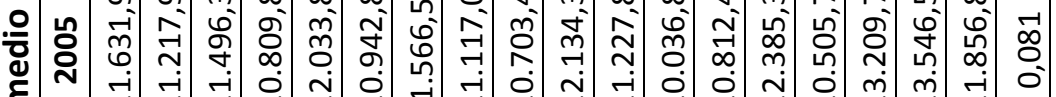

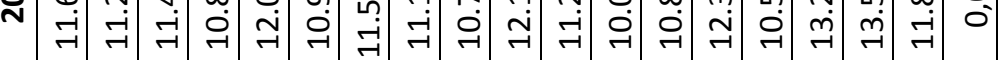

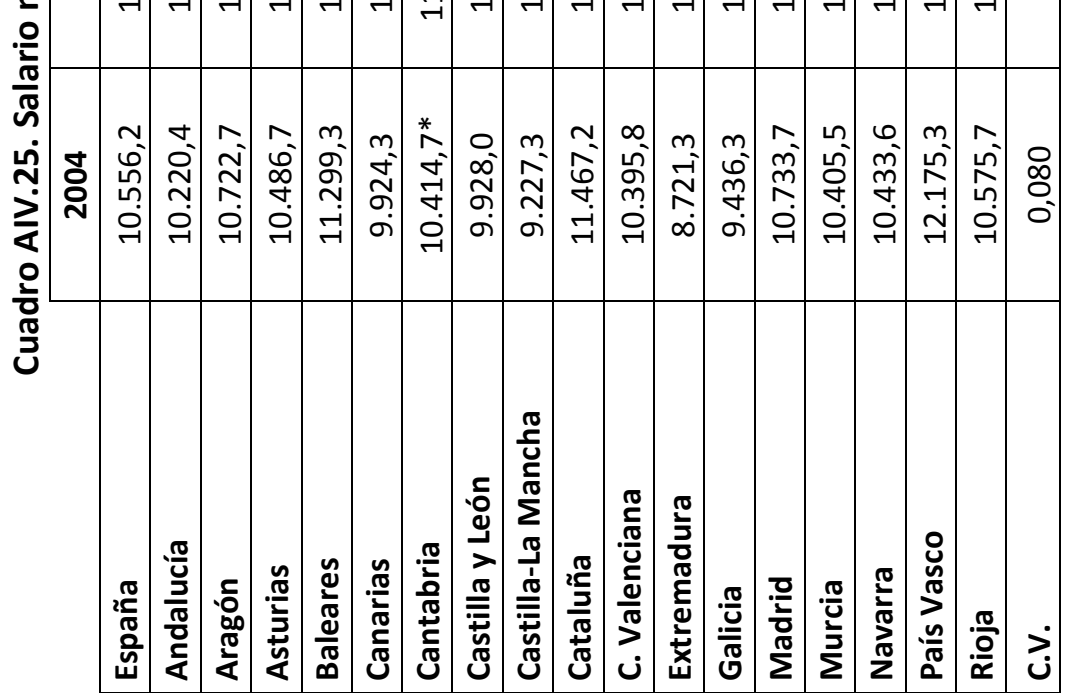

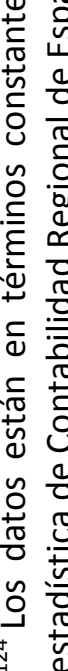




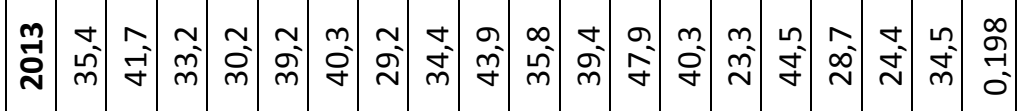

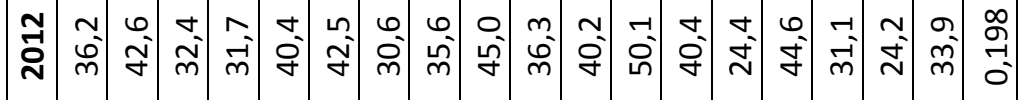

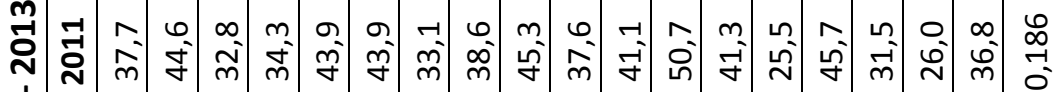

ธิ

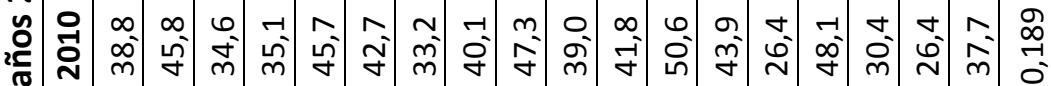

$\frac{5}{0}$

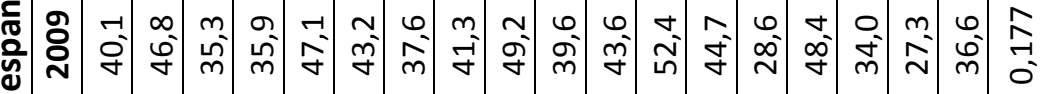

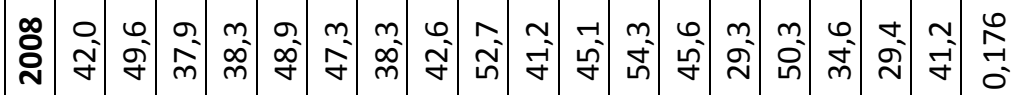
๘

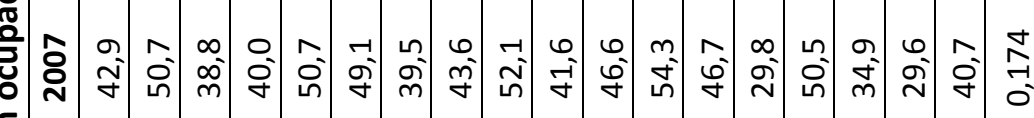

:든

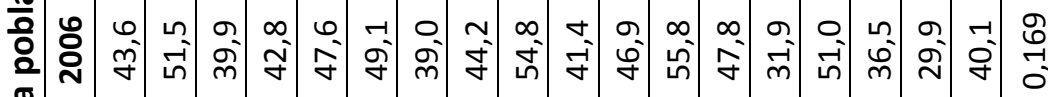

$\frac{\pi}{8}$

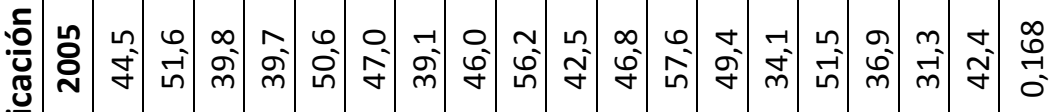

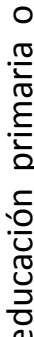

$\frac{1}{0}$

魚

ㅇํำ

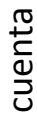

$\frac{\frac{\pi}{4}}{\frac{\pi}{0}}$

$\mathscr{y}$

$\frac{2}{\frac{\partial}{2}}$

$\frac{\pi}{\frac{\pi}{0}}$

동

$\frac{\pi}{\frac{\pi}{0}}$

$\frac{1}{0}$

ᄃำ

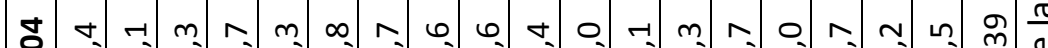

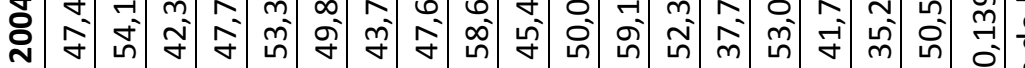

$\div$

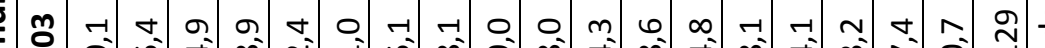

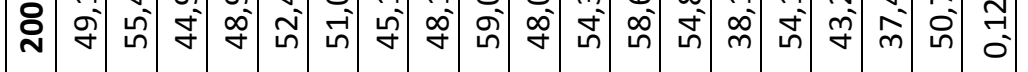

ڤั่

$\gtreqless$

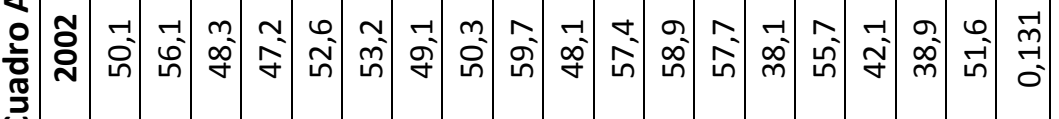

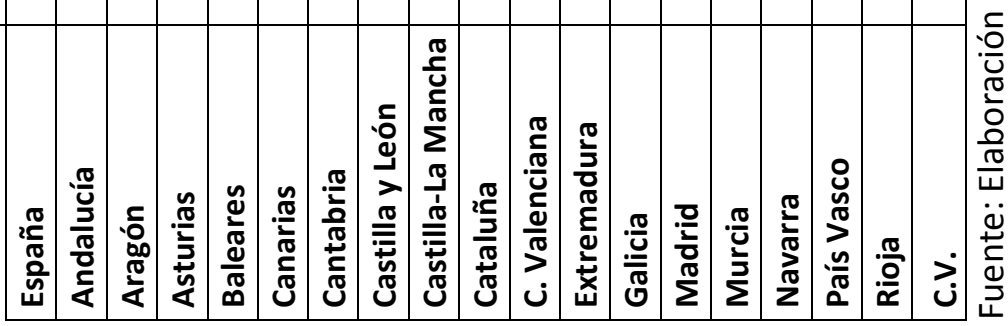




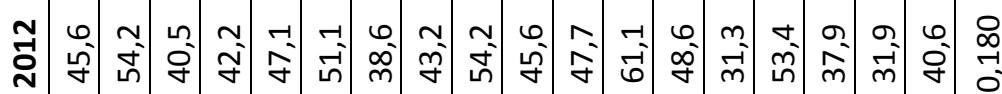

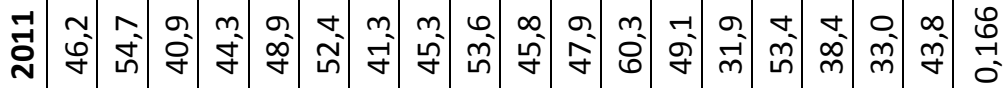

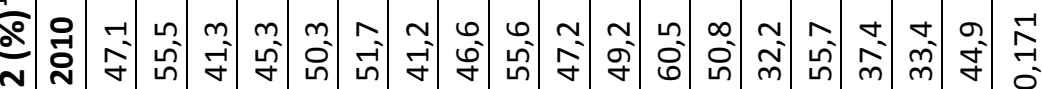
곤

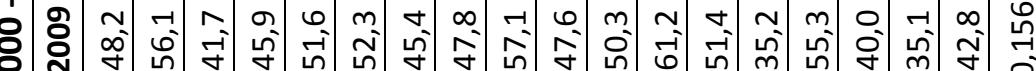
\%ิ้

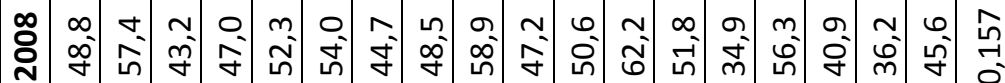
$\frac{5}{0}$

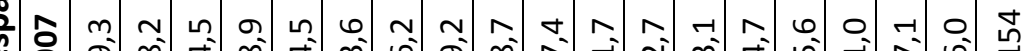

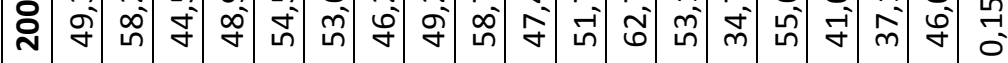

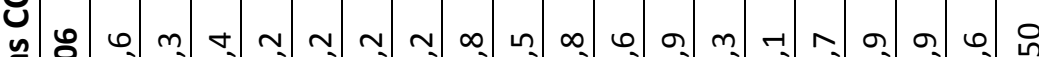
夏

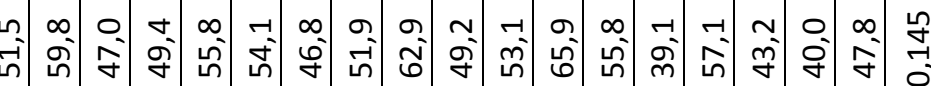

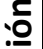

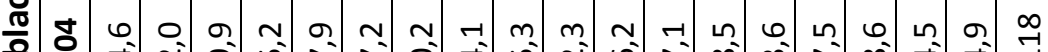

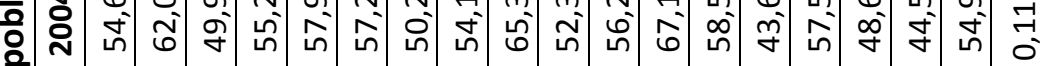
$\frac{\pi}{8}$

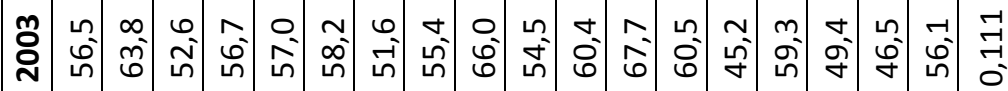

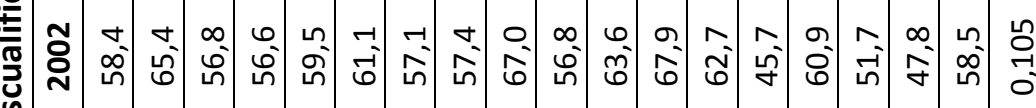

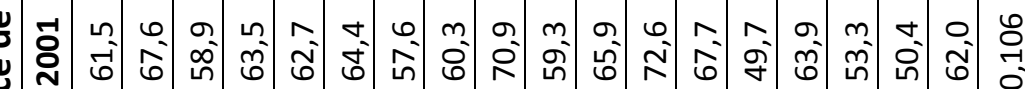

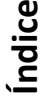

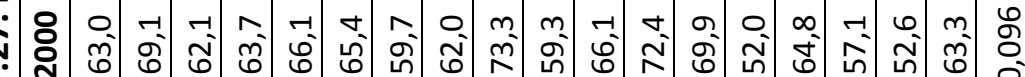
马

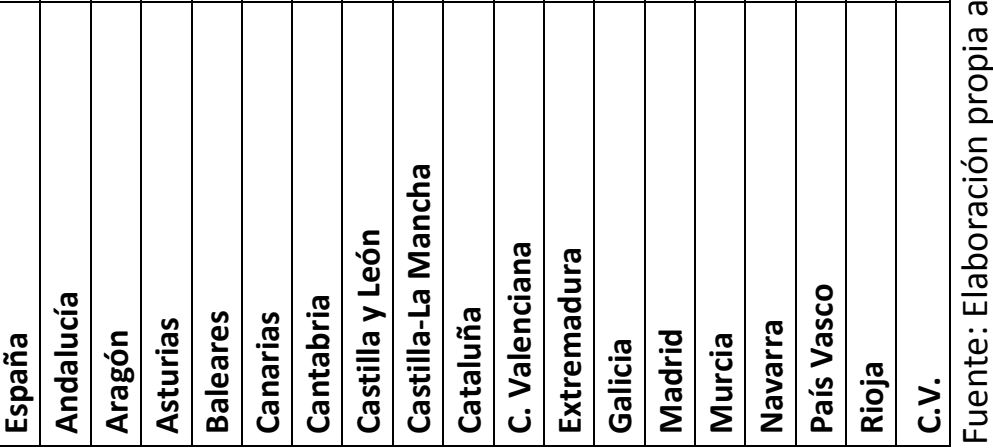




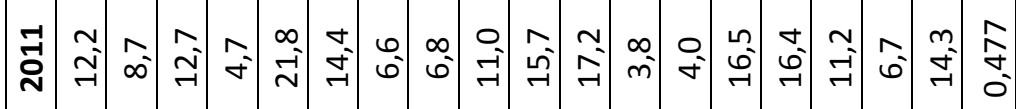

๖े

离

ठ்

?⿳亠口冋亍

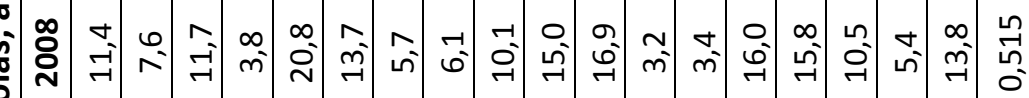

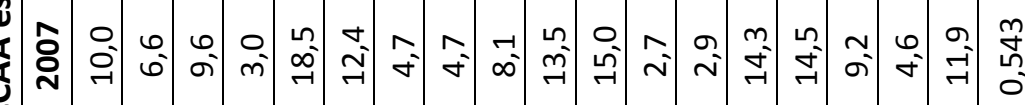

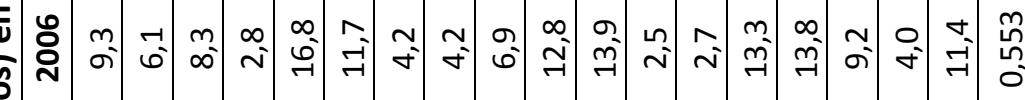

题

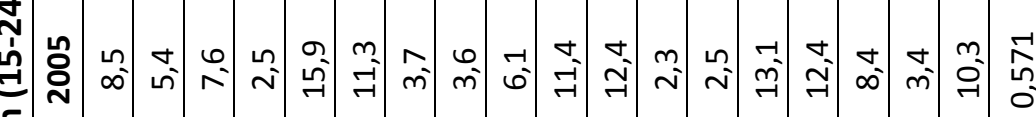

ఏ

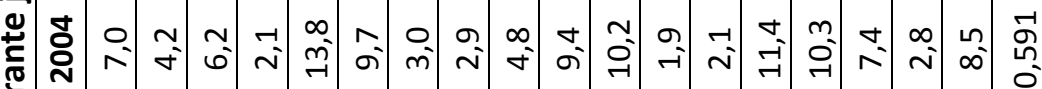

亮

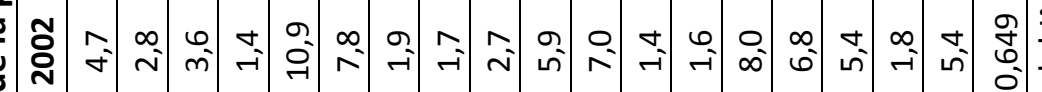

호

응

은

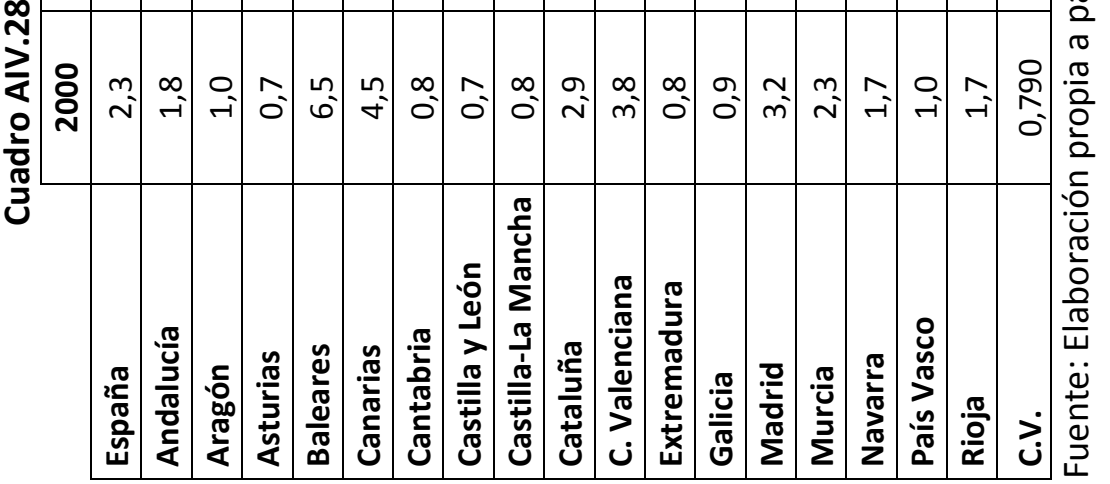




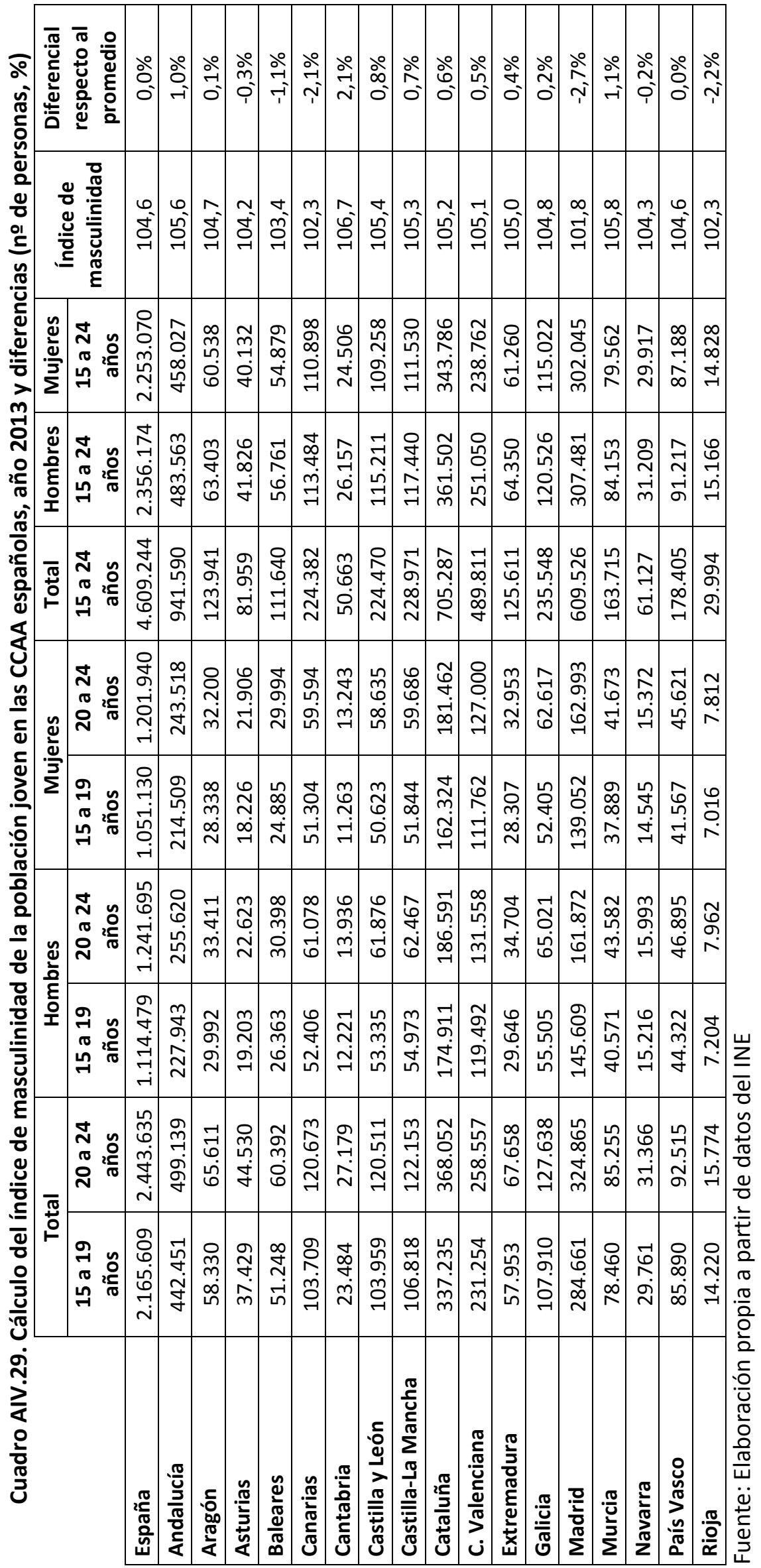




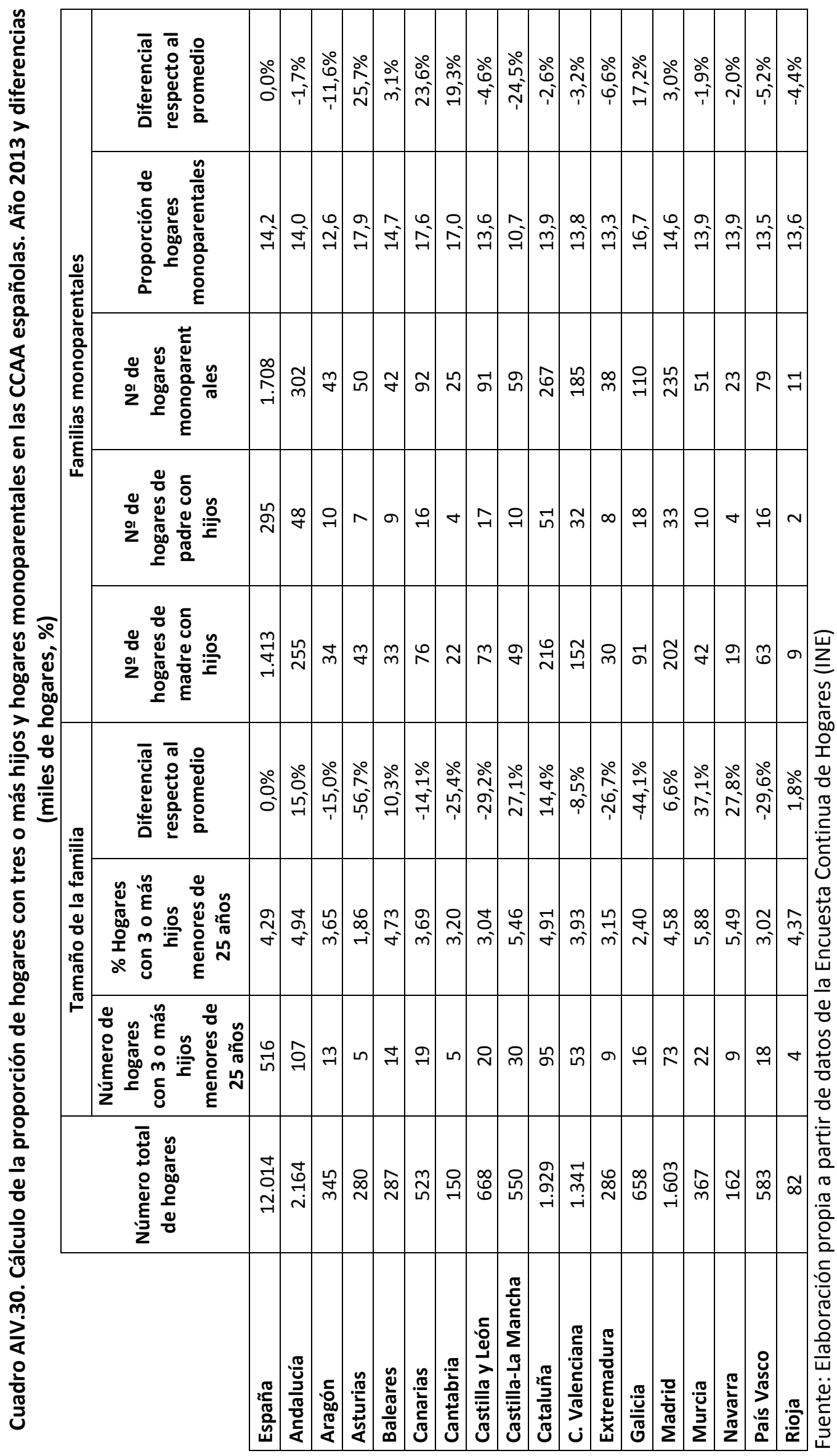




\section{ANEXO V: Resultados estadísticos adicionales}



Cuadro AV.1. Resultados de parámetros de variables explicativas en regresión simple con tasa de abandono escolar temprano realizadas en el Capítulo 5

\begin{tabular}{|c|c|c|c|c|c|c|}
\hline & \multicolumn{5}{|c|}{ Abandono escolar temprano } \\
\hline & & 2006 & 2008 & 2011 & 2012 & 2013 \\
\hline \multirow{3}{*}{$\begin{array}{l}\text { Gasto público por alumno en } \\
\text { educación no universitaria, 2010/11 }\end{array}$} & R2 & & & & & 0,337 \\
\hline & Coef. & & & & & $-0,005$ \\
\hline & P-valor & & & & & 0,009 \\
\hline \multirow{3}{*}{ Alumnos por grupo en ESO, 2010/11 } & $\mathbf{R 2}$ & & & & & 0,305 \\
\hline & Coef. & & & & & 1,551 \\
\hline & P-valor & & & & & 0,021 \\
\hline \multirow{3}{*}{$\begin{array}{l}\text { Gasto público en becas por alumno de } \\
\text { Educación Primaria, 2006/07 }\end{array}$} & $\mathbf{R 2}$ & & & & & 0,334 \\
\hline & Coef. & & & & & $-0,850$ \\
\hline & P-valor & & & & & 0,015 \\
\hline \multirow{3}{*}{$\begin{array}{l}\text { Gasto público en becas por alumno de } \\
\text { Educación Secundaria Obligatoria, } \\
2010 / 11\end{array}$} & R2 & & & & & 0,236 \\
\hline & Coef. & & & & & $-0,074$ \\
\hline & P-valor & & & & & 0,048 \\
\hline \multirow{3}{*}{$\begin{array}{l}\text { Gasto público en becas por alumno de } \\
\text { Bachillerato y Ciclos Formativos de } \\
\text { Grado Medio, 2011/12 }\end{array}$} & R2 & & & & & 0,273 \\
\hline & Coef. & & & & & 0,017 \\
\hline & P-valor & & & & & 0,032 \\
\hline \multirow{3}{*}{ PIB per cápita, 2013} & R2 & & & 0,376 & & \\
\hline & Coef. & & & $-0,001$ & & \\
\hline & P-valor & & & 0,009 & & \\
\hline \multirow{3}{*}{ Tasa de riesgo de pobreza, 2013} & R2 & & & & & 0,598 \\
\hline & Coef. & & & & & 0,618 \\
\hline & P-valor & & & & & 0,000 \\
\hline \multirow{3}{*}{$\begin{array}{l}\text { Tasa de paro de la población menor de } \\
25 \text { años, } 2013\end{array}$} & $\mathbf{R 2}$ & & & & & 0,310 \\
\hline & Coef. & & & & & 0,540 \\
\hline & P-valor & & & & & 0,200 \\
\hline \multirow{3}{*}{$\begin{array}{l}\text { Tasa de paro de la población menor de } \\
25 \text { años, } 2006\end{array}$} & R2 & 0,380 & & & & \\
\hline & Coef. & 0,415 & & & & \\
\hline & P-valor & 0,454 & & & & \\
\hline \multirow{3}{*}{ Tasa de paro, 2011} & R2 & & & & & 0,752 \\
\hline & Coef. & & & & & 1,025 \\
\hline & P-valor & & & & & 0,000 \\
\hline \multirow{3}{*}{ Tasa de paro, 2004} & R2 & 0,226 & & & & \\
\hline & Coef. & 1,095 & & & & \\
\hline & P-valor & 0,054 & & & & \\
\hline \multirow{3}{*}{$\begin{array}{l}\text { Porcentaje de ocupados en el sector de } \\
\text { la construcción, } 2008\end{array}$} & R2 & & 0,576 & & & \\
\hline & Coef. & & 3,486 & & & \\
\hline & P-valor & & 0,000 & & & \\
\hline \multirow{3}{*}{$\begin{array}{l}\text { Salario medio anual por trabajador } \\
\text { menor de } 25 \text { años }\end{array}$} & R2 & & 0,246 & & & \\
\hline & Coef. & & $-0,004$ & & & \\
\hline & P-valor & & 0,043 & & & \\
\hline
\end{tabular}

Fuente: Elaboración propia 
Cuadro AV.1. (continuación) Resultados de parámetros de variables explicativas en regresión simple con tasa de abandono escolar temprano realizadas en el Capítulo 5

\begin{tabular}{|c|c|c|c|c|c|c|}
\hline & & \multicolumn{5}{|c|}{ Abandono escolar temprano } \\
\hline & & 2006 & 2008 & 2011 & 2012 & 2013 \\
\hline \multirow{3}{*}{$\begin{array}{l}\text { Índice de descualificación de la } \\
\text { población ocupada, } 2006\end{array}$} & $\mathbf{R 2}$ & 0,694 & & & & \\
\hline & Coef. & 0,877 & & & & \\
\hline & P-valor & 0,000 & & & & \\
\hline \multirow{3}{*}{$\begin{array}{l}\text { Índice de descualificación de la } \\
\text { población ocupada, } 2013\end{array}$} & R2 & & & & & 0,667 \\
\hline & Coef. & & & & & 0,721 \\
\hline & P-valor & & & & & 0,000 \\
\hline \multirow{3}{*}{$\begin{array}{l}\text { Índice de descualificación de la } \\
\text { población adulta, } 2012\end{array}$} & $\mathbf{R 2}$ & & & & 0,683 & \\
\hline & Coef. & & & & 0,611 & \\
\hline & P-valor & & & & 0,000 & \\
\hline \multirow{3}{*}{$\begin{array}{l}\text { Proporción de la población inmigrante } \\
\text { joven, } 2011\end{array}$} & R2 & & & 0,098 & & \\
\hline & Coef. & & & 0,373 & & \\
\hline & P-valor & & & 0,221 & & \\
\hline \multirow{3}{*}{$\begin{array}{l}\text { Índice de masculinidad de la población } \\
\text { joven, } 2013\end{array}$} & R2 & & & & & 0,021 \\
\hline & Coef. & & & & & $-0,674$ \\
\hline & P-valor & & & & & 0,582 \\
\hline \multirow{3}{*}{$\begin{array}{l}\text { Proporción de hogares con } 3 \text { o más } \\
\text { hijos, } 2013\end{array}$} & $\mathbf{R 2}$ & & & & & 0,133 \\
\hline & Coef. & & & & & 199,177 \\
\hline & P-valor & & & & & 0,149 \\
\hline \multirow{3}{*}{$\begin{array}{l}\text { Proporción de hogares } \\
\text { monoparentales, } 2013\end{array}$} & R2 & & & & & 0,017 \\
\hline & Coef. & & & & & $-0,439$ \\
\hline & P-valor & & & & & 0,617 \\
\hline \multirow{3}{*}{$\begin{array}{l}\text { \% de alumnado de ESO en enseñanza } \\
\text { privada concertada, } 2010 / 11\end{array}$} & R2 & & & & & 0,584 \\
\hline & Coef. & & & & & $-0,557$ \\
\hline & P-valor & & & & & 0,000 \\
\hline \multirow{3}{*}{$\begin{array}{l}\text { \% de alumnado de ESO en enseñanza } \\
\text { privada no concertada, } 2010 / 11\end{array}$} & R2 & & & & & 0,039 \\
\hline & Coef. & & & & & 0,465 \\
\hline & P-valor & & & & & 0,448 \\
\hline \multirow{3}{*}{$\begin{array}{l}\text { \% gasto público de educación no } \\
\text { universitaria en conciertos y } \\
\text { subvenciones a la enseñanza privada, } \\
2011\end{array}$} & R2 & & & & & 0,325 \\
\hline & Coef. & & & & & $-0,609$ \\
\hline & P-valor & & & & & 0,017 \\
\hline
\end{tabular}

Fuente: Elaboración propia 


\section{Cuadro AV.2. Resultados de la estimación de panel de datos agrupadas por MCO}

\begin{tabular}{|c|c|c|c|c|c|c|}
\hline Source & SS & \multicolumn{2}{|r|}{ MS } & & \multicolumn{2}{|c|}{ Number of obs $=187$} \\
\hline & - & & - - - - - - - & & $F(8,178)$ & $=108,58$ \\
\hline Model & 8973,34049 & 8 & 1121,66756 & & Prob $>F$ & $\odot, 0 \odot \odot \odot$ \\
\hline Residua & 1838,8539 & 178 & 10,3306402 & & R-squared & $=0,8299$ \\
\hline & 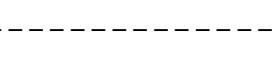 & $\cdots$ & - - - - - - - & & Adj R-squared & $=0,8223$ \\
\hline Total & 10812,1944 & 186 & 58,1300776 & & Root MSE & 3,2141 \\
\hline AET & Coef. & Std. Err. & $\mathrm{t}$ & $P>|t|$ & [95\% Conf. & Interval] \\
\hline GPA &,- 002204 &, 0005952 & $-3,70$ & $\odot, \odot \odot \odot$ &,$- 0 \odot 33786$ & - , 0010295 \\
\hline PG &,- 1568159 & 2659145 & $-0,59$ & $\odot, 556$ &,- 6815665 & 3679347 \\
\hline PIB &, 0004504 & , 0001389 & 3,24 & $\odot, \odot \odot 1$ & , $\odot \odot \odot 1762$ &, $00 \odot 7245$ \\
\hline Tparo &,- 0463459 &, 0681274 & $-\odot, 68$ & $\odot, 497$ & -1807872 &, 0880954 \\
\hline IDESPA & 8743033 & 0713383 & 12,26 & $\odot, 0 \odot \odot$ & 7335256 & 1,015081 \\
\hline PPIJ & 8232235 & 0732573 & 11,24 & $\odot, \odot \odot \odot$ & 678659 & 967788 \\
\hline PACC & 2035537 & 0982171 & 2,07 & $\odot, 04 \odot$ & , 0097339 &, 3973735 \\
\hline GPC & -, 4987082 & 1478648 & $-3,37$ & $\odot, 0 \odot 1$ &,- 7905017 & -2069147 \\
\hline cons & $-16,96466$ & 9,681798 & $-1,75$ & 0,081 & $-36,07054$ & 2,141213 \\
\hline
\end{tabular}

Fuente: Elaboración propia. Salida de resultados de STATA 


\section{Cuadro AV.3. Resultados de la estimación de panel de datos con efectos fijos}

Fixed-effects (within) regression

Group variable: comunidad

R-sq: within $=0,4603$

between $=0,4552$

overall $=0,4132$

$\operatorname{corr}\left(u \_i, x b\right)=0,3543$

\author{
Number of obs $=187$ \\ Number of groups $=17$ \\ Obs per group: $\min =11$ \\ $\operatorname{avg}=11,0$ \\ $\max =11$
}

\begin{tabular}{|c|c|c|c|c|c|c|}
\hline AET & Coef. & Std. Err. & $\mathrm{t}$ & $P>|t|$ & [95\% Conf & Interval] \\
\hline & & & & & & \\
\hline GPA &,- 0027337 & , 0005854 & $-4,67$ & $\odot, 0 \odot \odot$ & - , 0038898 & - , 0015777 \\
\hline APG & - , 0843166 & 2606697 & $-\odot, 32$ & $\odot, 747$ &,- 5990652 &, 430432 \\
\hline PIB &, 0002027 &, 0001218 & 1,66 & $\odot, 098$ &,- 0000378 &, 0004432 \\
\hline Tparo & -, 2918252 &, 060893 & $-4,79$ & $\odot, \odot \odot \odot$ & - , 4120716 & - , 1715788 \\
\hline IDESPA & 2533419 & 106687 & 2,37 & $\odot, 019$ & , $\odot 426655$ & 4640184 \\
\hline PPIJ & 2849341 & 1174383 & 2,43 & 0,016 & 0530268 & 5168414 \\
\hline PACC &, 3520596 & 1104705 & 3,19 & $\odot, \odot \odot 2$ & 1339118 &, 5702075 \\
\hline GPC & -, 5366859 & 1552265 & $-3,46$ & $\odot, \odot \odot 1$ & - , 8432142 &,- 2301576 \\
\hline _cons & 23,59548 & 12,61206 & 1,87 & $\odot, 063$ & $-1,309753$ & 48,50072 \\
\hline sigma_u & & & & & & \\
\hline sigma_e & 1,943 & & & & & \\
\hline & & & of & iance & e to $\left.u \_i\right)$ & \\
\hline
\end{tabular}

Fuente: Elaboración propia. Salida de resultados de STATA 


\section{Cuadro AV.4. Resultados de la estimación de panel de datos con efectos aleatorios}

Random-effects GLS regression

Group variable: comunidad

R-sq: within $=0,3972$

between $=0,8398$

overall $=0,7831$

$\operatorname{corr}\left(u_{-} i, x\right)=0$ (assumed)
Number of obs $=187$

Number of groups $=17$

Obs per group: $\min =11$

$\operatorname{avg}=11,0$

$\max =11$

Wald $\operatorname{chi2}(8)=232,65$

Prob $>$ chi2 $=0,000 \odot$

\begin{tabular}{|c|c|c|c|c|c|c|}
\hline AET & Coef. & Std. Err. & Z & $P>|z|$ & {$[95 \%$ Conf } & Interval] \\
\hline & $\ldots$ & - - & - & -- & - - - & ------- \\
\hline GPA & - , 0030177 &, 0005585 & $-5,40$ & $\odot, 00 \odot$ &,- 0041124 & - ,, 01923 \\
\hline APG & - , 4894878 & , 2581074 & $-1,90$ & 0,058 & - , 995369 & , 0163935 \\
\hline PIB & , 0002831 & , 0001268 & 2,23 & 0,026 &, 0000345 & , 0005316 \\
\hline Tparo & - , 2825578 &, 0629724 & $-4,49$ & $0,0 \odot \odot$ & - , 4059815 & - , 1591341 \\
\hline IDESPA &, 5678027 & , 094034 & 6,04 & $\odot, \odot \odot \odot$ & , 3834995 & , 7521059 \\
\hline PPIJ &, 6618456 &, 09445 & 7,01 & 0,000 &, 4767269 & , 8469643 \\
\hline PACC & , 1678341 & , 0980668 & 1,71 & $\odot, \odot 87$ &,- 0243733 &, 3600414 \\
\hline GPC &,- 6066326 &, 1475325 & $-4,11$ & 0,000 & - , 8957909 &,- 3174742 \\
\hline _cons & 20,57278 & 11,04186 & 1,86 & 0,062 & $-1,068879$ & 42,21444 \\
\hline---- & -------- & ------ & 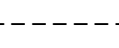 & $-\ldots$ & 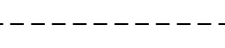 & ---- \\
\hline sigma & 1,83 & 89 & & & & \\
\hline igma & 1,94 & 34 & & & & \\
\hline &, 471 & 89 & $n$ of & rianc & e to u_i) & \\
\hline
\end{tabular}

Fuente: Elaboración propia. Salida de resultados de STATA 
Cuadro AV.5. Resultados de la estimación de panel de datos de efectos fijos con efectos temporales

Fixed-effects (within) regression

Group variable: comunidad

$\begin{aligned} \text { R-sq: } & \text { within }=0,5410 \\ \text { between } & =0,0025 \\ \text { overall } & =0,0029\end{aligned}$

$\operatorname{corr}\left(u \_i, \quad x b\right)=-\odot, 4767$

\author{
Number of obs $=187$ \\ Number of groups $=17$ \\ Obs per group: $\min =11$ \\ $\operatorname{avg}=11,0$ \\ $\max =11$
$F(18,152)=9,95$
Prob $>\mathrm{F}=0,000$

\begin{tabular}{|c|c|c|c|c|c|c|}
\hline AET & Coef. & Std. Err. & $\mathrm{t}$ & $P>|t|$ & [95\% Conf. & Interval] \\
\hline GPA &,- 0028474 &, 0010254 & $-2,78$ & $\odot, 0 \odot 6$ & - , $\odot \odot 48732$ & - ,, 0008216 \\
\hline APG & - , 0779264 & 2514526 & $-\odot, 31$ & $\odot, 757$ & - , 5747197 & 4188669 \\
\hline PIB &, 0008943 &, $0 \odot \odot 2233$ & $4, \odot \odot$ & $\odot, \odot \odot \odot$ & , $\odot \odot \odot 4531$ & , 0013355 \\
\hline Tparo & -, 2267378 & 0965941 & $-2,35$ & $\odot, 020$ & -, 4175781 & -, 0358975 \\
\hline IDESPA & , 2581696 & , 1253053 & 2,06 & 0,041 &, $0106 \odot 48$ & 5057345 \\
\hline PPIJ & , $36 \odot 2 \odot \odot 8$ & 1540014 & 2,34 & $\odot, 021$ & , 0559412 &, 6644604 \\
\hline PACC & , 4712845 & , 1416701 & 3,33 & $\odot, 001$ & 1913878 &, 7511812 \\
\hline GPC &,- 5720362 & , 1839996 & $-3,11$ & $\odot, 0 \odot 2$ &,- 935563 &,- 2085093 \\
\hline I2๑๑2 &,- 9645584 & 9998353 & $-\odot, 96$ & $\odot, 336$ & $-2,939927$ & 1,01081 \\
\hline I2003 & $-1,386997$ & 1,468364 & $-\odot, 94$ & $\odot, 346$ & $-4,288035$ & 1,514041 \\
\hline I2004 & $-2,668017$ & 1,701897 & $-1,57$ & $\odot, 119$ & $-6,030446$ &, 6944108 \\
\hline I2005 & $-5,017245$ & 2,117844 & $-2,37$ & 0,019 & $-9,201457$ &,- 8330331 \\
\hline I2006 & $-6,675881$ & 2,465915 & $-2,71$ & $\odot, 0 \odot 8$ & $-11,54777$ & $-1,803988$ \\
\hline I2007 & $-7,442113$ & 2,889122 & $-2,58$ & 0,011 & $-13,15013$ & $-1,734092$ \\
\hline I2008 & $-7,208299$ & 3,235798 & $-2,23$ & 0,027 & $-13,60125$ &,- 8153526 \\
\hline I2009 & $-5,589881$ & 3,309386 & $-1,69$ & $\odot, 093$ & $-12,12822$ &, 948453 \\
\hline I2010 & $-5,85242$ & 3,450546 & $-1,70$ & $\odot, \odot 92$ & $-12,66964$ & 9648025 \\
\hline I2011 & $-6,372698$ & 3,304616 & $-1,93$ & 0,056 & $-12,90161$ & , 1562113 \\
\hline _cons & 10,20574 & 13,88232 & $\odot, 74$ & $\odot, 463$ & $-17,22148$ & 37,63297 \\
\hline \multicolumn{7}{|c|}{ sigma u 8,6854757} \\
\hline \multicolumn{7}{|c|}{ sigma e 1,8499841} \\
\hline &, 9566 & & of & an & to $\left.u \_i\right)$ & \\
\hline
\end{tabular}

Fuente: Elaboración propia. Salida de resultados de STATA 
Cuadro AV.6. Resultados de la estimación de panel de datos de efectos fijos con término autorregresivo de grado 1 y efectos temporales

FE(within)regression with $A R(1)$ disturbances Number of obs $=170$ Group variable: comunidad

Number of groups $=17$

$\begin{aligned} \text { R-sq: } & \text { within }=0,4981 \\ \text { between } & =0,1257 \\ \text { overall } & =0,1662\end{aligned}$

$\operatorname{corr}\left(u_{-} i, \quad x b\right)=-\odot, 1006$
Obs per group: $\min =10$ $\operatorname{avg}=10,0$

$\max =10$

\begin{tabular}{|c|c|c|c|c|c|c|}
\hline AET & Coef. & Std. Err. & $\mathrm{t}$ & $P>|t|$ & {$[95 \%$ Conf } & Interval] \\
\hline GPA &,- 003377 &, 001288 & $-2,62$ & 0,010 &,- 005924 & - , , 00083 \\
\hline APG & - , 1304912 & , 3036972 & $-0,43$ & 0,668 & - , 7310708 & 4700885 \\
\hline PIB &, 0007374 & , 0003094 & 2,38 & 0,019 &, 0001256 & , 0013492 \\
\hline Tparo & - , 1268212 & 1117901 & $-1,13$ & 0,259 & - , 3478928 & , 0942505 \\
\hline IDESPA & , 3743914 & 1467876 & 2,55 & 0,012 &, 08411 &, 6646728 \\
\hline PPIJ & , 3493878 & , 2957519 & 1,18 & 0,240 & - , 2354796 & ,9342553 \\
\hline PACC & , 4179158 & , 2356724 & 1,77 & 0,078 & - , 0481406 & , 8839723 \\
\hline GPC &,- 4867364 & , 2308247 & $-2,11$ & 0,037 &,- 9432063 &,- 0302665 \\
\hline I2002 & 1,801145 & 2,489559 & $\odot, 72$ & 0,471 & $-3,12211$ & 6,724399 \\
\hline I2003 & 2,898554 & 2,934809 & $\odot, 99$ & 0,325 & $-2,90521$ & 8,702317 \\
\hline I2004 & 2,199211 & 2,794819 & $\odot, 79$ & 0,433 & $-3,327713$ & 7,726134 \\
\hline I2005 & 5175376 & 2,202015 & 0,24 & 0,815 & $-3,837082$ & 4,872157 \\
\hline I2006 & - , 7042192 & 1,783023 & $-0,39$ & 0,693 & $-4,230256$ & 2,821818 \\
\hline I2007 & - , 7494332 & 1,53772 & $-0,49$ & 0,627 & $-3,790368$ & 2,291502 \\
\hline I2008 &,- 1261159 & 1,36617 & $-\odot, 09$ & $\odot, 927$ & $-2,8278$ & 2,575568 \\
\hline I2009 & 1,667257 & 1,177429 & 1,42 & 0,159 & - , 6611803 & 3,995695 \\
\hline I2010 & 1,210429 & , 877137 & 1,38 & 0,170 & - , 5241628 & 2,945021 \\
\hline I2011 & 0 & (omitted) & & & & \\
\hline _cons & 4,366409 & 13,67739 & 0,32 & $\odot, 750$ & $-22,68146$ & 31,41428 \\
\hline rho_ar & 323675 & & & & & \\
\hline sigma_u & 6,92937 & & & & & \\
\hline sigma_e & 1,79867 & & & & & \\
\hline 10_fov & 936875 & & of & & use of $u$ & \\
\hline
\end{tabular}

Fuente: Elaboración propia. Salida de resultados de STATA 
Cuadro AV.7. Resultados de la estimación de panel de datos de efectos fijos incorporando efectos temporales por mínimos cuadrados generalizados factibles

Cross-sectional time-series FGLS regression

Coefficients: generalized least squares

Panels:

heteroskedastic

Correlation: common AR(1) coefficient for all panels $(0,2189)$

Estimated covariances $=17$

Estimated autocorrelations $=1$

Estimated coefficients $=35$

\author{
Number of obs $=187$ \\ Number of groups $=17$ \\ Time periods $=11$ \\ Wald $\operatorname{chi2}(34)=3460,66$ \\ Prob $>$ chi2 $=0,0000$
}

\begin{tabular}{|c|c|c|c|c|c|c|}
\hline AET & Coef. & Std. Err & z & $P>|z|$ & [95\% Conf & Interval] \\
\hline GPA & - , , 0037245 & , 000861 & $-4,33$ & $\odot, 0 \odot \odot$ & - , , 005412 & - , , 002037 \\
\hline APG & - , 1599893 & , 2176807 & $-0,73$ & 0,462 & - , 5866356 &, 266657 \\
\hline PIB &, 0007911 & , 0001857 & 4,26 & $\odot, 0 \odot \odot$ &, 0004272 &, 001155 \\
\hline Tparo & - , 1796248 & , 0809414 & $-2,22$ & 0,026 & - , 3382669 & - , , 0209826 \\
\hline IDESPA & , 2763227 & , 1056697 & 2,61 & $\odot, 0 \odot 9$ & , 0692139 & , 4834315 \\
\hline PPIJ & , 102556 &, 1343 & 0,76 & $\odot, 445$ &,- 1606672 & , 3657792 \\
\hline PACC & , 2782769 & , 1282338 & 2,17 & 0,030 &, 0269432 &, 5296105 \\
\hline GPC & - , 6079586 & , 1474302 & $-4,12$ & $\odot, 0 \odot \odot$ & - , 8969165 & - , 3190007 \\
\hline RG & $-15,0343$ & 2,647646 & $-5,68$ & $\odot, 0 \odot \odot$ & $-20,22359$ & $-9,84501$ \\
\hline ST & $-13,04252$ & 1,882935 & $-6,93$ & $\odot, 0 \odot \odot$ & $-16,733$ & $-9,352033$ \\
\hline BAL & $-1,06342$ & 3,593566 & $-0,30$ & 0,767 & $-8,10668$ & 5,97984 \\
\hline CAN & $-6,382019$ & 1,706628 & $-3,74$ & $\odot, 0 \odot \odot$ & $-9,726949$ & $-3,037089$ \\
\hline CANT & $-10,55724$ & 2,379146 & $-4,44$ & $\odot, 0 \odot \odot$ & $-15,22028$ & $-5,894196$ \\
\hline CYL & $-11,5866$ & 2,046851 & $-5,66$ & $\odot, 0 \odot \odot$ & $-15,59836$ & $-7,574848$ \\
\hline CLM & $-1,0 \odot 4499$ & $1,277 \odot 24$ & $-\odot, 79$ & 0,432 & $-3,507421$ & 1,498423 \\
\hline CAT & $-9,929928$ & 3,393825 & $-2,93$ & $\odot, 003$ & $-16,5817$ & $-3,278152$ \\
\hline CVL & $-3,528667$ & 2,20629 & $-1,60$ & 0,110 & $-7,852916$ & , 7955812 \\
\hline EXT &,- 3872575 & 1,104462 & $-0,35$ & $\odot, 726$ & $-2,551963$ & 1,777448 \\
\hline GAL & $-10,59696$ & 1,31004 & $-8,09$ & $\odot, 0 \odot \odot$ & $-13,16459$ & $-8,029333$ \\
\hline MAD & $-16,79094$ & 3,319989 & $-5,06$ & $\odot, 0 \odot \odot$ & $-23,298$ & $-10,28388$ \\
\hline MUR & , 1618298 & 1,624427 & 0,10 & $\odot, 921$ & $-3,021989$ & 3,345649 \\
\hline NAV & $-17,88824$ & 4,042961 & $-4,42$ & $\odot, 0 \odot \odot$ & $-25,81229$ & $-9,964176$ \\
\hline PV & $-17,51659$ & $5,4 \odot 8035$ & $-3,24$ & 0,001 & $-28,11614$ & $-6,917032$ \\
\hline RIO & $-8,542283$ & 2,976122 & $-2,87$ & $\odot, 0 \odot 4$ & $-14,37537$ & $-2,709192$ \\
\hline $20 \odot 2$ &, 5777141 & , 7519548 & 0,77 & 0,442 & - , 8960903 & 2,051518 \\
\hline 2003 & , 8656219 & 1,22018 & 0,71 & 0,478 & $-1,525886$ & 3,25713 \\
\hline 2004 & - , 0395653 & 1,419003 & $-\odot, 03$ & 0,978 & $-2,820761$ & 2,74163 \\
\hline 2005 & $-1,430283$ & 1,774427 & $-0,81$ & 0,420 & $-4,908096$ & 2,047531 \\
\hline 2006 & $-2,506298$ & 2,085852 & $-1,20$ & 0,230 & $-6,594493$ & 1,581897 \\
\hline 2007 & $-3,230241$ & 2,474176 & $-1,31$ & 0,192 & $-8,079537$ & 1,619056 \\
\hline 2008 & $-2,408939$ & 2,780794 & $-\odot, 87$ & $\odot, 386$ & $-7,859195$ & 3,041316 \\
\hline 2009 &,- 4529413 & 2,85689 & $-0,16$ & $\odot, 874$ & $-6,052343$ & 5,146461 \\
\hline 2010 & - , 4769927 & 2,920681 & $-0,16$ & 0,870 & $-6,201423$ & 5,247437 \\
\hline 2011 & $-1,427798$ & 2,705522 & $-\odot, 53$ & $\odot, 598$ & $-6,730524$ & 3,874928 \\
\hline & 30,23261 & 11,33121 & 2,67 & $\odot, 0 \odot 8$ & 8,023855 & 52,44137 \\
\hline
\end{tabular}

Fuente: Elaboración propia. Salida de resultados de STATA 
Cuadro AV.8. Resultados de la estimación de panel de datos de efectos fijos incorporando efectos temporales por el método de estimadores con errores estándar corregidos para panel

Prais-Winsten regression, heteroskedastic panels corrected standard errors Group variable: comunidad

Time variable: year

Number of obs $=187$

Panels: heteroskedastic (balanced)

Number of groups $=17$

Autocorrelation: common AR(1)

Obs per group: $\min =11$

$\begin{aligned} \text { max } & =11 \\ \text { Estimated covariances }=17 & \text { R-squared }=0,9353 \\ \text { Estimated autocorrelations }=1 & \text { Wald chi2 }(34)=3393,68 \\ \text { Estimated coefficients }=35 & \text { Prob }>\text { chi2 }=0,0000\end{aligned}$

- - - - - -

\begin{tabular}{|c|c|c|c|c|c|c|}
\hline AET & Coef. & Std. Err. & z & $P>|z|$ & [95\% Conf. & Interval] \\
\hline GPA & - , 0030177 &, 0009876 & $-3,06$ & $\odot, 0 \odot 2$ & - , , 0049533 & - , , 0010821 \\
\hline APG &,- 1024744 & , 2482834 & $-\odot, 41$ & 0,680 & -, 5891009 & , 3841521 \\
\hline PIB &, 0008997 &, 0002212 & 4,07 & $\odot, 000$ &, 0004661 &, 0013333 \\
\hline Tparo & - , 1959393 & , 0949118 & $-2,06$ & 0,039 &,- 381963 &,- 0099156 \\
\hline IDESPA &, 2901035 & , 1215394 & 2,39 & 0,017 & , $\odot 518907$ & , 5283163 \\
\hline PPIJ &, 3052483 & , 1535623 & 1,99 & 0,047 & , 0042718 &, 6062248 \\
\hline PACC & 4703753 & , 1487376 & 3,16 & $\odot, 002$ & , 1788549 & , 7618957 \\
\hline GPC &,- 5767097 & 1634356 & $-3,53$ & $\odot, 0 \odot \odot$ & -, 8970376 &,- 2563817 \\
\hline ARG & $-19,27161$ & 3,073824 & $-6,27$ & $\odot, \odot \odot \odot$ & $-25,29619$ & $-13,24702$ \\
\hline AST & $-15,1961$ & 2,139272 & $-7,10$ & $\odot, 0 \odot \odot$ & $-19,38899$ & $-11,0032$ \\
\hline BAL & $-7,741478$ & 4,13733 & $-1,87$ & 0,061 & $-15,8505$ & , 3675385 \\
\hline CAN & $-7,173582$ & 1,882417 & $-3,81$ & $\odot, \odot \odot \odot$ & $-10,86305$ & $-3,484113$ \\
\hline CANT & $-14,04719$ & 2,741951 & $-5,12$ & $\odot, 0 \odot \odot$ & $-19,42132$ & $-8,673067$ \\
\hline CYL & $-14,51699$ & 2,336886 & $-6,21$ & $\odot, 0 \odot \odot$ & $-19,0972$ & $-9,936774$ \\
\hline CLM & $-1,151675$ & 1,422167 & $-0,81$ & 0,418 & $-3,93907$ & 1,63572 \\
\hline CAT & 16,11747 & 3,908648 & $-4,12$ & $\odot, 0 \odot \odot$ & $-23,77828$ & $-8,456659$ \\
\hline CVL & $-7,354866$ & 2,558236 & $-2,87$ & $\odot, 0 \odot 4$ & $-12,36892$ & $-2,340817$ \\
\hline EXT &, 1871957 & 1,188306 & 0,16 & 0,875 & $-2,141842$ & 2,516233 \\
\hline GAL & $-11,55873$ & 1,458242 & $-7,93$ & $\odot, 0 \odot \odot$ & $-14,41683$ & $-8,700625$ \\
\hline MAD & $-21,49112$ & 3,813816 & $-5,64$ & $\odot, 0 \odot \odot$ & $-28,96606$ & $-14,01618$ \\
\hline MUR & $-2,227469$ & 1,86116 & $-1,20$ & 0,231 & $-5,875276$ & 1,420337 \\
\hline NAV & $-24,40578$ & 4,685104 & $-5,21$ & $\odot, 00 \odot$ & $-33,58842$ & $-15,22314$ \\
\hline PV & $-26,59532$ & 6,278061 & $-4,24$ & $\odot, 000$ & $-38,90009$ & $-14,29054$ \\
\hline RIO & $-13,46431$ & 3,433515 & $-3,92$ & $\odot, 0 \odot \odot$ & $-20,19387$ & $-6,734741$ \\
\hline 2002 &,- 717303 & , 8960063 & $-\odot, 8 \odot$ & 0,423 & $-2,473443$ & 1,038837 \\
\hline 2003 & - , 8716533 & 1,442841 & $-\odot, 6 \odot$ & 0,546 & $-3,699571$ & 1,956264 \\
\hline $20 \odot 4$ & $-2,109671$ & 1,680935 & $-1,26$ & $\odot, 209$ & $-5,4 \odot 4242$ & 1,184901 \\
\hline 2005 & $-4,281217$ & 2,090933 & $-2,05$ & 0,041 & $-8,37937$ &,- 1830633 \\
\hline 2006 & $-5,882717$ & 2,449391 & $-2,40$ & 0,016 & $-10,68343$ & $-1,081999$ \\
\hline 2007 & $-6,511675$ & $2,9 \odot 8621$ & $-2,24$ & 0,025 & $-12,21247$ & - , 8108835 \\
\hline 2008 & $-6,127282$ & 3,275631 & $-1,87$ & 0,061 & $-12,5474$ & , 2928362 \\
\hline 2009 & $-4,350324$ & 3,391724 & $-1,28$ & 0,200 & $-10,99798$ & 2,297333 \\
\hline 2010 & $-4,62377$ & 3,474936 & $-1,33$ & 0,183 & $-11,43452$ & 2,18698 \\
\hline 2011 & $-5,351228$ & 3,243603 & $-1,65$ & $\odot, 099$ & $-11,70857$ & 1,006118 \\
\hline _cons & 21,09883 & 12,97891 & 1,63 & 0,104 & $-4,339374$ & 46,53704 \\
\hline & & & & & & \\
\hline
\end{tabular}

Fuente: Elaboración propia. Salida de resultados de STATA 

Lista de siglas y abreviaturas 

AAPP: Administraciones Públicas

AEA: American Economic Association

AET: Abandono escolar temprano

AGUA: Programa de Actuaciones para la Gestión y Utilización del Agua

AND: Andalucía

APA: American Psychological Association

APG: Alumnos por grupo

AR1: Estimación con término autorregresivo de orden 1

ARG: Aragón

AST: Asturias

BAL: Baleares

BUP: Bachillerato Unificado Polivalente

CAN: Canarias

CANT: Cantabria

CAT: Cataluña

CCAA: Comunidades autónomas

CFGM: Ciclo Formativo de Grado Medio

CFGS: Ciclo Formativo de Grado Superior

CINE: Clasificación Internacional Normalizada de Educación

CLM: Castilla-La Mancha

CPS: Current Population Survey

CSE: Conferencia Sectorial de Educación

CV: Coeficiente de variación

CVL: Comunidad Valenciana

CYL: Castilla y León

EECP: Errores estándar corregidos para panel 
EGD: Evaluación General de Diagnóstico

EPA: Encuesta de Población Activa

ESO: Educación Secundaria Obligatoria

ET: Education and Training

EXT: Extremadura

FP: Formación Profesional

FPI: Formación Profesional Inicial

GAL: Galicia

GPA: Gasto público por alumno

GPC: Porcentaje de gasto público en conciertos

IDESPA: Índice de descualificación de la población adulta

IAEP: International Assessment of Educational Progress

IEA: International Association for the Evaluation of Educational Achievement

INE: Instituto Nacional de Estadística

INEE: Instituto Nacional de Evaluación Educativa

INES: Indicators of Education System

ISCED: International Standard Classification of Education

IVIE: Instituto Valenciano de Investigaciones Económicas

LGE: Ley General de Educación

LOE: Ley Orgánica de Educación

LOGSE: Ley de Ordenación General del Sistema Educativo

MAD: Madrid

MECD: Ministerio de Educación, Cultura y Deporte

MCGF: Mínimos cuadrados generalizados factibles

MCO: Mínimos cuadrados ordinarios

MECD: Ministerio de Educación, Cultura y Deporte 
MRW: Mankiw-Romer-Weil (Modelo de crecimiento)

MUR: Murcia

NAV: Navarra

NUTS: Nomenclatura de las Unidades Territoriales Estadísticas (del francés Nomenclature des Unités Territoriales Statistiques)

OCDE: Organización para la Cooperación y el Desarrollo Económicos

ONU: Organización de Naciones Unidas

PACC: Proporción de alumnado en centros concertados

PCPI: Programa de Cualificación Profesional Inicial

PEIT: Plan Estratégico de Infraestructuras y Transporte

PCT-RATE: Programa de Cooperación Territorial para la Reducción del Abandono Temprano de la Educación

PIB: Producto Interior Bruto

PISA: Programme for International Student Assessment

PNR: Programa Nacional de Reformas

PPIJ: Proporción de población inmigrante joven

PV: País Vasco

RIO: La Rioja

SEIE: Sistema Estatal de Indicadores de la Educación

SPSS: Statistical Package for Social Sciences

STAR (Proyecto): for Student/Teacher Achievement Ratio

TAET: Tasa de abandono escolar temprano

TCMAA: Tasa de Crecimiento Medio Anual Acumulativo

TICs: Tecnologías de la información y la comunicación

TPARO: Tasa de paro

UE: Unión Europea

UEM: Unión Económica Monetaria 
UNESCO: United Nations Educational, Scientific and Cultural Organization WOS: Web of Science 